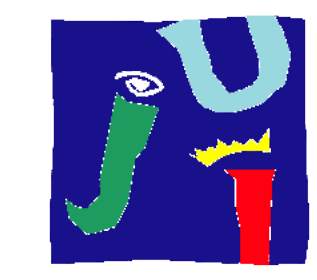

$\mathbf{U}_{\text {NIVERSITAT }}$

JAUME•I

Programa de Doctorado en Tecnologías Industriales y Materiales Escuela de Doctorado de la Universitat Jaume I

\title{
Diseño de una metodología para el control de calidad de los rechazos producidos en las plantas de tratamiento mecánico-biológico de residuos sólidos urbanos
}

Memoria presentada por Natalia Edo Alcón para optar al grado de doctora por la Universitat Jaume I

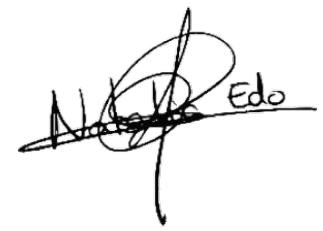

Fdo:

Natalia Edo Alcón

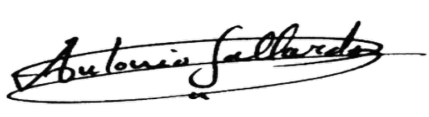

Fdo:

Antonio Gallardo Izquierdo

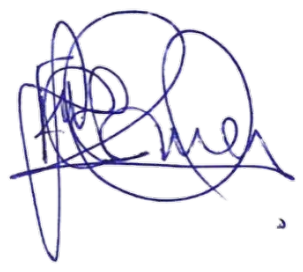

Fdo:

Francisco J. Colomer Mendoza 

Para la realización de la presente Tesis se ha contado con la financiación de las siguientes ayudas y proyectos:

- $\quad$ Ayuda predoctoral para la formación de personal investigador de la Universitat Jaume I (FPI-UJI). Financiación: Convocatoria de ayudas predoctorales para la formación de personal investigador en el marco del Plan de Promoción a la Investigación de la Universitat Jaume I para el año 2014. Duración: 01/04/2015 hasta 31/03/2018.

- Proyecto: "Metodología para la caracterización y control de calidad de los rechazos producidos en las plantas de tratamiento de residuos domiciliarios". Financiación: Convocatoria de proyectos de investigación científica y desarrollo tecnológico en el marco del Plan de Promoción de la Investigación de la Universitat Jaume I para el año 2016 (Evaluación ANEP). Duración: 01/01/2017 hasta 31/12/2017.

- Proyecto: "Metodología para el muestreo y caracterización de los materiales recuperados y los rechazos de plantas de tratamiento mecánico-biológico". Financiación: Convocatoria de proyectos de investigación científica y desarrollo tecnológico en el marco del Plan de Promoción de la Investigación de la Universitat Jaume I para el año 2017 (Evaluación ANEP). Duración: 01/01/2018 hasta 31/12/2019.

- Proyecto: "Estudio de valorización del rechazo de la planta de tratamiento de RSU de la UTE Zona 1 de Castellón". Financiación: Teconma SA, Azahar Environment SA, Ecodeco SRL, UTE. Duración: 05/05/2015 hasta 31/08/2018.

- Proyecto: “EI CSR producido a partir de rechazos de la planta de tratamiento mecánico-biológica de Onda: consideración de subproducto y comparación con otros combustibles alternativos". Financiación: RECIPLASA S.A. Duración: 09/06/2016 hasta 03/10/2018.

Para la inscripción y asistencia a congresos se ha contado con la financiación y ayuda de:

- Plan Estratégico del Departamento de Ingeniería Mecánica y Construcción (Dpto. EMC).

- Programa Iberoamericano Ciencia y Tecnología para el Desarrollo (CYTED).

- $\quad$ Red Iberoamericana en Gestión y Aprovechamiento de Residuos (REDISA). 

"Make a sampling mistake and everything is wrong, make a sample preparation mistake and the analysis value is worthless"

W. Rasemann 

En primer lugar, quiero dar mi más sincero agradecimiento a mis directores de tesis, Antonio Gallardo y Francisco J. Colomer, por guiarme y ayudarme a la consecución de este trabajo, por los consejos y la dedicación durante estos años. Gracias por la exhaustiva revisión del documento y por todas las valiosas aportaciones realizadas al mismo. Muchas gracias por todo.

A mis compañeros del grupo INGRES y del Departamento, por los años de compañía, amistad, tiempo compartido y por vuestro apoyo en el día a día. En especial a Joan y Neus por acompañarme y ayudarme a realizar todas las caracterizaciones que han hecho posible la experimentación de esta Tesis, y a Sara por su inestimable ayuda en el laboratorio.

A Alejandro, por ser mi apoyo en los momentos difíciles, creer en mí y darme fuerza. Por su paciencia, por comprenderme y por ayudarme a desconectar cuando lo he necesitado. Gracias por sacarme siempre una sonrisa.

A mi familia, en especial a mis padres, por todo su apoyo y cariño recibido durante estos años. Por su esfuerzo desde que me fui a estudiar a Cheste, gracias a ellos hoy estoy aquí.

Muchas gracias también a todos los que han estado a mi lado y me han brindado su apoyo y animo durante el desarrollo de la tesis.

Finalmente, agradecer a la Universitat Jaume I por financiar este trabajo de investigación, a las empresas RECIPLASA S.A.; Teconma SA, Azahar Environment SA, Ecodeco SRL, UTE, y a BIONORD su colaboración y disposición para poder llevar a cabo los casos de aplicación de la presente tesis. Así como al Servicio Central de Instrumentación Científica de la UJI por poner a mi disposición sus equipos de análisis. 

El tratamiento mecánico-biológico (TMB) de residuos sólidos urbanos (RSU) es uno de los tratamientos más extendidos tanto a nivel nacional como europeo. Sin embargo, la principal problemática de este tipo de tratamiento es la gran cantidad de rechazo que se genera al final del proceso, por lo que encontrar alternativas para la valorización de los mismos es un objetivo estratégico para el sector. En este sentido, una vía para su aprovechamiento consiste en su transformación en un combustible sólido recuperado (CSR).

En la actualidad, la producción de CSR a partir de rechazos ha ido aumentando año tras año, debido al mayor interés que presentan las industrias del sector energético en la utilización de un combustible alternativo más económico y a la implantación de nuevas plantas de TMB. No obstante, para que los rechazos puedan ser clasificados y comercializados como CSR, deben cumplir los estándares de calidad europeos para estos combustibles y tener unas propiedades conocidas. Además, la calidad de los CSR es un factor clave para su demanda y utilización.

El objetivo fundamental de esta tesis es diseñar una metodología que permita llevar a cabo el control de calidad de los rechazos generados en las plantas de TMB y que se adapte a las características particulares de estas corrientes, de forma que se facilite su transformación en un CSR comercializable y que cumpla con los estándares de calidad.

Previo al desarrollo de la metodología, ha sido necesario realizar las siguientes tareas: se han modelizado y clasificado los diferentes tipos de plantas de TMB existentes; se ha estudiado la situación actual de TMB en España; se han determinado las variables que afectan a las propiedades de los rechazos y al peso de muestra necesario para su caracterización; se han identificado los parámetros que definen la calidad de los CSR; se han revisado las técnicas de muestreo estadísticas y los métodos y normas existentes para el muestreo de RSU y CSR, y se han revisado los procedimientos estadísticos aplicables a los RSU y los rechazos.

La metodología propuesta incluye un plan de muestreo que permite calcular el tamaño y número mínimo de muestras que se deben tomar a lo largo de un año de cada tipo de rechazo que se genera en la planta de tratamiento, y que son susceptibles de ser transformados en un CSR. También contempla un procedimiento de preparación de muestra en el laboratorio para el análisis de los parámetros de calidad. Este incluye el proceso de reducción de la muestra tomada en planta hasta un tamaño representativo y el secado óptimo de la misma.

El plan de muestreo diseñado ha sido implementado en dos plantas de TMB diferentes de la provincia de Castellón: la planta de recuperación y compostaje de Onda y la planta de biosecado y recuperación de Cervera del Maestre. Se han identificado todos los rechazos susceptibles de ser transformados en un CSR, determinándose el tamaño y número de muestras necesarias para el control de su calidad.

La metodología diseñada es una herramienta muy útil para los responsables de la gestión de los residuos, puesto que a partir de control de calidad de los rechazos se podrá producir un CSR con unas propiedades definidas y predecibles, favoreciendo su valorización. Esto contribuye a la recuperación energética de una fracción importante de residuos que actualmente se destina a vertedero, ayudando a cumplir los nuevos objetivos sobre la reducción de vertido de la Directiva europea de residuos (Directiva 2018/851/UE) y facilitando la transición hacia una economía circular. 

El tractament mecànic-biològic (TMB) de residus sòlids urbans (RSU) és un dels tractaments més estesos tant en l'àmbit nacional com europeu. No obstant això, la principal problemàtica d'aquest tipus de tractament és la gran quantitat de rebuig que es genera al final del procés, per la qual cosa trobar alternatives per a la valorització dels mateixos és un objectiu estratègic per al sector. En aquest sentit, una via per al seu aprofitament consisteix en la seva transformació en un combustible sòlid recuperat (CSR).

En l'actualitat, la producció de CSR a partir de rebutjos ha anat augmentant any rere any, a causa del major interès que presenten les indústries del sector energètic en la utilització d'un combustible alternatiu més econòmic i a la implantació de noves plantes de TMB. No obstant això, perquè els rebutjos puguin ser classificats i comercialitzats com CSR, han de complir els estàndards de qualitat europeus per a aquests combustibles i tenir unes propietats conegudes. A més, la qualitat dels CSR és un factor clau per a la seva demanda i utilització.

L'objectiu fonamental d'aquesta tesi és dissenyar una metodologia que permeti dur a terme el control de qualitat dels rebutjos generats en les plantes de TMB i que s'adapti a les característiques particulars d'aquests corrents, de manera que es faciliti la seva transformació en un CSR comercialitzable i que compleixi amb els estàndards de qualitat.

Previ al desenvolupament de la metodologia, ha estat necessari fer les següents tasques: s'han modelitzat i classificat els diferents tipus de plantes de TMB existents; s'ha estudiat la situació actual de TMB a Espanya; s'han determinat les variables que afecten les propietats dels rebutjos i al pes de mostra necessari per a la seva caracterització; s'han identificat els paràmetres que defineixen la qualitat dels CSR; s'han revisat les tècniques de mostreig estadístiques i els mètodes i normes existents per al mostreig de RSU i CSR, i s'han revisat els procediments estadístics aplicables als RSU i els rebutjos.

La metodologia proposada inclou un pla de mostreig que permet calcular la grandària i nombre mínim de mostres que s'han de prendre al llarg d'un any de cada tipus de rebuig que es genera en la planta de tractament, i que són susceptibles de ser transformats en un CSR. També contempla un procediment de preparació de mostra en el laboratori per a l'anàlisi dels paràmetres de qualitat. Aquest inclou el procés de reducció de la mostra agafada en planta fins a una grandària representativa i l'assecament òptim d'aquesta.

El pla de mostreig dissenyat ha estat implementat en dues plantes de TMB diferents de la província de Castelló: la planta de recuperació i compostatge d'Onda i la planta de bio-assecat i recuperació de Cervera del Maestrat. S'han identificat tots els rebutjos susceptibles de ser transformats en un CSR, determinant-se la grandària i nombre de mostres necessàries per al control de la seva qualitat.

La metodologia dissenyada és una eina molt útil per als responsables de la gestió dels residus, llevat que a partir de control de qualitat dels rebutjos es podrà produir un CSR amb unes propietats definides $i$ predictibles, afavorint la seva valorització. Això contribueix a la recuperació energètica d'una fracció important de residus que actualment es destina als abocadors, ajudant a complir els nous objectius sobre la reducció d'abocament de la Directiva europea de residus (Directiva 2018/851/UE) i afavorint la transició cap a una economia circular. 

Mechanical-biological treatment (MBT) of municipal solid waste (MSW) is one of the most widespread treatments at both national and European level. However, the main problem of this type of treatment is the large amount of reject generated at the end of the process, so finding alternatives for their recovery is a strategic objective for the sector. In this regard, a way for its use is to transform it into a solid recovered fuel (SRF).

Currently, the production of SRF from rejects has been increasing every year, due to the greater interest shown by energy sector industries in the use of a cheaper alternative fuel and the implantation of new MBT plants. Nevertheless, in order for rejects to be classified and traded as SRF, they must meet European quality standards for these fuels and have known properties. In addition, the quality of SRF is a key factor for their demand and use.

The main objective of this Thesis is to design a methodology that allows to carry out the quality control of the rejects generated in the MBT plants and that adapts to the particular characteristics of these flows, in a way that aids their transformation into a marketable SRF that meets the quality standards.

Prior to the development of the methodology, it has been necessary to perform the following tasks: the different types of MBT plants have been modelled and classified; the current situation of MBT in Spain has been studied; the variables that affect the properties of rejects and the sample weight required for their characterization have been determined; the parameters that define the quality of SRF have been identified; statistical sampling techniques and existing methods and standards for sampling of MSW and SRF have been revised, and statistical procedures applicable to MSW and rejects have been reviewed.

The proposed methodology includes a sampling plan that allows calculating the minimum size and number of samples to be taken throughout a year from each type of reject generated at the treatment plant, and which are liable to be transformed into a SRF. It also considers a sample preparation procedure in the laboratory for the analysis of quality parameters. This includes the process of reducing the sample taken in the plant to a representative size and its optimal drying thereof.

The designed sampling plan has been implemented in two different MBT plants in the province of Castellon: the Onda recovery and composting plant and the Cervera del Maestre bio-drying and recovery plant. All rejects that could be transformed into a SRF have been identified, determining the size and number of samples required for quality control.

The designed methodology is a very useful tool for those responsible for waste management, since through quality control of rejects a SRF with defined and predictable properties can be produced, favouring its valorisation. This contributes to the energy recovery of a significant fraction of waste that is currently going to landfill, helping to meet the new landfill reduction targets of the European Waste Directive (Directive 2018/851/EU) and facilitating the transition towards a circular economy. 



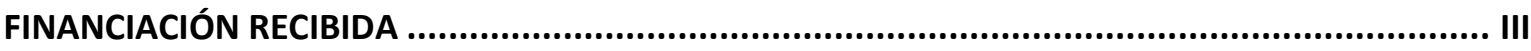

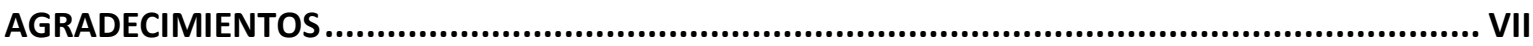

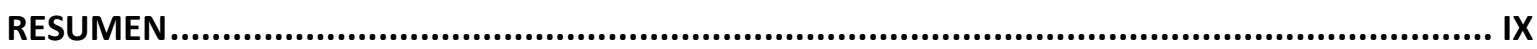

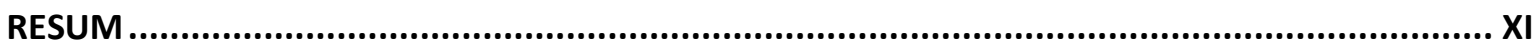

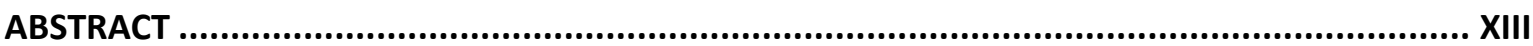

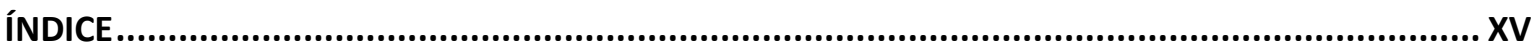

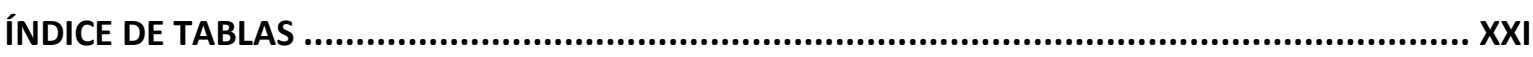

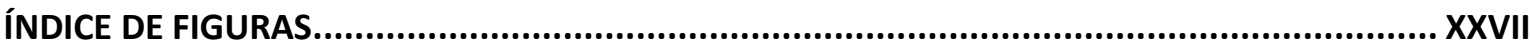

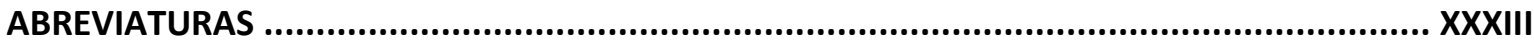

1. INTRODUCCIÓN

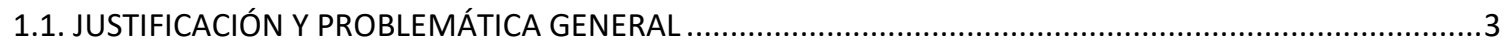

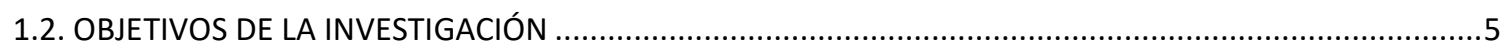

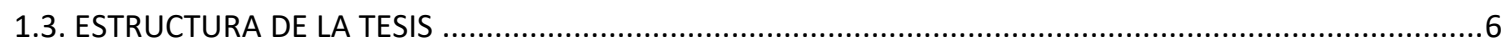

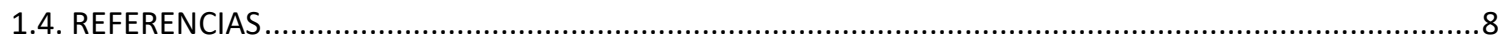

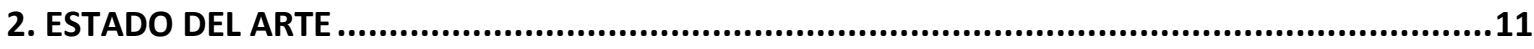

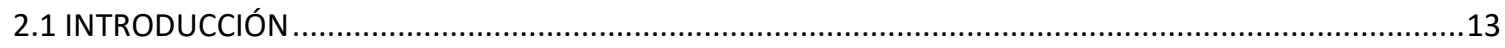

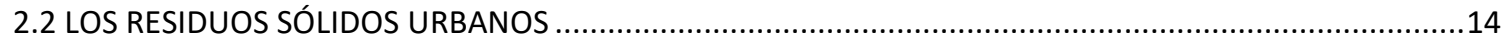

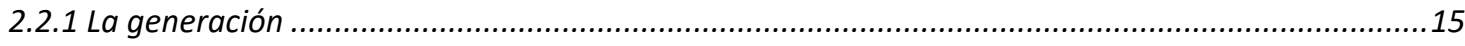

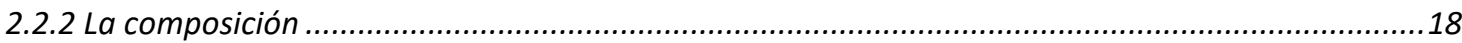

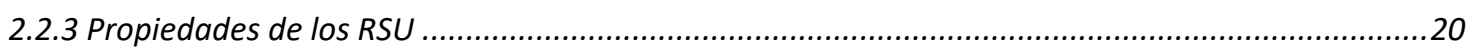

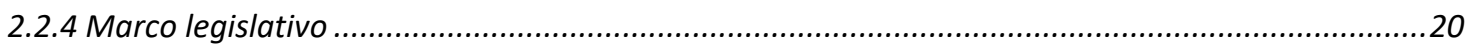

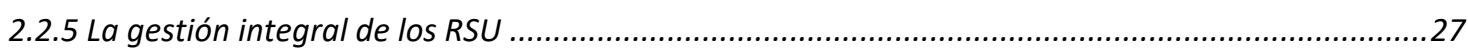

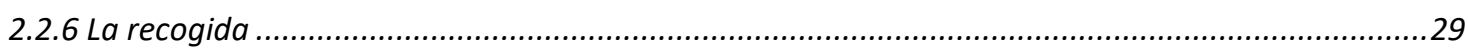

2.2.7 El tratamiento

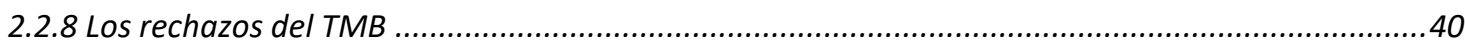

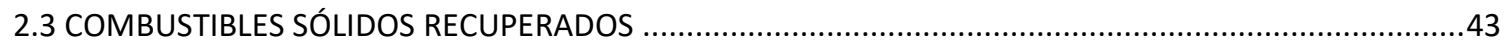

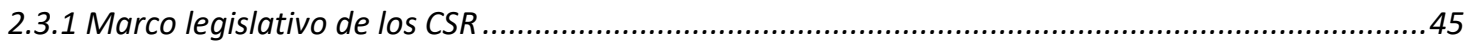

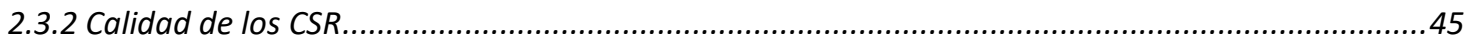

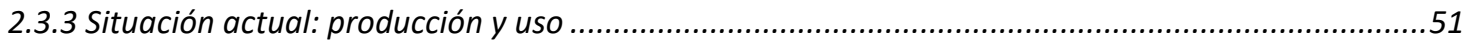

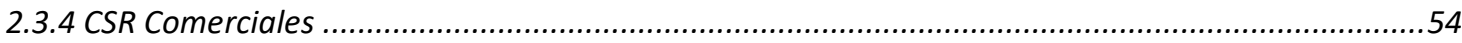

2.3.5 Desclasificación de los CSR como residuos ................................................................................5

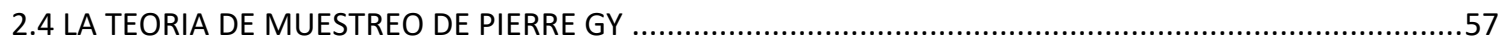




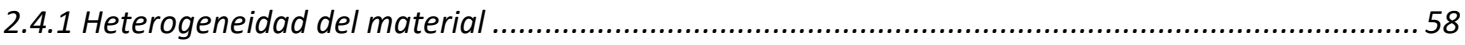

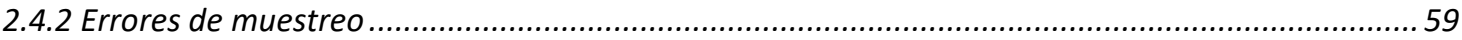

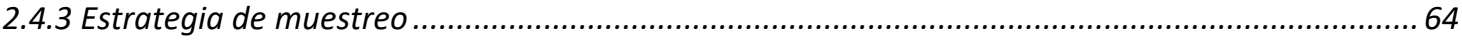

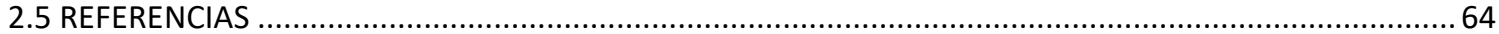

3. MODELIZACIÓN DE LAS PLANTAS DE TRATAMIENTO MECÁNICO-BIOLÓGICO .........................73

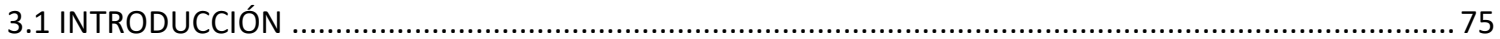

3.2 CLASIFICACIÓN DE LAS PLANTAS DE TRATAMIENTO MECÁNICO BIOLÓGICO ......................................... 75

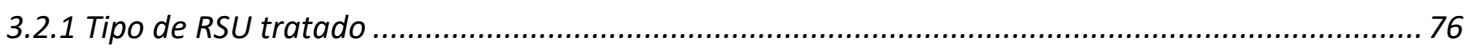

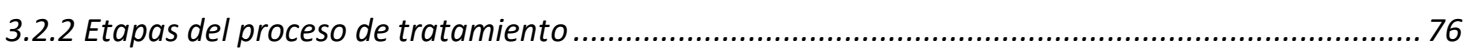

3.2.3 Tecnologías y procesos de tratamiento mecánico ....................................................................... 77

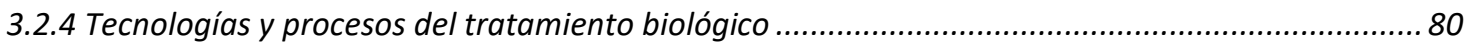

3.2.5 Resumen de la clasificación de las plantas de $T M B$................................................................. 82

3.3 MODELIZACIÓN E IDENTIFICACIÓN DE LAS CORRIENTES DE RECHAZO .............................................83

3.3.1 Modelización de los principales tipos de plantas de TMB ..................................................... 83

3.3.2 Modelización de la etapa mecánica y biológica.........................................................................8 88

3.3.3 Identificación de las corrientes de rechazo .......................................................................93

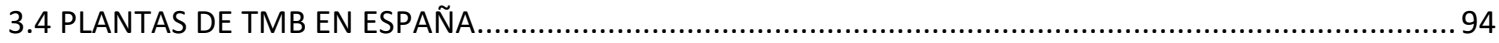

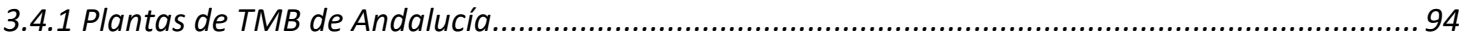

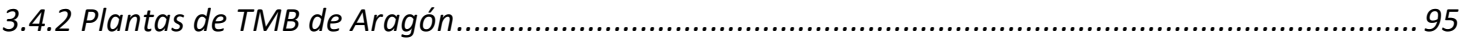

3.4.3 Plantas de TMB del Principado de Asturias............................................................................ 95

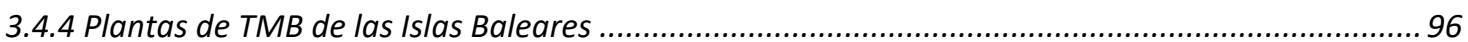

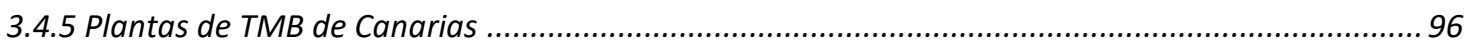

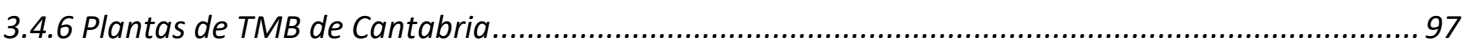

3.4.7 Plantas de TMB de Casilla - La Mancha................................................................................. 97

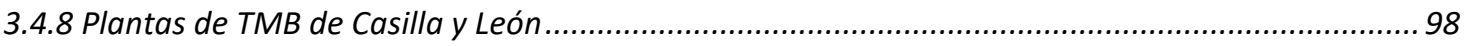

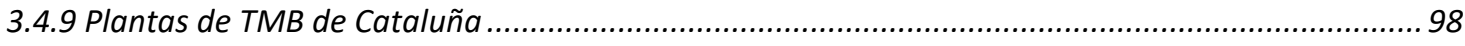

3.4.10 Plantas de TMB de la Comunidad Valenciana .................................................................... 100

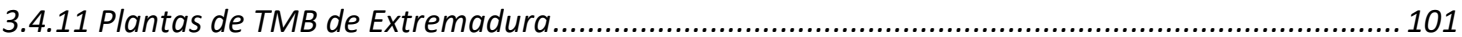

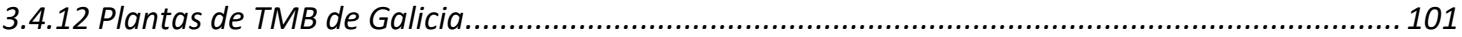

3.4.13 Plantas de TMB de La Rioja ........................................................................................... 102

3.4.14 Plantas de TMB de la Comunidad de Madrid ............................................................................. 102

3.4.15 Plantas de TMB de la Región de Murcia ............................................................................. 103

3.4.16 Plantas de TMB de la Comunidad Foral de Navarra ............................................................... 103

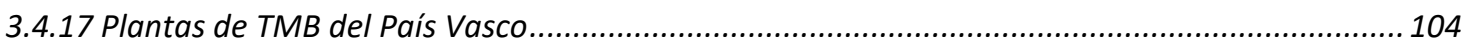

3.4.18 Resumen de la distribución de las plantas de TMB a nivel autonómico..................................... 105

3.4.19 Resumen de las plantas de TMB existentes en España ......................................................... 105 
3.5 BALANCES DE MATERIA, PRODUCCIÓN DE RECHAZO Y RENDIMIENTO DE LAS PLANTAS DE TMB ESPAÑOLAS

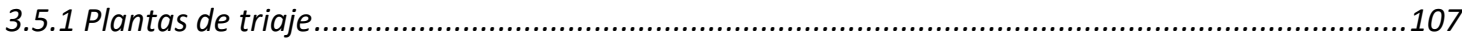

3.5.2 Plantas de recuperación y compostaje ..................................................................................109

3.5.3 Plantas de biosecado y recuperación .................................................................................112

3.5.4 Plantas de recuperación, biometanización y compostaje......................................................112

3.5.5 Plantas de compostaje de la FORS........................................................................................115

3.5.6 Plantas de biometanización y compostaje de la FORS ..............................................................117

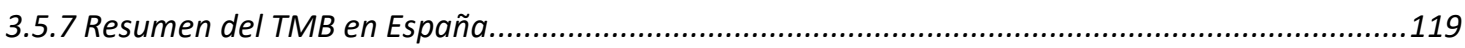

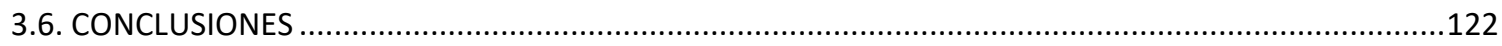

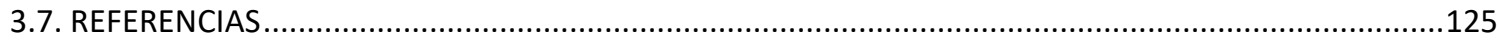

4. IDENTIFICACIÓN DE VARIABLES Y PARÁMETROS QUE INTERVIENEN EN LA METODOLOGÍA PARA EL CONTROL DE CALIDAD DE LOS RECHAZOS .....................................................127

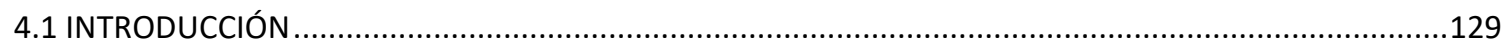

4.2 VARIABLES QUE AFECTAN A LA COMPOSICIÓN Y PROPIEDADES DE LOS RECHAZOS ..........................130

4.3 VARIABLES QUE AFECTAN AL TAMAÑO DE MUESTRA DE UN RECHAZO .......................................133

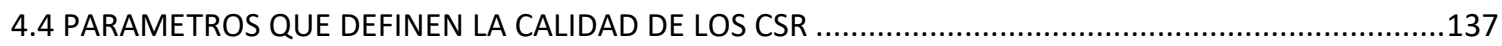

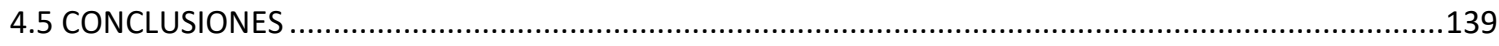

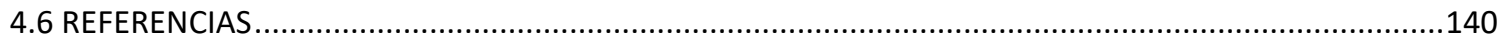

5. METODOLOGÍAS APLICABLES AL MUESTREO Y CARACTERIZACIÓN DE RECHAZOS ...............145

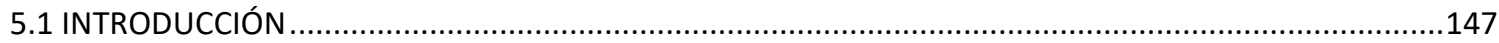

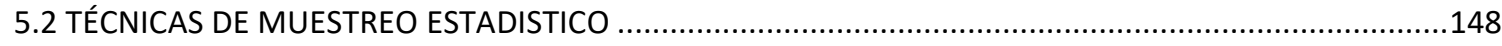

5.3 METODOLOGIAS PARA EL MUESTREO Y CARACTERIZACIÓN DE RSU Y CSR ....................................150

5.3.1 Normas aplicables al muestreo y caracterización de RSU y CSR ............................................150

5.3.2 Metodologías de muestreo y caracterización de RSU propuestas por organismos oficiales..........154

5.3.3 Metodologías de muestreo y caracterización propuestas por algunos investigadores.................157

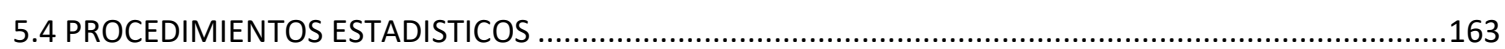

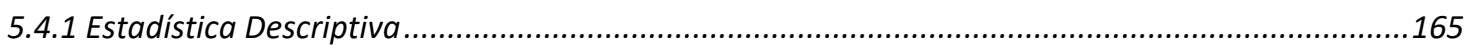

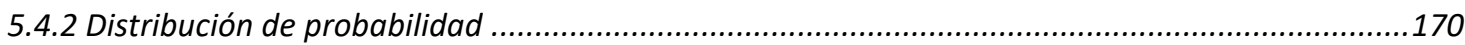

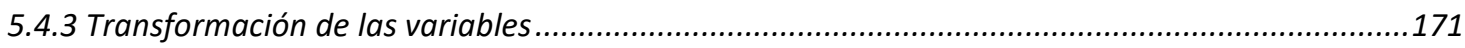

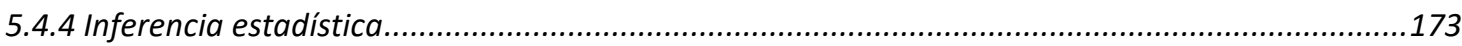

5.4.5 Procedimientos estadísticos aplicados en el diseño de la metodología de control de calidad de los rechazos.

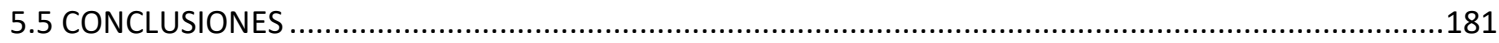

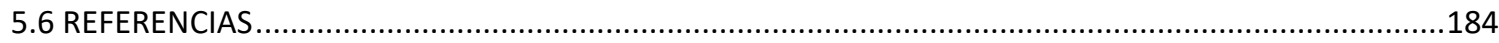

6. DESARROLlO DEL PLAN DE MUESTREO PARA EL CONTROL DE CALIDAD DE LOS RECHAZOS 
6.1 INTRODUCCIÓN

6.2 OBJETIVO Y ALCANCE DEL PLAN DE MUESTREO ..................................................................... 190

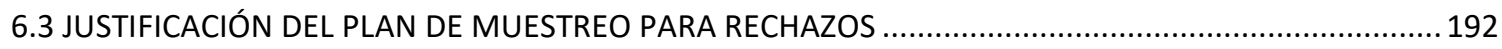

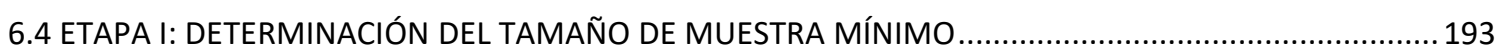

6.4.1 Cálculo del tamaño de muestra inicial .................................................................................. 194

6.4.2 Definición de las fracciones a caracterizar ........................................................................... 197

6.4.3 Procedimiento de división del tamaño de muestra inicial........................................................... 198

6.4.4 Determinación del tamaño mínimo de muestra ...................................................................... 200

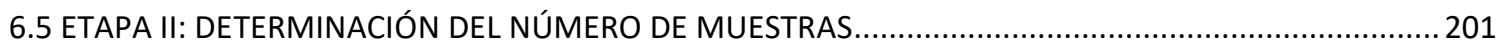

6.5.1 Determinación de las variables de estratificación................................................................. 201

6.5.2 Determinación de los niveles de variación temporal.............................................................203

6.5.3 Identificación de las corrientes de rechazo a muestrear ........................................................204

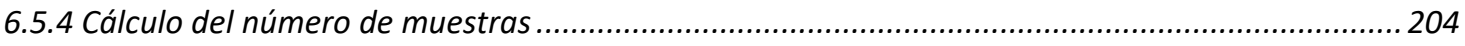

6.6 ETAPA III: DIRECTRICES PARA EL MUESTREO Y CARACTERIZACIÓN DE RECHAZOS ............................205

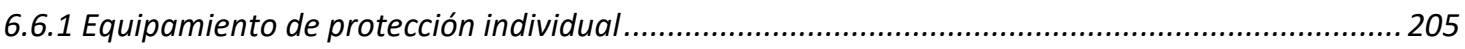

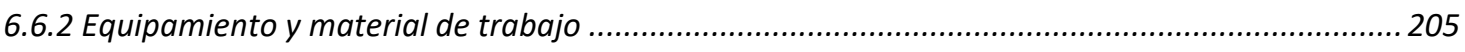

6.6.3 Consideraciones para la programación de las caracterizaciones.............................................. 205

6.6.4 Localización y condiciones para realizar las caracterizaciones ................................................ 206

6.6.5 Casos especiales en la clasificación de los materiales................................................................. 206

6.7 CASOS DE APLICACIÓN PARA DETERMINAR DEL TAMAÑO MÍNIMO DE MUESTRA (ETAPA I) .............206

6.7.1 Caso 1: Determinación del tamaño mínimo de muestra en la planta de recuperación y compostaje

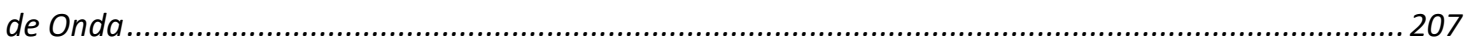

6.7.2 Caso 2: Determinación del tamaño mínimo de muestra en la planta de biosecado y recuperación de Cervera del Maestre ............................................................................................................. 240

6.8 CASO DE APLICACIÓN PARA DETERMINAR DEL NÚMERO DE MUESTRAS (ETAPA II) .........................263

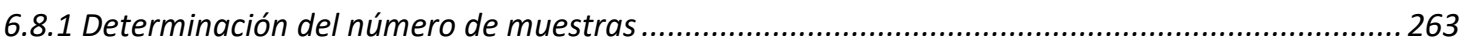

6.8.2 Validación de la metodología para la determinación del número de muestras .......................... 265

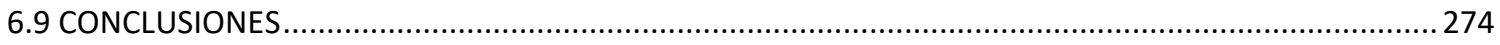

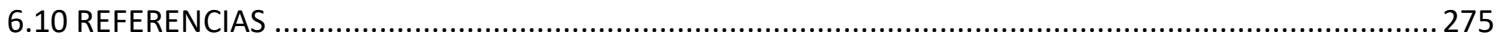

7. PREPARACIÓN DE MUESTRAS DE RECHAZO EN EL LABORATORIO PARA EL ANÁLISIS DE LOS PARÁMETROS DE CALIDAD ........................................................................ 279

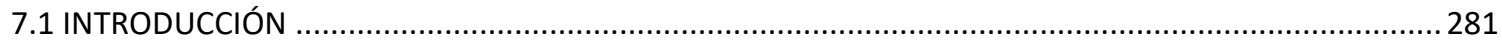

7.2 PROCEDIMIENTO PARA LA PREPARACIÓN DE MUESTRA PARA EL CONTROL DE CALIDAD DE LOS

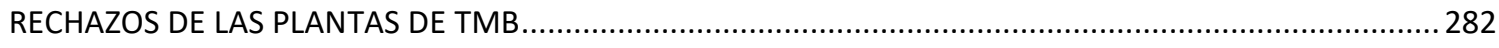

7.2.1 Recomposición de una muestra inicial representativa ......................................................... 283

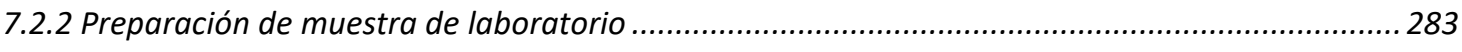

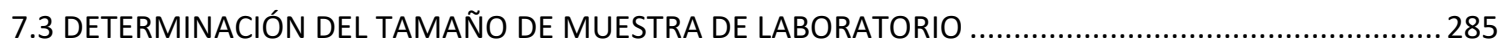




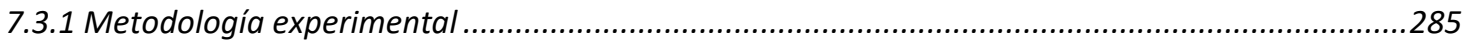

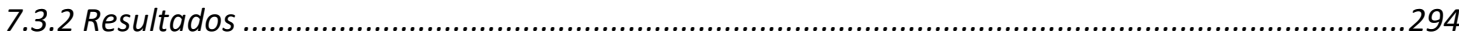

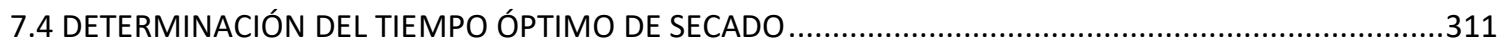

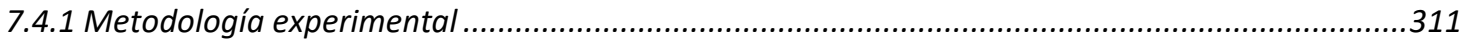

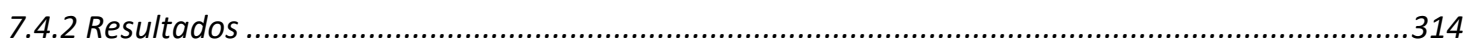

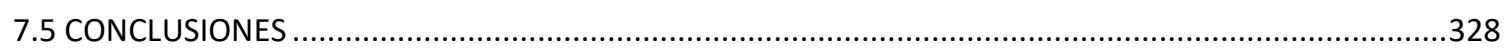

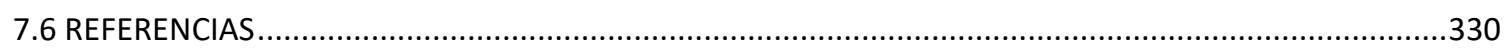

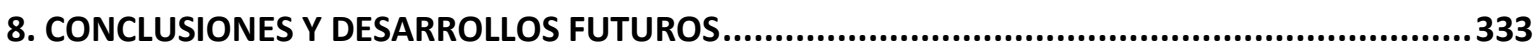

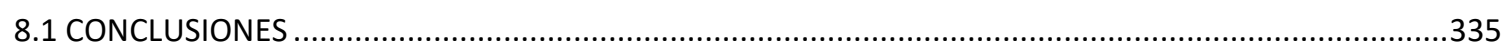

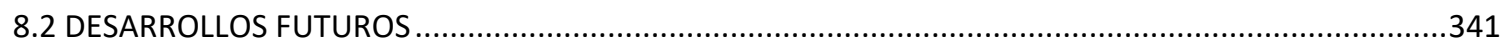

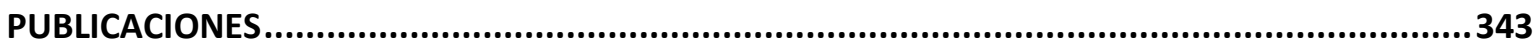



Tabla 2.1 Generación de RSU por CC.AA. en España, 2016 (Instituto Nacional de Estadística (INE), 2018) ....18

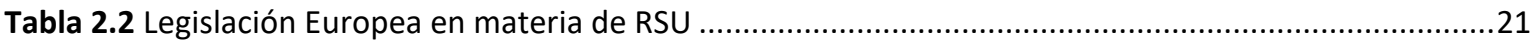

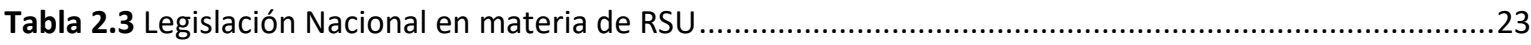

Tabla 2.4 Legislación de la Comunidad Valenciana en materia de RSU .....................................................26

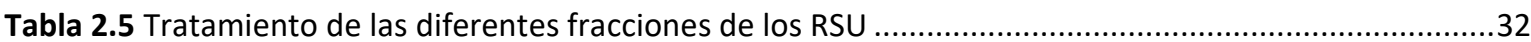

Tabla 2.6 Composición del rechazo de las plantas de TMB de la Comunidad Valenciana (Generallitat Valenciana, 2004)

Tabla 2.7 Composición media de los rechazos de plantas de compostaje de los FORS catalanas (Bernard, 2013).

Tabla 2.8 Caracterizaciones de los rechazos del TMB de RSU, expresado en materia seca .........................43

Tabla 2.9 Estándares de calidad del CSR en Europa (UNE-EN 15359, 2012) ..............................................46

Tabla 2.10 Estándares de calidad para el CSR en Alemania (BGS (Ed.), 2008) ........................................47

Tabla 2.11 Estándares de calidad para le CSR en Austria (Flamme and Geiping, 2012; Lorber et al., 2012) ...48

Tabla 2.12 Estándares de calidad del CSR en Finlandia (SFS 5875, 2000) ...............................................49

Tabla 2.13 Estándares de calidad del CSR en Italia (UNI 9903-1, 2004) ...................................................49

Tabla 2.14 Estándares de calidad del CSR en Francia (Republique Française, 2016) ..................................49

Tabla 2.15 Estándares de calidad del CSR en hornos de Cemento de Suiza (Flamme and Geiping, 2012;

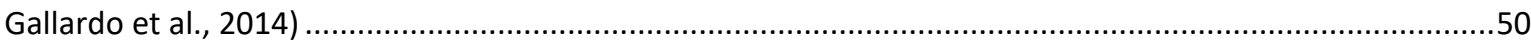

Tabla 2.16 Estándares de calidad del CSR en hornos de cemento en España (Gallardo et al., 2014).............50

Tabla 2.17 Estándares de calidad del CSR en hornos de cemento en Europa: EURITS (Gallardo et al., 2014;

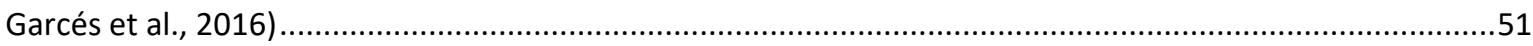

Tabla 2.18 Especificaciones de calidad para las marcas de CSR de REMONDIS (Glorius, 2009) .....................54

Tabla 2.19 Criterios para el EoW de los CSR en Italia (Italian Ministerial Decree, 2013) ...............................55

Tabla 2.20 Criterios para el EoW de otros combustibles de sustitución en Austria (BMLFUW (Ed.), 2010) ....56

Tabla 3.1 Subetapas, operaciones y equipamientos del tratamiento mecánico en plantas de TMB ..............78

Tabla 3.2 Tipos de tratamiento biológicos en las plantas de TMB y tecnologías asociadas ..........................80

Tabla 3.3 Tipo de plantas de TMB, etapas mecánicas y biológicas que las forman, y corrientes de rechazo

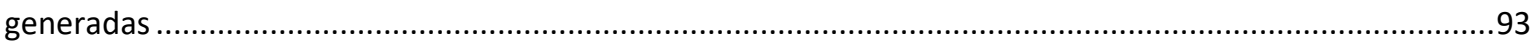

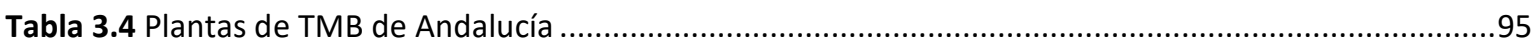

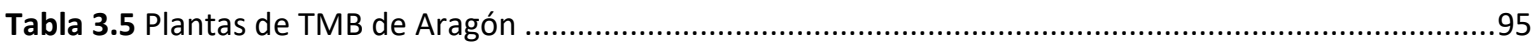

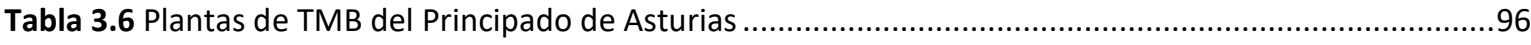

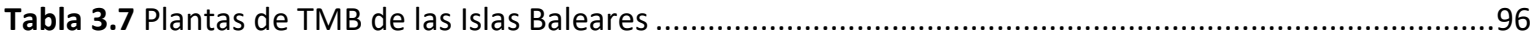

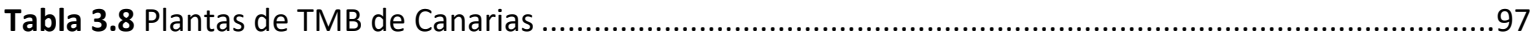

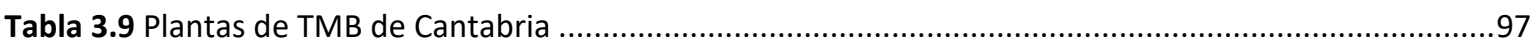

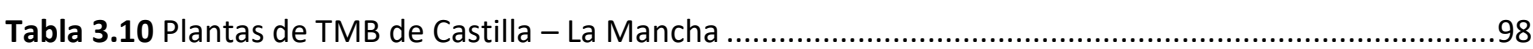

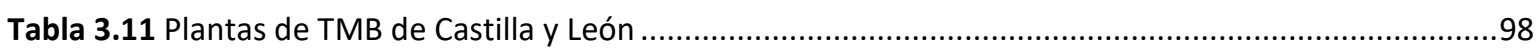




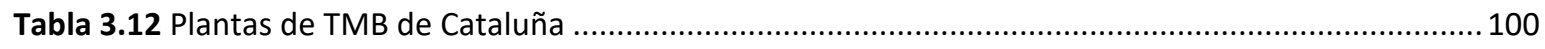

Tabla 3.13 Plantas de TMB de la Comunidad Valenciana .................................................................. 101

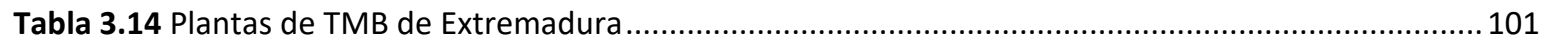

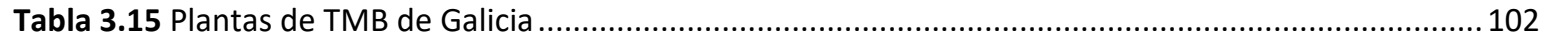

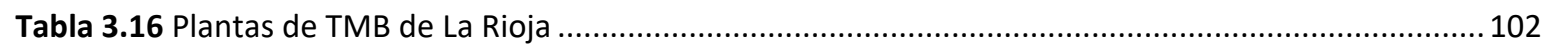

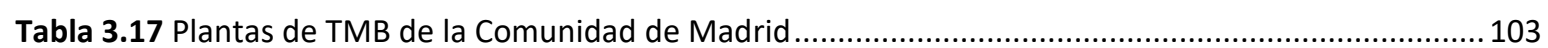

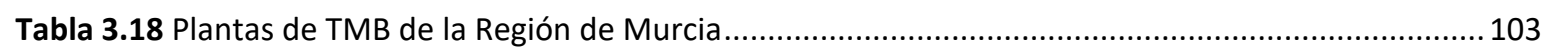

Tabla 3.19 Plantas de TMB de Comunidad Foral de Navarra ................................................................ 104

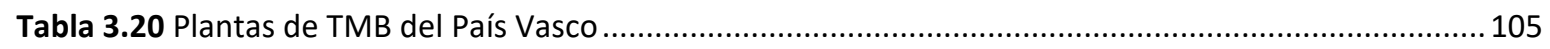

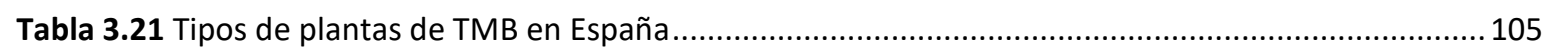

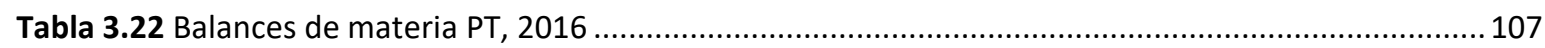

Tabla 3.23 Porcentajes de materiales recuperados en las PT, 2016 .................................................. 107

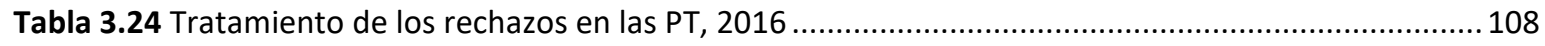

Tabla 3.25 RSU tratados e indicadores del rendimiento de las PT, 2016 ............................................ 108

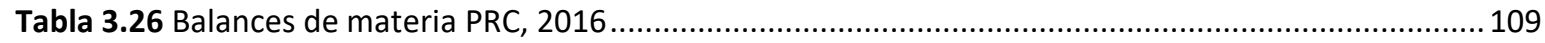

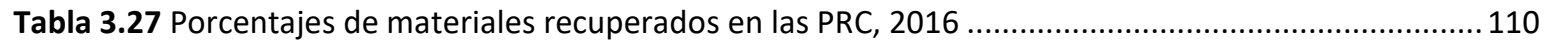

Tabla 3.28 Tratamiento de los rechazos en las PRC, 2016 .................................................................... 111

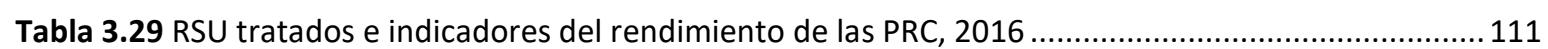

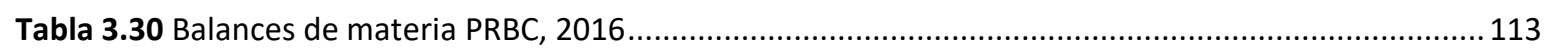

Tabla 3.31 Porcentajes de materiales recuperados en las PRBC, 2016 .................................................. 113

Tabla 3.32 Tratamiento de los rechazos en las PRBC, 2016 ............................................................ 114

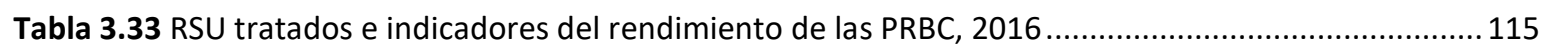

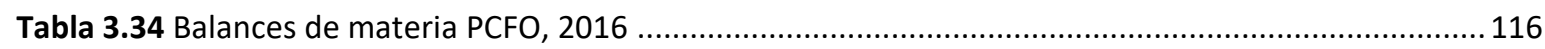

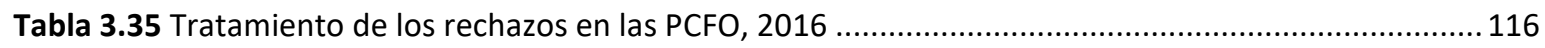

Tabla 3.36 FORS tratada e indicadores del rendimiento de las PCFO, 2016 ...........................................117

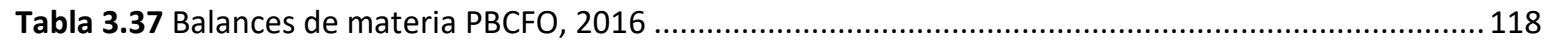

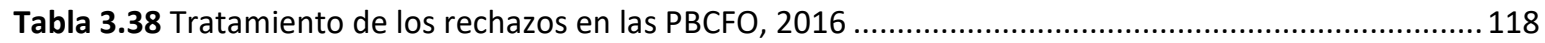

Tabla 3.39 FORS tratada e indicadores del rendimiento de las PBCFO, 2016 ........................................ 119

Tabla 3.40 Distribución del TMB de RSU y FORS por CC.AA ................................................................ 120

Tabla 3.41 Porcentaje de RSU mezclados y FORS tratados en las plantas de TMB por CC.AA. ....................121

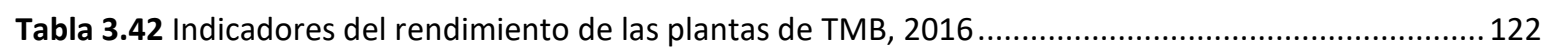

Tabla 4.1 Parámetros que definen la calidad de los CSR en los diferentes estándares europeos ................ 138

Tabla 6.1 Tipos de rechazos y plantas de TMB de RSU a considerar en el diseño del plan de muestreo...... 191

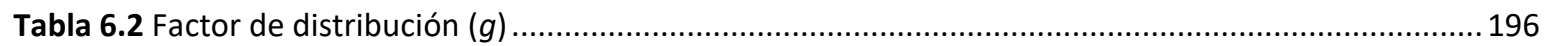

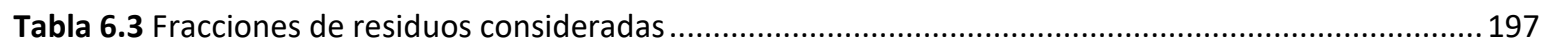

Tabla 6.4 Niveles de variación y variables identificadas en cada uno de ellos ........................................203 
Tabla 6.5 Tamaño nominal superior y tamaño mínimo de partícula del RRM-O......................................209

Tabla 6.6 Tamaño nominal superior y tamaño mínimo de partícula del RAB1-O......................................210

Tabla 6.7 Tamaño nominal superior y tamaño mínimo de partícula del RAB2-O......................................211

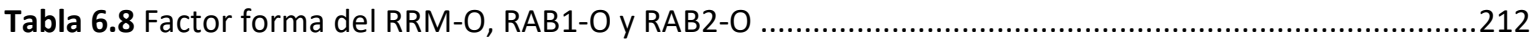

Tabla 6.9 Densidad de partícula del RRM-O, RAB1-O y RAB2-O ..............................................................213

Tabla 6.10 Tamaño de muestra inicial para RRM-O, RAB1-O y RAB2-O ....................................................214

Tabla 6.11 Programación temporal y número de muestras para la fase 1 en la PRC de Onda....................215

Tabla 6.12 Programación temporal y número de muestras para la fase 2 en la PRC de Onda ....................216

Tabla 6.13 Peso medio de muestra por nivel de submuestreo para el RRM-O ........................................221

Tabla 6.14 Composición media por nivel de submuestreo para el RRM-O, fase 1 ....................................222

Tabla 6.15 Composición media por nivel de submuestreo para el RRM-O, fase 2 …...............................222

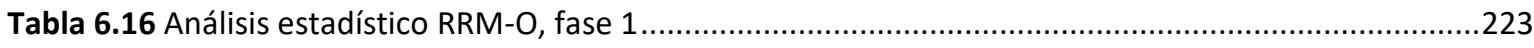

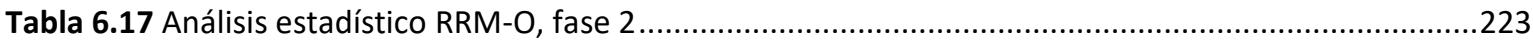

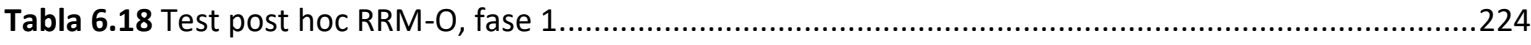

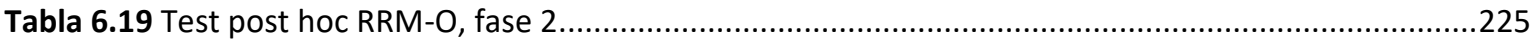

Tabla 6.20 Tamaño mínimo de muestra para el RRM-O ....................................................................226

Tabla 6.21 Peso medio de muestra por nivel de submuestreo para el RAB1-O ........................................226

Tabla 6.22 Composición media por nivel de submuestreo para el RAB1-O, fase 1 ...................................226

Tabla 6.23 Composición media por nivel de submuestreo para el RAB1-O, fase 2 ....................................227

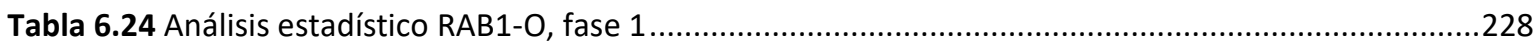

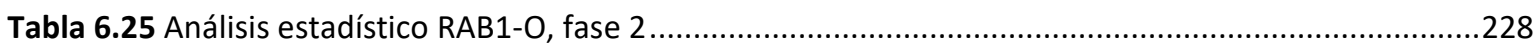

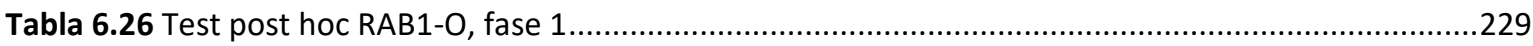

Tabla 6.27 Test post hoc RAB1-O, fase 2 (fracción orgánica, plástico rígido, textil y metales) .....................230

Tabla 6.28 Test post hoc RAB1-O, fase 2 (madera, inertes, RTP y otros) ................................................230

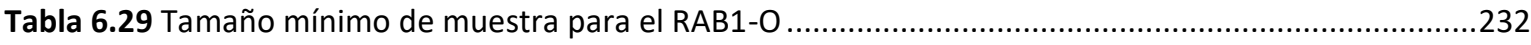

Tabla 6.30 Peso medio de muestra por nivel de submuestreo para el RAB2-O ......................................232

Tabla 6.31 Composición media por nivel de submuestreo para el RAB2-O, fase 1 .................................232

Tabla 6.32 Composición media por nivel de submuestreo para el RAB2-O, fase 2 .................................233

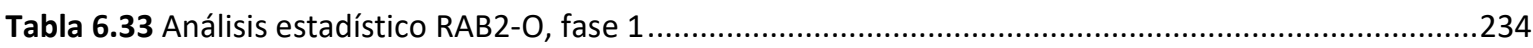

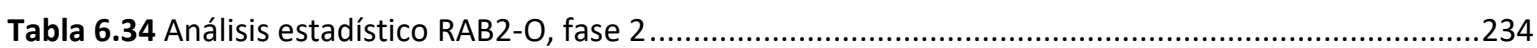

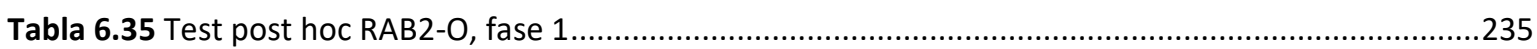

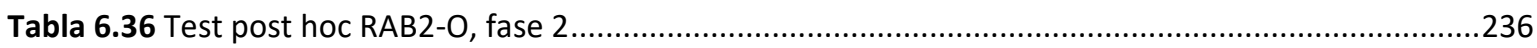

Tabla 6.37 Tamaño mínimo de muestra para el RAB2-O .......................................................................237

Tabla 6.38 Tiempo invertido para el muestreo y caracterización de RRM-O............................................238

Tabla 6.39 Tiempo invertido para el muestreo y caracterización de RAB1-O............................................239

Tabla 6.40 Tiempo invertido para el muestreo y caracterización de RAB2-O..........................................240 
Tabla 6.41 Tamaño nominal superior y tamaño mínimo de partícula del RRM-BS-C................................2242

Tabla 6.42 Tamaño nominal superior y tamaño mínimo de partícula del RABS1-C ..................................243

Tabla 6.43 Tamaño nominal superior y tamaño mínimo de partícula del RABS2-C .................................244

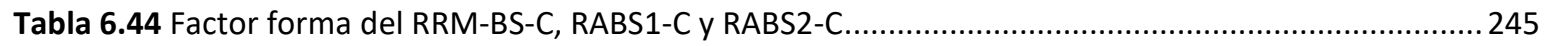

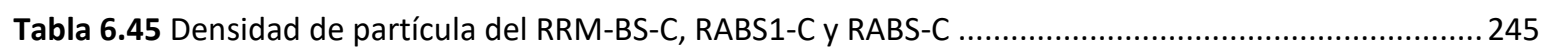

Tabla 6.46 Tamaño de muestra inicial para RRM-BS-C, RABS1-C y RABS2-C ..........................................246

Tabla 6.47 Programación temporal y número de muestras en la PBSR de Cervera ....................................247

Tabla 6.48 Peso medio de muestra por nivel de submuestreo para el RRM-BS-C ....................................252

Tabla 6.49 Composición media por nivel de submuestreo para el RRM-BS-C.........................................252

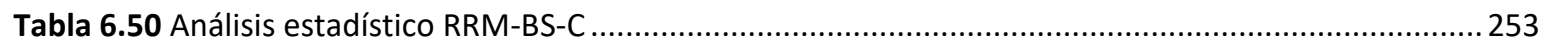

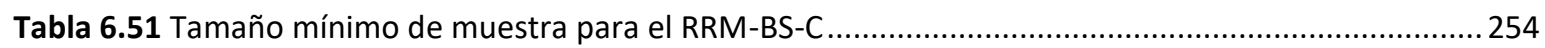

Tabla 6.52 Peso medio de muestra por nivel de submuestreo para el RABS1-C....................................254

Tabla 6.53 Composición media por nivel de submuestreo para el RABS1-C ...........................................255

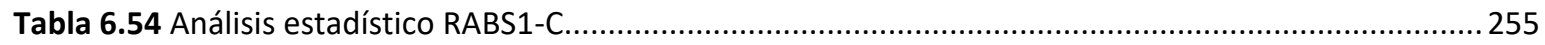

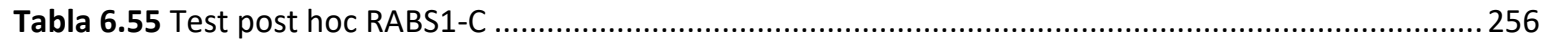

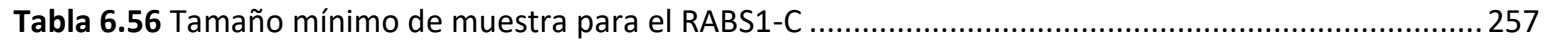

Tabla 6.57 Peso medio de muestra por nivel de submuestreo para el RABS2-C......................................257

Tabla 6.58 Composición media por nivel de submuestreo para el RABS2-C ............................................257

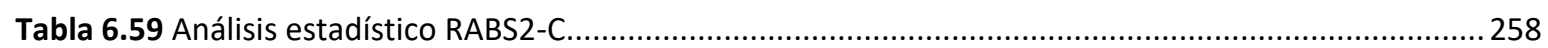

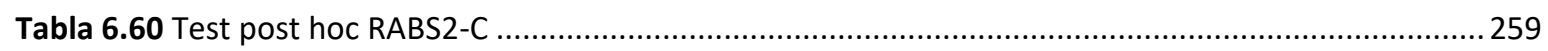

Tabla 6.61 Tamaño mínimo de muestra para el RABS2-C ................................................................260

Tabla 6.62 Tiempo necesario para el muestreo y caracterización de RRM-BS-C ....................................261

Tabla 6.63 Tiempo necesario para el muestreo y caracterización de RABS1-C.........................................262

Tabla 6.64 Tiempo necesario para el muestreo y caracterización de RABS2-C ........................................262

Tabla 6.65 Niveles de variación y variables identificadas para el RRM-O y RAB1-O ..................................264

Tabla 6.66 Determinación del número de muestras mínimo de la PRC de Onda......................................265

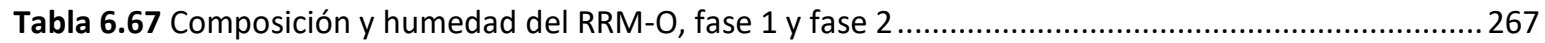

Tabla 6.68 Análisis estadístico RRM-O: comprobación de supuestos ....................................................268

Tabla 6.69 Análisis estadístico RRM-O: comparación de medias entre las dos fases..................................268

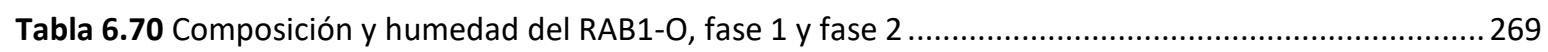

Tabla 6.71 Análisis estadístico RAB1-O: comprobación de supuestos .......................................................2 270

Tabla 6.72 Análisis estadístico RAB1-O: comparación de medias entre las dos fases ................................ 271

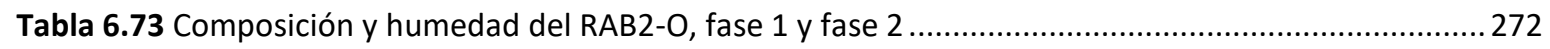

Tabla 6.74 Análisis estadístico RAB2-O: comprobación de supuestos ...................................................22

Tabla 6.75 Análisis estadístico RAB2-O: comparación de medias entre las dos fases ................................273

Tabla 7.1 Composición de referencia para el diseño de las muestras de rechazo artificial (Gallardo et al., 2014) y materiales limpios utilizados 286 
Tabla 7.2 Procedimientos de preparación de muestra en el laboratorio estudiados y muestras obtenidas .289

Tabla 7.3 Peso y composición de las cuatro muestras diseñadas .........................................................294

Tabla 7.4 Tamaño nominal superior y tamaño mínimo de partícula de las muestras artificiales..................296

Tabla 7.5 Características de las muestras de laboratorio CNL2, CNL3, CNL4, CNL5 Y CNL6 .......................297

Tabla 7.6 Características de las muestras de laboratorio C60L2, C60L3, C60L4, C60L5 Y C60L6 .................299

Tabla 7.7 Características de las muestras de laboratorio C30L2, C30L3, C30L4, C30L5 Y C30L6 .................301

Tabla 7.8 Porcentaje de fracción no combustible de las muestra de referencia y las 15 muestras de laboratorio

Tabla 7.9 Humedad, $\mathrm{PCl}$, contenido en $\mathrm{Cl}$ y en $\mathrm{Hg}$ de la muestra de referencia y las 15 muestras de laboratorio 304

Tabla 7.10 Test post hoc para los resultados de $\mathrm{PCI}$ .306

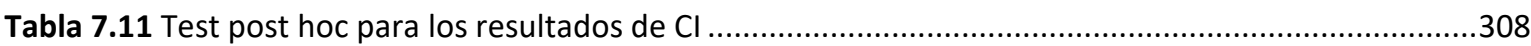

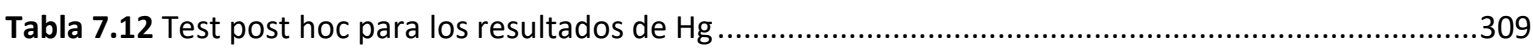

Tabla 7.13 Tamaños de muestra de laboratorio necesarias para el control de calidad de los rechazos ........310

Tabla 7.14 Clases de tamaños consideradas para la determinación del tiempo óptimo de secado .............313

Tabla 7.15 Distribución del tamaño de partícula y composición del RRM-O ............................................314

Tabla 7.16 Distribución del tamaño de partícula y composición del RAB1-O ..........................................316

Tabla 7.17 Distribución del tamaño de partícula y composición del RRAP-G ..........................................318

Tabla 7.18 Distribución del tamaño de partícula y composición del RRAL-G .............................................320

Tabla 7.19 Distribución del tamaño de partícula y composición del H60-G .............................................322

Tabla 7.20 Distribución del tamaño de partícula y composición del H6090-G ............................................324

Tabla 7.21 Distribución del tamaño de partícula y composición del H70-G ................................................326

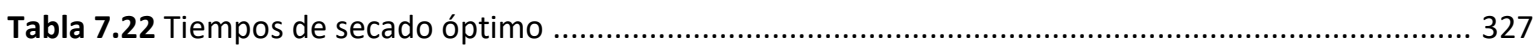





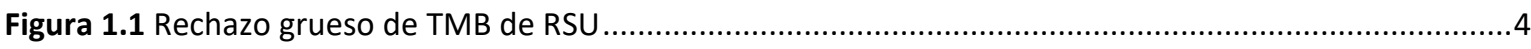

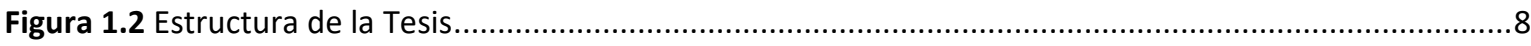

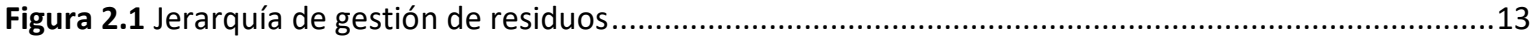

Figura 2.2 Generación mundial de residuos, año 2016 (Kaza et al., 2018) ...............................................16

Figura 2.3 Generación RSU en la Unión Europea, 2017 (Eurostat, 2019) ...................................................17

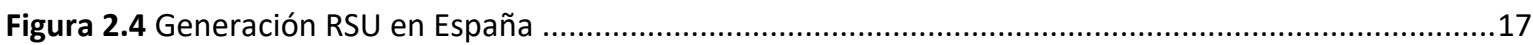

Figura 2.5 Composición de los RSU en función del nivel de renta (Kaza et al., 2018)..................................19

Figura 2.6 Composición media de los RSU mezclados en España (MAGRAMA, 2015) .................................19

Figura 2.7 Recogida y tratamiento de los RSU en un sistema integrado de gestión.....................................29

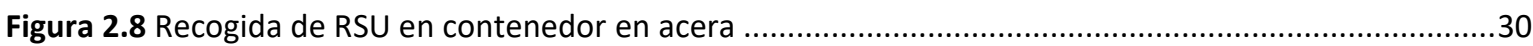

Figura 2.9 Recogida de RSU en áreas de aportación: contenedores en superficie (1) y soterrados (2) ..........30

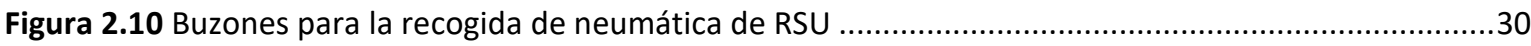

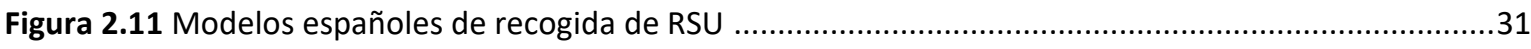

Figura 2.12 Materiales recuperados en el tratamiento mecánico: PEAD (1), PET (2) y papel/cartón (3) ........33

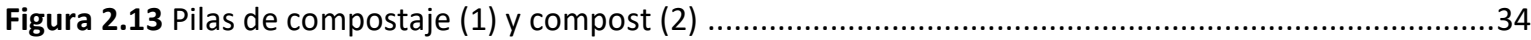

Figura 2.14 Recuperación mecánica de materiales: trómel (1 y 2) equipos de separación (3); Compostaje de la fracción orgánica: reactor de fermentación (4), reactor de maduración (5) y compost (6) .........................35

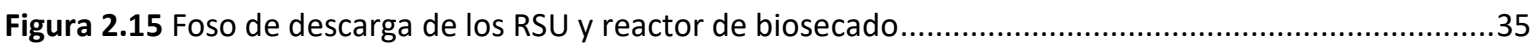

Figura 2.16 Vaso de vertido impermeabilizado (1), balsa para la recogida de lixiviados (2), chimenea para la

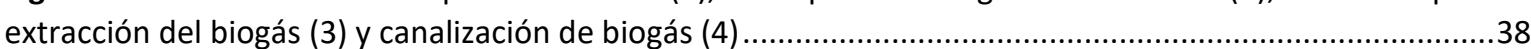

Figura 2.17 Frente de vertido (1), clausura parcial (2) y sellado y clausura final (3) .....................................39

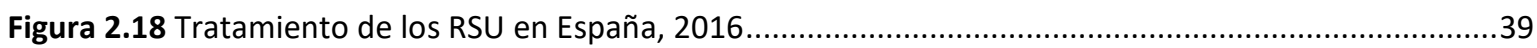

Figura 2.19 Balas de rechazo para su depósito en vertedero $(1$ y 2 ) y rechazo del TMB (3) .........................40

Figura 2.20 CSR producido a partir de rechazo del TMB ........................................................................44

Figura 2.21 Grado de sustitución de combustibles fósiles por alternativos en la industria del cemento en la

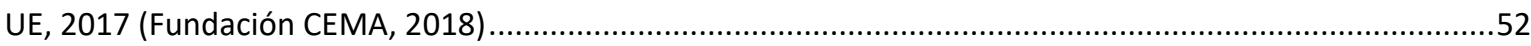

Figura 2.22 Grado de sustitución de combustibles fósiles por alternativos en la industria del cemento en España, 2017 (Institut Cerdà, 2019)

Figura 2.23 Combustibles alternativos más usados en las cementeras españolas en toneladas, 2017 (Institut Cerdà, 2019) .53

Figura 2.24 Heterogeneidad de constitución y de distribución en los materiales ......................................59

Figura 2.25 Errores de muestreo de la Teoría de Muestreo de Gy (Petersen et al., 2005)

Figura 2.26 Regla del centro de gravedad para la extracción de incrementos según la Teoría de Muestreo de Gy (Petersen et al., 2005)

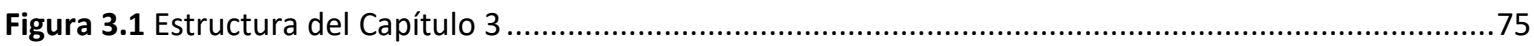

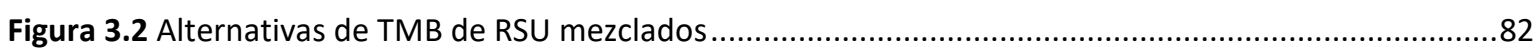


Figura 3.3 Alternativas de TMB de FORS

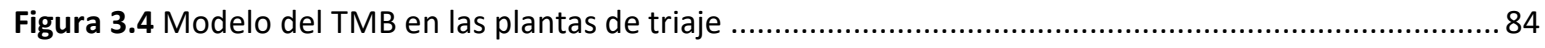

Figura 3.5 Modelo del TMB en las plantas de recuperación y compostaje ...............................................84

Figura 3.6 Modelo del TMB en las plantas de biosecado y recuperación.................................................. 85

Figura 3.7 Modelo del TMB en las plantas de recuperación, biometanización y compostaje.........................86

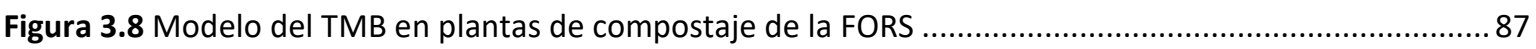

Figura 3.9 Modelo del TMB en las plantas de biometanización y compostaje de la FORS ............................8 88

Figura 3.10 Modelo de la etapa mecánica de recuperación manual de materiales reciclables en las PT, PRC y PRBC. .. 89

Figura 3.11 Modelo de la etapa mecánica de recuperación automática de materiales reciclables en las PT,

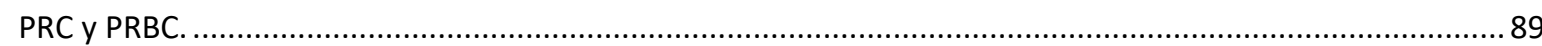

Figura 3.12 Modelo de la etapa mecánica de acondicionamiento de la FORS en las PCFO y las PBCFO........ 90

Figura 3.13 Modelo de la etapa biológica de compostaje en NA, NC o T en las PRC y las PCFO ....................91

Figura 3.14 Modelo de la etapa biológica de biometanización y compostaje de las PRBC y las PBCFO .........92

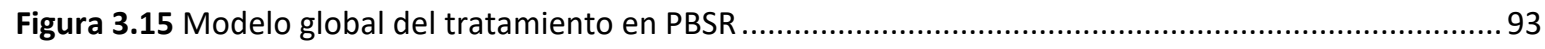

Figura 3.16 Flujos considerados en el balance de materia de las plantas de TMB obtenidos a partir de los

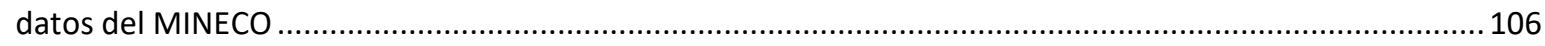

Figura 3.17 Distribución de la generación de rechazo por plantas de TMB ......................................... 120

Figura 4.1 Rechazos generados en las diferentes etapas y procesos de una planta de TMB ..................... 129

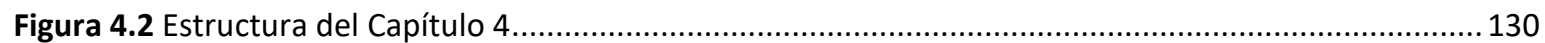

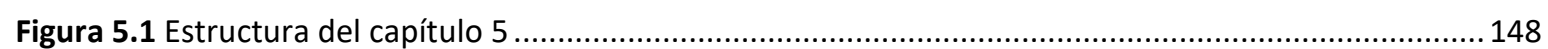

Figura 5.2 Patrones de muestreo para las diferentes técnicas de muestreo estadístico. ............................ 149

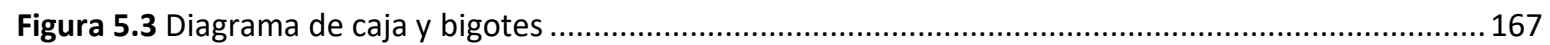

Figura 5.4 Posición de las medias de tendencia central en distribuciones asimétricas..............................168

Figura 5.5 Distribución Normal de una población con media $(\mu)$ de 12 y deviación estándar $(\sigma)$ de $2 \ldots . . . . .170$

Figura 5.6 Distribución logaritmo-Norma de una población media $(\mu)$ de 3 y deviación estándar $(\sigma)$ de 2,4 171

Figura 5.7 Procedimiento estadístico para la comparación de dos grupos de muestras para comprobar si pertenecen a la misma población (son iguales) cuando $n \geq 10$ 179

Figura 5.8 Procedimiento estadístico comparación de $k$ grupos de muestras para comprobar si pertenecen a

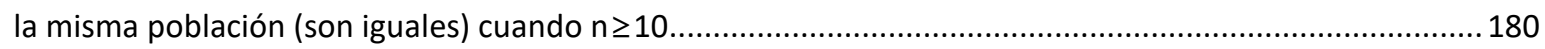

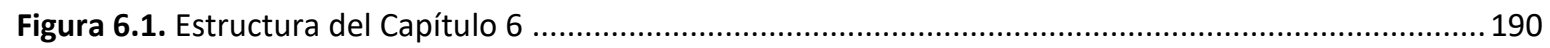

Figura 6.2 Muestreo estratificado en una pila de rechazo .................................................................. 199

Figura 6.3 Esquema del procedimiento de división de tamaño de muestra inicial ...................................200

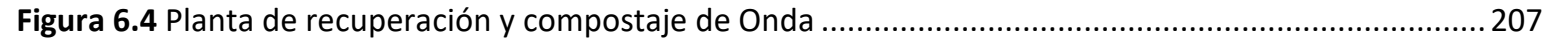

Figura 6.5 Rechazos generados en la planta de recuperación y compostaje de Onda...............................208

Figura 6.6 Tamaño nominal superior, tamaño mínimo de partícula y tamaño de partícula predominante en el RRM-O 
Figura 6.7 Tamaño nominal superior, tamaño mínimo de partícula y tamaño de partícula predominante en el RAB1-O

Figura 6.8 Tamaño nominal superior, tamaño mínimo de partícula y tamaño de partícula predominante en el RAB2-O

Figura 6.9 Determinación del volumen de partícula RRM-O: cuarteo de muestra control (1), recipiente (2) y muestra sumergida ( 3 y 4 )

Figura 6.10 Determinación del volumen de partícula RAB1-O: cuarteo de muestra control (1), artilugio (2) y muestra preparada para sumergirla (3) y muestra sumergida (4) .......................................................213

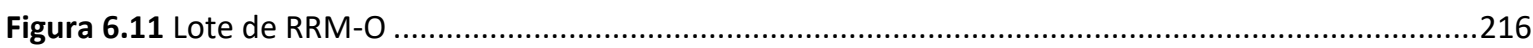

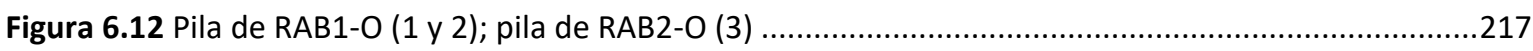

Figura 6.13 Esquema de procedimiento de división del tamaño de muestra inicial del RRM-O ..................217

Figura 6.14 Toma de muestras ( 1 y 2 ) y caracterización $(3$ y 4 ) del RRM-O...........................................218

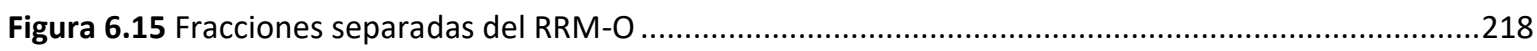

Figura 6.16 Esquema de procedimiento de división del tamaño de muestra inicial del RAB1-O ..................219

Figura 6.17 Esquema de procedimiento de división del tamaño de muestra inicial del RAB2-O .................219

Figura 6.18 Cuarteo y caracterización del RAB1-O (1, 2 y 3), caracterización RAB2-O (4) ..........................219

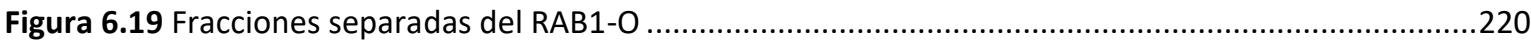

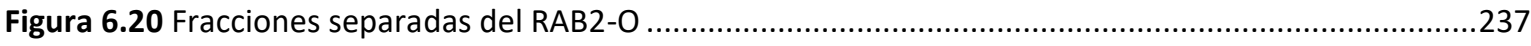

Figura 6.21 Ajuste ecuación del tamaño de muestra de la PRC de Onda ...............................................240

Figura 6.22 Planta de biosecado y recuperación de Cervera del Maestre ...............................................241

Figura 6.23 Rechazos generados en la planta de biosecado y recuperación de Cervera..............................243

Figura 6.24 Tamaño nominal superior, tamaño mínimo de partícula y tamaño de partícula predominante en el RRM-BS-C

Figura 6.25 Tamaño nominal superior, tamaño mínimo de partícula y tamaño de partícula predominante en el RABS1-C

Figura 6.26 Tamaño nominal superior, tamaño mínimo de partícula y tamaño de partícula predominante en el RABS2-C.

Figura 6.27 Material y equipamiento para realizar las caracterizaciones .248

Figura 6.28 Pala mecánica depositando un lote de RRM-BS-C (1); lotes de RRM-BS-C de dos días (2) .........248

Figura 6.29 Esquema de procedimiento de división del tamaño de muestra inicial del RRM-BS-C .............249

Figura 6.30 Zona de caracterización (1) y caracterización (2) del RRM-BS-C ..........................................249

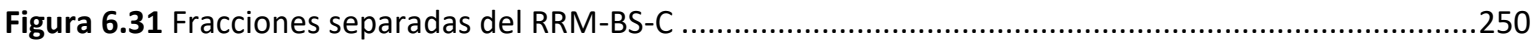

Figura 6.32 Esquema de procedimiento de división del tamaño de muestra inicial del RABS1-C...............250

Figura 6.33 Esquema de procedimiento de división del tamaño de muestra inicial del RABS2-C................250

Figura 6.34 Cuarteo y caracterización del RABS1-C (1 y 2), caracterización RABS2-C (3) ............................251

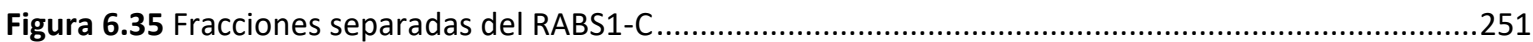

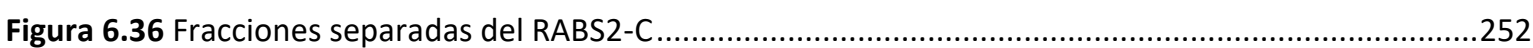

Figura 6.37 Ajuste ecuación del tamaño de muestra de la PBSR de Cervera..............................................260

Figura 7.1 Muestra tomada en una planta de TMB (1); pellets de 1 gramo para el análisis del $\mathrm{PCl}$.............281 
Figura 7.2 Estructura del Capítulo 7.

Figura 7.3 Diseño del experimento para la determinación del tamaño de muestra de laboratorio ..............288

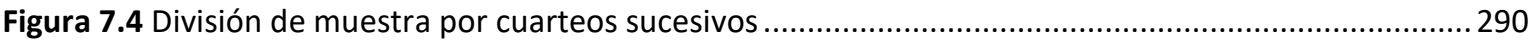

Figura 7.5 Estufa CARBOLITE para el secado (1) y molino de corte RETSCH modelo SM-2000 (2 y 3) ..........290

Figura 7.6 Prensa de pastillas (1), pastilla con el hilo de ignición (2), llenado de la bomba con $\mathrm{O}_{2}$ (3), bomba

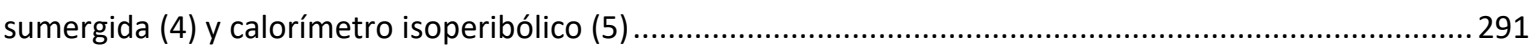

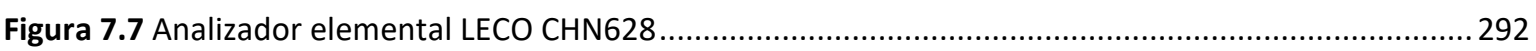

Figura 7.8 Soluciones preparadas para su análisis y cromatógrafo iónico DIONEX DX-120 .........................292

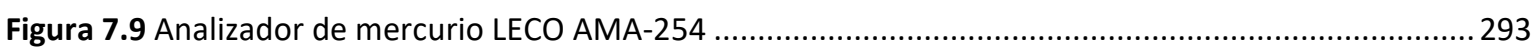

Figura 7.10 Materiales vírgenes utilizados en el diseño de las muestras ...............................................295

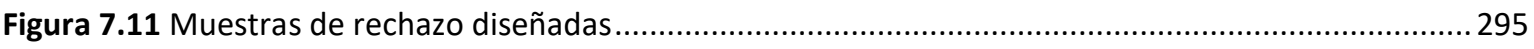

Figura 7.12 Tamaño nominal superior y tamaño de partícula predominante en las muestras artificiales de

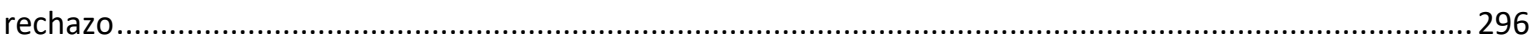

Figura 7.13 Tamaños de partícula antes de la división por cuarteo: MA2 (1), MA3 (2) y MA4 (3) ...............297

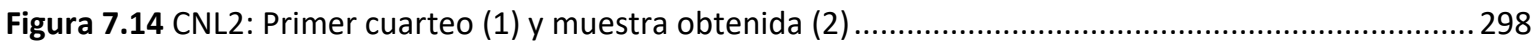

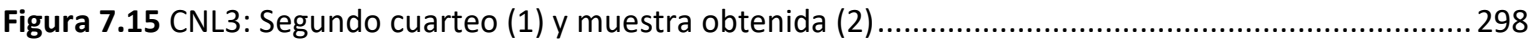

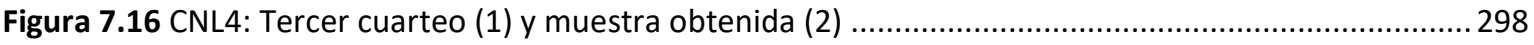

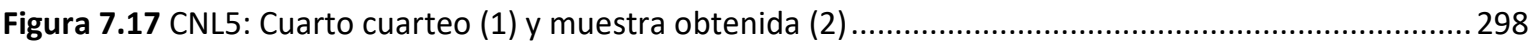

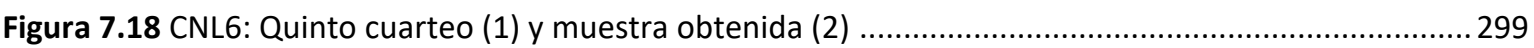

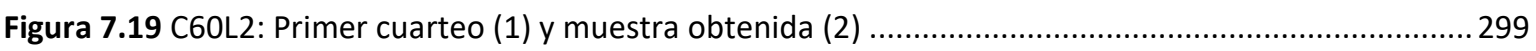

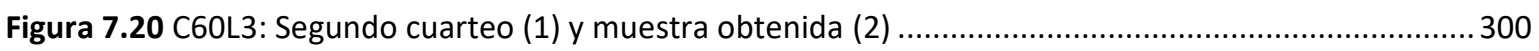

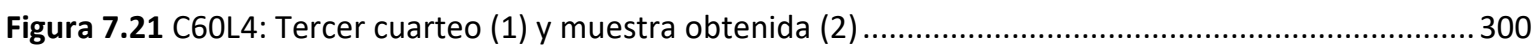

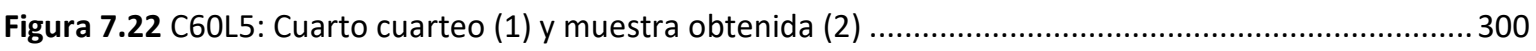

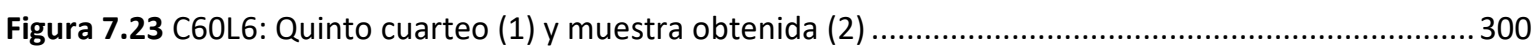

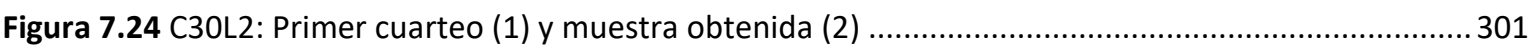

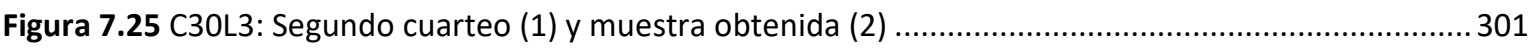

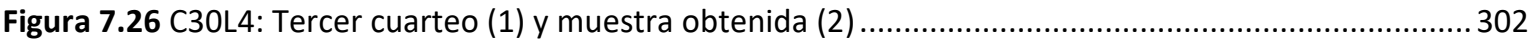

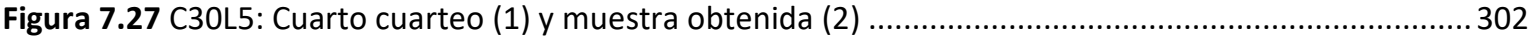

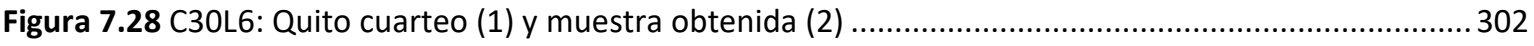

Figura 7.29 Fracción no combustible eliminada de la muestra de laboratorio C60L2 ................................303

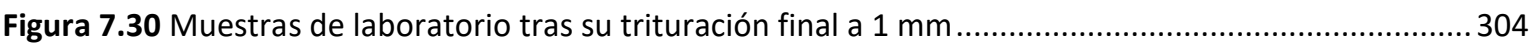

Figura 7.31 Esquema de tratamiento de las etapas mecánicas (pretratamiento y recuperación de

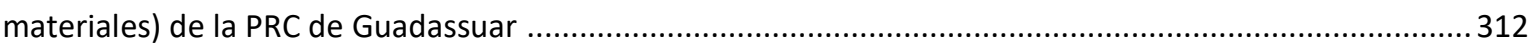

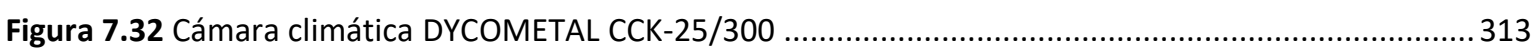

Figura 7.33 Bandejas de RRM-O para la monitorización del proceso de secado........................................314

Figura 7.34 Variación del porcentaje de masa inicial del RRM-O a lo largo del tiempo de secado ...............315

Figura 7.35 Bandejas de RAB1-O para la monitorización del proceso de secado......................................316 
Figura 7.36 Variación del porcentaje de masa inicial del RAB1-O a lo largo del tiempo de secado 317

Figura 7.37 Bandejas de RRAP-G para la monitorización del proceso de secado ......................................318

Figura 7.38 Variación del porcentaje de masa inicial del RRAP-G a lo largo del tiempo de secado ..............319

Figura 7.39 Bandejas de RRAL-G para la monitorización del proceso de secado ......................................320

Figura 7.40 Variación del porcentaje de masa inicial del RRAL-G a lo largo del tiempo de secado...............321

Figura 7.41 Bandejas de H60-G para la monitorización del proceso de secado .........................................321

Figura 7.42 Variación del porcentaje de masa inicial del H60-G a lo largo del tiempo de secado.................323

Figura 7.43 Bandejas de H6090-G para la monitorización del proceso de secado ......................................323

Figura 7.44 Variación del porcentaje de masa inicial del H6090-G a lo largo del tiempo de secado.............325

Figura 7.45 Bandejas de H70-G para la monitorización del proceso de secado .......................................325

Figura 7.46 Variación del porcentaje de masa inicial del H70-G a lo largo del tiempo de secado.................326 

AENOR Asociación Española de Normalización y Certificación

ARC Agencia de Residuos de Cataluña

ASTM American Society for Testing and Materials

AUT Planta de TMB con recuperación de materiales automática

BGAS Total producción de biogás (t/año)

BIOST Total producción de bioestabilizado (t/año)

C30L2 Muestra de laboratorio obtenida a partir de MA4 mediante un cuarteo y con reducción de tamaño de partícula a $30 \mathrm{~mm}$

C30L3 Muestra de laboratorio obtenida a partir de MA4 mediante dos cuarteos y con reducción de tamaño de partícula a $30 \mathrm{~mm}$

C30L4 Muestra de laboratorio obtenida a partir de MA4 mediante tres cuarteos y con reducción de tamaño de partícula a $30 \mathrm{~mm}$

C30L5 Muestra de laboratorio obtenida a partir de MA4 mediante cuatro cuarteos y con reducción de tamaño de partícula a $30 \mathrm{~mm}$

C30L6 Muestra de laboratorio obtenida a partir de MA4 mediante cinco cuarteos y con reducción de tamaño de partícula a $30 \mathrm{~mm}$

C60L2 Muestra de laboratorio obtenida a partir de MA3 mediante un cuarteo y con reducción de tamaño de partícula a $60 \mathrm{~mm}$

C60L3 Muestra de laboratorio obtenida a partir de MA3 mediante dos cuarteos y con reducción de tamaño de partícula a $60 \mathrm{~mm}$

C60L4 Muestra de laboratorio obtenida a partir de MA3 mediante tres cuarteos y con reducción de tamaño de partícula a $60 \mathrm{~mm}$

C60L5 Muestra de laboratorio obtenida a partir de MA3 mediante cuatro cuarteos y con reducción de tamaño de partícula a $60 \mathrm{~mm}$

C60L6 Muestra de laboratorio obtenida a partir de MA3 mediante cinco cuarteos y con reducción de tamaño de partícula a $60 \mathrm{~mm}$

C.A Comunidad autónoma

CC.AA. Comunidades autónomas

CDR Combustible derivado de residuos

CEN Comité Europeo de Estandarización

CNL1 Muestra de laboratorio de referencia que corresponde a MA1

CNL2 Muestra de laboratorio obtenida a partir de MA2 mediante un cuarteo y sin reducción de tamaño de partícula

CNL3 Muestra de laboratorio obtenida a partir de MA2 mediante dos cuarteos y sin reducción de tamaño de partícula

CNL4 Muestra de laboratorio obtenida a partir de MA2 mediante tres cuarteos y sin reducción de tamaño de partícula 
CNL5 Muestra de laboratorio obtenida a partir de MA2 mediante cuatro cuarteos y sin reducción de tamaño de partícula

CNL6 Muestra de laboratorio obtenida a partir de MA2 mediante cinco cuarteos y sin reducción de tamaño de partícula

COMP Total producción de compost (t/año)

CSR Combustible sólido recuperado

cv Coeficiente de variación

Efors $\quad$ Entradas de FORS (t/año)

EoW Fin de condición de residuos (End of Waste)

EPA United States Environmental Protection Agency

ERFO European Recovered Fuel Organisation

ERSU Entradas de RSU mezclados (t/año)

ERV-L Entradas de otro tipo de residuos biodegradables, como restos de poda y lodos (t/año)

EURITS European Union for Responsible Incineration and Treatment of Special Waste

FORS Fracción orgánica recogida selectivamente

FORS $\quad$ Porcentaje de FORS tratada

FSE Error Fundamental de Muestreo (Fundamental sampling error)

g Factor de corrección para la distribución en el tamaño de partícula

GEE Error de Estimación Global (Global Estimation Error)

GSE Error de Agrupación de Muestreo (Grouping and Segregation Error)

H6090-G Flujo correspondiente al segundo hundido del trómel doble de pretratamiento de la PRC de Guadassuar

H60-G Flujo correspondiente al primer hundido del trómel doble de pretratamiento de la PRC de Guadasuar

H70-G Flujo correspondiente al hundido del trómel de la etapa de recuperación de envases de la PRC de Guadassuar

hab habitante

IDE Error de Delimitación de Incremento (Increment Delimitation Error)

IEE Error de Extracción de Incremento (Increment Extraction Error)

INE Instituto Nacional de Estadística

IQR Rango intercuartil

IPE Error de Preparación de Incremento (Increment Preparation Error)

ISE Error de Muestreo Incorrecto (Incorrect Sampling Error)

LER Lista Europea de Residuos

Li Nivel de submuestreo, donde $i$ va de 1 a 5

M Mermas del proceso de tratamiento (\%)

MAGRAMA Ministerio de Agricultura, Alimentación y Medio Ambiente

MAi Muestra de rechazo artificial, donde $i$ va de 1 a 4 
MANU Planta de TMB con recuperación de materiales manual

$\mathbf{m}_{\mathbf{f}} \quad$ tamaño mínimo de muestra para el control de calidad del rechazo $(\mathrm{kg})$

MITECO Ministerio para la Transición Ecológica

mL Tamaño de muestra de laboratorio para los análisis de los parámetros de calidad (kg)

$\mathbf{m}_{\mathbf{m}} \quad$ Tamaño de muestra inicial $(\mathrm{kg})$

NA Planta de TMB con compostaje en nave abierta

NC Planta de TMB con compostaje en nave cerrada

NCR Número de corrientes de rechazo a muestrear

NDIR Infrarrojo no dispersivo

NIR Radiación infrarroja cercana

NM Número de muestras necesarias para el control de calidad de los rechazos

p Fracción de las partículas con la característica especifica que se quiere evaluar $(\mathrm{kg} / \mathrm{kg})$

PBSR-C Planta de biosecado y recuperación de Cervera del Maestre

PCl Poder calorífico inferior

PCS Poder calorífico superior

$\mathbf{P}_{\mathbf{d}} \quad$ Número de estratos para el nivel de variación diario

PEAD Polietileno de alta densidad

PEBD Polietileno de baja densidad

PEMAR Plan Estatal Marco de Residuos

PER Plan Energías Renovables

PET Polietileno de teraftalato

PIRCV Plan Integral de Residuos de la Comunidad Valenciana

PIRCVA Plan Integral de Residuos de la Comunidad Valenciana Actualizado

$\mathbf{P}_{\mathbf{m}} \quad$ Número de estratos para el nivel de variación mensual

PP Polipropileno

PRC-O Planta de recuperación y compostaje de Onda

Ps Número de estratos para el nivel de variación semanal

PS Poliestireno

PT Planta de triaje

PVC Policloruro de vinilo

RAB1 Rechazo de afino primario del bioestabilizado

RAB1-O Rechazo de afino primario del bioestabilizado de la PRC de Onda

RAB2 Rechazo de afino secundario del bioestabilizado

RAB2-O Rechazo de afino secundario del bioestabilizado de la PRC de Onda

RABS1 Rechazo de afino primario del biosecado

RABS1-C Rechazo de afino primario del biosecado de la PBSR de Cervera del Maestre 
RABS2 Rechazo de afino secundario del biosecado

RABS2-C Rechazo de afino secundario del biosecado de la PBSR de Cervera del Maestre

RAC1 Rechazo de afino primario del compost

RAC2 Rechazo de afino secundario del compost

RAEE Residuos de aparatos eléctricos y electrónicos

RECHAZO Porcentaje de rechazo

RFR Rechazo fino de recuperación

RGGGAS Rendimiento producción de biogás (m3/t RSU tratado)

RG

RGcomp Rendimiento global de compost (\%)

$\mathbf{R G}_{\mathrm{MR}} \quad$ Rendimiento global de materiales recuperados (\%)

RLFO Rechazo de limpieza de la FORS

RRA Rechazo de recuperación automática

RRA-BS Rechazo de recuperación automática del biosecado

RRAL-G Rechazo ligero de recuperación automática de la PRC de Guadassuar

RRAP-G Rechazo pesado de recuperación automática de la PRC de Guadassuar

RRM Rechazo de recuperación manual

RRM-BS Rechazo de recuperación manual del biosecado

RRM-BS-C Rechazo de recuperación manual del biosecado de la PBSR de Cervera del Maestre

RRM-O Rechazo de recuperación manual de la PRC de Onda

RSU Residuos sólidos urbanos

RSU $_{\text {T }} \quad$ Porcentaje de RSU tratados

RTP Residuos tóxicos y peligrosos

s Desviación estándar

SFo Total salidas fracción orgánica recuperada

SEPA Scottish Environment Protection Agency

smh Resultados sobre muestra húmeda

SMR Total salidas materiales reciclables recuperados

sms resultados sobre muestra seca

T Planta de TMB con compostaje en túneles

TAE Error Analítico Total (Total Analytical Error)

TGD Tasa de generación diaria (kg/hab-día)

TMB Tratamiento mecánico biológico

TOS Teoría de Muestreo (Theory of Sampling)

TSE Error Total de Muestreo (Total Sampling Error)

UE Unión Europea 





\subsection{JUSTIFICACIÓN Y PROBLEMÁTICA GENERAL}

En los últimos años, los objetivos para la correcta gestión de los residuos sólidos urbanos (RSU) se centran en la reducción de la generación y en el aprovechamiento al máximo de los recursos contenidos en los mismos, buscando con ello minimizar la cantidad enviada a vertedero. Por ello, tanto en España como en otros países europeos, la legislación obliga a tratar por diferentes vías todos los RSU antes de su disposición final. No obstante, en todos los sistemas de tratamiento aparecen varias corrientes de rechazos cuyo principal destino es el vertedero. Estas están compuestas por aquellos materiales que no han podido ser separados o no son reciclables desde un enfoque técnico, económico y/o ambiental.

Dentro de los diferentes tratamientos a los que pueden ser sometidos los RSU, el tratamiento mecánico biológico (TMB) es uno de los más extendidos en Europa y España (Gallardo et al., 2014). Sin embargo, una de las principales problemáticas de las plantas de TMB radica en la gran cantidad de rechazo generado en el proceso. Esto se debe a la heterogeneidad del material entrante (Colomer and Gallardo, 2007), ya que junto con los residuos solicitados entran gran cantidad de materiales que no pueden ser recuperados y que finalmente acaban formando parte del rechazo (de Araújo Morais et al., 2008). Estos rechazos tienen un contenido energético elevado debido a que están compuestos mayoritariamente por materiales combustibles (Di Lonardo et al., 2012; Gallardo et al., 2014), sobre todo cuando los RSU de los que proceden tienen un alto poder calorífico (Bessi et al., 2016). Por lo que, una alternativa para la valorización de los mismos es su transformación en un combustible sólido recuperado (CSR) (Garcés et al., 2016; Sarc et al., 2014; Velis et al., 2010).

Por otro lado, el desarrollo de la sociedad ha venido acompañado de un gran consumo de energía y del uso de combustibles fósiles. Por lo que, con el objetivo de reducir el efecto negativo del uso de estos combustibles, ha sido necesario el desarrollo de nuevas medidas desde el punto de vista energético y ambiental. En este sentido, la Unión Europea en la Directiva 2018/2001/UE establece como uno de sus objetivos cubrir al menos el 32\% del consumo de energía final en el año 2030 con fuentes de energías renovables (Parlamento Europeo y Consejo de la Unión Europea, 2018). Por su parte, el Plan de Energías Renovables 2011-2020 (PER) de España contempla como fuentes de energía renovables los RSU (IDAE, 2011).

Además, dentro del marco de la estrategia Europa 2020, se pretende generar un crecimiento sostenible e integrador mediante el uso eficaz de los recursos. En diciembre de 2015 la Comisión Europea adoptó un ambicioso paquete de medidas para impulsar la transición de Europa hacia una economía circular. Las acciones propuestas contribuirán a "cerrar el círculo" de los ciclos de vida de los productos a través de un mayor reciclado y reutilización. En este sentido, en mayo de 2018 el Parlamento Europeo y el Consejo de la UE publicó las nuevas direcivas del paquete de economia circular. En ellas se incluyen las nuevas propuestas legislativas del paquete de residuos, las cuales establecen nuevos objetivos más estrictos para el reciclaje de residuos y la reducción del vertido. Entre estos objetivos se encuentra la preparación para la reutilización y el reciclaje del 55\% de los RSU en 2025 y del 60\% en 2030; el reciclaje de un 65\% del total del residuos de envases para el 2025 y del 70\% para el 2030, y la reducción del vertido de residuos al 10\% para el 2030 (Parlamento Europeo y Consejo de la Unión Europea, 2018b, 2018c, 2018d). Por tanto, las entidades responsbles de la gestión de residuos deberan encontrar y adoptar nuevas soluciones para el cumplimiento de los mismos.

Dentro de este contexto, la producción de CSR a partir de los rechazos de las plantas de TMB tiene una serie de ventajas medioambientales y económicas importantes; puesto que reduce la cantidad de residuos enviada a vertedero y se consigue recuperar la energía contenida en los mismos, proporciona combustibles alternativos a las industrias que hacen un uso intensivo de combustibles fósiles y contribuye a la transición a la economía circular y el cumplimiento de sus objetivos (European Commision, 2017; Gug et al., 2015).

Sin embargo, cabe señalar que los rechazos son un material muy heterogéneo (Figura 1.1) (formado por distintos materiales en proporciones diferentes) y su composición y propiedades pueden depender de numerosos factores, tanto del entorno (estacionalidad, climatología, etc.) como socio-económicos (turismo, 
modo de vida de la población, etc.) o relacionados con el sistema de gestión (sistema de recogidas selectivas, tipos de instalaciones, procesos de tratamiento, etc.) (Brás et al., 2017; Di Lonardo et al., 2016). Además, sus características físico-químicas también dependen de los RSU de entrada a las plantas (Di Lonardo et al., 2012) y de la configuración de las mismas (Nasrullah et al., 2017; Velis et al., 2012). En consecuencia, los CSR producidos a partir de estos rechazos también son combustibles muy heterogéneos y sus características físicas y químicas pueden ser muy variables, dependiendo en gran medida del rechazo o residuos utilizado y del proceso de tratamiento aplicado para su producción.

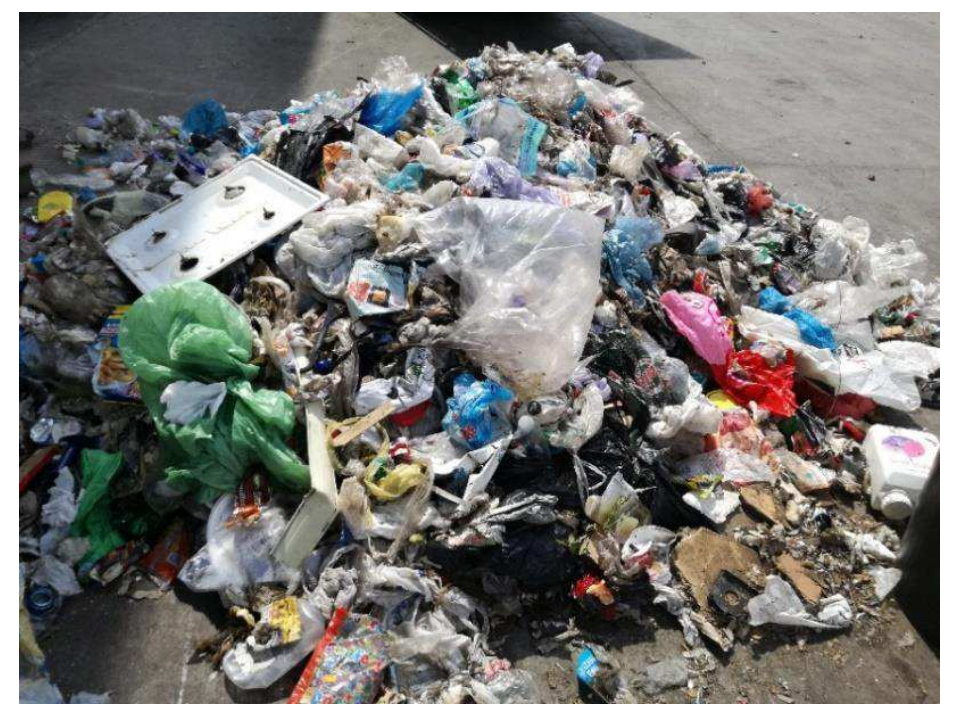

Figura 1.1 Rechazo grueso de TMB de RSU

Así pues, el tipo, naturaleza y composición de los rechazos, así como la variabilidad de sus propiedades a lo largo del tiempo, afectará a la calidad del CSR obtenido a partir de los mismos (Nasrullah et al., 2017; Velis et al., 2012). Por ello, en Europa, este tipo de combustibles están sujetos a unos parámetros específicos de calidad y deben cumplir una serie de estándares de calidad que aseguren la protección del medio ambiente, de los equipos utilizados para su combustión y de la calidad del producto final si existe (por ejemplo, el cemento). Además, su contenido energético y mineral debe ser lo suficientemente estable en el tiempo y su forma física debe asegurar una manipulación, almacenamiento y alimentación higiénica y segura. A nivel europeo, esta estandarización ha sido llevada a cabo por el Comité Europeo de Estandarización (CEN), en concreto por el comité técnico CEN/TC 343 - Solid Recovered Fuels, el cual ha definido qué parámetros son importantes para la calidad del CSR y ha propuesto un sistema para la clasificación de su calidad a partir de los mismos. Además, ha elaborado una serie de normas donde se establecen los métodos a seguir para la determinación de los diferentes parámetros que permiten caracterizar los CSR. Adicionalmente, algunos países como Alemania, Italia, Finlandia, Austria o Suiza han definido sus propios estándares de calidad (Flamme and Geiping, 2012; Gallardo et al., 2014), pudiendo variar en función del tipo de instalación donde los CSR pueden ser utilizados (hornos de cemento, centrales eléctricas o instalaciones de co-incineración) (Lorber et al., 2012). Por otro lado, países como Italia y Austria tienen legislación específica donde se establecen los criterios para la desclasificación de los CSR como residuos, pasando a ser un subproducto, lo que incentiva su producción, comercialización y utilización como combustible (Gallardo et al., 2017).

La normativa europea define CSR como aquellos combustibles producidos a partir de residuos no peligrosos (como el rechazo de las plantas de TMB), tras su adecuado tratamiento, y que cumplen los requisitos de clasificación y especificaciones (estándares de calidad) establecidos en la norma UNE-EN 15359 (2012). Por lo que, aquellos combustibles que no cumplan los estándares fijados en esta norma no serán considerados CSR, simplemente serán Combustibles Derivados de Residuos (CDR).

En la actualidad, la producción de CSR a partir de rechazos aumenta año tras año, debido al mayor interés que presentan las industrias del sector energético en la utilización de un combustible alternativo más económico y a la implantación en muchos países de nuevas plantas de TMB (Gallardo et al., 2014). No 
obstante, para que los rechazos puedan ser clasificados y comercializados como CSR, deben tener unas propiedades físico-químicas homogéneas y conocidas, aumentando su calidad si estas propiedades no varían con el tiempo. Además, la calidad de los CSR es un factor clave para su demanda y utilización tanto en el sector de la producción de energía, como para su co-incineración en hornos de cemento. Por lo tanto, para que los CSR sean aceptados como un combustible alternativo y puedan remplazar a los actuales combustibles fósiles, es imprescindible lograr la calidad exigida o requerida por estos sectores (Glorious, 2014; Nasrullah et al., 2017). Asimismo, esta debe ser constante para garantizar un proceso termoquímico uniforme.

Por todo ello es necesario que en las plantas de TMB se lleve a cabo un control de calidad de aquellos rechazos que sean susceptibles de ser convertidos en CSR, de manera que se transformen en un combustible fiable y comercializable. Además, esto permitirá obtener información respecto al cumplimiento o no de los estándares de calidad fijados en la normativa y de los requisitos para su uso como CSR en diferentes instalaciones de valorización energética (Lorber et al., 2012; Rotter et al., 2011). Por otra parte, una adecuada metodología de caracterización y control permitirá conocer qué factores o elementos afectan a la calidad de las corrientes de rechazo y por tanto de los CSR producidos a partir de las mismas, lo que aportará una información muy valiosa a la hora de configurar o modificar los procesos de tratamiento de la planta con el objetivo de producir un CSR con una calidad determinada.

Actualmente existen diferentes metodologías y normas para el muestreo y caracterización de los RSU mezclados, así como un conjunto de normas para la caracterización y control de calidad de los CSR. No obstante, en la práctica, ninguna de ellas es aplicable a los rechazos debido a la naturaleza de los mismos. Por un lado, los rechazos son un material más homogéneo que los RSU mezclados, pero más heterogéneo que los CSR. Por otro lado, están formados por componentes con diferentes tamaños de partícula, normalmente mayores de los que forman parte de un CSR (en especial en aquellos rechazos originados en las etapas de recuperación de materiales (Figura 1.1)). Estas dos características hacen que, si se tomaran las metodologías aplicadas a los RSU o a los CSR, sea necesario trabajar con cantidades muy grandes de material, suponiendo un elevado coste económico, así como de mano de obra y tiempo invertido.

Así pues, hoy en día no existe una metodología para el muestro y caracterización de rechazos que sea sencilla, clara, fácil de aplicar y se adecue a las características de este tipo de materiales. Por tanto, es imprescindible el desarrollo de una metodología propia que, basándose en las existentes para RSU y CSR, se adapte a las características de las corrientes de rechazo generadas en las plantas de TMB, en especial a aquellas que son susceptibles de ser transformadas en un CSR. Esta metodología, junto con el diseño de unos procedimientos adecuados para el tratamiento y análisis de muestras en el laboratorio, son una herramienta fundamental para llevar a cabo el control de calidad de estas corrientes, de forma que los resultados proporcionen datos fiables sobre las propiedades de los rechazos y se obtenga un CSR de características definidas a partir de los mismos, lo que facilitará su valorización y comercialización.

Todas las razones anteriormente expuestas han llevado al desarrollo de la presente Tesis, cuyos objetivos se presentan a continuación.

\subsection{OBJETIVOS DE LA INVESTIGACIÓN}

La hipótesis de partida del estudio es que ciertos rechazos producidos en las plantas de TMB pueden ser transformados en un CSR valorizable, el cual debe tener unas propiedades homogéneas y conocidas para que pueda ser comercializado. Para ello es imprescindible que en las plantas de TMB se lleve un control de calidad de aquellos rechazos que sean susceptibles de ser convertidos en CSR, controlando aquellas variables importantes para la producción de estos combustibles.

En base a esto, el objetivo principal de la tesis es el diseño de una metodología para el control de calidad de los rechazos producidos en las plantas de tratamiento mecánico-biológico de RSU, que sea clara, fácil de aplicar y adecuada a las características de este tipo de corrientes. La metodología debe abarcar los siguientes aspectos: 
- La toma de muestras de los rechazos en la planta de TMB, teniendo en cuenta la variabilidad temporal de sus propiedades, de manera que los resultados obtenidos sean representativos del total de la producción.

- La preparación de esas muestras en el laboratorio, de forma que los resultados obtenidos a partir de las mismas proporcionen datos fiables sobre los parámetros de calidad de los CSR.

Para alcanzar el objetivo principal se deberán desarrollar los objetivos específicos que se definen a continuación:

- Conocer la situación actual del TMB en relación al tipo de instalaciones existentes, los procesos de tratamiento llevados a cabo, tecnologías utilizadas, corrientes de rechazo generadas, etc.

- Conocer la situación actual de los CSR producidos a partir de rechazos de plantas de TMB en España y en otros países, respecto a la producción y uso de este tipo de combustibles, al marco legal, a los estándares de calidad existentes, etc.

- Modelizar el funcionamiento de los diferentes tipos de plantas de TMB que permita identificar los flujos de entrada y salida de materiales, así como las corrientes de rechazo susceptibles de ser transformadas en un CSR.

- Identificar las variables que afectan a la composición y características físico-químicas de los rechazos y que, por ende, afectarán a la calidad de los CSR producidos a partir de los mismos.

- Determinar las características y propiedades que definen la calidad de los CSR.

- Revisar las metodologías existentes sobre el muestreo y caracterización de residuos y CSR, así como los métodos estadísticos aplicables.

- Desarrollar un plan de muestreo para la toma de muestra de los rechazos producidos en una planta de TMB, que sea adecuado a cada tipo de corriente y que permita determinar el número y tamaño de muestra mínimo necesario para que los resultados obtenidos sean representativos de la producción total.

- Establecer los procedimientos más adecuados para la preparación de las muestras en el laboratorio de manera que todos los parámetros de control de la calidad se determinen con las máximas garantías.

- Validar la metodología mediante su aplicación a dos plantas de TMB de la provincia de Castellón.

La metodología diseñada será una herramienta útil y sencilla que permitirá el control de la calidad de los rechazos producidos en una planta de TMB, de manera que se pueda obtener un CSR de características definidas a partir de los mismos. Además, proporcionará una serie de procedimientos para el muestreo y caracterización de este tipo de material, minimizando al máximo su coste económico, así como de mano de obra y tiempo invertido.

\subsection{ESTRUCTURA DE LA TESIS}

La presente Tesis se estructura en ocho capítulos. A continuación, se resumen el contenido de cada uno de ellos, a partir de este primero de introducción.

$>$ En el Capítulo 2 se lleva a cabo una revisión del estado del arte de los diferentes aspectos relevantes para el desarrollo de la Tesis. Respecto a los RSU, tras estudiar su generación, composición, propiedades y marco legislativo, se describe el sistema de gestión de los mismos, prestando especial atención a los tipos y modelos de recogida existentes y a los procesos e instalaciones de tratamiento más habituales en España. Además, se lleva a cabo una exhaustiva revisión en relación a las propiedades y características de los rechazos generados en el TMB y a su caracterización como combustible. En cuanto a los CSR, se presenta el marco legislativo de este tipo de combustibles en España, destacándose los aspectos más relevantes. Se estudian los estándares de calidad existentes en diferentes países de la Unión Europea y su situación actual respecto a la producción y uso de los 
mismos, tanto a nivel europeo como nacional. Asimismo, se presentan los CSR comerciales producidos en Europa y la legislación existente en Italia y Austria para su desclasificación como residuos. Por último, se describe la Teoría de Muestreo de Gy, puesto que varias de las metodologías que actualmente se utilizan para el muestreo y caracterización de RSU y CSR se basan en la misma.

En el Capítulo 3 se clasifican los diferentes tipos de plantas de TMB en función del tipo de RSU tratado, etapas de tratamiento y tecnologías y procesos utilizados. Se modeliza el funcionamiento de cada tipo de planta, identificándose las diferentes etapas que las conforman y las corrientes de rechazo que generan y que son susceptibles de transformarse en un CSR. Se realiza un estudio en profundidad de la situación actual del TMB en España en relación al número y tipo de instalaciones existentes, a sus balances de materia y a sus rendimientos respecto a la recuperación de materiales reciclables, producción de biogás, producción de bioestabilizado o compost y generación de rechazos.

- En el Capítulo 4 se identifican las variables y parámetros implicados en el diseño de la metodología para el control de calidad de los rechazos. Para ello se realiza un a revisión exhaustiva de diferentes estudios e investigaciones sobre la caracterización y muestreo de los rechazos y los RSU, así como de los estándares de calidad de los CSR. Como resultado se determinan las variables que afectan a las propiedades de los rechazos y que son responsables de su variabilidad temporal, así como las variables que influyen en el tamaño de muestra. Todas ellas se integran en el plan de muestreo de la metodología. Además, se identifican los tres parámetros más utilizados para definir la calidad de los CSR y que se utilizan para determinar los procedimientos de preparación de muestra de laboratorio.

En el Capítulo 5 se analizan en profundidad de las diferentes técnicas de muestreo estadístico y los métodos y normas existentes para el muestreo y caracterización de RSU y CSR, obteniéndose los fundamentos y principios que sirven como punto de partida para el diseño de la metodología de control de calidad de los rechazos. Asimismo, se revisan los métodos estadísticos aplicables a los residuos y rechazos y se desarrollan los procedimientos estadísticos utilizados para el análisis de los resultados de las diferentes experimentaciones realizadas en la Tesis.

En el Capítulo 6 se diseña el plan de muestreo para el control de calidad de los rechazos de una planta de TMB, que está formado por tres etapas. En la primera etapa se propone y desarrolla una metodología para determinar el tamaño mínimo de muestra más adecuado para cada corriente de rechazo. En la segunda, se propone y desarrolla una metodología para calcular el número mínimo de muestras que se deben tomar a lo largo de un año. En la tercera, se establecen una serie de recomendaciones a tener en cuenta en el muestreo y caracterización de los rechazos. Por último, se presenta la aplicación de la primera etapa del plan de muestreo a dos plantas de TMB diferentes, así como la aplicación de la segunda etapa a una planta. Como resultado de dichas aplicaciones, se identifican todos los rechazos susceptibles de transformarse en un CSR generados en estas plantas y se determina el tamaño y número de muestras necesarios para llevar el control de su calidad.

$>$ En el Capítulo 7 se establece un procedimiento de preparación de muestra en el laboratorio para el análisis de los parámetros de calidad, de manera que la muestra tomada en planta se reduce a una muestra de laboratorio más pequeña sobre la que se realizan los análisis. Se determina el tamaño de muestra de laboratorio con la que se obtienen resultados representativos y se establecen los procedimientos de reducción de tamaño de partícula y división de muestras más adecuados para alcanzarlo. Además, se determina el tiempo de secado óptimo para varios tipos de rechazos diferentes.

Por último, en el Capítulo 8 se presentan las principales conclusiones obtenidas en la Tesis y se proponen varias líneas de investigación para desarrollos futuros.

En la Figura 1.2 se presenta la estructura de la tesis y la relación entre los diferentes Capítulos que la conforman. 


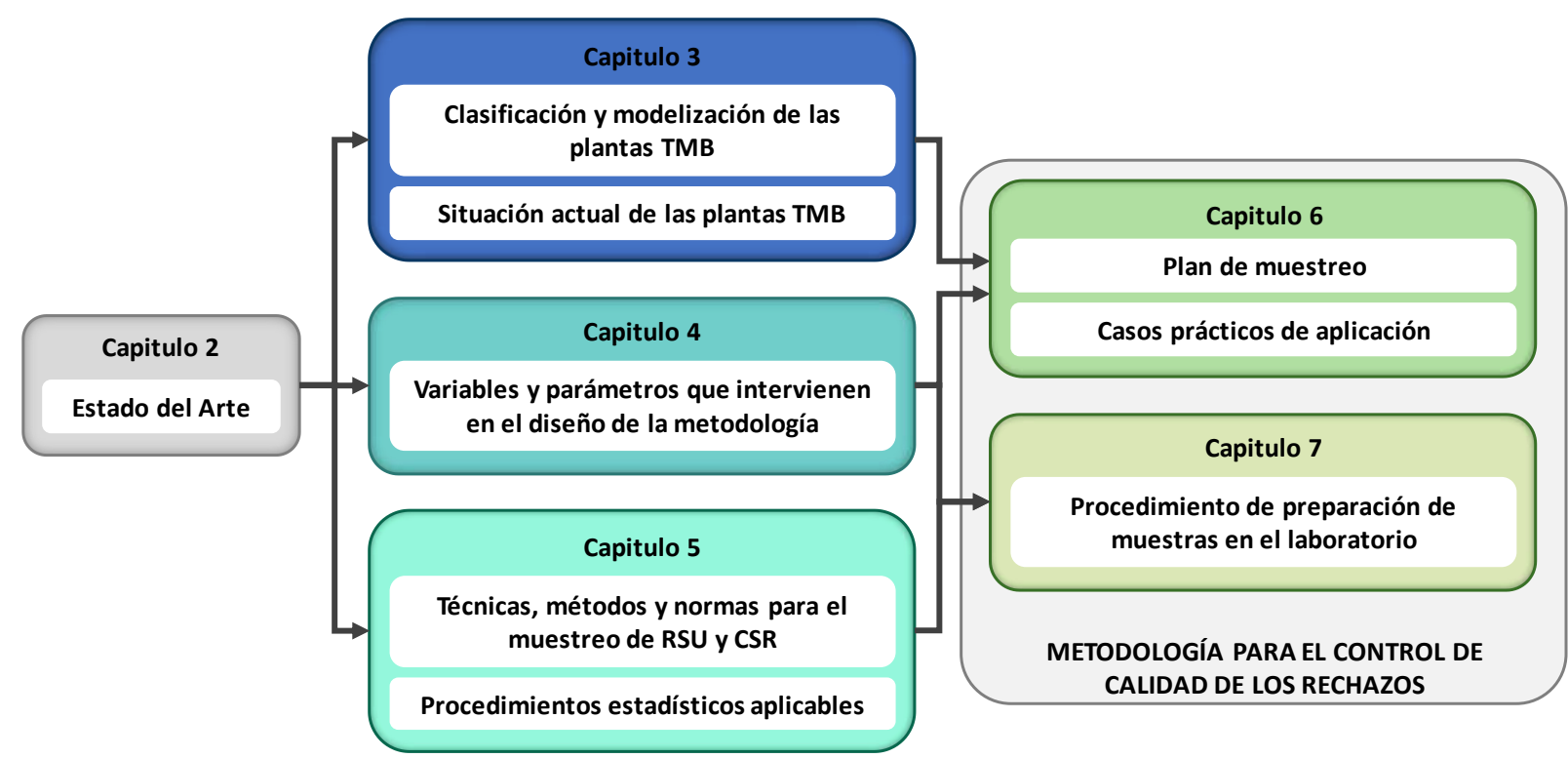

Figura 1.2 Estructura de la Tesis

\subsection{REFERENCIAS}

Bessi, C., Lombardi, L., Meoni, R., Canovai, A., Corti, A., 2016. Solid recovered fuel: An experiment on classification and potential applications. Waste Manag. 47, 184-194. https://doi.org/10.1016/j.wasman.2015.08.012

Brás, I., Silva, M.E., Lobo, G., Cordeiro, A., Faria, M., De Lemos, L.T., 2017. Refuse Derived Fuel from Municipal Solid Waste rejected fractions- a Case Study. Energy Procedia 120, 349-356. https://doi.org/10.1016/j.egypro.2017.07.227

Colomer, F.J., Gallardo, A., 2007. Tratamiento y gestión de residuos sólidos. Editorial Universidad Politecnica de valencia, Valencia, España.

de Araújo Morais, J., Ducom, G., Achour, F., Rouez, M., Bayard, R., 2008. Mass balance to assess the efficiency of a mechanical-biological treatment. Waste Manag. 28, 1791-1800. https://doi.org/10.1016/j.wasman.2007.09.002

Di Lonardo, M.C., Franzese, M., Costa, G., Gavasci, R., Lombardi, F., 2016. The application of SRF vs. RDF classification and specifications to the material flows of two mechanical-biological treatment plants of Rome: Comparison and implications. Waste Manag. 47, 195-205. https://doi.org/10.1016/j.wasman.2015.07.018

Di Lonardo, M.C., Lombardi, F., Gavasci, R., 2012. Characterization of MBT plants input and outputs: A review. Rev. Environ. Sci. Biotechnol. 11, 353-363. https://doi.org/10.1007/s11157-012-9299-2

European Commision, 2017. The role of waste-to-energy in the circular economy (Documento COM(2017) 34 final). Communication from the Commission to the European Parliament, the Council, the European Economic and Social Committee and the Committee of the Regions, Brussels, 26.1.2017.

Flamme, S., Geiping, J., 2012. Quality standards and requirements for solid recovered fuels: a review. Waste Manag. Res. 30, 335-53. https://doi.org/10.1177/0734242X12440481

Gallardo, A., Carlos, M., Bovea, M.D., Colomer, F.J., Albarrán, F., 2014. Analysis of refuse-derived fuel from the municipal solid waste reject fraction and its compliance with quality standards. J. Clean. Prod. 83, 118-125. https://doi.org/10.1016/j.jclepro.2014.07.085

Gallardo, A., Edo-Alcón, N., Albarrán, F., 2017. El combustible sólido recuperado: Producción y marco regulador. RETEMA 8-16. 
Garcés, D., Díaz, E., Sastre, H., Ordóñez, S., González-LaFuente, J.M., 2016. Evaluation of the potential of different high calorific waste fractions for the preparation of solid recovered fuels. Waste Manag. 47, 164-173. https://doi.org/10.1016/j.wasman.2015.08.029

Glorious, T., 2014. Production and Use of Solid Recovered Fuels - Developments and Prospects. ZKG 9, 7280.

Gug, J., Cacciola, D., Sobkowicz, M.J., 2015. Processing and properties of a solid energy fuel from municipal solid waste (MSW) and recycled plastics. Waste Manag. 35, 283-292. https://doi.org/10.1016/j.wasman.2014.09.031

IDAE, 2011. Plan de Energías Renovables (PER) 2011-2020 de España. Instituto para la Diversificación y Ahorro de la Energía, Madrid, España.

Lorber, K.E., Sarc, R., Aldrian, a., 2012. Design and quality assurance for solid recovered fuel. Waste Manag. Res. 30, 370-380. https://doi.org/10.1177/0734242X12440484

Nasrullah, M., Hurme, M., Oinas, P., Hannula, J., Vainikka, P., 2017. Influence of input waste feedstock on solid recovered fuel production in a mechanical treatment plant. Fuel Process. Technol. 163, 35-44. https://doi.org/10.1016/j.fuproc.2017.03.034

Parlamento Europeo y Consejo de la Unión Europea, 2018a. Directiva 2018/2001/UE del Parlamento Europeo y del Consejo de 11 de diciembre de 2018 relativa al fomento del uso de energía procedente de fuentes renovables. D. Of. la Unión Eur. Ser. L 82-209.

Parlamento Europeo y Consejo de la Unión Europea, 2018b. Directiva 2018/850/UE del Parlamento Europeo y del Consejo de 30 de mayo de 2018 por la que se modifica la Directiva 1999/31/CE relativa al vertido de residuos. D. Of. la Unión Eur. Ser. L 100-108.

Parlamento Europeo y Consejo de la Unión Europea, 2018c. Directiva 2018/851/UE del Parlamento Europeo y del Consejo de 30 de mayo de 2018 por la que se modifica la Directiva 2008/98/CE sobre los residuos. D. Of. la Unión Eur. Ser. L 109-140.

Parlamento Europeo y Consejo de la Unión Europea, 2018d. Directiva 2018/852/UE del Parlamento Europeo y del Consejo de 30 de mayo de 2018 por la que se modifica la Directiva 94/62/CE relativa a los envases y residuos de envases. D. Of. la Unión Eur. Ser. L 141-154.

Rotter, V.S., Lehmann, A., Marzi, T., Möhle, E., Schingnitz, D., Hoffmann, G., 2011. New techniques for the characterization of refuse-derived fuels and solid recovered fuels. Waste Manag. Res. 29, 229-236. https://doi.org/10.1177/0734242X10364210

Sarc, R., Lorber, K., Pomberger, R., Rogetzer, M., Sipple, E., 2014. Design, quality, and quality assurance of solid recovered fuels for the substitution of fossil feedstock in the cement industry. Waste Manag. Res. 32, 565-585. https://doi.org/10.1177/0734242X14536462

UNE-EN 15359, 2012. Combustibles sólidos recuperados: Especificaciones y clases. AENOR, Asocición Española de Normalizaciónj y Certificación, Madrid.

Velis, C.A., Longhurst, P.J., Drew, G.H., Smith, R., Pollard, S.J.T., 2010. Production and quality assurance of solid recovered fuels using Mechanical- Biological Treatment (MBT) of waste: a comprehensive assessment. Crit. Rev. Environ. Sci. Technolgy 40, 979-1105. https://doi.org/10.1080/10643380802586980

Velis, C., Wagland, S., Longhurst, P., Robson, B., Sinfield, K., Wise, S., Pollard, S., 2012. Solid recovered fuel: Influence of waste stream composition and processing on chlorine content and fuel quality. Environ. Sci. Technol. 46, 1923-1931. https://doi.org/10.1021/es2035653 


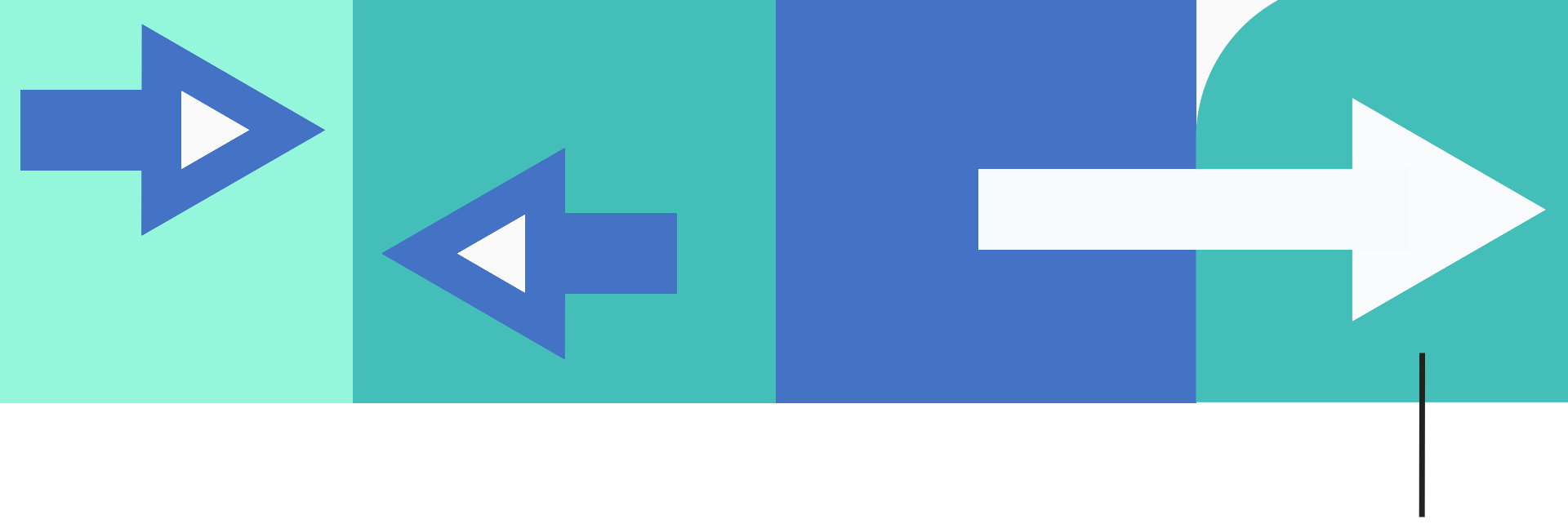

02

CAPÍTULO 2

ESTADO DEL ARTE 



\subsection{INTRODUCCIÓN}

Hoy en día, la generación de residuos ha aumentado considerablemente debido al crecimiento de la población, el desarrollo de la sociedad, los cambios en el estilo de vida y la rápida urbanización. Además, esto se ve reforzado por el modelo de desarrollo actual, el cual se basa en una producción desmesurada de productos de consumo sin tener en cuenta los impactos ambientales o sobre la salud que esto genera en la sociedad.

Hasta hace pocas décadas, la gestión de residuos consistía en su eliminación mediante depósito en vertedero, puesto que se creía que la Tierra era capaz de asimilarlos de forma ilimitada. No obstante, en los últimos años ha sufrido una gran evolución para adaptarse a los principios del desarrollo sostenible, centrándose en la reducción de la generación, el aprovechamiento de los recursos contenidos en los residuos y la minimización de la cantidad enviada a vertedero.

En la Unión Europea (UE), la gestión sostenible de los residuos sólidos urbanos (RSU) es una de las principales preocupaciones medioambientales, por lo que la regulación en materia de gestión de residuos desempeña un papel fundamental (Sastre et al., 2018). En este sentido, la Directiva 2008/98/CE sobre residuos (Parlamento Europeo y Consejo de la Unión Europea, 2008), modificada por la Directiva 2018/851/UE (Parlamento Europeo y Consejo de la Unión Europea, 2018a), son las piezas principales de la legislación en este contexto. En ellas se establece la obligación para los estados miembros de fomentar el desarrollo de tecnologías limpias, la prevención de la generación de residuos y la valorización de los mismos mediante políticas de reutilización, reciclaje y recuperación energética, de manera que se minimice la cantidad de residuos enviada a vertedero y se fomente el resto de alternativas de gestión más sostenibles. En este sentido, la actual política de gestión de residuos en la UE gira entorno a la Jerarquía de gestión de residuos (Figura 2.1).

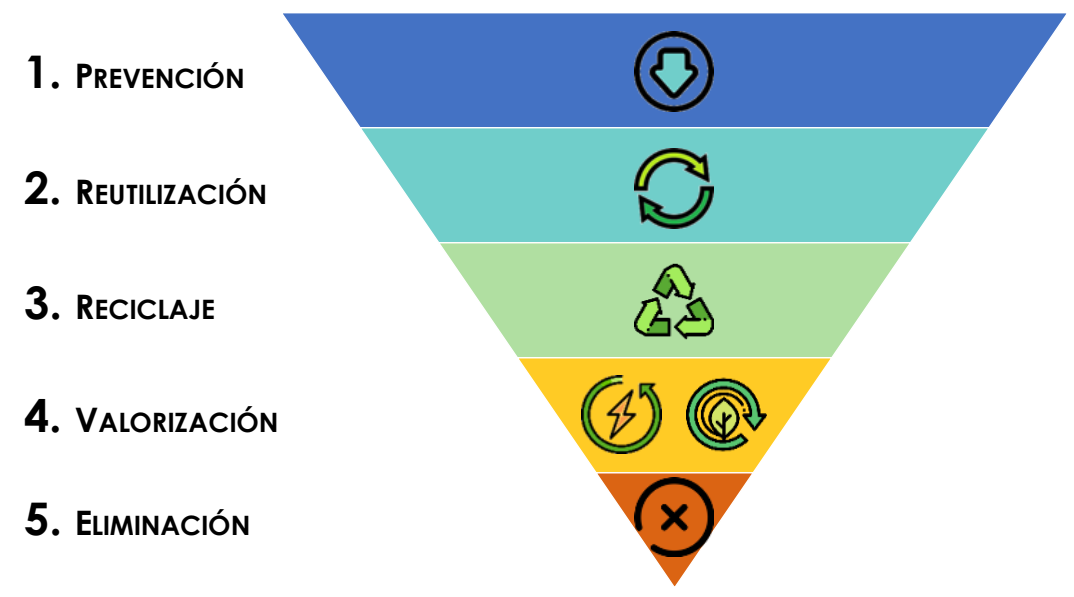

Figura 2.1 Jerarquía de gestión de residuos

La Jerarquía parte de la base de que la generación de residuos debe prevenirse o evitarse y los residuos generados deben reutilizarse, reciclarse o valorizarse, siendo la eliminación en vertedero la última opción y la más nociva para el medio ambiente y la salud humana. Además, este orden de prioridad optimiza el uso de recursos en la gestión de los residuos y también refleja la opción preferible desde el punto de vista de las emisiones de gases de efecto invernadero (European Commision, 2017). Cabe señalar que, para algunos flujos de residuos específicos, es posible saltarse la jerarquía de gestión por motivos de viabilidad técnica, viabilidad económica o protección del medio ambiente, no obstante, esto debe de justificarse.

Adicionalmente, a finales de 2015, la Comisión Europea adoptó un paquete de medidas para impulsar la transición hacia una economía circular. Este incluye un plan de acción que tiene como objetivo "cerrar el 
círculo" de los ciclos de vida de los productos a través de una mayor prevención, reutilización y reciclado. Por lo tanto, la gestión de residuos juega un papel fundamental en dicha transición.

Por otro lado, con el fin de obtener a partir de los RSU productos que puedan tener un interés económico, al mismo tiempo que se minimiza su vertido, estos pueden someterse a distintos procesos de tratamiento. La alternativa de tratamiento más adecuada se elegirá en función el objetivo establecido en los planes integrales de gestión de RSU. No obstante, esta también puede variar de unas regiones a otras en función de factores socio-económicos y culturales (Montejo Méndez, 2015). Existen plantas de selección de materiales (manuales o automáticas) para las fracciones de envases, papel/cartón y vidrio que, mediante tratamientos mecánicos, recuperan los diferentes materiales reciclables. Existen tratamientos biológicos basados en la trasformación aeróbica de la fracción orgánica de los RSU para obtener compost o bioestabilizado (compostaje), así como basados en transformaciones anaeróbicas con el fin de producir biogás (biometanización). Además, los residuos mezclados se tratan en plantas mixtas denominadas de tratamiento mecánico-biológico. Por último, otros tratamientos que suelen emplearse para la recuperación energética son los de carácter termoquímico: incineración, gasificación, pirolisis y tecnología de plasma.

En todas estas plantas, excepto en las termoquímicas, se genera una gran cantidad de rechazos al final del proceso, los cuales están formados por los materiales que no pueden ser separados, reciclados o valorizados desde un punto de vista técnico, económico y/o ambiental. Esta corriente oscila entre el 30 y el $70 \%$ de material entrante a la instalación y, en su mayor parte, se destinan a vertedero. Por lo tanto, encontrar alternativas para su valorización es un objetivo estratégico para el sector. En este sentido, una de las alternativas para su aprovechamiento consiste en su transformación en un combustible sólido recuperado (CSR), de manera que se logre la recuperación energética de estos materiales y se minimice la cantidad de residuos vertida.

Así pues, un sistema moderno y sostenible de gestión integrada de RSU tienen que incluir (Arena and Di Gregorio, 2014; Brunner and Rechberger, 2015; Nasrullah, 2015):

- La prevención efectiva de la generación de residuos.

- Prácticas eficaces de separación en origen y de todas las actividades de reciclado, sin que ello implique un consumo excesivo de recursos.

- El tratamiento biológico eficiente de las fracciones orgánicas.

- Le recuperación energética de aquellos materiales que no puedan reciclarse de manera eficiente.

- La eliminación únicamente de aquellos materiales que no puedan reciclarse, valorizarse o recuperarse energéticamente.

\subsection{LOS RESIDUOS SÓLIDOS URBANOS}

Los residuos sólidos urbanos (RSU) son aquellas sustancias u objetos de los cuales su poseedor se desprende o tenga la intención o la obligación de desprenderse dentro del ámbito urbano. En España, la Ley 22/2011 de residuos y suelos contaminados (España, 2011) no establece una definición propia para los RSU, sino que define por separado los dos grandes grupos que los forman: los residuos domésticos y los residuos comerciales. En ella los residuos domésticos se definen como: "los generados en los hogares como consecuencia de las actividades domésticas". Además, también son considerados residuos domésticos los "similares a los anteriores generados en servicios e industria"; los "que se generan en los hogares de aparatos eléctricos y electrónicos, ropa, pilas, acumuladores, muebles y enseres así como los residuos y escombros procedentes de obras menores de construcción y reparación domiciliaria", y los "procedentes de limpieza de vías públicas, zonas verdes, áreas recreativas y playas, los animales domésticos muertos y los vehículos abandonados". Mientras que los residuos comerciales se definen como: "los generados por la actividad propia del comercio, al por mayor y al por menor, de los servicios de restauración y bares, de las oficinas y de los mercados, así como del resto del sector servicios".

La cantidad y composición de los RSU generados es muy variable y depende de numerosos factores, tales como: el nivel de desarrollo, nivel de renta y modo de vida de la población, época del año, climatología, grado y tipo de actividad comercial y de servicios existente, estacionalidad de la población por el turismo, 
tipo de población (urbana, rural, etc.) y tipo de vivienda (Colomer and Gallardo, 2007; Tchobanoglous et al., 1994).

Además, los RSU también tienen características diferentes dependiendo donde se hayan originado dentro del núcleo urbano (Gallardo, 2000), pudiéndose clasificar en función de su origen en los siguientes tipos (Otero del Peral, 1996; Tchobanoglous et al., 1994):

- Residuos domésticos: originados en las distintas actividades desarrolladas en los hogares. Suelen incluir restos de comida, papel, cartón, plásticos de diferentes tipos, textiles, goma, cuero, celulosa sanitaria, madera, vidrio, metales, residuos de jardinería y otros elementos comunes del consumo residencial. En este grupo también se incluyen algunos residuos que tienen recogidas especiales como pilas, medicamentos, residuos de aparatos eléctricos y electrónicos (RAEE), fluorescentes, aceites, residuos voluminosos, etc.

- Residuos comerciales y de servicios: originados en las actividades de los diferentes circuitos de distribución de bienes de consumo y servicios como: restaurantes, bares, tiendas, mercados, oficinas, hoteles, gasolineras, centros comerciales, etc. Estos residuos están compuestos por los mismos materiales que los residuos domésticos, pero su composición es diferente y depende del sector comercial.

- Residuos institucionales: incluyen los residuos generados en las instituciones públicas como escuelas, ayuntamientos, institutos, universidades, cárceles, centros administrativos, etc. Así como los originados en los hospitales o centros sanitarios y que son residuos asimilables a urbanos.

- Residuos sanitarios hospitalarios: corresponden a los residuos generados en cualquier establecimiento o servicio en el que se desarrollen actividades de atención a la salud humana y que no son asimilables a urbanos. Incluyen los residuos clínicos o biológicos como textiles manchados de fluidos corporales, contenedores vacíos de sangre o suero, goteros, jeringuillas, etc. Así como los residuos especiales patógenos y/o infecciosos.

- Residuos de construcción y demolición: son residuos procedentes de la construcción, remodelación y reparación de viviendas individuales, edificios comerciales, arreglos en la vía publica u otras estructuras. Están compuestos principalmente por suciedad, piedras, ladrillos, hormigón, madera, piezas de fontanería, electricidad o calefacción, vidrios, etc.

- Residuos de servicios municipales: provienen de la limpieza viaria, residuos de jardinería, limpieza de mercados, vaciado de papeleras, etc. También se incluyen otros residuos de origen más difuso como animales muertos o vehículos abandonados.

- Residuos industriales asimilables a urbanos: tienen la misma composición que los RSU, pero el porcentaje de cada material depende del tipo de actividad industrial donde se ha originado. Las fuentes generadoras son: talleres mecánicos, talleres de pintura, carpinterías, establecimientos de reparación, etc. También incluyen los residuos de este tipo generado en los polígonos industriales.

Conocer la generación y composición de los RSU es imprescindible para llevar a cabo una gestión eficiente de los mismos, además, a partir de esta información se deben de definir las estrategias a seguir para alcanzar los objetivos marcados por la legislación.

Cabe señalar que obtener datos de generación en función del origen es complicado, puesto que en la mayoría de los municipios los flujos de recogida municipal se componen por residuos de diferentes procedencias. Además, los RSU generados se recogen por diferentes vías, ya sea de forma mezclada o como fracciones recogidas selectivamente, pudiendo acabar en distintos contenedores e instalaciones de tratamiento.

\subsubsection{La generación}

El estudio de las cantidades de residuos generadas y recogidas en un determinado municipio, región o país es el punto de partida de la gestión de los RSU (Gallardo, 2000). No obstante, debido a que la generación no es constante y depende de diferentes factores, como se ha indicado anteriormente, su correcta estimación a largo plazo no es fácil. 
Desde mediados del siglo XX el incremento en la generación de residuos ha sido un fenómeno frecuente en las grandes ciudades de los países desarrollados. El crecimiento de la población, junto con la mejora del nivel de vida y el aumento del consumismo y de la cultura del "usar y tirar", provocaron que la generación de residuos domiciliarios e industriales aumentara considerablemente (Colomer and Gallardo, 2007).

En 2016 la generación de residuos a nivel mundial fue 2,01 billones de toneladas, lo que supone una generación diaria de 5,5 millones de toneladas. Si se extrapolan las tendencias socioeconómicas mundiales, se espera que en el año 2030 se superen los 7 millones de $t$ al día y que en 2050 se alcancen los 9 millones de t diarias (Kaza et al., 2018). Además, cabe destacar que las regiones más desarrolladas o industrializadas como Norteamérica, Europa Occidental y Australia, son los que mayores tasas de generación por habitante y día presentan (Figura 2.2). Islandia, Singapur, Mónaco y Puerto Rico son los países que se encuentran a la cabeza en generación de RSU por cápita. Por el contrario, Lesotho, Timor Oriental, Laos y Nepal son los países que menos generan (Kaza et al., 2018).

Generación diaria de RSU por cápita (kg/hab-día)

$$
\begin{array}{l|l|l|l|l|l|l|}
0-0,49 & \text { No disponible }
\end{array}
$$

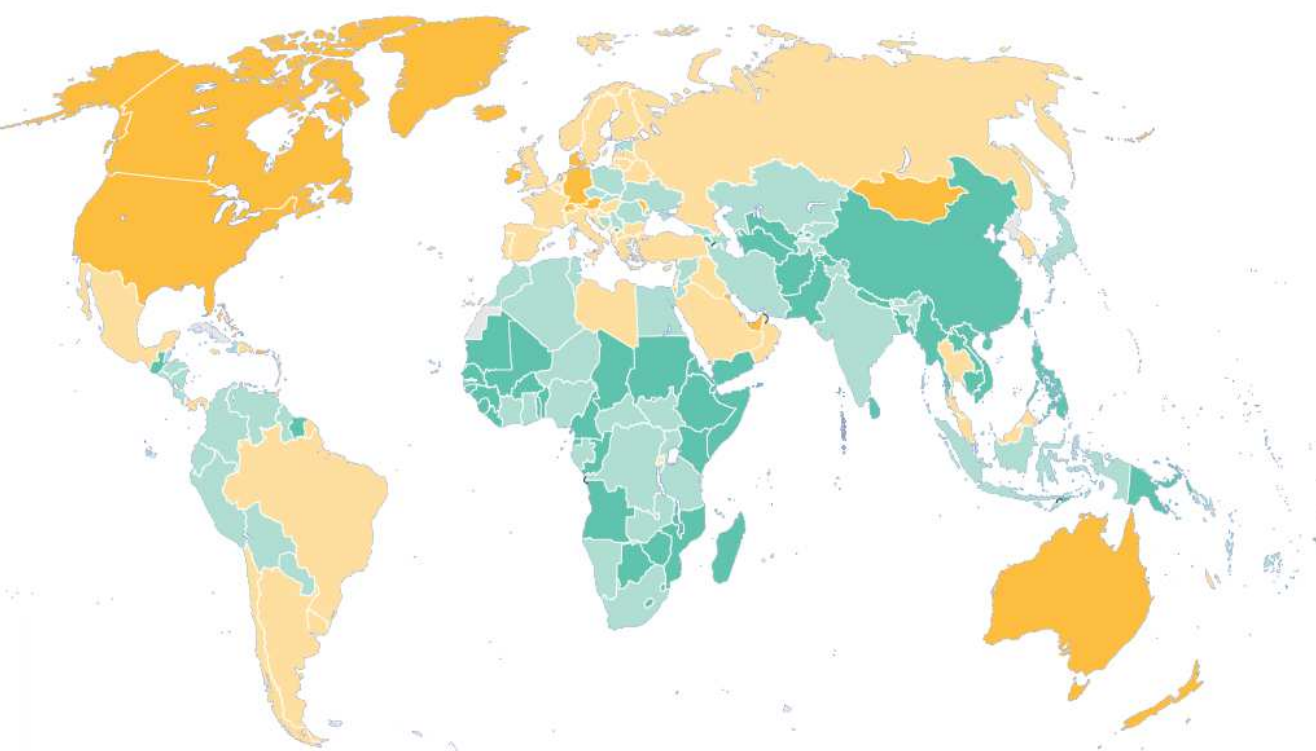

Figura 2.2 Generación mundial de residuos, año 2016 (Kaza et al., 2018)

En el caso de los RSU, en la Unión Europea (EU-28) durante el año 2017 se generaron $486 \mathrm{~kg} / \mathrm{hab}$ (1,31 $\mathrm{kg} /$ hab-día) (Eurostat, 2019). Los países donde la generación fue mayor son Dinamarca, Noruega y Suiza, con valores entre los $800-700 \mathrm{~kg} / \mathrm{hab}$. Por el contrario, en Rumania, Polonia y la Republica Checa se dieron los valores más bajos, entre 250 - 350 kg/hab. En España la generación de RSU fue de 462 kg/hab (1,27 $\mathrm{kg} /$ hab-día), valor que se encuentra por debajo de la media europea (Figura 2.3). 


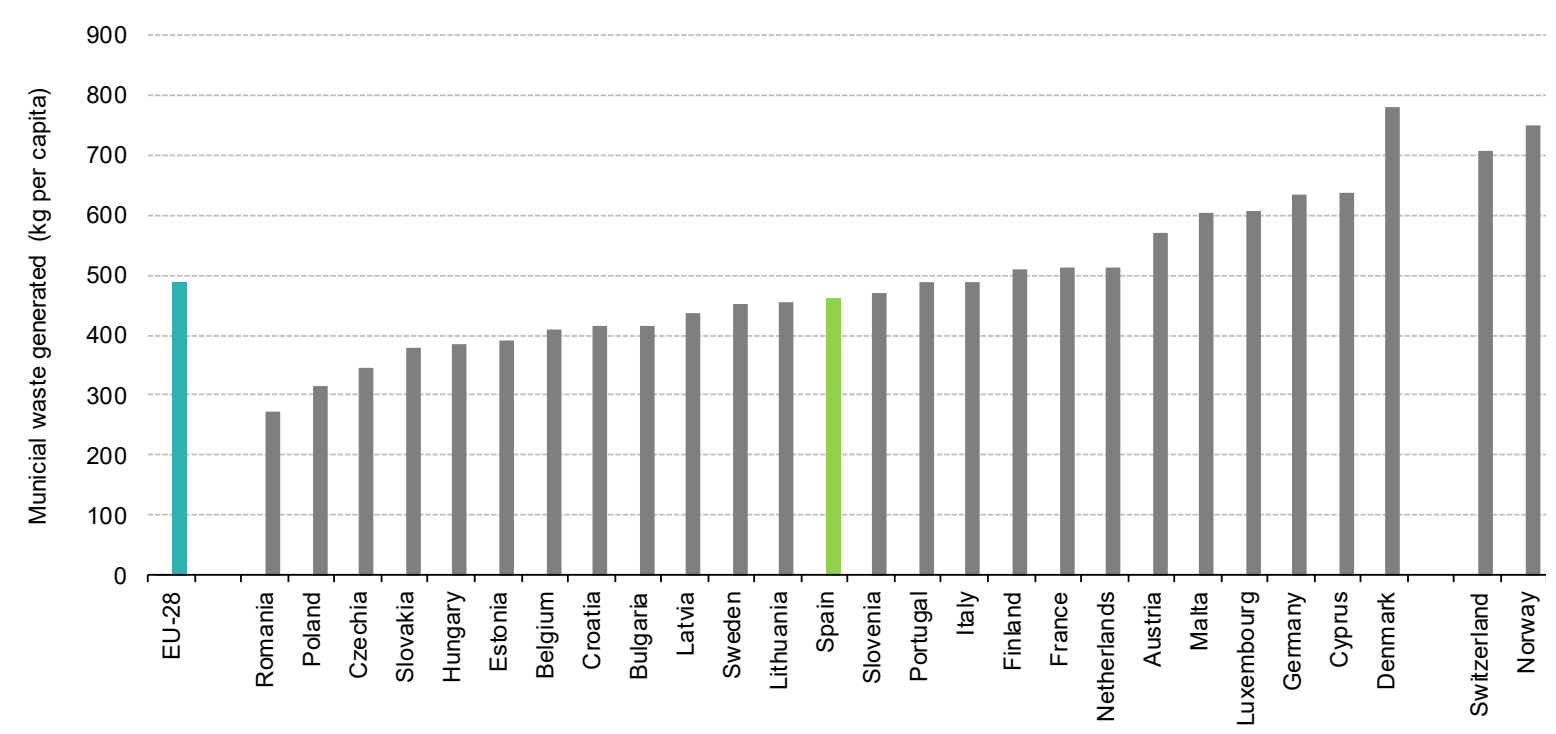

Figura 2.3 Generación RSU en la Unión Europea, 2017 (Eurostat, 2019)

Respecto a España, en la Figura 2.4 se muestra la evolución que ha sufrido la generación de RSU en los últimos años. En ella se puede observar que hasta el comienzo de la crisis en el año 2008 existía un incremento continuado de la cantidad de RSU generada anualmente. Sin embargo, desde el año 2008 la tendencia ha sido descendiente a pesar de que la población ha seguido aumentando. Esto puede ser explicado por una menor comercialización y consumo de todo tipo de productos debido a la recesión económica; por una mayor presencia de "recicladores informales" que recogen directamente de los contenedores aquellos materiales que pueden ser aprovechados, así como por una mayor concienciación de la población respecto a la prevención de la generación de RSU.

En la actualidad, la cantidad total de RSU generados se encuentran en valores similares a los del año 1999, con 21,9 Mt. De ellas, 18,1 Mt corresponden a residuos recogidos de forma mezclada y 3,8 Mt a residuos recogidos selectivamente. La tasa de generación diaria (TGD), con 1,29 kg/hab-día, es menor a la existente en el año 1998, último año de la serie disponible (Instituto Nacional de Estadística (INE), 2018).

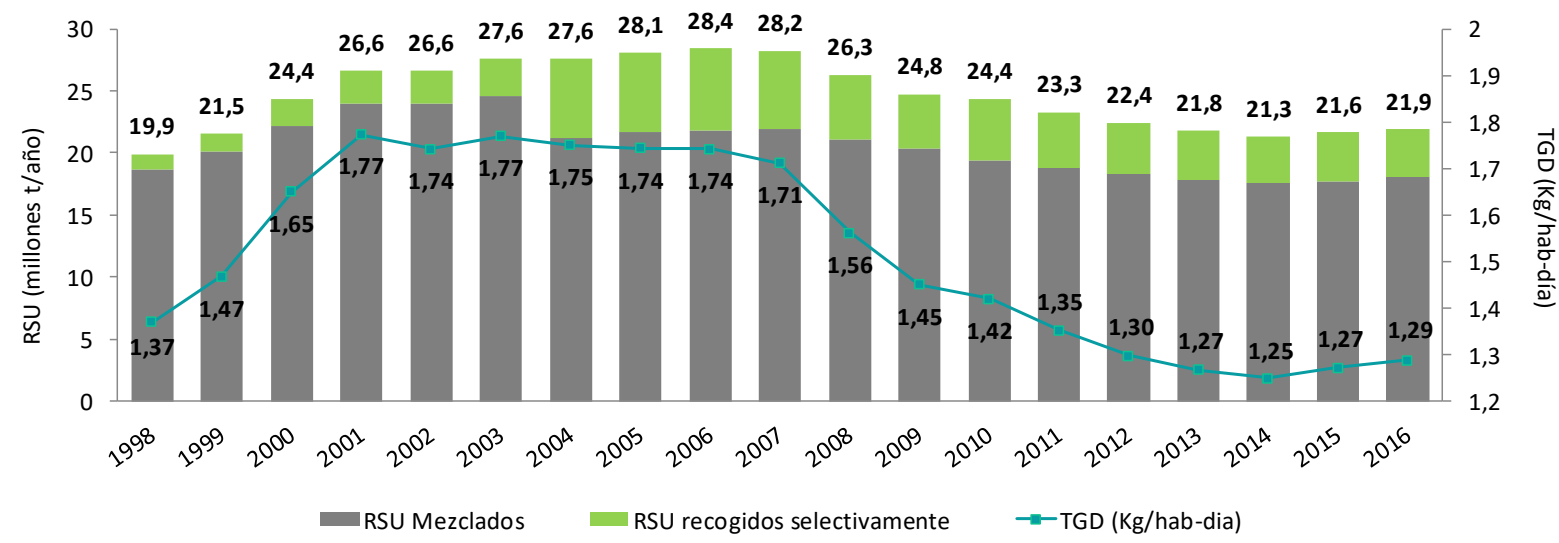

Figura 2.4 Generación RSU en España

Por otro lado, en la Tabla 2.1 se recogen los datos de generación de RSU por Comunidades Autónomas (CC.AA.) para el año 2016. En ella se observa que existe una gran variabilidad en las TGD entre las distintas comunidades, las cuales pueden deberse a factores como: condiciones climáticas, nivel de renta, tipo de población, etc. 
Cabe destacar que las TGD más altas corresponden a las Islas Baleares y Canarias como consecuencia de la gran afluencia de turismo que estas CC.AA. presentan durante ciertas épocas del año. Adicionalmente, Andalucía, Asturias y Cantabria también presentan valores de TGA por encima de la media europea. Las generaciones por cápita más pequeñas se dan en la Comunidad de Madrid, Galicia y Aragón.

Tabla 2.1 Generación de RSU por CC.AA. en España, 2016 (Instituto Nacional de Estadística (INE), 2018)

\begin{tabular}{|c|c|c|}
\hline CC.AA. & $\begin{array}{c}\text { Generación total } \\
\text { RSU (t/año) }\end{array}$ & $\begin{array}{c}\text { TGD de } \\
\text { RSU(kg/hab-día) }\end{array}$ \\
\hline Andalucía & 4.395 .591 & 1,44 \\
\hline Aragón & 529.040 & 1,11 \\
\hline Principado de Asturias & 537.945 & 1,41 \\
\hline Islas Balearas & 846.128 & 2,09 \\
\hline Canarias & 1.245 .102 & 1,62 \\
\hline Cantabria & 312.927 & 1,47 \\
\hline Castilla - La Mancha & 970.900 & 1,30 \\
\hline Castilla y León & 1.064 .948 & 1,19 \\
\hline Cataluña & 3.539 .278 & 1,29 \\
\hline Comunidad Valenciana & 2.209 .773 & 1,22 \\
\hline Extremadura & 486.066 & 1,22 \\
\hline Galicia & 1.110 .604 & 1,12 \\
\hline La Rioja & 138.085 & 1,20 \\
\hline Comunidad de Madrid & 2.471 .956 & 1,05 \\
\hline Región de Murcia & 693.514 & 1,30 \\
\hline Comunidad Foral de Navarra & 289.655 & 1,24 \\
\hline País Vasco & 987.223 & 1,24 \\
\hline TOTAL ESPAÑA & 21.878.373 & 1,29 \\
\hline
\end{tabular}

\subsubsection{La composición}

La composición física es el término utilizado para describir los componentes individuales que constituyen los RSU y su distribución relativa, normalmente en porcentaje en peso. Además, la gran diversidad de fuentes generadoras hace que la composición de los RSU sea muy variada y heterogénea (Gallardo, 2000). Conocer esta información es importante a la hora de llevar a cabo un correcta y eficiente gestión de los RSU, puesto que permite evaluar las necesidades de sistemas de tratamiento y planes de gestión, adaptándolos a las características de los residuos, así como diseñar los sistemas de recogida y reciclaje, dimensionar las instalaciones de tratamiento y elegir las tecnologías más adecuadas para ello.

La composición de los RSU no es constante y puede variar de una región, país o CC.AA. a otra, puesto que se ve afectada por aspectos como la estacionalidad y la climatología de la zona, el modo y nivel de vida de la población, el tipo de población y la actividad comercial y de servicios existente (Colomer and Gallardo, 2007). En la Figura 2.5 se muestra la composición de los RSU en función del nivel de renta a nivel mundial (Kaza et al., 2018). En ella se observa que, a medida que el nivel de económico aumenta, el contenido en fracción orgánica disminuye. Además, los RSU de los países con mayores ingresos incluyen un mayor porcentaje de residuos de papel/cartón, metales, madera, gomas y cueros que los de ingresos más bajos. Este tipo de materiales son propios de los modelos de consumo de los países más desarrollados, mientras que en los países en desarrollo se generan en menor cantidad y son más valiosos, por lo que gran parte de los mismos son aprovechados y desviados del flujo de residuos. 


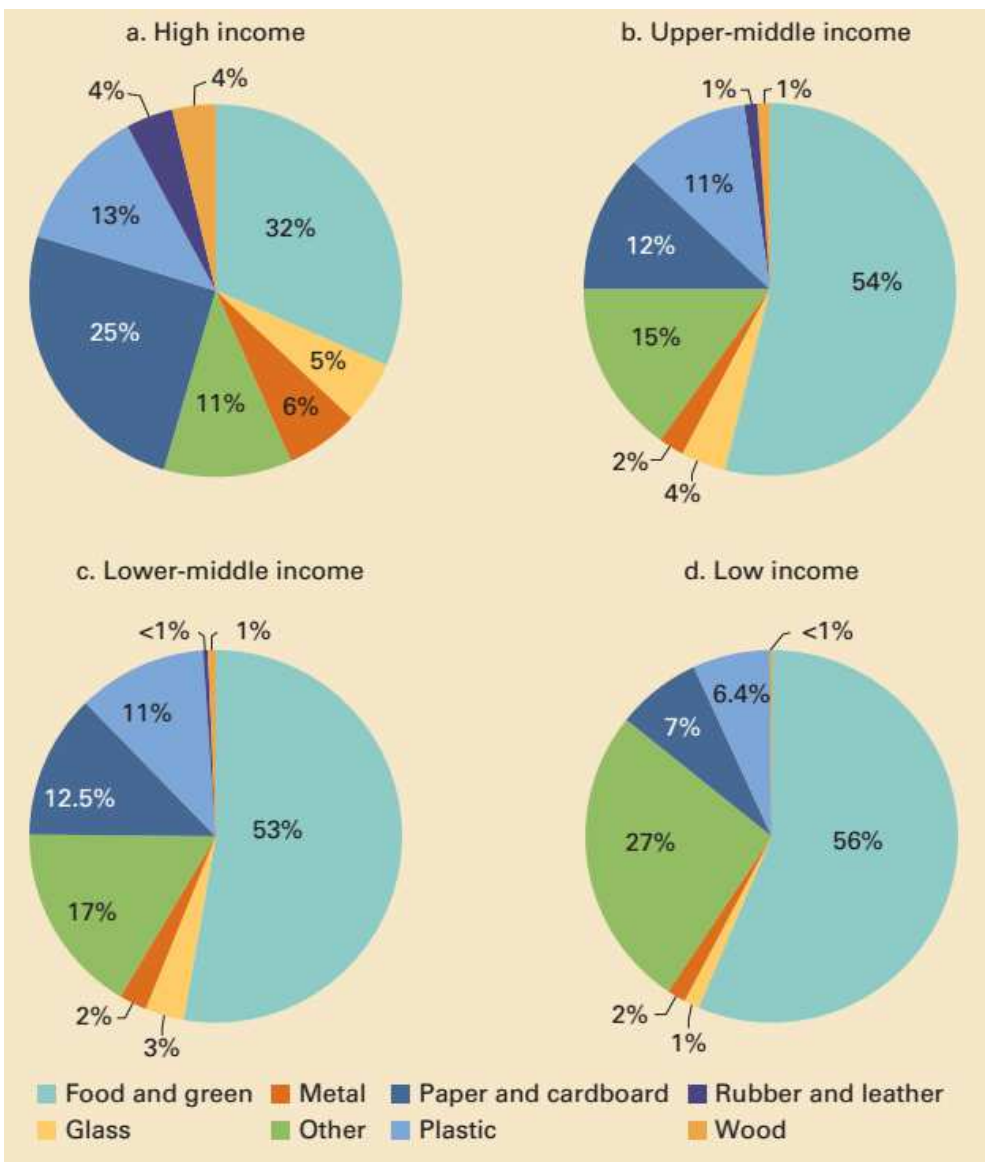

Figura 2.5 Composición de los RSU en función del nivel de renta (Kaza et al., 2018)

A nivel de España, el Plan Estatal Marco de Residuos (PEMAR) 2016 - 2022 (MAGRAMA, 2015) recoge la composición media de los residuos de competencia municipal, de los RSU recogidos de forma mezclada (fracción resto) y de las distintas fracciones de residuos que se recogen selectivamente (envases ligeros, vidrio, papel/cartón y biorresiduos).

En la Figura 2.6 se presenta la composición de los RSU mezclados para España. En ella se puede apreciar que el componente mayoritario corresponde a la fracción orgánica (47\%), seguido por el papel/cartón (11\%) y los plásticos (9\%). Así pues, gran parte de los materiales presentes en los RSU mezclados aún pueden ser separados para su reciclaje o valorización, lo que justifica la necesidad de someterlos a un tratamiento mecánico-biológico, minimizando de esta forma su depósito en vertedero y contribuyendo a la transición a una economía circular.

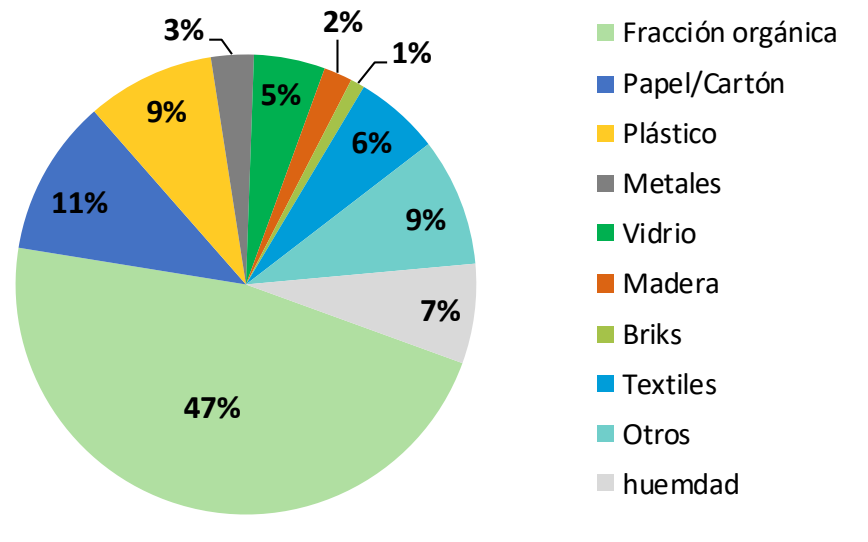

Figura 2.6 Composición media de los RSU mezclados en España (MAGRAMA, 2015) 


\subsubsection{Propiedades de los RSU}

Junto con la generación y la composición, para realizar un adecuada gestión y tratamiento de los RSU, es esencial conocer y tener en cuenta otra serie de propiedades físicas y químicas de los residuos. Dentro de las propiedades físicas, destacan las siguientes (Colomer and Gallardo, 2007; FUCOVASA et al. 2015):

- Contenido en humedad: la humedad hace referencia a la cantidad de agua presente en los RSU, esta depende de varios factores como la composición, la época del año, las condiciones ambientales y las condiciones climáticas. Normalmente las fracciones orgánicas son las que mayor contenido de humedad aportan.

- Peso específico o densidad: es un dato fundamental para dimensionar los sistemas de recogida (contenedores y camiones). Su valor dependerá del grado de compactación, siendo diferente en la bolsa de basura, en el contenedor, en el camión o en el vertedero. En los cubos o contenedores la densidad se encuentra entre los $150-250 \mathrm{~kg} / \mathrm{m}^{3}$, mientras que en los camiones compactadores pueden darse alcanzarse valores de $600 \mathrm{~kg} / \mathrm{m}^{3}$.

- Granulometría: conocer el tamaño y la distribución del tamaño de partícula de los componentes que forman los RSU es fundamental para el dimensionamiento y diseño de los procesos mecánicos de separación y recuperación de materiales. El tamaño medio para las partículas de los RSU se encuentra entre $178-203 \mathrm{~mm}$. Las fracciones de cartón son las que suelen tener un tamaño mayor y las menores dimensiones corresponden a los restos de comida. No obstante, existe una gran diversidad de tamaños.

Las propiedades químicas de los RSU pueden ser factores condicionantes para determinados procesos de valorización y tratamiento. Además, aportarán información sobre la viabilidad de su incineración y las posibilidades de compostaje y/o biometanización. Entre las propiedades químicas más importantes destacan (Colomer and Gallardo, 2007; FUCOVASA et al. 2015):

- Análisis elemental de los componentes: consiste en la determinación del porcentaje de carbono, hidrógeno, oxígeno, nitrógeno, azufre. Tiene como objetivo prever las posibles emisiones y subresiduos que se producirán en el tratamiento. En el caso de la incineración, debido a la creciente preocupación respecto a la emisión de compuestos clorados (dioxinas y furanos) o volatilización de metales pesados (mercurio), estos análisis incluyen la determinación de compuestos halógenos y de algunos metales pesados. En el caso de la fracción orgánica, estos datos se utilizan para conocer las relaciones $\mathrm{C} / \mathrm{N}$ en los procesos de conversión biológica. Generalmente los RSU tienen una composición química muy variada debido a la heterogeneidad de los materiales que los forman.

- Poder calorífico: hace referencia al contenido energético o capacidad calorífica de los RSU, es un parámetro importante a la hora de estimar la recuperación energética que se puede alcanzar con cierta cantidad de RSU.

- Punto de fusión de las cenizas: determina la temperatura a la que la ceniza resultante de la incineración se transforma en un sólido o escoria por la fusión y la aglomeración.

- Análisis de los componentes combustibles de los residuos: incluye la determinación de la humedad, materia volátil, carbono fijo y cenizas. Son necesarios cuando un RSU va a ser utilizado como combustible.

- Nutrientes esenciales y otros elementos: esta información es importante cuando los residuos se van a someter a un proceso de conversión biológica, puesto que aporta información sobre la disponibilidad de nutrientes para los microorganismos. Además, permiten conocer los usos que puedan tener los productos obtenidos.

\subsubsection{Marco legislativo}

En este apartado se presenta la legislación vigente en materia de RSU más relevante en el ámbito de la Tesis a nivel europeo, nacional y autonómico. 


\subsubsection{Legislación Europea}

En la Tabla 2.2 se presenta la normativa más relevante a nivel europeo en materia de RSU.

Tabla 2.2 Legislación Europea en materia de RSU

\begin{tabular}{|c|c|}
\hline Normativa Europea & Objetivos principales \\
\hline $\begin{array}{l}\text { Directiva 2008/98/CE del } \\
\text { Parlamento Europeo y del Consejo, } \\
\text { de } 19 \text { de noviembre de } 2008 \text {, sobre } \\
\text { los residuos y por la que se derogan } \\
\text { determinadas directivas. }\end{array}$ & $\begin{array}{l}\text { Establece un marco jurídico para la gestión y tratamiento de los residuos en la } \\
\text { Unión Europea. Su objetivo es proteger el medio ambiente y la salud humana } \\
\text { mediante la prevención o la reducción de los impactos de la generación y } \\
\text { gestión de los residuos (Parlamento Europeo y Consejo de la Unión Europea, } \\
\text { 2008). }\end{array}$ \\
\hline
\end{tabular}

Directiva 2018/851/UE del Parlamento Europeo y del Consejo, de 30 de mayo de 2018, por la que se modifica la Directiva 2008/98/CE sobre los residuos.

Directiva 1994/62/CE del Parlamento Europeo y del Consejo, de 20 de diciembre de 1994, relativa a los envases y residuos de envases.

Directiva 2018/852/EU del Parlamento Europeo y del Consejo, de 30 de mayo de 2018, por la que se modifica la Directiva 94/62/CE relativa a los envases y residuos de envases.

Directiva 2015/720/UE del Parlamento Europeo y del Consejo, de 29 de abril de 2015, por la que se modifica la Directiva 94/62/CE en lo que se refiere a la reducción del consumo de bolsas de plástico ligeras.

Directiva 2019/904/UE del Parlamento Europeo y del Consejo, de 5 de junio de 2019, relativa a la reducción del impacto de determinados productos de plástico en el medio ambiente.

Directiva 1999/31/CE del Consejo, de 26 de abril de 1999, relativa al vertido de residuos.

Directiva 2018/850/UE del Parlamento Europeo y del Consejo, de 30 de mayo de 2018, por la que se modifica la Directiva 1999/31/CE relativa al vertido de residuos.
Normativa perteneciente a las nuevas directivas del paquete de economía circular y que modifica la Directiva 2008/98/CE. Destacan los nuevos objetivos para la preparación para la reutilización y la implementación de la recogida selectiva (Parlamento Europeo y Consejo de la Unión Europea, 2018a).

Establece un marco jurídico para le gestión de envases y residuos de envases en la Unión Europea. Su objetivo proteger el medioambiente mediante la prevención de la producción de residuos de envases a través de su reutilización, reciclado y otras formas de valorización, reduciendo la eliminación final de estos residuos (Parlamento Europeo y Consejo de la Unión Europea, 1994).

Normativa perteneciente a las nuevas directivas del paquete de economía circular y que modifica la Directiva 94/62/CE. Destacan los nuevos objetivos para el reciclaje de los residuos de envases (Parlamento Europeo y Consejo de la Unión Europea, 2018b).

Modifica a la Directiva 94/62/CE. Establece las medidas que han de adoptar los estados miembros para reducir el consumo de bolsas de plástico ligeras (Parlamento Europeo y Consejo de la Unión Europea, 2015).

Su objetivo es prevenir y reducir el impacto de determinados productos de plástico en el medio ambiente, especialmente en el medio acuático, y en la salud humana, así como fomentar la transición a una economía circular. Su ámbito de aplicación son los plásticos de un solo uso, los plásticos oxodegradables y los artes de pesca que contienen plástico. En algunos casos se establecen medidas para la reducción paulatina de su consumo, en otros se prohíbe su introducción en el mercado. Además se establecen condiciones espaciales para su diseño, etiquetado y recogida separada (Parlamento Europeo y Consejo de la Unión Europea, 2019).

En ella se establecen medidas, procedimientos, orientaciones y requisitos técnicos para impedir o reducir los efectos negativos en el medioambiente del vertido de residuos, en concreto la contaminación de las aguas superficiales y subterráneas, el suelo, el aire, incluido el efecto invernadero, así como cualquier riesgo derivado para la salud humana. Destaca la necesidad de que los residuos hayan sido tratados antes de si disposición en vertedero (Consejo de la Unión Europea, 1999).

Normativa perteneciente a las nuevas directivas del paquete de economía circular y que modifica la Directiva 1999/31/CE. Su objetivo es garantizar la reducción progresiva del depósito de residuos en vertedero, en concreto de aquellos materiales aptos para el reciclado u otro tipo de valorización. Destacan los nuevos objetivos para la reducción de vertido (Parlamento Europeo y Consejo de la Unión Europea, 2018c). 


\begin{tabular}{|c|c|}
\hline Normativa Europea & Objetivos principales \\
\hline $\begin{array}{l}\text { 2003/33/CE: Decisión del Consejo, } \\
\text { de } 19 \text { de diciembre de } 2002 \text {, por la } \\
\text { que se establecen los criterios y } \\
\text { procedimientos de admisión de } \\
\text { residuos en los vertederos con } \\
\text { arreglo al artículo } 16 \text { y al anexo II de } \\
\text { la Directiva } 1999 / 31 / \text { CE. }\end{array}$ & $\begin{array}{l}\text { Establece los criterios y procedimientos de admisión de residuos en los } \\
\text { vertederos con arreglo a los principios establecidos en la Directiva 1999/31/CE, } \\
\text { en particular en su anexo II (Consejo de la Unión Europea, 2003). }\end{array}$ \\
\hline $\begin{array}{l}\text { Directiva 2010/75/UE del } \\
\text { Parlamento Europeo y del Consejo, } \\
\text { de } 24 \text { de noviembre de } 2010 \text {, sobre } \\
\text { las emisiones industriales } \\
\text { (prevención y control integrados de } \\
\text { la contaminación). }\end{array}$ & $\begin{array}{l}\text { Establece las normas sobre la prevención y el control integrado de la } \\
\text { contaminación procedente de las actividades industriales. En ella se establecen } \\
\text { también normas para evitar o reducir las emisiones a la atmosfera, el agua y el } \\
\text { suelo, y evitar la generación de residuos con el fin de alcanzar un nivel elevado } \\
\text { de protección del medioambiente. En su Capítulo IV se incluye una disposición } \\
\text { especial sobre las instalaciones de incineración y co-incineración de residuos } \\
\text { (Parlamento Europeo y Consejo de la Unión Europea, 2010). }\end{array}$ \\
\hline
\end{tabular}

A nivel europeo, destaca la Directiva 2008/98/CE sobre residuos y la Directiva 2018/851/UE que la modifica. El objetivo y ámbito de aplicación de estas Directivas es "establecer medidas destinadas a proteger el medio ambiente y la salud humana mediante la prevención y la minimización de los impactos adversos de la generación y gestión de los residuos, la reducción de los impactos globales del uso de los recursos y la mejora de la eficacia de dicho uso". Quedan excluidas de esta Directiva las emisiones gaseosas, los residuos radiactivos, explosivos desclasificados, aguas residuales, materiales fecales, subproductos animales, cadáveres de animales que no hayan sido sacrificados, residuos procedentes de la explotación minera y sustancias que se destinen a ser utilizadas como material primas para piensos. En ellas se establece que los estados miembros deben adoptar medidas para la gestión y el tratamiento de los residuos de acuerdo con la siguiente jerarquía de prioridades:

1. Prevención

2. Preparación para la reutilización

3. Reciclado

4. Otro tipo de valorización, incluida la energética

5. Eliminación

Respecto a la valorización de los residuos, se establece que "los estados miembros adoptarán las medidas necesarias para garantizar que los residuos sean objeto de preparación para la reutilización, de reciclado o de otras operaciones de valorización; siguiendo la jerarquía de tratamiento establecida y sin crear riesgos para el agua, el suelo, el aire, la fauna y la flora, sin provocar incomodidades por el ruido y los olores y sin atentar contra paisajes y lugares de especial interés". Además, los residuos se recogerán por separado para facilitar o mejorar su reutilización, reciclado o valorización siempre que resulte técnica, medioambiental y económicamente viable.

La Directiva 2018/851/UE establece que los estados miembros deben tener implementada la recogida separada de textiles y residuos peligrosos de origen doméstico para el 1 de enero de 2025, que se suma a las ya existentes para el papel/cartón, vidrio, metales y plásticos. Asimismo, deberán garantizar la recogida selectiva de biorresiduos (materia orgánica) o su reciclaje en origen (por ejemplo, mediante el compostaje doméstico o comunitario) para el 31 de diciembre de 2023. Además, con el objetivo de avanzar hacia una economía circular en Europa, la Directiva establece los siguientes objetivos de preparación para la reutilización y reciclaje de residuos municipales:

- $\quad$ Un 55\% en peso para el año 2025

- Un 60\% para el año 2030

- $\quad$ Un 65\% para el año 2035

Respecto a los residuos de envases, la Directiva 2018/852/EU establece nuevos objetivos específicos para el reciclaje de este tipo de residuos con el objetivo de contribuir a la transición hacia una economía circular, 
los cuales se exponen a continuación. Además, los estados miembros deberán establecer medidas para aumentar la cantidad de envases reutilizables comercializados y el uso de sistemas de reutilización de envases.

- $\quad$ Envases de todo tipo: un 65\% en peso para el año 2025 y un 70\% para el año 2030

- Plástico: un 50\% para el año 2025 y un 55\% para el año 2030

- Metales férreos: un 70\% para el año 2025 y un 80\% para el año 2030

- $\quad$ Aluminio: un 50\% para el año 2025 y un 60\% para el año 2030

- Vidrio: un 70\% para el año 2025 y un $75 \%$ para el año 2030

- Papel/cartón: un 75\% para el año 2025 y un 85\% para el año 2030

- Madera: un 25\% para el año 2025 y un 30\% para el año 2030

Respecto a la reducción de vertido, la Directiva 2018/850/EU establece nuevos objetivos específicos de reducción de vertido, en este sentido para el año 2035 la cantidad de residuos municipales enviados a vertedero deberá ser de un $10 \%$ del total de los residuos municipales generados. Esto contribuirá a que los estados miembros inviertan más en nuevas técnicas o tecnologías para el reciclaje y valorización de los residuos, como puede ser la producción de CSR a partir de los rechazos generados en el TMB, puesto que actualmente se destinan a vertedero en su mayor parte. Además, a partir de 2030, los residuos municipales susceptibles de ser reciclados o recuperados no serán admitidos en los vertederos, salvo aquellos residuos para los que el vertido es la mejor solución desde el punto de vista ambiental.

\subsubsection{Legislación Nacional}

En la Tabla 2.3 se presenta la normativa más relevante a nivel nacional en materia de RSU.

Tabla 2.3 Legislación Nacional en materia de RSU

Normativa Nacional

Ley 22/2011, de 28 de julio, de residuos y suelos contaminados.

Ley 11/1997, de 24 de abril, de envases y residuos de envases.

Real Decreto 782/1998, de 30 de abril, por el que se aprueba el Reglamento para el desarrollo y ejecución de la Ley 11/1997, de 24 de abril, de Envases y Residuos de Envases.

Real Decreto 252/2006, de 3 de marzo, por el que se revisan los objetivos de reciclado y valorización establecidos en la Ley 11/1997, de 24 de abril, de Envases y Residuos de Envases, y por el que se modifica el Reglamento para su ejecución, aprobado por el Real Decreto 782/1998, de 30 de abril.
Objetivos principales

Establece un marco jurídico para la regulación de la gestión de los residuos en España. Tiene como objetivo la prevención de la generación de residuos y la minimización de los impactos negativos sobre la salud humana y el medioambiente asociados a la generación y gestión de los mismos. Además, también regula el régimen jurídico de los suelo contaminados (España, 2011).

Esta Ley tiene como objetivo prevenir y reducir el impacto sobre el medioambiente de los envases y la gestión de los residuos de envases. Para ello establece medidas destinadas, en primer lugar, a la prevención de la producción de residuos de envases, y en segundo lugar, a la reutilización de los envases, su reciclado y demás formas de valorización, evitando o reduciendo su eliminación (España, 1997).

Establece el reglamento necesario para el desarrollo y ejecución de la Ley 11/1997, de 24 de abril, de Envases y Residuos de Envases (España, 1998).

Modifica los objetivos de reciclado y valorización establecidos en la Ley 11/1997, de 24 de abril, de Envases y Residuos de Envases (España, 2006). Estos objetivos son los últimos que se han publicado en una legislación a nivel nacional para los residuos de envases, no obstante, han sido actualizados por el Plan Estatal Marco de Residuos 2016-2020. 


\begin{tabular}{|c|}
\hline Normativa Nacional \\
\hline 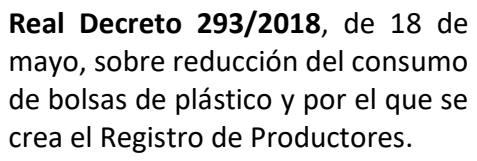 \\
\hline $\begin{array}{l}\text { Real Decreto } \mathbf{1 4 8 1 / 2 0 0 1} \text {, de } 27 \text { de } \\
\text { diciembre, por el que se regula la } \\
\text { eliminación de residuos mediante } \\
\text { depósito en vertedero. }\end{array}$ \\
\hline
\end{tabular}

Real Decreto Legislativo 1/2016, de 16 de diciembre, por el que se aprueba el texto refundido de la Ley de prevención y control integrados de la contaminación.

Real Decreto 815/2013, de 18 de octubre, por el que se aprueba el Reglamento de emisiones industriales y de desarrollo de la Ley 16/2002, de 1 de julio, de prevención y control integrados de la contaminación.

Resolución de 20 de diciembre de 2013, de la Dirección General de Calidad y Evaluación Ambiental y Medio Natural, por la que se publica el Acuerdo del Consejo de Ministros de 13 de diciembre de 2013, por el que se aprueba el Programa Estatal de Prevención de Residuos 2014-2020.

Resolución de 16 de noviembre de 2015, de la Dirección General de Calidad y Evaluación Ambiental y Medio Natural, por la que se publica el Acuerdo del Consejo de Ministros de 6 de noviembre de 2015, por el que se aprueba el Plan Estatal Marco de Gestión de Residuos (PEMAR) 2016-2022.

\section{Objetivos principales}

Tiene como objetico adoptar las medidas necesarias para reducir el consumo de bolsas de plástico, con la finalidad de prevenir y reducir los impactos adversos que los residuos de dichas bolsas producen en el medioambiente, especialmente a los ecosistemas acuáticos. También tiene como objetivo evitar la pérdidas de recursos materiales y económicos que supone el abandono de estas bolsas y su dispersión por el medio ambiente (España, 2018).

Establece un marco jurídico y técnico para las actividades de eliminación de residuos mediante depósito en vertedero. Regula las características de estas instalaciones y su correcta gestión y explotación con la finalidad de proteger la salud de las personas y el medio ambiente (España, 2001).

En él se aprueba el texto refundido de la Ley de prevención y control integrados de la contaminación, que se incluye en el anexo de la misma. Esta Ley tiene como objetivo evitar, reducir y controlar la contaminación de la atmosfera, del agua y del suelo, mediante el establecimiento de un sistema de prevención y control integrados de la contaminación para diferentes actividades industriales. Dentro del ámbito de esta Ley se encuentran las instalaciones para la valorización o eliminación de residuos (España, 2016).

Deroga el Real Decreto 653/2003, de 30 de mayo, sobre incineración de residuos. En este Real Decreto se establece el régimen jurídico aplicable a las emisiones industriales con el fin de proteger el medioambiente, así como las disposiciones para evitar y reducir la contaminación provocada por ciertas instalaciones industriales. En su Capítulo IV establece las disposiciones especiales para evitar y reducir la contaminación provocada por las instalaciones de incineración y co-incineración de residuos (España, 2013a).

Aprueba el Plan Estatal de Prevención de Residuos 2014-2020. Este Plan desarrolla la política de prevención de residuos, conforme a la normativa vigente, para avanzar en el cumplimiento de reducción de los residuos generados en 2020 en un $10 \%$ respecto del peso de los residuos generados en 2010 (España, 2013b).

Aprueba del Plan Estatal Marco de Gestión de Residuos (PEMAR) 2016-2022. Este Plan es un instrumento para orientar la política de residuos en España durante el periodo de vigencia y junto con el Plan Estatal de Prevención de Residuos 2014-2020 configuran los instrumentos generales de prevención y gestión de residuos en España (España, 2015a; MAGRAMA, 2015).

A nivel nacional, la Ley $22 / 2011$ de residuos y suelos contaminados traspone a la legislación española la Directiva 2008/98/CE. El objetivo de esta Ley es "Ia regulación de la gestión de los residuos, impulsando medidas que prevengan su generación y minimicen los impactos asociados a su generación y gestión sobre la salud humana y el medioambiente, así como mejorando la eficiencia en el uso de los recursos". En ella se establece la jerarquía de residuos de cinco niveles (prevención, reutilización, reciclaje, valorización y eliminación) que debe aplicarse como principio rector en la gestión de los residuos para conseguir el mejor resultado ambiental global. La Ley establece que deben existir recogidas separadas para, al menos, el papel/cartón, plástico y vidrio. También promueve medidas para impulsar la recogida selectiva de los biorresiduos para destinarlos a compostaje o digestión anaerobia; de forma que se logre un uso seguro del compost producido a partir de los mismos en el sector agrícola, la jardinería y la regeneración de áreas degradas, consiguiendo la sustitución de otras enmiendas orgánicas o fertilizantes minerales. Además, 
establece que la cantidad de residuos domésticos y comerciales que se destinan a la preparación para la reutilización y el reciclado de las fracciones de papel, metales, vidrio, plástico, biorresiduos u otras fracciones reciclables deberá alcanzar, en conjunto, el 50\% antes de 2020. Asimismo, los residuos deberán ser tratados previamente a su eliminación, salvo que el tratamiento de los mismos no sea técnicamente viable o quede justificado por razones de protección de la salud humana y del medio ambiente.

El vertido de los residuos está regulado mediante el Real Decreto 1481/2001, donde se establece que para el año 2016 la cantidad de residuos urbanos biodegradables destinada a vertedero debía ser menor al 35\% de la cantidad destinada en 1995, lo que supone que no se debería haber vertido más de 4,18 Mt. No obstante, en 2016 se enviaron a vertedero 5,6 Mt de residuos urbanos biodegradables (Iriani Bordas et al., 2018).

Por otro lado, con el fin de desarrollar las políticas de residuos y unificar objetivos en su gestión, en España se desarrolla el Plan Estatal Marco de Gestión de Residuos (PEMAR) 2016-2020. Este Plan tiene como objetivo "orientar las políticas de residuos de España, impulsando las medidas necesarias para mejorar las deficiencias detectadas y promoviendo las actuaciones que proporcionan un mejor resultado ambiental y que aseguran la consecución de los objetivos establecidos en la legislación". El objetivo final del Plan es convertir a España en una sociedad eficiente en el uso de los recursos, que avance hacia una economía circular. Además, el plan incluye un conjunto de medidas que configuran la Estrategia de Reducción de Vertido de Residuos Biodegradables, para conseguir el objetivo de reducción de 2016.

Dentro del apartado de residuos domésticos y comerciales destacan los siguientes objetivos específicos:

- Alcanzar el 50\% de preparación para la reutilización y el reciclado en 2020 de la fracción resto (no recogida selectivamente). Esto supone un reciclaje por material de: un 50\% para los biorresiduos, un $60 \%$ para los metales, un $55 \%$ para los plásticos, un $70 \%$ para el papel/cartón, un $60 \%$ para el vidrio, un $55 \%$ para la madera, un $55 \%$ para los briks, un $50 \%$ para los textiles (incluye la reutilización) y un $10 \%$ para otros residuos (incluye la reutilización).

- Implantar de forma progresiva y gradual la recogida separada de biorresiduos para su tratamiento biológico y fomentar el autocompostaje.

- Regular el fin de la condición de residuo para el compost de calidad y promocionar su uso como producto.

- Incrementar la valorización energética en 2020 hasta el 15\% de los RSU generados mediante la preparación de combustibles y el uso de residuos en instalaciones de incineración y coincineración.

- Valorizar energéticamente parte de los rechazos producidos en las instalaciones de TMB, directamente o mediante su transformación en un CSR que puede ser utilizado en instalaciones de co-incineración.

- Incrementar la valorización energética del material bioestabilizado generado en instalaciones de incineración y co-incineración.

- $\quad$ Limitar el vertido total de los RSU generados al 35\% en 2020.

Dentro del apartado de residuos de envases destacan los siguientes objetivos específicos para el reciclado que se deben alcanzar en el año 2020:

- Un 70\% para el total de los envases

- Un 85\% para el papel/cartón

- $\quad$ Un 75\% para el vidrio

- $\quad$ Un 70\% para los metales férricos

- Un $\quad$ 70\% para el aluminio

- Un 40\% para los plásticos

- Un $60 \%$ para la madera 


\subsubsection{Legislación autonómica de la Comunidad Valenciana}

En la Tabla 2.4 se presenta la normativa más relevante a nivel de la Comunidad Valenciana en materia de RSU.

Tabla 2.4 Legislación de la Comunidad Valenciana en materia de RSU

\begin{tabular}{|c|c|}
\hline Normativa Comunidad Valenciana & Objetivos principales \\
\hline $\begin{array}{l}\text { Ley } \mathbf{1 0 / 2 0 0 0} \text {, de } 12 \text { de diciembre, } \\
\text { de Residuos de la Comunitat } \\
\text { Valenciana. }\end{array}$ & $\begin{array}{l}\text { Tiene como objeto, en el marco de competencias de la Generalitat Valenciana, } \\
\text { establecer el régimen jurídico de la producción y gestión de los residuos, así } \\
\text { como la regulación de los suelos contaminados, con el fin de proteger la salud } \\
\text { humana y el medio ambiente (Comunidad Valenciana, 2000). }\end{array}$ \\
\hline $\begin{array}{l}\text { Decreto } \mathbf{8 1 / 2 0 1 3} \text {, de } 21 \text { de junio, } \\
\text { del Consell, de aprobación } \\
\text { definitiva del Plan Integral de } \\
\text { Residuos de la Comunitat } \\
\text { Valenciana (PIRCV). }\end{array}$ & $\begin{array}{l}\text { Aprueba definitivamente la revisión y actualización del Plan Integral de Residuos } \\
\text { de la Comunitat Valenciana (PIRCV), en cumplimiento con lo dispuesto en el } \\
\text { artículo } 27 \text { de la Ley } 10 / 2000 \text {, de } 12 \text { de diciembre, de la Generalitat, de Residuos } \\
\text { de la Comunitat Valenciana y en la Ley } 4 / 2004 \text {, de } 30 \text { de junio, de la Generalitat, } \\
\text { de Ordenación del Territorio y Protección del Paisaje, para los planes de acción } \\
\text { territorial de carácter sectorial (Comunidad Valenciana, 2013). }\end{array}$ \\
\hline $\begin{array}{l}\text { Decreto } 55 / 2019 \text {, de } 5 \text { de abril, del } \\
\text { Consell, por el que se aprueba la } \\
\text { Revisión del Plan integral de } \\
\text { residuos de la Comunitat } \\
\text { Valenciana. }\end{array}$ & $\begin{array}{l}\text { Aprueba definitivamente la revisión y actualización del Plan integral de Residuos } \\
\text { de la Comunitat Valenciana (PIRCVA), en cumplimiento con lo dispuesto en el } \\
\text { artículo } 27 \text { de la Ley } 10 / 2000 \text {, de } 12 \text { de diciembre, de la Generalitat, de Residuos } \\
\text { de la Comunitat Valenciana y en la Ley } 5 / 2014 \text {, de } 25 \text { de julio, de la Generalitat, } \\
\text { de Ordenación del Territorio, Urbanismo y Paisaje, así como en la Ley } 1 / 2019 \text {, de } \\
5 \text { de febrero, de la Generalitat que la modifica, para los planes de acción } \\
\text { territorial de carácter sectorial (Comunidad Valenciana, 2019). }\end{array}$ \\
\hline
\end{tabular}

A nivel autonómico, en la Comunidad Valenciana, los residuos están regulados por la Ley 10/2000 cuyos objetivos son: "garantizar que los residuos se gestionan sin poner en peligro la salud humana, mejorando la calidad de vida de los ciudadanos de la Comunidad Valenciana; dar prioridad a las actuaciones que previenen y reducen la cantidad de residuos generados y su peligrosidad, obtener un alto nivel de protección, utilizando procedimientos o métodos que no provoquen incomodidad por el ruido o los olores, no atenten contra los paisajes o lugares de especial interés, ni perjudiquen el medioambiente creando riesgos para el agua, el aire, el suelo, la flora y la fauna; desarrollar instrumentos de planificación, inspección y control que favorezcan la suficiencia, seguridad y eficiencia de las actividades de gestión de los residuos, y asegurar la información a los ciudadanos sobre la acción pública en materia de gestión de residuos, promoviendo su participación en el desarrollo de las acciones previstas". Esta Ley es aplicable a todos los residuos que se originan o se gestionen en al ámbito territorial de la comunidad, a excepción de las emisiones atmosféricas, los residuos radioactivos, los vertidos de efluentes líquidos y aquellos residuos que tienen una legislación propia.

La Comunidad Valenciana también cuenta con un Plan Integral de Residuos (PIRCVA) propio que fue revisado y actualizado en 2019. Este PIRCVA tiene como objetivo revisar y actualizar los objetivos y acciones propuestas en el Plan de Residuos de la Comunidad Valenciana de 2013 para su adaptación a la situación actual, constituyendo la estrategia a seguir en materia de residuos en la Comunidad Valenciana. Dicha estrategia se enmarca en los principios establecidos por la Directiva 2008/98/CE y la modificación de la misma por la Directiva 2018/851/UE.

El Plan establece que la generación total de rechazos no valorizables originados en el tratamiento de los RSU, y que tienen como destino el vertedero, no podrá superar el $48 \%$ sobre el total de RSU producidos en 2019 (tomando en consideración las entradas de residuos en plantas de TMB, en plantas de tratamiento de la fracción orgánica, en ecoparques y las cantidades totales recogidas selectivamente). Los objetivos para el 2020 son del 35\%, para el 2021 del 34\% y para el 2022 del 30\%. Además, independientemente de la tecnología utilizada y del proceso de tratamiento, en 2020 las instalaciones para la valorización de RSU mezclados deberán tener rendimientos de recuperación de materiales como mínimo del 9\% (excluyendo la 
materia orgánica) respecto a las entradas, así como una configuración de circuito cerrado en la línea de recuperación de dichos materiales.

En relación a los rechazos de las plantas de TMB, una vez agotadas todas las posibilidades de reutilización, reciclado y valorización material, el PIRCVA establece que los rechazos de estas instalaciones (incluida la fracción orgánica bioestabilizada que no sea apta para uso agrícola) deberán ser destinados a operaciones de valorización energética o transformación en un CSR antes que a eliminación, como indica la Jerarquía de gestión de residuos. El destino del CSR será la recuperación energética mediante generación de calor/electricidad para autoconsumo en las propias plantas de TMB o en otras instalaciones o sectores industriales, reduciendo el porcentaje que se envía a vertedero; así como la utilización como materia prima para la síntesis de biocombustibles y bioproductos de segunda generación que puedan ser introducidos en el mercado. El porcentaje de CSR estimado por instalación será de hasta un máximo del 15\% de las entradas en planta. Además, la producción de CSR contribuirá a aumentar al porcentaje de materiales valorizados en determinadas condiciones.

Respecto a los biorresiduos, el PIRCVA establece que antes del 2020 todos los municipios o entidades locales deberán tener implantada de la recogida selectiva de los mismos y que estos biorresiduos deberán tratarse adecuadamente de forma que se produzca un compost seguro. Los objetivos de recogida selectiva a nivel autonómico son: del 25\% del total de biorresiduos producidos para el 2020; del 30\% para el 2021 y del $50 \%$ para el 2022.

Finalmente, el Plan estable una serie de objetivos anuales de reciclado para diferentes tipos de residuos, entre los que destacan los siguientes:

- Para residuos domésticos: un 50\% para el 2019 respecto al total de residuos domésticos producidos, un 65\% para el 2020, un 66\% para 2021 y un 67\% para 2022.

- Para residuos de envases ligeros:

- Metales (aluminio y acero): un $80 \%$ de ambas fracciones por separado en 2019 y un $90 \%$ en 2020

- Plásticos: un $74 \%$ en 2019 y un $75 \%$ en 2020

- Brik: un $88 \%$ en 2019 y un $90 \%$ en 2020

- Papel/cartón: un 85\% en 2019 y un $90 \%$ en 2020

- Vidrio: un $75 \%$ en 2019 y un $80 \%$ en 2020

\subsubsection{La gestión integral de los RSU}

La gestión integral de los RSU comprende el conjunto de operaciones que permiten dar a los RSU generados en una determinada zona el tratamiento global más adecuado, desde la perspectiva ingenieril, económica, medioambiental y sanitaria, de acuerdo con las características de los mismos y los recursos disponibles (Colomer and Gallardo, 2007). En España, la Ley 22/2011 de residuos y suelos contaminados (España, 2011) define la gestión como "la recogida, el transporte y tratamiento de los residuos, incluida la vigilancia de estas operaciones, así como el mantenimiento posterior al cierre de los vertederos".

El objetivo de la gestión integral de los RSU es gestionar los residuos generados por la sociedad teniendo en cuenta el medio ambiente, la salud pública y los objetivos marcados en la legislación. Además, debe cumplir dos funciones fundamentales: la eliminación de los residuos y la recuperación de los recursos.

Actualmente en España se lleva a cabo la gestión integral y tratamiento de prácticamente todos los residuos generados en el país, teniendo en cuenta siempre la jerarquía de gestión definida por la legislación. No obstante, lograr una gestión eficaz de los RSU es un proceso complejo debido a las grandes cantidades de residuos generadas y la heterogeneidad de los mismos, así como a las limitaciones económicas y la incorporación de nuevas políticas y objetivos de reciclaje. 
La gestión de los RSU puede ser considerada como un sistema compuesto por un conjunto de actividades o procesos cuya finalidad es la gestión eficiente de los mismos, desde que son generados hasta su tratamiento final. Este sistema está dividido en seis etapas interrelacionadas donde se encuentran dichas actividades (Colomer and Gallardo, 2007; Tchobanoglous et al., 1994):

- Generación de RSU: esta etapa incluye las actividades en las que los materiales son identificados como residuos, los cuales será necesario gestionar. Esto ocurre cuando un objeto deja de tener valor en el contexto en el que se ha producido y su poseedor tiene la necesidad de desprenderse de mismo. Además, también abarca el análisis de las cantidades generadas, la composición y las variaciones temporales que puedan existir. Con los datos obtenidos se diseñarán las etapas posteriores.

- Prerrecogida: etapa que comprende las actividades de manipulación, separación, almacenamiento y procesamiento de los RSU en origen. Estas actividades son realizadas por los ciudadanos (generador) en sus domicilios hasta que los residuos son depositados en el punto de recogida de la vía pública. Esta segunda etapa es importante a la hora de facilitar la recogida de manera que esta se realice en unas condiciones higiénico-sanitarias adecuadas. Asimismo, influye considerablemente en la eficiencia de los tratamientos posteriores que se le da a los RSU.

- Recogida: incluye las actividades de carga y transporte de los RSU desde los puntos de recogida en la vía pública hasta el lugar donde se descarga el vehículo. Este punto puede ser una estación de transferencia, una planta de tratamiento o el vertedero (solo para aquellos casos donde el tratamiento no sea técnica, económica o medioambientalmente viable).

- Transferencia y transporte: supone las actividades de traslado de residuos entre las distintas instalaciones de gestión. En esta etapa los RSU se alejan de las zonas donde se han generado. Para ello, en las estaciones de transferencia, los camiones de recogida vacían los residuos a otro camión de mayor capacidad que realiza el transporte hasta la instalación de tratamiento o eliminación. Adicionalmente, los residuos pueden ser compactados en los camiones de gran tonelaje, lo que economiza el trasporte de los mismos.

- Tratamiento: comprende las actividades de separación, procesado y transformación de los residuos antes de su disposición final en vertedero. La separación y procesado de los RSU se lleva a cabo en instalaciones de recuperación de materiales y tiene como objetivo la obtención de diferentes materiales con una calidad suficiente para su reciclado o posterior transformación. En estas instalaciones, tanto los RSU que han sido separados en origen como los que se recogen de forma mezclada, se someten a una serie de procesos como: separación de voluminosos, clasificación mecánica, separación manual o automática de los materiales reciclables, prensado y embalado. Tras el tratamiento se obtienen varios flujos de materiales que se entregan a empresas recicladoras o se destinan a la siguiente etapa de transformación y un flujo de rechazo destinado a vertedero, en la mayoría de los casos, o a incineración. Los procesos de transformación tienen como finalidad reducir el peso y volumen de los RSU y disminuir su biodegradabilidad, así como recuperar productos de conversión y energía a partir de los mismos. Los más extendidos son el compostaje, la biometanización, la incineración y la gasificación.

- Eliminación o disposición final: es el destino final de las RSU o de los rechazos generados en las instalaciones de tratamiento. Normalmente esta evacuación se realiza en vertederos controlados y es la última opción de la Jerarquía de gestión. Además, la legislación establece que todos los RSU deben someterse a algún tipo de tratamiento, siempre que sea viable, antes de su disposición final.

De todas estas etapas en los siguientes apartados se van a estudiar más extensamente las correspondientes a la recogida y al tratamiento (Figura 2.7). 

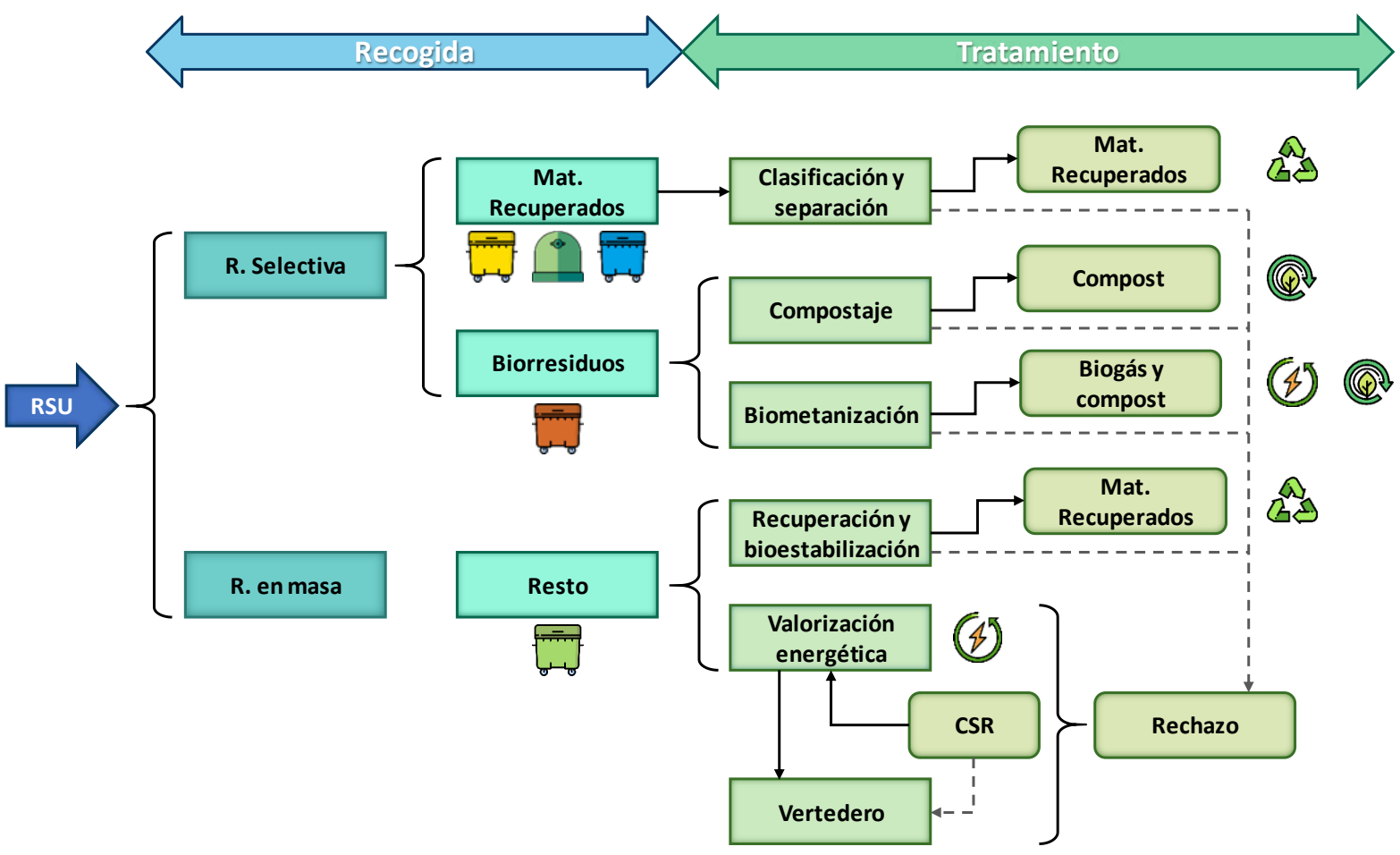

Figura 2.7 Recogida y tratamiento de los RSU en un sistema integrado de gestión

\subsubsection{La recogida}

En el ámbito español, la Ley 22/2011 de residuos y suelos contaminados (España, 2011) define la recogida como "operación consistente en el acopio de residuos, incluida la clasificación y almacenamiento iniciales para su transporte a una instalación de tratamiento". Esta etapa de la gestión comprende el traslado de los RSU del lugar donde han sido depositados por los ciudadanos hasta el camión de recogida, la carga del camión, el transporte a las estaciones de transferencia o instalaciones de tratamiento y la descarga de los residuos allí (Gallardo, 2000). Para ello se utiliza una gran variedad de sistemas y vehículos en función de la fracción de residuos a recoger.

Establecer un sistema de recogida eficiente para los RSU es imprescindible, puesto que supone entre el 60 $80 \%$ de los costes totales de la gestión (Fernández, 2010). Para ello, es necesario determinar adecuadamente los parámetros de operación como el número de rutas, frecuencia de recogida y horarios, equipo y personal necesario, tipos de contenedores, tipo de recogida y modelo de recogida.

La recogida de los RSU se puede clasificar en función de dos criterios: el tipo de prerrecogida y el grado de fraccionamiento en origen (Gallardo, 2000).

El criterio de tipo de prerrecogida está relacionado con la distancia que han de recorrer los operarios para trasladar los RSU desde donde han sido depositados por los ciudadanos al camión. En función de esta distancia la recogida se divide en:

- Recogida puerta a puerta: los RSU son recogidos en el punto de generación, es decir, en la puerta de los ciudadanos. Estos pueden estar depositados en bolsas, cubos o pequeños contenedores.

- Recogida en contenedor en acera: los residuos se recogen en grandes contenedores de 240 a 1.100 litros de volumen colocados en las aceras de los municipios, pueden estar en superficie o soterrados. Su vaciado se realiza de forma mecánica y los operarios deben acercar el contenedor al camión y engancharlo al sistema de descarga (Figura 2.8). 


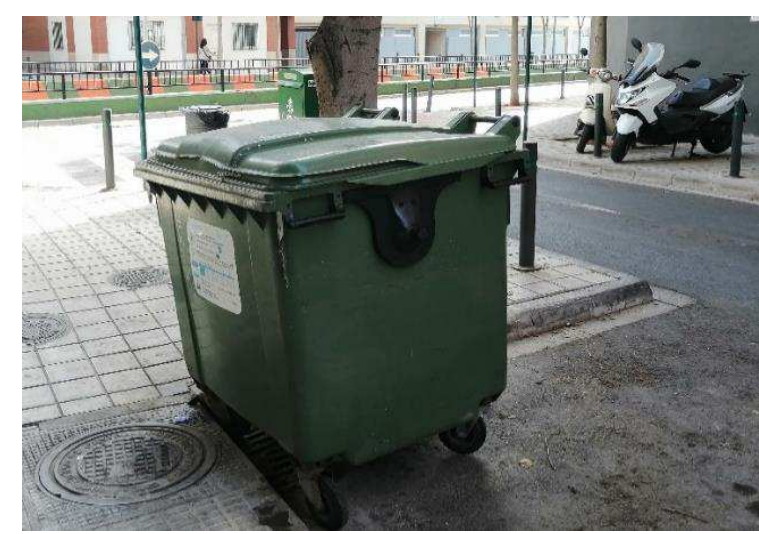

Figura 2.8 Recogida de RSU en contenedor en acera

- Recogida en áreas de aportación: los RSU se recogen en grandes contendores de 1.800 a 3.500 litros. Estas áreas de aportación son zonas en la vía pública donde se colocan varios contenedores, normalmente para distintos materiales. Estos pueden estar en superficie o soterrados (Figura 2.9). Los operarios no tienen que acercar el contenedor al camión, solo deben engancharlo para ser vaciado.
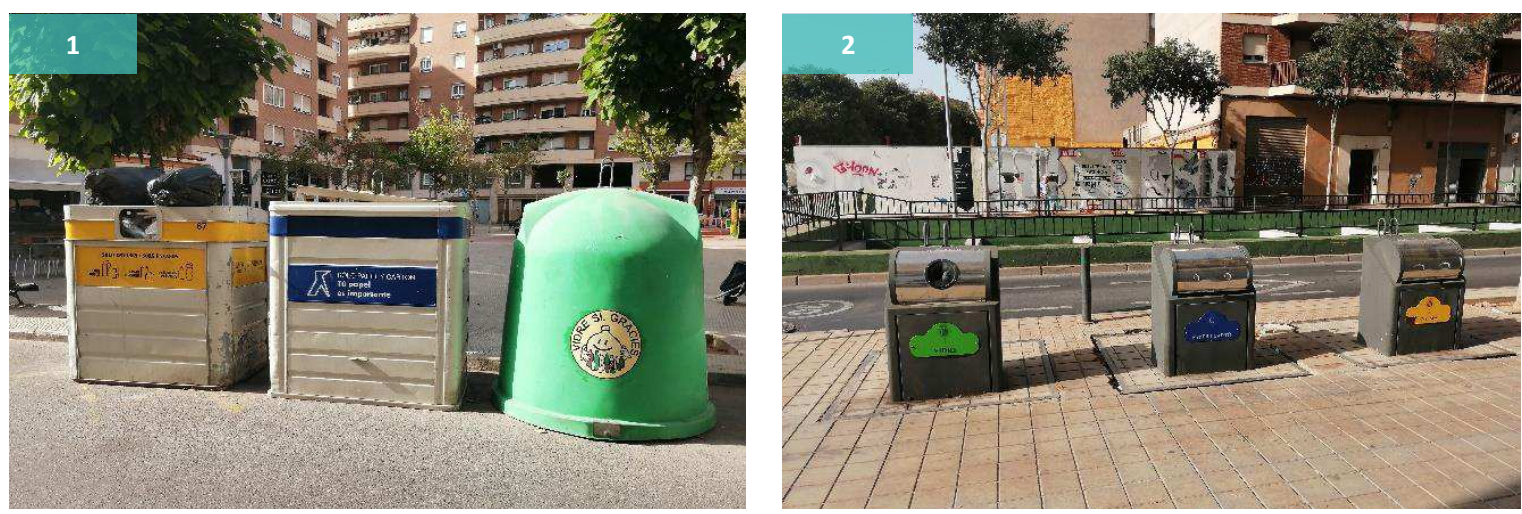

Figura 2.9 Recogida de RSU en áreas de aportación: contenedores en superficie (1) y soterrados (2)

- Recogida neumática: los residuos son depositados por los ciudadanos en buzones soterrados que están conectados mediante tuberías a una central donde son recogidos por los operarios. El transporte de los RSU por las tuberías se realiza neumáticamente mediante un sistema de vacío (Figura 2.10).

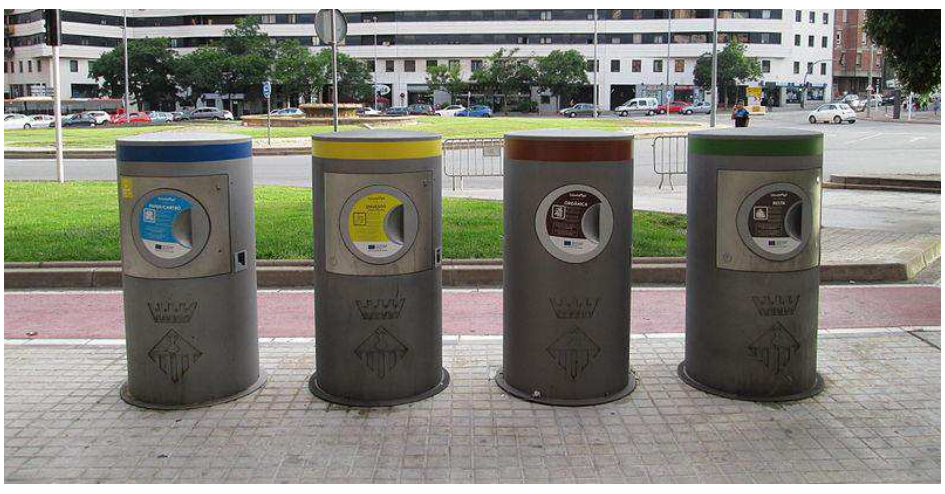

Figura 2.10 Buzones para la recogida de neumática de RSU 
- Recogida por llamada previa: los residuos se recogen en el lugar de generación previa llamada del generador. Se utiliza para la recogida de residuos como los voluminosos que tienen una baja frecuencia de generación.

El criterio de grado de fraccionamiento está relacionado con la separación en origen y recogida selectiva de ciertas fracciones de los RSU. En función de este criterio se distinguen dos tipos de recogida:

- Recogida en masa: los RSU son depositados por los ciudadanos de forma mezclada debido a que no existe una recogida diferenciada para los mismos, por lo que se recogen todos juntos. A esta fracción de residuos se les suele denominar RSU mezclados o fracción resto.

- Recogida selectiva: los residuos son separados en origen y recogidos de forma diferenciada, por lo que cada camión recoge un tipo de material: vidrio, papel/cartón, envases, fracción orgánica recogida selectivamente (FORS), etc.

La recogida selectiva tiene un papel fundamental en la gestión integral de los RSU, puesto que favorece la recuperación de los recursos, minimiza la cantidad de residuos enviada a vertedero y permite alcanzar los objetivos marcados en la legislación respecto a la reutilización y el reciclaje de los materiales. En el ámbito nacional, la Ley 22/2011 define la recogida selectiva como "la recogida en la que un flujo de residuos se mantiene por separado, según su tipo y naturaleza, para facilitar un tratamiento específico". El objetivo principal de este tipo de recogida es conseguir la separación en origen y la recogida diferenciada de la mayor cantidad de materiales (vidrio, papel-cartón, envases, fracción orgánica, ropa y/o aceites de cocina), lo que facilita el tratamiento posterior de estos materiales, de forma que se mejora su valorización mediante la reutilización, el reciclado, el compostaje o la biometanización.

En España existen 5 modelos diferentes para la recogida de RSU, también relacionados con el grado de fraccionamiento. Estos modelos de recogida se diferencian por en número y tipo de flujos de residuos que se recogen por separado y que pueden incluir: papel/cartón, vidrio, envases ligeros, FORS y resto (Figura 2.11).

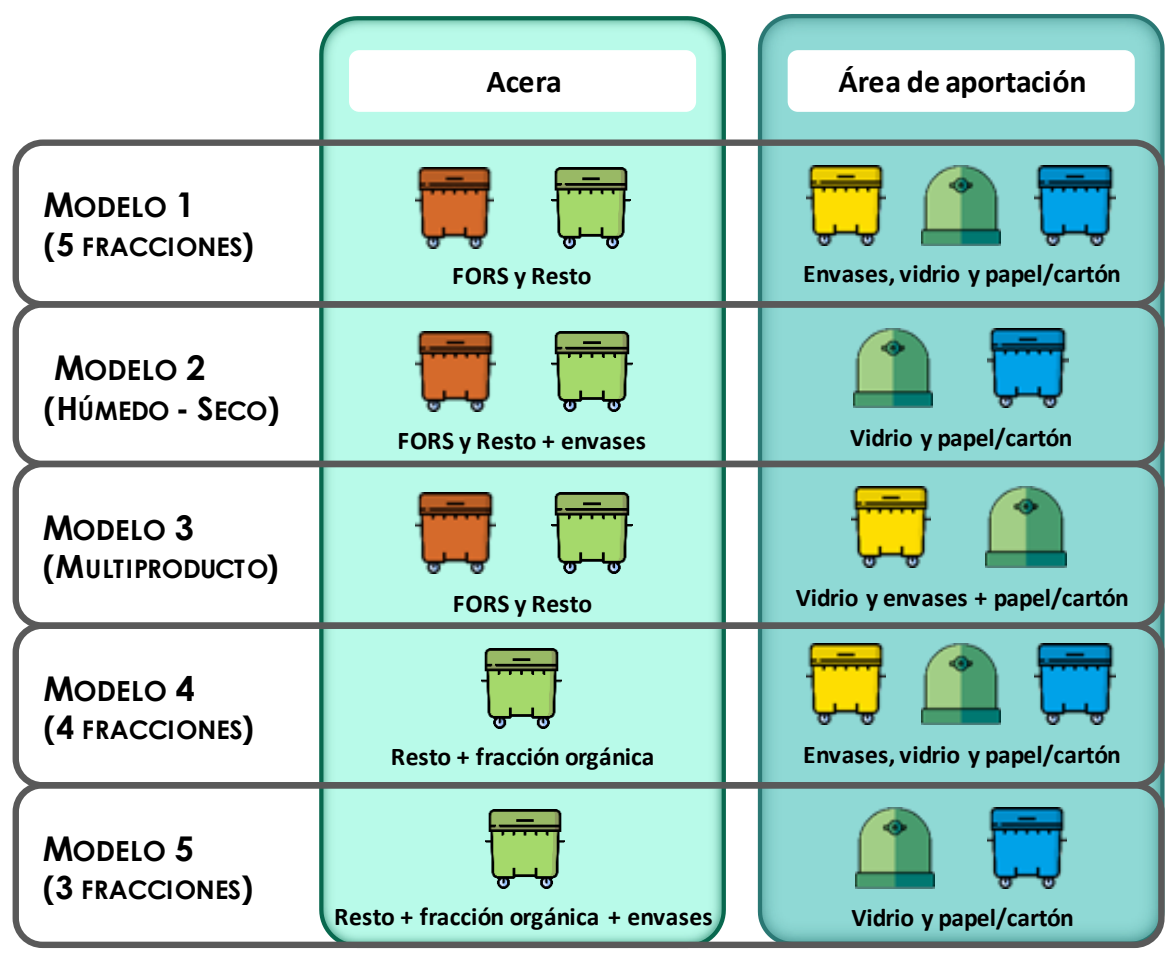

Figura 2.11 Modelos españoles de recogida de RSU 
El Modelo 1 se utiliza principalmente en Cataluña, Navarra y País Vasco, aunque en los últimos años la recogida selectiva de FORS se ha empezado a implantar en nuevas ciudades de algunas CC.AA. (Andalucía, Aragón, Islas Baleares, Islas Canarias, Madrid, La Rioja o Comunidad Valenciana) con el objetivo de cumplir los nuevos objetivos de reciclaje y minimización de vertido propuestos en la legislación. El Modelo 2 consiste principalmente en la separación de la fracción orgánica de la inorgánica (que incluye los residuos de envases). Este modelo no está muy extendido y solo se da en algunos municipios de Navarra, Galicia y Cataluña, así como en las ciudades de Valladolid y Córdoba. El Modelo 3 existe solamente en algunas comarcas catalanas y en él se recogen de manera conjunta el papel/cartón y los envases ligeros. El Modelo 4 es el más habitual en España y en algunos lugares incluye también la recogida diferenciada de los residuos de jardinería. Finalmente, el Modelo 5 es un modelo residual y está limitado solo a unas pocas zonas rurales (MAGRAMA, 2015; Sastre et al., 2018). Además de estas recogidas ordinarias existen otras recogidas específicas para residuos especiales que se generan en menor medida y de forma más puntual como: voluminosos, pilas, textiles, aceites de cocina, medicamentos, residuos de la construcción y demolición, lámparas, luminarias, RAEE, fitosanitarios y diferentes residuos que se recogen en los puntos limpios.

\subsubsection{El tratamiento}

El tratamiento de los RSU comprende una serie de operaciones y transformaciones que tienen como objetivos: recuperar los recursos contenidos en los mismos, de forma que se obtienen una serie de subproductos que tengan interés económico y/o energía; reducir su volumen y peligrosidad, y adecuarlos para su posterior disposición final.

El tratamiento de los RSU es diferente en función del modelo de recogida y la separación en origen de los distintos materiales. En la Tabla 2.5 se presentan los tratamientos más habituales para cada fracción.

Tabla 2.5 Tratamiento de las diferentes fracciones de los RSU

\begin{tabular}{|c|c|c|}
\hline Fracción & Tipo de tratamiento & Instalación de tratamiento \\
\hline \multirow{2}{*}{ FORS } & \multirow{2}{*}{$\begin{array}{l}\text { Biológico: compostaje } \\
\text { y/o biometanización }\end{array}$} & Plantas de compostaje de la FORS \\
\hline & & Plantas de biometanización y compostaje de la FORS \\
\hline \multirow{6}{*}{ RSU mezclados } & Mecánico & Plantas de Triaje \\
\hline & \multirow{3}{*}{ Mecánico-biológico } & Plantas de recuperación y compostaje \\
\hline & & Plantas de recuperación, biometanización y compostaje \\
\hline & & Plantas de biosecado y recuperación \\
\hline & Térmico: incineración & Planta de incineración y recuperación energética \\
\hline & Disposición final & Vertedero controlado \\
\hline Envases ligeros & Mecánico & Plantas de selección de envases \\
\hline Vidrio & Mecánico & Instalación de preparación del vidrio \\
\hline Papel/cartón & Mecánico & Instalación de preparación del papel/cartón \\
\hline
\end{tabular}

A continuación, se explica en qué consiste cada tipo de tratamiento:

\section{Tratamiento mecánico}

Este tratamiento tiene como finalidad seleccionar y recuperar los diferentes materiales valorizables contenidos en los RSU para su preparación y entrega a empresas recicladoras (Figura 2.12). Para ello se utilizar una serie de operaciones y procesos mecánicos automatizados (plantas automáticas) o mano de obra directa (plantas manuales). En el capítulo tres de la presente tesis se hace una revisión completa de las tecnologías y equipamientos utilizados para este tratamiento. Finalmente, los materiales no separados forman el rechazo de estas instalaciones que se destina principalmente a vertedero. 
Las plantas de preparación del vidrio y del papel/cartón tienen un rendimiento cercano al 100\%, puesto que la cantidad de impropios en los contenedores de recogida de estos materiales es muy pequeña, del 1,7\% para el vidrio y de 3,8\% para el papel/cartón (MAGRAMA, 2015).

Las plantas de selección de envases tienen unos rendimientos menores, con una media del 78,28\% en 2016 respecto a los residuos entrantes (MITECO, 2019). Esto se debe, por un lado, a que los residuos de entrada son una mezcla de envases de metal, plástico y brik, lo que dificulta su separación, por otro, a que el porcentaje de impropios en el contenedor para esta fracción es mayor, un 28\% (MAGRAMA, 2015)

En plantas de triaje se lleva a cabo una separación mecánica de los distintos materiales que se encuentran en los RSU mezclados, las distintas fracciones seleccionadas pueden destinarse a fines diferentes: reciclaje de materiales recuperados (papel/cartón, plásticos, vidrio, metales, biriks, etc.), compostaje/ biometanización de la fracción orgánica o la recuperación energética. Estas plantas suelen aparecer como tratamiento de la fracción seca en el modelo de recogida "húmedo-seco" o como una fase previa al tratamiento térmico de los RSU. El rendimiento medio de las instalaciones españolas de este tipo en 2016 fue de 22,90\% (MITECO, 2019).
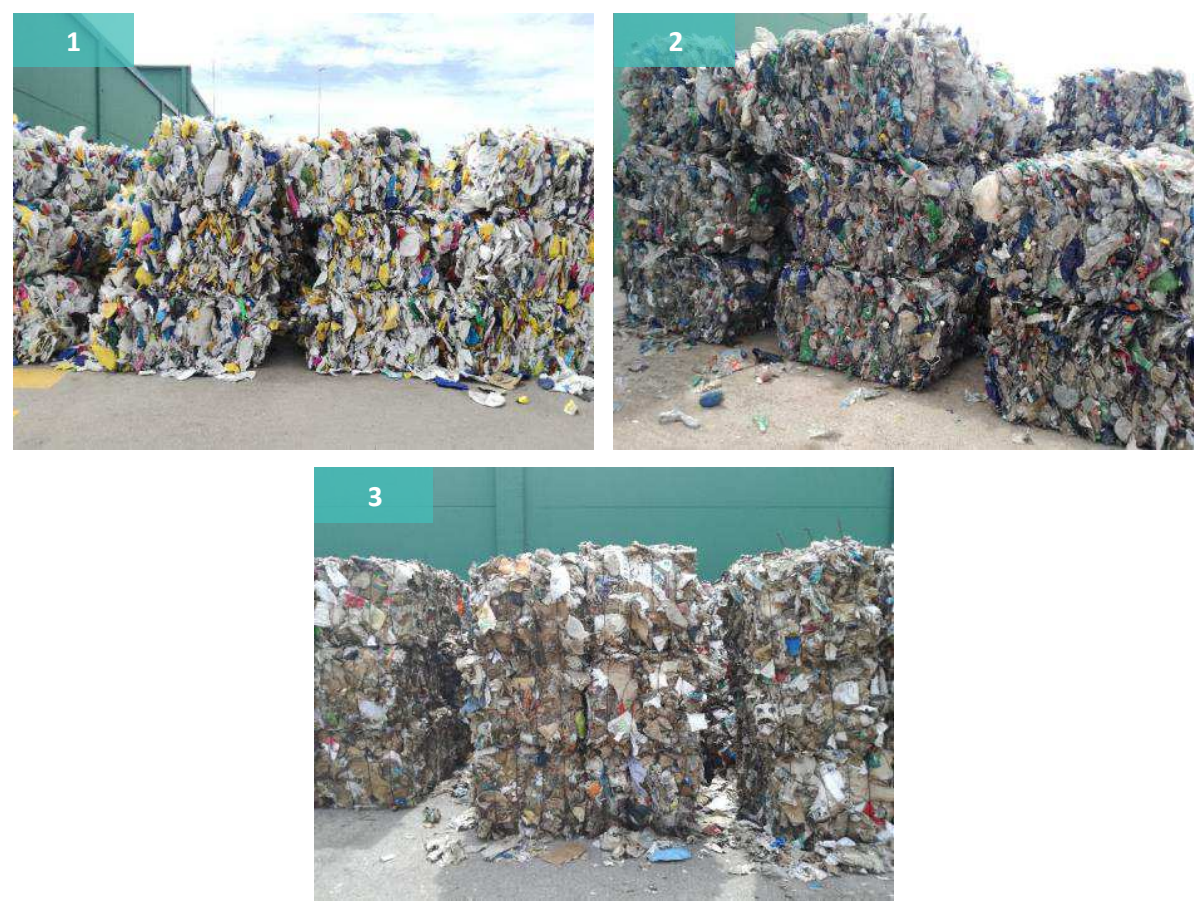

Figura 2.12 Materiales recuperados en el tratamiento mecánico: PEAD (1), PET (2) y papel/cartón (3)

\section{Tratamiento biológico}

Los tratamientos biológicos comprenden una serie de procesos y tratamientos para la degradación biológica de la materia orgánica presente en los RSU, tanto de la que proviene de la recogida selectiva como de los RSU mezclados. Además, en este último caso se combina con tratamientos mecánicos como se explica en el siguiente punto. El objetivo de esta biodegradación es la valorización de la materia orgánica presente en los RSU, transformándola en compost y/o biogás, así como su estabilización y la disminución de su volumen.

Principalmente se pueden distinguir dos tipos de tratamiento en función de si la degradación llevada a cabo por los microorganismos se realiza en presencia de oxígeno o no: compostaje y biometanización respectivamente. En el capítulo tres de la presente tesis se hace una revisión completa de las tecnologías y sistemas utilizados para ambos tipos de tratamiento.

El compostaje es el proceso que consiste en la biodegradación aerobia y posterior estabilización de los materiales orgánicos presentes en los residuos mediante reacciones metabólicas, la cuales transforman los compuestos orgánicos originales en otras formas químicas. Este tratamiento biológico es el más utilizado 
para la estabilización de la fracción biodegradable de los RSU, transformándola en bioestabilizado si procede de RSU mezclados o en compost si procede de la FORS (Figura 2.13). Además, en el caso del compost, se trata de un subproducto que puede utilizarse como fertilizante, abono o enmienda orgánica.

El proceso de compostaje ocurre en diferentes etapas (Colomer and Gallardo, 2007; FUCOVASA et al., 2015): la primera está caracterizada por una elevada actividad microbiana llevada a cabo principalmente por bacterias mesofílicas, las cuales utilizan gran parte del carbono como fuente de energía generando $\mathrm{CO}_{2}$ y calor $\left(10-40^{\circ} \mathrm{C}\right)$. El aumento de la temperatura da paso a la segunda etapa, donde la materia orgánica alcanza su bioestabilización por acción de la microflora termofílica. En esta etapa se alcanzan temperaturas elevadas $\left(40-70^{\circ} \mathrm{C}\right)$ que aseguran la destrucción organismos patógenos, hongos, esporas, semillas y elementos biológicos indeseables, permitiendo la higienización del material. En la última etapa la temperatura disminuye y la actividad microbiana es mucho menor, actuando hongos y actinomicetos que contribuyen a la estabilidad del material. Esta etapa se conoce como etapa de maduración y, cuando la temperatura desciende hasta valores cercanos a la temperatura ambiente, se da por terminado el proceso.
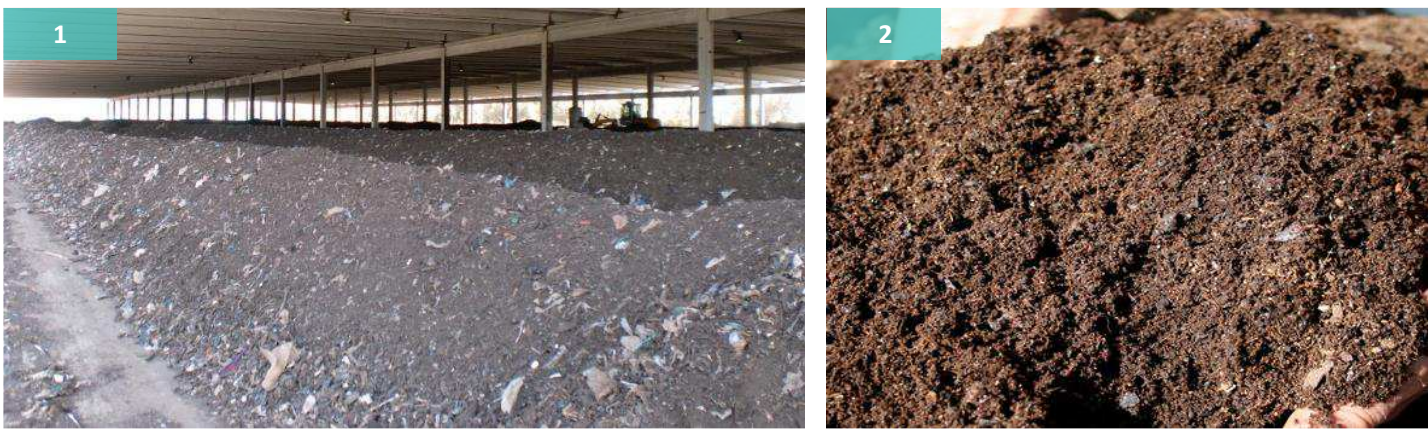

Figura 2.13 Pilas de compostaje (1) y compost (2)

Las plantas de compostaje de la FORS aparecen cuando el sistema de gestión de RSU incluye la separación en origen y recogida diferenciada de la fracción orgánica de los RSU, la cual es compostada en estas instalaciones. El rendimiento medio de las plantas españolas de este tipo en 2016 fue del 71,91\% respecto a los residuos entrantes (MITECO, 2019).

La biometanización o digestión anaerobia es también un proceso de degradación y descomposición de la materia orgánica presente en los RSU, el cual es llevado a cabo por la acción de microrganismo en ausencia de oxígeno. Tras el tratamiento se obtienen un producto gaseoso denominado biogás, formado por una mezcla de metano y dióxido de carbono principalmente, que puede destinarse a su uso como combustible o para la generación de electricidad o calor. Además, se obtienen un producto semisólido que contienen aquellos componentes que son difíciles de degradar y que se denomina digestato, el cual puede someterse a un proceso de compostaje para su estabilización de forma que se obtiene compost. Este tratamiento es mucho más complejo que el compostaje y, por lo tanto, tiene una menor implantación en la gestión de los RSU. Para conseguir la transformación de la fracción orgánica en biogás se necesitan una gran cantidad de reacciones bioquímicas que se dan en varias etapas, siendo las principales: hidrólisis, fermentación ácida y fermentación metánica.

Las plantas de biometanización y compostaje de la FORS también aparecen cuando el sistema de gestión incluye la recogida separada de la fracción orgánica. En ellas la materia orgánica se destina a biometanización y el digestato obtenido se somete a un proceso de compostaje. El rendimiento medio de estas instalaciones en España en el año 2016 fue de 69,36\% (MITECO, 2019).

\section{Tratamiento mecánico-biológico}

El tratamiento mecánico-biológico (TMB) comprende la combinación de procesos mecánicos y biológicos para el tratamiento de los RSU mezclados o fracción resto, puesto que estos residuos contienen un contenido significativo de fracción orgánica mezclada con diferentes materiales. 
Este tipo de tratamiento está muy extendido y permite realizar un tratamiento diferenciado de la fracción orgánica y de los materiales reciclables contenidos en los RSU mezclados. Por un lado, los procesos mecánicos permiten separar y recuperar los distintos materiales para su entrega a empresas recicladoras. Por otro lado, los procesos biológicos permiten estabilizar la materia orgánica disminuyendo su biodegradabilidad y volumen.

En las plantas de recuperación y compostaje se lleva a cabo una clasificación mecánica de los RSU mezclados, junto con la estabilización de la fracción orgánica contenida en los mismos mediante compostaje (Figura 2.14). El rendimiento global de estas plantas en el año 2016 en España fue de 32,34\% respecto al material entrante (MITECO, 2019).
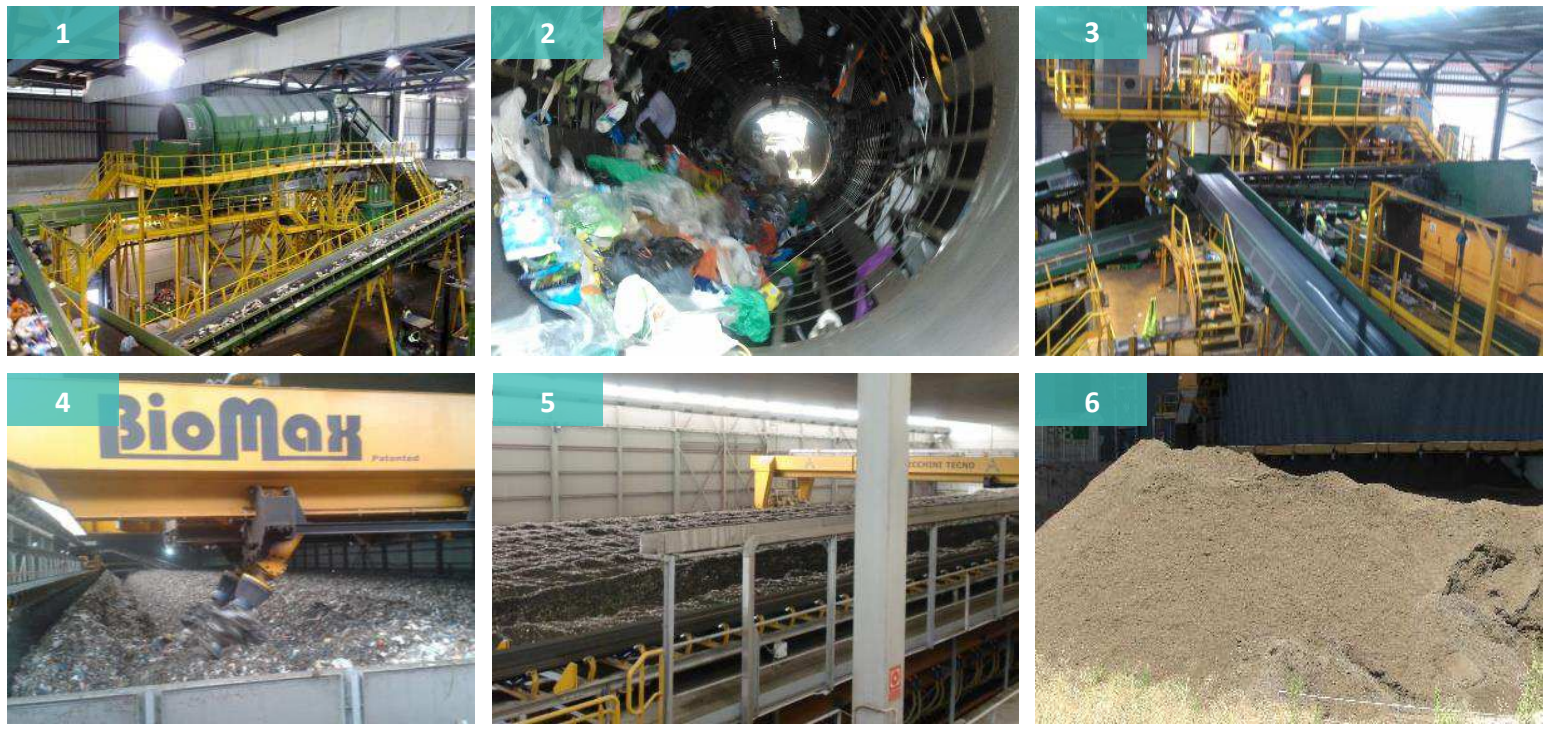

Figura 2.14 Recuperación mecánica de materiales: trómel (1 y 2) equipos de separación (3); Compostaje de la fracción orgánica: reactor de fermentación (4), reactor de maduración (5) y compost (6)

En las plantas de recuperación, biometanización y compostaje, además de la clasificación mecánica y recuperación de materiales, la fracción orgánica se trata mediante biometanización. Posteriormente, el digestato obtenido se composta y bioestabiliza. Para este tipo de plantas el rendimiento global medio en España para 2016 fue de 26,36\% (MITECO, 2019).

Las plantas de biosecado y recuperación son menos habituales y en ellas, en primer lugar, se lleva a cabo el biosecado de los RSU mezclados (Figura 2.15). En segundo lugar, mediante procesos mecánicos se seleccionan los materiales $y$, finalmente, la fracción orgánica biosecada se estabiliza mediante su maduración. La única planta de este tipo existente en España tuvo un rendimiento global del 54,33\% en 2016 respecto a los residuos entrantes (MITECO, 2019).

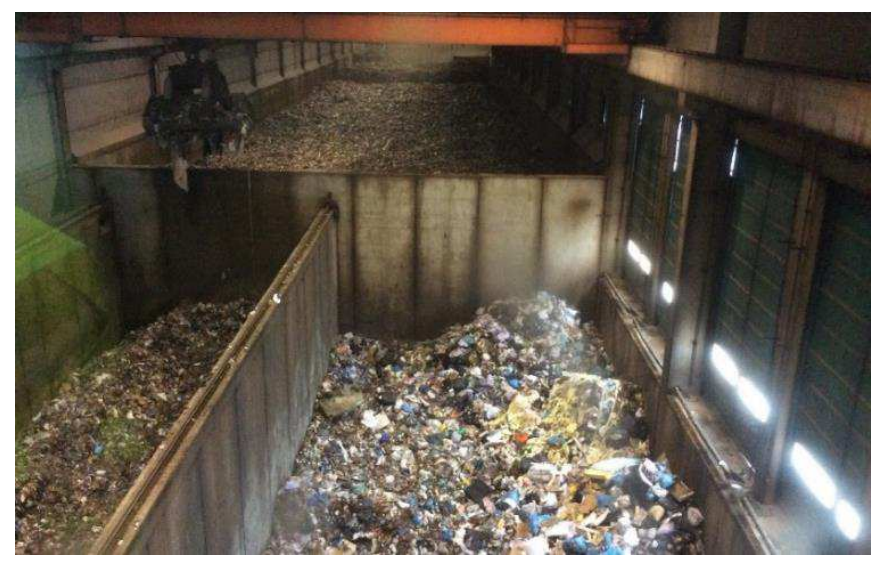

Figura 2.15 Foso de descarga de los RSU y reactor de biosecado 
De forma general, los menores rendimientos de las plantas de TMB son consecuencia de la gran heterogeneidad del material entrante debido a que no proviene de la recogida selectiva.

Cabe señalar que en el capítulo 3 de la presente tesis se ha realizado la modelización de todos los tipos de plantas de TMB existentes y se ha estudiado en profundidad la situación de este tipo de tratamiento en España.

\section{Tratamiento térmico}

Los tratamientos térmicos de los residuos comprenden todos los procesos destinados a la trasformación de los RSU mediante la aplicación de energía calorífica (incineración, gasificación, pirolisis, etc.). El objetivo de estos tratamientos es la recuperación energética de los residuos y la reducción del peso (70-80\%) y volumen (80-90\%) de los mismos, minimizando la cantidad enviada a vertedero. Además, los tratamientos térmicos tienen otra serie de ventajas como: la destrucción de contaminantes orgánicos (Buekens and Cen, 2011; McKay, 2002); la concentración e inmovilización de contaminantes inorgánicos (Astrup, 2008; Samaras et al., 2010); el reciclado de los metales de las cenizas y escorias (Crillesen and Skaarup, 2006), y la reducción de las emisiones de gases de efecto invernadero en comparación a los que se emitirían con la descomposición de los RSU en los vertederos (Psomopoulos et al., 2009).

En la actualidad existen diferentes tecnologías de tratamiento térmico: combustión controlada o incineración, pirolisis, gasificación y gasificación por plasma. De todas ellas, la incineración es la que está más ampliamente desarrollada y probada y es la más utilizada internacionalmente. En España, el control de la contaminación de los gases de combustión y su impacto sobre la salud es una preocupación importante para la mayor parte de la población, por lo que la incineración tiene una baja aceptación social y no se ha llegado a imponer frente a la disposición final en vertedero. Esto, junto con la expectativa de conseguir una recuperación energética más eficiente, ha supuesto un aumento en la implantación de otro tipo de instalaciones de tratamiento térmico, principalmente instalaciones de gasificación, aunque los procesos a gran escala para estas tecnologías aún están siendo desarrollados.

A continuación, se resume brevemente en qué consisten las diferentes tecnologías de tratamiento térmico:

La incineración o combustión controlada consiste en un proceso de combustión en medio oxidante a una temperatura de $850-1100^{\circ} \mathrm{C}$ y con un exceso de oxígeno que asegure su completa oxidación (6\% respecto al estequeométrico (Colomer and Gallardo, 2007)). El objetivo es, por un lado, la reducción del volumen y peso de los residuos y, por otro, la recuperación de parte de la energía calorífica contenida en los mismos para la producción de electricidad, vapor o calefacción. Posteriormente a la incineración, los efluentes (emisiones atmosféricas, cenizas y escorias), deben ser tratados adecuadamente (Gallardo et al., 2019).

Existen tecnologías de combustión que se han desarrollados para diferentes tipos y formas físicas de residuos, los más importantes son los diseños de inyección líquida, hornos rotatorios, hornos fijos y lechos fluidizados (Kisuk CPE, 1998; Oppelt, 1986). La opción de horno de parrilla es la más extendida para el tratamiento de RSU, puesto que no se requiere una trituración previa y tolera variaciones en composición y poder calorífico de los RSU. El lecho fuidizado proporciona mayor eficiencia, pero requiere un control en el tamaño y composición de los residuos, los cuales generalmente necesitan un pretratamiento (Arena et al., 2011).

La incineración ha sido y es objeto de múltiples críticas desde el punto de vista ambiental, generándose una fuerte oposición social, debido a la posible emisión de compuestos tóxicos (dioxinas, furanos y metales pesados). No obstante, el desarrollo de una legislación cada vez más estricta en relación a los límites de emisión de las incineradoras, junto con la evolución de las tecnologías de control y depuración de los gases de combustión hacia procedimientos más eficaces en la eliminación de contaminantes, hace que la incineración sea un tratamiento eficaz para los RSU. Además, las plantas incineradoras están sometidas a inspecciones muy rigurosas y continuas en el tiempo, incluso más exigentes que las de algunas industrias, donde se analizan numerosos parámetros que pueden suponer un riesgo para el medio ambiente o la salud humana.

En España existen 10 plantas incineradoras donde se trataron un total de 2,4 millones de toneladas de residuos en 2016, de ellas 1 millón corresponden a RSU mezclados y el resto a los rechazos de las 
instalaciones de tratamiento de RSU. La energía generada fue de $1.760 \mathrm{GWh}(4,9 \mathrm{MWh} /$ tonelada RSU) y durante el proceso se produjeron medio millón de residuos (cenizas y escorias) (MITECO, 2019).

La pirolisis es un proceso de valorización energética que consiste en el calentamiento de un material combustible en un rango de temperatura de $500-900^{\circ} \mathrm{C}$ en ausencia total de oxígeno. Esto hace que la parte volátil de los residuos se vaporice debido a la rotura de las cadenas de hidrocarburos (proceso endotérmico). La reacción da lugar a tres productos (FUCOVASA 2015; Gallardo et al., 2019):

- Un vapor que puede ser condensado a líquido en forma de aceites ligeros (mezclas de benceno, tolueno, xileno y otros), fenoles, metanol, ceras, acetona o ácido acético. Con esta fracción líquida puede obtenerse un bioaceite que se refina para producir fuel o gasolina. Si no se refina se obtienen otros productos como aditivos para combustibles tradicionales, resinas sintéticas, etc.

- Un gas de síntesis compuesto por monóxido y dióxido de carbono, hidrógeno, metano, etano, propano, butano, pentano, amoníaco, oxígeno y nitrógeno; con un poder calorífico elevado. Tras su lavado y filtrado es utilizado para generar electricidad.

- Un residuo sólido carbonoso llamado "char o coque” y que está formado por carbón, alquitrán, cenizas, sales y metales reducidos. Este puede utilizarse como combustible o para fabricar carbón activo.

Los sistemas pirolíticos pueden clasificarse en dos tipos: los que utilizan pirolisis convencional y los que desarrollan la pirolisis a altas temperaturas. Estos últimos se caracterizan por una elevada producción de gas.

La gasificación consiste en la descomposición térmica mediante una oxidación parcial de los residuos empleando una cantidad de oxígeno menor a la requerida estequiométricamente (un 25-30\%) y a una temperatura de trabajo por encima de $\operatorname{los} 750^{\circ} \mathrm{C}$. Como resultado se obtiene un gas de síntesis combustible (syngas) que contiene concentraciones variables de monóxido y dióxido de carbono, hidrógeno, metano, nitrógeno y otros hidrocarburos ligeros. El syngas tiene un poder calorífico elevado y puede utilizarse como combustible en turbinas, motores de combustión interna o calderas para producir energía eléctrica o térmica (Gallardo et al., 2019). Como agente oxidante se puede usar aire, oxígeno o vapor de agua. En función del uso de uno u otro el syngas tendrá un poder calorífico diferente: un $25 \%$ de poder calorífico del gas natural cuando se usa aire y entre un $25-40 \%$ cuando se usa oxígeno o aire enriquecido (Colomer and Gallardo, 2007). Además, en el proceso también se genera un residuo sólido parecido a las escorias que se debe gestionar correctamente.

Existen diferentes tipos de reactores de gasificación, los más comercializados son: lecho descendente (fijo), lecho fluidizado, lecho de arrastre y reactor rotativo (Gallardo et al., 2019).

La gasificación por plasma es una variante de la gasificación con la que se alcanza una reducción en peso y volumen de los residuos mayor al 90\%. El plasma es la ionización de un flujo gaseoso, eléctricamente neutro, por medio de un campo electromagnético para formar un gas ionizado que contiene partículas eléctricamente cargadas, neutras y átomos excitados. Las antorchas de plasma consiguen concentrar mucha energía en una zona reducida por medio de la ionización con arco eléctrico de un gas (generalmente aire). Las temperatura que se alcanza es de 2.000 a $4.000^{\circ} \mathrm{C}$ (Gallardo et al., 2019).

En un reactor de gasificación con antorcha de plasma, la altísima temperatura alcanzada permite romper los enlaces moleculares de los residuos, formando un gas de síntesis y una lava fundida que al enfriar se transforma en un producto vítreo inerte. Tras el tratamiento se obtienen un material vitrificado y un gas combustible compuesto principalmente de hidrogeno, monóxido de carbono, nitrógeno, cloro y azufre. El gas de síntesis, una vez sometido a un proceso de limpieza, puede ser utilizado como combustible (Gallardo et al., 2019).

\section{Eliminación o disposición final en vertedero}

La eliminación es la última etapa de la jerarquía de gestión de RSU e implica el depósito de los residuos de forma permanente en un vertedero controlado. La legislación española, en el Real Decreto 1481/2001 por el que se regula la eliminación de residuos mediante depósito en vertedero (España, 2001), define 
vertedero como "instalación de eliminación de residuos mediante su depósito subterráneo o en la superficie, por períodos de tiempo superiores a los establecidos para el almacenamiento temporal". Además, la Ley 22/2011 establece que todos los RSU deben ser sometidos a algún tipo de tratamiento antes de su vertido, salvo que el tratamiento previo de los mismos no sea viable desde una perspectiva técnica o económica, como puede ocurrir en las islas o en zonas rurales y aisladas.

Un vertedero controlado es una instalación utilizada para la disposición final de los residuos y de los rechazos de las diferentes instalaciones de tratamiento, en condiciones totales de seguridad y reduciendo al máximo las afecciones al medio ambiente. Es una obra de ingeniería con la que se consigue enterrar el máximo volumen de residuos en el mínimo espacio y que, además, está diseñada y provista con las medidas constructivas y de control necesarias para que no se produzcan efectos negativos irreversibles sobre el medio ambiente o la salud humana.

En los vertederos controlados el vaso de vertido está completamente impermeabilizado del suelo para evitar la infiltración de los lixiviados generados, existiendo un sistema de canalizaciones para su recogida y extracción (Figura 2.16). Además, como consecuencia del confinamiento de los residuos y la acción de microorganismos, el material biodegradable presente se descompone anaeróbicamente generándose biogás en su interior. Este se recoge mediante chimeneas y tuberías para su tratamiento o aprovechamiento energético (Figura 2.16).
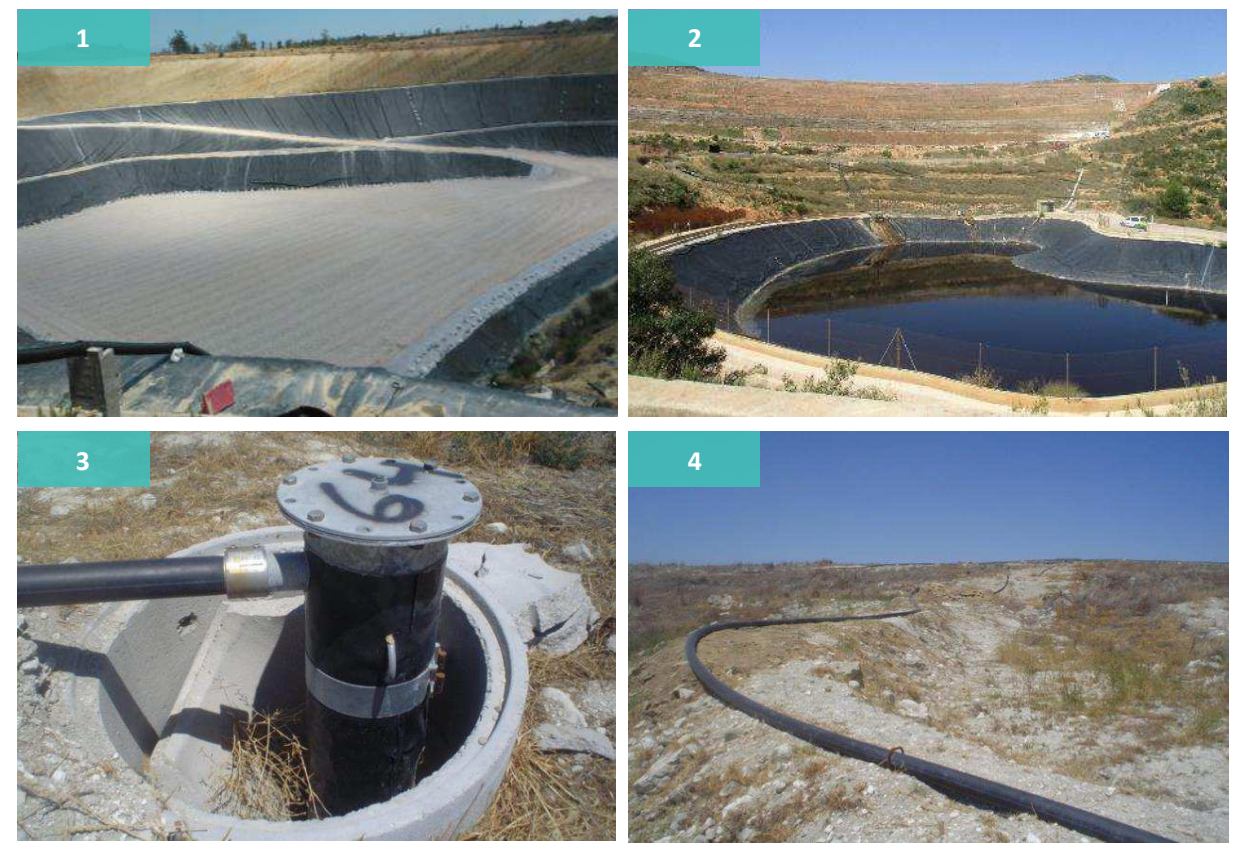

Figura 2.16 Vaso de vertido impermeabilizado (1), balsa para la recogida de lixiviados (2), chimenea para la extracción del biogás (3) y canalización de biogás (4)

Los residuos son sometidos a un proceso de compactación y, diariamente, se cubren por una capa de tierra formando las celdas de vertido. Una vez que el vertedero se ha llenado completamente y no admite más residuos se procede a su clausura y sellado (Figura 2.17). El sellado consiste en la impermeabilización de la capa superior de forma que el agua de lluvia no pueda entrar en contacto con la masa de residuos. En los años posteriores, un vertedero sigue produciendo biogás y lixiviados, lo que puede suponer un riesgo. Por ello, la legislación hace responsable a la empresa que explota el vertedero del mantenimiento, vigilancia, análisis y control de los lixiviados y gases generados durante un periodo de 30 años tras su clausura definitiva. 

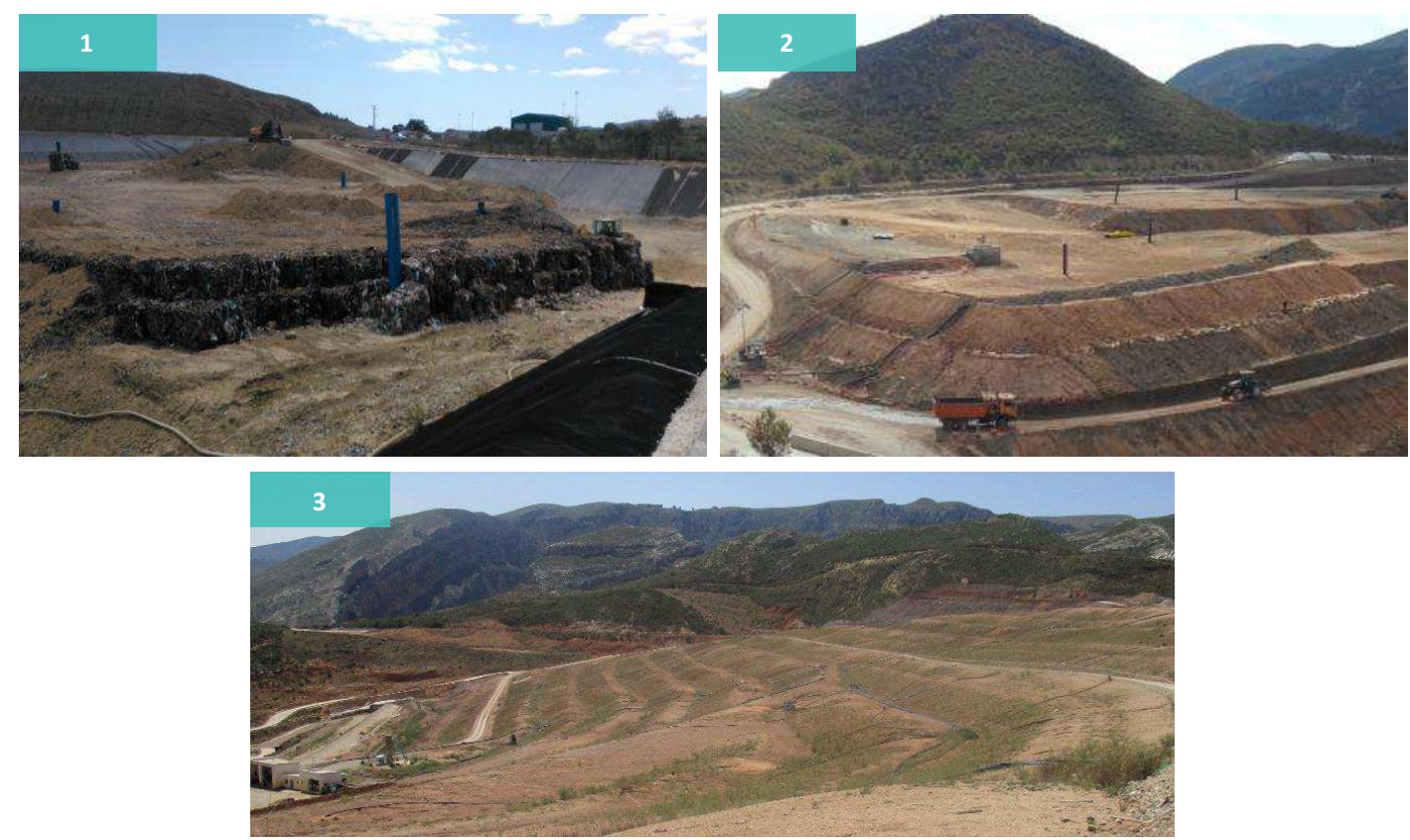

Figura 2.17 Frente de vertido (1), clausura parcial (2) y sellado y clausura final (3)

Cabe señalar que, a pesar de que el objetivo último de la gestión de los RSU es estar lo más cerca posible del vertido cero, en muchos países del sur y este de la Unión Europea, Sudamérica, África y Asia el destino final mayoritario de los RSU es el vertedero. En el caso de España, en 2016 se depositaron en vertedero 13,3 Mt de residuos, de ellas 7,8 millones corresponden a rechazos de las instalaciones de tratamiento, 4,2 a RSU mezclados, 1,3 Mt a otros residuos y 0,06 millones a lodos de EDAR (MITECO, 2019). Estos valores suponen que el 54,8\% de los RSU generados en España en 2016 se destinaron a estas instalaciones.

\section{Tratamiento de los RSU en España}

En el año 2016, en España se generaron 21,9 Mt de RSU, de todas ellas un 70,10\% fue tratado en diferentes instalaciones de tratamiento, un 4,49\% fue incinerado directamente y un $25,41 \%$ se depositó directamente en vertedero sin un tratamiento previo (Figura 2.18).

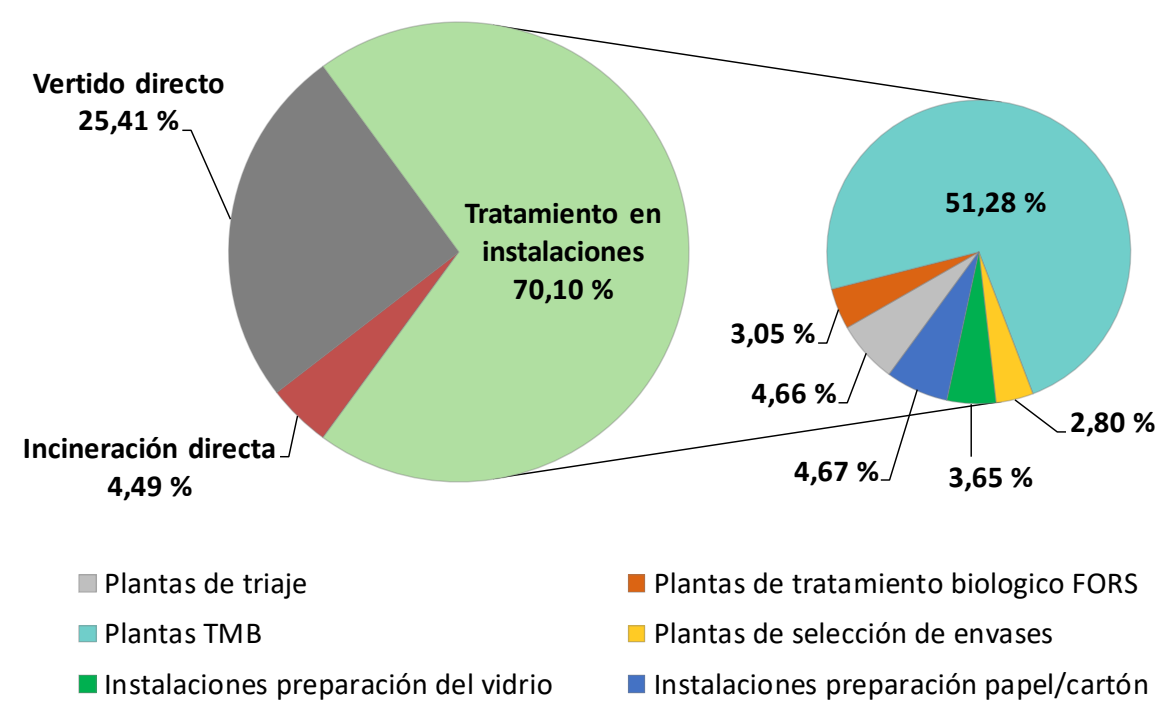

Figura 2.18 Tratamiento de los RSU en España, 2016 
En relación al tratamiento en diferentes instalaciones: un 4,66\% de los RSU fueron tratados en plantas de triaje; un 3,05\% en plantas de compostaje o biometanización de la FORS; un 51,28\% en plantas de TMB; el $2,80 \%$ fue tratado en plantas de selección de envases recogidos selectivamente; un 3,65\% en instalaciones de preparación del vidrio recogido selectivamente, y el 4,67\% en instalaciones de preparación del papel/cartón recogido selectivamente (Figura 2.18).

\subsubsection{Los rechazos del TMB}

Los principales flujos de una planta de TMB son: material orgánico estabilizado, que se produce a partir del tratamiento biológico de la fracción orgánica presente en los RSU; materiales reciclables que son recuperados mediante diferentes procesos mecánicos, y varias corrientes de rechazos formadas por aquellos materiales que no pueden ser separados, reciclados o valorizados desde una perspectiva técnica, económica y/o ambiental.

Una de las principales problemáticas existentes en relación al TMB radica en la gran cantidad de rechazo generado en el proceso (Figura 2.19), sobre todo cuando se tratan RSU mezclados, y que supone entre el 30 y el $70 \%$ de las entradas. Esto es consecuencia de la gran heterogeneidad del material entrante (Colomer and Gallardo, 2007), puesto que junto con los residuos solicitados entra una gran cantidad de materiales que no pueden ser recuperados y acaban en el rechazo (de Araújo Morais et al., 2008).
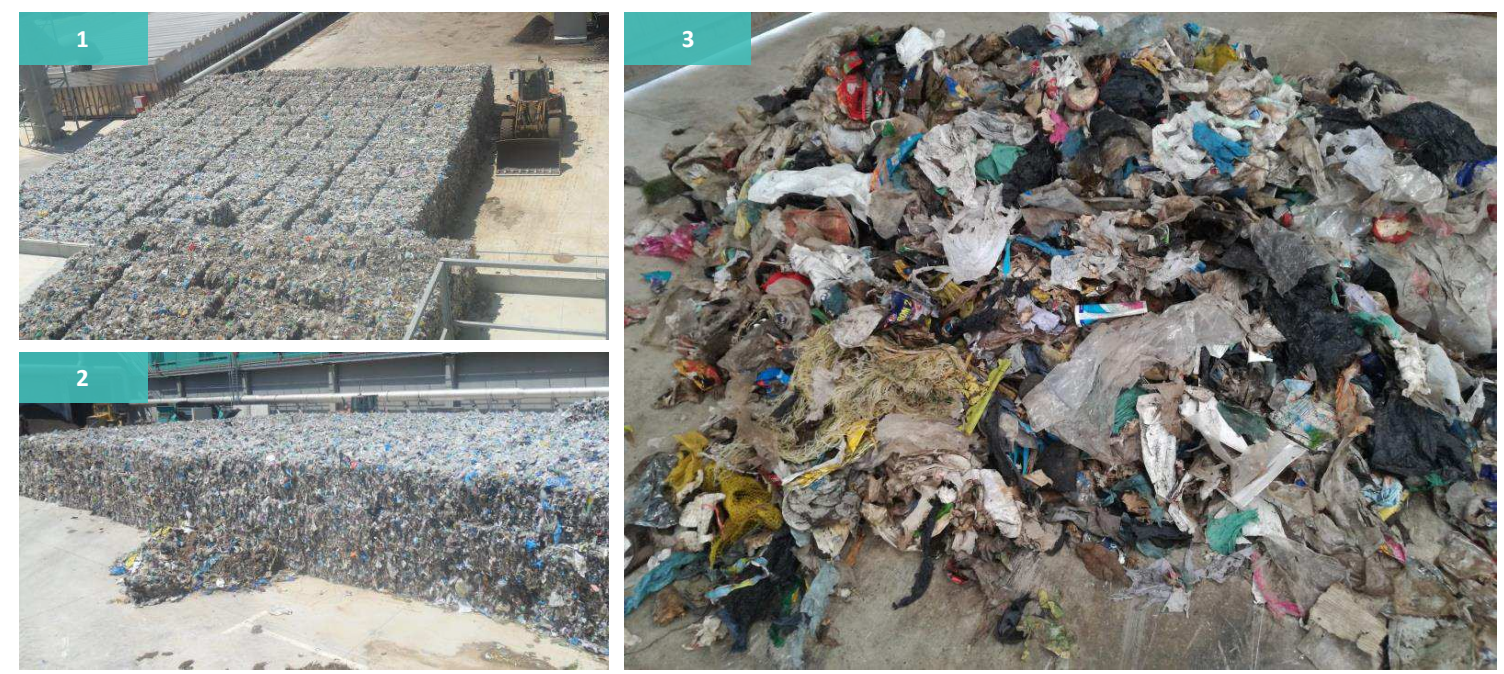

Figura 2.19 Balas de rechazo para su depósito en vertedero (1 y 2) y rechazo del TMB (3)

Los rechazos del TMB están formado en su mayor parte por materiales combustibles (Figura 2.19) y presentan un contenido energético elevado (Di Lonardo et al., 2012; Gallardo et al., 2014), especialmente cuando los RSU de entrada tienen un alto poder calorífico (Bessi et al., 2016). Por lo tanto, desde una perspectiva técnica, pueden ser aprovechados energéticamente mediante incineración, co-incineración, gasificación o pirolisis (McKendry, 2002). Así pues, una alternativa para su valorización es su transformación en un combustible sólido recuperado (CSR) (Garcés et al., 2016; Lorber et al., 2012; Sarc et al., 2014; Velis et al., 2010). Además, la producción de CSR a partir de estos rechazos supone una serie de ventajas medioambientales y económicas importantes: disminuye la cantidad de RSU depositados en vertedero, posibilita la recuperación de la energía contenida en los mismos, proporciona combustibles alternativos a las industrias que hacen un uso intensivo de combustibles fósiles y contribuye a la transición a la economía circular y el cumplimiento de sus objetivos (European Commision, 2017; Gug et al., 2015). Por ello, cuando se habla de los residuos como recurso, la valorización de los rechazos como CSR se ha convertido en una herramienta clave de la gestión moderna de los mismos (Sarc et al., 2014).

En las plantas de TMB existen varias etapas o procesos de tratamiento y cada una de ellas genera su propia corriente de rechazo, las cuales presentan propiedades y composiciones distintas (Edo-Alcón et al., 2016). De forma general, los rechazos de una planta TMB de RSU mezclados se pueden dividir en dos: 
- Rechazos de recuperación: generados en las etapas de recuperación de materiales y formados por aquellos materiales que no han podido ser recuperados para su reciclaje, suponen alrededor del $75 \%$ del total del rechazo.

- Rechazos de afino: generados en las distintas etapas de limpieza del material bioestabilizado, está formado por impropios como: vidrio, inertes, plásticos, materia orgánica no biodegradada, etc. y supone alrededor del $25 \%$ del total del rechazo. Dentro de estos rechazos se distinguen los originados en el afino primario (limpieza del material antes de su maduración) y el de afino secundario (limpieza final del bioestabilizado).

En la Tabla 2.6 se presenta la composición media de estos rechazos para la Comunidad Valenciana, así como la del rechazo global.

Tabla 2.6 Composición del rechazo de las plantas de TMB de la Comunidad Valenciana (Generallitat Valenciana, 2004)

\begin{tabular}{c|c|c|c}
\hline Fracción (\%) & $\begin{array}{c}\text { Rechazo de } \\
\text { recuperación }\end{array}$ & $\begin{array}{c}\text { Rechazo de } \\
\text { afino }\end{array}$ & $\begin{array}{c}\text { Rechazo } \\
\text { global }\end{array}$ \\
\hline Papel/Cartón & 31,7 & 22,3 & 29,4 \\
\hline Plásticos & 30,5 & 13,8 & 26,3 \\
\hline Materia orgánica & 12,7 & 21,4 & 14,9 \\
\hline Textil & 8,9 & 2,2 & 7,4 \\
\hline Brik & 2,3 & - & 1,7 \\
\hline Madera & 1,9 & 2,0 & 1,9 \\
\hline Metales & 4,7 & 3,4 & 4,4 \\
\hline Vidrio & 0,4 & 24,7 & 6,4 \\
\hline Inertes & 0,4 & 9,7 & 2,7 \\
\hline Otros & 6,5 & 0,5 & 4,9 \\
\hline
\end{tabular}

Como se observa en la tabla anterior los dos tipos de corrientes de rechazo, así como la global, están formadas mayoritariamente por material combustible, siendo de un 94,5\% para el rechazo de recuperación, de un $60,2 \%$ para el de afino y de un $86,5 \%$ para el global. Este material combustible está compuesto principalmente por papel/cartón y plásticos, ambos con un poder calorífico elevado, por lo que su valorización energética puede ser una opción de tratamiento adecuada para los mismos.

En cuanto a las plantas de TMB de la FORS, la producción de rechazo en estas instalaciones es mucho menor, aproximadamente del $30 \%$ de las entradas. Esto se debe a que el material entrante corresponde a la fracción orgánica recogida selectivamente $y$, por lo tanto, tiene un menor contenido en impropios. Los rechazos que se generan en estas instalaciones se pueden clasificar en dos tipos:

- Rechazo grueso o de acondicionamiento: generados en las etapas de acondicionamiento y limpieza inicial de la FORS y en el afino primario, está formado por los impropios presentes en la fracción orgánica.

- Rechazos de afino del compost: generado en el afino final del compost antes de su venta.

En la Tabla 2.7 se presenta la composición media de estos dos tipos de rechazos de varias plantas de compostaje de la FORS catalanas. 
Tabla 2.7 Composición media de los rechazos de plantas de compostaje de los FORS catalanas (Bernard, 2013)

\begin{tabular}{c|c|c}
\hline Fracción (\%) & $\begin{array}{c}\text { Rechazo } \\
\text { acondicionamiento }\end{array}$ & $\begin{array}{c}\text { Rechazo de afino } \\
\text { del compost }\end{array}$ \\
\hline Material biodegradable & 82,4 & 91,6 \\
\hline Plástico & 6,3 & 1,1 \\
\hline Textil & 2,1 & 2,1 \\
\hline Vidrio & 7,2 & 4,3 \\
\hline Inertes & 1,4 & 0,5 \\
\hline Metales & 0,5 & 0,4 \\
\hline Residuos peligrosos & 0,1 & - \\
\hline
\end{tabular}

En la tabla anterior se observa que la fracción principal de ambos rechazos es el material biodegradable, principalmente materia orgánica de gran tamaño en el caso del rechazo de acondicionamiento, y material estructurante (residuos de jardinería y poda) en el caso del rechazo de afino. El porcentaje de material combustible es de un 90,8\% para el rechazo de acondicionamiento y de un 94,8\% para el rechazo de afino.

Cabe señalar que los rechazos son un material muy heterogéneo (formado por distintos materiales en proporciones diferentes) y sus características físicas y químicas pueden ser muy variables y depender de muchos factores, entre ellos: la estacionalidad, el modo de vida de la población, las estrategias de gestión adoptadas en la zona, el tipo de instalación, los RSU que entrantes, el proceso de tratamiento y la configuración de la planta (Brás et al., 2017; Di Lonardo et al., 2016, 2012; Edo-Alcón et al., 2016; Nasrullah et al., 2017; Velis et al., 2012). Como consecuencia, la calidad de los CSR obtenidos a partir de los mismos dependerán del tipo, naturaleza y composición de los rechazos, así como de la variabilidad de sus propiedades a lo largo del tiempo (Nasrullah et al., 2017). En este sentido, en el capítulo cuatro de la presente tesis se han identificado todas las variables que influyen en la composición y propiedades de los rechazos tras una extensa revisión bibliográfica.

Por otro lado, a la hora de planificar las diferentes opciones para el aprovechamiento energético de estos rechazos, es fundamental la caracterización y control de cada una de las corrientes de rechazo que se generan en una planta. Esto permitirá obtener información en cuanto al cumplimiento o no de los estándares de calidad para su uso como CSR en diferentes instalaciones de valorización energética (Lorber et al., 2012; Rotter et al., 2011).

Respecto a la caracterización de los rechazos del TMB como combustible, se han publicado diferentes trabajos de investigación. Di Lonardo et al. (2012) realizó una revisión detallada de las características de los flujos de entrada y salida de las plantas TMB italianas, evaluando la calidad de los mismos y la eficiencia de este tipo de instalaciones para producir CSR. En dicho trabajo establecieron que los rechazos tienen un gran potencial para producir CSR pero que sus características dependerán de los RSU de entrada. Por otro lado, Montejo et al. (2011) compararon la valorización energética del CSR producidos a partir de rechazos de recuperación de plantas de TMB españolas respecto a los RSU en bruto, observando una mayor riqueza energética en los CSR y, por lo tanto, una mayor idoneidad para la recuperación energética. Ramos Casado et al. (2016) caracterizaron el rechazo de una planta de TMB navarra para valorar su potencial de aprovechamiento energético mediante su pelletización y co-combustión junto con pellets de madera de olivo. Los resultados obtenidos muestran que el rechazo tiene las propiedades adecuadas para ser utilizado como CSR. Además, las condiciones de combustión de los pellets de madera de olivo mejoran al añadir dicho CSR, sin embargo, se produce un aumento de emisiones contaminantes. Nithikul et al. (2011) caracterizaron los rechazos generados antes y después del tratamiento biológico en una planta de TMB de Tailandia, estableciendo que los rechazos originados en las etapas anteriores al tratamiento biológico tienen un mayor potencial para la producción de CSR. Gallardo et al. (2014) caracterizaron un rechazo de recuperación de una planta TMB española, lo compararon con diferentes estándares de calidad y determinaron las emisiones generadas en su combustión. En este sentido observaron que, desde el punto 
de vista de las emisiones de $\mathrm{CO}_{2}$ y $\mathrm{SO}_{2}$, el CSR obtuvo mejores resultados que la antracita y el lignito. Por su parte, Di Lonardo et al. (2016) y Bessi et al. (2016) caracterizaron y comprobaron si diferentes corrientes de rechazo originadas en el TMB en Italia podían ser clasificadas como CSR siguiendo los criterios del Estándar Europeo (UNE-EN 15359, 2012), demostrando que todos ellos se podían clasificar como combustible aunque con una amplia gama de calidades. Finalmente, Edo-Alcón et al. (2016) analizaron las propiedades químicas, físicas y térmicas de 6 rechazos distintos, generados en los tres tipos de plantas TMB de mayor implantación en España. Los resultados demostraron que todos ellos podían ser transformados en CSR, pero en función del tipo de planta, tecnología utilizada y etapa del proceso donde se originan los rechazos, se obtienen CSR de diferentes calidades.

En la Tabla 2.8 se muestran los resultados obtenidos en las caracterizaciones de los diferentes rechazos del TMB para los cuatro últimos trabajos de investigación revisados en el párrafo anterior, expresados en materia seca.

Tabla 2.8 Caracterizaciones de los rechazos del TMB de RSU, expresado en materia seca

\begin{tabular}{|c|c|c|c|c|c|c|}
\hline Fuente & $\begin{array}{l}\text { Tipo de } \\
\text { rechazo }\end{array}$ & $\begin{array}{l}\text { Humedad } \\
\text { (\%) }\end{array}$ & $\begin{array}{c}\mathrm{PCl} \\
(\mathrm{MJ} / \mathrm{kg})\end{array}$ & $\begin{array}{c}\text { Cenizas } \\
\text { (\%) }\end{array}$ & $\begin{array}{l}\mathrm{Cl} \\
(\%)\end{array}$ & $\begin{array}{c}\mathrm{Hg} \\
(\mathrm{ppm})\end{array}$ \\
\hline $\begin{array}{c}\text { Gallardo et al. } \\
\text { (2014) }\end{array}$ & $\mathrm{RF}$ & 34,46 & 21,36 & 10,69 & 0,34 & 82,66 \\
\hline \multirow{3}{*}{$\begin{array}{l}\text { Di Lonardo et al. } \\
\qquad(2016)^{*}\end{array}$} & DLF & 29,18 & 14,00 & 17,35 & 0,32 & 0,31 \\
\hline & $\mathrm{HR}$ & 31,93 & 10,45 & 21,59 & 0,27 & 0,37 \\
\hline & SR & 24,68 & 8,54 & 45,93 & 0,49 & 0,45 \\
\hline \multirow{4}{*}{$\begin{array}{l}\text { Bessi et al. } \\
\text { (2016)* }\end{array}$} & SRF-F & 17,8 & 18,4 & 7,1 & 0,3 & 0,18 \\
\hline & SRF-L & 14,7 & 18,1 & 11,9 & 0,4 & 0,36 \\
\hline & SRF-S & 31,4 & 12,7 & 13,4 & 0,3 & 0,12 \\
\hline & SRF-P & 12,5 & 17,5 & 18,5 & 0,2 & 0,18 \\
\hline \multirow{6}{*}{$\begin{array}{l}\text { Edo-Alcón et al. } \\
\text { (2016) }\end{array}$} & RRA & 14,03 & 22,16 & 10,31 & 0,91 & 0,13 \\
\hline & RRM & 31,77 & 19,90 & 22,84 & 0,74 & 0,05 \\
\hline & RAB1 & 40,55 & 15,00 & 24,73 & 0,70 & 0,36 \\
\hline & RAB2 & 28,52 & 11,22 & 43,33 & 0,64 & 0,74 \\
\hline & RAC1 & 20,21 & 17,27 & 20,76 & 1,71 & 0,06 \\
\hline & RAC2 & 12,98 & 7,99 & 60,04 & 0,67 & 0,05 \\
\hline
\end{tabular}

*En estos trabajos el $\mathrm{PCl}$ y el $\mathrm{Hg}$ esta expresado sobre materia húmeda

RF: Rechazo de recuperación manual de materiales DLF: Rechazo ligero de recuperación de materiales SRF-P: Rechazo de recuperación automática de materiales HR: Rechazo pesado de recuperación de materiales RRA: Rechazo de recuperación automática de materiales RRM: Rechazo de recuperación manual de materiales SR: Rechazo de afino del material bioestabilizado RAB1: Rechazo de afino primario del bioestabilizado SRF-F: Rechazo de recuperación de materiales refinado SRF-L: Rechazo de recuperación de materiales sin refinar SRF-S: Rechazo afino del material bioestabilizado RAB2: Rechazo de afino secundario del bioestabilizado RAC1: Rechazo de acondicionamiento de la FORS RAC2: Rechazo del afino final del compost

\subsection{COMBUSTIBLES SÓLIDOS RECUPERADOS}

La normativa europea define los CSR como aquellos combustibles sólidos producidos a partir de residuos no peligrosos, destinados a ser utilizados para la recuperación energética en plantas de incineración o coincineración y que cumple con los requisitos de clasificación y las especificaciones establecidas en la norma UNE-EN 15359 (2012). Por otro lado, aquellos combustibles que no cumplan con estándares fijados por dicha norma serán considerados como Combustibles Derivados de Residuos (CDR) y no como CSR. 
Los CSR están compuestos principalmente por papel/cartón y plásticos, siendo estos materiales los responsables de sus elevados poderes caloríficos (Nasrullah et al., 2017). Además, los residuos no peligrosos a partir de los cuales se producen pueden provenir de múltiples fuentes como: RSU, rechazos del tratamiento de RSU, residuos comerciales, residuos industriales, residuos voluminosos o residuos de construcción y demolición (Garcés et al., 2016; UNE-EN 15359, 2012). Para su fabricación es necesaria la eliminación de los materiales no combustibles o no deseados (por ejemplo, PVC), la trituración, el secado y, en algunos casos, su pelletización (Nasrullah et al., 2015a; Pressley et al., 2014).

A nivel europeo, los rechazos generados en el TMB son una opción cada vez más utilizada para la producción de CSR (Rada and Andreottola, 2012; Ragazzi and Rada, 2012), puesto que los rechazos de estas instalaciones tienen un elevado poder calorífico y pueden ser transformados en un CSR tras su procesado (Rotter et al., 2011) (Figura 2.20).

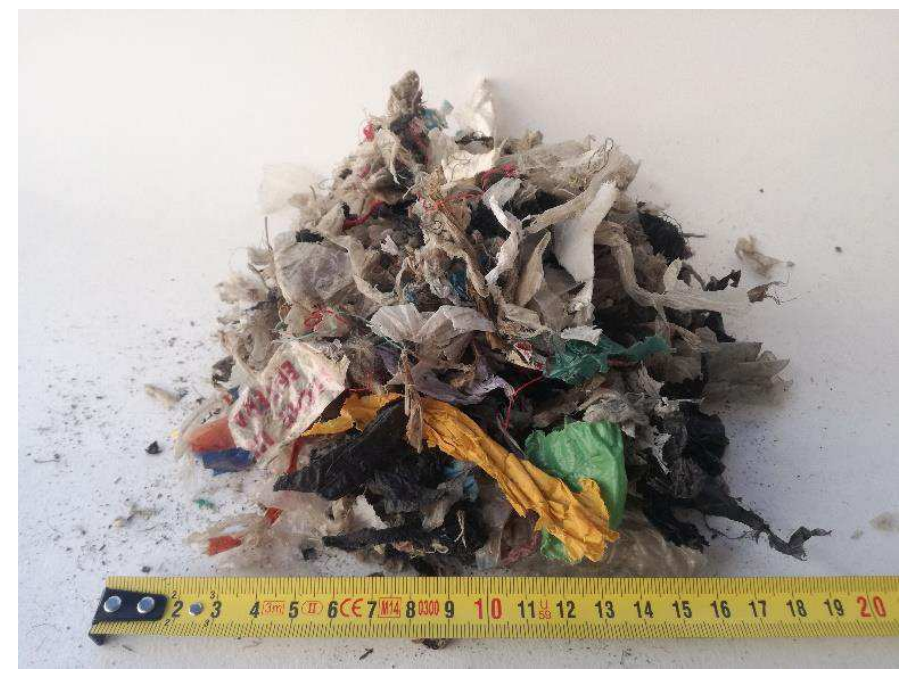

Figura 2.20 CSR producido a partir de rechazo del TMB

Por otra parte, los CSR son una alternativa viable a los combustibles fósiles convencionales y puede reemplazarlos parcialmente en industrias productoras de calor y electricidad (Nasrullah et al., 2017). En este sentido, los CSR son usados principalmente en plantas de producción de energía y hornos de cemento (co-combustión), así como en plantas incineradoras (mono-combustión) (Flamme and Geiping, 2012; lacovidou et al., 2018; Rotter et al., 2011).

El uso de CSR en plantas de producción de energía tiene dos ventajas principales desde el punto de vista medioambiental. Por un lado, reduce las emisiones de $\mathrm{CO}_{2}$ debido a que los CSR poseen una parte de carbono de origen biogénico del flujo de residuos inicial y cuyas emisiones se consideran neutras (Nasrullah, 2015; Séverin et al., 2010). Por otro, las emisiones de $\mathrm{NO}_{x}$ y $\mathrm{SO}_{x}$ son menores en comparación a otros combustibles convencionales como el carbón debido a su bajo contenido en nitrógeno y azufre (Gallardo et al., 2014; Sami et al., 2001; Velis et al., 2010). Además, el coste de abastecimiento de estos combustibles es menor al asociado a los combustibles fósiles, por lo que son más asequibles (lacovidou et al., 2018; Sami et al., 2001). Sin embargo, también tiene algunos inconvenientes como: la mayor producción de cenizas y escorias en las calderas (Jappe Frandsen, 2005), o su mayor contenido en cloro que puede afectar a las cenizas volantes y, por lo tanto, al uso de las mismas para la producción de cemento (Brás et al., 2017). Asimismo, este elevado contenido en cloro también es responsable de los mayores costes operativos y de mantenimiento requeridos para mitigar los efectos de la corrosión en los equipos producidos por dicho elemento (lacovidou et al., 2018). 


\subsubsection{Marco legislativo de los CSR}

En la Lista Europea de Residuos (LER), los CSR reciben el código 1912 10: Residuos combustibles (combustible derivado de desperdicios) (Comisión Europea, 2014). Por lo tanto, la legislación aplicable a los CSR tanto en la Unión Europea como en España es la misma que se aplica a los residuos:

- Directiva 2008/98/CE de 19 de noviembre, sobre los residuos (Parlamento Europeo y Consejo de la Unión Europea, 2008).

- Directiva 2010/75/UE, de 24 de noviembre, sobre las emisiones industriales (Parlamento Europeo y Consejo de la Unión Europea, 2010).

- $\quad$ Ley 22/2011, de 28 de julio, de residuos y suelos contaminados (España, 2011).

- Real Decreto Legislativo 1/2016, de 16 de diciembre, por el que se aprueba el texto refundido de la Ley de prevención y control integrados de la contaminación (España, 2016).

- Real Decreto 815/2013, de 18 de octubre, por el que se aprueba el Reglamento de emisiones industriales y de desarrollo de la Ley 16/2002 (España, 2013a).

Derivado de esta legislación, destacan los siguientes aspectos:

- Los CSR en ningún caso pierden su condición de residuo. Por lo tanto, los titulares de actividades en cuyo proceso se utilicen estos combustibles tienen que adquirir la condición de gestores de residuos y sus obligaciones, por lo que están sometidos a la autorización por parte de la Administración con competencia en Medioambiente de las CC.AA. correspondientes.

- Su utilización como combustible alternativo está sometido al Reglamento de emisiones industriales, donde se establecen unos valores límites de emisión específicos para las instalaciones de incineración y co-incineración de residuos.

- Cuando la instalación de incineración o co-incineración esté afectada por la normativa de prevención y control integrados de la contaminación, su régimen de explotación queda sometido a la Autorización Ambiental Integrada. En ella se determinan las características de los materiales a incinerar o co-incinerar y los límites de emisión. Estos se fijan teniendo en cuenta las Mejores Tecnologías Disponibles para el sector de actividad, las características técnicas de la instalación y el ámbito geográfico en el que se ubica.

Además, cabe destacar que dentro del BREF sobre el tratamiento de residuos (Documento de referencia sobre las Mejores Técnicas Disponibles para el sector del tratamiento de residuos) (Comisión Europea, 2006), existe un apartado dedicado a la preparación de combustible residual sólido mediante tratamiento mecánico (y biológico) a partir de residuos sólidos no peligrosos. Dentro de este apartado está incluida la producción de CSR a partir de rechazos del tratamiento de RSU.

Finalmente, el traslado de CSR está regulado en la UE por el Reglamento CE 1013/2006 del Parlamento Europeo y del Consejo de 14 de junio de 2006 relativo a los traslados de residuos (Parlamento Europeo y Consejo de la Unión Europea, 2006); y en España por Real Decreto 180/2015, de 13 de marzo, por el que se regula el traslado de residuos en el interior del territorio del Estado (España, 2015b).

\subsubsection{Calidad de los CSR}

Los CSR son combustibles muy variados y sus características físico-químicas y calidad pueden ser distintas dependiendo principalmente del residuo y del tratamiento utilizado para su producción (Nasrullah et al., 2017; Sarc and Lorber, 2013). Independientemente de su aplicación en diferentes sectores, los CSR deben cumplir unos criterios generales de calidad para que puedan ser utilizados de manera eficiente y segura: poder calorífico bien definido, bajo contenido en cloro, pocas impurezas, un tamaño de partícula y densidad definidos y disponibilidad de suficiente cantidad de CSR con la calidad requerida (Flamme and Geiping, 2012). Además, la calidad de los CSR es un factor clave para que sean aceptados como sustitutos de los combustibles fósiles y para su demanda y utilización (Glorius, 2014; Nasrullah et al., 2017). 
El control y garantía de calidad de los CSR en Europa comenzó en la década de los 90. En Alemania, Suiza e Italia se desarrollaron guías especificas donde se definían estándares de calidad para diferentes campos de aplicación (Flamme and Geiping, 2012), puesto que la calidad requerida en cada caso es diferente. En 2002, el Comité Europeo de Normalización (CEN) fundó el Comité Técnico CEN/TC 343 "Solid Recovered Fuels" con el objetivo de crear un marco de normas comunes para la Unión Europea, así como estandarizar la producción y uso del CSR en Europa (Flamme and Geiping, 2012). Este trabajo se completó en 2011 con la publicación de 6 informes técnicos y 25 normas (Glorius, 2014).

Así pues, en Europa los CSR están sujetos a unos parámetros específicos de calidad y deben cumplir una serie de estándares que aseguren la protección del medio ambiente, de los equipos utilizados para su recuperación energética y la calidad del producto final si existe, como ocurre con el cemento. Además, el contenido energético y mineral debe ser estable en el tiempo y la forma física debe asegurar una manipulación, almacenamiento y alimentación higiénica y segura. En este sentido el CEN ha definido los parámetros que son importantes para la calidad de los CSR y ha establecido un sistema para la clasificación de su calidad, el cual se recoge en la norma UNE-EN 15359 (2012): “Combustibles sólidos recuperados: especificaciones y clases". El sistema propuesto está basado en los valores límite de tres parámetros que dan una idea inmediata, pero simplificada, de cómo es el combustible en cuestión:

- El poder calorífico inferior (PCI) como parámetro económico, puesto que describe la cantidad de calor o energía generada en su combustión.

- El contenido en cloro como parámetro técnico, dado que es una medida de los efectos potenciales de corrosión, escorificación y ensuciamiento en las calderas. Además, en el caso de las cementeras, un contenido elevado en cloro también afecta a la calidad del cemento obtenido. Este parámetro es uno de los factores más limitantes respecto a la comerciabilidad de los CSR (Rotter et al., 2011).

- El contenido en mercurio como parámetro medioambiental, puesto que es una medida de la toxicidad liberada al medio ambiente como consecuencia de la combustión del material. De entre todos los metales pesados, se elige el mercurio como parámetro medioambiental debido a sus impactos en la salud humana a medio y largo plazo; así como por su alta volatilidad, lo que hace que sea más difícil de capturar por los sistemas de control y depuración de los gases de combustión (lacovidou et al., 2018).

Cada uno de estos tres parámetros se divide en cinco clases con sus correspondientes valores límite (Tabla 2.9) y se le asigna un número del uno al cinco en función del valor obtenido para el mismo. La clase 1 hace referencia a las especificaciones más deseables para un CSR y a medida que el número de clase aumenta la calidad del CSR va disminuyendo. La combinación de los números obtenidos para cada parámetro constituye el código clase del CSR, teóricamente existen 125 combinaciones de códigos clase (Del Zotto et al., 2015; Di Lonardo et al., 2016).

Tabla 2.9 Estándares de calidad del CSR en Europa (UNE-EN 15359, 2012)

\begin{tabular}{c|c|c|c|c|c|c|c}
\hline \multirow{2}{*}{$\begin{array}{c}\text { Parámetro de } \\
\text { clasificación }\end{array}$} & $\begin{array}{c}\text { Medida } \\
\text { estadística }\end{array}$ & Unidad & \multicolumn{5}{|c}{ Clases } \\
\cline { 4 - 8 } & Media & MJ/kg (ar) & $\geq 25$ & $\geq 20$ & $\geq 15$ & $\mathbf{3}$ & $\mathbf{4}$ \\
\hline $\mathbf{P C l}$ & Media & $\%(\mathrm{~d})$ & $\leq 0,2$ & $\leq 0,6$ & $\leq 1,0$ & $\leq 1,5$ & $\leq 3$ \\
\hline $\mathbf{C l}$ & Mediana & $\mathrm{mg} / \mathrm{MJ}(\mathrm{ar})$ & $\leq 0,02$ & $\leq 0,03$ & $\leq 0,08$ & $\leq 0,15$ & $\leq 0,50$ \\
\hline \multirow{2}{*}{$\mathbf{H g}$} & Percentil 80 & $\mathrm{mg} / \mathrm{MJ}(\mathrm{ar})$ & $\leq 0,04$ & $\leq 0,06$ & $\leq 0,16$ & $\leq 0,30$ & $\leq 1,00$ \\
\hline
\end{tabular}

En el caso del $\mathrm{Hg}$, el mayor de los dos valores estadísticos es el que determina el número de clase

ar: según se recibe

d: en base seca 
Adicionalmente, algunos países como Alemania, Italia, Finlandia, Austria, Francia o Suiza han definido sus propios estándares de calidad para los CSR (Flamme and Geiping, 2012; Gallardo et al., 2014). Además, estos estándares pueden variar en función del tipo de instalación (hornos de cemento, centrales eléctricas o instalaciones de co-incineración), puesto que en función del proceso de recuperación energética la calidad requerida para el CSR será diferente (Sarc and Lorber, 2013).

Las normas para cada uno de estos países son:

- Alemania: RAL-GZ 724 (2008) Quality and test instructions Solid Recovered Fuels (BGS (Ed.), 2008).

- Austria: BMLFUW (2008) Richtlinie für Ersatzbrennstoffe [Guideline for Waste Fuels] y BMLFUW (2010) Verordnung über die Verbrennung von Abfällen Abfallverbrennungsverordnung - AVV [Waste Incineration Directive].

- $\quad$ Finlandia: SFS 5875 (2000) Solid Recovered Fuel - Quality Control System

- Italia: UNI 9903 (2004) Non mineral refuse derived fuels RDF.

- Francia: Arrêté du 23/05/16 relatif à la préparation des combustibles solides de récupération en vue de leur utilisation dans des installations relevant de la rubrique 2971 de la nomenclature des installations classées pour la protection de l'environnement (Republique Française, 2016)

- Suiza: BUWAL (2005) Richtlinie zur Entsorgung von Abfällen in Zementwerken [Guideline for the disposal of waste in cement plants].

En las siguientes tablas (Tabla 2.10 a Tabla 2.15) se presentan los valores límites definidos por las diferentes normas. Cabe señalar que las normas de Finlandia e Italia en la actualidad han sido remplazadas por la norma del CEN (Flamme and Geiping, 2012).

En el caso de Alemania, además de los valores límites expuestos en la Tabla 2.10 para metales pesados, existen una serie de parámetros que también deben tenerse en cuenta a la hora de determinar la calidad de un CSR: humedad, $\mathrm{PCl}$, cenizas y contenido en cloro. Para estos parámetros el valor límite depende del uso que vaya a dársele al CSR y del acuerdo al que se llegue con el consumidor (Flamme and Geiping, 2012; Rotter et al., 2011).

Tabla 2.10 Estándares de calidad para el CSR en Alemania (BGS (Ed.), 2008)

\begin{tabular}{|c|c|c|c|c|}
\hline $\begin{array}{c}\text { Contenido en } \\
\text { metales pesados }\end{array}$ & \multicolumn{2}{|c|}{ Media (ppm) } & \multicolumn{2}{|c|}{ Percentil 80 (ppm) } \\
\hline Cd & \multicolumn{2}{|c|}{4} & \multicolumn{2}{|c|}{9} \\
\hline $\mathrm{Hg}$ & \multicolumn{2}{|c|}{0,6} & \multicolumn{2}{|c|}{1,2} \\
\hline TI & \multicolumn{2}{|c|}{1} & \multicolumn{2}{|c|}{2} \\
\hline As & \multicolumn{2}{|c|}{5} & \multicolumn{2}{|c|}{13} \\
\hline Co & \multicolumn{2}{|c|}{6} & \multicolumn{2}{|c|}{12} \\
\hline $\mathbf{N i}$ & $25^{1)}$ & $80^{21}$ & $50^{1)}$ & $160^{2)}$ \\
\hline Se & \multicolumn{2}{|c|}{3} & \multicolumn{2}{|c|}{5} \\
\hline Te & \multicolumn{2}{|c|}{3} & \multicolumn{2}{|c|}{5} \\
\hline Sb & \multicolumn{2}{|c|}{25} & \multicolumn{2}{|c|}{60} \\
\hline $\mathrm{Pb}$ & $70^{1)}$ & $190^{2)}$ & $200^{1)}$ & $500^{21}$ \\
\hline $\mathrm{Cr}$ & $40^{1)}$ & $125^{2)}$ & $120^{1)}$ & $250^{2)}$ \\
\hline $\mathrm{Cu}$ & $120^{1)}$ & $350^{2)}$ & $500^{1)}$ & $1000^{2)}$ \\
\hline Mn & $50^{1)}$ & $250^{2)}$ & $100^{1)}$ & $500^{2)}$ \\
\hline
\end{tabular}




\begin{tabular}{c|c|c}
\hline $\begin{array}{c}\text { Contenido en } \\
\text { metales pesados }{ }^{3)}\end{array}$ & Media (ppm) & Percentil 80 (ppm) \\
\hline V & 10 & 25 \\
\hline Sn & 30 & 70 \\
\hline Be & 0,5 & 2 \\
\hline
\end{tabular}

1) Para CSR procedentes de residuos específicos.

2) Para CSR procedentes de las fracciones de elevado poder calorífico de los residuos municipales.

3) Los contenidos de metales pesados que se mencionan son válidos hasta un poder calorífico de $\geq 16 \mathrm{MJ} / \mathrm{kg}$ para las fracciones de elevado poder calorífico de los residuos municipales y hasta un poder calorífico de $\geq 20 \mathrm{MJ} / \mathrm{kg}$ para los procedentes de residuos específicos. Para poderes caloríficos que no estén dentro de este límite, deben reducirse consecuentemente los valores mencionados, puesto que no se permite un aumento.

Tabla 2.11 Estándares de calidad para le CSR en Austria (Flamme and Geiping, 2012; Lorber et al., 2012)

\begin{tabular}{|c|c|c|c|c|c|c|c|}
\hline \multirow{2}{*}{ Parámetro } & \multicolumn{5}{|c|}{ Co-incineración de residuos } & \multicolumn{2}{|c|}{$\begin{array}{l}\text { Co-incineración en } \\
\text { hornos de cemento }\end{array}$} \\
\hline & $\begin{array}{l}\text { Central } \\
\text { térmica }\end{array}$ & Calcinador & $\begin{array}{l}\text { Caldera de } \\
\text { parrilla }\end{array}$ & $\begin{array}{l}\text { Caldera de } \\
\text { lecho } \\
\text { fluidizado }\end{array}$ & Alto horno & $\begin{array}{l}\text { Pre- } \\
\text { calcinador }\end{array}$ & $\begin{array}{c}\text { Quemador } \\
\text { primario } \\
\text { del horno }\end{array}$ \\
\hline $\mathrm{PCl}(\mathrm{MJ} / \mathrm{kg})$ & $11-15$ & $11-18$ & $11-16$ & $11-16$ & $>25$ & $14-16$ & $20-25$ \\
\hline $\begin{array}{l}\text { Tamaño partícula } \\
\text { (mm) }\end{array}$ & $<50$ & $<50-80$ & $<300$ & $<20-100$ & $<10$ & $<120$ & $<10-30$ \\
\hline Impurezas (\%) & $<1$ & 0 & $<3$ & $<1-2$ & 0 & - & $<1$ \\
\hline $\mathrm{Cl}(\%)$ & $<1,5$ & $<0,8$ & $<0,8-1$ & $<0,8-1$ & $<2$ & $0,6-0,8$ & $<0,8-1$ \\
\hline Cenizas (\%) & $<35$ & - & - & $<20$ & $<10$ & $20-30$ & $<10$ \\
\hline As (mg/MJ)* & \multicolumn{5}{|c|}{$1,00 / 1,5$} & \multicolumn{2}{|c|}{$2,00 / 3,00$} \\
\hline $\mathrm{Cd}(\mathrm{mg} / \mathrm{MJ})^{*}$ & \multicolumn{5}{|c|}{$0,17 / 0,34$} & \multicolumn{2}{|c|}{$0,23 / 0,34$} \\
\hline $\mathrm{Co}(\mathrm{mg} / \mathrm{MJ})^{*}$ & \multicolumn{5}{|c|}{$0,90 / 1,60$} & \multicolumn{2}{|c|}{$1,50 / 2,70$} \\
\hline $\mathrm{Cr}(\mathrm{mg} / \mathrm{MJ}) *$ & \multicolumn{5}{|c|}{$19,0 / 28,0$} & \multicolumn{2}{|c|}{$25,0 / 37,0$} \\
\hline $\mathrm{Hg}(\mathrm{mg} / \mathrm{MJ})^{*}$ & \multicolumn{5}{|c|}{$0,075 / 0,15$} & \multicolumn{2}{|c|}{$0,075 / 0,15$} \\
\hline $\mathrm{Ni}(\mathrm{mg} / \mathrm{MJ})^{*}$ & \multicolumn{5}{|c|}{$7,00 / 12,0$} & \multicolumn{2}{|c|}{$10,0 / 18,0$} \\
\hline $\mathrm{Pb}(\mathrm{mg} / \mathrm{MJ}) *$ & \multicolumn{5}{|c|}{$15,0 / 27,0$} & \multicolumn{2}{|c|}{$20,0 / 36,0$} \\
\hline $\mathrm{Sb}(\mathrm{mg} / \mathrm{MJ})^{*}$ & \multicolumn{5}{|c|}{$7,00 / 10,0$} & \multicolumn{2}{|c|}{$7,00 / 10,0$} \\
\hline
\end{tabular}

* Valor para la media / Valor para el percentil 80 
Tabla 2.12 Estándares de calidad del CSR en Finlandia (SFS 5875, 2000)

\begin{tabular}{c|c|c|c}
\hline \multirow{2}{*}{ Parámetro } & \multicolumn{3}{|c}{ Clases } \\
\cline { 2 - 4 } & $\mathbf{I}$ & II & III \\
\hline $\mathbf{C l}(\%)$ & $<0,15$ & $<0,5$ & $<1,5$ \\
\hline $\mathbf{S}(\%)$ & $<0,2$ & $<0,3$ & $<0,5$ \\
\hline $\mathbf{N}$ (\%) & $<1,0$ & $<1,5$ & $<2,5$ \\
\hline $\mathbf{K} \mathbf{~ N a}(\%)$ & $<0,2$ & $<0,4$ & $<0,5$ \\
\hline $\mathbf{H g}$ (ppm) & $<0,1$ & $<0,2$ & $<0,5$ \\
\hline $\mathbf{C d}$ (ppm) & $<1,0$ & $<4,0$ & $<5,0$ \\
\hline Aluminio (metálico) & $1)$ & $2)$ & $3)$ \\
\hline
\end{tabular}

1) El aluminio metálico no está permitido, pero se acepta dentro de los límites de precisión.

2) El aluminio metálico se minimiza por separación de fuentes y en el proceso de producción del combustible.

3) El contenido en aluminio metálico se acuerda por separado.

Tabla 2.13 Estándares de calidad del CSR en Italia (UNI 9903-1, 2004)

\begin{tabular}{c|c|c}
\hline Parámetro & CSR estándar & CSR alta calidad \\
\hline Humedad (\%) & $<25$ & $<15$ \\
\hline $\mathrm{PCl}$ (MJ/kg) & $>15$ & $>19$ \\
\hline Cenizas (\%) & $<20$ & $<15$ \\
\hline $\mathrm{Cl}$ (\%) & $<0,9$ & $<0,7$ \\
\hline $\mathrm{S}$ (\%) & $<0,6$ & $<0,3$ \\
\hline $\mathrm{Pb}$ (ppm) & $<200$ & $<100$ \\
\hline $\mathrm{Cu}$ (ppm) & $<300$ & $<50$ \\
\hline $\mathrm{Mn}$ (ppm) & $<400$ & $<200$ \\
\hline $\mathrm{Cr}$ (ppm) & $<100$ & $<70$ \\
\hline $\mathrm{Ni}$ (ppm) & $<40$ & $<30$ \\
\hline $\mathrm{As}$ (ppm) & $<9$ & $<5$ \\
\hline $\mathrm{Cd}+\mathrm{Hg}(\mathbf{p p m})$ & $<7$ & $<4$ \\
\hline
\end{tabular}

Tabla 2.14 Estándares de calidad del CSR en Francia (Republique Française, 2016)

\begin{tabular}{c|c}
\hline Parámetro & Estándar \\
\hline $\mathrm{PCl}(\mathrm{MJ} / \mathrm{kg})$ & $>12$ \\
\hline $\mathrm{Cl}(\%)$ & $<1,5$ \\
\hline $\mathrm{Hg}(\mathrm{mg} / \mathrm{Kg})$ & $<3$ \\
\hline $\mathrm{Br}(\%)$ & $<1,5$ \\
\hline Total halógenos (\%) & $<2$ \\
\hline
\end{tabular}


Tabla 2.15 Estándares de calidad del CSR en hornos de Cemento de Suiza (Flamme and Geiping, 2012; Gallardo et al., 2014)

\begin{tabular}{|c|c|}
\hline Parámetro & $\begin{array}{l}\text { Estándar hornos de } \\
\text { cemento }\end{array}$ \\
\hline Humedad (\%) & $<10$ \\
\hline $\mathrm{PCl}(\mathrm{MJ} / \mathrm{kg})$ & $25,1-31,4$ \\
\hline $\mathrm{Cl}(\%)$ & $<1$ \\
\hline S (\%) & $<0,5$ \\
\hline As (mg/MJ) & 0,60 \\
\hline $\mathrm{Cd}$ (mg/MJ) & 0,08 \\
\hline Co (mg/MJ) & 0,80 \\
\hline $\mathrm{Cr}(\mathrm{mg} / \mathrm{MJ})$ & 4,00 \\
\hline $\mathrm{Cu}$ (mg/MJ) & 4,00 \\
\hline $\mathrm{Hg}$ (mg/MJ) & 0,02 \\
\hline $\mathrm{Ni}$ (mg/MJ) & 4,00 \\
\hline $\mathrm{Pb}$ (mg/MJ) & 8,00 \\
\hline $\mathrm{Sb}$ (mg/MJ) & 0,20 \\
\hline Sn (mg/MJ) & 0,40 \\
\hline TI (mg/MJ) & 0,12 \\
\hline $\mathrm{V}(\mathrm{mg} / \mathrm{MJ})$ & 4,00 \\
\hline
\end{tabular}

Junto con las diferentes normativas expuesta anteriormente, en España se han definido unas estándares de calidad del CSR para los hornos de cemento (Tabla 2.16) (Carlos Alberola et al., 2017; Gallardo et al., 2014). Además, a nivel europeo también existen unos valores límite para el uso de CSR en cementeras propuestos por EURITS (European Union for Responsible Incineration and Treatment of Special Waste) (Gallardo et al., 2014; Garcés et al., 2016), los cuales se presentan en la Tabla 2.17.

Tabla 2.16 Estándares de calidad del CSR en hornos de cemento en España (Gallardo et al., 2014)

\begin{tabular}{c|c}
\hline Parámetro & $\begin{array}{c}\text { Estándar horno de } \\
\text { cemento }\end{array}$ \\
\hline Humedad (\%) & $<1$ \\
\hline Cenizas (\%) & $<10$ \\
\hline $\mathrm{S}(\%)$ & $<3$ \\
\hline $\mathbf{N}(\%)$ & $<3$ \\
\hline $\mathrm{Pb}(\mathrm{mg} / \mathrm{kg})$ & $<2.500$ \\
\hline $\mathrm{Cr}(\mathrm{mg} / \mathrm{kg})$ & $<1.500$ \\
\hline $\mathrm{Ba}(\mathrm{mg} / \mathrm{kg})$ & $<5.500$ \\
\hline Halógenos (\%) & $<5$ \\
\hline
\end{tabular}


Tabla 2.17 Estándares de calidad del CSR en hornos de cemento en Europa: EURITS (Gallardo et al., 2014; Garcés et al., 2016)

\begin{tabular}{|c|c|c|c|}
\hline Parámetro & $\begin{array}{l}\text { Estándar hornos } \\
\text { de cemento }\end{array}$ & Parámetro & $\begin{array}{c}\text { Estándar hornos } \\
\text { de cemento }\end{array}$ \\
\hline $\mathrm{PCl}(\mathrm{MJ} / \mathrm{kg})$ & 15 & $\mathrm{Hg}(\mathrm{mg} / \mathrm{kg})$ & 2 \\
\hline Cenizas (\%) & 5 & Tl (mg/kg) & 2 \\
\hline $\mathrm{Cl}(\%)$ & 0,5 & Mo $(\mathrm{mg} / \mathrm{kg})$ & 20 \\
\hline S (\%) & 0,4 & V (mg/kg) & 200 \\
\hline N (\%) & 0,7 & $\mathrm{Cr}(\mathrm{mg} / \mathrm{kg})$ & 200 \\
\hline$F(\%)$ & 0,1 & $\mathrm{Co}(\mathrm{mg} / \mathrm{kg})$ & 200 \\
\hline $\mathrm{Br} / \mathrm{I}(\mathrm{mg} / \mathrm{kg})$ & 0,01 & $\mathrm{Ni}(\mathrm{mg} / \mathrm{kg})$ & 200 \\
\hline As (mg/kg) & 10 & $\mathrm{Cu}(\mathrm{mg} / \mathrm{kg})$ & 200 \\
\hline Se (mg/kg) & 10 & $\mathrm{~Pb}(\mathrm{mg} / \mathrm{kg})$ & 200 \\
\hline $\mathrm{Te}$ (mg/kg) & 10 & $\mathrm{Mn}(\mathrm{mg} / \mathrm{kg})$ & 200 \\
\hline $\mathrm{Cd}(\mathrm{mg} / \mathrm{kg})$ & 10 & Sn (mg/kg) & 200 \\
\hline $\mathrm{Sb}$ (mg/kg) & 10 & $\mathrm{Zn}(\mathrm{mg} / \mathrm{kg})$ & 500 \\
\hline
\end{tabular}

Así pues, como se ha visto en los diferentes estándares revisados, además de los tres parámetros propuestos por el $\mathrm{CEN}(\mathrm{PCl}, \mathrm{Cl}$ y $\mathrm{Hg}$ ), existen otras propiedades como el contenido en humedad, fracción volátil, tamaño de partícula, contenido en ceniza, metales pesados, etc. que también son importantes para evaluar la calidad de los CSR, sus posibles usos y su comportamiento en las instalaciones de recuperación energética (Di Lonardo et al., 2016; Lorber et al., 2012; Rotter et al., 2011; Sarc and Lorber, 2013; Velis et al., 2010).

Por otra parte, la calidad de los CSR puede mejorarse mediante un proceso de producción que concentre las fracciones combustibles más adecuadas como: el plástico film, el papel/cartón y la madera, puesto que estos materiales tienen un poder calorífico elevado y presentan las concentraciones más bajas de elementos contaminantes y tóxicos (Nasrullah et al., 2017). Además, este proceso también tiene que permitir eliminar la fracción no combustible y otros elementos contaminantes. En este sentido los materiales con un alto contenido en cloro se consideran indeseables y su eliminación es una prioridad (lacovidou et al., 2018). Diferentes estudios informaron que el cloro presente en los CSR procede principalmente de los plásticos rígidos no envases, especialmente del PVC, y del caucho (Nasrullah et al., 2017; Rada and Ragazzi, 2014; Rotter et al., 2004). Estos materiales, junto con los textiles sintéticos, son las fuentes potenciales de elementos contaminantes y tóxicos (Nasrullah et al., 2017). Además, se ha observado que elementos como baterías, RAEE, termómetros, pinturas o metales galvanizados presentan concentraciones elevadas de metales pesados (lacovidou et al., 2018; Rotter et al., 2004), por lo tanto, la eliminación de estos materiales es indispensable para obtener un CSR de calidad.

\subsubsection{Situación actual: producción y uso}

En Europa los CSR generalmente se producen en plantas de tratamiento mecánico, plantas de recuperación de materiales y plantas TMB (Ionescu et al., 2013; Nasrullah et al., 2017; Pressley et al., 2015; Rada and Ragazzi, 2014; Velis et al., 2010). En ellas se utilizan diferentes tecnologías de clasificación para la eliminación de impurezas o materiales no deseables (inertes, metales, componentes altamente clorados o contaminantes) de manera que a la salida se obtenga un CSR de calidad (Nasrullah et al., 2014). Los procesos más comunes son: trituración en múltiples etapas, cribado, separación de los metales férricos y no férricos, clasificación neumática y separación óptica por infrarrojo cercano (NIR) de los materiales no deseados (por ejemplo, PVC) (Nasrullah et al., 2014; Pieber et al., 2012; Sarc et al., 2014). En la producción de CSR a partir de RSU mezclados, tras el proceso se obtienen los siguientes flujos: CSR (72\%), metales 
férricos $(2,6 \%)$, metales no férricos $(0,4 \%)$, rechazo grueso $(13 \%)$ y rechazo fino $(12 \%)$ (Nasrullah et al., 2015b).

Los CSR son utilizados industrialmente en procesos de combustión y gasificación como combustible o cocombustible para la producción de electricidad y de calefacción (Nasrullah et al., 2017), suponiendo un ahorro de energía primaria. Los principales usos a escala comercial de los CSR son: los hornos de cemento, los hornos de cal, las plantas de producción energética de carbón, las calderas industriales, la cogeneración basada en la combustión o en la gasificación y las plantas de producción de calor y energía (Beckmann et al., 2012; Del Zotto et al., 2015; Nasrullah et al., 2017; Rada et al., 2014).

En base a los datos de la European Recovered Fuel Organisation (ERFO, 2015), la producción potencial de CSR en la Unión Europea es de 63,5 Mt/año, de ellas 24,5 Mt/año se podrían producir a partir de RSU, 20 $\mathrm{Mt} / \mathrm{año}$ a partir de residuos comerciales e industriales y $19 \mathrm{Mt} / \mathrm{año}$ a partir de residuos de la construcción y demolición. No obstante, en el año 2015, se estimó que en la Unión Europea sólo se produjeron 13,5 Mt de CSR/CDR, de ellas $7 \mathrm{Mt}$ fueron producidas a partir de RSU y 6,5 Mt a partir de residuos comerciales e industriales y de residuos de la construcción y demolición. Por lo tanto, actualmente aún hay una gran cantidad de residuos que se podrían recuperar energéticamente en forma de combustible, evitando su depósito en vertedero.

ERFO (2015) también ha estimado que en la Unión Europea el mercado de los CSR podría aumentar hasta las $53 \mathrm{Mt} / \mathrm{año}$, siendo los principales demandantes las plantas de generación de energía (16 Mt/año), la industria el cemento (12 Mt/año), otros tipo de aplicaciones industriales (12 Mt/año), la co-combustión con biomasa para la generación de energía (6 Mt/año) y la calefacción urbana (2 Mt/año).

Respecto al uso actual de estos combustibles en la Unión Europea, los CSR producidos en 2015 se utilizaron principalmente en incineradoras con recuperación energética $(7 \mathrm{Mt})$ y en cementeras $(5 \mathrm{Mt})$. El resto (1,5 $\mathrm{Mt}$ ) fueron destinados a otras aplicaciones como: plantas de generación de energía, gasificación/pirolisis, calderas industriales, altos hornos y hornos de cal (ERFO, 2015).

Alemania es el país donde el uso de estos combustibles está más extendido. Allí, en 2012 se usaron $4 \mathrm{Mt}$ de CSR/CDR en incineradoras, 2,2 Mt en cementeras y 0,8 Mt en plantas de producción de energía. Además, en el caso de las cementeras la sustitución de combustibles fósiles por CSR ha llegado hasta el 62\%, por lo que los CSR se han convertido en una fuente de energía indispensable en esta industria (Glorius, 2014).

En cuanto al uso en la industria del cemento, en Europa la sustitución de combustibles fósiles por combustibles alternativos como los CSR aumenta cada año, con una sustitución media del 43,1 \% (Figura 2.21) (Fundación CEMA, 2018).

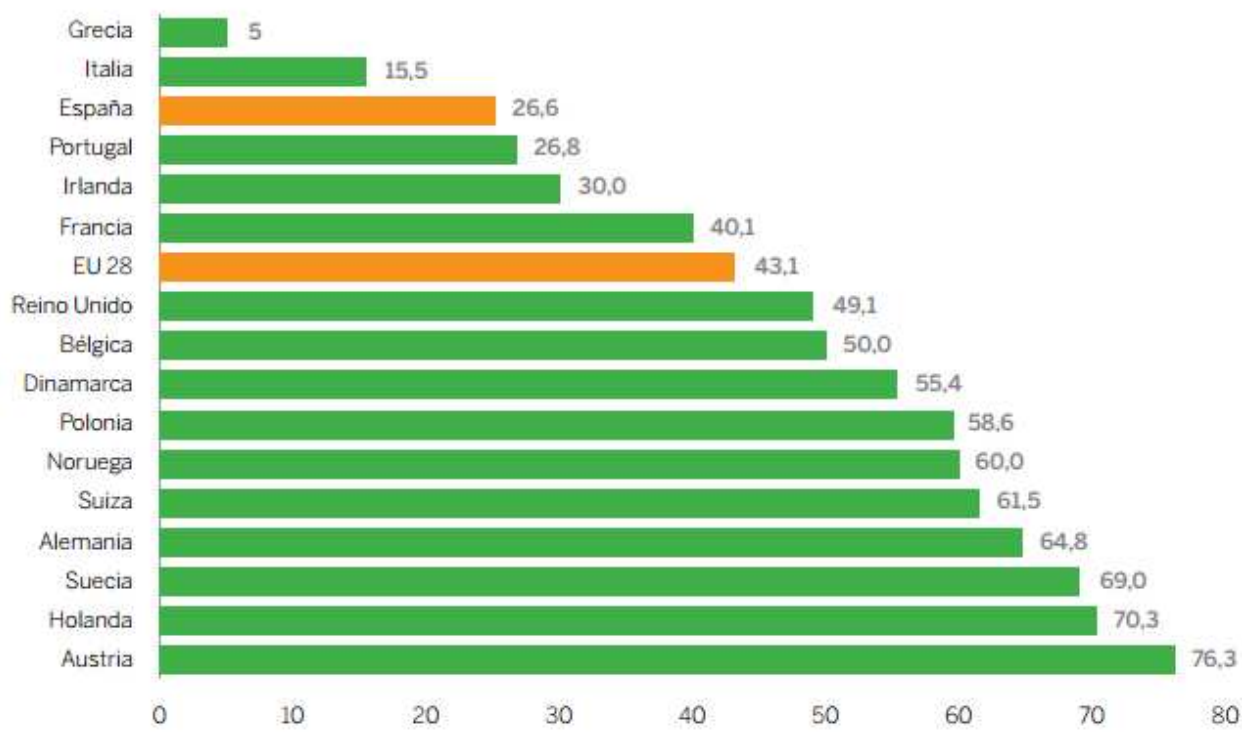

Figura 2.21 Grado de sustitución de combustibles fósiles por alternativos, en porcentaje, en la industria del cemento en la UE, 2017 (Fundación CEMA, 2018) 
En España el sector del cemento, siguiendo los principios de gestión de residuos y el ejemplo de otros países europeos, también ha incrementado el uso de combustibles alternativos en sus hornos, pasando de las 327.046 t utilizadas en el año 2007 a las 819.249 t que se utilizaron en 2017. Esto supone un porcentaje de sustitución de combustibles fósiles por alternativos del 26,6\% para el año 2017 (Figura 2.21) (Fundación CEMA, 2018). A nivel autonómico, Aragón y Castilla - La Mancha son las CC.AA. donde el porcentaje de sustitución energética es mayor, con valores entre el 40 - 50\%. Destacan también las comunidades de Extremadura y Navarra, ya que a pesar de existir cementeras en su territorio el grado de sustitución es $0 \%$ (Figura 2.22) (Institut Cerdà, 2019).

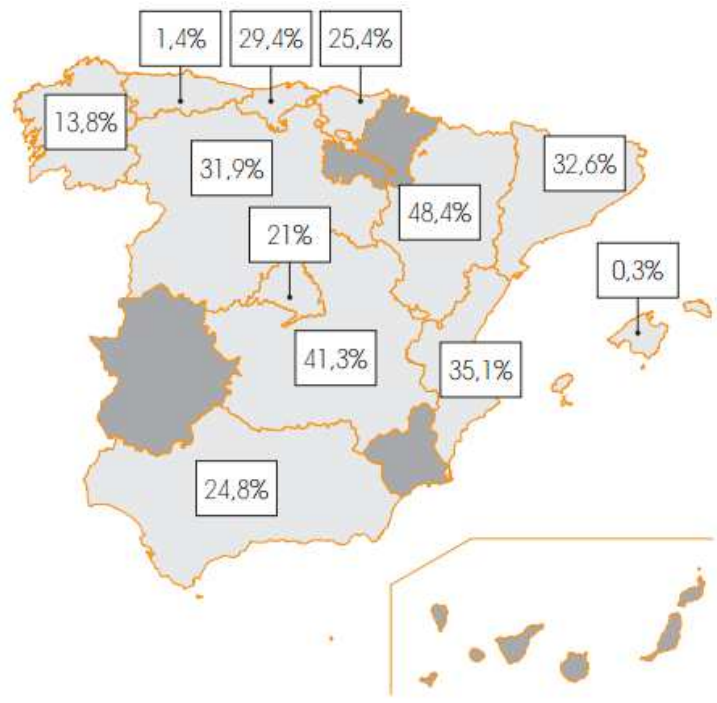

Figura 2.22 Grado de sustitución de combustibles fósiles por alternativos en la industria del cemento en España, 2017 (Institut Cerdà, 2019)

Los CSR/CDR producidos a partir de RSU y residuos industriales son el combustible alternativo más usado en las cementeras españolas (Figura 2.23). En el año 2017, de las 33 fábricas existentes en España, 26 contaban con la autorización necesaria para emplearlos y en ellas se utilizaron $241.933 \mathrm{t}$ de CSR/CDR. Esto corresponde a un $29,54 \%$ de consumo de combustibles alternativos y un $7,86 \%$ del consumo total de combustibles. A nivel autonómico, Cataluña es la CC.AA. donde el uso de CSR/CDR producidos a partir de RSU en hornos de cemento es mayor (100.150 t en 2017), seguida por la Comunidad Valenciana (56.456 t), Aragón (29.529 t) y Castilla - La Mancha (25.836 t). Por el contrario, las cementeras ubicadas en Extremadura, Navarra, Asturias y Cantabria estos combustibles alternativos no son utilizados (Institut Cerdà, 2019).
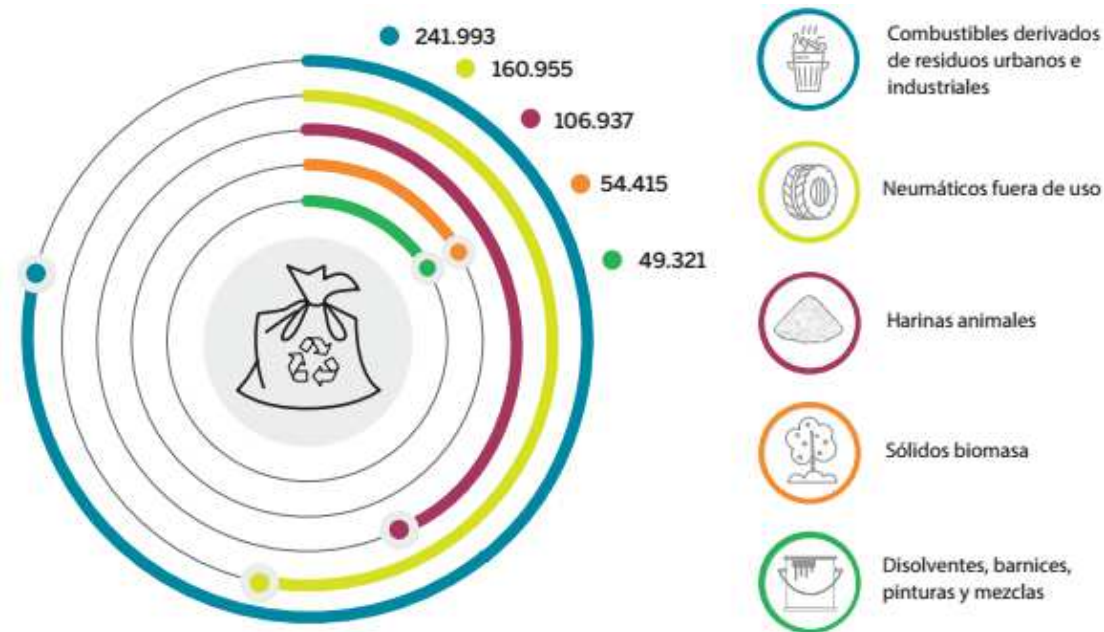

Figura 2.23 Combustibles alternativos más usados en las cementeras españolas en toneladas, 2017 (Institut Cerdà, 2019) 


\subsubsection{CSR Comerciales}

La combustión o co-combustión de CSR en plantas de producción de energía (centrales eléctricas) y en cementeras requiere que estos combustibles tengan un alto nivel de calidad, de manera que puedan sustituir los combustibles fósiles sin causar limitaciones operativas y técnicas (Glorius, 2014). En este sentido, existen empresas que se dedican a la fabricación de CSR de alta calidad y que han registrado sus propias marcas.

La empresa alemana REMONDIS ha desarrollado dos CSR que están sujetos a un control de calidad y protegidos por una marca registrada: $\mathrm{BPG}^{\circledR}$ y $\mathrm{SBS}^{\circledR}$. Además, su uso y el cumplimiento de las regulaciones está garantizado por la etiqueta de calidad RAL-GZ 724 (estándar de calidad alemán). El BPG ${ }^{\circledR}$ es un CSR producido a partir de residuos industriales o comerciales específicos y que se separan en origen. El SBS ${ }^{\circledR}$ es un CSR producido a partir de fracciones de elevado poder calorífico de los RSU (Glorius, 2014). Adicionalmente, la empresa también produce otro CSR, que no está registrado, a partir de fracciones de alto poder calorífico con un alto contenido biogénico y de diferentes residuos biológicos denominado BIOBS. Los materiales que utiliza para su fabricación son: fracciones de elevado poder calorífico procedentes de plantas de TMB, residuos voluminosos, madera, rechazos de afino del compostaje y otros biorresiduos (Glorius, 2015). Las especificaciones de las dos marcas registradas de combustibles y las clases que existen de cada uno de ellos se presentan en la Tabla 2.18.

Tabla 2.18 Especificaciones de calidad para las marcas de CSR de REMONDIS (Glorius, 2009)

\begin{tabular}{|c|c|c|c|c|c|}
\hline Parámetro & $\begin{array}{c}\text { BPG }^{\circledR} 1 \\
\text { Centrales } \\
\text { eléctricas }\end{array}$ & $\begin{array}{c}\text { BPG }^{\circledR} 2 \\
\text { Cementeras }\end{array}$ & $\begin{array}{c}\text { BPG }^{\circledR} 3 \\
\text { Hornos de cal }\end{array}$ & $\begin{array}{c}\text { SBS }^{\circledR} 1 \\
\text { Centrales } \\
\text { eléctricas }\end{array}$ & $\begin{array}{c}\mathrm{SBS}^{\circledR} 2 \\
\text { Centrales eléctricas } \\
\text { /cementeras }\end{array}$ \\
\hline $\mathrm{PCl}(\mathrm{MJ} / \mathrm{kg})$ & $16-12$ & $20-24$ & $23-27$ & $13-18$ & $18-23$ \\
\hline $\mathrm{Cl}(\%)$ & $<1$ & $<1$ & $<1$ & $<0,7$ & $<1$ \\
\hline$F(\%)$ & $<0,05$ & $<0,05$ & $<0,05$ & $<0,05$ & $<0,05$ \\
\hline Humedad (\%) & $<35$ & $<20$ & $<12,5$ & $<35$ & $<20$ \\
\hline S (\%) & $<0,2$ & $<0,3$ & $<0,3$ & $<0,5$ & $<0,8$ \\
\hline Cenizas (\%)* & $<20$ & $<15$ & $<9$ & $<20$ & $<15$ \\
\hline As $(\mathrm{mg} / \mathrm{kg})^{*}$ & $<10$ & $<10$ & $<10$ & $<10$ & $<10$ \\
\hline $\mathrm{Be}(\mathrm{mg} / \mathrm{kg})^{*}$ & $<1$ & $<1$ & $<1$ & $<1$ & $<1$ \\
\hline $\mathrm{Cd}(\mathrm{mg} / \mathrm{kg})^{*}$ & $<9$ & $<9$ & $<9$ & $<9$ & $<9$ \\
\hline Co $(\mathrm{mg} / \mathrm{kg})^{*}$ & $<12$ & $<12$ & $<12$ & $<12$ & $<12$ \\
\hline $\mathrm{Cr}(\mathrm{mg} / \mathrm{kg})^{*}$ & $<120$ & $<120$ & $<120$ & $<250$ & $<250$ \\
\hline $\mathrm{Cu}(\mathrm{mg} / \mathrm{kg})^{*}$ & $<400$ & $<400$ & $<400$ & $<1.000$ & $<1.000$ \\
\hline $\mathrm{Hg}(\mathrm{mg} / \mathrm{kg})^{*}$ & $<0,5$ & $<0,5$ & $<0,5$ & $<1$ & $<1$ \\
\hline $\mathrm{Mn}(\mathrm{mg} / \mathrm{kg})^{*}$ & $<100$ & $<100$ & $<100$ & $<400$ & $<400$ \\
\hline $\mathrm{Ni}(\mathrm{mg} / \mathrm{kg})^{*}$ & $<50$ & $<50$ & $<50$ & $<160$ & $<160$ \\
\hline $\mathrm{Pb}(\mathrm{mg} / \mathrm{kg})^{*}$ & $<100$ & $<100$ & $<100$ & $<400$ & $<400$ \\
\hline $\mathrm{Sb}(\mathrm{mg} / \mathrm{kg})^{*}$ & $<120$ & $<120$ & $<120$ & $<120$ & $<120$ \\
\hline Se $(\mathrm{mg} / \mathrm{kg})^{*}$ & $<4$ & $<4$ & $<4$ & $<5$ & $<5$ \\
\hline $\mathrm{Sn}(\mathrm{mg} / \mathrm{kg})^{*}$ & $<70$ & $<70$ & $<70$ & $<70$ & $<70$ \\
\hline $\mathrm{Te}(\mathrm{mg} / \mathrm{kg}) *$ & $<4$ & $<4$ & $<4$ & $<5$ & $<5$ \\
\hline $\mathrm{Tl}(\mathrm{mg} / \mathrm{kg})^{*}$ & $<1$ & $<1$ & $<1$ & $<1$ & $<1$ \\
\hline$V(\mathrm{mg} / \mathrm{kg})^{*}$ & $<15$ & $<15$ & $<15$ & $<25$ & $<25$ \\
\hline
\end{tabular}

*Valores sobe muestra seca 
La transformación de los residuos a los diferentes tipos de CSR se realiza a través de un complejo proceso que incluye dos etapas de reducción de tamaño de partícula, dos etapas se separación neumática de los materiales no combustibles, varias etapas de separación de los metales y la separación de impurezas mediante separación óptica con NIR. El CSR que se obtienen puede usarse como sustituto del carbón o del lignito sin ningún efecto sobre el medio ambiente, puesto que cumplen las normas técnicas alemanas y europeas. Además, el proceso de producción puede combinarse con plantas de tratamiento mecánico, plantas de TMB o plantas de recuperación de residuos industriales (Glorius, 2014).

En Reino Unido, la empresa CEMEX ha registrado también una marca comercial de CSR de alta energía denominada ClimaFuel $^{\oplus}$. Este CSR se fabrica a partir de RSU y residuos comerciales e industriales, principalmente papel, cartón, madera, alfombras, textiles y plásticos. Los residuos se someten a un proceso de tratamiento que permite separar los metales y los materiales no combustibles, así como eliminar los materiales con un alto contenido en humedad o que tienen una concentración elevada de cloro. El CSR obtenido es utilizado en las cementeras de la propia empresa como sustituto del carbón. Las características de ClimaFuel ${ }^{\circledR}$ son: un poder calorífico de 17 a $22 \mathrm{MJ} / \mathrm{kg}$, una humedad menor al $15 \%$ y un contenido en $\mathrm{Cl}$ inferior al 1\% (CEMEX, n.d.; Puig Ventosa et al., 2012).

Asimismo, en España, CEMEX también ha desarrollado una marca registrada de CSR de alta energía: EnerFuel ${ }^{\circledR}$. Este CSR se fabrica a partir de RSU y residuos industriales del mismo modo que el ClimaFuel $^{\circledR}$ y está compuesto principalmente por madera, plásticos, briks, textil y papel/cartón. Las características del EnerFuel ${ }^{\circledR}$ son: una humedad inferior al $20 \%$, un tamaño de partícula de hasta $4 \mathrm{~cm}$ y cumplir los estándares de calidad europeos definidos por la norma UNE-EN 15359 (2012) (Berganza, 2012; Puig Ventosa et al., 2012).

\subsubsection{Desclasificación de los CSR como residuos}

La desclasificación del CSR como residuos, cumpliendo ciertas exigencias de calidad y uso, facilitaría una mayor utilización como combustible, tanto en los actuales sectores donde se viene utilizando como en otros nuevos (Gallardo et al., 2017). En este sentido, tan solo Italia tiene una legislación específica para la desclasificación de los CSR (Velzeboer and van Zomeren, 2017); mientras que Austria establece unos límites para la desclasificación de combustibles producidos a partir de residuos de madera y otros combustibles de sustitución en general.

En Italia, el Decreto Ministerial n. 22 (Italian Ministerial Decree, 2013) introdujo los criterios de fin de condición de residuos (EoW, en inglés) para clasificar a los CSR como combustibles (Di Lonardo et al., 2016). Esta Ley establece que, de las 125 combinaciones de código clase para un CSR que se obtienen con la norma UNE-EN 15359 (2011), no todas son adecuadas para clasificarlos como combustible, sino solo las combinaciones que tienen un número de clase mayor o igual a 3 para el $\mathrm{PCl}$ y el $\mathrm{Cl}$ y un número de 1 o 2 para el Hg. Además, también se fijan unos valores límite máximos para los metales pesados indicados por la norma UNE-EN 15359 (2012) que los CSR deben de cumplir (Tabla 2.19). Finalmente, el decreto establece que solo se permite el uso de los CSR clasificados como combustible para la co-combustión en plantas de cemento y centrales térmicas con una capacidad mayor a $50 \mathrm{MW}$. Aquellos CSR cuyos códigos clases no cumplan los criterios de EoW seguirán considerándose residuos y sus usuarios serán las plantas de producción de energía y estaciones de combustión autorizadas para la valorización de residuos.

Tabla 2.19 Criterios para el EoW de los CSR en Italia (Italian Ministerial Decree, 2013)

\begin{tabular}{c|c|c}
\hline Parámetro & $\begin{array}{c}\text { Medida } \\
\text { estadística }\end{array}$ & Valor límite \\
\hline $\mathrm{PCl}(\mathrm{MJ} / \mathrm{kg})$ & - & Código clase $\geq 3$ \\
\hline $\mathrm{Cl}(\%)$ & - & Código clase $\geq 3$ \\
\hline $\mathrm{Hg}(\%)$ & - & Código clase $\geq 2$ \\
\hline Cenizas (\%)* & Media & (véase nota 1) \\
\hline
\end{tabular}




\begin{tabular}{|c|c|c|}
\hline Parámetro & $\begin{array}{c}\text { Medida } \\
\text { estadística }\end{array}$ & Valor límite \\
\hline Humedad (\%) & Media & (véase nota 1) \\
\hline $\mathrm{Sb}(\mathrm{mg} / \mathrm{kg})^{*}$ & Mediana & 50 \\
\hline As $(\mathrm{mg} / \mathrm{kg})^{*}$ & Mediana & 5 \\
\hline $\mathrm{Cd}(\mathrm{mg} / \mathrm{kg})^{*}$ & Mediana & 4 \\
\hline $\mathrm{Co}(\mathrm{mg} / \mathrm{kg})+$ & Mediana & 100 \\
\hline $\mathrm{Cr}(\mathrm{mg} / \mathrm{kg})^{*}$ & Mediana & 18 \\
\hline $\mathrm{Mn}(\mathrm{mg} / \mathrm{kg})^{*}$ & Mediana & 250 \\
\hline $\mathrm{Ni}(\mathrm{mg} / \mathrm{kg})^{*}$ & Mediana & 30 \\
\hline $\mathrm{Pb}(\mathrm{mg} / \mathrm{kg})^{*}$ & Mediana & 240 \\
\hline $\mathrm{Cu}(\mathrm{mg} / \mathrm{kg})^{*}$ & Mediana & 500 \\
\hline $\mathrm{TI}(\mathrm{mg} / \mathrm{kg})^{*}$ & Mediana & 5 \\
\hline$V(\mathrm{mg} / \mathrm{kg})^{*}$ & Mediana & 10 \\
\hline
\end{tabular}

* Sobre materia seca

Nota: (1) No hay valores límite de las cenizas y humedad. Los valores límite son acordados entre productor y consumidor.

Por su parte, Austria, en su Ordenanza de Incineración de Residuos (AAV) (BMLFUW (Ed.), 2010), establece unos criterios para la EoW de "otros combustibles de sustitución" en general (Tabla 2.20), de los cuales quedan excluidos los residuos peligrosos y los desechos médicos. No obstante, estos criterios no son específicos para CSR. Por último, la ordenanza limita la valorización energética de aquellos combustibles que cumplan estos criterios a instalaciones de incineración con una potencia térmica nominal $\geq 50 \mathrm{~kW}$ y un valor límite de emisiones para partículas y polvo de $20 \mathrm{mg} / \mathrm{m}^{3}$, así como a instalaciones comprendidas en el ámbito de la AAV.

Tabla 2.20 Criterios para el EoW de otros combustibles de sustitución en Austria (BMLFUW (Ed.), 2010)

\begin{tabular}{c|c|c}
\hline \multirow{2}{*}{ Parámetro } & \multicolumn{2}{|c}{ Valor límite (mg/MJ) } \\
\cline { 2 - 3 } & Media & Percentil 80 \\
\hline S & 200 & 300 \\
\hline Cl & 100 & 150 \\
\hline Hg & 0,02 & 0,03 \\
\hline Sb & 0,5 & 0,75 \\
\hline As & 0,8 & 1,2 \\
\hline Pb & 4 & 6 \\
\hline Cd & 0,05 & 0,075 \\
\hline $\mathbf{C r}$ & 1,4 & 2,1 \\
\hline Co & 0,7 & 1,05 \\
\hline $\mathbf{N i}$ & 1,6 & 2,4 \\
\hline
\end{tabular}




\subsection{LA TEORIA DE MUESTREO DE PIERRE GY}

En el campo de los residuos, el muestreo tiene como objetivo extraer una porción de los mismos (muestra) que sea representativa del volumen total de residuos que se quiere estudiar (población), de forma que mediante su análisis se pueden obtener conclusiones fiables acerca de las características de la población. No obstante, el muestreo correcto de residuos es un gran desafío, puesto que se trata de un material muy heterogéneo.

Una orientación general sobre cómo llevarlo a cabo se puede obtener de la Teoría de Muestreo de Pierre Gy, la cual fue desarrollada en el ámbito de la industria minera. Dicha teoría solo se puede aplicar parcialmente a los residuos, pero puede ayudar a minimizar o evitar los errores de muestreo. Según Gy, siempre es posible hacer un muestreo correcto, pero no siempre tiene un coste aceptable (Dahlén and Lagerkvist, 2008; Pehlken et al., 2000). A continuación se presentan los principales aspectos de esta teoría, la información se ha obtenido en su mayor parte del trabajo de investigación "Representative sampling for reliable data analysis: Theory of Sampling" realizado por Petersen et al. (2005), donde realizaron una extensa revisión de la misma.

La Teoría de Muestreo (TOS en inglés) fue desarrollada por Pierre Gy en 1950 y proporciona una descripción de todos los errores involucrados en el muestreo de materiales heterogéneos, como pueden ser los residuos, así como las herramientas necesarias para su evaluación, eliminación y/o minimización, Además, también proporciona un enfoque científico para obtener una muestra representativa cuya masa sea acorde a la heterogeneidad de material muestreado.

Para entender la TOS se debe conocer primero una serie de conceptos básicos:

- Lote: es el conjunto de materiales que se quiere muestrear, es decir, todo el material original que está sujeto a muestreo. Puede ser, un flujo de proceso, una carga de un camión, un montón de material, un contenedor, etc.

- Muestra: cantidad de materia extraída de forma correcta del lote y que es representativa de este.

- Espécimen: cantidad de material producido por un proceso de selección no correcto y que por tanto no es representativo del lote.

- $\quad$ Fragmento: partícula más pequeña que es físicamente separable del lote.

- Incrementos: es una unidad de muestra parcial o submuestra, que cuando se combinan entre ellas, proporciona la muestra final. Pueden estar formados por un solo fragmento o por uno o varios grupos de fragmentos dependiendo de la herramienta de muestreo.

- Grupo: es la asociación de fragmentos espacialmente correlacionados que actúan como una unidad independiente durante las operaciones de muestreo. El tamaño del grupo depende del procedimiento de muestreo y normalmente corresponde al conjunto de fragmentos que forman el volumen de muestra o incremento. De forma general un grupo denota el volumen de material que es extraído con la herramienta de muestreo.

- Componente crítico: es el componente de interés que se quiere analizar y por lo que se realiza el muestreo, por ejemplo, en un análisis químico sería el analito o componente químico analizado.

- Grado de componente crítico: relación de la cantidad de analito respecto a la masa total. Los grados en la muestra y el lote se definen como:

- $\quad$ as = masa del analito en la muestra / masa total de la muestra

- $\quad a\llcorner=$ masa del analito en el lote/ masa total del lote

- Error relativo de muestreo: se define a partir de los grados del componente crítico en la muestra (as) y en el lote (a $\mathrm{a}_{\mathrm{L}}$ (Ec. 2.1) y representa la desviación del grado de componente crítico encontrado en la muestra respecto al encontrado en el lote (valor real). El error relativo de muestreo será cero cuando el lote completo se toma como muestra. 


$$
e=\frac{a_{S}-a_{L}}{a_{L}}
$$

- Muestra representativa: una muestra es representativa cuando se selecciona de forma adecuada haciendo que el proceso de muestreo sea preciso y reproducible. El proceso de muestreo es preciso cuando el error de muestreo es pequeño y es reproducible cuando la varianza del error de muestreo es pequeña (es decir, el error es constante).

- Principio fundamental del muestreo: todas las partículas presentes en el lote tienen la misma probabilidad de ser seleccionadas como parte de la muestra.

Un proceso de muestreo correcto es aquel en el que todos los fragmentos, grupos de fragmentos o incrementos del lote tienen la misma probabilidad (distinta de cero) de ser seleccionados como parte de la muestra. El muestreo representativo tiene como objetivo evitar la desviación del resultado medio obtenido para un material respecto al valor real mediante un adecuado muestreo (Pehlken et al., 2000). Para poderlo llevar a cabo es fundamental entender el concepto de heterogeneidad del material y conocer los principales errores de muestreo y por qué estos ocurren.

\subsubsection{Heterogeneidad del material}

Todos los materiales que conforman el mundo físico son heterogéneos en mayor o menor medida, la ausencia teórica de heterogeneidad se denomina homogeneidad. Generalmente, para un material que consiste en partículas de distintos tipos (como pueden ser los residuos o los rechazos) y debido a la variación aleatoria, no existe la posibilidad de hacer un análisis con varias réplicas y obtener resultados idénticos.

La heterogeneidad de un material se puede dividir en dos tipos, la heterogeneidad de constitución y la heterogeneidad de distribución. La primera depende solamente de la composición del material, mientras que la segunda depende la distribución física y espacial del componente crítico en el lote o muestra.

\section{Heterogeneidad de constitución}

La heterogeneidad de constitución es inherente del material y depende de una serie de propiedades intrínsecas de mismo como: su composición, forma, tamaño y densidad de las partículas o fragmentos que forman el lote. Este tipo de heterogeneidad es consecuencia de que cada partícula del lote tiene un grado de componente crítico distinto. Si existe una gran diferencia en cuanto a la composición entre los fragmentos individuales, la heterogeneidad de constitución es alta, si los fragmentos son más homogéneos, será menor. Sin embargo, nunca podrá ser nula ya que esto solo ocurre cuando todos los fragmentos son exactamente idénticos. La heterogeneidad de constitución nunca podrá cambiarse mezclando el material, la única forma de alterarla es mediante la trituración u otros medios que cambian las propiedades físicas del material.

\section{Heterogeneidad de distribución}

La heterogeneidad de distribución es consecuencia de las diferencias que se observan entre un grupo de fragmentos o partículas (incremento) a otro. Depende de la distribución física y espacial de las partículas del material (y grupos de partículas) en el lote, del método de extracción de muestras y en última instancia de la heterogeneidad de constitución. Además, también se ve influenciada por el tamaño y/o densidad de las partículas. Por ejemplo, las partículas con grandes diferencias de tamaños y/o densidad tienden a segregarse o estratificarse, acabando las partículas más pequeñas y/o más densas en la parte inferior del lote, de ahí la importancia del mezclado antes de seleccionar la muestra. Por otra parte, el tamaño del incremento en la toma de muestras también influye en este tipo de heterogeneidad, en concreto el número de fragmentos que se extrae en cada incremento. En este sentido, la heterogeneidad de distribución es cero cuando cada incremento corresponde a un único fragmento y aumenta a medida que el número de fragmentos por incremento crece. 
En resumen, la heterogeneidad de constitución se debe a las diferencias entre fragmentos, mientras que la de distribución se debe a las diferencias entre grupos de fragmentos, lo que se puede ver de forma gráfica en la Figura 2.24. Cabe señalar que, si todos los fragmentos fueran iguales en forma y composición, la heterogeneidad de constitución sería cero y, por lo tanto, tampoco existiría heterogeneidad de distribución ya que todos los grupos serían idénticos.

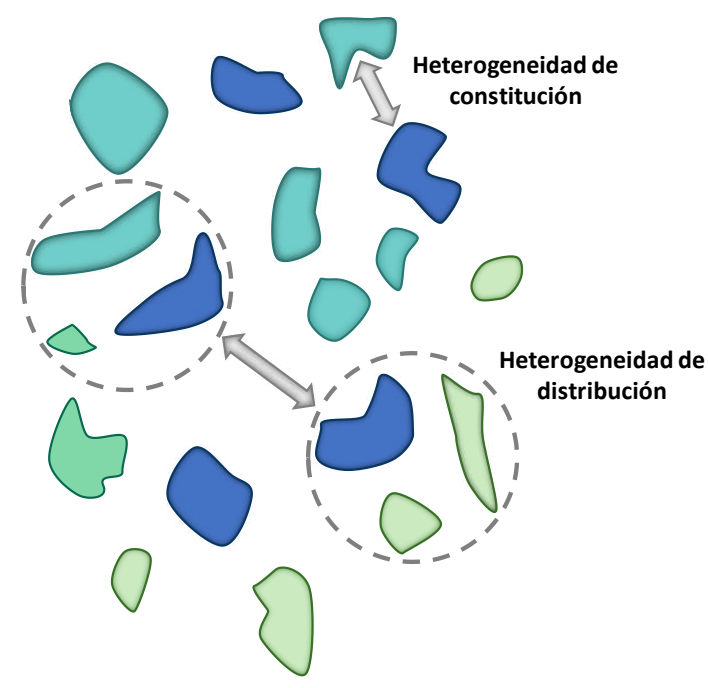

Figura 2.24 Heterogeneidad de constitución y de distribución en los materiales

\subsubsection{Errores de muestreo}

La Teoría de Muestreo de Gy diferencia entre siete errores de muestreo que, en conjunto, suman el error global de la estimación (Figura 2.25). El Error de Estimación Global (GEE), tal como lo nombró Gy, se compone de dos errores: el Error Analítico Total (TAE) y el Error Total de Muestreo (TSE).

EI TAE habitualmente está bajo control del laboratorio analítico. No obstante, los equipos analíticos modernos cada vez utilizan cantidades de muestra de análisis más pequeños. Esto dificulta la obtención de muestras representativas a medida que la masa de la muestra de análisis se reduce en relación a la masa del lote.

EI TSE es consecuencia de las propiedades del material (heterogeneidad) y de los errores generados en el proceso de muestreo en sí. Así pues, los resultados obtenidos se pueden mejorar optimizando el proceso de muestreo mediante un correcto plan de muestreo. Sin embargo, en algunas ocasiones esto choca con la opinión de que el muestreo debe de ser directo y fácil debido a las limitaciones de recursos (mano de obra, tiempo, dinero, etc.) que pueden existir. Respecto a la heterogeneidad, para disminuir su influencia, es recomendable manipular el material del lote de forma que se obtengan muestras representativas. En el caso de los residuos esto suele ser difícil, caro o ambos, no obstante, no tratar con esto en la medida de lo posible es uno de los errores que normalmente se cometen en los muestreos convencionales.

En cuanto a las operaciones de muestreo, siempre existen dos errores básicos: el Error de Muestreo Fundamental (FSE) y el Error de Agrupación y Segregación (GSE). La heterogeneidad del lote es responsable del FSE, que se considera el error de muestreo mínimo que existe incluso cuando todos los demás errores han sido eliminados. El GSE está relacionado tanto con la heterogeneidad del material como con el proceso de muestreo, es consecuencia de la composición y distribución espacial del material en el lote y su magnitud depende del proceso de muestreo.

Otras tres fuentes de error que se atribuyen al proceso de muestreo son: el Error de Delimitación del Incremento (IDE), el Error de Extracción del Incremento (IEE) y el Error de Preparación del Incremento (IPE), todos juntos forman el Error de Muestreo Incorrecto (ISE). En la Figura 2.25 se resumen todos los errores de muestreo, en ella se proporciona una visión general de las diferentes fuentes de error y sus interacciones. 


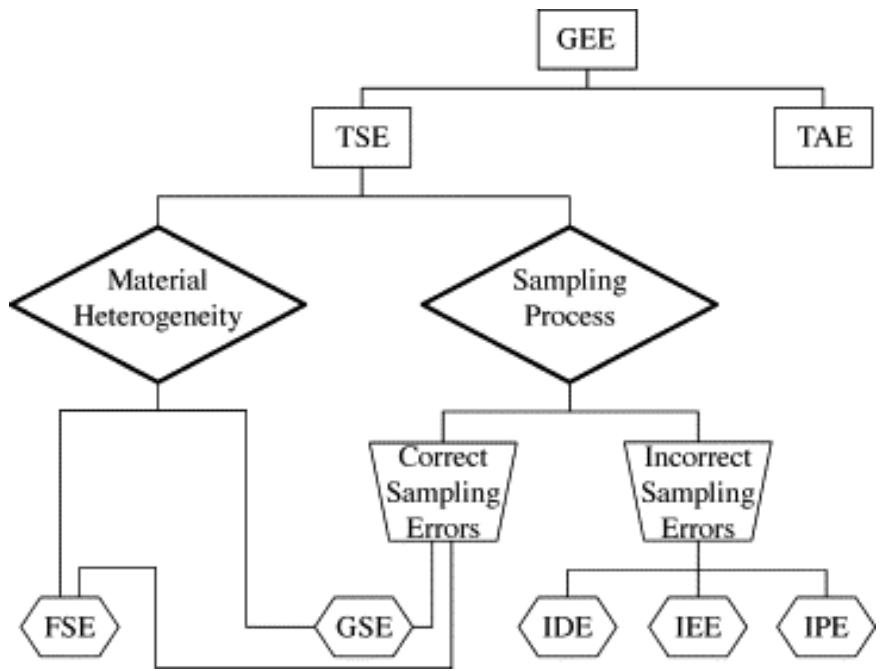

Figura 2.25 Errores de muestreo de la Teoría de Muestreo de Gy (Petersen et al., 2005)

Como se observa en la Figura 2.25, durante el proceso de muestreo varios errores pueden influir en el Error Total de Muestreo, los cuales Gy clasifica como errores de muestreo correcto y errores de muestreo incorrecto.

\subsubsection{Errores de muestreo correcto}

Los errores de muestreo correcto están comprendidos por el Error Fundamental de Muestreo (FSE) y el Error de Agrupación y Segregación (GSR), los cuales son inevitables.

\section{Error de muestreo fundamental (FSE):}

Como se ha comentado con anterioridad, el FSE es inherente a las propiedades del material (tamaño, forma, densidad y composición) y es el error mínimo que habrá en el muestreo de un material sólido, a pesar de que todos los otros tipos de errores hayan sido eliminados. Para un lote cuyas propiedades están definidas, este error es constante y no puede alterarse. Además, solo en dos situaciones el FSE será cero: cuando la muestra es el lote completo o cuando el lote es estrictamente homogéneo.

Una forma de minimizarlo es mejorar físicamente las características del lote de manera que se pueda llevar a cabo un muestreo más representativo. El método más frecuente es triturar los fragmentos a un tamaño menor de partícula. Sin embargo, si el objetivo del muestreo es conocer la composición física de los RSU, identificando que materiales o elementos están presentes en los mismos, no es posible minimizarlo mediante la reducción de tamaño. En ese caso la única forma de hacerlo es aumentando el tamaño de muestra.

El error fundamental de muestreo se puede calcular a partir de una serie de parámetros físicos del material, lo que a su vez permite estimar el tamaño de muestra. Para ello se utiliza la "Fórmula de Gy" correspondiente a la siguiente expresión y que es válida para muestras de materiales particulados:

$$
s^{2}(F S E)=C \cdot d^{3}\left(\frac{1}{M_{S}}-\frac{1}{M_{L}}\right) \approx \frac{C \cdot d^{3}}{M_{S}}
$$

Donde:

$s^{2}$ (FSE) es la varianza del error fundamental de muestreo;

Ms es la masa de muestra necesaria;

ML es la masa del lote y casi siempre se elimina de la ecuación debido a que su tamaño es muy grande;

d es el tamaño nominal superior de partícula en la que un tamiz con esa luz de malla retiene el $95 \%$ de las partículas; 
C es la Constante de muestreo y se calcula mediante el producto de cuatro parámetros del material: c, f, g y $\beta$ :

$$
C=c \cdot f \cdot g \cdot \beta
$$

A continuación, se presenta una breve descripción introductoria de dichos parámetros:

- Factor de composición mineralógica o parámetro de constitución (c): depende de la cantidad de componente crítico en el lote, la densidad de las partículas que contienen el componente crítico y la densidad media del lote. Sus unidades son $\mathrm{g} / \mathrm{cm}^{3}$ y puede calcularse con la siguiente ecuación:

$$
c=\frac{\left(1-\frac{a_{L}}{\alpha}\right)^{2}}{\frac{a_{L}}{\propto}} \rho_{c}+\left(1-\frac{a_{L}}{\propto}\right) \rho_{m}
$$

Donde: a es la proporción de componente crítico en el lote; $\alpha$ es la concentración de partículas críticas; $\rho_{c}$ es la densidad de las partículas críticas, y $\rho_{m}$ es la densidad media de la matriz (lote).

- Factor de forma de partícula (f): describe la desviación de la forma de las partículas respecto a la forma ideal de un cubo y relaciona el volumen y el diámetro de las mismas. Un cubo tiene un $\mathrm{f}=1$, una esfera una $f=0,52(\pi / 6)$ y un disco casi plano una $f=0,1$. Es adimensional y se puede calcular a partir de la fórmula del volumen de las partículas:

$$
V_{p}=f \cdot d^{3}
$$

Donde $V_{p}$ es el volumen de las partículas; $f$ es el factor forma, y d es el tamaño nominal superior de las partículas.

- Factor de distribución de tamaños (g): describe el intervalo de tamaños de partículas que hay en el lote y es adimensional. Si todas las partículas tienen el mismo tamaño, $\mathrm{g}=1$; si $1<\mathrm{d} / \mathrm{d}_{05}<2$, entonces $g=0,75$; si $2<d / d_{05}<4$, entonces $g=0,5$; si $d / d_{05}>4$, entonces $g=0.25$. Siendo $d_{05}$ el tamaño nominal inferior.

- Factor de liberación $(\boldsymbol{\beta})$ : describe el grado de liberación del componente crítico en la matriz y es adimensional. Para partículas totalmente liberadas $\beta=1$ y para partículas totalmente incorporadas $\beta=0$. De lo contrario se puede calcular a partir de:

$$
\beta=\sqrt{\frac{L}{d}}
$$

Donde: L es el tamaño de liberación, y d es el tamaño nominal superior de las partículas.

El tamaño de liberación es el tamaño nominal al que las partículas deben triturarse para que el componente crítico sea liberado (es un parámetro procedente de la industria minera). Es mejor establecer $\beta=1$ si no se conoce el factor de liberación.

La fórmula de Gy, además, permite estimar la masa mínima de muestra (Ms) cuando se fija el nivel de incertidumbre deseado (es decir, la varianza del error fundamental admitida: so $^{2}$ (FSE)), puesto que C y d siempre podrán ser calculados para casi cualquier material particulado:

$$
M_{S}=\frac{C \cdot d^{3}}{s_{0}^{2}(F S E)}
$$

Además, también puede despejarse de manera que permita calcular el tamaño de partícula al que debe triturarse un material, para que una masa de muestra determinada corresponda a una varianza deseada:

$$
d^{3}=\frac{C \cdot s_{0}^{2}(F S E)}{M_{S}}
$$


Cabe señalar que en el campo de los residuos estas ecuaciones tienen algunas limitaciones, puesto que en origen fueron desarrolladas para el muestreo de materiales minerales (Pehlken et al., 2000).

\section{Error de agrupación y segregación (GSE)}

EI GSE es un tipo de error prácticamente inevitable en cualquier muestreo y es resultado de la heterogeneidad de distribución del material y del proceso de muestreo en sí, debido a que los fragmentos o partículas no están distribuidos uniformemente en el material.

Este error aparece cuando los incrementos del muestreo no son ideales, es decir, cuando no se muestrea los fragmentos uno por uno y un incremento está formado por varios de ellos. Como consecuencia no todos los fragmentos tienen la misma probabilidad de ser seleccionados, ya que cuando se extrae un fragmento específico también se extraen los "vecinos". Además, habitualmente, existe una correlación local significativa entre los fragmentos vecinos que puede ser inducida por agentes físicos externos o internos. Por ejemplo, la segregación o estratificación que produce la gravedad o la mezcla incompleta debido a las propiedades de la superficie del grano (pegajosidad) que hace que las partículas se agrupen. El GSE se reduce a medida que el número de fragmentos seleccionados en cada incremento disminuye, y alcanza el cero cuando se seleccionan fragmentos individuales para formar la muestra.

El GSE depende principalmente de la segregación de los fragmentos dentro del lote, lo que a su vez depende en gran medida de las diferencias en el tamaño, forma y densidad de partícula. Para minimizarlo es fundamental mezclar siempre minuciosamente el material del lote antes de cualquier proceso de muestreo. Cabe destacar que normalmente se necesita un tiempo de mezcla significativamente más largo del que se suele realizar para poder reducir el GSE. Sin embargo, un meticuloso mezclado no garantiza un mínimo GSE, puesto que siempre queda una heterogeneidad residual debida a que muchos materiales por su naturaleza son propensos a estratificarse, incluso inmediatamente después de la mezcla (por ejemplo, materiales de pequeño tamaño con una alta densidad como tierras, trozos de vidrio, etc.).

En resumen, el GSE se compone de dos fuentes de error: agrupación y segregación. La agrupación se puede minimizar disminuyendo el tamaño de los incrementos de manera que se usen el mayor número de ellos para formar la muestra. La segregación se puede minimizar removiendo y mezclado minuciosamente el material que conforma el lote antes de muestreo, si es posible. Si no es posible, se debe optar por un muestreo compuesto sistemático o estratificado. Además, la mezcla del material debe realizarse en todas las etapas de muestreo que existan.

\subsubsection{Errores de muestreo incorrecto}

Los errores de muestreo incorrecto aparecen cuando no se cumplen los principios de un correcto muestreo $y$, al contrario de los errores de muestreo correctos, pueden minimizarse en gran medida o incluso eliminarse completamente siguiendo las pautas dadas en la Teoría de Muestreo. Este error se compone de tres fuentes de error que se definen a continuación.

\section{Error de delimitación del incremento (IDE)}

Este error se produce cuando la forma real del incremento extraído es diferente del incremento teórico delimitado geométricamente. Por ejemplo, en el muestreo de una cinta transportadora es importante que los lados del dispositivo de corte sean paralelos, de forma que todo el ancho de la cinta este representado por igual en la muestra. La desviación de la forma correcta del incremento es la causa fundamental del IDE. Para que este error sea completamente suprimido la forma del incremento debe corresponder exactamente con el plano geométrico y todo el material dentro del mismo debe ser extraído. En la toma de muestra se recomienda minimizar la superficie de corte mediante el muestreo de una pila plana y alargada o una cinta trasportadora utilizando el corte de dos planos paralelos.

\section{Error de extracción del incremento (IEE)}

El IEE ocurre cuando se toma un incremento que se ha delimitado correctamente, pero no se respetan un conjunto de reglas de extracción prácticas. Por ejemplo, cuando se manipula material particulado se debe 
cumplir la regla del centro de gravedad. Esta regla establece que un fragmento que tiene su centro de gravedad dentro del incremento delimitado debe formar parte de la muestra (Figura 2.26).

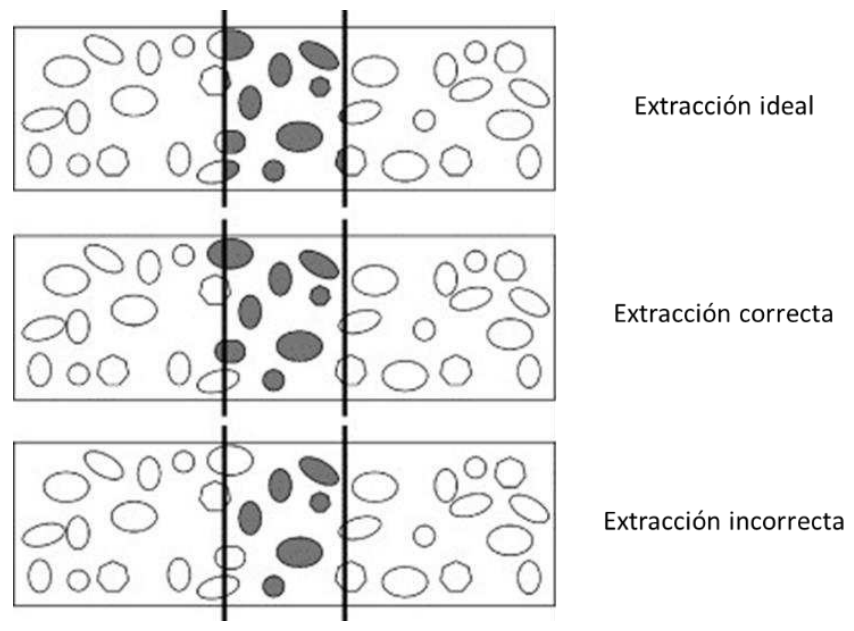

Figura 2.26 Regla del centro de gravedad para la extracción de incrementos según la Teoría de Muestreo de Gy (Petersen et al., 2005)

En la figura anterior, el primer esquema muestra cómo sería el incremento ideal; el del medio como sería realmente el incremento extraído de forma correcta, y el tercero sería una extracción incorrecta. La diferencia entre la ideal y la real es una contribución al error de muestreo que no se puede evitar sin alterar el estado físico del material (supondría cortar las partículas para solo extraer la parte correspondiente). Por tanto, incluso el muestreo correcto no elimina completamente el IEE. Otra fuente de este tipo de error es la pérdida de partículas que pertenecen a la muestra a la hora de extraer el material, por ejemplo, cuando se muestrea en una pila pueden quedarse partículas finas en el suelo. Esto puede evitarse eligiendo cuidadosamente el procedimiento de trabajo y la herramienta de muestreo.

\section{Error de preparación del incremento (IPE)}

Después de la toma de la muestra, aún pueden llevarse a cabo varios pasos adicionales antes de realizarse el análisis. En estas etapas la muestra puede verse alterada también por varios factores como: errores humanos, derrames, contaminación, adhesión de componentes a las paredes de los contenedores, bolsas o herramientas, pérdida de partículas finas (polvo) durante la manipulación, trituración, secado, etc. Dentro de estos errores también se encuentran las alteraciones deliberadas de las muestras como sabotajes o fraudes. Estos errores pueden controlarse con la información y formación del personal de manera que comprendan la importancia de un adecuado procedimiento de muestreo.

Así pues, el muestreo correcto se define como el conjunto de estas pautas prácticas que permiten suprimir, minimizar o evitar la aparición de los errores incorrectos de muestreo.

\subsubsection{Otros errores}

Junto con los errores descritos anteriormente, la Teoría de Muestreo de Gy también identifica dos errores más, los cuales no están relacionados directamente con el procedimiento de muestro pero que son muy importantes en el campo de los residuos. Estos son el error de fluctuación de heterogeneidad de largo alcance y el error de fluctuación de la heterogeneidad periódica (Dahlén and Lagerkvist, 2008).

\section{Error de fluctuación de heterogeneidad de largo alcance}

Este error se produce como consecuencia de la variación espacial del material en el lote, puesto que la muestra tomada en un lugar puede no ser representativa de otra parte del área investigada. Esta variación se puede abordar y minimizar mediante el muestreo estratificado. Otra forma sería la utilización una muestra combinada juntando incrementos de varios puntos. 


\section{Error de fluctuación de la heterogeneidad periódica}

Este error hace referencia a las variaciones periódicas que pueden afectar al material a muestrear: los RSU. La variación periódica se puede examinar comparando muestreos realizados en diferentes estaciones, por ejemplo, en los periodos de vacaciones o temporadas turísticas, o en las diferentes épocas del año. Si no es posible realizar el muestreo en varias temporadas, se recomienda elegir la temporada que sea más relevante para el estudio. Además, cada periodo de muestreo debe cubrir al menos una semana completa, puesto que también existen variaciones entre los fines de semana en comparación con los días laborables.

\subsubsection{Estrategia de muestreo}

Para poder tomar muestras representativas es fundamental establecer una estrategia de muestreo correcta. Para ello se puede seguir el siguiente procedimiento (Petersen et al., 2005):

1. Realizar siempre un estudio inicial de la heterogeneidad del material, esto es imprescindible tanto para desarrollar el plan de muestro como para tomar una muestra representativa.

2. Utilizar los medios y equipos apropiados para afrontar los problemas del muestreo y así muestrear correctamente.

3. Eliminar todo el error de muestreo incorrecto y optimizar el plan de muestreo para minimizar el FSE y el GSE.

4. Minimizar las fluctuaciones periódicas.

En todos los pasos del muestreo, la exactitud debe controlarse respetando las reglas y los procedimientos proporcionados por la teoría de muestreo, puesto que esto eliminará los errores de muestreo incorrecto y garantizará muestras representativas. La elección del procedimiento a utilizar depende del material a muestrear y de la experiencia, pero los principios son siempre los mismos.

Finalmente, señalar que el capítulo 5 de la presente tesis se lleva a cabo una extensa revisión de las diferentes técnicas de muestreo estadístico, así como de las metodologías y normas existentes para el muestreo y caracterización de RSU y CSR. Algunas de estas metodologías revisadas se basan en la Teoría de Muestreo de Gy presentada en este apartado.

\subsection{REFERENCIAS}

Arena, U., Di Gregorio, F., 2014. A waste management planning based on substance flow analysis. Resour. Conserv. Recycl. 85, 54-66. https://doi.org/10.1016/J.RESCONREC.2013.05.008

Arena, U., Di Gregorio, F., Amorese, C., Mastellone, M.L., 2011. A techno-economic comparison of fluidized bed gasification of two mixed plastic wastes. Waste Manag. 31, 1494-1504. https://doi.org/10.1016/J.WASMAN.2011.02.004

Astrup, T., 2008. Management of APC residues from W-t-E Plants (ISWA-WG Thermal Treatment of Waste Subgroup APC Residues from W-t-E plants). International Solid Waste Association (ISWA).

Beckmann, M., Pohl, M., Bernhardt, D., Gebauer, K., 2012. Criteria for solid recovered fuels as a substitute for fossil fuels - a review. Waste Manag. Res. 30, 354-369. https://doi.org/10.1177/0734242X12441237

Berganza, C., 2012. ENERFUEL: la energía del futuro, la energía infinita. RETEMA 157, 32-39.

Bernard, D., 2013. Integración de la metodología de Análisis de Ciclo de Vida (ACV) y Sistemas de Información Geográfica (SIG) para la evaluación ambiental de sistemas de gestión de residuos (Tesis doctoral). Universitat Jaume I, Escuela Superior de Tecnología y Ciencias Experimentales.

Bessi, C., Lombardi, L., Meoni, R., Canovai, A., Corti, A., 2016. Solid recovered fuel: An experiment on classification and potential applications. Waste Manag. 47, 184-194. https://doi.org/10.1016/j.wasman.2015.08.012 
BGS (Ed.), 2008. Quality label RAL-GZ 724 Quality and test instructions Solid Recovered Fuels (German version only). BGS: Bundesgü tegemeinschaft Sekundä rbrennstoffe und Recyclingholz e.V., Münster, Germany.

BMLFUW (Ed.), 2010. Verordnung über die Verbrennung von Abfällen Abfallverbrennungsverordnung - AVV [Waste Incineration Ordinance]. BMLFUW: Bundesministerium für Land- und Forstwirtschaft, Umwelt und Wasserwirtschaft, Vienna, Austria.

BMLFUW (Ed.), 2008. Richtlinie für Ersatzbrennstoffe [Guideline for Waste Fuels]. BMLFUW: Bundesministerium für Land- und Forstwirtschaft, Umwelt und Wasserwirtschaft, Vienna, Austria.

Brás, I., Silva, M.E., Lobo, G., Cordeiro, A., Faria, M., De Lemos, L.T., 2017. Refuse Derived Fuel from Municipal Solid Waste rejected fractions- a Case Study. Energy Procedia 120, 349-356. https://doi.org/10.1016/j.egypro.2017.07.227

Brunner, P.H., Rechberger, H., 2015. Waste to energy - key element for sustainable waste management. Waste Manag. 37, 3-12. https://doi.org/10.1016/J.WASMAN.2014.02.003

Buekens, A., Cen, K., 2011. Waste incineration, PVC, and dioxins. J. Mater. Cycles Waste Manag. 13, 190197. https://doi.org/10.1007/s10163-011-0018-9.

BUWAL (Ed.), 2005. Richtlinie zur Entsorgung von Abfällen in Zementwerken [Guideline for the disposal of waste in cement plants]. BUWAL, Bern, Suiza.

Carlos Alberola, M., Gallardo Izquierdo, A., Colomer Mendoza, F.J., Edo-Alcón, N., 2017. Producción y consumo de CSR. Estudio comparativo de la situación europea, in: Lobo, A., López, A., Esteban-García, A.L., Cuartas, M. (Eds.), Libro de Actas VII Simposio Iberoamericano de Ingeniería de Residuos. Universidad de Cantabria, Santander, España, pp. 359-364.

CEMEX, n.d. CEMEX: Alternative Fuels [WWW Document]. URL https://www.cemex.co.uk/alternativefuels.aspx (accessed 5.2.19).

Colomer, F.J., Gallardo, A., 2007. Tratamiento y gestión de residuos sólidos. Editorial Universidad Politecnica de valencia, Valencia, España.

Comisión Europea, 2014. Decisión de la Comisión de 18 de diciembre de 2014 por la que se modifica la Decisión 2000/532/CE, sobre la lista de residuos, de conformidad con la Directiva 2008/98/CE del Parlamento Europeo y del Consejo. D. Of. la Unión Eur. Ser. L 44-86.

Comisión Europea, 2006. Prevención y control integrados de la contaminación. Documento de referencia sobre las mejores técnicas disponibles para el sector del tratamiento de residuos (BREF). European Commission's Joint Research Centre (JRC): IPPC Bureau, Sevilla, España.

Comunidad Valenciana, 2019. Decreto 55/2019, de 5 de abril, del Consell, por el que se aprueba la revisión del Plan integral de residuos de la Comunitat Valenciana. D. Of. la General. Valencia. 19686-19753.

Comunidad Valenciana, 2013. Decreto 81/2013, de 21 de junio, del Consell, de aprobación definitiva del Plan Integral de Residuos de la Comunitat Valenciana (PIRCV). D. Of. la General. Valencia. 1888818933.

Comunidad Valenciana, 2000. Ley 10/2000, de 12 de diciembre, de Residuos de la Comunidad Valenciana. D. Of. la General. Valencia. 22778-22809.

Consejo de la Unión Europea, 2003. 2003/33/CE: Decisión del Consejo de 19 de diciembre de 2002 por la que se establecen los criterios y procedimientos de admision de residuos en los vertederos con arreglo al artículo 16 y al anexo II de la Directiva 1999/31/CE. D. Of. la Unión Eur. Ser. L 27-49.

Consejo de la Unión Europea, 1999. Directiva 1999/31/CE del Consejo de 26 de abril de 1999 relativa al vertido de residuos. D. Of. la Unión Eur. Ser. L 1-19.

Crillesen, K., Skaarup, J., 2006. Management of Bottom Ash from WTE Plants (ISWA-WG Thermal Treatment Subgroup Bottom Ash from WTE-Plants). International Solid Waste Association (ISWA).

Dahlén, L., Lagerkvist, A., 2008. Methods for household waste composition studies. Waste Manag. 28, 1100-1112. https://doi.org/10.1016/j.wasman.2007.08.014 
de Araújo Morais, J., Ducom, G., Achour, F., Rouez, M., Bayard, R., 2008. Mass balance to assess the efficiency of a mechanical-biological treatment. Waste Manag. 28, 1791-1800. https://doi.org/10.1016/j.wasman.2007.09.002

Del Zotto, L., Tallini, A., Di Simone, G., Molinari, G., Cedola, L., 2015. Energy Enhancement of Solid Recovered Fuel within Systems of Conventional Thermal Power Generation. Energy Procedia 81, 319338. https://doi.org/10.1016/J.EGYPRO.2015.12.102

Di Lonardo, M.C., Franzese, M., Costa, G., Gavasci, R., Lombardi, F., 2016. The application of SRF vs. RDF classification and specifications to the material flows of two mechanical-biological treatment plants of Rome: Comparison and implications. Waste Manag. 47, 195-205. https://doi.org/10.1016/j.wasman.2015.07.018

Di Lonardo, M.C., Lombardi, F., Gavasci, R., 2012. Characterization of MBT plants input and outputs: A review. Rev. Environ. Sci. Biotechnol. 11, 353-363. https://doi.org/10.1007/s11157-012-9299-2

Edo-Alcón, N., Gallardo, A., Colomer-Mendoza, F.J., 2016. Characterization of SRF from MBT plants: Influence of the input waste and of the processing technologies. Fuel Process. Technol. 153, 19-27. https://doi.org/10.1016/j.fuproc.2016.07.028

ERFO, 2015. Markets for Solid Recovered Fuels - Data and Assessments on Markets for SRF (Doc 7296/VM). European Recovered Fuel Organisation (ERFO) y The European Cement Associatión (CEMBUREAU).

España, 2018. Real Decreto 293/2018, de 18 de mayo, sobre reducción del consumo de bolsas de plástico y por el que se crea el Registro de Productores. Boletín Of. Estado 52591-52601.

España, 2016. Real Decreto Legislativo 1/2016, de 16 de diciembre, por el que se aprueba el texto refundido de la Ley de prevención y control integrados de la contaminación. Boletín Of. Estado 91806-91842.

España, 2015a. Resolución de 16 de noviembre de 2015, de la Dirección General de Calidad y Evaluación Ambiental y Medio Natural, por la que se publica el Acuerdo del Consejo de Ministros de 6 de noviembre de 2015, por el que se aprueba el Plan Estatal Marco de Gestión d. Boletín Of. Estado.

España, 2015b. Real Decreto 180/2015, de 13 de marzo, por el que se regula el traslado de residuos en el interior del territorio del Estado. Boletín Of. Estado 29388-29406.

España, 2013a. Real Decreto 815/2013, de 18 de octubre, por el que se aprueba el Reglamento de emisiones industriales y de desarrollo de la Ley 16/2002, de 1 de julio, de prevención y control integrados de la contaminación. Boletín Of. Estado 85173-85276.

España, 2013b. Resolución de 20 de diciembre de 2013, de la Dirección General de Calidad y Evaluación Ambiental y Medio Natural, por la que se publica el Acuerdo del Consejo de Ministros de 13 de diciembre de 2013, por el que se aprueba el Programa Estatal de Prevención. Boletín Of. Estado 4170-4272.

España, 2011. Ley 22/2011, de 28 de julio, de residuos y suelos contaminados. Boletín Of. Estado 8565085705.

España, 2006. Real Decreto 252/2006, de 3 de marzo, por el que se revisan los objetivos de reciclado y valorización establecidos en la Ley 11/1997, de 24 de abril, de envases y residuos de envases, y por el que se modifica el Reglamento para su ejecución, aprobado por. Boletín Of. Estado 8961-8967.

España, 2001. Real Decreto 1481/2001, de 27 de diciembre, por el que se regula la eliminación de residuos mediante depósito en vertedero. Boletín Of. Estado 65671-65672.

España, 1998. Real Decreto 782/1998, de 30 de abril, por el que se aprueba el Reglamento para el desarrollo y ejecución de la Ley 11/1997, de 24 de abril, de Envases y Residuos de Envases. Boletín Of. Estado 14701-14716.

España, 1997. Ley 11/1997, de 24 de abril, de Envases y Residuos de Envases. Boletín Of. Estado 1327013277.

European Commision, 2017. The role of waste-to-energy in the circular economy (Documento COM(2017) 34 final). Communication from the Commission to the European Parliament, the Council, the European Economic and Social Committee and the Committee of the Regions, Brussels, 26.1.2017. 
Eurostat, 2019. Waste statistics at EU [WWW Document]. URL https://ec.europa.eu/eurostat/web/waste (accessed 6.20.19).

Fernández, J., 2010. Optimización de la digestión anaerobia seca de la Fracción Orgánica de los Residuos Sólidos Urbanos (FORSU) en reactores en fases de temperatura (Tesis doctoral). Universidad de Cadiz.

Flamme, S., Geiping, J., 2012. Quality standards and requirements for solid recovered fuels: a review. Waste Manag. Res. 30, 335-53. https://doi.org/10.1177/0734242X12440481

Fundación CEMA, 2018. Guía de buenas prácticas para el manejo seguro de Combustibles Alternativos en Fábricas de Cemento (Cod. Acción: AS2017-0010). Fundación Laboral del Cemento y el Medio Ambiente (CEMA), Madrid, España.

Fundación Conde del Valle de Salaza (FUCOVASA), Federación Española de Municipios (FEMP), ECOEMBES (Eds.), 2015. Guia tecnica: La gestión de residuos municipales, 2nd ed. Editorial MIC, Madrid, España.

Gallardo, A., 2000. Metodología para el diseño de redes de recogida selectiva de RSU utilizando sistemas de información geográfica. Creación de una base de satos aplicable a España. Universidad Politécnica de Valencia.

Gallardo, A., Carlos, M., Bovea, M.D., Colomer, F.J., Albarrán, F., 2014. Analysis of refuse-derived fuel from the municipal solid waste reject fraction and its compliance with quality standards. J. Clean. Prod. 83, 118-125. https://doi.org/10.1016/j.jclepro.2014.07.085

Gallardo, A., Edo-Alcón, N., Albarrán, F., 2017. El combustible sólido recuperado: Producción y marco regulador. RETEMA 197, 8-16.

Gallardo, A., Edo-Alcón, N., Sánchez-López, I., 2019. Producción de combustibles sólidos a partir de residuos domiciliarios, in: Gallardo Izquierdo, A., Colomer Mendoza, F.J., Campos Rodríguez, R., Arias Aguilar, D. (Eds.), Aprovechamiento Energético de Residuos. Publicaciones de la Universitat Jaume I, Castellón de la Plana, España, pp. 39-68.

Gallardo, A., Edo, N., Colomer, F.J., Goméz, A., 2014. SRFs produced from reject fraction from different processes in a MSW management. A comparative study, in: 18th International Congress on Project Management and Engineering. Alcañiz.

Garcés, D., Díaz, E., Sastre, H., Ordóñez, S., González-LaFuente, J.M., 2016. Evaluation of the potential of different high calorific waste fractions for the preparation of solid recovered fuels. Waste Manag. 47, 164-173. https://doi.org/10.1016/j.wasman.2015.08.029

Generallitat Valenciana, 2004. Inventario y Catalogo de Residuos de la Comunidad Valenciana 2003-2004. Conselletia de Medi Ambient, Aigua, Urbanisme i Habitatge, Generallitat Valenciana, Valencia, España.

Glorius, T., 2015. SRF-production and use in CHP-plants, example EU-project RECOMBIO. Bruselas (22.04.2015).

Glorius, T., 2014. Production and Use of Solid Recovered Fuels - Developments and Prospects. ZKG 9, 7280.

Glorius, T., 2009. Conference "Solid Recovered Fuels (SRF) - A sustainable option for Spain". SRF in a CHPplant in Germany. Madrid, España (17.11.2009).

Gug, J., Cacciola, D., Sobkowicz, M.J., 2015. Processing and properties of a solid energy fuel from municipal solid waste (MSW) and recycled plastics. Waste Manag. 35, 283-292. https://doi.org/10.1016/j.wasman.2014.09.031

lacovidou, E., Hahladakis, J., Deans, I., Velis, C., Purnell, P., 2018. Technical properties of biomass and solid recovered fuel (SRF) co-fired with coal: Impact of on multi-dimensional resource recovery value. Waste Manag. 73, 535-545. https://doi.org/10.1016/j.wasman.2017.07.001

Institut Cerdà, 2019. Reciclado y valorización de residuos en la Industria Cementera en España (Actualización año 2017) (Cuaderno Técnico). Fundación Laboral del Cemento y el Medio Ambiente (CEMA), Madrid, España. 
Instituto Nacional de Estadística (INE), 2018. Estadística sobre recogida de residuos urbanos - Año 2016. Instituto Nacional de Estadistica (INE), Madrid, España.

Ionescu, G., Rada, E.C., Ragazzi, M., Mărculescu, C., Badea, A., Apostol, T., 2013. Integrated municipal solid waste scenario model using advanced pretreatment and waste to energy processes. Energy Convers. Manag. 76, 1083-1092. https://doi.org/10.1016/J.ENCONMAN.2013.08.049

Iriani Bordas, M., Puig Ventosa, I., Sastre Sanz, S., 2018. Las tasa de residuos en España 2018. Fundació ENT, Vilanova i la Geltrú, España.

Italian Ministerial Decree, 2013. Decreto 14 febbraio 2013, n.22. Regolamento recante disciplina della cessazione della qualifica di rifiuto di determinate tipologie di combustibili solidi secondari (CSS), ai sensi dell'articolo 184-ter, comma 2, del decreto legislativo 3 aprile 2006, n. . Gazz. Uff. della Repub. Ital.

Jappe Frandsen, F., 2005. Utilizing biomass and waste for power production - a decade of contributing to the understanding, interpretation and analysis of deposits and corrosion products. Fuel 84, 12771294. https://doi.org/10.1016/J.FUEL.2004.08.026

Kaza, S., Yao, L., Bhada-Tata, P., Woerden, F. Van, 2018. What a Waste 2.0 A Global Snapshot of Solid Waste Management to 2050. International Bank for Reconstruction and Development / The World Bank, Washington, DC.

Kisuk CPE, 1998. Solid waste incineration (Report TI 814-21). U.S. Corps. of Engineers, Engineering Division, Washington D.C.

Lorber, K.E., Sarc, R., Aldrian, a., 2012. Design and quality assurance for solid recovered fuel. Waste Manag. Res. 30, 370-380. https://doi.org/10.1177/0734242X12440484

MAgRAMA, 2015. Plan Estatal Marco de Gestión de Residuos (PEMAR) 2016-2022. Minsiterio de Agricultura, Alimentación y Medio Ambiente. Boletín Of. Estado 117395-117397.

McKay, G., 2002. Dioxin characterisation, formation and minimisation during municipal solid waste (MSW) incineration: Review. Chem. Eng. J. 86, 343-368. https://doi.org/10.1016/S1385-8947(01)00228-5

McKendry, P., 2002. Energy production from biomass (part 2): conversion technologies. Bioresour. Technol. 83, 47-54. https://doi.org/10.1016/S0960-8524(01)00119-5

MITECO, 2019. Memoria anual de generación y gestión de residuos: residuos de competencia municipal, 2016. Minsiterio para la Transisción Ecológica, Madrid, España.

Montejo, C., Costa, C., Ramos, P., Márquez, M.D.C., 2011. Analysis and comparison of municipal solid waste and reject fraction as fuels for incineration plants. Appl. Therm. Eng. 31, 2135-2140. https://doi.org/10.1016/j.applthermaleng.2011.03.041

Montejo Méndez, C., 2015. Optimización en el tratamiento de las fracciones orgánica y de rechazo procedentes de residuos urbanos (Tesis Doctoral). Universidad de Salamanca.

Nasrullah, M., 2015. Material and energy balance of solid recovered fuel production (Tesis Doctoral). Aalto University, School of Chemical Technology.

Nasrullah, M., Hurme, M., Oinas, P., Hannula, J., Vainikka, P., 2017. Influence of input waste feedstock on solid recovered fuel production in a mechanical treatment plant. Fuel Process. Technol. 163, 35-44. https://doi.org/10.1016/j.fuproc.2017.03.034

Nasrullah, M., Vainikka, P., Hannula, J., Hurme, M., 2015a. Elemental balance of SRF production process: Solid recovered fuel produced from commercial and industrial waste. Fuel 145, 1-11. https://doi.org/10.1016/j.fuel.2014.12.071

Nasrullah, M., Vainikka, P., Hannula, J., Hurme, M., Kärki, J., 2015b. Mass, energy and material balances of SRF production process. Part 3: solid recovered fuel produced from municipal solid waste. Waste Manag. Res. 33, 146-56. https://doi.org/10.1177/0734242X14563375

Nasrullah, M., Vainikka, P., Hannula, J., Hurme, M., Kärki, J., 2014. Mass, energy and material balances of SRF production process. Part 1: SRF produced from commercial and industrial waste. Waste Manag. 34, 1398-1407. https://doi.org/10.1016/j.wasman.2014.03.011 
Nithikul, J., Karthikeyan, O.P., Visvanathan, C., 2011. Reject management from a mechanical biological treatment plant in Bangkok, Thailand. Resour. Conserv. Recycl. 55, 417-422. https://doi.org/10.1016/j.resconrec.2010.11.004

Oppelt, E.T., 1986. Hazardous Waste Destruction: Thermal Techniques will be Increasingly Used as Legal Restrictions on Land Disposal Take Effect. Environ. Sci. Technol. 20, 312-318.

Otero del Peral, L.R., 1996. Guia profesional para la gestión ecologíca de los residuos sólidos urbanos. La Casa de la Ecología D.L, Madrid, España.

Parlamento Europeo y Consejo de la Unión Europea, 2019. Directiva 2019/904/UE del Parlamento Europeo y del Consejo de 5 de junio de 2019 relativa a la reducción del impaacto de determinados productos de plástico en el medio ambiente. D. Of. la Unión Eur. Ser. L 1-19.

Parlamento Europeo y Consejo de la Unión Europea, 2018a. Directiva 2018/851/UE del Parlamento Europeo y del Consejo de 30 de mayo de 2018 por la que se modifica la Directiva 2008/98/CE sobre los residuos. D. Of. la Unión Eur. Ser. L 109-140.

Parlamento Europeo y Consejo de la Unión Europea, 2018b. Directiva 2018/852/UE del Parlamento Europeo y del Consejo de 30 de mayo de 2018 por la que se modifica la Directiva 94/62/CE relativa a los envases y residuos de envases. D. Of. la Unión Eur. Ser. L 141-154.

Parlamento Europeo y Consejo de la Unión Europea, 2018c. Directiva 2018/850/UE del Parlamento Europeo y del Consejo de 30 de mayo de 2018 por la que se modifica la Directiva 1999/31/CE relativa al vertido de residuos. D. Of. la Unión Eur. Ser. L 100-108.

Parlamento Europeo y Consejo de la Unión Europea, 2015. Directiva 2015/720/UE del Parlamento Europeo y del Consejo de 29 de abril de 2015 por la que se modifica la Directiva 94/62/CE en lo que se refiere a la reducción del consumo de bolsas de plástico ligeras. D. Of. la Unión Eur. Ser. L 11-15.

Parlamento Europeo y Consejo de la Unión Europea, 2010. Directiva 2010/75/UE del Parlamento Europeo y el consejo de 24 de noviembre de 2010 sobre las emisiones industriales (prevención y control integrados de la contaminación). D. Of. la Unión Eur. Ser. L 17-119.

Parlamento Europeo y Consejo de la Unión Europea, 2008. Directiva 2008/98/CE del Parlamento Europeo y del Consejo de 19 de noviembre de 2008 sobre los residuos y por la que se derogan determinadas Directivas. D. Of. la Unión Eur. Ser. L 3-30.

Parlamento Europeo y Consejo de la Unión Europea, 2006. Reglamento (CE) Num. 1013/2006 del Parlamento Europeo y del Consejo de 14 de junio de 2006 relativo a los traslados de residuos. D. Of. la Unión Eur. Ser. L 1-98.

Parlamento Europeo y Consejo de la Unión Europea, 1994. Directiva 94/62/CE del Parlamento Europeo y del Consejo de 20 de diciembre de 1994 relativa a los envases y residuos de envases. D. Of. la Unión Eur. Ser. L 10-23.

Pehlken, A., Von Blottnitz, H., Pretz, T., 2000. Requirements for the sampling of residual waste - Approach to developing a new sampling model. Aufbereit. Tech. 41, 409-415.

Petersen, L., Minkkinen, P., Esbensen, K.H., 2005. Representative sampling for reliable data analysis: Theory of Sampling. Chemom. Intell. Lab. Syst. 77, 261-277. https://doi.org/10.1016/j.chemolab.2004.09.013

Pieber, S., Ragossnig, A., Pomberger, R., Curtis, A., 2012. Biogenic carbon-enriched and pollutant depleted SRF from commercial and pretreated heterogeneous waste generated by NIR sensor-based sorting. Waste Manag. Res. 30, 381-391. https://doi.org/10.1177/0734242X12437567

Pressley, P.N., Aziz, T.N., Decarolis, J.F., Barlaz, M.A., He, F., Li, F., Damgaard, A., 2014. Municipal solid waste conversion to transportation fuels: A life-cycle estimation of global warming potential and energy consumption. J. Clean. Prod. 70, 145-153. https://doi.org/10.1016/j.jclepro.2014.02.041

Pressley, P.N., Levis, J.W., Damgaard, A., Barlaz, M.A., DeCarolis, J.F., 2015. Analysis of material recovery facilities for use in life-cycle assessment. Waste Manag. 35, 307-317. https://doi.org/10.1016/J.WASMAN.2014.09.012 
Psomopoulos, C.S., Bourka, A., Themelis, N.J., 2009. Waste-to-energy: A review of the status and benefits in USA. Waste Manag. 29, 1718-1724. https://doi.org/10.1016/J.WASMAN.2008.11.020

Puig Ventosa, I., Jofra Sora, M., Calaf Forn, M., 2012. La puerta de atrás de la incineración de residuos: Análisis económico-ambiental de la utilización de combustibles derivados de los residuos (CDR) en España. Greenpeace y Fundación ENT.

Rada, E.C., Andreottola, G., 2012. RDF/SRF: Which perspective for its future in the EU. Waste Manag. 32, 1059-1060. https://doi.org/10.1016/J.WASMAN.2012.02.017

Rada, E.C., Ragazzi, M., 2014. Selective collection as a pretreatment for indirect solid recovered fuel generation. Waste Manag. 34, 291-297. https://doi.org/10.1016/j.wasman.2013.11.013

Rada, E.C., Squazardo, L., Ionescu, G., Badea, A., 2014. Economic viability of SRF co-combustion in cement factory. U.P.B. Sci. Bull., Ser. D 76.

Ragazzi, M., Rada, E.C., 2012. RDF/SRF evolution and MSW bio-drying, in: WIT Transactions on Ecology and the Environment. WIT Press, pp. 199-208. https://doi.org/10.2495/WM120191

Ramos Casado, R., Arenales Rivera, J., Borjabad García, E., Escalada Cuadrado, R., Fernández Llorente, M., Bados Sevillano, R., Pascual Delgado, A., 2016. Classification and characterisation of SRF produced from different flows of processed MSW in the Navarra region and its co-combustion performance with olive tree pruning residues. Waste Manag. 47, 206-16. https://doi.org/10.1016/j.wasman.2015.05.018

Republique Française, 2016. Arrêté du 23 mai 2016 relatif à la préparation des combustibles solides de récupération en vue de leur utilisation dans des installations relevant de la rubrique 2971 de la nomenclature des installations classées pour la protection de l'environnement. J. Off. Repub. Française.

Rotter, V.S., Kost, T., Winkler, J., Bilitewski, B., 2004. Material flow analysis of RDF-production processes. Waste Manag. 24, 1005-1021. https://doi.org/10.1016/j.wasman.2004.07.015

Rotter, V.S., Lehmann, A., Marzi, T., Möhle, E., Schingnitz, D., Hoffmann, G., 2011. New techniques for the characterization of refuse-derived fuels and solid recovered fuels. Waste Manag. Res. 29, 229-236. https://doi.org/10.1177/0734242X10364210

Samaras, P., Karagiannidis, A., Kalogirou, E., Themelis, N., Kontogianni, S., 2010. An inventory of characteristics and treatment processes for fly ash from waste-to- energy facilities for municipal solid wastes, in: Proceedings of the 3rd International Symposium on Energy from Biomass and Waste (VENICE 2010). CISA Publisher, Venice, Italy.

Sami, M., Annamalai, K., Wooldridge, M., 2001. Co-firing of coal and biomass fuel blends. Prog. Energy Combust. Sci. 27, 171-214. https://doi.org/10.1016/S0360-1285(00)00020-4

Sarc, R., Lorber, K., Pomberger, R., Rogetzer, M., Sipple, E., 2014. Design, quality, and quality assurance of solid recovered fuels for the substitution of fossil feedstock in the cement industry. Waste Manag. Res. 32, 565-585. https://doi.org/10.1177/0734242X14536462

Sarc, R., Lorber, K.E., 2013. Production, quality and quality assurance of Refuse Derived Fuels (RDFs). Waste Manag. 33, 1825-1834. https://doi.org/10.1016/j.wasman.2013.05.004

Sastre, S., Llopart, J., Puig Ventosa, I., 2018. Mind the gap: A model for the EU recycling target applied to the Spanish regions. Waste Manag. 79, 415-427. https://doi.org/10.1016/J.WASMAN.2018.07.046

Séverin, M., Velis, C.A., Longhurst, P.J., Pollard, S.J.T., 2010. The biogenic content of process streams from mechanical-biological treatment plants producing solid recovered fuel. Do the manual sorting and selective dissolution determination methods correlate? Waste Manag. 30, 1171-1182. https://doi.org/10.1016/J.WASMAN.2010.01.012

SFS 5875, 2000. Solid Recovered Fuel - Quality Control System. Finnish Standards Association.

Tchobanoglous, G., Theisen, H., Vigil, S.A., 1994. Gestión integral de residuos sólidos. McGraw-Hill, Madrid, España. 
UNE-EN 15359, 2012. Combustibles sólidos recuperados: Especificaciones y clases. AENOR, Asocición Española de Normalizaciónj y Certificación, Madrid.

UNI 9903-1, 2004. Combustibili solidi non minerali ricavati da rifiuti (RDF) - Specifiche e classificazione (in Italian). UNI: Italian National Agency for Standardization, Milano, Italy.

Velis, C.A., Longhurst, P.J., Drew, G.H., Smith, R., Pollard, S.J.T., 2010. Production and quality assurance of solid recovered fuels using Mechanical- Biological Treatment (MBT) of waste: a comprehensive assessment. Crit. Rev. Environ. Sci. Technolgy 40, 979-1105. https://doi.org/10.1080/10643380802586980

Velis, C., Wagland, S., Longhurst, P., Robson, B., Sinfield, K., Wise, S., Pollard, S., 2012. Solid recovered fuel: Influence of waste stream composition and processing on chlorine content and fuel quality. Environ. Sci. Technol. 46, 1923-1931. https://doi.org/10.1021/es2035653

Velzeboer, I., van Zomeren, A., 2017. End of Waste criteria for inert aggregates in member states (ECN-E-17010). Energy Research Centre of the Netherlands (ECN), Petten, The Netherlands. 




\subsection{INTRODUCCIÓN}

EI TMB de RSU es el término genérico que engloba diferentes tecnologías para el tratamiento de los residuos. Estas tienen como finalidad procesar los materiales presentes en los RSU para recuperar aquellos que sean reciclables, transformándolos en productos comercializables, y bioestabilizar la materia orgánica mediante su transformación en compost.

Las plantas de TMB se pueden clasificar en función del tipo de residuos tratado; las diferentes etapas que conforman el proceso, así como el orden en el que se llevan a cabo; el grado de automatización y las tecnologías utilizadas para la recuperación de los materiales reciclables, y la tecnología empleada para la transformación de los residuos biodegradables. Por ello, dependiendo del tipo de planta, el número, naturaleza y características de las corrientes de rechazo generadas serán diferentes, presentando unas composiciones y propiedades distintas. Como consecuencia, su calidad como combustible y alternativas de valorización pueden diferir.

El presente capitulo se centra en modelar el funcionamiento de diferentes plantas de TMB. De esta manera se identificarán los flujos de entrada y salida de materiales, así como las corrientes de rechazos susceptibles de ser transformadas en un CSR.

Para ello, en primer lugar, se ha hecho una clasificación de los tipos de plantas de TMB en base a las características enumeradas anteriormente, estudiando los procesos de tratamiento llevado a cabo en las mismas. En segundo lugar, una vez definidos los tipos de instalaciones, se ha realizado un modelo conceptual para cada una de ellas. Estos modelos describen el proceso de tratamiento y las operaciones unitarias utilizadas, así como los flujos de entrada y salida de materiales existentes, permitiendo identificar las corrientes de rechazo generadas. Finalmente, se ha determinado el número de plantas de TMB de RSU existentes en España, clasificándolas en cada uno de los tipos definidos, así como los flujos de materiales entrantes y salientes en cada una de ellas. Estos datos han permitido definir los balances de materia, estimar la cantidad de rechazos generados a nivel nacional y establecer su rendimiento respecto a las entradas de RSU en las mismas. En la Figura 3.1 se muestra la estructura del capítulo, la cual se desarrolla en los siguientes apartados.

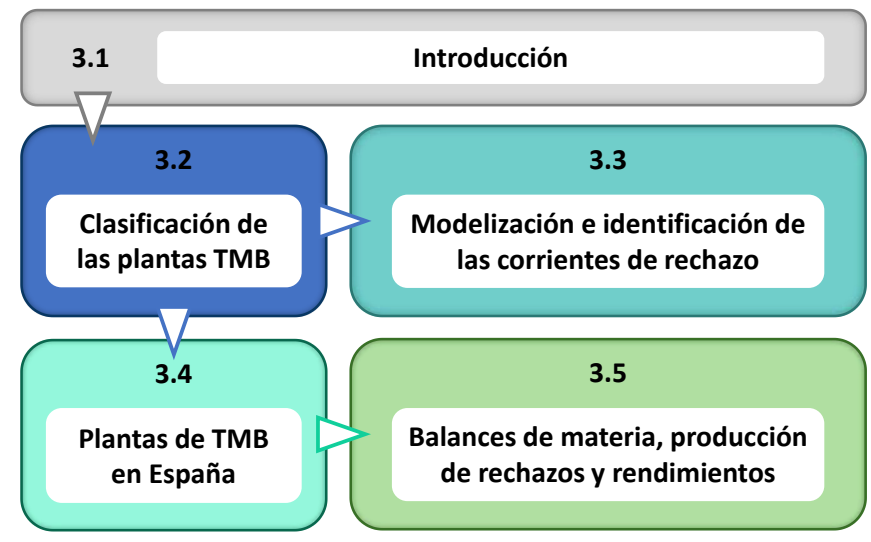

Figura 3.1 Estructura del Capítulo 3

\subsection{CLASIFICACIÓN DE LAS PLANTAS DE tRATAMIENTO MECÁNICO BIOLÓGICO}

De forma general, las plantas de TMB son instalaciones donde se lleva a cabo el tratamiento diferenciado de la fracción orgánica y de los materiales reciclables contenidos en los RSU. Por una parte, mediante un tratamiento mecánico, se separan y clasifican los diferentes materiales reciclables (vidrio, papel/cartón, metales, plásticos, etc.) que serán entregados a empresas recicladoras. Por otra parte, mediante un 
tratamiento biológico, se estabiliza la fracción orgánica y se transforma en un material bioestabilizado o en compost, haciendo que disminuya su volumen y degradabilidad.

Los aspectos que permiten diferenciar los tipos de plantas son:

- $\quad$ El tipo de RSU tratado

- Las etapas del proceso de tratamiento

- Las tecnologías y procesos de tratamiento mecánico

- Las tecnologías y procesos de tratamiento biológico

En los siguientes apartados se expone la clasificación de los diferentes tipos de plantas TMB en base a estas características.

\subsubsection{Tipo de RSU tratado}

En función de los residuos tratados se pueden distinguir dos tipos de instalaciones: las que tratan RSU mezclados y las que admiten solo los biorresiduos o fracción orgánica recogida selectivamente (FORS).

En las primeras, el tratamiento mecánico para la recuperación de los materiales reciclables es mucho más exhaustivo que en las segundas, puesto que los residuos entrantes son muy heterogéneos y contienen una gran cantidad de materiales reciclables que pueden ser aprovechados. Para ello se utiliza una gran variedad de equipos y procesos distintos.

El segundo tipo de planta aparece cuando el sistema de gestión de residuos incluye la separación en origen y posterior recogida selectiva de la fracción orgánica presente en los RSU, la cual está formada por materia orgánica biodegradable y una pequeña cantidad de impropios. El tratamiento mecánico en estas plantas consiste simplemente en el acondicionamiento de la FORS para el posterior tratamiento biológico, sometiéndola a un proceso de limpieza y recuperación de materiales (principalmente metales férricos).

Respecto al tratamiento biológico, tanto si se tratan RSU mezclados como FORS, el objetivo es el mismo: disminuir el volumen y la capacidad de biodegradación. Para ello la fracción orgánica se transforma en un material bioestabilizado, cuando procede de residuos mezclados, o en compost si procede de biorresiduos. En el caso del compost, este es un subproducto que puede utilizarse como fertilizante, abono o enmienda orgánica.

\subsubsection{Etapas del proceso de tratamiento}

Otro enfoque a tener en cuenta es la diferenciación y clasificación de las plantas de TMB en función de los distintos procesos de tratamiento en que se llevan a cabo en las mismas y que, de forma general, se pueden clasificar en etapas de tratamiento mecánico y etapas de tratamiento biológico.

Así pues, debido a que no en todas las instalaciones se presentan ambas etapas, ni tampoco en el mismo orden, las plantas de TMB se pueden clasificar en cuatro tipos:

- Plantas de tratamiento mecánico de los RSU o plantas de triaje: son aquellas instalaciones en las que solo se produce la clasificación y selección mecánica de la fracción no biodegradable de los RSU mezclados, por lo que no cuentan con una etapa de tratamiento biológico. En ellas simplemente se lleva a cabo una separación de los diferentes materiales reciclables con el fin de conseguir su máximo aprovechamiento. Suelen darse en lugares donde existe una recogida selectiva de la fracción orgánica o un sistema de recogida húmedo-seco, lo que limita la presencia de materia orgánica en el contenedor de residuos mezclados. También pueden aparecer como un tratamiento previo a la valorización energética.

- Plantas TMB de RSU: son las instalaciones de mayor implantación para el tratamiento los RSU mezclados. En ellas existe una primera etapa mecánica para la recuperación de los materiales reciclables y la separación de la fracción orgánica, la cual pasa a la etapa biológica para su bioestabilización. Esta puede llevarse a cabo de dos formas: mediante compostaje (tratamiento aerobio) o mediante biometanización (tratamiento anaerobio) y posterior compostaje del 
digestato. La etapa biológica también incluye los diferentes procesos de afino del material bioestabilizado.

- $\quad$ Plantas TBM de RSU o plantas de biosecado: este tipo de instalaciones se tratan RSU mezclados y se caracterizan porque el proceso comienza con el biosecado de los residuos tal cual son recibidos. En segundo lugar, se realiza el tratamiento mecánico para la separación de los materiales reciclables, así como para la limpieza y afino de la fracción orgánica. Esta última pasa directamente a la etapa de maduración, donde se obtiene el bioestabilizado.

- Plantas de tratamiento biológico de FORS: en ellas se lleva a cabo el tratamiento biológico de la FORS, por lo que aparecen en lugares donde existe una recogida diferenciada de biorresiduos. Estas instalaciones no cuentan con una etapa de tratamiento mecánico específica para la recuperación de materiales 0 , si existe, es muy simple y consiste en el acondicionamiento de la fracción orgánica y recuperación de los metales. La principal etapa de tratamiento es la biológica, que puede llevarse a caobo mediante compostaje o mediante biometanización y compostaje del digestato. Esta etapa también incluye los procesos de afino del compost.

\subsubsection{Tecnologías y procesos de tratamiento mecánico}

Las plantas de TMB también se pueden clasificar en base a las diferentes tecnologías o procesos mecánicos que se utilizan para el tratamiento de los RSU y el grado de automatización a la hora de recuperar los diferentes materiales reciclables. De forma general, las plantas se pueden clasificar en aquellas que llevan a cabo el proceso de forma totalmente automatizada y en las que este se realiza mediante medios mecánicos y manuales.

Los tratamientos mecánicos dentro de estas instalaciones tienen varios objetivos: eliminar los componentes de los residuos de entrada que pueden dificultar o impedir las etapas de tratamiento posteriores; preparar o acondicionar los residuos para los siguientes procesos; cambiar las características físicas de los residuos; clasificar y separar los materiales; refinar los productos obtenidos facilitando su posterior uso, y servir para fines específicos dentro de los procesos biológicos. Los procesos que pueden incluir son: la reducción de tamaño (trituración), el mezclado y homogeneización, la clasificación y separación, la densificación (compactación) y la manipulación de los materiales incluyendo su carga, transporte y almacenamiento (Velis et al., 2010).

En primer lugar, cuando los RSU son recibidos en las plantas de TMB, pasan por un pretratamiento o fase inicial de acondicionamiento mecánico que consiste en la eliminación de los elementos voluminosos que entorpecen el resto del proceso, la apertura de bolsas y/o trituración y la separación de la fracción orgánica de la no biodegradable por tamaños, forma o densidad. Tras este pretratamiento, la fracción no biodegradable pasa a la etapa mecánica de recuperación de materiales. En función de cómo se lleva a cabo el proceso de separación de los materiales reciclables las plantas de TMB se pueden clasificar en dos tipos:

- Automáticas (AUT): en ellas la recuperación se realiza de forma totalmente automatizada mediante diferentes tecnologías o equipos, los cuales se muestran en la Tabla 3.1, que consiguen separar la corriente de RSU en los diferentes materiales reciclables. Finalmente existe un control de calidad donde una serie de operarios revisan que la separación se haya llevado a cabo correctamente.

- Manual (MANU): en estas plantas el proceso de separación se hace principalmente de forma manual. La corriente de residuos pasa por una cabina donde una serie de operarios se encargan de clasificar los diferentes materiales, depositándolos en unas tolvas. Además, en algunos casos también intervienen equipos mecánicos como: electroimanes, corrientes de Foucault o separadores neumáticos para la aspiración del plástico film.

Adicionalmente, dentro de la etapa biológica, también existen procesos mecánicos. Por un lado, están los procesos mecánicos de mezclado y homogeneización de material dentro del proceso biológico en sí, por ejemplo, el volteo que sufre la fracción orgánica en las pilas de compostaje. Por otro, están los procesos de afino primario y secundario del bioestabilizado/compost. Los cuales tienen como objetivo el acondicionamiento o limpieza de estos materiales, ya sea para el siguiente proceso biológico en el caso del 
afino primario o para obtener el material final en el caso del secundario. Además, durante estos procesos de afino también pueden existir imanes o electroimanes para la recuperación de los metales férricos.

En la Tabla 3.1 se muestra el conjunto de subetapas principales, operaciones y equipamientos o tecnologías que forman parte de la etapa de tratamiento mecánico de las plantas de TMB, así como en qué tipo de plantas se utilizan cada uno de ellos.

Tabla 3.1 Subetapas, operaciones y equipamientos del tratamiento mecánico en plantas de TMB

\begin{tabular}{|c|c|c|c|c|}
\hline $\begin{array}{l}\text { Subetapas } \\
\text { principales }\end{array}$ & Operación & $\begin{array}{c}\text { Equipo/tecnología } \\
\text { asociada }\end{array}$ & Características del proceso & $\begin{array}{l}\text { Tipo de } \\
\text { planta }\end{array}$ \\
\hline \multirow{5}{*}{ Pretratamiento } & \multirow{2}{*}{ Alimentación } & Pala cargadora & $\begin{array}{l}\text { Utilizada cuando los residuos son } \\
\text { descargados en playa. }\end{array}$ & $\begin{array}{l}\text { AUT/ } \\
\text { MANU }\end{array}$ \\
\hline & & Puente grúa y pulpo & $\begin{array}{l}\text { Utilizado cuando los residuos son } \\
\text { descargados en foso. }\end{array}$ & $\begin{array}{l}\text { AUT/ } \\
\text { MANU }\end{array}$ \\
\hline & Triaje primario & $\begin{array}{l}\text { Cintas } \\
\text { transportadoras }\end{array}$ & $\begin{array}{l}\text { Separación manual de los elementos } \\
\text { voluminosos. }\end{array}$ & $\begin{array}{l}\text { AUT/ } \\
\text { MANU }\end{array}$ \\
\hline & Apertura de bolsas & Abrebolsas & $\begin{array}{c}\text { Apertura de las bolsas para facilitar la } \\
\text { clasificación y separación de los } \\
\text { materiales. }\end{array}$ & $\begin{array}{l}\text { AUT/ } \\
\text { MANU }\end{array}$ \\
\hline & $\begin{array}{l}\text { Clasificación por } \\
\text { tamaño, forma y/o } \\
\text { densidad }\end{array}$ & Separador balístico & $\begin{array}{l}\text { Equipo que permite separar los } \\
\text { residuos en función de su densidad } \\
\text { en tres fracciones: planares o ligeros, } \\
\text { rodantes o pesados y finos. Se ubica } \\
\text { antes de la separación óptica para } \\
\text { mejorar el proceso de clasificación } \\
\text { automática. }\end{array}$ & AUT \\
\hline \multirow{3}{*}{$\begin{array}{l}\text { Recuperación de } \\
\text { materiales } \\
\text { (clasificación y } \\
\text { separación) }\end{array}$} & $\begin{array}{l}\text { Separación } \\
\text { neumática }\end{array}$ & $\begin{array}{l}\text { Aspiración } \\
\text { automática }\end{array}$ & $\begin{array}{l}\text { El material a separar es aspirado } \\
\text { automáticamente mediante una } \\
\text { campana colocada en un salto entre } \\
\text { dos cintas. }\end{array}$ & AUT \\
\hline & \multirow[t]{2}{*}{$\begin{array}{l}\text { Separación } \\
\text { magnética }\end{array}$} & Electroimán & $\begin{array}{l}\text { Mediante un bobinado eléctrico se } \\
\text { genera un campo magnético que } \\
\text { atrae los metales férricos. Según su } \\
\text { posición pueden ser: Over-band } \\
\text { (elevado sobre la cinta } \\
\text { transportadora) o de tambor (en el } \\
\text { interior del tambor de cabeza de la } \\
\text { cinta transportadora). }\end{array}$ & $\begin{array}{l}\text { AUT/ } \\
\text { MANU }\end{array}$ \\
\hline & & Imán permanente & $\begin{array}{l}\text { Consiste en un material imantado } \\
\text { que atrae a los metales férricos. } \\
\text { Tiene menor alcance que el } \\
\text { electroimán (menor altura de } \\
\text { trabajo). Mismos tipos en función de } \\
\text { la posición. }\end{array}$ & $\begin{array}{l}\text { AUT/ } \\
\text { MANU }\end{array}$ \\
\hline
\end{tabular}




\begin{tabular}{|c|c|c|c|c|}
\hline $\begin{array}{l}\text { Subetapas } \\
\text { principales }\end{array}$ & Operación & $\begin{array}{l}\text { Equipo/ tecnología } \\
\text { asociada }\end{array}$ & Características del proceso & $\begin{array}{l}\text { Tipo de } \\
\text { planta }\end{array}$ \\
\hline \multirow{3}{*}{$\begin{array}{l}\text { Recuperación de } \\
\text { materiales } \\
\text { (clasificación y } \\
\text { separación) }\end{array}$} & $\begin{array}{l}\text { Separación por } \\
\text { inducción }\end{array}$ & $\begin{array}{l}\text { Corrientes de } \\
\text { Foucault }\end{array}$ & $\begin{array}{c}\text { Equipo que genera un campo } \\
\text { magnético alternativo y unas } \\
\text { corrientes de inducción que repelen } \\
\text { los metales no férricos } \\
\text { (principalmente aluminio). }\end{array}$ & $\begin{array}{l}\text { AUT/ } \\
\text { MANU }\end{array}$ \\
\hline & Separación óptica & Separadores ópticos & $\begin{array}{l}\text { Utilizados habitualmente para la } \\
\text { separación de los diferentes tipos de } \\
\text { plásticos y brik. Mediante sensores } \\
\text { ópticos son capaces de detectar los } \\
\text { diferentes tipos de materiales. Un } \\
\text { bloque de electroválvulas sopla el } \\
\text { material a separar, impulsándolo } \\
\text { fuera de la corriente de residuos. } \\
\text { Pueden ser de una o doble válvula y } \\
\text { normalmente utilizan radiación } \\
\text { infrarroja. }\end{array}$ & AUTO \\
\hline & $\begin{array}{l}\text { Triaje secundario o } \\
\text { separación manual }\end{array}$ & $\begin{array}{l}\text { Cintas } \\
\text { transportadoras y } \\
\text { tolvas }\end{array}$ & $\begin{array}{l}\text { Selección manual de los diferentes } \\
\text { materiales reciclables. Una serie de } \\
\text { operarios clasifican los diferentes } \\
\text { materiales depositándolos en tolvas. }\end{array}$ & MANU \\
\hline \multirow{3}{*}{$\begin{array}{l}\text { Control de } \\
\text { calidad y } \\
\text { adecuación de } \\
\text { los materiales } \\
\text { reciclables }\end{array}$} & Control de calidad & $\begin{array}{l}\text { Cintas } \\
\text { transportadoras y } \\
\text { tolvas }\end{array}$ & $\begin{array}{c}\text { Corrección de errores en la } \\
\text { separación automática por unos } \\
\text { pocos operarios. }\end{array}$ & AUT \\
\hline & $\begin{array}{l}\text { Almacenamiento } \\
\text { temporal }\end{array}$ & $\begin{array}{l}\text { Silos de } \\
\text { almacenamiento de } \\
\text { los materiales } \\
\text { recuperados }\end{array}$ & $\begin{array}{l}\text { Almacenaje intermedio de los } \\
\text { materiales separados. }\end{array}$ & $\begin{array}{l}\text { AUT/ } \\
\text { MANU }\end{array}$ \\
\hline & Prensado & $\begin{array}{c}\text { Prensas } \\
\text { compactadoras }\end{array}$ & $\begin{array}{c}\text { Prensado de los materiales } \\
\text { separados en balas para su } \\
\text { almacenamiento final y transporte. }\end{array}$ & $\begin{array}{l}\text { AUT/ } \\
\text { MANU }\end{array}$ \\
\hline \multirow{6}{*}{ Etapa biológica } & \multirow{3}{*}{$\begin{array}{l}\text { Volteo de la } \\
\text { fracción orgánica }\end{array}$} & Palas cargadoras & $\begin{array}{l}\text { Maquinaria pesada que recoge y } \\
\text { suelta el material, es necesario } \\
\text { reconstruir de nuevo la pila de } \\
\text { compostaje al finalizar. }\end{array}$ & $\begin{array}{l}\text { AUT/ } \\
\text { MANU }\end{array}$ \\
\hline & & Volteadora móvil & $\begin{array}{l}\text { Máquina específica para el volteo de } \\
\text { pilas de compostaje. Consisten en } \\
\text { unos grandes tornillos sinfín que } \\
\text { giran volteando el material. Además, } \\
\text { existen sistemas que se pueden } \\
\text { acoplar a maquinaria agrícola y que } \\
\text { rotan o trasiegan las pilas. }\end{array}$ & $\begin{array}{l}\text { AUT/ } \\
\text { MANU }\end{array}$ \\
\hline & & $\begin{array}{l}\text { Tronillo sinfín sobre } \\
\text { puente grúa }\end{array}$ & $\begin{array}{l}\text { Volteo automático del material } \\
\text { mediante uno o varios tornillos } \\
\text { sinfín. Utilizado normalmente en el } \\
\text { compostaje en reactores abiertos. }\end{array}$ & $\begin{array}{l}\text { AUT/ } \\
\text { MANU }\end{array}$ \\
\hline & Afino primario & Trómel & $\begin{array}{l}\text { Limpieza del material mediante criba } \\
\text { rotatoria. Separación por tamaños. }\end{array}$ & $\begin{array}{l}\text { AUT/ } \\
\text { MANU }\end{array}$ \\
\hline & \multirow[b]{2}{*}{ Afino secundario } & Trómel & $\begin{array}{l}\text { Limpieza del material mediante criba } \\
\text { rotatoria. Separación por tamaños. }\end{array}$ & $\begin{array}{l}\text { AUT/ } \\
\text { MANU }\end{array}$ \\
\hline & & Mesa densimetría & $\begin{array}{l}\text { Limpieza del material en función de } \\
\text { la densidad de las partículas. } \\
\text { Separación ligeros (fracción orgánica) } \\
\text { de pesados (impurezas). }\end{array}$ & $\begin{array}{l}\text { AUT/ } \\
\text { MANU }\end{array}$ \\
\hline
\end{tabular}




\begin{tabular}{c|c|c|c|c|}
\hline $\begin{array}{c}\text { Subetapas } \\
\text { principales }\end{array}$ & Operación & $\begin{array}{c}\text { Equipo/tecnología } \\
\text { asociada }\end{array}$ & Características del proceso & $\begin{array}{c}\text { Tipo de } \\
\text { planta }\end{array}$ \\
\hline \multirow{2}{*}{$\begin{array}{c}\text { Gestión de } \\
\text { rechazo }\end{array}$} & Prensado & Prensa compactadora & $\begin{array}{c}\text { Prensado del rechazo en balas para } \\
\text { su traslado a vertedero. }\end{array}$ & $\begin{array}{c}\text { AUT/ } \\
\text { MANU }\end{array}$ \\
\cline { 2 - 5 } & $\begin{array}{c}\text { Almacenamiento } \\
\text { temporal }\end{array}$ & $\begin{array}{c}\text { Contenedor abierto o } \\
\text { autocompactador }\end{array}$ & $\begin{array}{c}\text { Almacenaje temporal del rechazo } \\
\text { para su posterior traslado a } \\
\text { vertedero o valorización energética. }\end{array}$ & $\begin{array}{c}\text { AUT/ } \\
\text { MANU }\end{array}$ \\
\hline
\end{tabular}

\subsubsection{Tecnologías y procesos del tratamiento biológico}

Como se ha visto en el estado del arte, las plantas de TMB pueden llevar a cabo el tratamiento biológico de los RSU de forma aerobia (compostaje) o anaerobia (biometanización). Las tecnologías y procesos utilizados en cada caso son diferentes, estas se exponen en la Tabla 3.2.

Tabla 3.2 Tipos de tratamiento biológicos en las plantas de TMB y tecnologías asociadas

\begin{tabular}{|c|c|c|c|c|}
\hline $\begin{array}{l}\text { Tipo de } \\
\text { tratamiento } \\
\text { biológico }\end{array}$ & Subcategoría & $\begin{array}{c}\text { Sistema/tecnología } \\
\text { asociada }\end{array}$ & Descripción & $\begin{array}{l}\text { Tipo de } \\
\text { planta }\end{array}$ \\
\hline Aerobio & Compostaje & $\begin{array}{l}\text { Pilas o hileras de } \\
\text { fermentación }\end{array}$ & $\begin{array}{l}\text { Pilas o hileras de sección triangular o } \\
\text { trapezoidal construidas con la } \\
\text { fracción orgánica y aireadas por } \\
\text { volteo o ventilación forzada. Puede } \\
\text { darse en nave cerrada, abierta o a la } \\
\text { intemperie. }\end{array}$ & $\mathrm{NA} / \mathrm{NC}$ \\
\hline \multirow{5}{*}{ Aerobio } & \multirow{5}{*}{ Compostaje } & $\begin{array}{l}\text { Reactor abierto en } \\
\text { nave cerrada }\end{array}$ & $\begin{array}{l}\text { Cubas-reactores abiertos que son } \\
\text { cargados automáticamente por un } \\
\text { tripper. La fracción orgánica forma } \\
\text { una meseta que se va volteando } \\
\text { automáticamente mediante tornillo } \\
\text { sinfín sobre un puente grúa, este va } \\
\text { desplazando el material hacia la } \\
\text { salida. Siempre se dan en nave } \\
\text { cerrada. }\end{array}$ & NC \\
\hline & & Canales & $\begin{array}{l}\text { Canales descubiertos en nave } \\
\text { cerrada. Por un extremo se } \\
\text { introduce la fracción orgánica, sobre } \\
\text { las paredes de los canales circula } \\
\text { una maquina volteadora que } \\
\text { homogeneiza y traslada el material } \\
\text { hacia la salida. }\end{array}$ & NC \\
\hline & & Túneles & $\begin{array}{l}\text { Reactores o compartimentos } \\
\text { cerrados y largos, pueden operar } \\
\text { con flujo continuo o discontinuo, } \\
\text { algunos poseen volteo mecánico. }\end{array}$ & $\mathrm{T}$ \\
\hline & & $\begin{array}{l}\text { Reactor cilíndrico } \\
\text { horizontal rotatorio }\end{array}$ & $\begin{array}{l}\text { Cilindro horizontal que gira respecto } \\
\text { al eje horizontal homogeneizando el } \\
\text { material. Pueden operar en flujo } \\
\text { continuo o discontinuo. } \\
\text { Periódicamente se introduce } \\
\text { material nuevo por un extremo y se } \\
\text { descarga simultáneamente por el } \\
\text { otro. }\end{array}$ & $\mathrm{T}$ \\
\hline & & Pilas de maduración & $\begin{array}{c}\text { Pilas o hileras de material } \\
\text { fermentado, normalmente sin volteo } \\
\text { ni aireación. }\end{array}$ & $\mathrm{NA} / \mathrm{NC} / \mathrm{T}$ \\
\hline
\end{tabular}




\begin{tabular}{|c|c|c|c|c|}
\hline $\begin{array}{c}\text { Tipo de } \\
\text { tratamiento } \\
\text { biológico }\end{array}$ & Subcategoría & $\begin{array}{c}\text { Sistema/tecnología } \\
\text { asociada }\end{array}$ & Descripción & $\begin{array}{l}\text { Tipo de } \\
\text { planta }\end{array}$ \\
\hline Aerobio & Biosecado & Reactor de biosecado & $\begin{array}{l}\text { Cuba-reactor abierto en nave } \\
\text { cerrada. El reactor se carga con los } \\
\text { RSU en bruto, tal cual llegan a la } \\
\text { planta. El calor liberado en la } \\
\text { descomposición, junto con la } \\
\text { aireación controlada, es usado para } \\
\text { su secado y estabilización. } \\
\text { Normalmente sin volteo. }\end{array}$ & NC \\
\hline \multirow[t]{2}{*}{ Anaerobio } & \multirow[t]{2}{*}{$\begin{array}{c}\text { Digestión o } \\
\text { biometanización }\end{array}$} & $\begin{array}{l}\text { Reactor de mezcla } \\
\text { completa sin } \\
\text { recirculación }\end{array}$ & $\begin{array}{l}\text { Reactor donde se mantiene una } \\
\text { distribución uniforme de } \\
\text { concentraciones mediante agitación } \\
\text { mecánica o neumática. El tiempo de } \\
\text { retención es elevado. Opera en flujo } \\
\text { discontinuo, dejando siempre parte } \\
\text { del digestato para inocuo de la } \\
\text { nueva carga. }\end{array}$ & $\mathrm{NA} / \mathrm{NC} / \mathrm{T}$ \\
\hline & & $\begin{array}{l}\text { Reactor de mezcla } \\
\text { completa con } \\
\text { recirculación }\end{array}$ & $\begin{array}{l}\text { La recirculación de los } \\
\text { microorganismos permite tener } \\
\text { tiempos de retención más bajos y } \\
\text { trabajar en flujo continuo. Para ello } \\
\text { es necesario un sistema de } \\
\text { desgasificación y decantación. }\end{array}$ & $\mathrm{NA} / \mathrm{NC} / \mathrm{T}$ \\
\hline
\end{tabular}

Cabe destacar que, en las instalaciones donde la fracción orgánica de los residuos es destinada a biometanización, tras este proceso se obtienen dos subproductos: un biogás que puede ser utilizado como combustible alternativo, y unos fangos o digestato. Este digestato normalmente es mezclado con astillas de madera o residuos de poda para su compostaje, utilizando los mismos sistemas que en las plantas donde se realiza el compostaje de la fracción orgánica en crudo (Tabla 3.2). Tras esta última etapa de tratamiento biológico y el afino del material se obtiene el bioestabilizado o compost.

En la presente tesis no se van a contemplar los distintos reactores para el tratamiento anaerobio a la hora de clasificar las plantas de TMB en función de los procesos biológicos. Esto se debe a que en el tratamiento anaerobio no se produce ninguna corriente de rechazo y, por tanto, el sistema utilizado no influye en la generación y características de este material. Así pues, solo se va a considerar los sistemas o tecnologías utilizados en la etapa aerobia (compostaje o biosecado). En base a estos las plantas de TMB se pueden clasificar en tres tipos:

- Compostaje en nave abierta (NA): en estas plantas el proceso de compostaje se lleva a cabo en una nave abierta, es decir sin cerramientos laterales. A través de maquinaria pesada se forman pilas de sección trapezoidal con la fracción orgánica. Las pilas son volteadas periódicamente exponiendo el material al oxígeno atmosférico con el objetivo de homogeneizar su temperatura, controlar su humedad, aumentar la porosidad de la pila, mejorar su ventilación y evitar la creación de zonas anaeróbicas. El volteo se realiza con palas cargadoras o volteadora móvil conducida por un operario (Tabla 3.1). El proceso de compostaje no cuenta con sistemas para la captación y depuración de olores.

- Compostaje en nave cerrada (NC): en este caso el proceso se realiza en el interior de una nave completamente cerrada. Las tecnologías utilizadas pueden ser muy variadas: pilas, reactor abierto, canales, reactor de biosecado (Tabla 3.2). El material suele airearse mediante aireación forzada a través de unos ventiladores que captan el aire de la nave y hacen pasar una parte del mismo por el material a compostar. La otra parte es conducida al sistema de depuración de olores, habitualmente un biofiltro. Normalmente el volteo se lleva a cabo con un tornillo sinfín o con una maquina volteadora si se trata de canales o pilas. 
- Compostaje en túneles (T): el proceso se desarrolla en una serie de túneles o reactores, estos son construcciones realizadas generalmente en hormigón y de planta rectangular. En ellos se introduce la fracción orgánica y se realiza un control total de los parámetros del proceso (temperatura, humedad y aireación), pudiendo ser estáticos o dinámicos. En los estáticos no existe un volteo del material, el proceso ocurre en un reactor cerrado. En los dinámicos existe un volteo periódico, este se realiza mediante la entrada de una volteadora móvil o mediante la rotación del túnel (reactor cilíndrico rotatorio) (Tabla 3.2). Ambos tipos presentan un sistema de ventilación forzada y de recogida de lixiviados, los cuales se utilizan para controlar la humedad. El aire extraído de los túneles es tratado en un sistema de depuración de olores mediante un biofiltro.

\subsubsection{Resumen de la clasificación de las plantas de TMB}

Tras estudiar todas las características que permiten diferenciar las plantas de TMB, se ha realizado una clasificación general de las mismas que englobe todos los tipos identificados.

Las plantas de TMB de RSU mezclados se pueden clasificar en cuatro categorías principales:

- $\quad$ Plantas de triaje (PT)

- $\quad$ Plantas de recuperación y compostaje (PRC)

- $\quad$ Plantas de biosecado y recuperación (PBSR)

- $\quad$ Plantas de recuperación, biometanización y compostaje (PRBC)

Dentro de estas categorías principales existen diferentes alternativas de tratamiento en función de cómo se realicen los procesos mecánicos y biológicos, las cuales se muestran en la Figura 3.2. Así pues, teniendo en cuenta todas las alternativas posibles, las plantas de TMB de RSU mezclados se pueden clasificar en 16 tipos distintos.

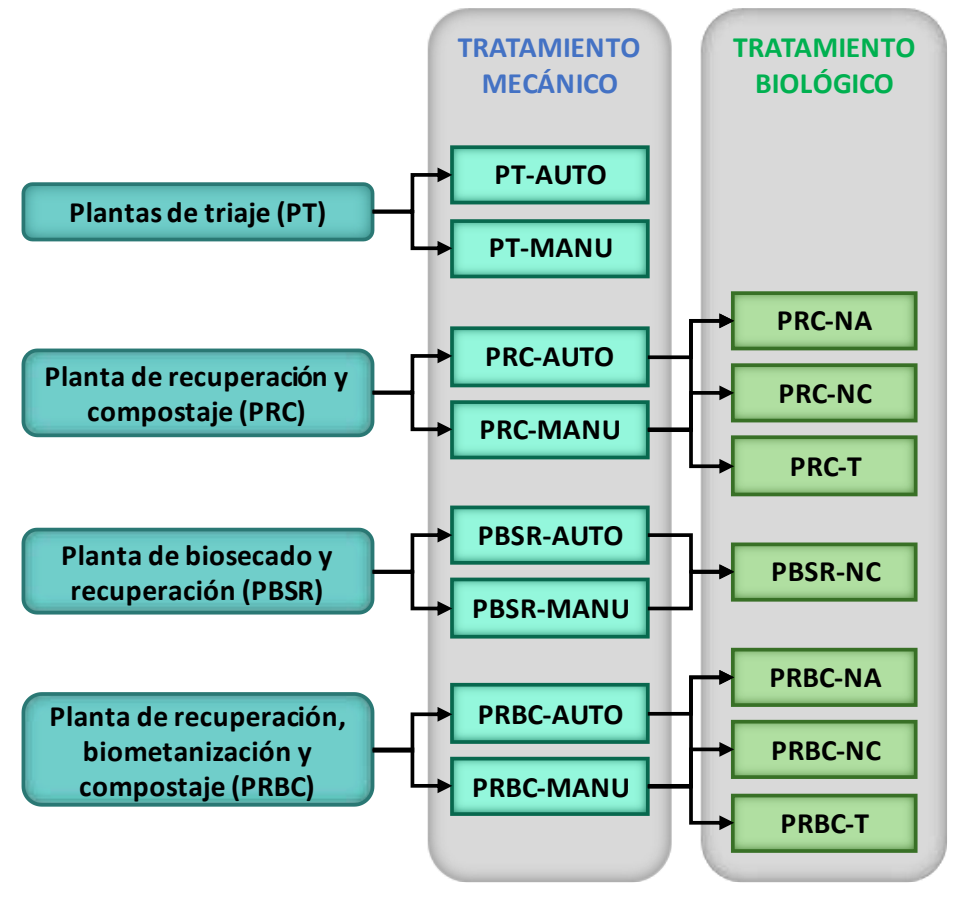

Figura 3.2 Alternativas de TMB de RSU mezclados

Respecto a las plantas de TMB de la FORS, estas se pueden clasificar en dos categorías principales:

- $\quad$ Plantas de compostaje de la FORS (PCFO)

- $\quad$ Plantas de biometanización y compostaje de la FORS (PBCFO) 
Estas plantas pueden utilizar diferentes alternativas para el tratamiento biológico de los biorresiduos, las cuales se muestran en la Figura 3.3. Teniendo en cuenta todas las alternativas se obtienen 6 tipos distintos.

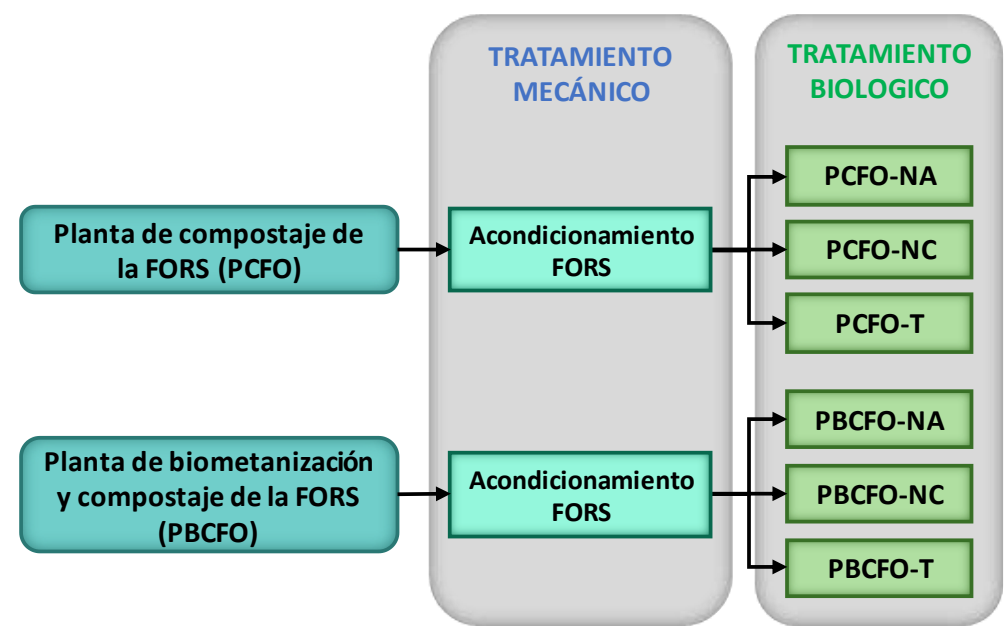

Figura 3.3 Alternativas de TMB de FORS

\subsection{MODELIZACIÓN E IDENTIFICACIÓN DE LAS CORRIENTES DE RECHAZO}

En el presente apartado se va a modelizar los diferentes tipos de plantas de TMB y las alternativas de tratamiento identificadas en el punto anterior. Un modelo simplifica y resume todos los procesos que se llevan a cabo en un conjunto de relaciones físicas y matemáticas que, debidamente formuladas, permiten representar adecuadamente el sistema (Gallardo, 2000). En este caso se van a elaborar varios modelos conceptuales que permitirán identificar las múltiples corrientes de rechazo generadas en una planta TMB.

\subsubsection{Modelización de los principales tipos de plantas de TMB}

En primer lugar, se ha realizado un modelo para las seis categorías principales de plantas TMB, en ellos se indican las subetapas de tratamiento existentes y los principales flujos de entrada y salida de materiales (subproductos y rechazos).

\section{Plantas de triaje:}

Las PT están formadas por una única etapa mecánica como se ve en la Figura 3.4, que se divide en tres subetapas:

- Pretratameinto de los residuos entrantes

- Recuperación de los materiales reciclables

- Control de calidad y adecuación de los materiales recuperados para su entrega a empresas recicladoras

En ellas se trata la fracción no biodegradable de los RSU mezclados, como resultado se obtienen los siguientes flujos de salida:

- Voluminosos

- Materiales recuperados

- Rechazo de recuperación

- Rechazo fino 


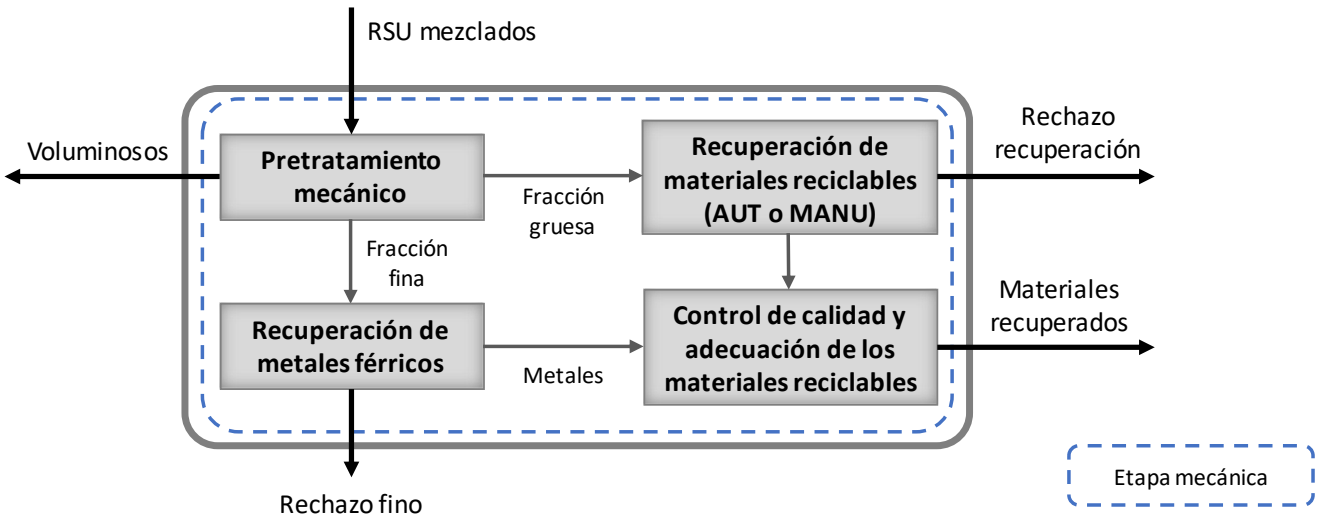

Figura 3.4 Modelo del TMB en las plantas de triaje

\section{Plantas de recuperación y compostaje}

Las PRC están compuestas por una etapa mecánica y otra biológica (Figura 3.5). La etapa mecánica se divide en tres subetapas:

- Pretratamiento de los residuos entrantes

- Recuperación de los materiales reciclables

- Control de calidad y adecuación de los materiales recuperados

La etapa biológica está formada por dos subetapas:

- Compostaje de la fracción orgánica

- Afino del material bioestabilizado

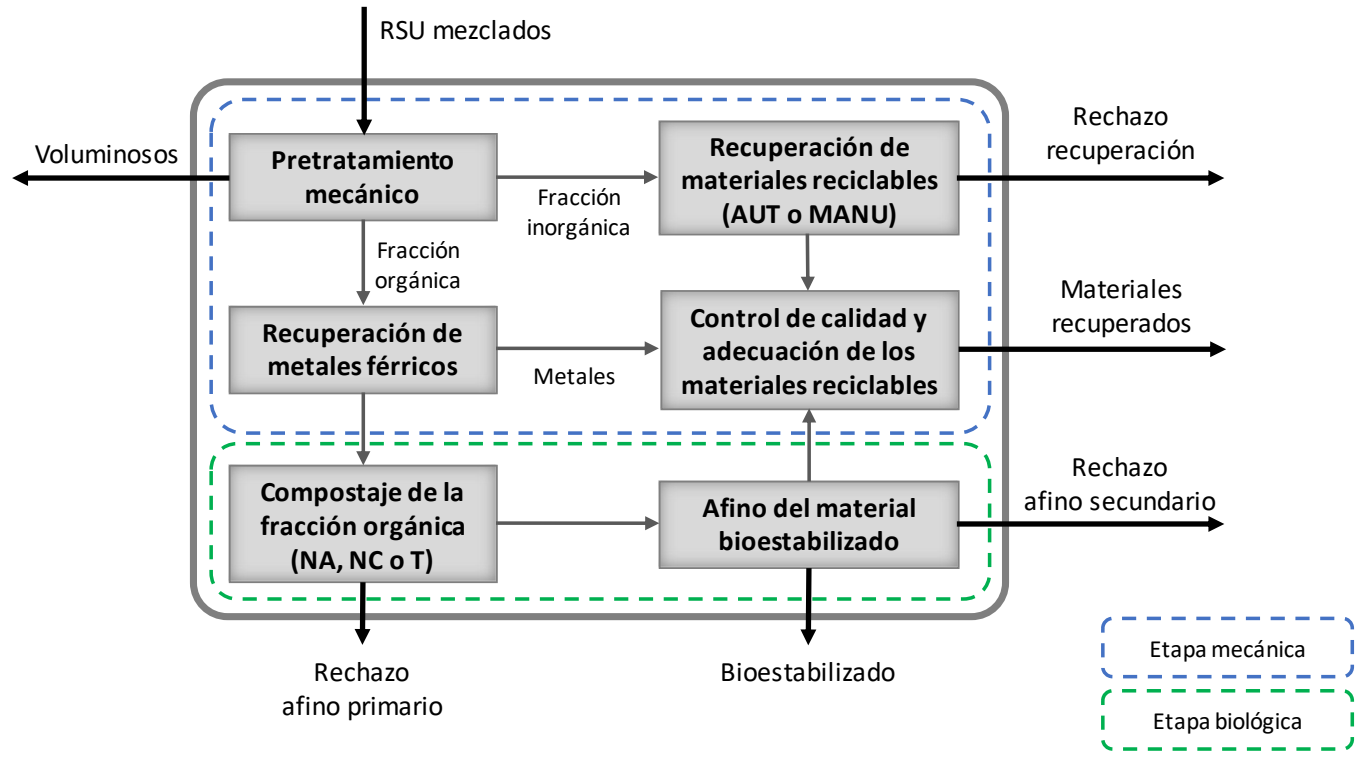

Figura 3.5 Modelo del TMB en las plantas de recuperación y compostaje 
A estas instalaciones llegan los RSU mezclados y tras el tratamiento se obtienen los siguientes flujos de salida:

- Voluminosos

- Materiales recuperados

- Bioestabilizado

- Rechazo de recuperación

- $\quad$ Rechazo de afino primario del bioestabilizado

- Rechazo de afino secundario del bioestabilizado

\section{Plantas de biosecado y recuperación}

En las PBSR se lleva a cabo un tratamiento más complejo que en las anteriores (Figura 3.6), puesto que se van intercalando subetapas mecánicas y biológicas. Los RSU mezclados son sometidos primeramente a un pretratamiento mecánico y, a continuación, se procede al biosecado de los mismos. Tras esta subetapa biológica se realiza a la clasificación mecánica de la fracción seca (fracción no biodegradable) de la húmeda (fracción orgánica). La primera se destina a la recuperación de los materiales y posterior acondicionamiento para su entrega a recicladores (subetapas mecánicas). La segunda pasa a la etapa de maduración del biosecado y posterior afino (subetapas biológicas).

Como resultado del proceso se obtienen los siguientes flujos de salida:

- Materiales recuperados

- Bioestabilizado

- Rechazo de recuperación

- Rechazo de afino primario del biosecado

- Rechazo de afino secundario del biosecado

Este tipo de plantas son muy poco comunes en España, existiendo tan solo una de ellas. Esta se localiza en la Comunidad Valenciana, en concreto en el Municipio de Cervera del Maestre al norte de la provincia de Castellón.

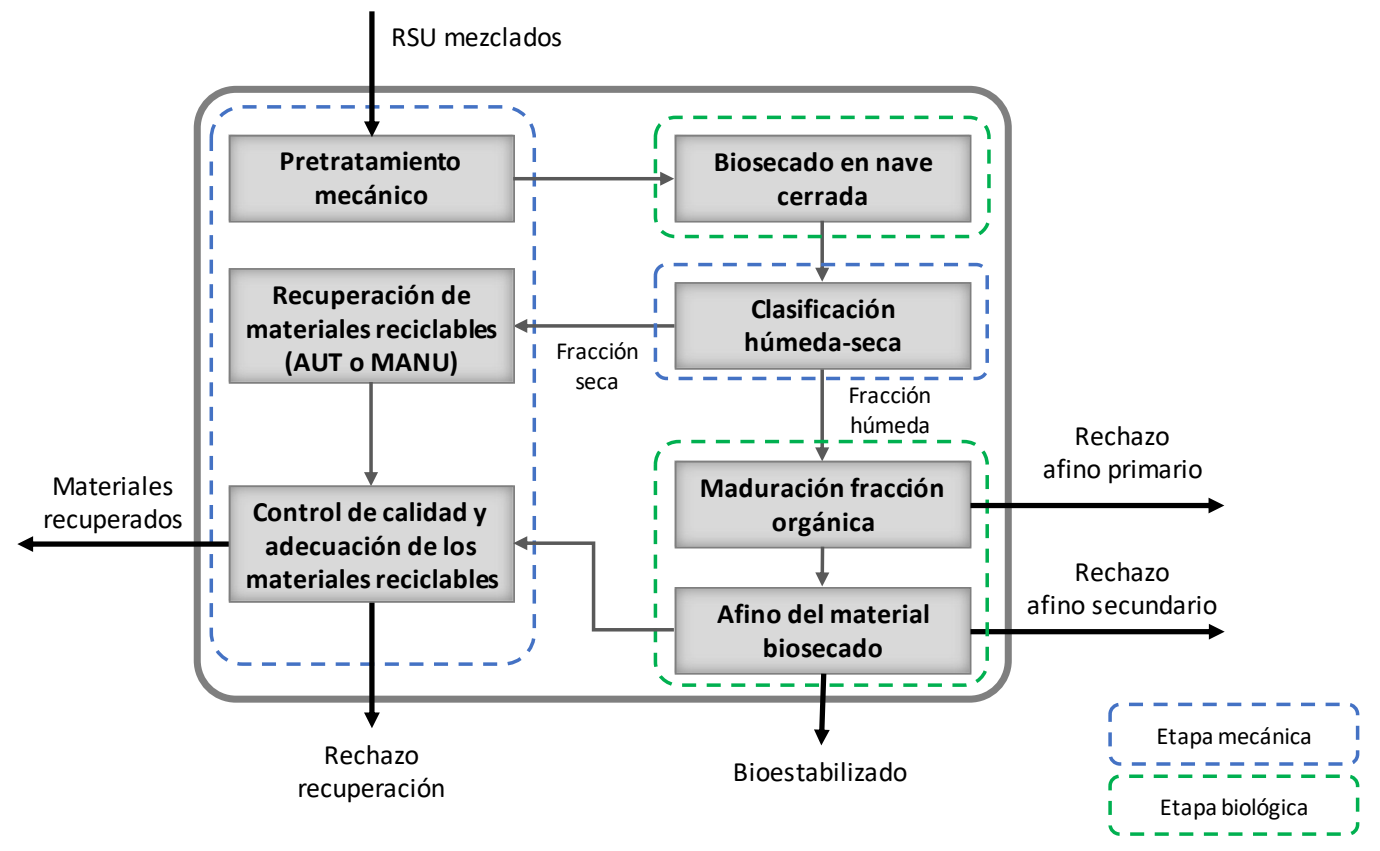

Figura 3.6 Modelo del TMB en las plantas de biosecado y recuperación 


\section{Plantas de recuperación, biometanización y compostaje:}

Las PRBC están compuestas por una etapa mecánica y una biológica. La etapa mecánica es igual a la llevada a cabo en las PT y en las PRC (Figura 3.7). Sin embargo, la etapa biológica está formada por tres subetapas:

- Biometanización de la fracción orgánica

- Compostaje del digestato mezclado con restos de poda

- $\quad$ Afino del material bioestabilizado

Los flujos obtenidos tras el tratamiento de los RSU mezclados son:

- Voluminosos

- Materiales recuperados

- Biogás

- Bioestabilizado

- Rechazo de recuperación

- Rechazo de afino primario del bioestabilizado

- Rechazo de afino secundario del bioestabilizado

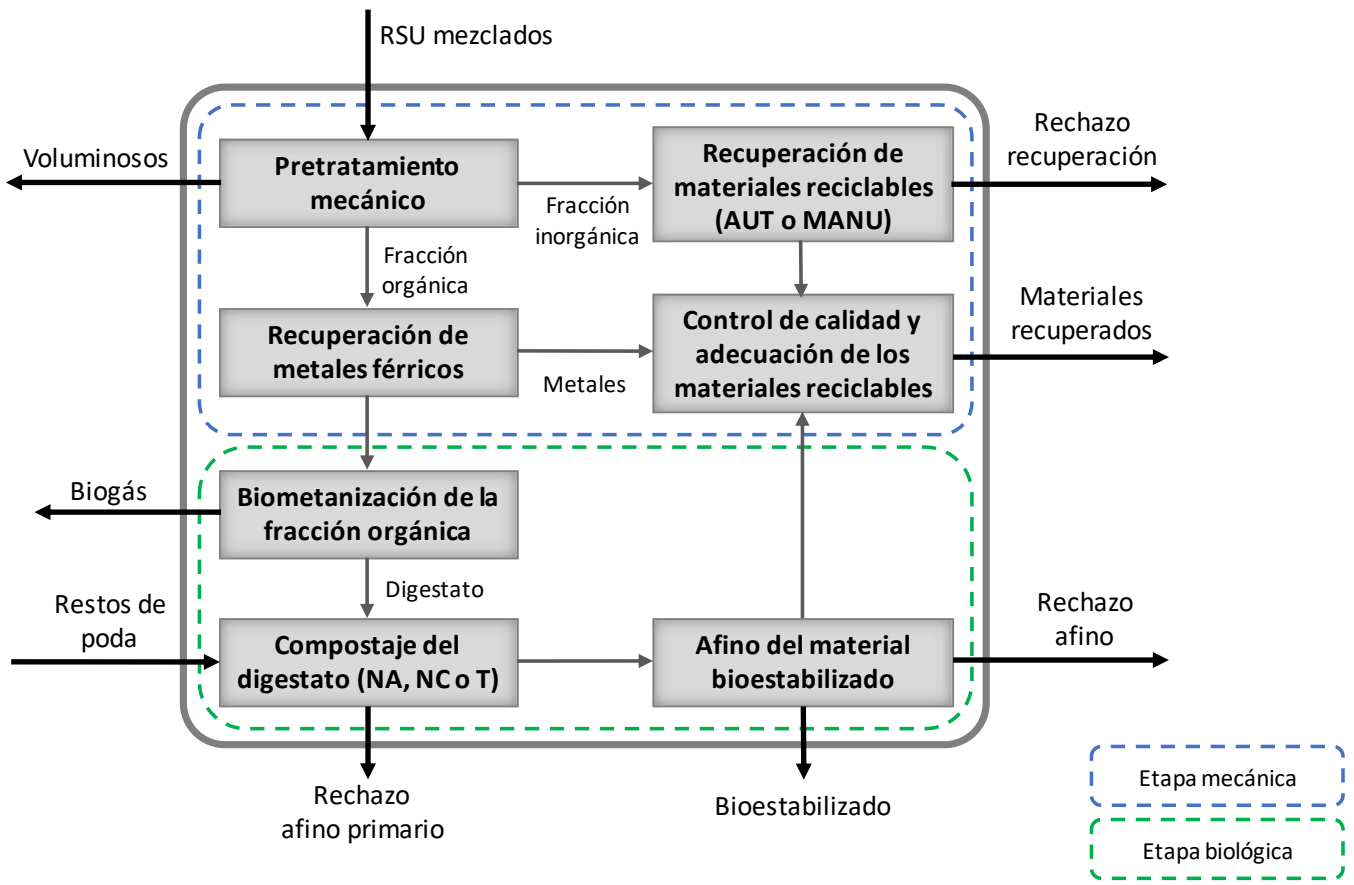

Figura 3.7 Modelo del TMB en las plantas de recuperación, biometanización y compostaje

\section{Plantas de compostaje de la FORS}

Las PCFO presentan una pequeña etapa mecánica inicial en la que se realiza el pretratamiento de la FORS con el objetivo de eliminar las impurezas y recuperar de los metales férricos que pueda contener (Figura 3.8). Esta consta de dos subetapas:

- $\quad$ Pretratameinto de la FORS

- $\quad$ Recuperación de los metales 
A continuación, la fracción orgánica pasa a la etapa biológica que se divide de dos subetapas:

- Compostaje de la FORS, junto con restos de poda

- $\quad$ Afino del compost

Como resultado del tratamiento se obtienen los siguientes flujos:

- Metales férricos

- Compost

- $\quad$ Rechazo de limpieza inicial

- $\quad$ Rechazo de afino del compost

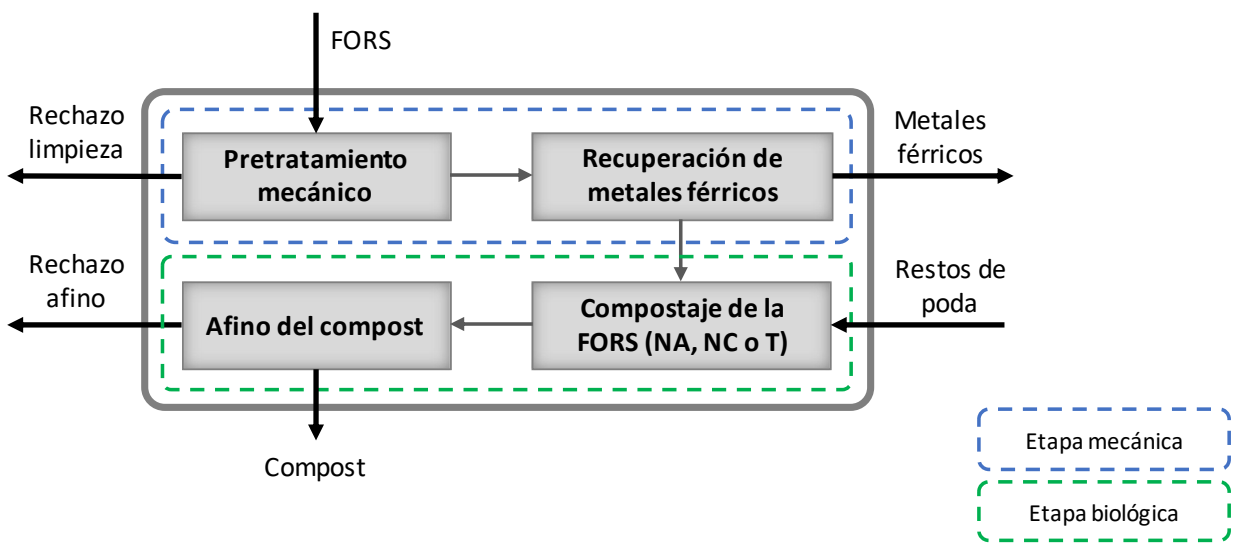

Figura 3.8 Modelo del TMB en plantas de compostaje de la FORS

\section{Plantas de biometanización y compostaje de la FORS}

El tratamiento en las PBCFO comienza de la misma forma que en las PCFO, con una pequeña etapa mecánica para el acondicionamiento de la de FORS y recuperación de metales (Figura 3.9). Seguidamente, la fracción orgánica pasa a la etapa biológica, formada por tres subetapas:

- Biometanización de la FORS

- Compostaje del digestato junto con restos de poda

- Afino del compost

Tras el proceso se obtienen los siguientes flujos:

- Metales férricos

- Biogás

- Compost

- Rechazo de limpieza inicial

- Rechazo de afino del compost 


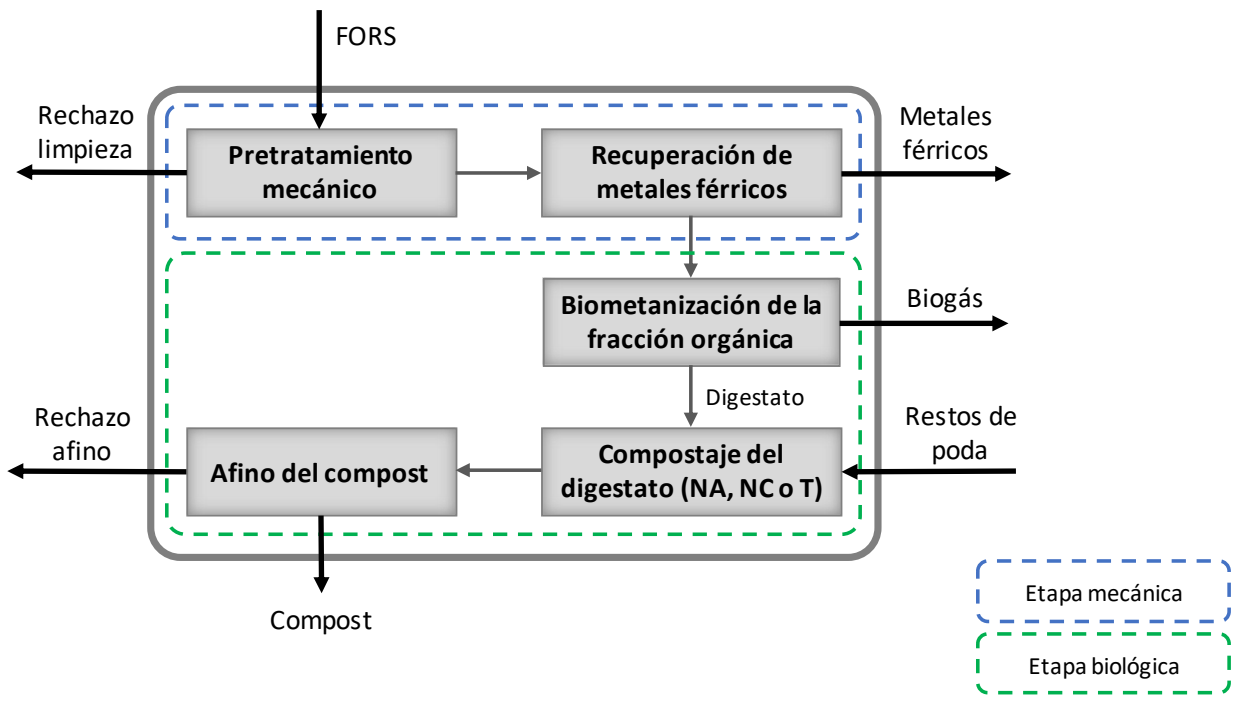

Figura 3.9 Modelo del TMB en las plantas de biometanización y compostaje de la FORS

\subsubsection{Modelización de la etapa mecánica y biológica}

En segundo lugar, se ha realizado un modelo más detallado de la etapa mecánica y biológica, así como de las diferentes alternativas de tratamiento. Mediante su combinación se obtienen los modelos de los 22 tipos de plantas de TMB (Figura 3.2 y Figura 3.3).

En estos modelos se indican las operaciones unitarias utilizadas en las diferentes subetapas, lo que permite conocer de manera más precisa el número de corrientes de rechazo generadas y el origen de las mismas. Cabe señalar que en el caso de las PBSR se ha desarrollado un modelo global de todo el proceso, ya que las subetapas de tratamiento para este tipo de planta son más específicas.

\subsubsection{Modelización de la etapa mecánica}

En el caso de la etapa mecánica, se ha diferenciado entre las plantas donde la subetapa de recuperación de materiales se lleva a cabo de forma manual (Figura 3.10) y las que la hacen de forma automática (Figura 3.11). Estos tipos de subetapas son los presentan las PT, las PRC y las PRBC.

Como se observa en los dos modelos, en estas instalaciones el pretratamiento de los RSU mezclados y la adecuación de los materiales reciclables se realiza de mismo modo, no obstante, la subetapa de recuperación es completamente diferente en función de cómo se lleve a cabo el proceso.

En las manuales la clasificación de los materiales se realiza principalmente en la cabina de triaje secundario. Allí una serie de operarios separan los diferentes tipos de plásticos (PET, PEAD, film, etc.), el papel/cartón y los briks, posteriormente mediante separadores magnéticos y de inducción se separan los metales (Figura 3.10). 


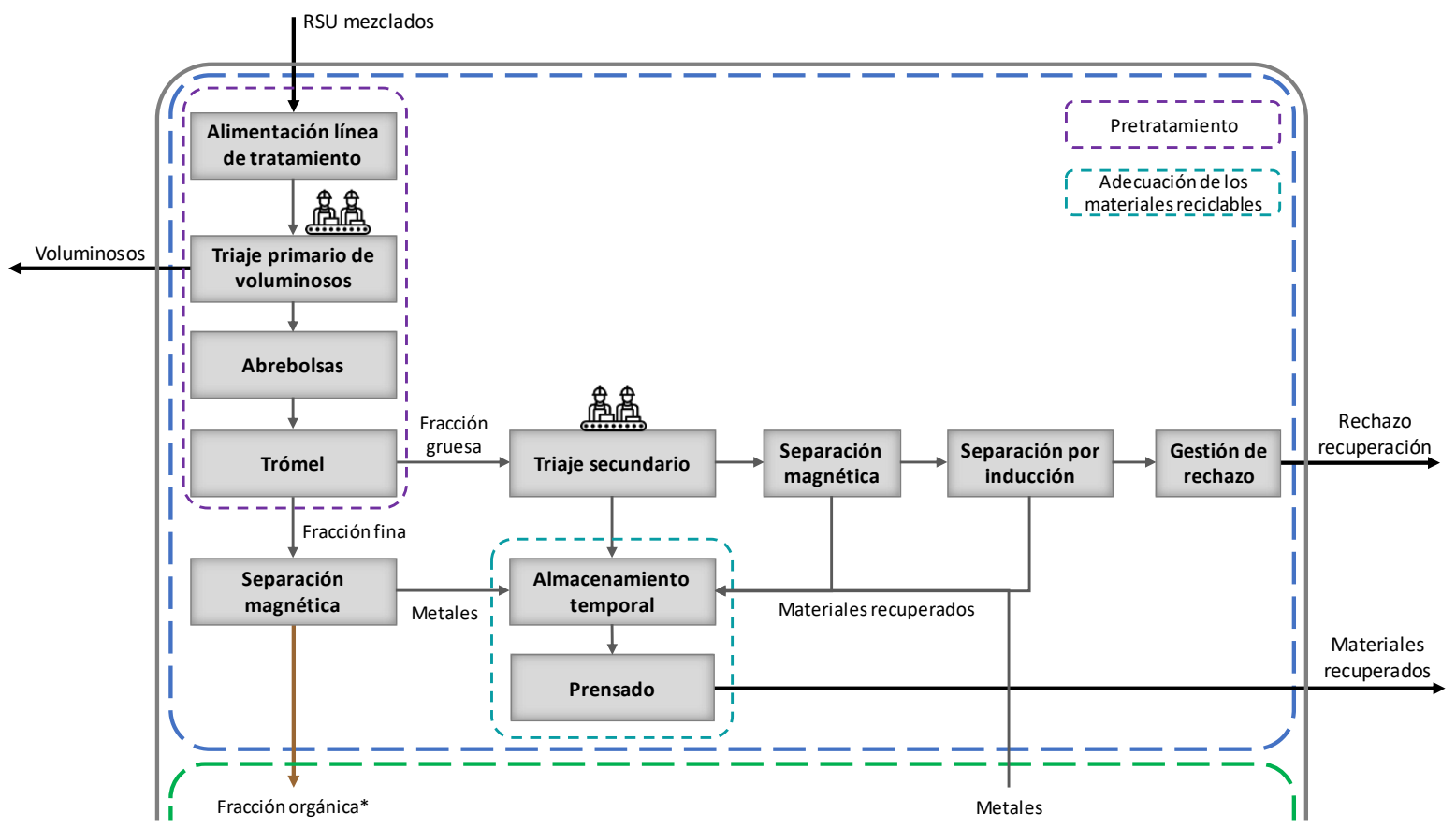

* En las PT esta corriente sería un rechazo

Figura 3.10 Modelo de la etapa mecánica de recuperación manual de materiales reciclables en las PT, PRC y PRBC

En cambio, en las automáticas este proceso está totalmente automatizado y es realizado mediante diferentes equipos como: separadores balísticos, neumáticos (film), magnéticos (metales férricos), de inducción (metales no férricos) y ópticos (PET, PEAD, briks, etc.). Finalmente unos operarios se encargan del control de calidad de los materiales recuperados (Figura 3.11).

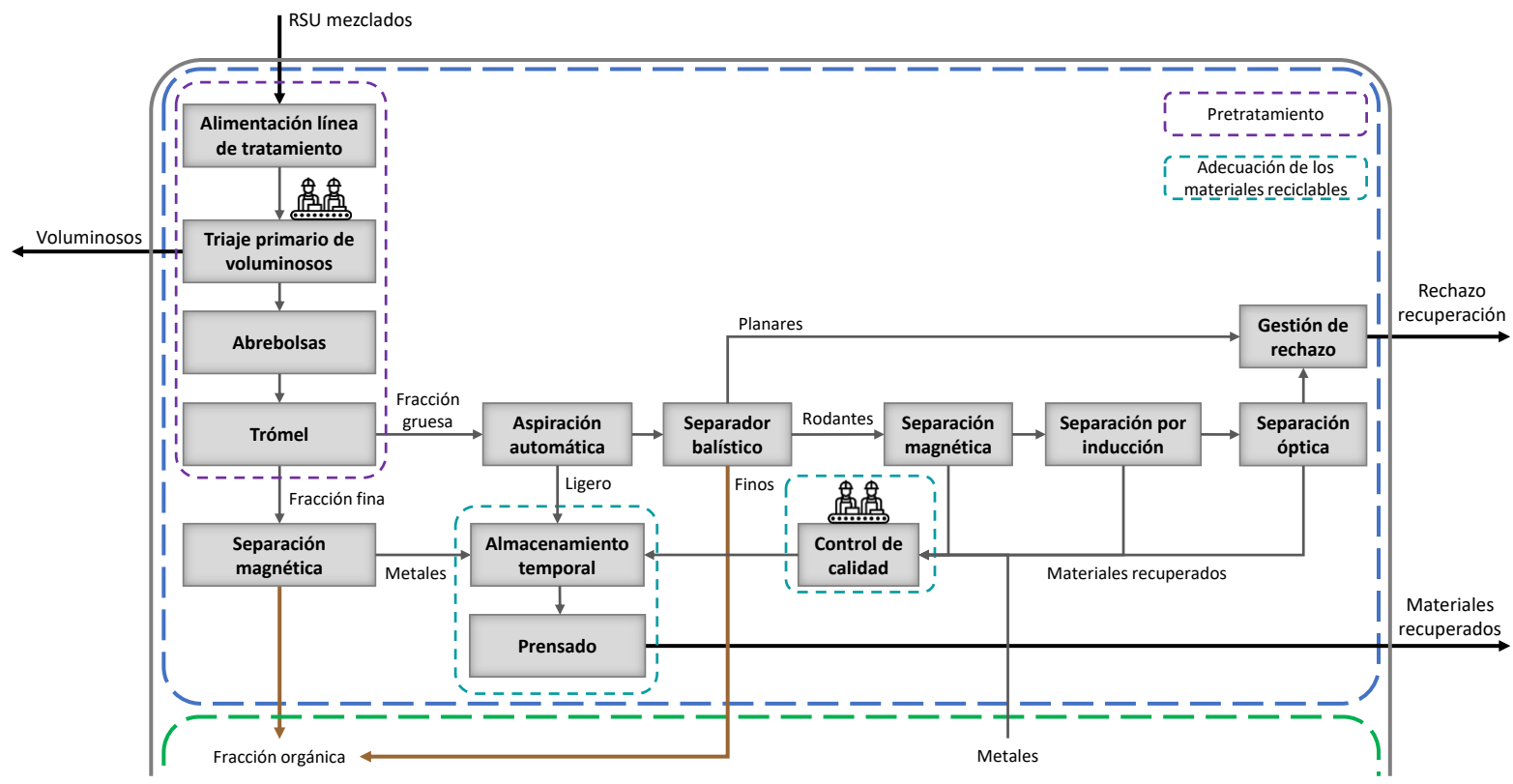

* En las PT esta corriente sería un rechazo

Figura 3.11 Modelo de la etapa mecánica de recuperación automática de materiales reciclables en las PT, PRC y PRBC.

En ambos modelos la fracción orgánica obtenida en el pretratamiento se destina a la etapa biológica tras la separación de los metales férricos que pueda contener; los materiales recuperados se presan para su 
entrega a empresas recicladoras, y se obtiene una corriente de rechazo (en el caso de las PT la fracción orgánica también se considera un rechazo).

Por otro lado, también se ha modelizado la etapa mecánica de acondicionamiento y limpieza de las FORS (Figura 3.12) que existe en las PCFO y las PBCFO. Esta etapa es mucho más sencilla que las anteriores, ya que el material entrante en mucho más homogéneo. Consiste en la eliminación de los impropios de forma manual en un triaje primario y la separación magnética de los metales férricos. La fracción orgánica se destina a la etapa biológica, los metales se envían a reciclaje y se obtiene una corriente de rechazo.

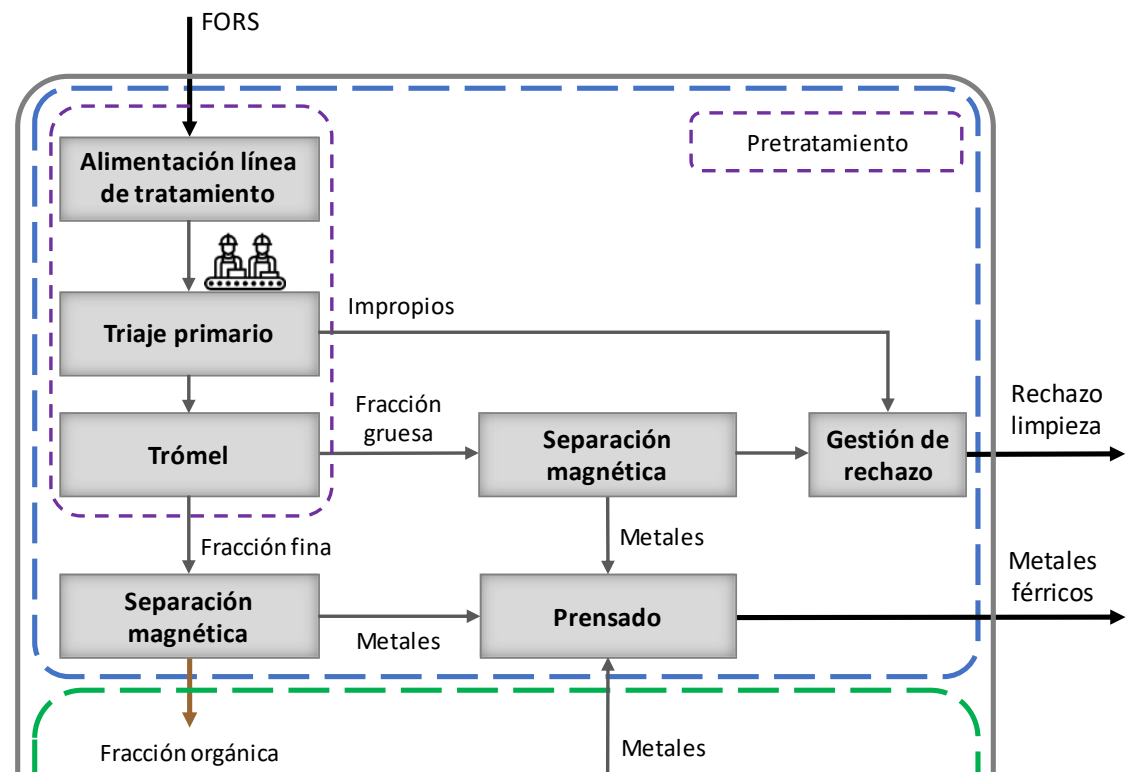

Figura 3.12 Modelo de la etapa mecánica de acondicionamiento de la FORS en las PCFO y las PBCFO.

\subsubsection{Modelización de la etapa biológica}

En el caso de la etapa biológica se ha diferenciado entre las instalaciones que el proceso consiste en una única subetapa del compostaje de la fracción orgánica y las que consisten en dos: la biometanización y posterior compostaje del digestato.

Las plantas donde la etapa biológica consiste en el compostaje de la fracción orgánica son las PRC y las PCFO, el modelo de este proceso se muestra en la Figura 3.13. Este comienza con la fermentación de la fracción orgánica mediante cualquiera de las tecnologías que se han visto en la Tabla 3.2 (nave abierta (NA), nave cerrada (NC), o túneles (T)). En el caso de las PCFO, antes de la fermentación, la FORS es mezclada con restos de poda para mejorar el proceso. Tras la fermentación el material sufre un proceso de afino primario, en el que mediante un trómel y separación magnética se eliminan las impurezas que pueda contener. Los metales son enviados a la subetapa mecánica de acondicionamiento de los materiales reciclables y las impurezas forman el rechazo de afino primario. El resto pasa al proceso de maduración en pilas donde se finaliza la estabilización de la materia orgánica. La última subetapa consiste en el afino secundario mediante un trómel o mesa densimétrica en el que se procede a la limpieza del material para obtener un producto final de mayor calidad: bioestabilizado/compost. Las impurezas eliminadas forman el rechazo del afino secundario. 


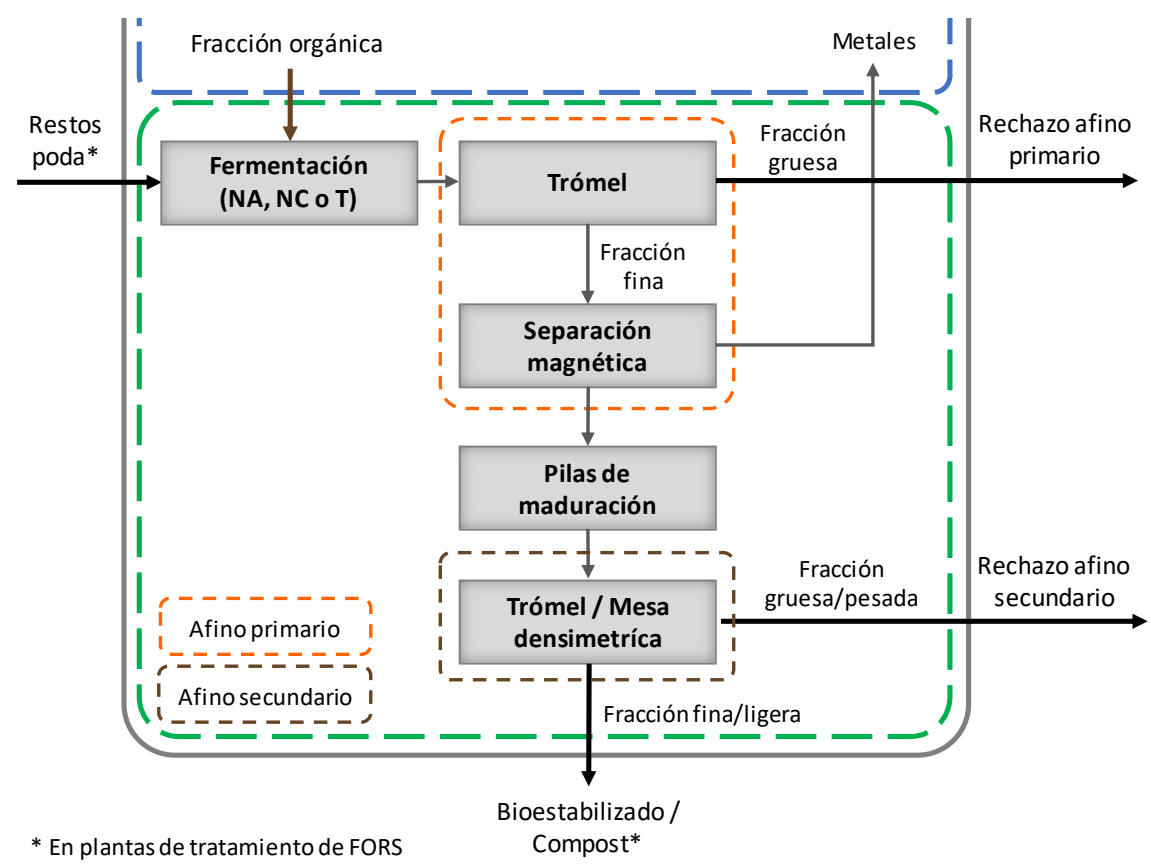

Figura 3.13 Modelo de la etapa biológica de compostaje en NA, NC o T en las PRC y las PCFO

Las plantas donde la etapa biológica consiste en una primera subetapa de biometanización y una segunda de compostaje del digestato son las PRBC y PBCFO, el modelo de este proceso puede verse en la Figura 3.14. En la subetapa de biometanización, la fracción orgánica es triturada y mezclada con agua. A continuación, esta suspensión se introduce en los digestores donde se lleva a cabo la digestión. Tras el proceso de biometanización se obtiene un biogás y un digestato. El compostaje del digestato conforma la segunda subetapa de la etapa biológica, en ella el digestato se mezcla con restos de poda y se procede a su fermentación. El proceso se puede realizar mediante cualquiera de las tecnologías de compostaje explicados en la Tabla 3.2 y es el mismo explicado en el párrafo anterior. En él se obtiene un flujo de bioestabilizado/compost; otro de metales que es enviado a la etapa de acondicionamiento de materiales reciclables, y dos corrientes de rechazo: una en el afino primario y otra en el secundario. 


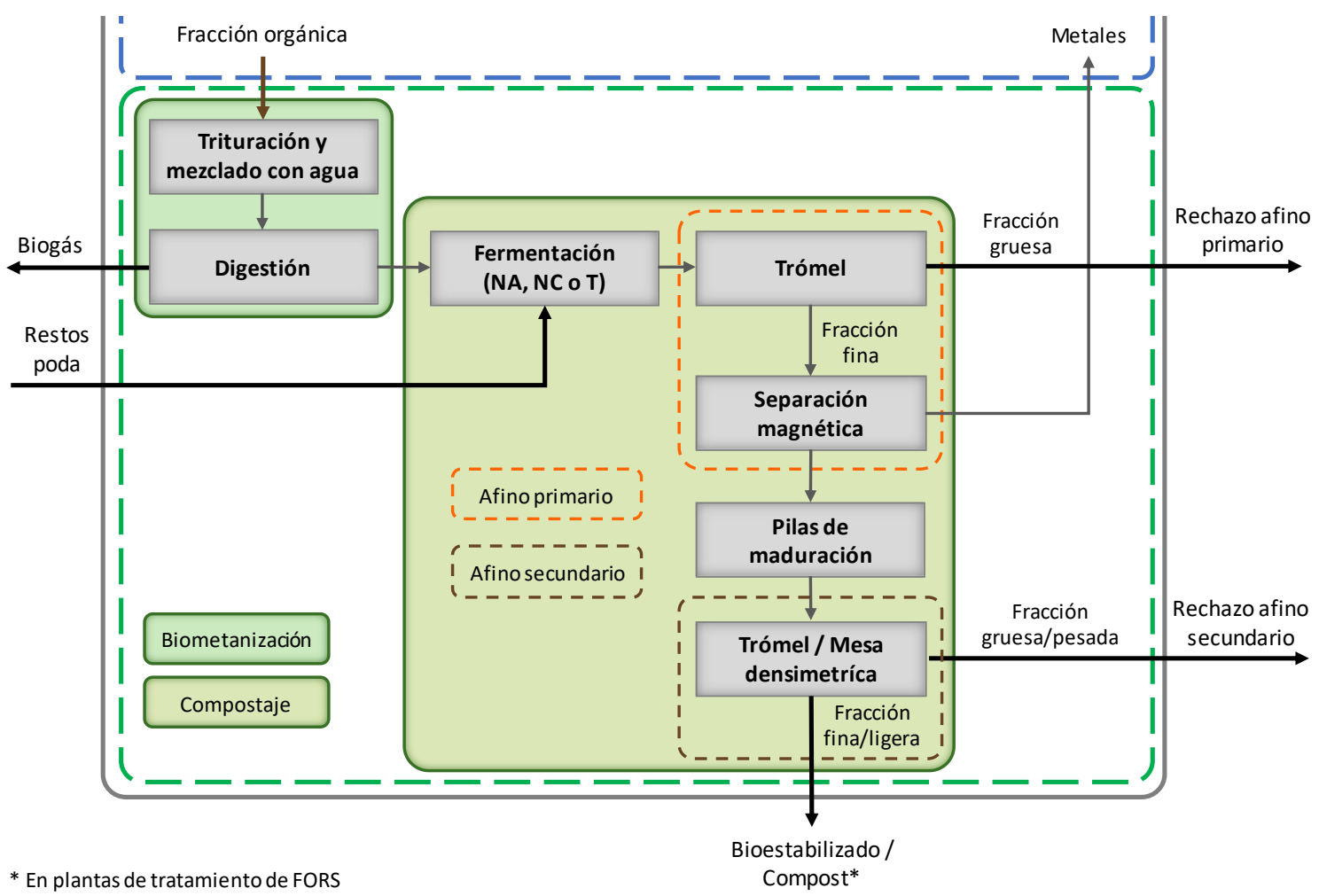

Figura 3.14 Modelo de la etapa biológica de biometanización y compostaje de las PRBC y las PBCFO

\subsubsection{Modelización de la planta de biosecado y recuperación}

Por último, se ha realizado un modelo detallado para las PBSR (Figura 3.15) ya que su proceso de tratamiento es más complejo, el cual se basa en el proceso llevado a cabo en la única planta de este tipo existente en España. El tratamiento comienza con una subetapa mecánica de pretratamiento, que consiste en un triturado y homogeneización de los RSU mezclados, seguidamente estos son introducidos en el reactor de biosecado en nave cerrada (subetapa biológica). Una vez finalizado el biosecado se procede a la separación mediante un trómel de la fracción húmeda de la seca.

La fracción húmeda, que corresponde principalmente a la materia orgánica, entra en la subetapa biológica de maduración tras la separación magnética de los metales que se destinan al acondicionamiento de los materiales reciclables. La subetapa de maduración comienza con el afino primario mediante trómel de la fracción húmeda del biosecado. Este afino tiene como objetivo de eliminar las impurezas que pueda contener, las cuales forman el rechazo de afino primario. El resto de material pasa al proceso de maduración en pilas donde se finaliza la estabilización de la materia orgánica. Posteriormente se realiza el afino secundario mediante trómel obteniéndose material bioestabilizado y una corriente de impurezas que forman el rechazo de afino secundario.

La fracción seca, formada principalmente por los materiales reciclables, es destinada a la subetapa mecánica de recuperación. Esta consiste en un triaje secundario donde unos operarios separan los diferentes tipos de plásticos (PET, PEAD, etc.), el papel/cartón y los briks. Posteriormente, mediante separadores magnéticos se separan los metales y mediante un separador óptico se separa el plástico film. Todos estos materiales se envían a la subetapa de adecuación de los mismos para entregarlos a empresas recicladoras. Finalmente se obtiene una corriente de rechazo de recuperación. 


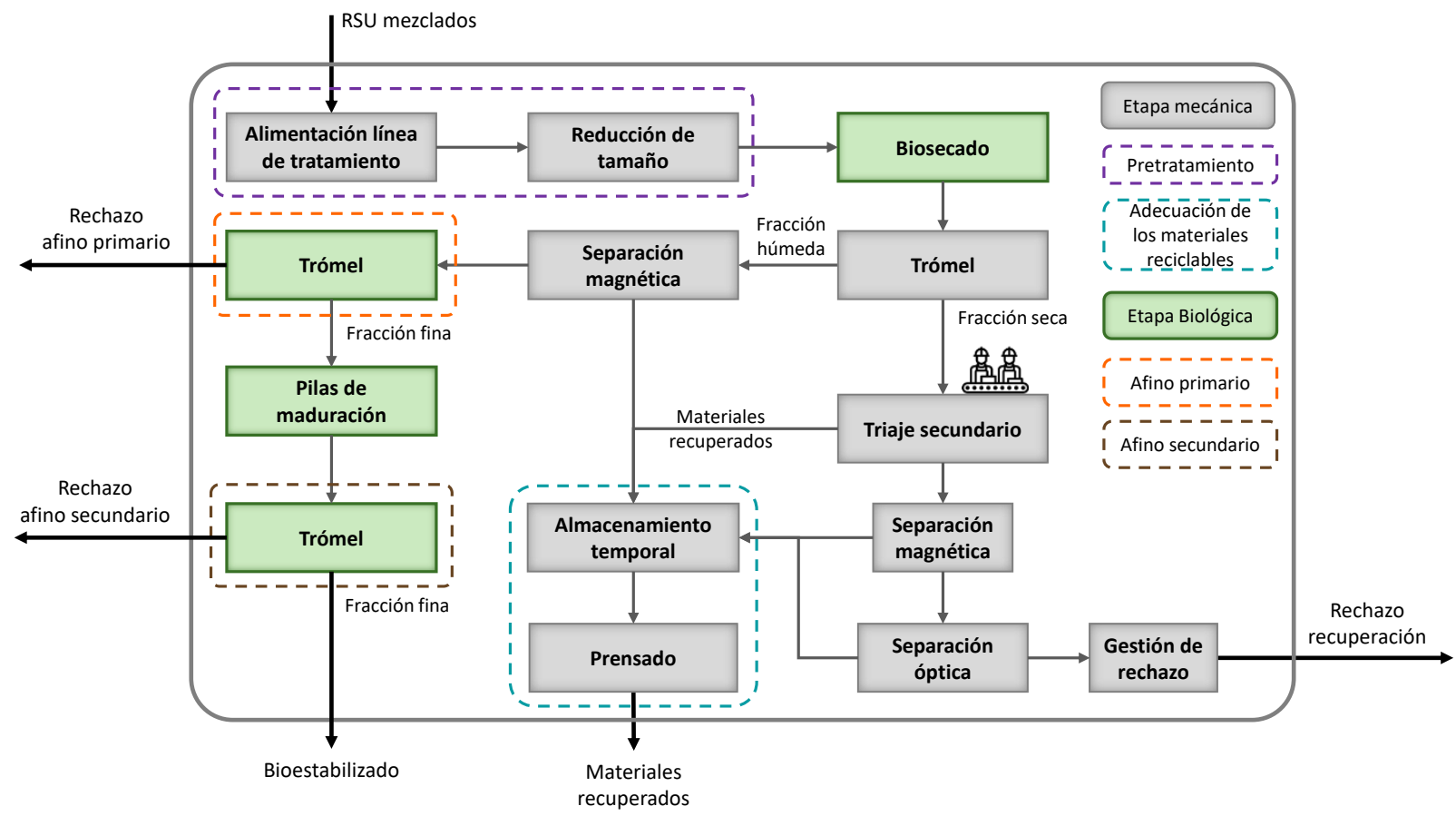

Figura 3.15 Modelo global del tratamiento en PBSR

\subsubsection{Identificación de las corrientes de rechazo}

El modelado de los seis tipos principales de plantas de TMB y de las diferentes alternativas de tratamiento que se dan en las mismas ha permitido, por un lado, conocer todas las operaciones unitarias que participan en el tratamiento de los residuos en este tipo de instalaciones y las interacciones existentes entre ellas. Por otro, identificar los diferentes flujos de entrada y salida de materiales, así como de las corrientes de rechazo que son susceptibles de ser transformadas en CSR y que son el objeto de estudio de la presente tesis.

En la Tabla 3.3 se muestra un resumen con la clasificación de las plantas de TMB, los tipos de residuos que tratan, las etapas mecánicas y biológicas que se dan en cada una de ellas y el número y origen de las corrientes de rechazo que se generan.

Tabla 3.3 Tipo de plantas de TMB, etapas mecánicas y biológicas que las forman, y corrientes de rechazo generadas

\begin{tabular}{|c|c|c|c|c|c|}
\hline \multirow[b]{2}{*}{ Tipo de RSU } & \multirow{2}{*}{$\begin{array}{l}\text { Tipo de } \\
\text { planta }\end{array}$} & \multirow{2}{*}{$\begin{array}{l}\text { Tipos de etapa } \\
\text { mecánica }\end{array}$} & \multirow{2}{*}{$\begin{array}{c}\text { Tipo de etapa } \\
\text { biológica }\end{array}$} & \multicolumn{2}{|c|}{ Núm. de corrientes de rechazo } \\
\hline & & & & $\begin{array}{c}\text { Etapa } \\
\text { mecánica }\end{array}$ & $\begin{array}{c}\text { Etapa } \\
\text { biológica }\end{array}$ \\
\hline \multirow{4}{*}{$\begin{array}{c}\text { RSU } \\
\text { mezclado }\end{array}$} & PT & MANU / AUTO & - & 2 & - \\
\hline & PRC & MANU / AUTO & $\mathrm{NA} / \mathrm{NC} / \mathrm{T}$ & 1 & 2 \\
\hline & PBSR & MANU / AUTO & NC & 1 & 2 \\
\hline & PRBC & MANU / AUTO & $\mathrm{NA} / \mathrm{NC} / \mathrm{T}$ & 1 & 2 \\
\hline \multirow{2}{*}{ FORS } & PCFO & MANU & $\mathrm{NA} / \mathrm{NC} / \mathrm{T}$ & 1 & 2 \\
\hline & PBCFO & MANU & $\mathrm{NA} / \mathrm{NC} / \mathrm{T}$ & 1 & 2 \\
\hline
\end{tabular}




\subsection{PLANTAS DE TMB EN ESPAÑA}

A finales del año 2018 España contaba con 137 plantas de TMB de RSU. En los siguientes apartados se exponen una serie de tablas donde se muestra: la distribución de estas instalaciones a nivel autonómico y provincial, los tipos de plantas existentes y el tipo de etapa mecánicas y biológica que en ellas se dan.

Esta información se ha obtenido tras realizar una extensa búsqueda, consulta y recopilación de datos e información en numerosas fuentes como: el Ministerio para la Transición Ecológica (MITECO), gobiernos autonómicos, consorcios de gestión de residuos, ayuntamientos, mancomunidades, diputaciones, consejos comarcales, empresas privadas, etc., así como en revistas científicas y revistas especializadas.

En el caso de la etapa mecánica, solo se ha distinguido entre automática (AUT) y manual (MANU) en las plantas que tratan RSU mezclados, puesto que en las plantas donde se trata FORS este proceso es más sencillo y siempre se lleva a cabo de forma manual.

\subsubsection{Plantas de TMB de Andalucía}

Andalucía cuenta con 22 plantas de TMB, de ellas 20 son PRC, una es una PT y otra una PCFO. A la PT llega la fracción seca de la recogida selectiva mediante el sistema húmedo-seco. Respecto al tipo de tratamiento mecánico para la recuperación de materiales de los RSU mezclados, como se muestra la Tabla 3.4, existe el mismo número de instalaciones que lo realizan de forma automática que manual. En cuanto al tratamiento biológico mediante compostaje, los procesos de nave abierta y nave cerrada son los más utilizados. A continuación, se muestra un listado con las instalaciones existentes en esta C.A., así como la provincia a la que pertenecen.

\section{Plantas de triaje:}

- Complejo medioambiental de Córdoba (Córdoba)

\section{Plantas de recuperación y compostaje:}

- Planta de recuperación y compostaje de Albox (Almería)

- Planta de clasificación y compostaje de Almería (Almería)

- $\quad$ Planta de recuperación y compostaje de Gador (Almería)

- Complejo medioambiental Sur de Europa, Los Barrios (Cádiz)

- Planta de reciclaje y compostaje Las Calandrinas, Jerez de la Frontera (Cádiz)

- $\quad$ Complejo medioambiental Miramundo, Medina Sidonia (Cádiz)

- Complejo medioambiental de Montalbán (Córdoba)

- Complejo medioambiental de Veléz de Benaudalla (Granada)

- $\quad$ Ecocentral Granada, Loma de Manzanares - Alhedín (Granada)

- Centro de tratamiento de residuos El Andévalo, Tharsis - La Puebla de Guzmán (Huelva)

- $\quad$ Planta de tratamiento de residuos sólidos urbanos de Villarrasa (Huelva)

- Planta de recuperación y compostaje de Jaén (Jaén)

- Complejo medioambiental de Gaudiel, Linares (Jaén)

- Centro medioambiental de la Costa del Sol, Casares (Málaga)

- $\quad$ Centro medioambiental Los Raíces, Málaga (Málaga)

- Complejo medioambiental Valsequillo, Antequera (Málaga)

- Centro de tratamiento de residuos Monte Marta - Cónica, Alcalá de Guadaira (Sevilla)

- Complejo medioambiental La Vega, Alcalá del Rio (Sevilla) 
- $\quad$ Complejo ambiental MataGrande, Estepa (Sevilla)

- Complejo ambiental Campiña 2000, Marchena (Sevilla)

Plantas de compostaje de la FORS:

- Complejo medioambiental de Córdoba (Córdoba)

Tabla 3.4 Plantas de TMB de Andalucía

\begin{tabular}{|c|c|c|c|c|c|c|c|}
\hline \multirow{2}{*}{$\begin{array}{l}\text { Tipo de } \\
\text { RSU }\end{array}$} & \multirow{2}{*}{$\begin{array}{l}\text { Tipo de } \\
\text { planta }\end{array}$} & \multirow{2}{*}{$\begin{array}{l}\text { Número de } \\
\text { instalaciones }\end{array}$} & \multicolumn{2}{|c|}{ Tipos de etapa mecánica } & \multicolumn{3}{|c|}{ Tipo de etapa biológica } \\
\hline & & & AUT & MANU & NA & NC & $\mathbf{T}$ \\
\hline \multirow{3}{*}{$\begin{array}{c}\text { RSU } \\
\text { mezclados }\end{array}$} & PT & 1 & 1 & 0 & - & - & - \\
\hline & PRC & 20 & 9 & 11 & 7 & 8 & 5 \\
\hline & PRBC & 1 & 1 & 0 & 0 & 0 & 1 \\
\hline FORS & PCFO & 1 & - & - & 1 & 0 & 0 \\
\hline \multicolumn{2}{|c|}{ TOTAL ANDALUCÍA } & 23 & 11 & 11 & 8 & 8 & 6 \\
\hline
\end{tabular}

\subsubsection{Plantas de TMB de Aragón}

Aragón tan solo cuenta con una planta de TMB, en concreto con una PRBC donde la recuperación de materiales se realiza de forma automática y el compostaje del digestato en túneles (Tabla 3.5). Esta instalación está situada en Zaragoza y en ella se tratan los residuos de la capital y de 61 municipios más de alrededor. Destaca que en las provincias de Teruel y Huesca no exista actualmente ninguna instalación de este tipo, siendo las únicas provincias en España donde todos los RSU mezclados generados son destinados directamente a vertedero.

Plantas de recuperación, biometanización y compostaje:

- $\quad$ CTRUZ: Complejo para el tratamiento de residuos urbanos de Zaragoza (Zaragoza)

Tabla 3.5 Plantas de TMB de Aragón

\begin{tabular}{c|c|c|c|c|c|c|c}
\hline \multirow{2}{*}{$\begin{array}{c}\text { Tipo de } \\
\text { RSU }\end{array}$} & \multirow{2}{*}{$\begin{array}{c}\text { Tipo de } \\
\text { planta }\end{array}$} & $\begin{array}{c}\text { Número de } \\
\text { instalaciones }\end{array}$ & \multicolumn{2}{c|}{ Tipos de etapa mecánica } & \multicolumn{3}{|c}{ Tipo de etapa biológica } \\
\cline { 5 - 9 } & AUT & MANU & NA & NC & T \\
\hline $\begin{array}{c}\text { RSU } \\
\text { mezclados }\end{array}$ & PRBC & 1 & 1 & 0 & 0 & 0 & 1 \\
\hline \multicolumn{2}{c|}{ TOTAL ARAGÓN } & $\mathbf{1}$ & $\mathbf{1}$ & $\mathbf{0}$ & $\mathbf{0}$ & $\mathbf{0}$ & $\mathbf{1}$ \\
\hline
\end{tabular}

\subsubsection{Plantas de TMB del Principado de Asturias}

El principado de Asturias cuenta con dos plantas de TMB, ambas para el tratamiento de loa FORS, en concreto una PCFO y una PBCFO. Las dos están situadas en el Centro de tratamiento de residuos de Asturias y el proceso de compostaje se realiza en nave cerrada, tanto de la fracción orgánica en bruto como del digestato (Tabla 3.6).

\section{Plantas de compostaje de la FORS:}

- Centro del tratamiento de residuos de Asturias: Planta de compostaje, Serín (Gijón)

\section{Plantas de biometanización y compostaje de la FORS:}

- Centro del tratamiento de residuos de Asturias: Planta de biometanización, Serín (Gijón) 
Tabla 3.6 Plantas de TMB del Principado de Asturias

\begin{tabular}{c|c|c|c|c|c|c|c|}
\hline \multirow{2}{*}{$\begin{array}{c}\text { Tipo de } \\
\text { RSU }\end{array}$} & $\begin{array}{c}\text { Tipo de } \\
\text { planta }\end{array}$ & \multirow{2}{*}{$\begin{array}{c}\text { Número de } \\
\text { instalaciones }\end{array}$} & \multicolumn{2}{c|}{ Tipos de etapa mecánica } & \multicolumn{3}{|c}{ Tipo de etapa biológica } \\
\cline { 5 - 9 } & AUT & MANU & NA & NC & T \\
\hline \multirow{2}{*}{ FORS } & PCFO & 1 & - & - & 0 & 1 & 0 \\
\cline { 2 - 8 } & PBCFO & 1 & - & - & 0 & 1 & 0 \\
\hline
\end{tabular}

\subsubsection{Plantas de TMB de las Islas Baleares}

Las Islas Baleares cuentan con dos plantas de TMB: una PRC ubicada en Menorca y una PBCFO en Mallorca (Tabla 3.7). En la PRC la recuperación de materiales se realiza de forma manual y el compostaje en túneles, no obstante, en el año 2019 han comenzado las obras para su modernización. El compostaje del digestato en la PBCFO también se lleva a cabo en túneles. Cabe señalar que durante el año 2019 se iniciaran las obras para la construcción una nueva PRC en Ibiza, en la actualidad los RSU mezclados generados en esta isla se destinan a vertedero directamente.

\section{Plantas de recuperación y compostaje:}

- $\quad$ Área de gestión integral de residuos Es Mila, Mahón (Menorca)

\section{Plantas de biometanización y compostaje de la FORS:}

- $\quad$ Parque de Tecnologías Ambientales de Mallorca Can Canut, Marratxí (Mallorca)

Tabla 3.7 Plantas de TMB de las Islas Baleares

\begin{tabular}{c|c|c|c|c|c|c|c|}
\hline $\begin{array}{c}\text { Tipo de } \\
\text { RSU }\end{array}$ & $\begin{array}{c}\text { Tipo de } \\
\text { planta }\end{array}$ & $\begin{array}{c}\text { Número de } \\
\text { instalaciones }\end{array}$ & \multicolumn{2}{|c|}{ Tipos de etapa mecánica } & \multicolumn{3}{|c|}{ Tipo de etapa biológica } \\
\hline $\begin{array}{c}\text { RSU } \\
\text { mezclados }\end{array}$ & PRC & 1 & 0 & MANU & NA & NC & T \\
\hline FORS & PBCFO & 1 & - & - & 0 & 0 & 1 \\
\hline $\begin{array}{c}\text { TOTAL ISLAS } \\
\text { BALEARES }\end{array}$ & $\mathbf{2}$ & $\mathbf{0}$ & $\mathbf{1}$ & $\mathbf{0}$ & $\mathbf{0}$ & $\mathbf{2}$ \\
\hline
\end{tabular}

\subsubsection{Plantas de TMB de Canarias}

En Canarias existen seis plantas de TMB, de ellas tres son PRC, dos PRBC y una PCFO. Respecto al tipo de tratamiento mecánico utilizado para la recuperación de los materiales presentes en los RSU mezclados, tres lo realizan de forma automática y dos de forma manual (Tabla 3.8). En cuanto al tratamiento biológico mediante compostaje, de las seis plantas, tres lo realizan en nave cerrada y tres en túneles. Como se observa en el listado, la isla de Fuerteventura, La Gomera y El Hierro no cuentan con plantas de TMB. En ellas los RSU mezclados se destinan directamente a vertedero. No obstante, en El Hierro existe el Complejo medioambiental El Majano, el cual no está en funcionamiento actualmente.

\section{Plantas de recuperación y compostaje:}

- $\quad$ Complejo medioambiental de Tenerife, Arico (Tenerife, Santa Cruz de Tenerife)

- Complejo ambiental de Los Morenos, Villa de Mazo (La Palma, Santa Cruz de Tenerife)

- Ecoparque Gran Canaria Sur, antiguo complejo ambiental de Juan Grande (Gran Canaria, Las Palmas) 


\section{Plantas de recuperación, biometanización y compostaje:}

- Ecoparque Gran Canaria Norte, antiguo complejo medioambiental Salto del Negro, (Gran Canaria, Las Palmas)

- Complejo medioambiental de Zonzamas, San Bartolomé (Lanzarote, Las Palmas)

\section{Plantas de compostaje de la FORS:}

- Complejo ambiental de Los Morenos, Villa de Mazo (La Palma, Santa Cruz de Tenerife)

Tabla 3.8 Plantas de TMB de Canarias

\begin{tabular}{|c|c|c|c|c|c|c|c|}
\hline \multirow{2}{*}{$\begin{array}{l}\text { Tipo de } \\
\text { RSU }\end{array}$} & \multirow{2}{*}{$\begin{array}{l}\text { Tipo de } \\
\text { planta }\end{array}$} & \multirow{2}{*}{$\begin{array}{l}\text { Número de } \\
\text { instalaciones }\end{array}$} & \multicolumn{2}{|c|}{ Tipos de etapa mecánica } & \multicolumn{3}{|c|}{ Tipo de etapa biológica } \\
\hline & & & AUT & MANU & NA & NC & $\mathbf{T}$ \\
\hline \multirow{2}{*}{$\begin{array}{c}\text { RSU } \\
\text { mezclados }\end{array}$} & PRC & 3 & 1 & 2 & 0 & 2 & 1 \\
\hline & PRBC & 2 & 2 & 0 & 0 & 1 & 1 \\
\hline FORS & PCFO & 1 & - & - & 0 & 0 & 1 \\
\hline \multicolumn{2}{|c|}{ TOTAL CANARIAS } & 6 & 3 & 2 & 0 & 3 & 3 \\
\hline
\end{tabular}

\subsubsection{Plantas de TMB de Cantabria}

Cantabria tan solo cuenta con una PRC ubicada en el Centro medioambiental de Meruelo, en ella los materiales reciclables se recuperan de forma manual y el compostaje de la fracción orgánica se realiza en nave cerrada (Tabla 3.9).

\section{Plantas de recuperación y compostaje:}

- $\quad$ Centro medioambiental de Meruelo: Planta de tratamiento integral de residuos domésticos

Tabla 3.9 Plantas de TMB de Cantabria

\begin{tabular}{c|c|c|c|c|c|c|c|}
\hline \multirow{2}{*}{$\begin{array}{c}\text { Tipo de } \\
\text { RSU }\end{array}$} & $\begin{array}{c}\text { Tipo de } \\
\text { planta }\end{array}$ & $\begin{array}{c}\text { Número de } \\
\text { instalaciones }\end{array}$ & \multicolumn{2}{|c|}{ Tipos de etapa mecánica } & \multicolumn{3}{|c|}{ Tipo de etapa biológica } \\
\cline { 5 - 9 } & AUT & MANU & NA & NC & T \\
\hline $\begin{array}{c}\text { RSU } \\
\text { mezclados }\end{array}$ & PRC & 1 & 0 & 1 & 0 & 1 & 0 \\
\hline \multicolumn{2}{r|}{ TOTAL CANTABRIA } & $\mathbf{1}$ & $\mathbf{0}$ & $\mathbf{1}$ & $\mathbf{0}$ & $\mathbf{1}$ & $\mathbf{0}$ \\
\hline
\end{tabular}

\subsubsection{Plantas de TMB de Casilla - La Mancha}

En Castilla - La Mancha existen seis plantas de TMB, todas ellas PRC. En tres la recuperación de materiales se hace de forma automática y en las otras tres de forma manual. Respecto al tratamiento biológico, los tres tipos de tecnologías son utilizadas por igual (Tabla 3.10).

\section{Plantas de recuperación y compostaje:}

- $\quad$ Centro de tratamiento de residuos de Albacete (Albacete)

- Centro de tratamiento de residuos de Alcázar de San Juan (Ciudad Real)

- Centro de tratamiento de residuos de Almagro (Ciudad Real)

- Centro de tratamiento de residuos de Cuenca (Cuenca)

- Centro de tratamiento de residuos de Guadalajara, Torija (Guadalajara)

- Ecoparque de Toledo (Toledo) 
Tabla 3.10 Plantas de TMB de Castilla - La Mancha

\begin{tabular}{c|c|c|c|c|c|c|c|}
\hline \multirow{2}{*}{$\begin{array}{c}\text { Tipo de } \\
\text { RSU }\end{array}$} & $\begin{array}{c}\text { Tipo de } \\
\text { planta }\end{array}$ & $\begin{array}{c}\text { Número de } \\
\text { instalaciones }\end{array}$ & \multicolumn{2}{|c|}{ Tipos de etapa mecánica } & \multicolumn{3}{|c}{ Tipo de etapa biológica } \\
\cline { 4 - 8 } & AUT & MANU & NA & NC & T \\
\hline $\begin{array}{c}\text { RSU } \\
\text { mezclados }\end{array}$ & PRC & 6 & 3 & 3 & 2 & 2 & 2 \\
\hline $\begin{array}{r}\text { TOTAL CASTILLA - LA } \\
\text { MANCHA }\end{array}$ & 6 & 3 & 3 & 2 & 2 & 2 \\
\hline
\end{tabular}

\subsubsection{Plantas de TMB de Casilla y León}

Castilla y León cuenta con doce plantas de TMB, de ellas seis son PRC y seis PRBC. El tipo de proceso más utilizado para la recuperación de materiales es el manual, mientras que el proceso biológico de compostaje se realiza mediante túneles en todas ellas (Tabla 3.11).

\section{Plantas de recuperación y compostaje:}

- CTRU Ávila Sur, Arenas de San Pedro (Ávila)

- $\quad$ CTRU de Aranda de Duero (Burgos)

- $\quad$ CTRU de Abajas (Burgos)

- $\quad$ CTRU de Los Huertos (Segovia)

- $\quad$ CTRU de Soria, Golmayo (Soria)

- CTRU de Zamora (Zamora)

\section{Plantas de recuperación, biometanización y compostaje:}

- CTR Ávila Sur, Urraca de Miguel (Ávila)

- CTR Barrio Cortes: Ecoparque de Burgos (Burgos)

- Planta de reciclaje y compostaje San Román de la Vega (León)

- CTR Palencia (Palencia)

- CTR de Salamanca, Gomecello (Salamanca)

- $\quad$ CTR Valladolid (Valladolid)

Tabla 3.11 Plantas de TMB de Castilla y León

\begin{tabular}{|c|c|c|c|c|c|c|c|}
\hline \multirow{2}{*}{$\begin{array}{l}\text { Tipo de } \\
\text { RSU }\end{array}$} & \multirow{2}{*}{$\begin{array}{l}\text { Tipo de } \\
\text { planta }\end{array}$} & \multirow{2}{*}{$\begin{array}{l}\text { Número de } \\
\text { instalaciones }\end{array}$} & \multicolumn{2}{|c|}{ Tipos de etapa mecánica } & \multicolumn{3}{|c|}{ Tipo de etapa biológica } \\
\hline & & & AUT & MANU & NA & NC & $\mathbf{T}$ \\
\hline \multirow{2}{*}{$\begin{array}{c}\text { RSU } \\
\text { mezclados }\end{array}$} & PRC & 6 & 2 & 4 & 0 & 0 & 6 \\
\hline & PRBC & 6 & 2 & 4 & 0 & 0 & 6 \\
\hline \multicolumn{2}{|c|}{$\begin{array}{l}\text { TOTAL CASTILLA Y } \\
\text { LEÓN }\end{array}$} & 12 & 4 & 8 & 0 & 0 & 12 \\
\hline
\end{tabular}

\subsubsection{Plantas de TMB de Cataluña}

Cataluña es la C.A. con más plantas de TMB, 39 en total, y con una mayor variedad en cuanto a las clases existentes: una PT, 8 PRC, 3 PRBC, 23 PCFO y 4 PBCFO (Tabla 3.12). El tipo de etapa mecánica para la recuperación de materiales que predomina es la automática. Respecto al tratamiento biológico, la tecnología más usada para el compostaje son los túneles, seguidos por la nave abierta. Esta última se utiliza principalmente en las PCFO. Cabe destacar que, en la PRBC del Ecoparc 3 el compostaje del digestato esta 
externalizado y no se realiza en la propia planta. Asimismo, Cataluña es la comunidad autonoma donde la recogida y tratamiento de la FORS tiene una mayor implantación, por lo que cuenta con un gran número de PCFO (23 de las 34 existentes en España) y de PBCFO (4 de las 8 existentes a nivel nacional), estado repartidas por todas las provincias.

\section{Plantas de triaje:}

- $\quad$ Planta de triatge de residus inorgànics municipals de Molins de Rei (Barcelona)

\section{Plantas de recuperación y compostaje:}

- $\quad$ Ecoparque 1, Barcelona (Barcelona)

- Ecoparque 2, Montcada i Reixac (Barcelona)

- $\quad$ CTR EI Valles, Valcarisses - Terrasa (Barcelona)

- Ecoparque 4, Hostalets de Pierola (Barcelona)

- Centro de Tratamiento de Residuos de Osona y Ripollés, Orís (Barcelona)

- $\quad$ CTR Alt Emporda, Pedret i Marza (Girona)

- $\quad$ CTR Lloret de Mar (Girona)

- $\quad$ CTR Solsones, Clariana de Carcadener (Lleida)

\section{Plantas de recuperación, biometanización y compostaje:}

- $\quad$ Ecoparc 3, Sant Adria de Besos (Barcelona)

- Centro Integral de Valorización de Residuos del Maresme, Mataró (Barcelona)

- Planta mecánica-biológica Botarell II, Botarell (Tarragona)

\section{Plantas de compostaje de la FORS:}

- $\quad$ Ecoparc 4, Hostalets de Pierola (Barcelona)

- Parc Ambiental de Bufalvent, Manresa (Barcelona)

- Planta de gestió de la matèria orgànica, Malla (Barcelona)

- Planta de compostaje de Jorba (Barcelona)

- Planta de compostaje de Sant Cugat del Valles (Barcelona)

- Planta de compostaje de Sant Pere de Ribes (Barcelona)

- Planta de compostaje de Torrelles de Llobregat (Barcelona)

- Planta de compostaje de Centelles (Barcelona)

- Centro de tratamiento de residuos de Osona y Ripollés, Orís (Barcelona)

- Planta de compostaje de Boadella i Les Escaules (Girona)

- Planta de compostaje de Llagostera (Girona)

- Planta de compostaje de Olot (Girona)

- Planta de compostaje de Santa Coloma de Farners (Girona)

- $\quad$ AGROSCA, SL, Alguaire (Lleida)

- $\quad$ Centre de tractament de residus municipals del Segria, Montoliu de Lleida (Lleida)

- Planta de compostaje de Tremp, Pallars Jussa (Lleida)

- Planta de Compostaje la Seu d'Urgell (Lleida)

- $\quad$ Planta de Compostaje de Tarrega, L'Urgel (Lleida) 
- $\quad$ Planta de tratamiento biológico de Sort, Pallars de Sobira, (Lleida)

- $\quad$ CTR Solsones, Clariana de Carcadener (Lleida)

- Planta de Compostaje Botarel I, Botarell (Tarragona)

- $\quad$ Centro de tratamiento de Residuos de La Conca de Barbera, L'Espluga de Francoli (Tarragona)

- $\quad$ Centro de tratamiento de residuos de Mas de Barberans, (Tarragona)

\section{Plantas de biometanización y compostaje de la FORS:}

- $\quad$ Ecoparque 1, Barcelona (Barcelona)

- Ecoparque 2, Montcada i Reixac (Barcelona)

- Planta de Biometanización de Can Barba, Terrasa (Barcelona)

- Planta de Biometanización de Granollers (Barcelona)

Tabla 3.12 Plantas de TMB de Cataluña

\begin{tabular}{|c|c|c|c|c|c|c|c|}
\hline \multirow{2}{*}{$\begin{array}{l}\text { Tipo de } \\
\text { RSU }\end{array}$} & \multirow{2}{*}{$\begin{array}{l}\text { Tipo de } \\
\text { planta }\end{array}$} & \multirow{2}{*}{$\begin{array}{l}\text { Número de } \\
\text { instalaciones }\end{array}$} & \multicolumn{2}{|c|}{ Tipos de etapa mecánica } & \multicolumn{3}{|c|}{ Tipo de etapa biológica } \\
\hline & & & AUT & MANU & NA & NC & $\mathbf{T}$ \\
\hline \multirow{3}{*}{$\begin{array}{c}\text { RSU } \\
\text { mezclados }\end{array}$} & PT & 1 & 1 & 0 & - & - & - \\
\hline & PRC & 8 & 4 & 4 & 0 & 5 & 3 \\
\hline & PRBC & 3 & 2 & 1 & 0 & 1 & 1 \\
\hline \multirow{2}{*}{ FORS } & PCFO & 23 & - & - & 13 & 2 & 8 \\
\hline & PBCFO & 4 & - & - & 0 & 0 & 4 \\
\hline \multicolumn{2}{|c|}{ TOTAL CATALUÑA } & 39 & 7 & 5 & 13 & 8 & 16 \\
\hline
\end{tabular}

\subsubsection{Plantas de TMB de la Comunidad Valenciana}

La Comunidad Valenciana cuenta con 14 plantas de TMB, todas ellas para el tratamiento de los RSU mezclados, que consisten en: 10 PRC, una PBSR y dos PRBC. Es la única C.A. que cuenta con una planta de biosecado y recuperación, la cual se encuentra al norte de la provincia de Castellón. Por otro lado, las dos PRBC se encuentran en la provincia de Alicante. Respecto a las tecnologías utilizadas, la recuperación de materiales se realiza principalmente de forma automática, mientras que en el compostaje se realiza mayoritariamente en nave cerrada seguido por el compostaje en túneles (Tabla 3.13).

\section{Plantas de recuperación y compostaje:}

- $\quad$ Planta de reciclaje y compostaje del Baix Vinalop, Elche (Alicante)

- Centro de tratamiento de residuos de Villena (Alicante)

- Planta de tratamiento de residuos Piedra Negra, Jijona (Alicante)

- Planta de reciclaje y compostaje, Onda (Castellón)

- Complejo de valorización de residuos de Guadassuar (Valencia)

- Planta de tratamiento de residuos y compostaje Los Hornillos (Instalación 1), Quart de Poblet, (Valencia)

- $\quad$ Planta de tratamiento de residuos sólidos urbanos de Algimia (Valencia)

- $\quad$ Planta de tratamiento de residuos y compostaje (Instalación 3), Manises (Valencia)

- Planta de Tratamiento de Residuos de Lliria (Valencia)

- $\quad$ Planta de tratamiento de residuos de Caudete de las Fuentes (Valencia) 


\section{Plantas de biosecado y recuperación:}

- Planta de tratamiento de Cervera del Maestre (Castellón)

\section{Plantas de recuperación, biometanización y compostaje:}

- Centro de Tratamiento de Residuos Urbanos de la Ciudad de Alicante (Alicante)

- Centro de Tratamiento Integral de Residuos “Las Marinas”, El Campello (Alicante)

Tabla 3.13 Plantas de TMB de la Comunidad Valenciana

\begin{tabular}{c|c|c|c|c|c|c|c|}
\hline \multirow{2}{*}{$\begin{array}{c}\text { Tipo de } \\
\text { RSU }\end{array}$} & $\begin{array}{c}\text { Tipo de } \\
\text { planta }\end{array}$ & $\begin{array}{c}\text { Número de } \\
\text { instalaciones }\end{array}$ & \multicolumn{2}{|c|}{ Tipos de etapa mecánica } & \multicolumn{3}{|c}{ Tipo de etapa biológica } \\
\cline { 4 - 9 } & ARC & 10 & 7 & MANU & NA & NC & T \\
\hline \multirow{2}{*}{$\begin{array}{c}\text { RSU } \\
\text { mezclados }\end{array}$} & PBSR & 1 & 0 & 1 & - & 1 & - \\
\cline { 2 - 9 } & PRBC & 2 & 1 & 1 & 0 & 2 & 0 \\
\hline $\begin{array}{c}\text { TOTAL COMUNIDAD } \\
\text { VALENCIANA }\end{array}$ & $\mathbf{1 3}$ & $\mathbf{8}$ & $\mathbf{5}$ & $\mathbf{0}$ & $\mathbf{8}$ & $\mathbf{5}$ \\
\hline
\end{tabular}

\subsubsection{Plantas de TMB de Extremadura}

En Extremadura existen siete plantas de TMB. Todas ellas son PRC que llevan a cabo la etapa mecánica de recuperación de materiales de forma manual. En cuanto a la etapa biológica de compostaje, seis lo realizan en nave abierta y tan solo el Ecoparque de Mirabel lo hace en túneles (Tabla 3.14).

\section{Plantas de recuperación y compostaje:}

- Ecoparque de Mérida (Badajoz)

- Ecoparque de Talarrubias (Badajoz)

- $\quad$ Ecoparque de Badajoz (Badajoz)

- Ecoparque de Villanueva (Badajoz)

- Ecoparque de Mirabel (Cáceres)

- Ecoparque de Navalmoral (Cáceres)

- Ecoparque de Cáceres (Cáceres)

Tabla 3.14 Plantas de TMB de Extremadura

\begin{tabular}{c|c|c|c|c|c|c|c|}
\hline $\begin{array}{c}\text { Tipo de } \\
\text { RSU }\end{array}$ & $\begin{array}{c}\text { Tipo de } \\
\text { planta }\end{array}$ & $\begin{array}{c}\text { Número de } \\
\text { instalaciones }\end{array}$ & \multicolumn{2}{|c|}{ Tipos de etapa mecánica } & \multicolumn{3}{|c|}{ Tipo de etapa biológica } \\
\hline $\begin{array}{c}\text { RSU } \\
\text { mezclados }\end{array}$ & PRC & 7 & 0 & MANU & NA & NC & T \\
\hline $\begin{array}{c}\text { TOTAL } \\
\text { EXTREMADURA }\end{array}$ & $\mathbf{7}$ & $\mathbf{0}$ & $\mathbf{7}$ & 6 & 0 & 1 \\
\hline
\end{tabular}

\subsubsection{Plantas de TMB de Galicia}

Galicia cuenta con cinco plantas de TMB, en concreto dos PT, una PRBC y dos PCFO. Todas están situadas en la provincia de La Coruña, no obstante, en ellas se tratan los RSU generados en toda la C.A., ya que en el Complejo ambiental de Cerceda se reciben los residuos de las provincias de Lugo, Orense y Pontevedra. El tipo de tratamiento que se lleva a cabo en la PT del Complejo medioambiental de Cerceda es un triaje 
previo a la incineración. Mientras que el Complejo medioambiental Serra do Barbanza se trata de un triaje de la fracción no biodegradable recogida en contenedor mediante el sistema húmedo-seco. En esta comunidad la recuperación automática de los materiales reciclables predomina frente a la manual. Respecto al tratamiento biológico mediante compostaje, el proceso en túneles es el más utilizado, mientras que el de nave abierta no se utiliza en ninguna instalación (Tabla 3.15).

\section{Plantas de triaje:}

- Complejo ambiental de Cerceda: Planta de Reciclaje, Tratamiento y Elaboración de Combustible (La Coruña)

- Complejo medioambiental Serra do Barbanza, Lousame (La Coruña)

\section{Plantas de recuperación, biometanización y compostaje:}

- Complejo ambiental Nostián, La Coruña (La Coruña)

\section{Plantas de compostaje de la FORS:}

- Complejo medioambiental Serra do Barbanza, Lousame (La Coruña)

- Planta de Compostaje de Areosa, Cerceda (La Coruña)

Tabla 3.15 Plantas de TMB de Galicia

\begin{tabular}{|c|c|c|c|c|c|c|c|}
\hline \multirow{2}{*}{$\begin{array}{c}\text { Tipo de } \\
\text { RSU }\end{array}$} & \multirow{2}{*}{$\begin{array}{l}\text { Tipo de } \\
\text { planta }\end{array}$} & \multirow{2}{*}{$\begin{array}{l}\text { Número de } \\
\text { instalaciones }\end{array}$} & \multicolumn{2}{|c|}{ Tipos de etapa mecánica } & \multicolumn{3}{|c|}{ Tipo de etapa biológica } \\
\hline & & & AUT & MANU & NA & NC & $T$ \\
\hline \multirow{2}{*}{$\begin{array}{c}\mathrm{RSU} \\
\text { mezclados }\end{array}$} & PT & 2 & 1 & 1 & - & - & - \\
\hline & PRBC & 1 & 1 & 0 & 0 & 1 & 0 \\
\hline FORS & PCFO & 2 & - & - & 0 & 0 & 2 \\
\hline \multicolumn{2}{|c|}{ TOTAL GALICIA } & 5 & 2 & 1 & 0 & 1 & 2 \\
\hline
\end{tabular}

\subsubsection{Plantas de TMB de La Rioja}

En La Rioja solo existe una planta de TMB, en concreto una PRBC. En ella la etapa mecánica de recuperación de materiales se realiza de forma automática y el compostaje del digestato en nave cerrada (Tabla 3.16).

\section{Plantas de recuperación, biometanización y compostaje:}

- $\quad$ Ecoparque de La Rioja, Logroño

Tabla 3.16 Plantas de TMB de La Rioja

\begin{tabular}{c|c|c|c|c|c|c|c|}
\hline \multirow{2}{*}{$\begin{array}{c}\text { Tipo de } \\
\text { RSU }\end{array}$} & $\begin{array}{c}\text { Tipo de } \\
\text { planta }\end{array}$ & $\begin{array}{c}\text { Número de } \\
\text { instalaciones }\end{array}$ & \multicolumn{2}{|c|}{ Tipos de etapa mecánica } & \multicolumn{3}{|c|}{ Tipo de etapa biológica } \\
\cline { 5 - 9 } & AUT & MANU & NA & NC & T \\
\hline RSU & PRBC & 1 & 1 & 0 & 0 & 1 & 0 \\
\hline mezclados & POTAL LA RIOJA & $\mathbf{1}$ & $\mathbf{1}$ & $\mathbf{0}$ & $\mathbf{0}$ & $\mathbf{1}$ & $\mathbf{9}$ \\
\hline
\end{tabular}

\subsubsection{Plantas de TMB de la Comunidad de Madrid}

La Comunidad de Madrid cuenta con cuatro plantas de TMB, de ellas una es una PT y tres son PRBC. Respecto al tipo de tratamiento mecánico, como se muestra en la Tabla 3.17, existe el mismo número de instalaciones que lo realizan de forma automática que manual. Mientras que el tratamiento biológico de la fracción orgánica se lleva a cabo en túneles de compostaje en todas ellas. En el caso de la PT, se trata de 
una antigua PRC en la que el proceso de compostaje dejo de funcionar en 2011. Actualmente, la fracción orgánica separada en esta planta se destina a otras instalaciones del Parque tecnológico de Valdemingómez para su tratamiento biológico.

\section{Plantas de triaje:}

- $\quad$ Parque tecnológico de Valdemingómez: Centro de tratamiento integral de RSU Las Lomas, Madrid

\section{Plantas de recuperación, biometanización y compostaje:}

- Parque tecnológico de Valdemingómez: Centro de tratamiento integral de RSU La Paloma, Madrid

- Parque tecnológico de Valdemingómez: Centro de tratamiento integral de RSU Las Dehesas, Madrid

- Planta de biometanización y compostaje de Pinto

Tabla 3.17 Plantas de TMB de la Comunidad de Madrid

\begin{tabular}{c|c|c|c|c|c|c|c|}
\hline $\begin{array}{c}\text { Tipo de } \\
\text { RSU }\end{array}$ & $\begin{array}{c}\text { Tipo de } \\
\text { planta }\end{array}$ & $\begin{array}{c}\text { Número de } \\
\text { instalaciones }\end{array}$ & \multicolumn{2}{|c|}{ Tipos de etapa mecánica } & \multicolumn{3}{|c}{ Tipo de etapa biológica } \\
\cline { 4 - 9 } & AUT & MANU & NA & NC & T \\
\hline $\begin{array}{c}\text { RSU } \\
\text { mezclados }\end{array}$ & PT & 1 & 0 & 1 & - & - & - \\
\cline { 2 - 9 } & PRBC & 3 & 2 & 1 & 0 & 0 & 3 \\
\hline $\begin{array}{c}\text { TOTAL COMUIDAD } \\
\text { DE MADRID }\end{array}$ & $\mathbf{4}$ & $\mathbf{2}$ & $\mathbf{2}$ & $\mathbf{0}$ & $\mathbf{0}$ & $\mathbf{3}$ \\
\hline
\end{tabular}

\subsubsection{Plantas de TMB de la Región de Murcia}

En la Región de Murcia existen cuatro plantas de TMB, siendo todas PRC. La recuperación de los materiales reciclables se realiza en todas ellas automáticamente. En relación al proceso biológico de compostaje, una planta lo realiza en nave abierta y tres en nave cerrada (Tabla 3.18).

\section{Plantas de recuperación y compostaje:}

- Centro de tratamiento de residuos de Cañada Hermosa, Murcia

- $\quad$ Centro de tratamiento de residuos de Ulea

- Centro de tratamiento de residuos El Gorguel, Cartagena

- $\quad$ Centro de tratamiento de residuos de Lorca

Tabla 3.18 Plantas de TMB de la Región de Murcia

\begin{tabular}{|c|c|c|c|c|c|c|c|}
\hline \multirow{2}{*}{$\begin{array}{l}\text { Tipo de } \\
\text { RSU }\end{array}$} & \multirow{2}{*}{$\begin{array}{l}\text { Tipo de } \\
\text { planta }\end{array}$} & \multirow{2}{*}{$\begin{array}{l}\text { Número de } \\
\text { instalaciones }\end{array}$} & \multicolumn{2}{|c|}{ Tipos de etapa mecánica } & \multicolumn{3}{|c|}{ Tipo de etapa biológica } \\
\hline & & & AUT & MANU & NA & NC & $\mathbf{T}$ \\
\hline $\begin{array}{c}\text { RSU } \\
\text { mezclados }\end{array}$ & PRC & 4 & 4 & 0 & 1 & 3 & 0 \\
\hline \multicolumn{2}{|c|}{$\begin{array}{l}\text { TOTAL REGIÓN DE } \\
\text { MURCIA }\end{array}$} & 4 & 4 & 0 & 1 & 3 & 0 \\
\hline
\end{tabular}

\subsubsection{Plantas de TMB de la Comunidad Foral de Navarra}

La Comunidad Foral de Navarra cuenta con 5 plantas de TMB: una PRBC, dos PCFO y dos PBCFO. En la PRBC los materiales reciclados se recuperan de forma automática y el compostaje del digestato se realiza en nave cerrada (Tabla 3.19). Respecto a las plantas de tratamiento de la FORS, en las PCFO el compostaje se lleva a 
cabo en nave abierta, mientras que en las PBCFO el digestato no se composta, si no que se centrifuga para desecarlo y la parte sólida se utiliza directamente como abono.

\section{Plantas de recuperación, biometanización y compostaje:}

- Centro de tratamiento de residuos Mancomunidad de la Ribera, El Culebrete: Planta biometanización, Tudela

\section{Plantas de compostaje de la FORS:}

- $\quad$ Planta de reciclaje Tecnología Industrial del Reciclaje IB SLU, Funes

- Centro de tratamiento de residuos Mancomunidad de Montejurra: Planta de Compostaje y Reciclaje de Cárcar

\section{Plantas de biometanización y compostaje de la FORS:}

- Planta de biometanización de Caparroso

- $\quad$ Planta de biometanización Bioenergia Mendi SL, Mendigorría

Tabla 3.19 Plantas de TMB de Comunidad Foral de Navarra

\begin{tabular}{|c|c|c|c|c|c|c|c|}
\hline \multirow{2}{*}{$\begin{array}{l}\text { Tipo de } \\
\text { RSU }\end{array}$} & \multirow{2}{*}{$\begin{array}{l}\text { Tipo de } \\
\text { planta }\end{array}$} & \multirow{2}{*}{$\begin{array}{l}\text { Número de } \\
\text { instalaciones }\end{array}$} & \multicolumn{2}{|c|}{ Tipos de etapa mecánica } & \multicolumn{3}{|c|}{ Tipo de etapa biológica } \\
\hline & & & AUT & MANU & NA & NC & $\mathbf{T}$ \\
\hline $\begin{array}{c}\text { RSU } \\
\text { mezclados }\end{array}$ & PRBC & 1 & 1 & 0 & 0 & 1 & 0 \\
\hline \multirow{2}{*}{ FORS } & PCFO & 2 & - & - & 2 & 0 & 0 \\
\hline & PBCFO & 2 & - & - & - & - & - \\
\hline \multicolumn{2}{|c|}{$\begin{array}{l}\text { TOTAL COMUNIDAD } \\
\text { FORAL DE NAVARRA }\end{array}$} & 5 & 1 & 0 & 2 & 1 & 0 \\
\hline
\end{tabular}

\subsubsection{Plantas de TMB del País Vasco}

El País Vasco cuenta con seis plantas de TMB, en concreto una PRC, una PRBC y cuatro PCFO. En las dos primeras, la etapa mecánica de recuperación de materiales se realiza de forma automática. En cuanto al compostaje, todas las tecnologías son utilizadas por igual (Tabla 3.20). Cabe destacar que, junto con Cataluña, el País Vaco fue una de las primeras C.A. en implantar la recogida y tratamiento diferenciado de la FORS. De ahí que el número de PCFO sea elevado y que todas las provincias cuenten en su territorio con al menos una instalación de este tipo.

\section{Plantas de recuperación y compostaje:}

- $\quad$ Planta de tratamiento mecánico-biológico de Monte Arraiz, Bilbao (Vizcaya)

\section{Plantas de recuperación, biometanización y compostaje:}

- Planta de tratamiento mecánico biológico (Biocompost) de Vitoria-Gasteiz, Jundiz (Álava)

\section{Plantas de compostaje de la FORS:}

- Planta de Tratamiento mecánico biológico (Biocompost) de Vitoria-Gasteiz, Jundiz (Álava)

- $\quad$ Planta de Compostaje de Lapatx (Guipúzcoa)

- $\quad$ Planta de Compostaje de Epele (Guipúzcoa)

- $\quad$ Planta de Compostaje de Bilbao, Artigas (Vizcaya) 
Tabla 3.20 Plantas de TMB del País Vasco

\begin{tabular}{|c|c|c|c|c|c|c|c|}
\hline \multirow{2}{*}{$\begin{array}{l}\text { Tipo de } \\
\text { RSU }\end{array}$} & \multirow{2}{*}{$\begin{array}{l}\text { Tipo de } \\
\text { planta }\end{array}$} & \multirow{2}{*}{$\begin{array}{l}\text { Número de } \\
\text { instalaciones }\end{array}$} & \multicolumn{2}{|c|}{ Tipos de etapa mecánica } & \multicolumn{3}{|c|}{ Tipo de etapa biológica } \\
\hline & & & AUT & MANU & NA & NC & $\mathbf{T}$ \\
\hline \multirow{2}{*}{$\begin{array}{c}\text { RSU } \\
\text { mezclados }\end{array}$} & PRC & 1 & 1 & 0 & 0 & 0 & 1 \\
\hline & PRBC & 1 & 1 & 0 & 0 & 1 & 0 \\
\hline FORS & PCFO & 4 & - & - & 2 & 1 & 1 \\
\hline \multicolumn{2}{|c|}{ TOTAL PAÍS VASCO } & 6 & 2 & 0 & 2 & 2 & 2 \\
\hline
\end{tabular}

\subsubsection{Resumen de la distribución de las plantas de TMB a nivel autonómico}

Como se observa en los apartados anteriores, en todo el territorio español hay un alto grado de cobertura en cuanto a plantas de TMB, existiendo instalaciones de este tipo en todas las CC.AA. Andalucía es la comunidad con un mayor número de PRC, seguida por la Comunidad Valenciana, con 20 y 10 instalaciones respectivamente. Galicia es la comunidad con más PT ( 2 instalaciones) y, como ya se ha mencionado anteriormente, la Comunidad Valenciana es la única donde existe una PBSR. El mayor número de PRBC se da en Castilla y León con 6 plantas de este tipo. Respecto a las plantas de tratamiento de la FORS, Cataluña es la comunidad donde más instalaciones hay con 23 PCFO y 4 PBCFO. En segundo lugar, en cuanto a las PCFO, está el País Vasco con 4 instalaciones.

\subsubsection{Resumen de las plantas de TMB existentes en España}

En la Tabla 3.21 se muestra una tabla resumen a nivel nacional. En ella se puede observar que a finales del año 2018 España contaba con 137 plantas de TMB. Las instalaciones más extendidas para el TMB de RSU mezclados son las PRC seguidas de las PRBC, con 67 y 22 plantas respectivamente. Respecto al tratamiento de la FORS, el tipo de planta predominante es la PCFO con 34 instalaciones de este tipo.

Tabla 3.21 Tipos de plantas de TMB en España

\begin{tabular}{|c|c|c|c|c|c|c|c|}
\hline \multirow{2}{*}{$\begin{array}{l}\text { Tipo de } \\
\text { RSU }\end{array}$} & \multirow{2}{*}{$\begin{array}{l}\text { Tipo de } \\
\text { planta }\end{array}$} & \multirow{2}{*}{$\begin{array}{l}\text { Número de } \\
\text { instalaciones }\end{array}$} & \multicolumn{2}{|c|}{ Tipos de etapa mecánica } & \multicolumn{3}{|c|}{ Tipo de etapa biológica } \\
\hline & & & AUT & MANU & NA & NC & $\mathbf{T}$ \\
\hline \multirow{4}{*}{$\begin{array}{c}\text { RSU } \\
\text { mezclados }\end{array}$} & PT & 5 & 3 & 2 & - & - & - \\
\hline & PRC & 67 & 31 & 36 & 16 & 27 & 24 \\
\hline & PBSR & 1 & - & 1 & - & 1 & - \\
\hline & PRBC & 22 & 7 & 15 & 0 & 8 & 13 \\
\hline \multirow{2}{*}{ FORS } & PCFO & 34 & - & - & 18 & 4 & 12 \\
\hline & PBCFO & 8 & - & - & 0 & 1 & 5 \\
\hline \multicolumn{2}{|c|}{ TOTAL ESPAÑA } & 137 & 41 & 54 & 34 & 41 & 54 \\
\hline
\end{tabular}

En relación al proceso de recuperación de los materiales reciclables contenidos en los RSU mezclados, este se realiza en la mayoría de las plantas de forma manual. No obstante, el proceso automático está también bastante extendido, existiendo en 3 PT, 31 PRC y 7 PRBC, es decir en un 43\% de las plantas de TMB de RSU mezclados.

En cuanto al proceso biológico, cuando se trata del compostaje de la fracción orgánica separada de los RSU mezclados (PRC y PBSR), el sistema más utilizado es la nave cerrada (28 instalaciones) seguido por los túneles (24 instalaciones). En el caso de las PCFO, el proceso mayoritario es el compostaje de la FORS en nave abierta (18 plantas) seguido por los túneles (12 plantas). Mientras que el compostaje del digestato obtenido en la biometanización (PRBC y PBCFO) se realiza principalmente en túneles (18 instalaciones) y nunca en nave abierta, ya que en el proceso se generan fuertes olores y por tanto necesita un sistema para 
la depuración de los mismos. A nivel global, en España el compostaje en túneles es el más utilizado, mientras que el compostaje en nave abierta es el de menor uso (Tabla 3.21).

\subsection{BALANCES DE MATERIA, PRODUCCIÓN DE RECHAZO Y RENDIMIENTO DE LAS PLANTAS DE TMB ESPAÑOLAS}

Tras la búsqueda bibliográfica y recopilación de información sobre las plantas de TMB en España, cabe destacar los pocos datos disponibles y actualizados sobre las cantidades de materiales entrantes y salientes en estas instalaciones. La información más actual se ha encontrado en la "Memoria anual de generación y gestión de residuos: residuos de Competencia Municipal, 2016" la cual fue publicada a principios del año 2019 por el Ministerio para la Transición Ecológica (MITECO, 2019). En esta memoria se recopilan los datos del año 2016 sobre las cantidades de residuos recogidos y tratados procedentes de los hogares y del sector servicios (comercios, oficinas e instituciones públicas o privadas), cuya gestión es asumida por las Entidades Locales. Estos datos incluyen las cantidades de materiales entrantes y salientes de las instalaciones de tratamiento de RSU españolas. En la Figura 3.16 se muestran los flujos de materia contabilizados en esta memoria para las plantas de TMB.

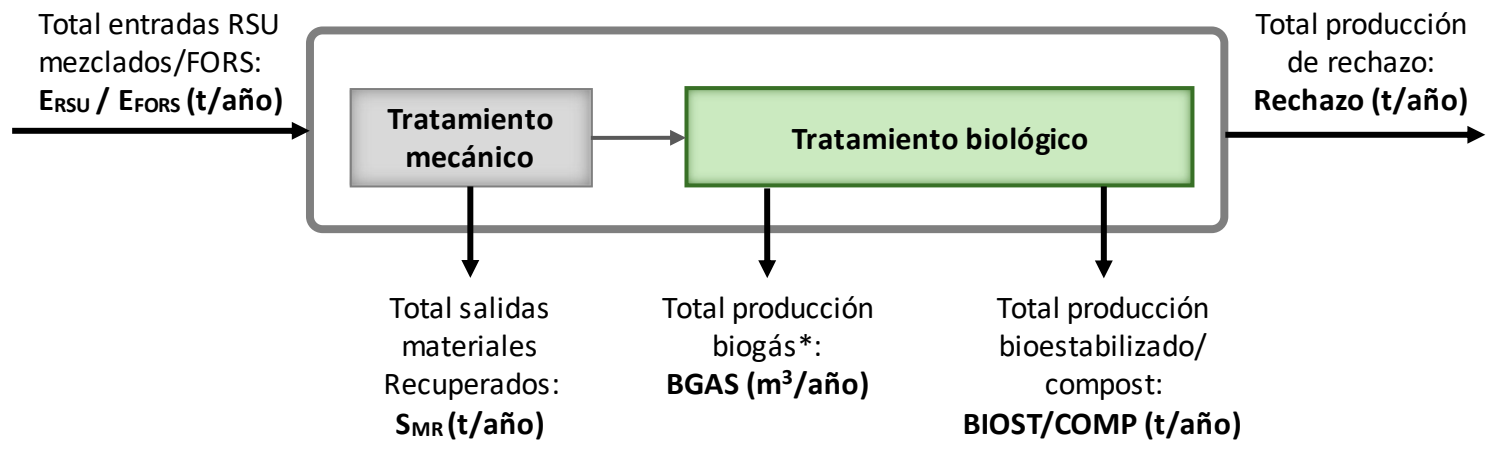

* En las PRBC y en las PBFO

Figura 3.16 Flujos considerados en el balance de materia de las plantas de TMB obtenidos a partir de los datos del MINECO

Se consideran materiales recuperados a los diferentes subproductos valorizables que se recuperan en las instalaciones y se entregan a empresas recicladoras: metal, plástico, vidrio, papel/cartón, brik y Otros. Este dato solo está disponible para las plantas donde se tratan RSU mezclados, por lo que no se dispone de datos sobre los metales recuperados en las instalaciones donde se trata la FORS.

Así pues, a partir de la información proporcionada por la memoria del MITECO se han obtenido los balances de materia de las plantas de TMB españolas para el año 2016 (último año disponible), se ha estimado la cantidad de rechazos generados a nivel nacional para ese año y se han establecido el rendimiento de estas instalaciones respecto a las entradas de RSU en las mismas. Los indicadores utilizados para el cálculo del rendimiento han sido los siguientes:

- Porcentaje de RSU mezclados tratados (RSUT): relación entre la entrada de residuos a la planta y la generación de RSU mezclados, expresada en tanto por ciento.

- Porcentaje de FORS tratada (FORST): relación entre la entrada de FORS a la planta y la recogida de FORS, expresada en tanto por ciento.

- Rendimiento global de subproductos (RGi): relación entre la cantidad de subproducto i y la entrada total de residuos a la planta, expresado en tanto por ciento. Donde i puede ser: materiales recuperados (MR), bioestabilizado (BIOST) o compost (COMP). 
- Rendimiento en la producción de biogás (RGGAS): relación entre los $\mathrm{m}^{3}$ de biogás producidos en el proceso de biometanización y la entrada total de residuos a la planta, expresado en $\mathrm{m}^{3} / \mathrm{t}$ RSU tratado.

- Porcentaje de rechazo (RECHAZO): relación entre el rechazo generado y la entrada total de residuos a la planta, expresado en tanto por ciento.

- Mermas (M): pérdidas de material (emisiones gaseosas y líquidas) en el proceso de tratamiento, expresadas en tanto por ciento.

En el presente apartado se muestran los resultados de balances e indicadores del rendimiento de forma agrupadas por CC.AA. para las seis clases principales de plantas de tratamiento definidas.

\subsubsection{Plantas de triaje}

En el año 2016 las PT trataron algo más de 1 millón de t de RSU mezclados. Como se puede ver en la Tabla 3.22, Galicia es la comunidad donde se trataron una mayor cantidad de residuos y, además, la única que cuenta con dos instalaciones de este tipo.

Tabla 3.22 Balances de materia PT, 2016

\begin{tabular}{c|c|c|c|c|c|c}
\hline CC.AA. & $\begin{array}{c}\text { Generación RSU } \\
\text { mezclados (t/año) }\end{array}$ & $\begin{array}{c}\text { Núm. de } \\
\text { instalaciones }\end{array}$ & $\begin{array}{c}\mathrm{E}_{\mathrm{RSU}} \\
\text { (t/año) }\end{array}$ & $\begin{array}{c}\mathrm{S}_{\mathrm{MR}} \\
\text { (t/año) }\end{array}$ & $\begin{array}{c}\mathrm{S}_{\mathrm{Fo}}{ }^{1} \\
\text { (t/año) }\end{array}$ & $\begin{array}{c}\text { Rechazo } \\
\text { (t/año) }\end{array}$ \\
\hline Andalucía & 3.907 .576 & 1 & 50.021 & 10.417 & - & 39.234 \\
\hline Cataluña & 2.440 .229 & 1 & 17.096 & 6.469 & - & 11.113 \\
\hline Galicia & 945.835 & 2 & 591.360 & 19.504 & 168.194 & 575.322 \\
\hline Comunidad de Madrid ${ }^{1}$ & 2.077 .644 & 1 & 360.666 & 19.381 & - & 160.051 \\
\hline TOTAL ESPAÑA & $\mathbf{1 8 . 0 5 2 . 0 7 5}$ & $\mathbf{5}$ & $\mathbf{1 . 0 1 9 . 1 4 3}$ & $\mathbf{5 5 . 7 7 1}$ & $\mathbf{1 6 8 . 1 9 4}$ & $\mathbf{7 8 5 . 7 2 0}$ \\
\hline
\end{tabular}

* Fuente: INE (2018) Estadísticas sobre recogida de residuos urbanos - Año 2016

1 La PT de la C. de Madrid recupera también la fracción orgánica (FO), esta se trata en las PRBC del Parque Tecnológico de Valdemingomez

En cuanto a las salidas de materiales reciclables, a nivel nacional en estas plantas se recuperaron $55.771 \mathrm{t}$. En Galicia y la Comunidad de Madrid es donde se han recuperado mayores cantidades, lo que puede estar muy relacionado con la mayor entrada de RSU en sus instalaciones. Así pues, para comparar correctamente las diferentes comunidades, será necesario utilizar los indicadores definidos al inicio de este apartado y no los valores absolutos. Respecto a los diferentes subproductos valorizables, en la Tabla 3.23 se muestran los porcentajes relativos obtenidos de cada uno de ellos respecto al total de materiales recuperados.

Tabla 3.23 Porcentajes de materiales recuperados en las PT, 2016

\begin{tabular}{c|c|c|c|c|c|c}
\hline \multirow{2}{*}{ CC.AA. } & \multicolumn{7}{|c}{ S $_{\text {MR }}$ por tipo de subproducto (\%) } \\
\cline { 2 - 7 } & Metal & Plástico & Vidrio & Papel/Cartón & Brik & Otros \\
\hline Andalucía & 20,24 & 65,30 & 0,00 & 8,82 & 5,64 & 0,00 \\
\hline Cataluña & 9,18 & 29,87 & 2,24 & 9,65 & 3,14 & 45,93 \\
\hline Galicia & 42,03 & 10,83 & 37,02 & 8,44 & 1,67 & 0,00 \\
\hline Comunidad de Madrid & 50,95 & 4,58 & 0,00 & 44,47 & 0,00 & 0,00 \\
\hline TOTAL ESPAÑA & 37,25 & 21,04 & 13,21 & 21,17 & 2,00 & 5,33 \\
\hline
\end{tabular}

En España el 37,25\% de los materiales recuperados en las PT correspondieron a los metales (férricos y no férricos), seguidos por el papel/cartón con un $21,17 \%$ y los plásticos con un $21,04 \%$. El brik, por el contrario, es el que se recuperó en menor medida con un $2 \%$ del total. Por comunidades los materiales con mayor recuperación fueron: en Andalucía los plásticos y los metales; en Cataluña los Otros y los plásticos; en 
Galicia los metales y el vidrio, y en la Comunidad de Madrid los metales y el papel/cartón. En la Tabla 3.23 se puede observar que en el caso de Galicia y la Comunidad de Madrid la recuperación de plásticos es muy baja, esto puede estar relacionado con que en estas comunidades el principal tratamiento para el rechazo generado es la incineración.

Resaltar también que, como se ve en la Tabla 3.22, la PT madrileña recuperó 168.194 t de fracción orgánica que se compostó en las PRBC existentes en el Parque tecnológico de Valdemingómez.

El último flujo a analizar es el del rechazo, que además es el objeto de estudio de la presente tesis. La cantidad de rechazo generado en las PT españolas fue de 785.720 t (Tabla 3.22). Galicia y la Comunidad de Madrid son las CC.AA. donde se ha producido una mayor cantidad de rechazos, aunque esto está relacionado con la mayor entrada de RSU en sus instalaciones. A nivel nacional, el principal destino de los rechazos generados en las PT es la valorización energética (Tabla 3.24). Esto es debido a que el tipo de tratamiento que se lleva a cabo en estas plantas es el triaje previo a la incineración o el triaje de la fracción no biodegradable recogida mediante el sistema húmedo-seco, lo que hace que el rechazo tenga un elevado poder calorífico. El tratamiento de los rechazos en cada una de las CC.AA. se muestra en la siguiente tabla.

Tabla 3.24 Tratamiento de los rechazos en las PT, 2016

\begin{tabular}{c|c|c|}
\hline \multirow{2}{*}{ CC.AA. } & \multicolumn{2}{|c}{ Tratamiento del rechazo (\%) } \\
\cline { 2 - 3 } & Vertedero & Incineración \\
\hline Andalucía & 100,00 & 0,00 \\
\hline Cataluña & 78,69 & 21,31 \\
\hline Galicia & 9,74 & 90,26 \\
\hline Comunidad de Madrid & 4,03 & 95,97 \\
\hline TOTAL ESPAÑA & $\mathbf{1 4 , 0 6}$ & $\mathbf{8 5 , 9 4}$ \\
\hline
\end{tabular}

Como se observa en la Tabla 3.24, Andalucía es la única comunidad en la que el $100 \%$ de los rechazos de las PT se depositaron en vertedero. Mientras que el Galicia y la Comunidad de Madrid, más del $90 \%$ de los mismos se aprovecharon energéticamente. A nivel nacional, solo el 14,06\% se destinó a vertedero, suponiendo el $0,83 \%$ de los residuos que llegaron a los mismos. El resto del rechazo, un 85,94\% (675.281 t), tuvo como destino la valorización energética, lo que supuso el $28,16 \%$ del material entrante en las incineradoras españolas.

Una vez obtenidos los balances de materia, se han determinado los rendimientos de estas instalaciones respecto a los residuos entrantes utilizando los indicadores definidos anteriormente, lo que permite hacer una comparación más exacta entre CC.AA. En la Tabla 3.25 se exponen los rendimientos calculados para las PT españolas.

Tabla 3.25 RSU tratados e indicadores del rendimiento de las PT, 2016

\begin{tabular}{c|c|c|c|c|c}
\hline CC.AA. & $\mathbf{R S U}_{\mathbf{T}}$ (\%) & $\mathbf{R G}_{\mathbf{M R}}$ (\%) & $\mathbf{R G}_{\mathrm{FO}}$ (\%) & RECHAZO (\%) & $\mathbf{M}$ (\%) \\
\hline Andalucía & 1,28 & 20,83 & - & 78,44 & 0,74 \\
\hline Cataluña & 0,70 & 37,84 & - & 65,00 & $-2,84$ \\
\hline Galicia & 62,52 & 3,30 & 46,63 & 97,29 & $-0,59$ \\
\hline Comunidad de Madrid & 17,36 & 5,37 & - & 44,38 & 8,99 \\
\hline TOTAL ESPAÑA & $\mathbf{5 , 6 5}$ & $\mathbf{5 , 4 7}$ & $\mathbf{1 6 , 5 0}$ & $\mathbf{7 7 , 1 0}$ & $\mathbf{0 , 9 3}$ \\
\hline
\end{tabular}

A nivel nacional, en el año 2016, tan solo el 5,65\% de los RSU mezclados generados fueron tratados en las PT, esto es debido a que este tipo de instalaciones son poco habituales y solo existen en cinco CC.AA. No obstante, a nivel autonómico destaca Galicia, donde el principal destino de los RSU mezclados fueron estas 
plantas con un tratamiento del $62,52 \%$ de los mismos. Por el contrario, en Cataluña tan solo se trataron un $0,70 \%$.

Respecto a los rendimientos globales de los materiales recuperados, a nivel nacional este fue del 5,47\%. Cataluña con un $37,84 \%$ y Andalucía con un $20,83 \%$ fueron las comunidades con mayor recuperación de materiales reciclables. Mientras que Galicia y la Comunidad de Madrid las que menos, a pesar de que las cantidades recuperadas absolutas eran las más elevadas, como se ha visto en la Tabla 3.22. Esto puede estar relacionado con que en estas dos comunidades el tipo de tratamiento que se realiza en estas instalaciones es principalmente un triaje previo a la incineración, lo que puede penalizar la recuperación de materiales.

En cuanto al porcentaje de rechazo en España, esta se situó en un 77,10\%, lo que significa que de todos los RSU entrantes a las PT españolas más de tres cuartos acabaron convertidos en rechazo. A nivel autonómico, la Comunidad de Madrid es la que menos cantidades de rechazo produjo (44,38\%) y Galicia la que más, con valores por encima del $97 \%$ de los residuos entrantes (Tabla 3.25).

Las mermas del proceso de tratamiento en PT españolas son de un 0,93\% de media.

\subsubsection{Plantas de recuperación y compostaje}

Las PRC españolas trataron en 2016 más de 8 Mt de RSU mezclados, siendo Andalucía y la Comunidad Valenciana las CC.AA. donde las entradas en estas instalaciones fueron mayores, con casi $3 \mathrm{Mt}$ en la primera y casi 1,5 Mt en la segunda (Tabla 3.26). Además, en estas comunidades es donde existe un mayor número de instalaciones de este tipo. La menor entrada se dio en las Islas Baleares. Por otro lado, Aragón, Asturias, Galicia, Navarra, La Rioja y la Comunidad de Madrid no cuentan con PRC en su territorio.

Tabla 3.26 Balances de materia PRC, 2016

\begin{tabular}{|c|c|c|c|c|c|c|}
\hline CC.AA. & $\begin{array}{l}\text { RSU mezclados } \\
\text { (t/año)* }\end{array}$ & $\begin{array}{c}\text { Núm. de } \\
\text { instalaciones }\end{array}$ & $\begin{array}{c}E_{\text {RSU }} \\
\text { (t/año) }\end{array}$ & $\begin{array}{c}\mathrm{S}_{\mathrm{MR}} \\
\text { (t/año) }\end{array}$ & $\begin{array}{c}\text { BIOST } \\
\text { (t/año) }\end{array}$ & $\begin{array}{c}\text { Rechazo } \\
\text { (t/año) }\end{array}$ \\
\hline Andalucía & 3.907 .576 & 20 & 2.849 .299 & 145.650 & 108.572 & 2.032 .466 \\
\hline Islas Balearas ${ }^{1}$ & 698.764 & 1 & 46.249 & 259 & n. d. & 19.652 \\
\hline Canarias & 1.096 .600 & 3 & 510.630 & 25.570 & 31.321 & 447.774 \\
\hline Cantabria & 264.089 & 1 & 223.573 & 13.039 & 25.963 & 159.102 \\
\hline Castilla - La Mancha & 881.455 & 6 & 634.107 & 37.974 & 62.953 & 419.008 \\
\hline Castilla y León & 918.165 & 6 & 242.820 & 9.656 & 25.698 & 167.251 \\
\hline Cataluña ${ }^{1}$ & 2.440 .229 & 8 & 966.785 & 81.949 & n. d. & 451.563 \\
\hline Región de Murcia & 624.223 & 4 & 607.527 & 21.352 & 47.142 & 448.883 \\
\hline País Vasco ${ }^{1}$ & 670.781 & 1 & 113.078 & 5.810 & n. d. & 80.837 \\
\hline TOTAL ESPAÑA & 18.052 .075 & 67 & 8.023 .325 & 444.798 & 534.595 & 5.428 .976 \\
\hline
\end{tabular}

* Fuente: INE (2018) Estadísticas sobre recogida de residuos urbanos - Año 2016

${ }^{1}$ La C.A. no ha proporcionado los datos correspondientes a algunas corrientes en la memoria del MITECO

La cantidad total de materiales recuperados durante 2016 en las PRC fue de 444.798 t. Andalucía, la Comunidad Valenciana y Cataluña son las comunidades con valores más altos y juntas suman más del $75 \%$ del material total recuperado. En cuanto a los porcentajes relativos de los diferentes subproductos obtenidos en la recuperación, estos se exponen en la Tabla 3.27. 
Tabla 3.27 Porcentajes de materiales recuperados en las PRC, 2016

\begin{tabular}{c|c|c|c|c|c|c}
\hline \multirow{2}{*}{ CC.AA. } & \multicolumn{7}{c}{ S } & \multicolumn{7}{c}{ MR por tipo de subproducto (\%) } \\
\cline { 2 - 7 } & Metal & Plástico & Vidrio & Papel/Cartón & Brik & Otros \\
\hline Andalucía & 26,02 & 26,05 & 3,49 & 31,95 & 4,38 & 8,11 \\
\hline Islas Balearas & 32,82 & 0,00 & 14,29 & 52,90 & 0,00 & 0,00 \\
\hline Canarias & 22,40 & 40,26 & 1,65 & 31,78 & 3,92 & 0,00 \\
\hline Cantabria & 25,78 & 7,95 & 10,52 & 54,44 & 1,31 & 0,00 \\
\hline Castilla - La Mancha & 31,25 & 24,04 & 2,01 & 33,09 & 7,57 & 2,05 \\
\hline Castilla y León & 37,15 & 20,92 & 0,78 & 34,72 & 4,61 & 1,82 \\
\hline Cataluña & 23,91 & 38,01 & 10,77 & 8,98 & 2,30 & 16,03 \\
\hline Comunidad Valenciana & 24,12 & 27,02 & 0,00 & 26,52 & 7,22 & 15,12 \\
\hline Extremadura & 31,14 & 15,19 & 8,94 & 44,62 & 0,11 & 0,00 \\
\hline Región de Murcia & 35,46 & 34,84 & 8,06 & 16,19 & 2,57 & 2,89 \\
\hline País Vasco & 1,51 & 68,66 & 0,00 & 29,83 & 0,00 & 0,00 \\
\hline TOTAL ESPAÑA & $\mathbf{2 6 , 0 4}$ & $\mathbf{2 9 , 0 5}$ & $\mathbf{4 , 4 2}$ & $\mathbf{2 7 , 1 0}$ & $\mathbf{4 , 4 3}$ & $\mathbf{8 , 9 7}$ \\
\hline
\end{tabular}

A nivel nacional, los subproductos con una mayor recuperación en las PRC fueron los plásticos (29,05\%), el papel/cartón $(27,10 \%)$ y los metales $(26,04 \%)$. Mientras que el brik y el vidrio son los que tuvieron una menor recuperación, con un 4,4\% respecto al total de materiales recuperados. El País Vasco es la comunidad con mayor recuperación de plásticos, con un $68,66 \%$ del total, y Cantabria lo es para el papel/cartón con un $54,44 \%$. En cuanto a los metales, todas la CC.AA. presentan un elevado porcentaje de recuperación, con valores por encima del $20 \%$, menos el País Vasco (1,51\%).

En relación al bioestabilizado, la producción a nivel nacional fue de 534.595 t. De ellas, más de la mitad fueron producidas en Andalucía y la Comunidad Valenciana (Tabla 3.26), donde las entradas de RSU mezclados son más elevadas. Por lo que para una correcta comparación entre las diferentes CC.AA. es necesario utilizar los indicadores del rendimiento.

Finalmente, el rechazo total generado en estas instalaciones fue de casi 5,5 Mt. De ellas, 2 millones se generaron en la PRC andaluzas y casi otro millón en las PRC valencianas (CC.AA. con mayores entradas de RSU). Las Islas Baleares es la comunidad donde la generación de rechazo fue menor.

En la Tabla 3.28 se muestra el tratamiento que se les dio a estos rechazos, en ella se observa que tan solo en las Isla Baleares, Cantabria, Cataluña, la Comunidad Valenciana y el País Vasco parte de sus rechazos fueron valorizados energéticamente, en el resto de las CC.AA. españolas el destino fue el vertedero. Cantabria es la comunidad que mayor porcentaje de rechazos incineró $(72,57 \%)$, seguida por el País Vasco (54,59\%). Por otra parte, la Comunidad Valenciana solo valorizó el 1,06\% de sus rechazos. No obstante, hay que destacar que no dispone de incineradoras en su territorio, por lo que la valorización de los mismos se realizó mediante su transformación en un CSR que fue utilizado en cementeras. A nivel nacional, tan solo el $4,72 \%$ del rechazo se valorizó energéticamente, suponiendo un 10,68\% del material entrante a las incineradoras españolas. El resto, un $95,28 \%(5,2 \mathrm{Mt})$, tuvo como destino el vertedero, lo que supuso un $38,80 \%$ del material entrante a los mismos. 
Tabla 3.28 Tratamiento de los rechazos en las PRC, 2016

\begin{tabular}{c|c|c}
\hline \multirow{2}{*}{ CC.AA. } & \multicolumn{2}{|c}{ Tratamiento del rechazo (\%) } \\
\cline { 2 - 3 } & Vertedero & Incineración \\
\hline Andalucía & 100,00 & 0,00 \\
\hline Islas Balearas & 74,63 & 25,37 \\
\hline Canarias & 100,00 & 0,00 \\
\hline Cantabria & 27,43 & 72,57 \\
\hline Castilla - La Mancha & 100,00 & 0,00 \\
\hline Castilla y León & 100,00 & 0,00 \\
\hline Cataluña & 81,88 & 18,12 \\
\hline Comunidad Valenciana & 98,94 & 1,06 \\
\hline Extremadura & 100,00 & 0,00 \\
\hline Región de Murcia & 100,00 & 0,00 \\
\hline País Vasco & 45,41 & 54,59 \\
\hline TOTAL ESPAÑA & 95,28 & 4,72 \\
\hline
\end{tabular}

Tras definir los balances de materia de las PRC, se han determinado los indicadores del rendimiento de estas instalaciones, en la Tabla 3.29 se muestran los valores obtenidos.

Tabla 3.29 RSU tratados e indicadores del rendimiento de las PRC, 2016

\begin{tabular}{|c|c|c|c|c|c|}
\hline CC.AA. & $\mathrm{RSU}_{\mathrm{T}}(\%)$ & $\mathrm{RG}_{\mathrm{MR}}(\%)$ & $\mathrm{RG}_{\text {BIOST }}(\%)$ & RECHAZO (\%) & $M(\%)$ \\
\hline Andalucía & 72,92 & 5,11 & 3,81 & 71,33 & 19,75 \\
\hline Islas Balearas ${ }^{1}$ & 6,62 & 0,56 & n. d. & 42,49 & n. d. \\
\hline Canarias & 46,56 & 5,01 & 7,78 & 87,69 & $-0,47$ \\
\hline Cantabria & 84,66 & 5,83 & 11,61 & 71,16 & $11, .39$ \\
\hline Castilla - La Mancha & 71,94 & 5,99 & 9,93 & 66,08 & 18,01 \\
\hline Castilla y León & 26,45 & 3,98 & 10,58 & 68,88 & 16,56 \\
\hline Cataluña ${ }^{1}$ & 39,62 & 8,48 & n. d. & 46,71 & n. d. \\
\hline Comunidad Valenciana & 73,84 & 6,19 & 13,98 & 64,98 & 14,85 \\
\hline Extremadura & 95,81 & 3,77 & 8,26 & 68,44 & 19,53 \\
\hline Región de Murcia & 97,33 & 3,51 & 7,76 & 73,89 & 14,84 \\
\hline País Vasco ${ }^{1}$ & 16,86 & 5,14 & n. d. & 71,49 & n. d. \\
\hline TOTAL ESPAÑA & 44,45 & 5,54 & 7,75 & 67,66 & 19,04 \\
\hline
\end{tabular}

${ }^{1}$ La C.A. no ha proporcionado los datos correspondientes a algunas corrientes en la memoria del MITECO.

En el año 2016 en España el 44,45\% de los RSU mezcla generados fueron tratados en las PRC. Además, para las CC.AA. de Andalucía, Cantabria, Castilla - La Mancha, Comunidad Valenciana, Extremadura y Región de Murcia este fue el principal destino de sus RSU, con un tratamiento de más del 70\% de los mismos (Tabla 3.29). Las Islas Baleares $(6,62 \%)$ y el País Vasco $(16,86 \%)$ son las comunidades con un menor porcentaje de RSU mezclados tratados en estas instalaciones. 
En la Tabla 3.29 también se exponen los rendimientos globales de subproductos. A nivel nacional, para los materiales recuperados este fue del 5,54\%. Los rendimientos más altos se dieron en las CC.AA. de Cataluña y Comunidad Valenciana, con un $8,48 \%$ y un 6,19\% respectivamente. Las Islas Baleares es donde se obtuvo una menor recuperación de materiales reciclables con un $0,56 \%$ de los residuos entrantes. En el caso de la producción de bioestabilizado, el rendimiento global para España fue del 7,75\%. A nivel autonómico, Cantabria, Castilla y León y la Comunidad Valenciana tuvieron rendimientos por encima del 10\%, mientras que Andalucía obtuvo los peores valores con un 3,81\%.

Respecto al porcentaje de rechazo, este alcanzo valores del $67,66 \%$ respecto a las entradas totales en las PRC españolas, por lo que más de la mitad de los RSU mezclados que entraron en estas instalaciones acabaron en el rechazo de las mismas. Estos valores son muy similares en todas las CC.AA., siendo las Islas Baleares $(42,49 \%)$ y Cataluña $(46,71 \%)$ las que generaron una menor cantidad de rechazo y Canarias la que más $(87,69 \%)$ (Tabla 3.29).

Las mermas del proceso de tratamiento en PRC españolas son de un 19,04\% de media.

\subsubsection{Plantas de biosecado y recuperación}

Como se ha visto en el apartado 3.4, en España solo existe una planta que utilice la tecnología de biosecado para el tratamiento biológico de los RSU mezclados. Esta instalación está situada al norte de la Comunidad Valenciana, en la provincia de Castellón.

En el año 2016 en esta planta se trataron 62.013 t de RSU mezclados y del proceso se obtuvieron $2.949 \mathrm{t}$ de materiales recuperados, 3.085 t de material bioestabilizado y 28.323 t de rechazo, el cual se destinó íntegramente a vertedero. De todos los subproductos valorizables, los plásticos son los que se recuperaron en mayor medida con un $58,66 \%$ del total de material recuperado, seguido por los metales con un $28,62 \%$. Los subproductos de menor recuperación son el papel/cartón (7,39\%) y los Otros (5,32\%). En esta instalación no se lleva a cabo la separación del vidrio, mientras que de los briks no se aporta información.

De todos los RSU mezclados que se generaron en la Comunidad Valenciana en 2016, esta instalación trató el 3,20\%. Los rendimientos para los subproductos obtenidos en el proceso respecto a las entradas fueron: del 4,76\% para la recuperación de materiales y del 4,97\% para la producción de bioestabilizado. El porcentaje de rechazo generado fue de $45,67 \%$. Cabe señalar que las mermas del proceso (emisiones gaseosas y liquidas) son muy elevadas, del $44,60 \%$, debido al tipo de tratamiento llevado a cabo en la misma.

\subsubsection{Plantas de recuperación, biometanización y compostaje}

En 2016, la cantidad de RSU mezclados tratados en estas instalaciones fue de 3,2 Mt (Tabla 3.30). Castilla León con 668.214 t, la Comunidad de Madrid con 622.243 t y Cataluña con 509.296 t fueron las CC.AA. con una mayor cantidad de entradas a este tipo de instalaciones, coincidiendo también con las que más número de PRBC tienen. El tratamiento de los RSU en este tipo de planta está implantado en casi todo el territorio español, salvo Asturias, Cantabria, Castilla - La Mancha, Extremadura y Murcia.

La cantidad total materiales reciclables recuperados a nivel nacional en las PRBC fue de $158.664 \mathrm{t}$ y las CC.AA. donde esta recuperación fue mayor son, en este orden: Cataluña, Comunidad de Madrid y Castilla y León. En la Tabla 3.31 se muestra el porcentaje relativo de los diferentes tipos de material reciclables obtenidos respecto al total recuperado. 
Tabla 3.30 Balances de materia PRBC, 2016

\begin{tabular}{|c|c|c|c|c|c|c|c|}
\hline CC.AA. & $\begin{array}{l}\text { RSU mezclados } \\
\text { (t/año)* }\end{array}$ & $\begin{array}{c}\text { Núm. de } \\
\text { instalaciones }\end{array}$ & $\begin{array}{c}E_{\text {RSU }} \\
\text { (t/año) }\end{array}$ & $\begin{array}{c}\mathrm{S}_{\mathrm{MR}} \\
\text { (t/año) }\end{array}$ & $\begin{array}{c}\text { BGAS } \\
\text { (m3/año) }\end{array}$ & $\begin{array}{c}\text { BIOST } \\
\text { (t/año) }\end{array}$ & $\begin{array}{c}\text { Rechazo } \\
\text { (t/año) }\end{array}$ \\
\hline Andalucía & 3.907 .576 & 1 & 89.845 & 4.665 & 350.615 & 2.338 & 74.500 \\
\hline Aragón & 458.616 & 1 & 249.032 & 10.773 & 7.390 .116 & 10.001 & 174.240 \\
\hline Canarias & 1.096 .600 & 2 & 263.268 & 11.584 & 3.429 .875 & 3.189 & 205.584 \\
\hline Castilla y León & 918.165 & 6 & 668.214 & 23.912 & 3.657 .323 & 66.686 & 507.278 \\
\hline Cataluña ${ }^{1}$ & 2.440 .229 & 3 & 509.296 & 43.108 & n. d. & 10.596 & 349.451 \\
\hline $\begin{array}{l}\text { Comunidad } \\
\text { Valenciana }\end{array}$ & 1.937 .324 & 2 & 397.672 & 15.101 & 3.370 .786 & 44.497 & 267.542 \\
\hline Galicia & 945.835 & 1 & 159.744 & 12.478 & 8.895 .710 & 9.038 & 92.279 \\
\hline La Rioja & 107.762 & 1 & 106.233 & 5.458 & 4.594.193 & 10.867 & 65.460 \\
\hline $\begin{array}{c}\text { Comunidad de } \\
\text { Madrid }\end{array}$ & 2.077 .644 & 3 & 622.243 & 24.904 & 34.236 .153 & 29.126 & 638.693 \\
\hline $\begin{array}{c}\text { Comunidad Foral } \\
\text { de Navarra }\end{array}$ & 165.385 & 1 & 66.736 & 1.025 & 1.977 .118 & 3.486 & 35.103 \\
\hline País Vasco ${ }^{1}$ & 670.781 & 1 & 83.783 & 5.656 & n. d. & n. d. & 49.971 \\
\hline TOTAL ESPAÑA & 18.052 .075 & 22 & 3.216 .066 & 158.664 & 67.901 .889 & 189.824 & 2.460 .101 \\
\hline
\end{tabular}

* Fuente: INE (2018) Estadísticas sobre recogida de residuos urbanos - Año 2016

${ }^{1}$ La C.A. no ha proporcionado los datos correspondientes a algunas corrientes en la memoria del MITECO

Tabla 3.31 Porcentajes de materiales recuperados en las PRBC, 2016

\begin{tabular}{|c|c|c|c|c|c|c|}
\hline \multirow{2}{*}{ CC.AA. } & \multicolumn{6}{|c|}{$\mathrm{S}_{\mathrm{MR}}$ por tipo de subproducto (\%) } \\
\hline & Metal & Plástico & Vidrio & Papel/Cartón & Brik & Otros \\
\hline Andalucía & 30,12 & 21,56 & 8,30 & 35,65 & 4,37 & 0,00 \\
\hline Aragón & 27,00 & 39,13 & 0,38 & 22,59 & 10,47 & 0,42 \\
\hline Canarias & 21,74 & 37,91 & 0,00 & 36,06 & 4,29 & 0,00 \\
\hline Castilla y León & 34,23 & 18,28 & 1,53 & 29,24 & 4,40 & 12,31 \\
\hline Cataluña & 22,58 & 44,09 & 7,67 & 22,89 & 2,77 & 0,00 \\
\hline $\begin{array}{l}\text { Comunidad } \\
\text { Valenciana }\end{array}$ & 29,47 & 35,73 & 0,00 & 26,42 & 4,09 & 4,28 \\
\hline Galicia & 17,86 & 58,37 & 0,00 & 19,09 & 4,68 & 0,00 \\
\hline La Rioja & 35,69 & 16,36 & 6,71 & 35,69 & 3,72 & 1,83 \\
\hline $\begin{array}{l}\text { Comunidad de } \\
\text { Madrid }\end{array}$ & 29,71 & 17,55 & 1,02 & 46,96 & 2,16 & 2,61 \\
\hline $\begin{array}{l}\text { Comunidad Foral de } \\
\text { Navarra }\end{array}$ & 47,12 & 29,76 & 0,00 & 20,00 & 2,34 & 0,78 \\
\hline País Vasco & 29,21 & 18,35 & 9,64 & 42,70 & 0,00 & 0,11 \\
\hline TOTAL ESPAÑA & 27,05 & 32,95 & 3,32 & 30,11 & 3,81 & 2,77 \\
\hline
\end{tabular}

En 2016, el 32,95\% de los materiales recuperados en las PRBC españolas correspondieron a plásticos, el $30,11 \%$ a papel/cartón y el 27,05\% a los metales. La fracción con menor recuperación fueron los Otros con un $2,77 \%$. Galicia fue la comunidad con una mayor recuperación de plásticos con un $58,37 \%$ respecto al 
total. La Comunidad de Madrid y el País Vasco es donde más elevada fue la recuperación de papel/cartón, con valores superiores al $40 \%$. Mientras que los metales fueron recuperados en mayor medida en la Comunidad Foral de Navarra (47,12\%).

Respecto al tratamiento biológico, por un lado, en la etapa de biometanización se produjeron a nivel estatal 67,9 millones de $\mathrm{m}^{3}$ de biogás (Tabla 3.30), siendo la Comunidad de Madrid la principal productora con más de la mitad del volumen total generado. Por otro, el compostaje del digestato permitió obtener un total de 189.824 t de bioestabilizado, siendo Castilla y León la mayor productora.

Por último, el rechazo generado en 2016 por las PRBC españolas fue de 2,5 Mt (Tabla 3.30). Las CC.AA. donde se generaron mayores cantidades de rechazo fueron la Comunidad de Madrid seguida por Castilla y León, mientras que la menor generación se dio en la Comunidad Foral de Navarra. El destino de estos rechazos fue mayoritariamente la disposición en vertedero, sin embargo, algunas comunidades aprovecharon energéticamente una parte. El tratamiento de los rechazos en cada una de las CC.AA. se muestra en la Tabla 3.32. En ella se puede observar que las únicas CC.AA. que valorizaron energéticamente parte de sus rechazos son Cataluña $(83,81 \%)$ y la Comunidad de Madrid (18,18\%). A nivel global, del total de rechazo producido en las PRBC españolas, un 16,62\% se aprovechó energéticamente, suponiendo el 17,05\% del material entrante en las incineradoras. El resto $(83,38 \%)$ fue enviado a vertedero, donde supuso un $15,39 \%$ de sus entradas.

Tabla 3.32 Tratamiento de los rechazos en las PRBC, 2016

\begin{tabular}{c|c|c}
\hline \multirow{2}{*}{ CC.AA. } & \multicolumn{2}{c}{ Tratamiento del rechazo (\%) } \\
\cline { 2 - 3 } & Vertedero & Incineración \\
\hline Andalucía & 100,00 & 0,00 \\
\hline Aragón & 100,00 & 0,00 \\
\hline Canarias & 100,00 & 0,00 \\
\hline Castilla y León & 100,00 & 0,00 \\
\hline Cataluña & 16,19 & 83,81 \\
\hline Comunidad Valenciana & 100,00 & 0,00 \\
\hline Galicia & 100,00 & 0,00 \\
\hline La Rioja & 100,00 & 0,00 \\
\hline Comunidad de Madrid & 81,82 & 18,18 \\
\hline Comunidad Foral de Navarra & 100,00 & 0,00 \\
\hline País Vasco & 100,00 & 0,00 \\
\hline TOTAL ESPAÑA & $\mathbf{8 3 , 3 8}$ & $\mathbf{1 6 , 6 2}$ \\
\hline
\end{tabular}

A continuación, se han calculado los indicadores del rendimiento de las PRBC, los cuales se exponen en la Tabla 3.33. En ella se observa que el $17,82 \%$ de los RSU mezclados que se generaron en 2016 fueron tratados en estas instalaciones. La Rioja destino a sus PRBC el 98,58\% de sus residuos generados, siendo también el principal tratamiento para las CC.AA. de Castilla y León y Aragón. Mientras que en Andalucía este tratamiento fue minoritario $(2,30 \%)$. 
Tabla 3.33 RSU tratados e indicadores del rendimiento de las PRBC, 2016

\begin{tabular}{|c|c|c|c|c|c|}
\hline CC.AA. & $\mathrm{RSU}_{\mathrm{T}}(\%)$ & $\mathrm{RG}_{\mathrm{MR}}(\%)$ & $\begin{array}{l}R G_{B G A S} \\
\left(m^{3} / t\right)\end{array}$ & RG $_{\text {BIOST }}(\%)$ & $\begin{array}{c}\text { RECHAZO } \\
\text { (\%) }\end{array}$ \\
\hline Andalucía & 2,30 & 5,19 & 3,90 & 2,60 & 82,92 \\
\hline Aragón & 54,30 & 4,33 & 29,68 & 4,02 & 69,97 \\
\hline Canarias & 24,01 & 4,40 & 13,03 & 1,21 & 78,09 \\
\hline Castilla y León & 72,78 & 3,58 & 6,67 & 9,98 & 75,92 \\
\hline Cataluña ${ }^{1}$ & 20,87 & 8,46 & n. d. & 5,52 & 68,61 \\
\hline Comunidad Valenciana & 20,53 & 3,80 & 8,48 & 11,19 & 67,28 \\
\hline Galicia & 16,89 & 7,81 & 55,69 & 5,66 & 57,77 \\
\hline La Rioja & 98,58 & 5,14 & 43,25 & 10,23 & 61,62 \\
\hline Comunidad de Madrid & 29,95 & 4,00 & 55,02 & 6,81 & 81,69 \\
\hline $\begin{array}{c}\text { Comunidad Foral de } \\
\text { Navarra }\end{array}$ & 40,35 & 1,54 & 29,63 & 5,22 & 52,60 \\
\hline País Vasco ${ }^{1}$ & 12,49 & 6,75 & n. d. & n. d. & 59,64 \\
\hline TOTAL ESPAÑA & 17,82 & 4,93 & 21,93 & 6,61 & 70,64 \\
\hline
\end{tabular}

${ }^{1}$ La C.A. no ha proporcionado los datos correspondientes a algunas corrientes en la memoria del MITECO

Para los materiales reciclables, las PRBC españolas obtuvieron un rendimiento global de 4,93\% respecto al total de residuos entrantes (Tabla 3.33), siendo Cataluña y Galicia las comunidades con valores más altos ( $8,46 \%$ y $7,81 \%$ respectivamente). La menor recuperación de materiales reciclables se dio en la Comunidad Foral de Navarra (1,54\%). Para la producción de biogás, a nivel nacional, por cada tonelada de material entrante se produjeron 21,93 $\mathrm{m}^{3}$ del mismo. Las CC.AA. de Galicia y Madrid obtuvieron los mayores rendimientos para este subproducto y Andalucía los menores. Para la producción de bioestabilizado a partir del digestato, las PRBC españolas tuvieron un rendimiento global del 6,61\%. A nivel autonómico, la Comunidad Valenciana y La Rioja obtuvieron rendimientos superiores al 10\%, mientras que en Canarias y Andalucía se dieron los valores más bajos.

Respecto al porcentaje de rechazo, en 2016 esta se situó en el 70,64\% respecto a las entradas totales en las PRBC españolas, lo que supuso que casi tres cuartos de los RSU mezclados que fueron tratados en estas instalaciones acabaran en el rechazo de las mismas. Destacan las CC.AA. de Andalucía y Madrid por tener las mayores generaciones de rechazo, por encima del $80 \%$.

En el caso de las PRBC no se pueden determinar las mermas del proceso, ya que se desconocer la producción de biogás en peso.

\subsubsection{Plantas de compostaje de la FORS}

Las PCFO españolas trataron 303.380 t de FORS en 2016. Junto con la FORS, en estas plantas también se trataron 122.609 t de otro tipo de residuos biodegradables ( $\left.E_{R V-L}\right)$ como los restos de poda y los lodos, con unas entradas totales de $425.989 \mathrm{t}$.

Respecto a la FORS, más de la mitad de las toneladas fueron tratadas en Cataluña, ya que es la comunidad donde la recogida selectiva de la fracción orgánica está más extendida, contando con 23 instalaciones de este tipo para su tratamiento. Por el contrario, en Canarias y el País Vasco se dieron las menores entradas (Tabla 3.34). En cuanto a los restos de poda y los lodos, Cataluña con 45.265 t y Andalucía con 37.629 t, fueron las CC.AA. donde las entradas de estos residuos biodegradables fueron mayores. 
Tabla 3.34 Balances de materia PCFO, 2016

\begin{tabular}{|c|c|c|c|c|c|c|}
\hline \multirow{2}{*}{ CC.AA. } & \multirow{2}{*}{$\begin{array}{l}\text { Recogida FORS } \\
\text { (t/año)* }\end{array}$} & \multirow{2}{*}{$\begin{array}{c}\text { Núm. de } \\
\text { instalaciones }\end{array}$} & \multicolumn{2}{|c|}{ Entradas (t/año) } & \multirow{2}{*}{$\begin{array}{l}\text { COMP } \\
\text { (t/año) }\end{array}$} & \multirow{2}{*}{$\begin{array}{l}\text { Rechazo } \\
\text { (t/año) }\end{array}$} \\
\hline & & & $\mathrm{E}_{\mathrm{FORS}}$ & $E_{R V-L}$ & & \\
\hline Andalucía & 89.603 & 1 & 78.146 & 37.629 & 11.294 & 62.183 \\
\hline $\begin{array}{l}\text { Principado de } \\
\text { Asturias }\end{array}$ & 13.728 & 1 & 254 & 16.335 & 2.532 & $0^{2}$ \\
\hline Canarias & 19.956 & 1 & 237 & 99 & 30 & 5 \\
\hline Cataluña & 449.152 & 23 & 173.755 & 45.265 & 57.895 & 27.159 \\
\hline Galicia & 45.756 & 2 & 9.213 & 290 & 155 & 1.400 \\
\hline $\begin{array}{c}\text { Comunidad Foral } \\
\text { de Navarra }\end{array}$ & 49.360 & 2 & 33.486 & 17.102 & 6.472 & 6.276 \\
\hline País Vasco ${ }^{1}$ & 14.988 & 4 & 8.289 & 5.889 & 1.207 & n. d. \\
\hline TOTAL ESPAÑA & 835.703 & 34 & 303.380 & 122.609 & 79.585 & 97.023 \\
\hline
\end{tabular}

* Fuente: INE (2018) Estadísticas sobre recogida de residuos urbanos - Año 2016

${ }^{1}$ La C.A. no ha proporcionado los datos correspondientes a algunas corrientes en la memoria del MITECO

${ }^{2}$ No hay rechazo porque se recircula en el proceso

Como se ha visto anteriormente en este tipo de plantas se recuperan metales férricos, sin embargo, la Memoria del MITECO no proporciona datos sobre las cantidades recuperadas. En cuanto al compost, a nivel nacional la producción alcanzó las 79.585 t (Tabla 3.34), de ellas 57.895 t fueron producidas en las PCFO catalanas, lo que supone más del $70 \%$ de la producción. En Canarias la cantidad de compost producido fue la más baja, con tan solo 30 t, aunque también fue la C.A. con menores entradas a planta.

La generación de rechazo de las PCFO españolas fue de 97.023 t, siendo Andalucía la comunidad que más cantidad de rechazo produjo (62.183 t). En el Principado de Asturias no se generó rechazo, esto se debe a que la PCFO de esta comunidad lo recircula en el proceso. En la Tabla 3.35 se muestra el tratamiento que se le dio a estos rechazos en cada una de las CC.AA.

Tabla 3.35 Tratamiento de los rechazos en las PCFO, 2016

\begin{tabular}{c|c|c}
\hline \multirow{2}{*}{ CC.AA. } & \multicolumn{2}{c}{ Tratamiento del rechazo (\%) } \\
\cline { 2 - 3 } & Vertedero & Incineración \\
\hline Andalucía & 100,00 & 0,00 \\
\hline Principado de Asturias & 0,00 & 0,00 \\
\hline Canarias & 100,00 & 0,00 \\
\hline Cataluña & 97,15 & 2,85 \\
\hline Galicia & 100,00 & 0,00 \\
\hline Comunidad Foral de Navarra & 0,00 & 0,00 \\
\hline País Vasco & 0,00 & 0,00 \\
\hline TOTAL ESPAÑA & $\mathbf{9 9 , 2 0}$ & $\mathbf{0 , 8 0}$ \\
\hline
\end{tabular}

El principal tratamiento para los rechazos producidos en las PCFO fue la disposición final en vertedero, como se ve en la tabla anterior, tan solo Cataluña valorizó energéticamente parte de sus rechazos (2,85\%). A nivel nacional el $99,20 \%$ de los rechazos fueron depositados en vertedero, donde supusieron el $0,72 \%$ de las entradas de material a los mismos.

Tras definir los balances de materia para las PCFO se han determinado los indicadores del rendimiento de estas instalaciones, los valores obtenidos se muestran en la siguiente tabla. 
Tabla 3.36 FORS tratada e indicadores del rendimiento de las PCFO, 2016

\begin{tabular}{c|c|c|c|c}
\hline CC.AA. & FORS $_{\text {T }}$ (\%) & RG $_{\text {сOMP (\%) }}$ & RECHAZO (\%) & M (\%) \\
\hline Andalucía & 87,21 & 9,76 & 53,71 & 36,53 \\
\hline Principado de Asturias & 1,85 & 15,26 & $0^{2}$ & 84,74 \\
\hline Canarias & 1,19 & 8,93 & 1,49 & 89,58 \\
\hline Cataluña & 38,69 & 14,64 & 14,24 & 71,12 \\
\hline Galicia & 20,14 & 1,63 & 14,73 & 83,64 \\
\hline Comunidad Foral de Navarra $^{\text {País Vasco }}{ }^{1}$ & 67,84 & 12,79 & 37,33 & 55,15 \\
\hline TOTAL ESPAÑA & 55,30 & 30,14 & n. d. & 69,86 \\
\hline $\mathbf{3 6 , 3 0}$ & $\mathbf{1 2 , 6 4}$ & $\mathbf{2 8 , 0 9}$ & $\mathbf{5 9 , 2 7}$ \\
\hline
\end{tabular}

${ }^{1}$ La C.A. no ha proporcionado los datos correspondientes a algunas corrientes en la memoria del MITECO

${ }^{2}$ No hay rechazo porque se recircula en el proceso

En el año 2016 en España el 36,30\% de la FORS fue tratada en las PCFO (Tabla 3.36). Por CC.AA., Andalucía trató el $87,21 \%$ de la FORS en la única PCFO existente en su territorio. Esta instalación está situada en la ciudad de Córdoba, donde el sistema de recogida selectiva implantado es el húmedo-seco. Navarra trató en sus PCFO el $67,84 \%$, País Vasco el $55,30 \%$ y Cataluña el $38,69 \%$. Cataluña y Navarra son las comunidades donde la recogida y el tratamiento de la FORS están más implantados, por lo que entre las PCFO y las PBCFO se tratan casi el $100 \%$ de la FORS generada en las mismas.

Como se observa en la Tabla 3.36 el rendimiento global de producción de compost fue de 12,64\%. Los valores más altos se dieron en País Vasco $(30,14 \%)$, en el Principado de Asturias $(15,26 \%)$ y en Cataluña $(14,64 \%)$, mientras que los más bajos se obtuvieron en Galicia $(1,63 \%)$.

La generación de rechazo en las PCFO en 2016 se situó en el 28,09\% del material entrante a las instalaciones (Tabla 3.36), muy por debajo de los valores obtenidos en las instalaciones donde se tratan RSU mezclados. Esto se debe a que la FORS es un material más homogéneo y con un contenido en impropios muy bajo. Andalucía es la CC.AA. con mayor producción de rechazo con un $53,71 \%$ respecto a las entradas, seguida por la Comunidad Foral de Navarra con un 37,33\%. Como se ha comentado anteriormente en Asturias no se generó rechazo porque este fue recirculado en el proceso.

Las mermas del proceso de tratamiento en PCFO españolas son de un $59,26 \%$ de media.

\subsubsection{Plantas de biometanización y compostaje de la FORS}

La cantidad de FORS tratada en las PBCFO españolas en 2016 fue de 250.604 t. A esta cantidad hay que añadirle las entradas de otro tipo de residuos biodegradables ( $\left.E_{R V-L}\right)$ como los restos de poda y los lodos (39.923 t), sumando un total de $290.527 \mathrm{t}$.

Cataluña, con $220.693 \mathrm{t}$, fue la CC.AA donde el tratamiento de la FORS en este tipo de instalaciones fue mayor, coincidiendo con la comunidad que mayor número de PCFO tiene (Tabla 3.37). Respecto a los restos de poda y los lodos destaca el Principado de Asturias, donde las entradas de estos materiales son muy superiores a las de la FORS, suponiendo el $97,16 \%$ del total del material entrante.

Al igual que ocurre con las PCFO, la Memoria del MITECO no proporciona datos sobre las cantidades de metales férricos recuperados en estas instalaciones. 
Tabla 3.37 Balances de materia PBCFO, 2016

\begin{tabular}{|c|c|c|c|c|c|c|c|}
\hline \multirow{2}{*}{ CC.AA. } & \multirow{2}{*}{$\begin{array}{c}\text { Recogida } \\
\text { FORS (t/año)* }\end{array}$} & \multirow{2}{*}{$\begin{array}{c}\text { Núm. de } \\
\text { instalaciones }\end{array}$} & \multicolumn{2}{|c|}{ Entradas (t/año) } & \multirow{2}{*}{$\begin{array}{c}\text { BGAS } \\
\text { (m3/año) }\end{array}$} & \multirow{2}{*}{$\begin{array}{l}\text { COMP } \\
\text { (t/año) }\end{array}$} & \multirow{2}{*}{$\begin{array}{c}\text { Rechazo } \\
\text { (t/año) }\end{array}$} \\
\hline & & & $\mathrm{E}_{\mathrm{FORS}}$ & $E_{\text {RV-L }}$ & & & \\
\hline $\begin{array}{l}\text { Principado de } \\
\text { Asturias }^{1}\end{array}$ & 13.728 & 1 & 532 & 18.179 & 1.094 .548 & n. d. & 301 \\
\hline Islas Baleares & 36.739 & 1 & 18.825 & 19.122 & 1.490 .221 & 10.938 & 11.197 \\
\hline Cataluña ${ }^{1}$ & 449.152 & 4 & 220.693 & 2.622 & n. d. & 14.709 & 76.593 \\
\hline $\begin{array}{c}\text { Comunidad Foral } \\
\text { de Navarra }{ }^{1}\end{array}$ & 49.360 & 2 & 10.554 & 0 & n. d. & $0^{2}$ & 645 \\
\hline TOTAL ESPAÑA & 835.703 & 8 & 250.604 & 39.923 & 2.584 .769 & 25.647 & 88.736 \\
\hline
\end{tabular}

* Fuente: INE (2018) Estadísticas sobre recogida de residuos urbanos - Año 2016

${ }^{1}$ La C.A. no ha proporcionado los datos correspondientes a algunas corrientes en la memoria del MITECO

${ }^{2}$ El digestato no se composta, se centrifuga para desecarlo y la parte sólida se utiliza directamente como abono

Respecto a la biometanización solo se tienen datos de la producción de biogás en el Principado de Asturias y en las Islas Baleares, sumando entre las dos más de 2,5 millones de $\mathrm{m}^{3}$, a esta cantidad habría que añadirle el biogás que se produjo en las plantas de Cataluña y Navarra (Tabla 3.37). En cuanto al compostaje del digestato, la producción de compost fue de $25.647 \mathrm{t}$, siendo Cataluña la principal productora. Cabe señalar que en la Comunidad foral de Navarra el digestato no fue sometido al proceso de compostaje, sino que fue centrifugado y la parte sólida se utilizó directamente como abono.

El rechazo generado en las PBCFO españolas durante el 2016 fue de $88.736 \mathrm{t}$, de ellas $76.593 \mathrm{t}$ fueron producidas en las instalaciones existentes en Cataluña. A nivel nacional, el $61,85 \%$ de los rechazos generados fue destinado a valorización energética, suponiendo un 2,29\% del material entrante a las incineradoras españolas. El 38,15\% restante se depositó en vertedero, no obstante, hay CC.AA. como Asturias y Navarra en las que el $100 \%$ del rechazo generado tuvo este tratamiento (Tabla 3.38).

Tabla 3.38 Tratamiento de los rechazos en las PBCFO, 2016

\begin{tabular}{c|c|c}
\hline \multirow{2}{*}{ CC.AA. } & \multicolumn{2}{c}{ Tratamiento del rechazo (\%) } \\
\cline { 2 - 3 } & Vertedero & Incineración \\
\hline Principado de Asturias & 100,00 & 0,00 \\
\hline Islas Baleares & 0,00 & 100,00 \\
\hline Cataluña & 42,97 & 57,03 \\
\hline Comunidad Foral de Navarra & 100,00 & 0,00 \\
\hline TOTAL ESPAÑA & $\mathbf{3 8 , 1 5}$ & $\mathbf{6 1 , 8 5}$ \\
\hline
\end{tabular}

A continuación, se han calculado los indicadores del rendimiento de las PBCFO, los cuales se exponen en la Tabla 3.39. En ella se observa que en el año 2016 en España el 29,99\% de la FORS fue tratada e este tipo de instalaciones. La comunidad con un mayor tratamiento de este tipo de residuos en PBCFO es Islas Baleares con un $51,24 \%$. En Cataluña y Navarra el porcentaje de tratamiento en las PBCFO fue de un $49,14 \%$ y un $21,38 \%$, respectivamente. Por lo que, si a estos valeres se les suma el porcentaje de FORS tratada en la PCFO, se pueden afirmar que en estas dos CC.AA. casi el $100 \%$ de la FORS generada en las mismas es tratada en algún tipo de planta TMB. 
Tabla 3.39 FORS tratada e indicadores del rendimiento de las PBCFO, 2016

\begin{tabular}{|c|c|c|c|c|}
\hline CC.AA. & FORS $_{T}(\%)$ & $\mathrm{RG}_{\mathrm{BGAS}}\left(\mathrm{m}^{3} / \mathrm{t}\right)$ & $\mathbf{R G}_{\text {сомр }}(\%)$ & RECHAZO (\%) \\
\hline Principado de Asturias & 3,88 & 58,50 & n. d. & 1,61 \\
\hline Islas Baleares & 51,24 & 39,27 & 28,82 & 29,51 \\
\hline Cataluña ${ }^{1}$ & 49,14 & n. d. & 6,59 & 34,30 \\
\hline Comunidad Foral de Navarra ${ }^{1}$ & 21,38 & n. d. & $0^{2}$ & 6,11 \\
\hline TOTAL ESPAÑA & 29,99 & 43,60 & 9,18 & 30,54 \\
\hline
\end{tabular}

A nivel nacional, la producción de biogás por cada tonelada de material entrante fue de $43,60 \mathrm{~m}^{3}$, no obstante, este dato esta sesgado ya que no se tienen valores al respecto en las comunidades de Cataluña y Navarra. El rendimiento para la producción de compost a partir del digestato fue del 9,18\% (Tabla 3.39).

Respecto al porcentaje de rechazo, en 2016 esta se situó en el 30,54\% respecto a las entradas totales en las PBCFO españolas. La C.A. en la que se genera mayor rechazo fue Cataluña con un $34,30 \%$, por el contrario, en el Principado de Asturias tan solo se produjo un $1,61 \%$ de rechazo respecto al material entrante.

En el caso de las PBCFO no se pueden determinar las mermas del proceso, ya que se desconocer la producción de biogás en peso.

\subsubsection{Resumen del TMB en España}

En el año 2016 en España se generaron 21,9 Mt de RSU (INE 2018), de ellas, 18,1 Mt se recogieron de forma mezclada y $3,8 \mathrm{Mt}$ de forma selectiva. En total, la cantidad de RSU que fueron tratados en las plantas de TMB españolas ascendió a los $13 \mathrm{Mt}$, correspondiendo 12,3 t a RSU mezclados, 0,55 Mt a FORS y 0,16 Mt a otros residuos biodegradables (restos de poda y lodos).

Respecto a los RSU mezclados, un $8,27 \%$ fue tratado en PT, un $65,12 \%$ en PRC, un $0,51 \%$ en PBSR y un $26,10 \%$ en PRBC (Tabla 3.40), por lo que se puede afirmar que a nivel nacional el principal TMB para este tipo de residuos es el llevado a cabo en las PRC. A nivel autonómico, este tipo de plantas también es el más utilizado para el tratamiento de los RSU mezclados en la mayoría de las CC.AA., salvo para Galicia que se realiza principalmente en las PT y para Aragón, Castilla y León, Comunidad de Madrid y Navarra, que se lleva a cabo en las PRBC. En la Tabla 3.40 se muestra la distribución de TMB de RSU mezclados en función del tipo de planta por CC.AA..

En cuanto a la FORS, el 54,76\% fue tratada en PCFO y el 45,24\% en PBCFO. Por comunidades, Andalucía, Canarias, Galicia y País Vasco trataron el $100 \%$ de la misma en PCFO, mientras que en el Principado de Asturias, Islas Baleares y Cataluña, el tratamiento mayoritario de este tipo de residuos se hace en las PBCFO (Tabla 3.40).

Los materiales reciclables recuperados en las plantas de TMB de RSU mezclados alcanzaron las $662.182 \mathrm{t}$, correspondiendo un $29,44 \%$ a plásticos, un $27,23 \%$ a metales y otro $27,23 \%$ a papel/cartón. En todos los tipos de plantas de TMB de RSU mezclados el plástico fue el subproducto que se recuperó en mayor medida, seguido por los metales. Mientras que el papel/cartón solo se recuperó en porcentajes elevados en las PRC y en las PRBC. A estos materiales habría que sumarles la cantidad de metales férricos separados en las PCFO y las PBCFO, sin embargo, estos datos no están disponibles.

La producción de bioestabilizado en las plantas de TMB de RSU mezclados fue de $727.504 \mathrm{t}$, siendo las PRC las principales productoras del mismo. Por otro lado, la producción de compost en las instalaciones de tratamiento de la FORS fue de $105.232 \mathrm{t}$, las cuales se produjeron mayoritariamente en las PCFO. Además, en el proceso de biometanización, se generaron 68 millones de $\mathrm{m}^{3}$ de biogás a partir de RSU mezclados en las PRBC y 2,5 millones de $\mathrm{m}^{3}$ a partir de la FORS en las PBCFO. 
Tabla 3.40 Distribución del TMB de RSU y FORS por CC.AA

\begin{tabular}{|c|c|c|c|c|c|c|}
\hline \multirow{2}{*}{ CC.AA. } & \multicolumn{4}{|c|}{ RSU mezclados (\%) } & \multicolumn{2}{|c|}{ FORS (\%) } \\
\hline & PT & PRC & PBSR & PRBC & PCFO & PBCFO \\
\hline Andalucía & 1,67 & 95,32 & 0 & 3,01 & 100 & 0 \\
\hline Aragón & 0 & 0 & 0 & 100 & - & - \\
\hline Principado de Asturias & - & - & - & - & 32,32 & 67,68 \\
\hline Islas Balearas & 0 & 100 & 0 & 0 & 0 & 100 \\
\hline Canarias & 0 & 65,98 & 0 & 34,02 & 100 & 0 \\
\hline Cantabria & 0 & 100 & 0 & 0 & - & - \\
\hline Castilla - La Mancha & 0 & 100 & 0 & 0 & - & - \\
\hline Castilla y León & 0 & 48,69 & 0 & 51,31 & - & - \\
\hline Cataluña & 1,14 & 64,75 & 0 & 34,11 & 44,05 & 55,95 \\
\hline Comunidad Valenciana & 0 & 75,68 & 3,28 & 21,04 & - & - \\
\hline Extremadura & 0 & 100 & 0 & 0 & - & - \\
\hline Galicia & 78,73 & 0 & 0 & 21,27 & 100 & 0 \\
\hline La Rioja & 0 & 0 & 0 & 100 & - & - \\
\hline Comunidad de Madrid & 36,69 & 0 & 0 & 63,31 & - & - \\
\hline Región de Murcia & 0 & 100 & 0 & 0 & - & - \\
\hline $\begin{array}{c}\text { Comunidad Foral de } \\
\text { Navarra }\end{array}$ & 0 & 0 & 0 & 100 & 76,04 & 23,96 \\
\hline País Vasco & 0 & 57,44 & 0 & 42,56 & 100 & 0 \\
\hline TOTAL ESPAÑA & 8,27 & 65,12 & 0,51 & 26,10 & 54,76 & 45,24 \\
\hline
\end{tabular}

La generación de rechazo en las plantas de TMB Españolas se situó en 8,9 Mt, correspondiendo un 61,07\% a las PRC, un $27,68 \%$ a las PRBC, un $8,84 \%$ a las PT, un $1,09 \%$ a las PCFO, un $1,00 \%$ a las PBCFO y un $0,32 \%$ a las PBSR (Figura 3.17). El principal tratamiento para estos rechazos fue la disposición en vertedero $(84,29 \%)$, lo que supuso un $56,20 \%$ las entradas a los mismos. El resto se valorizó energéticamente $(15,71 \%)$, suponiendo el $58,21 \%$ del material entrante a las incineradoras españolas.

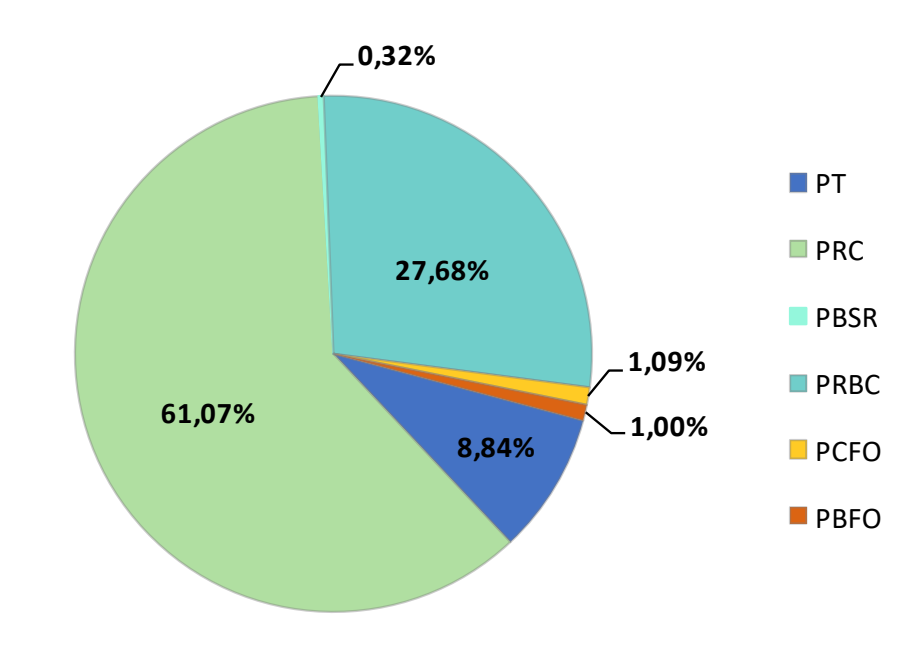

Figura 3.17 Distribución de la generación de rechazo por plantas de TMB 
Por otro lado, en la Tabla 3.41 se expone el porcentaje de RSU mezclados y FORS que fueron tratados en las plantas de TMB españolas respecto a la generación de estos residuos. En ella se puede observar que el TMB es el principal tratamiento para los RSU mezclados. Puesto que, del total de RSU mezclados que se generados en 2016 en España, un 44,45\% fueron tratados las PRC, un 17,82\% en las PRBC, un 5,65\% en las PT y un 0,34\% en las PBSR, sumando en conjunto un 68,25\%. Por CC.AA., se observa que Castilla y León, Comunidad Valenciana, Extremadura, La Rioja y Región de Murcia trataron casi el 100\% de sus RSU mezclados en plantas de TMB, con valores en todas ellas por encima del 95\%. En el lado opuesto se encuentra el Principado de Asturias, donde todos los RSU mezclados se destinaron a vertedero (no obstante, existe recogida selectiva de la fracción orgánica para su tratamiento diferenciado). En el caso de Andalucía, Aragón, Canarias, Castilla - La Mancha y Navarra, donde no existen instalaciones de incineración, parte de los RSU mezclados se destinaron directamente a vertedero. Esto se puede observar en la Tabla 3.41, puesto que en estas comunidades el porcentaje de tratamiento de este tipo de residuos tiene valores entre el $76,50 \%$ y $40,35 \%$. Por otra parte, en las CC.AA. que cuentan con instalaciones de incineración de RSU en su territorio (Islas Baleares, Cantabria, Cataluña, Galicia, Comunidad de Madrid y País Vasco) se observan porcentajes de tratamiento que van desde el $84,66 \%$ al 6,62\%. En estas autonomías la parte de los RSU mezclados que no se trataron en plantas de TMB se destinaron a valorización energética o vertedero.

En la Tabla 3.41 también se muestra el porcentaje de FORS tratada en plantas de TMB respecto a la recogida selectiva de biorresiduos. A nivel nacional en 2016, las PCFO tararon el $36,20 \%$ y las PBCFO el $29,99 \%$, sumando en total un $66,29 \%$. Andalucía con un $87,21 \%$, Cataluña con un $87,82 \%$ y Navarra con un $89,22 \%$ son las CC.AA. donde el tratamiento de la FORS en plantas de TMB es mayor, con valores cercanos al $100 \%$. En el País Vasco e Islas Baleares, la FORS tuvo un porcentaje de tratamiento de alrededor del $50 \%$. Mientras que en Asturias y Canarias solo alcanzo valores del 5,73\% y 1,19\% respectivamente. El resto de comunidades no cuentan con instalaciones para el tratamiento específico de la FORS.

Tabla 3.41 Porcentaje de RSU mezclados y FORS tratados en las plantas de TMB por CC.AA.

\begin{tabular}{|c|c|c|c|c|c|c|c|c|}
\hline \multirow{2}{*}{ CC.AA. } & \multicolumn{5}{|c|}{$\mathrm{RSU}_{\mathrm{T}}(\%)$} & \multicolumn{3}{|c|}{ FORS $(\%)$} \\
\hline & PT & PRC & PBSR & PRBC & TOTAL & PCFO & PBCFO & TOTAL \\
\hline Andalucía & 1,28 & 72,92 & 0 & 2,30 & 76,50 & 87,21 & 0 & 87,21 \\
\hline Aragón & 0 & 0 & 0 & 54,30 & 54,30 & 0 & 0 & 0 \\
\hline Principado de Asturias & 0 & 0 & 0 & 0 & 0 & 1,85 & 3,88 & 5,73 \\
\hline Islas Balearas & 0 & 6,62 & 0 & 0 & 6,62 & 0 & 51,24 & 51,24 \\
\hline Canarias & 0 & 46,56 & 0 & 24,01 & 70,57 & 1,19 & 0 & 1,19 \\
\hline Cantabria & 0 & 84,66 & 0 & 0 & 84,66 & 0 & 0 & 0 \\
\hline Castilla - La Mancha & 0 & 71,94 & 0 & 0 & 71,94 & 0 & 0 & 0 \\
\hline Castilla y León & 0 & 26,45 & 0 & 72,78 & 99,22 & 0 & 0 & 0 \\
\hline Cataluña & 0,70 & 39,62 & 0 & 20,87 & 61,19 & 38,69 & 49,14 & 87,82 \\
\hline Comunidad Valenciana & 0 & 73,84 & 3,20 & 20,53 & 97,57 & 0 & 0 & 0 \\
\hline Extremadura & 0 & 95,81 & 0 & 0 & 95,81 & 0 & 0 & 0 \\
\hline Galicia & 62,52 & 0,00 & 0 & 16,89 & 79,41 & 20,14 & 0 & 20,14 \\
\hline La Rioja & 0 & 0,00 & 0 & 98,58 & 98,58 & 0 & 0 & 0 \\
\hline Comunidad de Madrid & 17,36 & 0,00 & 0 & 29,95 & 47,31 & 0 & 0 & 0 \\
\hline Región de Murcia & 0 & 97,33 & 0 & 0 & 97,33 & 0 & 0 & 0 \\
\hline Comunidad Foral de Navarra & 0 & 0 & 0 & 40,35 & 40,35 & 67,84 & 21,38 & 89,22 \\
\hline País Vasco & 0 & 16,86 & 0 & 12,49 & 29,35 & 55,30 & 0 & 55,30 \\
\hline TOTAL ESPAÑA & 5,65 & 44,45 & 0,34 & 17,82 & 68,25 & 36,30 & 29,99 & 66,29 \\
\hline
\end{tabular}


En cuanto a los indicadores del rendimiento del tratamiento de las plantas de TMB, a continuación, se expone una tabla resumen con los valores obtenidos a nivel nacional para las distintas clases de instalaciones estudiadas.

Tabla 3.42 Indicadores del rendimiento de las plantas de TMB, 2016

\begin{tabular}{c|c|c|c|c}
\hline Tipo de planta & $\mathrm{RG}_{\mathrm{MR}}(\%)$ & $\mathrm{RG}_{\mathrm{BGAS}}\left(\mathbf{m}^{\mathbf{3}} / \mathbf{t}\right)$ & $\mathrm{RG}_{\text {BIOST/COMP }}(\%)$ & RECHAZO (\%) \\
\hline PT & 5,47 & - & - & 77,10 \\
\hline PRC & 5,54 & - & 7,75 & 67,66 \\
\hline PBSR & 4,76 & - & 4,97 & 45,67 \\
\hline PRBC & 4,93 & 21,93 & 6,61 & 70,64 \\
\hline PCFO & - & - & 12,64 & 28,09 \\
\hline PBCFO & - & 43,60 & 9,18 & 30,54 \\
\hline
\end{tabular}

Respecto al rendimiento global de recuperación de materiales, los valores obtenidos para todos los tipos de plantas de TMB son muy parecidos y se encuentra alrededor del $5 \%$.

Cuando se analizan los rendimientos globales de las etapas biológicas del tratamiento, ya sea el de la biometanización o el del compostaje, destacan las plantas donde se trata la FORS por su mayor rendimiento. Esto se debe a que la FORS es un material con una menor cantidad de impropios que la fracción orgánica separada en las plantas de tratamiento de los RSU mezclados, lo que hace que el tratamiento biológico de la misma sea más eficiente. Dentro de las instalaciones que tratan RSU mezclados, las PRC son las que obtuvieron unos rendimientos mayores en la producción de bioestabilizado (7,75\%). Mientras que en las que tratan FORS, los rendimientos más altos para la producción de compost se dieron en las PCFO (12,64\%). En cuanto a la producción de biogás, se observa que el rendimiento de la PBCFO es el doble que el de la PRBC, con $43,60 \mathrm{~m}^{3} / \mathrm{t}$ y $21,93 \mathrm{~m}^{3} / \mathrm{t}$ respectivamente.

Por último, respecto a la generación de rechazos, las plantas donde se lleva a cabo el tratamiento de la FORS (PCFO y PBCFO) son las que menor porcentaje de rechazo produjeron respecto al material entrante, con valores entorno al 29\%. Mientras que en aquellas plantas donde se trataron RSU mezclados, la generación de rechazo aumenta considerablemente hasta valores entre el 67 y $77 \%$, salvo las PBSR que tienen un valor intermedio $(45,67 \%)$.

\subsection{CONCLUSIONES}

En este capítulo se han analizado los diferentes aspectos que permiten clasificar las plantas de TMB. Estos son: el tipo de RSU tratado, las etapas del proceso de tratamiento, las tecnologías y procesos del tratamiento mecánico y las tecnologías y procesos de tratamiento biológico.

Respecto al tipo de RSU tratados, las plantas TMB se pueden dividir en aquellas que tratan RSU mezclados y las que tratan FORS. En base a las etapas del proceso de tratamiento se pueden clasificar en plantas de triaje, plantas de tratamiento mecánico-biológico, plantas de biosecado y plantas del tratamiento biológico de la FORS. En cuanto a las tecnologías y procesos de tratamiento, en función como se realiza el proceso mecánico de recuperación de materiales se pueden diferenciar entre plantas automáticas o manuales; mientras que en función de cómo se lleva cabo el proceso de compostaje se pueden distinguir entre plantas con compostaje en nave abierta, nave cerrada y en túneles.

Una vez estudiadas todas estas características, se ha realizado una clasificación general de las plantas de TMB que englobe todos los tipos de instalaciones identificados. De este modo, las plantas de TMB de RSU mezclados se pueden clasificar en cuatro categorías principales:

- $\quad$ Plantas de triaje (PT) 
- $\quad$ Plantas de recuperación y compostaje (PRC)

- Plantas de biosecado y recuperación (PBSR)

- Plantas de recuperación, biometanización y compostaje (PRBC)

Dentro de estas categorías principales existen diferentes alternativas de tratamiento en función de cómo se realicen los procesos mecánicos y biológicos. Teniendo en cuenta todas las alternativas posibles, se obtienen 16 tipos de plantas de TMB de RSU mezclados distintos.

En cuanto a las plantas de TMB de la FORS, estas se pueden clasificar en dos categorías principales:

- $\quad$ Plantas de compostaje de la FORS (PCFO)

- Plantas de biometanización y compostaje de la FORS (PBCFO)

Estas plantas pueden utilizar diferentes alternativas para el tratamiento biológico. Teniendo en cuenta todas las alternativas se obtienen 6 tipos distintos.

Tras la clasificación de las plantas de TMB, en primer lugar, se han elaborado un modelo conceptual para las seis categorías principales. Estos modelos han permitido identificar las subetapas de tratamiento existentes en las mismas y los principales flujos de entrada y salida de materiales (subproductos y rechazos).

Así pues, en una planta de TMB de RSU mezclados la etapa mecánica se puede dividir en las siguientes subetapas: el pretratamiento de los residuos entrantes; la recuperación de los materiales reciclables, y el control de calidad y adecuación de los materiales recuperados. Mientras que la etapa biológica, si consiste en el compostaje, se puede dividir en dos subetapas: el compostaje de la fracción orgánica y el afino del material bioestabilizado; o si consiste en la biometanización y compostaje en tres: la biometanización de la fracción orgánica, el compostaje del digestato y el afino del bioestabilizado. Los flujos de salida identificados para una planta de TMB de RSU mezclados son: voluminosos, materiales recuperados, bioestabilizado, biogás (solo en instalaciones con biometanización), rechazo fino (solo en PT), rechazo de recuperación, rechazo de afino primario del bioestabilizado y rechazo de afino secundario del bioestabilizado.

En cuanto a las plantas de TMB de la FORS, la etapa mecánica inicial de acondicionamiento se puede dividir en dos subetapas: pretratamiento del material entrante y recuperación de materiales. Mientras que la etapa biológica, si consiste en el compostaje, se puede dividir en dos subetapas: el compostaje de la FORS y el afino del compost; o si consiste en la biometanización en tres: la biometanización de la FORS, el compostaje del digestato y el afino del compost. Los flujos de salida de este tipo de instalaciones son: metales férricos, compost, biogás (solo en plantas con biometanización), rechazo de limpieza inicial y rechazo de afino del compost.

En segundo lugar, se ha realizado un modelo conceptual más detallado de la etapa mecánica y biológica por separado, así como de las diferentes alternativas que se pueden dar en cada una de ellas. Estos modelos incluyen las operaciones unitarias utilizadas en las diferentes subetapas, lo que permite conocer de forma más precisa el número de corrientes de rechazo generadas y el origen de las mismas. A partir de estos modelos se ha identificado un total de 17 corrientes de rechazo diferentes entre todos los tipos de plantas de TMB. Estas son susceptibles de ser transformadas en un CSR y, por tanto, conforman el objeto del estudio de la presente tesis.

En el tercer apartado del capítulo se ha determinado el número de plantas de cada tipo existente a nivel nacional y las tecnologías que utilizan, así como sus balances de materia e indicadores del rendimiento para el año 2016 (últimos datos disponibles).

Así pues, a finales del año 2018, España contaba con 137 plantas de TMB, existiendo un alto grado de cobertura ya que todas las CC.AA. cuentan al menos con una instalación de este tipo en su territorio. Las instalaciones más utilizadas para el TMB de los RSU mezclados son las PRC y las PRBC, con 67 y 22 plantas respectivamente. Respecto al tratamiento de la FORS, el tipo de planta predominante es la PCFO con 34 instalaciones de este tipo. A nivel autonómico, Andalucía es la comunidad con un mayor número de PRC (20), Castilla y León tiene el mayor número de PRBC (6) y Comunidad Valenciana es la única donde existe una PBSR. Respecto las plantas de tratamiento de loa FORS, Cataluña es la comunidad que tiene más 
instalaciones de este tipo, con 23 PCFO y 4 PBCFO. En segundo lugar, se encuentra el País Vasco con 4 PCFO.

El proceso de recuperación de materiales reciclables contenidos en los RSU mezclados se realiza en la mayoría de las plantas de forma manual (54 instalaciones), no obstante, el proceso automático está bastante extendido (41 instalaciones). En el caso de la etapa mecánica de limpieza y acondicionamiento de la FORS, esta se realiza de forma manual en todas las instalaciones donde se tratan este tipo de residuos.

En cuanto al proceso biológico, la nave cerrada es el sistema más utilizado para el compostaje de la fracción orgánica presente en los RSU mezclados (28 instalaciones) y la nave abierta para el compostaje de la FORS (18 plantas). Mientras que, a nivel global, los túneles son la tecnología más utilizada (54 instalaciones). Respecto al compostaje del digestato obtenido en la biometanización, este se realiza principalmente en túneles y nunca en nave abierta, ya que en el proceso se generan fuertes olores y por tanto necesita un sistema para la depuración de los mismos.

En el año 2016 en España se generaron 21,9 Mt de RSU, de ellas, 18,1 Mt se recogieron de forma mezclada y el resto de forma selectiva. Ese mismo año, la cantidad total de RSU tratados en las plantas de TMB españolas fue de $13 \mathrm{Mt}$, correspondiendo 12,3 Mt a RSU mezclados, 0,55 Mt a FORS y 0,16 Mt a otros residuos biodegradables como los restos de poda y los lodos.

Respecto a los RSU mezclados, las PT trataron un $8,27 \%$ de los mismos, las PRC un $65,12 \%$, las PBSR un $0,51 \%$ y las PRBC un $26,10 \%$. Así pues, se puede concluir que a nivel nacional las principales instalaciones para el TMB de este tipo de residuos son las PRC. A nivel autonómico este tipo de plantas también es el más utilizado para el tratamiento de los RSU mezclados en la mayoría de las CC.AA., salvo para Galicia que se realiza principalmente en las PT y para Aragón, Castilla y León, Comunidad de Madrid y Navarra, que se lleva a cabo en las PRBC.

En cuanto a la FORS, el 54,76\% fue tratada en PCFO y el 45,24\% en PBCFO. Por autonomías, en Andalucía, Canarias, Galicia y País Vasco el 100\% fue tratada en PCFO, mientras que en el Principado de Asturias, Islas Baleares y Cataluña el tratamiento mayoritario fue en las PBCFO.

Por otro lado, también se han obtenido datos en relación al porcentaje de RSU mezclados y FORS que fueron tratados en las plantas de TMB españolas respecto a la generación de estos residuos. Así pues, del total de RSU mezclados generados en el 2016 en España, un 44,45\% fueron tratados las PRC, un 17,82\% en las PRBC, un $5,65 \%$ en las PT y un $0,34 \%$ en las PBSR, sumando en conjunto un $68,25 \%$ (el resto se destinaron a incineración o vertido directo). A nivel autonómico, Castilla y León, Comunidad Valenciana, Extremadura, La Rioja y Región de Murcia trataron casi el 100\% de sus RSU mezclados en plantas de TMB, con valores en todas ellas por encima del 95\%. En el resto de CC.AA. (salvo en el Principado de Asturias, Islas Baleares y Navarra) el destino mayoritario para los RSU mezclados también fueron las plantas de TMB, pero con porcentajes de tratamiento menores. En el caso de la FORS, las PCFO españolas trataron un $36,20 \%$ respecto a la recogida selectiva de biorresiduos y las PBCFO un $29,99 \%$, sumando en total un $66,29 \%$. Andalucía, Cataluña y Navarra son las CC.AA. donde el tratamiento de la FORS en plantas de TMB es mayor, con porcentajes de tratamiento cercanos al $100 \%$.

Respecto al proceso de tratamiento, en las plantas de TMB españolas se recuperaron un total de $662.182 \mathrm{t}$ de materiales reciclables, correspondiendo un $29,44 \%$ a plásticos, un $27,23 \%$ a metales y otro $27,23 \%$ a papel/cartón. A estos materiales habría que sumarles la cantidad de metales férricos separados en las PCFO y las PBCFO, sin embargo, estos datos no están disponibles. En cuanto a los rendimientos globales de recuperación, los valores obtenidos para todos los tipos de plantas fueron muy parecidos, alrededor del 5\%.

Respecto al tratamiento biológico, en las plantas de TMB de RSU mezclados se produjeron 727.504 t de bioestabilizado y 68 millones de $\mathrm{m}^{3}$ de biogás a nivel nacional; mientras que en las instalaciones de tratamiento de la FORS se produjeron $105.232 \mathrm{t}$ de compost y 2,5 millones de $\mathrm{m}^{3}$ de biogás. Las PRC obtuvieron los rendimientos más altos para la producción de bioestabilizado (7,75\%), mientras que las PCFO los obtuvieron para la producción de compost (12,64\%). A nivel global destacan las plantas donde se trata la FORS por su mayor rendimiento, tanto para el proceso de compostaje como el de biometanización. Esto se 
debe a que la FORS tiene un menor contenido en impropios, haciendo que el tratamiento biológico sea más eficiente.

La generación de rechazos en las plantas de TMB españolas alcanzo las 8,9 Mt en el 2016, siendo las PRC y las PRBC las mayores productoras. Además, las instalaciones donde se trataron RSU mezclados son las que mayor porcentaje de rechazo generan respecto al material entrante, con valores entre el 67 y $77 \%$. Por lo que, en la actualidad, más de la mitad de los RSU tratados en estas instalaciones terminan como rechazo. Esto se debe, por un lado, a la heterogeneidad del material entrante, puesto que no proviene de recogida selectiva. Por otro, al bajo rendimiento de las plantas como consecuencia de que algunas de ellas están obsoletas y necesitan una remodelación, otras trabajan por encima de su capacidad de diseño y en otras existe una falta de trabajadores y/o equipos. Mejorando todo esto, el rendimiento de este tipo de instalaciones podría aumentar, ya que como se ha visto en el estado del arte, en los rechazos existen materiales que podrían recuperarse para su reciclaje (por ejemplo, envases de plástico, metal o brik).

En el caso de las plantas de tratamiento de la FORS, donde el material entrante es mucho más homogéneo, el porcentaje de rechazo disminuye considerablemente hasta valores entorno al $29 \%$.

Finalmente, de todos los rechazos generados en España en 2016, tan solo el 15,71 \% se valorizo energéticamente, suponiendo un $58,21 \%$ del material entrante a las incineradoras. El resto, un $84,29 \%(7,5$ $\mathrm{Mt}$ ), tuvo como destino el vertedero, lo que supuso un $56,20 \%$ del material entrante a los mismos.

\subsection{REFERENCIAS}

Gallardo, A., 2000. Metodología para el diseño de redes de recogida selectiva de RSU utilizando sistemas de información geográfica. Creación de una base de satos aplicable a España. Universidad Politécnica de Valencia.

Instituto Nacional de Estadística (INE), 2018. Estadística sobre recogida de residuos urbanos - Año 2016. Instituto Nacional de Estadistica (INE), Madrid, España.

MITECO, 2019. Memoria anual de generación y gestión de residuos: residuos de competencia municipal, 2016. Minsiterio para la Transisción Ecológica, Madrid, España.

Velis, C.A., Longhurst, P.J., Drew, G.H., Smith, R., Pollard, S.J.T., 2010. Production and quality assurance of solid recovered fuels using Mechanical- Biological Treatment (MBT) of waste: a comprehensive assessment. Crit. Rev. Environ. Sci. Technolgy 40, 979-1105. https://doi.org/10.1080/10643380802586980 



\section{0

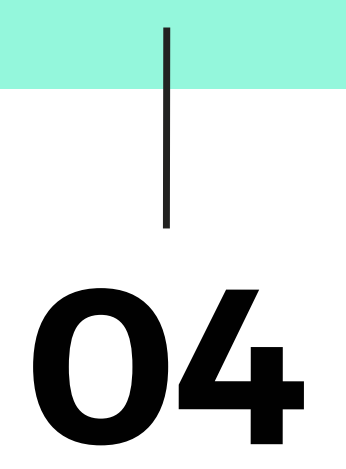

CAPÍTULO 4

IDENTIFICACIÓN DE VARIABLES Y PARÁMETROS

QUE INTERVIENEN EN LA METODOLOGÍA PARA

EL CONTROL DE CALIDAD DE LOS RECHAZOS 



\subsection{INTRODUCCIÓN}

Como se ha podido ver en el estado del arte, los rechazos generados en el TMB de los RSU son un material muy heterogéneo, formado por distintos materiales en proporciones muy diferentes. Por otro lado, dentro de las plantas de TMB existen varias etapas de tratamiento y cada una de ellas generan sus propias corrientes de rechazos, las cuales presentan características distintas (Edo-Alcón et al., 2016) (Figura 4.1). Además, sus propiedades físico-químicas también dependen de los RSU que entran en las plantas y de la configuración de las mismas (Brás et al., 2017; Di Lonardo et al., 2012; Edo-Alcón et al., 2016; Nasrullah et al., 2017; Velis et al., 2012). Así pues, la composición y características de los rechazos pueden variar en función de numerosos factores, tanto del entorno, como socioeconómicos o relacionadas con las estrategias de gestión adoptadas en la zona y los procesos de tratamiento (Brás et al., 2017; Di Lonardo et al., 2016).

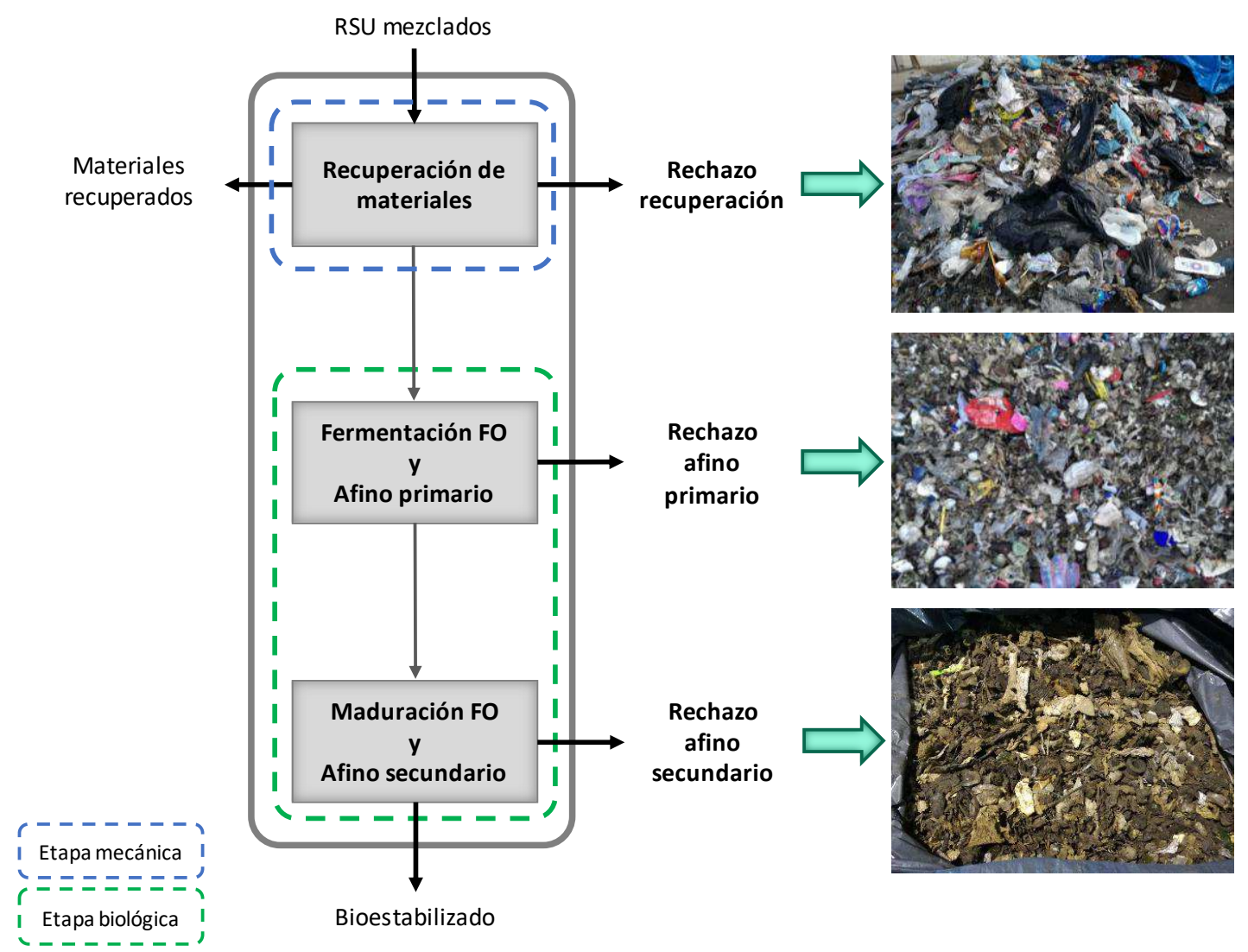

Figura 4.1 Rechazos generados en las diferentes etapas y procesos de una planta de TMB

Por otra parte, el tipo, naturaleza y composición de los rechazos, así como la variabilidad de sus propiedades a lo largo del tiempo, también afectará a la calidad del CSR obtenido a partir de los mismos (lacovidou et al., 2018; Nasrullah et al., 2017; Velis et al., 2012). Como consecuencia, los CSR producidos a partir de rechazo son combustibles muy heterogéneos y sus características fisicoquímicas pueden ser muy variables, dependido en gran medida del rechazo o materia prima utilizada y del proceso de tratamiento aplicado para su producción (Sarc et al., 2014). Por este motivo, en Europa, este tipo de combustibles está sujeto a unos parámetros específicos de calidad que garanticen su uso.

A la hora de diseñar la metodología para el control de calidad de los rechazos producidos en las plantas de $\mathrm{TMB}$, en concreto de aquellos que son susceptibles de ser convertidos en CSR, es fundamental conocer qué factores afectan a las propiedades de los mismos de manera que el plan de muestreo tenga en cuenta su 
variabilidad. Por otro lado, también es importante conocer cuáles son los parámetros que definen la calidad de un CSR, puesto que la metodología a diseñar deberá tenerlos en cuenta.

El objetivo del presente capítulo de la tesis es identificar y analizar las diferentes variables que afectan a la composición y propiedades de los rechazos, así como los parámetros que definen la calidad de los CSR. Las primeras permitirán desarrollar el plan de muestreo de manera que los resultados sean representativos del total de la producción. Teniendo en cuenta, por un lado, las variables que afectan al número mínimo de muestras necesarias y, por otro, las que afectan al tamaño (cantidad) de muestra mínima necesaria, es decir a la toma de muestras. Los parámetros de calidad se considerarán a la hora de diseñar los procedimientos para el tratamiento y análisis de las muestras en el laboratorio, puesto que aportan información clave sobre las condiciones que ha de tener la muestra de análisis, así como las mediciones o analíticas que se deben realizar.

Para la identificación y análisis de las variables se ha llevado a cabo una extensa revisión bibliográfica. Por un lado, se han analizado diferentes estudios e investigaciones sobre la caracterización y muestreo de los rechazos y RSU, así como sobre los factores que influyen en la composición de los mismos, con el fin de identificar de los factores que afectan a sus propiedades. Las variables identificadas se han clasificado en aquellas que afectan a la composición y propiedades de los rechazos, y aquellas que afectan al proceso de la toma de muestra. Por otro lado, se han revisado los diferentes estándares de calidad existentes en Europa con el objetivo de identificar los parámetros que se utilizan para definir la calidad de los CSR, determinando cuales son los más utilizados.

La estructura que sigue el capítulo se muestra en la Figura 4.2. En ella también se indica dónde se integran los diferentes tipos de variables dentro de la metodología para el control de calidad de los rechazos que se va a diseñar en la presente tesis.

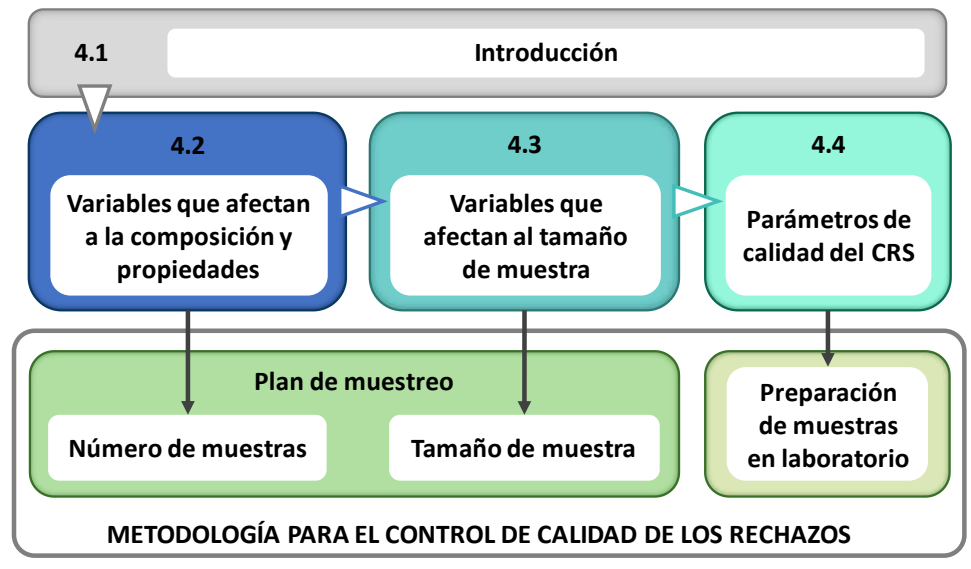

Figura 4.2 Estructura del Capítulo 4

\subsection{VARIABLES QUE AFECTAN A LA COMPOSICIÓN Y PROPIEDADES DE LOS RECHAZOS}

Después una exhaustiva revisión bibliográfica se ha podido identificar todas las variables que influyen en la composición y propiedades de los rechazos. Estas se han clasificado en tres categorías: del entorno, socioeconómicas y las relacionadas con el sistema de gestión de RSU.

\section{Variables del entorno}

- Estacionalidad: está ampliamente demostrado que la composición de los residuos puede sufrir cambios significativos en función de la época del año. Por ejemplo, en verano se produce un aumento en el consumo de frutas, verduras y hortalizas; mientras que en invierno aumenta la presencia de cenizas (Ozcan et al., 2016; Runfola and Gallardo, 2010). Por su parte, Burnley et al. (2007) y Boldrin and Christensen (2010) encontraron diferencias significativas en la cantidad de 
residuos de jardinería entre las diferentes épocas del año. Otras variaciones pueden ocurrir debido a eventos especiales como: periodos vacacionales, fiestas populares, festivales, ferias, eventos deportivos, convecciones, procesos agrícolas estacionales, etc. (Mccauley-bell et al., 1997; Zeng et al., 2005), como el aumento de papel/cartón y vidrio durante la Navidad. Como consecuencia de estos cambios, los RSU que entran a las plantas de TMB varían, lo que a su vez hace que la composición y las propiedades de los rechazos también cambien en función estacionalidad (Di Lonardo et al., 2012). En este sentido, Nasrullah et al. (2017, 2014) y Garcés et al. (2016) analizaron diferentes materias primas para la producción de CSR, entre ellas diferentes fracciones combustibles de los RSU, y observaron variaciones en el contenido de humedad como consecuencia de la estacionalidad. Además, Garcés et al. (2016) también hallaron variaciones en el contenido en cenizas, cloro y en el poder calorífico en función de la época del año debido a la variación estacional de la composición de los residuos utilizadas para producir CSR. Mientras que Moura et al. (2018) encontraron cambios significativos en la composición de los rechazos del tratamiento de RSU fruto de la estacionalidad.

- Climatología: el contenido en humedad de los residuos varía entre las épocas lluviosas y secas, por lo que se puede esperar residuos con un alto contenido en humedad en las estaciones lluviosas (Parizeau et al., 2006). Estas diferencias están muy relacionadas con la variación estacional.

- Área geográfica: las poblaciones situadas en el interior tienen hábitos y costumbres diferentes a las situadas en la costa (Gallardo, 2000), por lo que pueden existir diferencias en las composición de los RSU y por tanto de los rechazos en función del área geográfica.

\section{Variables socio-económicas}

- Turismo: el movimiento de la población durante periodos vacacionales hace aumentar o disminuir las cantidades generadas de residuos en función de la afluencia o no de visitantes (Gallardo, 2000), lo que también puede influir en la composición. En ese sentido, Bach et al. (2004) demostraron que se recogen mayores cantidades de residuos de papel en poblaciones con un número elevado de pernoctaciones por habitante. Por su parte, Gidarakos et al. (2006) observaron un aumento de la cantidad de latas de aluminio, botellas de vidrio y papel debido a la actividad turística. Además, el turismo conlleva un aumento en las actividades de restauración y, como consecuencia, se produce una mayor cantidad de residuos de comida.

- Nivel de renta: existen numerosos trabajos que han encontrado una correlación positiva entre el nivel de renta de una población y la generación de RSU (Abu-Qdais et al., 1997; Beigl et al., 2004; Emery et al., 2003; Lebersorger and Beigl, 2011; Qu et al., 2009). En cuanto a la composición, Márquez et al. (2008) observaron una mayor generación de residuos de plástico en las familias con niveles de renta alto, mientras que las de nivel medio generaron una mayor cantidad de residuos sanitarios y menor de metales. Esto se debe a que, en función del nivel de ingresos de las familias, existen diferentes hábitos de consumo. Por otro lado, en el estudio realizado por Thanh et al. (2010) hallaron una correlación positiva entre los ingresos y la generación de materia orgánica. El aumento de la fracción orgánica en familias con niveles de renta altos puede deberse al menor aprovechamiento alimentario y, como consecuencia, la mayor generación de residuos de comida. Por su parte, Ozcan et al. (2016) observaron que la generación de residuos de papel en los barrios con niveles de ingresos altos era el doble en comparación con los de niveles de ingresos bajos, mientras que las cenizas solo estaban presentes en los residuos de los barrios con una nivel bajo.

- Modo de vida: el modo de vida junto con los hábitos de consumo de la población puede influir en la variación de la composición a lo largo de la semana y, sobre todo, los fines de semana. Además, en lugares donde los habitantes migran diariamente desde la periferia al centro de la ciudad para trabajar (ciudades dormitorio) se consumen más comidas elaboradas, aumentado la cantidad de envases en los residuos (Gallardo, 2000).

- Tipo de población: las zonas rurales, urbanas, comerciales o residenciales tienen una generación y composición diferentes (Gallardo, 2000). Por ejemplo, en la zonas rurales se genera una mayor cantidad de materia orgánica debido al menor consumo de alimentos procesados (HernándezBerriel et al., 2016). Como consecuencia de estas diferencias, la metodología europea "SWA-Tool" para el análisis de residuos sólidos, al igual que otras metodologías, recomienda diferenciar entre zonas rurales, suburbanas, urbanas, comerciales y residenciales a la hora de realizar una 
caracterización de los RSU (European Commision, 2004). Por su parte, Di Lonardo et al. (2012) indican que las características del material de entrada a las plantas TMB varían en función del tipo de zona (urbana o rural) y que esto, a su vez, afecta a las propiedades de los rechazos.

- Nivel de urbanización: esta variable hace referencia a la estructura residencial del lugar, es decir, al tipo de viviendas existentes (viviendas unifamiliares o edificios multifamiliares). Algunos estudios han hallado diferencias entre los niveles de urbanización y la generación de plástico, papel, materia orgánica, textiles, vidrio y/o metales (Edjabou et al., 2015; Suthar and Singh, 2015; Thanh et al., 2010), o de residuos de poda (Maystre and Viret, 1995). Por otro lado, Boer et al. (2010) observaron que la composición de los residuos variaba en función del tipo de vivienda, sobre todo por la diferencias existentes en los sistemas de calefacción (chimeneas o estufas en viviendas unifamiliares frente a calefacción centralizada en edificios multifamiliares).

- Edad de la población: Burnley et al. (2007) encontraron diferencias significativas en la composición de RSU de los hogares en función del rango de edad: con personas por debajo de los 16 años se generaron una mayor cantidad de botellas de plástico y pañales; con miembros en el rango de 1744 años se produjeron más residuos orgánicos; con residentes entre 45-65 años se generaron mayor cantidad de residuos de periódicos y revistas, mientras que con personas por encima de los 65 se produjeron una menor cantidad de residuos de envases. Por su parte, Dennison et al. (1996) obtuvieron correlaciones positivas entre los hogares cuyos miembros tenían menos de 65 años y la generación de residuos de latas de bebida.

\section{Variables relacionadas con el sistema de gestión de RSU}

- Tipo de recogida: es razonable asumir que habrá diferencias significativas en la composición de los residuos en función de la existencia de recogida selectiva, así como de los tipos existentes (envases, papel/cartón, vidrio, fracción orgánica, voluminosos, restos de jardinería, etc.). Esto a su vez está relacionado con el tipo y heterogeneidad de los RSU que se tratan en las diferentes plantas de tratamiento y, por tanto, con la composición sus rechazos. Así pues, la composición y propiedades de los rechazos dependerán de los sistemas de recogida selectiva adoptadas en la zona (Bessi et al., 2016; Di Lonardo et al., 2016, 2012; lacovidou et al., 2018). En este sentido, Rada and Ragazzi (2014) analizaron diferentes escenarios de recogida selectiva y encontraron diferencias en las características de los rechazo en función del tipo de recogida existente.

- Frecuencia de recogida: en algunos municipios o regiones los RSU solo son recogidos 6 días a la semana, de lunes a sábado. En estos casos, debido a la acumulación de los residuos del fin de semana, pueden existir diferencias significativas en la composición de los RSU de los lunes en comparación del resto de días de la semana. Además, otros tipos de frecuencias de recogida también pueden suponer variaciones en la composición de los residuos que entran a la planta de tratamiento.

- Días de funcionamiento de la instalación: algunas plantas de TMB solo trabajan de lunes a viernes o sábado. Por lo que, si existen un desfase entre la frecuencia de recogida y los días de funcionamiento de la instalación, se producirá una acumulación de los residuos del fin de semana en el foso de descarga de la misma. Como consecuencia, pueden existir diferencias significativas entre la composición de los residuos tratados los lunes y el resto de días de la semana y, por lo tanto, también en los rechazos generados.

- Tipo de instalación: en función del tipo de planta de TMB, el número de corrientes de rechazo generadas y que se han de muestrear será diferente (tabla 3.3), puesto que cada una de las corrientes presenta una composición y propiedades distintas (Bessi et al., 2016; Di Lonardo et al., 2016). Asimismo, esto afectará a la calidad del CRS obtenido a partir de los rechazos, ya que la calidad de este tipo de combustible depende de la materia prima utilizada para su producción (Nasrullah et al., 2017; Sarc et al., 2014; Sarc and Lorber, 2013). En este sentido, Edo-Alcón et al. (2016) estudiaron seis corrientes de rechazo de tres plantas de TMB distintas y observaron diferencias en las propiedades de las mismas en función del tipo de planta de tratamiento, así como en la calidad de los CSR que se podrían obtener a partir de los mismos.

- Procesos de tratamiento: otro de los factores que influye en la composición de los rechazos es el proceso de tratamiento al que se someten los residuos dentro de la instalación (Velis et al., 2012). 
En concreto el tipo de operaciones unitarias mecánicas utilizadas en las plantas de tratamiento (Di Lonardo et al., 2012), por ejemplo el tipo de recuperación: manual o automática. Además, esto también influirá en la calidad del CSR producido a partir de los mismos (Sarc et al., 2014; Sarc and Lorber, 2013), pudiendo afectar al contenido en humedad y, por tanto, al poder calorífico inferior (lacovidou et al., 2018). Así pues, Rotter et al. (2004) analizaron diferentes tecnologías de separación y demostraron que el proceso mecánico utilizado afectaba a la calidad de los rechazos. Por su parte, Edo-Alcón et al. (2016) hallaron diferencias en las propiedades de los rechazos en función del proceso de tratamiento donde se originan y el sistema de separación utilizado.

\subsection{VARIABLES QUE AFECTAN AL TAMAÑO DE MUESTRA DE UN RECHAZO}

Tras la revisión bibliográfica de diferentes estudios sobre la caracterización de residuos, rechazos y CSR se ha identificado una serie de variables que afectan al tamaño de muestra mínimo requerido para que esta sea representativa; las cuales están relacionadas con las propiedades físicas de los rechazos y son: el grado de heterogeneidad del material, sus propiedades granulométricas (forma de partícula, tamaño y distribución del tamaño de partícula) y su densidad.

Estas variables están relacionadas con los aspectos geométricos del material involucrados en el muestreo, en concreto con los relacionados con la distribución espacial de sus partículas en el lote de rechazos a muestrear, considerando como partículas o fragmentos a los diferentes objetos que constituyen el rechazo, tan diversos como un pañal, un retal de tela, un trozo de cerámica, un envase de plástico o un trozo de pan.

\section{Heterogeneidad}

Como se ha podido comprobar en el estado del arte, los rechazos del TMB son un material muy heterogéneo. De forma general están constituidos por una mezcla de partículas de diferentes materiales. Así pues, el grado de heterogeneidad de los rechazos está relacionado con su composición física, es decir, con la diversidad de materiales que presenten, así como con el tamaño y forma de las partículas y con cómo de mezcladas están entre sí.

Las corrientes de rechazo presentan mayor o menor grado de heterogeneidad en función del tipo de residuos que se tratan en las plantas de TMB y de los procesos de tratamiento que se llevan a cabo en las mismas, los cuales generan corrientes de rechazo más o menos homogéneas. Además, esta heterogeneidad dificulta la toma de muestras de los rechazos en las plantas de tratamiento (Pehlken et al., 2000) y es responsable de una parte del error de muestreo (Pehlken et al., 2000; Petersen et al., 2005).

Según la Teoría de Muestreo para materiales particulados de Pierre Gy (como son los rechazos), la heterogeneidad es una de las causas del Error Total de Muestreo. En concreto es responsable del Error Fundamental de Muestreo, que se considera el error de muestreo mínimo que existe incluso cuando todos los demás componentes del error total de muestreo se han eliminado. Además, junto con el proceso de muestreo, también es responsable del Error de Agrupación y Segregación, el cual es consecuencia de la composición y distribución espacial del material en el lote (Petersen et al., 2005).

Para disminuir la influencia de la heterogeneidad y obtener muestras representativas es clave mezclar todo el material que está sujeto a muestreo (lote). Si esto no se tiene en cuenta, solo el material de más fácil acceso del lote tiene la posibilidad de terminar en la muestra final, lo que va en contra del principio fundamental de muestreo de que todas las partículas presentes en el lote tienen que tener la misma probabilidad de ser seleccionadas como parte de la muestra. En el caso de los RSU o de los rechazos, este mezclado suele ser difícil y siempre supone algún tipo de coste (económico, mano de obra o tiempo invertido). Sin embargo, no tratar con ello en la medida de lo posible es uno de los principales errores cometidos en los muestreos convencionales (Petersen et al., 2005).

Por otro lado, como se ha visto en el estado del arte, Pierre Gy en su Teoría de Muestreo divide la heterogeneidad de un material particulado en dos: la heterogeneidad de constitución y la heterogeneidad de distribución. La primera depende de la composición del material, y la segunda depende la distribución espacial de las partículas en el lote o muestra. 
- Heterogeneidad de constitución: este tipo de heterogeneidad es inherente del material, depende de la composición, forma, tamaño y densidad de las partículas o fragmentos que forman el lote, y es debida a las diferencias existentes entre las mismas. Por lo que, si existe una gran diferencia en cuanto a la composición entre los fragmentos individuales, la heterogeneidad de constitución es alta, mientras que si los fragmentos son más homogéneos, será menor. Esta heterogeneidad no cambia con el mezclado del material y la única forma de alterarla es a través de la reducción de tamaño de partícula mediante trituración.

- Heterogeneidad de distribución: este tipo de heterogeneidad es debida a las diferencias que se observan entre grupos de fragmentos y, principalmente, depende de la distribución física y espacial de las partículas del material en el lote. Además, también se ve influenciada por el tamaño y la densidad de estas partículas. Por ejemplo, las partículas con grandes diferencias de tamaños y/o densidad tienden a segregarse o estratificarse, acabando las partículas más pequeñas y/o más densas en la parte inferior del lote. Para su minimización es fundamental mezclar correctamente el material antes de la toma de muestra.

Como se ha comentado anteriormente, la heterogeneidad es la responsable de dos tipos de errores de muestreo: el Error Fundamental de Muestreo (FSE) y el Error de Agrupación y Segregación (GSE). El primero de ellos tiene una influencia directa en el tamaño de muestra mínimo, la cual se explica a continuación. El segundo está muy relacionado con el tamaño y densidad de partícula, por lo que tratará en los siguientes apartados.

EI FSE es un error inevitable en cualquier muestreo, siendo consecuencia de la heterogeneidad de constitución del material y, por tanto, de las propiedades intrínsecas del mismo como: el tamaño, forma, densidad y composición. Una forma de minimizarlo es mejorar las características físicas del lote de manera que pueda llevarse a cabo un muestreo más representativo, el método más frecuente es triturar los fragmentos a un tamaño de partícula menor (Petersen et al., 2005). Sin embargo, en el caso de los RSU o rechazos, si el objetivo del muestreo es conocer la composición física mediante la identificación de materiales presentes en los mismos, no es posible minimizarlo mediante la reducción de tamaño.

EI FSE se puede calcular a partir de una serie de parámetros físicos del material mediante la fórmula que Gy desarrolló para materiales particulados (como pueden ser los residuos o rechazos) (Ec.4.1):

$$
s^{2}(F S E)=C \cdot d^{3}\left(\frac{1}{M_{S}}-\frac{1}{M_{L}}\right) \approx \frac{C \cdot d^{3}}{M_{S}}
$$

La masa del lote $(\mathrm{M} L)$, casi siempre se elimina de la ecuación debido a que su tamaño es muy grande; $M_{s}$ es el tamaño mínimo de muestra, C es la denominada "Constante de Muestreo"; $d$ es el tamaño nominal superior de partícula, y s²(FSE) es la varianza del error fundamental.

La Constante de Muestreo (C) está relacionada con la heterogeneidad de constitución del material (al igual que el tamaño nominal superior (d)) y se obtiene a partir del producto de cuatro parámetros (Ec.4.2): factor de composición mineralógica o parámetro de constitución (c); factor de forma de partícula (f); factor de distribución de tamaños de partícula (g), y factor de liberación ( $\beta$ ). Los cuales están relacionados las propiedades intrínsecas del material.

$$
C=c \cdot f \cdot g \cdot \beta
$$

La fórmula de Gy, además, permite estimar el tamaño mínimo de muestra cuando se fija el nivel de incertidumbre deseado (es decir, la varianza del error fundamental admitida) mediante la siguiente ecuación:

$$
M_{S}=\frac{C \cdot d^{3}}{S_{0}^{2}(F S E)}
$$

De la ecuación 4.3 se puede deducir que el tamaño de muestra $\left(M_{s}\right)$ depende de la heterogeneidad del material (C), así como del tamaño nominal superior de partícula (d) y de la varianza del error fundamental admitida o nivel de incertidumbre deseado $\left(\mathrm{so}^{2}\right.$ (FSE)). Así pues, cuanto menos heterogéneo es un material, 
la masa de muestra necesaria será menor. Por otro lado, como se ha visto anteriormente, la heterogeneidad de un material disminuye con la reducción del tamaño de partícula, por lo que, un menor tamaño nominal superior supone también supone un menor tamaño de muestra.

\section{Propiedades granulométricas}

Dentro del muestreo siempre existe un problema físico o de escala geométrica involucrado, relacionado con los tamaños de los fragmentos o partículas del material respecto al tamaño de la herramienta utilizada para la toma de muestras y las dimensiones del lote en sí. Existiendo la contradicción de que es necesario coger la mayor cantidad de fragmentos en la muestra de manera que se represente correctamente el material, pero al mismo tiempo hay un deseo opuesto de mantener la masa total de la muestra lo más pequeña posible por razones prácticas y económicas. Además, generalmente, si el material a muestrear tiene un tamaño de partícula grande, el tamaño de la muestra necesario será mayor (Petersen et al., 2005).

Las propiedades granulométricas de los materiales incluyen el tamaño de partícula y su distribución, así como la forma de sus partículas. En el caso de los RSU, estas propiedades se utilizan para: describir el rendimiento de los equipos de trituración y separación de las plantas de tratamiento; modelar y simular su funcionamiento; controlar los procesos, y desarrollar protocolos de muestreo para la caracterización de residuos y el control de calidad (Velis et al., 2010). Así pues, esta última función es de especial interés en la presente tesis, además, el tamaño de partícula es utilizado por la Teoría de Muestreo de Gy para estimar el tamaño mínimo de muestra. En el caso de los rechazos, el tamaño y forma de partícula de los mismos dependerá del tipo de RSU que se trata en la planta de TMB y del proceso de tratamiento u operación unitaria donde se genera esa corriente.

El tamaño de partícula solo puede definirse de manera coherente cuando las partículas tienen formas más o menos regulares. Por lo que, en el caso de los RSU y rechazos, la irregularidad y variabilidad de las partículas presentes en los mismos complica su determinación, ya que el tamaño de sus partículas puede variar de unos milímetros (elementos finos) a un metro o más (un trozo de madera o una manguera). No obstante, habitualmente se utilizan adaptaciones de las técnicas usadas en la industria minera para estimar el tamaño nominal superior y describir la distribución del tamaño de partícula (Velis et al., 2010). El tamaño nominal superior ( $d_{95}$ ) es el tamaño de apertura de malla a través de la cual pasan el 95\% de la masa del material (es decir que retiene el 5\%), expresado en unidades de longitud.

Según la fórmula de Gy (Ec.4.1), el tamaño nominal superior es el parámetro que más influye en el FSE (está elevado al cubo y multiplicando). Como consecuencia, el tamaño de partícula es más relevante a la hora de obtener un error de muestreo pequeño que el propio tamaño de muestra (Grigorieff et al., 2004).

Por otro lado, y como se ha visto en el apartado anterior, el tamaño de partícula está muy relacionado con el tamaño de muestra, puesto que es uno de los parámetros utilizados en la fórmula de Gy para el cálculo de la masa de muestra mínima (Ec.4.3). De esta ecuación se deduce que, en el muestreo, tamaños de partículas muy grandes llevan a tamaños de muestra mayores. Así pues, en materiales heterogéneos como los RSU o los rechazos, el tamaño de partícula es un parámetro crucial para un muestreo representativo y, por tanto, para obtener unos resultados de calidad (Lorber et al., 2012), ya que el tamaño de muestra se determina en base al mismo (Flamme and Geiping, 2012). Por todo ello es fundamental su estimación.

En el caso de los CSR, este se puede calcular siguiendo el método definido en la norma UNE-EN 15415-1 (2012) “Combustibles sólidos recuperados: Determinación de la distribución de tamaño de partícula. Parte 1: Método del tamiz para partículas pequeñas" en el caso de partículas entre 25 y $100 \mathrm{~mm}$; o mediante la norma UNE-EN 15415-2 (2012) “Combustibles sólidos recuperados: Determinación de la distribución de tamaño de partícula. Parte 2: Método de la longitud máxima proyectada para partículas de grandes dimensiones" en el caso de partículas de más de $100 \mathrm{~mm}$.

Estas normas también pueden utilizarse para los rechazos, no obstante, hay que tener en cuenta algunas consideraciones (Velis et al., 2010; Von Blottnitz et al., 2002). Por un lado, los materiales flexibles pueden presentar diferente área de partícula proyectada en función de las fuerzas que actúan sobre ellos (por ejemplo, un plástico film de $1 \mathrm{~m}^{2}$ puede ser forzado a arrugarse y pasar por una luz de malla de menos de $100 \mathrm{~mm}$ ). Por otro, las partículas del rechazo, debido a su forma irregular, pueden no moverse sobre la 
superficie del tamiz como cabría esperar. Por lo tanto, dependiendo de la orientación de la partícula, el tamizado puede dar resultados muy diferentes debido a que algunas partículas con ciertas formas alargadas pueden pasar por aberturas menores a su tamaño máximo real. Esto está relacionado con que, dentro de los rechazos, se pueden encontrar partículas u objetos en las que la relación entre la longitud máxima y la mínima puede ser de muchos ordenes de magnitud (por ejemplo, películas de plástico, cintas de papel, retales de tela, cuerdas o cables). Además, el contenido en humedad de los rechazos puede hacer que las fracciones finas se adhieran a las fraccione gruesas $y$, por lo tanto, se midan incorrectamente. En este sentido, la norma para CSR recomienda el secado al aire de aquellas muestras que tengan una humedad superior al $20 \%$ antes de su tamizado.

Por otro lado, el tamaño y forma de partícula también influye en la heterogeneidad de distribución definida en el apartado anterior, la cual es responsable del Error de Agrupación y Segregación. Este error es prácticamente inevitable en los muestreos y es consecuencia de que los fragmentos o partículas no están distribuidos uniformemente en el material debido a sus diferencias de tamaño, forma y densidad (Petersen et al., 2005).

Respecto a la distribución de tamaño de partícula, es un parámetro ampliamente utilizado en el procesamiento de minerales, pero su aplicación en el campo de los residuos ha sido limitada debido a la irregularidad de sus partículas (Von Blottnitz et al., 2002). En el caso de los RSU, sobre todo se utilizan representaciones graficas de los datos de distribución de tamaño para conocer el rendimiento de los procesos mecánicos en las plantas de tratamiento y configurar así las operaciones unitarias (Velis et al., 2010). Respecto al muestreo, como se ha visto anteriormente, el cálculo del tamaño nominal superior se realiza a partir de la determinación de la distribución de tamaño de partícula. Por otra parte, el factor de distribución de tamaños (g) que se utiliza para el cálculo de la Constante de Muestreo de la fórmula de Gy describe el intervalo o distribución de tamaños de partículas que hay en el lote.

Por último, una de las peculiaridades de los rechazos es la forma de sus partículas. Los rechazos son un material sólido, pero normalmente sus partículas no son granulares, teniendo una forma muy variable (desde un palo de escoba, una cuerda o cable, a un trozo de pan, una manzana o un envase de yogurt). Además, muchos de los materiales que lo forman son materiales poco densos, alargados y, en algunos casos, planares (plástico film, textiles, celulosas sanitarias, papel/cartón, etc.). Esta particularidad hace que el cálculo del tamaño de muestra no pueda llevarse a cabo como se haría con un material cuyas partículas tienen un tamaño y forma regular, sino que habrá que adaptarlo a la naturaleza de estos materiales. En la industria minera, la forma esferoidal es la más frecuente y se caracteriza por un diámetro de partícula que es independiente a la orientación de la partícula. Sin embargo, en los rechazos esto no es así, por lo que para el cálculo del tamaño de muestra es necesario utilizar un factor de forma de las partículas (f), este corrige la no esfericidad (Von Blottnitz et al., 2002).

\section{Densidad}

La densidad de los RSU (y de los rechazos) depende de muchos factores como la humedad, el tipo de almacenamiento, el grado de compactación, tiempo de almacenamiento, tipo de residuos, estación del año, etc. Es un parámetro ampliamente utilizado en la gestión y recogida de RSU, puesto que permite conocer el volumen ocupado por una masa de residuos y, de ese modo, dimensionar los contendores para su recogida en la vía pública. Así como, conocer la frecuencia con la que estos tienen que ser recogidos, el volumen de los camiones de recogida y transporte, el coste del transporte y el tamaño de instalaciones de tratamiento. Por otro lado, dentro del tratamiento de los RSU, este parámetro es utilizado para describir el rendimiento de los equipos de separación por densidad (mesas densimétricas y separadores balísticos), así como para modelar y simular su funcionamiento y llevar a cabo el control del proceso.

Respecto al proceso de muestreo, la densidad se tiene en cuenta en la fórmula de Gy para el cálculo de la masa de muestra (Ec.4.3) a través del factor de composición mineralógica o parámetro de constitución (c). Este factor relaciona la cantidad de componente crítico (componente de interés que se quiere analizar) en el lote, la densidad de las partículas que lo contienen y la densidad media del lote. 
Por otra parte, la densidad de partícula también influye en la heterogeneidad de distribución y, por tanto, en el Error de Agrupación y Segregación. Esto se debe a que cuando existen diferencias en la densidad de las partículas, se produce una estratificación o segregación de los fragmentos de material en el lote como consecuencia de acción de la gravedad. Para evitar esta segregación es necesario mezclar minuciosamente el material. No obstante, esto no asegura su eliminación, puesto que algunos materiales por su naturaleza son propensos a estratificarse incluso inmediatamente después de la mezcla (Petersen et al., 2005), por ejemplo materiales de pequeño tamaño y con elevada densidad que se depositan rápidamente en la parte inferior del lote (tierras, piedras, trozos de vidrio, etc.).

\subsection{PARAMETROS QUE DEFINEN LA CALIDAD DE LOS CSR}

La hipótesis de partida del estudio es que los rechazos producidos en las plantas de TMB pueden ser transformados en un CSR valorizable. Pero para poder usar estos rechazos como CSR tienen que cumplir unos estándares en base a ciertos parámetros que definen la calidad de este tipo de combustibles.

La calidad de los CSR es un factor clave para su demanda, utilización y comercialización. En la industria de la producción de energía, para que un CSR sea aceptado como remplazo de los combustibles fósiles, es fundamental lograr la calidad requerida o exigida (Glorius, 2014). En general, la calidad de los CSR se define en términos de homogeneidad (composición), eficiencia energética (valor calorífico) y parámetros técnicos y ambientales (concentración de cloro y mercurio), además, la concentración de metales pesados en general debe de mantenerse lo más bajo posible (Nasrullah et al., 2017).

Las características de la corriente de rechazo a partir de la cual se producen un CSR (contenido de humedad, tamaño de las partículas, composición y naturaleza) afectaran a la propiedades físicas y químicas de los mismos, es decir, a la calidad final obtenida (Nasrullah et al., 2016). Además, la composición de los CSR es la responsable del contenido en cloro y otras propiedades del combustible (Velis et al., 2012), de ahí la importancia de llevar a cabo un control de la calidad de los propios rechazos del TMB mediante el análisis de los parámetros que definen la calidad de los CSR.

Como se ha descrito en el estado del arte, en la Unión Europea existe un paquete de normas desarrolladas por el Comité Europeo de Estandarización, en concreto por el Comité Técnico CEN/TC 343 - Solid Recovered Fuels, que regulan la calidad de los CSR. En ellas, se define CSR como aquellos combustibles producidos a partir de residuos no peligrosos (como los rechazos), tras su adecuado tratamiento, y que cumplen los requisitos de clasificación y especificaciones establecidas en la norma UNE-EN 15359 (2012): “Combustibles sólidos recuperados: especificaciones y clases". Esta norma propone un sistema de clasificación de la calidad de los CSR basado en los valores límite de tres parámetros: el poder calorífico inferior (PCI), como parámetro económico; el contenido en cloro $(\mathrm{Cl})$, como parámetro técnico, y el contenido en mercurio $(\mathrm{Hg})$, como parámetro medioambiental.

Además de estos tres parámetros existen otras propiedades como el contenido en humedad, fracción volátil, el tamaño de partícula, el contenido en ceniza, metales pesados etc., que también son importantes para evaluar el comportamiento de los CSR en las instalaciones de combustión (Di Lonardo et al., 2016; Lorber et al., 2012; Rotter et al., 2011; Velis et al., 2010). Los cuales son considerados por otros estándares como se muestra a continuación.

Junto con el estándar europeo, algunos países como Alemania, Italia, Francia, Finlandia, Austria, Suiza o España han definido sus propios estándares de calidad. Los cuales pueden variar en función del tipo de instalación donde los CSR vayan a utilizarse, como ocurre en Austria, o ser específicos para un único uso, como en España o Suiza con las cementeras. En la mayoría de los casos estos estándares propios se crearon antes que el europeo y en general son más restrictivos que este. Las normas o estándares existentes para cada uno de estos países se han expuesto en el estado del arte.

Así pues, tras la revisión de estos estándares propios (BGS (Ed.), 2008; BMLFUW (Ed.), 2010, 2008; BUWAL (Ed.), 2005; Carlos Alberola et al., 2017; Gallardo et al., 2014; Garcés et al., 2016; Republique Française, 2016; SFS 5875, 2000; UNI 9903-1, 2004), se ha observado que en ellos aparecen, junto con el PCl, el Cl y el $\mathrm{Hg}$, otros parámetros para definir la calidad de los CSR: humedad, cenizas, contenido en $\mathrm{S}$ y $\mathrm{N}$, tamaño de 
partícula, porcentaje de impurezas, contenido en diferentes metales pesados (principalmente: $\mathrm{Cd}, \mathrm{Pb}, \mathrm{Cr}$, $\mathrm{Ni}, \mathrm{As}, \mathrm{Cu}, \mathrm{Co}, \mathrm{Sb}, \mathrm{Mn}, \mathrm{Tl}, \mathrm{V}$ y $\mathrm{Sn}$ ), contenido en otros halógenos ( $\mathrm{F}, \mathrm{Br}$ y I) y contenido en $\mathrm{K}$ y $\mathrm{Na}$. Los parámetros que tienen en cuenta cada uno de estos estándares se muestran en la Tabla 4.1.

Tabla 4.1 Parámetros que definen la calidad de los CSR en los diferentes estándares europeos

\begin{tabular}{|c|c|c|c|c|c|c|c|c|c|c|}
\hline \multirow[b]{2}{*}{ Parámetro } & \multicolumn{9}{|c|}{ Estándar de calidad } & \multirow{2}{*}{$\begin{array}{l}\text { Estándares } \\
\text { que lo } \\
\text { consideran }\end{array}$} \\
\hline & $\begin{array}{c}\text { UNE-EN } \\
15359\end{array}$ & Alemania & Austria & Finlandia & Italia & Francia & Suiza* & España* & Eurits* & \\
\hline $\mathrm{PCl}$ & $x$ & $x$ & $x$ & & $x$ & $x$ & $x$ & $x$ & $x$ & 8 \\
\hline $\mathrm{Cl}$ & $x$ & $x$ & $x$ & $x$ & $x$ & $x$ & $x$ & & $x$ & 8 \\
\hline $\mathrm{Hg}$ & $x$ & $x$ & $x$ & $x$ & $x$ & $x$ & $x$ & & $x$ & 8 \\
\hline Cd & & $x$ & $x$ & $x$ & $x$ & & $x$ & & $x$ & 6 \\
\hline $\mathrm{Cr}$ & & $x$ & $x$ & & $x$ & & $x$ & $x$ & $x$ & 6 \\
\hline $\mathrm{Pb}$ & & $x$ & $x$ & & $x$ & & $x$ & $x$ & $x$ & 6 \\
\hline Cenizas & & $x$ & $x$ & & $x$ & & & $x$ & $x$ & 5 \\
\hline $\mathbf{s}$ & & & & $x$ & $x$ & & $x$ & $x$ & $x$ & 5 \\
\hline As & & $x$ & $x$ & & $x$ & & $x$ & & $x$ & 5 \\
\hline $\mathrm{Ni}$ & & $x$ & $x$ & & $x$ & & $x$ & & $x$ & 5 \\
\hline Humedad & & $x$ & & & $x$ & & $x$ & $x$ & & 4 \\
\hline Co & & $x$ & $x$ & & & & $x$ & & $x$ & 4 \\
\hline $\mathrm{Cu}$ & & $x$ & & & $x$ & & $x$ & & $x$ & 4 \\
\hline $\mathrm{Sb}$ & & $x$ & $x$ & & & & $x$ & & $x$ & 4 \\
\hline $\mathbf{N}$ & & & & $x$ & & & & $x$ & $x$ & 3 \\
\hline$M n$ & & $x$ & & & $x$ & & & & $x$ & 3 \\
\hline Sn & & $x$ & & & & & $x$ & & $x$ & 3 \\
\hline TI & & $x$ & & & & & $x$ & & $x$ & 3 \\
\hline v & & $x$ & & & & & $x$ & & $x$ & 3 \\
\hline $\mathrm{K}$ y Na & & & & $x$ & & & & & & 1 \\
\hline Se & & $x$ & & & & & & & $x$ & 2 \\
\hline Te & & $x$ & & & & & & & $x$ & 2 \\
\hline $\mathrm{Br} / \mathrm{I}$ & & & & & & & & & $x$ & 1 \\
\hline $\mathrm{Br}$ & & & & & & $x$ & & & & 1 \\
\hline $\mathbf{F}$ & & & & & & & & & $x$ & 1 \\
\hline $\begin{array}{c}\text { Halógenos } \\
\text { totales }\end{array}$ & & & & & & $x$ & & $x$ & & 2 \\
\hline Impurezas & & & $x$ & & & & & & & 1 \\
\hline $\begin{array}{l}\text { Tamaño } \\
\text { partícula }\end{array}$ & & & $x$ & & & & & & & 1 \\
\hline $\begin{array}{l}\text { Aluminio } \\
\text { metálico }\end{array}$ & & & & $x$ & & & & & & 1 \\
\hline
\end{tabular}




\begin{tabular}{c|c|c|c|c|c|c|c|c|c|c}
\hline \multirow{2}{*}{ Parámetro } & \multicolumn{9}{c|}{ Estándar de calidad } & \multicolumn{2}{c|}{$\begin{array}{c}\text { Estándares } \\
\text { que lo } \\
\text { consideran }\end{array}$} \\
\cline { 2 - 12 } & $\begin{array}{c}\text { UNE-EN } \\
15359\end{array}$ & Alemania & Austria & Finlandia & Italia & Francia & Suiza* & España* & Eurits* \\
\hline Be & & $X$ & & & & & & & & 1 \\
\hline Ba & & & & & & & & $X$ & & 1 \\
\hline Mo & & & & & & & & & $X$ & 1 \\
\hline Zn & & & & & & & & & $X$ & 1 \\
\hline TOTAL & 3 & 20 & 13 & 7 & 13 & 5 & 16 & 9 & 24 & \\
\hline
\end{tabular}

* Estándares para cementeras

Como se observa en la tabla anterior, entre todos los estándares analizados, un total de 33 parámetros diferentes se tienen en cuenta para definir la calidad de los CSR. El estándar para cementeras de Eurits y el de Alemania son los que mayor número de ellos consideran, 24 y 20 respectivamente, mientras que la norma UNE-EN 15359 solo considera tres: $\mathrm{PCl}, \mathrm{Cl}$ y Hg. No obstante, estos tres parámetros son los más usados, ya que 8 de los 9 estándares revisados los utilizan a la hora de definir la calidad de los CSR. Finlandia es el único país en el que su estándar no tiene en cuenta el $\mathrm{PCl}$, mientras el $\mathrm{Cl}$ y el $\mathrm{Hg}$ no son considerados en el estándar español para cementeras (aunque sí que considera los halógenos totales, donde se encuentra incluido el $\mathrm{Cl}$ ). Además, diferentes metales pesados son utilizados también para definir la calidad de los CSR, siendo los más usado el $\mathrm{Cd}$, el $\mathrm{Cr}$, y el $\mathrm{Pb}$, en 6 de los 9 estándares. Otros parámetros como las cenizas o el contenido en azufre también se tienen en cuenta habitualmente.

Así pues, se puede concluir que los parámetros más utilizados para definir la calidad de los CSR son: el PCI, el contenido en $\mathrm{Cl}$ y el contenido en $\mathrm{Hg}$, seguidos por el contenido en $\mathrm{Cd}, \mathrm{Pb}$ y $\mathrm{Cr}$. Los tres primeros son los que se tendrán en cuenta en el diseño de la metodología para el control de calidad de los rechazos, en concreto en el desarrollo de los procedimientos para el tratamiento y análisis de las muestras en el laboratorio, coincidiendo con los parámetros que usados por la norma UNE.

De forma resumida, el $\mathrm{PCl}$ describe la cantidad de calor o energía generada por unidad de peso con la combustión completa del CSR. Es utilizado como parámetro económico en la norma UNE-EN 15359, puesto que permite evaluar el rendimiento que tendrán los CSR en su valorización energética. El contenido en cloro es utilizado como parámetro técnico, ya que es una medida de los potenciales efectos de corrosión, escorificación y ensuciamiento de las calderas. Por otro lado, el cloro también es el responsable de la formación de dioxinas y furanos que son compuestos halogenados muy contaminantes y peligrosos (Flamme and Geiping, 2012). Además, respecto a la comercialización de los CSR, este parámetro es el mayor limitante (Rotter et al., 2011). Respecto al contenido en mercurio, es una medida de toxicidad potencial liberada en el medio ambiente como consecuencia de la incineración de los CSR. Su alta volatilidad hace que sea más difícil de capturar por los sistemas de control de la contaminación que tratan los gases de combustión (lacovidou et al., 2018), por lo que es utilizado como parámetro medioambiental.

\subsection{CONCLUSIONES}

En este capítulo se ha llevado a cabo una extensa revisión bibliográfica con el objetivo de identificar todas las variables y parámetros implicados en el diseño de la metodología para el control de calidad de los rechazos del TMB.

Por un lado, las variables que afectan a las propiedades de los rechazos identificadas se han clasificado en tres categorías. Estas se exponen a continuación junto con las variables que incluyen de cada una de ellas.

- Variables del entorno: estacionalidad, climatología y área geográfica.

- Variables socio-económicas: turismo, nivel de renta, modo de vida, tipo de población, nivel de urbanización y edad de la población. 
- Variables relacionadas con el sistema de gestión de RSU: tipo de recogida, frecuencia de recogida, días de funcionamiento de la instalación, tipo de instalación y procesos de tratamiento

Todas estas variables se deben de tener en cuenta en el desarrollo el plan de muestreo, en concreto a la hora de calcular el número de muestras mínimo necesarias, de manera que los resultados obtenidos tras la aplicación del mismo sean representativos del total de la producción y tengan en cuenta la variabilidad de los rechazos.

Por otro lado, respecto a las variables que afectan al tamaño de muestras, se ha observado que existe una serie de propiedades físicas de los rechazos que son responsables de algunos de los errores de muestreo y tienen una gran influencia en el tamaño mínimo de muestra necesario. Estas son: la heterogeneidad, el tamaño y distribución del tamaño de partícula, la forma de partícula y la densidad.

Todas estas variables están relacionadas con aspectos geométricos del material involucrados en el muestreo y con cómo se distribuyen las partículas en el lote de rechazos a muestrear. Por lo que deben contemplarse a la hora de diseñar el plan de muestreo, de manera que se llegue a un equilibrio entre el tamaño mínimo de muestra y la representatividad de la misma. Además, como se verá en el siguiente capítulo, algunas metodologías para la caracterización de residuos o CSR usan estos mismos parámetros en el cálculo del tamaño de muestra. Para ello utilizan ecuaciones derivadas de la fórmula de Gy, la cual se ha expuesto en el presente capítulo, adaptándola a la naturaleza de estos materiales.

Por último, se han revisado nueve estándares de calidad para CSR existentes en Europa, tanto a nivel comunitario (UNE-EN 15359 y EURITS) como a nivel nacional (Alemania, Austria, Finlandia, Italia, Francia, Suiza y España). Entre todos los estándares analizados, se han identificado un total de 33 parámetros diferentes que definen la calidad de los CSR. Los parámetros más utilizados son el $\mathrm{PCl}$, el contenido en $\mathrm{Cl}$ y el contenido en $\mathrm{Hg}$, seguidos por el contenido en $\mathrm{Cd}, \mathrm{Pb}$ y $\mathrm{Cr}$. Otros parámetros como las cenizas y el contenido en azufre también se tienen en cuenta habitualmente.

De todos ellos, el $\mathrm{PCl}$, el $\mathrm{Cl}$ y el $\mathrm{Hg}$ son los que se tendrán en cuenta en el desarrollo de la metodología, en concreto en la etapa dedicada a los procedimientos para el tratamiento y análisis de las muestras en el laboratorio. Puesto que aportan información sobre las características que ha de tener la muestra de análisis y las mediciones o analíticas que se deben realizar en el control de calidad.

Así pues, el diseño de la metodología para el control de calidad de los rechazos de las plantas de TMB deberá considerar todas las variables identificadas en el presente capítulo. Esto evidencia la gran cantidad de información que se necesita para desarrollar un adecuado plan de muestreo que tenga en cuenta la variabilidad de los rechazos, así como unos apropiados procedimientos de preparación de muestras en el laboratorio para el análisis de los parámetros que definen la calidad de los CSR.

\subsection{REFERENCIAS}

Abu-Qdais, H.A., Hamoda, M.F., Newham, J., 1997. Analysis of residential solid waste at generation sites. Waste Manag. Res. 15, 395-406. https://doi.org/10.1006/wmre.1996.0095

Bach, H., Mild, A., Natter, M., Weber, A., 2004. Combining socio-demographic and logistic factors to explain the generation and collection of waste paper. Resour. Conserv. Recycl. 41, 65-73. https://doi.org/10.1016/j.resconrec.2003.08.004

Beigl, P., Wassermann, G., Schneider, F., Salhofer, S., 2004. Forecasting Municipal Solid Waste Generation in Major European Cities.

Bessi, C., Lombardi, L., Meoni, R., Canovai, A., Corti, A., 2016. Solid recovered fuel: An experiment on classification and potential applications. Waste Manag. 47, 184-194. https://doi.org/10.1016/j.wasman.2015.08.012

BGS (Ed.), 2008. Quality label RAL-GZ 724 Quality and test instructions Solid Recovered Fuels (German version only). BGS: Bundesgü tegemeinschaft Sekundä rbrennstoffe und Recyclingholz e.V., Münster, Germany. 
BMLFUW (Ed.), 2010. Verordnung über die Verbrennung von Abfällen Abfallverbrennungsverordnung - AVV [Waste Incineration Ordinance]. BMLFUW: Bundesministerium für Land- und Forstwirtschaft, Umwelt und Wasserwirtschaft, Vienna, Austria.

BMLFUW (Ed.), 2008. Richtlinie für Ersatzbrennstoffe [Guideline for Waste Fuels]. BMLFUW: Bundesministerium für Land- und Forstwirtschaft, Umwelt und Wasserwirtschaft, Vienna, Austria.

Boer, E. den, Jędrczak, A., Kowalski, Z., Kulczycka, J., Szpadt, R., 2010. A review of municipal solid waste composition and quantities in Poland. Waste Manag. 30, 369-377. https://doi.org/10.1016/J.WASMAN.2009.09.018

Boldrin, A., Christensen, T.H., 2010. Seasonal generation and composition of garden waste in Aarhus (Denmark). Waste Manag. 30, 551-557. https://doi.org/10.1016/j.wasman.2009.11.031

Brás, I., Silva, M.E., Lobo, G., Cordeiro, A., Faria, M., De Lemos, L.T., 2017. Refuse Derived Fuel from Municipal Solid Waste rejected fractions- a Case Study. Energy Procedia 120, 349-356. https://doi.org/10.1016/j.egypro.2017.07.227

Burnley, S.J., Ellis, J.C., Flowerdew, R., Poll, a. J., Prosser, H., 2007. Assessing the composition of municipal solid waste in Wales. Resour. Conserv. Recycl. 49, 264-283. https://doi.org/10.1016/j.resconrec.2006.03.015

BUWAL (Ed.), 2005. Richtlinie zur Entsorgung von Abfällen in Zementwerken [Guideline for the disposal of waste in cement plants]. BUWAL, Bern, Suiza.

Carlos Alberola, M., Gallardo Izquierdo, A., Colomer Mendoza, F.J., Edo-Alcón, N., 2017. Producción y consumo de CSR. Estudio comparativo de la situación europea, in: Lobo, A., López, A., Esteban-García, A.L., Cuartas, M. (Eds.), Libro de Actas VII Simposio Iberoamericano de Ingeniería de Residuos. Universidad de Cantabria, Santander, España, pp. 359-364.

Dennison, G.J., Dodd, V.A., Whelan, B., 1996. A socio-economic based survey of household waste characteristics in the city of Dublin, Ireland. I. Waste composition. Resour. Conserv. Recycl. 17, 227244. https://doi.org/10.1016/0921-3449(96)01070-1

Di Lonardo, M.C., Franzese, M., Costa, G., Gavasci, R., Lombardi, F., 2016. The application of SRF vs. RDF classification and specifications to the material flows of two mechanical-biological treatment plants of Rome: Comparison and implications. Waste Manag. 47, 195-205. https://doi.org/10.1016/j.wasman.2015.07.018

Di Lonardo, M.C., Lombardi, F., Gavasci, R., 2012. Characterization of MBT plants input and outputs: A review. Rev. Environ. Sci. Biotechnol. 11, 353-363. https://doi.org/10.1007/s11157-012-9299-2

Edjabou, M.E., Jensen, M.B., Götze, R., Pivnenko, K., Petersen, C., Scheutz, C., Astrup, T.F., 2015. Municipal solid waste composition: Sampling methodology, statistical analyses, and case study evaluation. Waste Manag. 36, 12-23. https://doi.org/10.1016/j.wasman.2014.11.009

Edo-Alcón, N., Gallardo, A., Colomer-Mendoza, F.J., 2016. Characterization of SRF from MBT plants: Influence of the input waste and of the processing technologies. Fuel Process. Technol. 153, 19-27. https://doi.org/10.1016/j.fuproc.2016.07.028

Emery, A.D., Griffiths, A.J., Williams, K.P., 2003. An in depth study of the effects of socio-economic conditions on household waste recycling practices. Waste Manag. Res. 21, 180-190. https://doi.org/10.1177/0734242X0302100302

European Commision, 2004. Methodology for the Analysis of Solid Waste (SWA-Tool).

Flamme, S., Geiping, J., 2012. Quality standards and requirements for solid recovered fuels: a review. Waste Manag. Res. 30, 335-53. https://doi.org/10.1177/0734242X12440481

Gallardo, A., 2000. Metodología para el diseño de redes de recogida selectiva de RSU utilizando sistemas de información geográfica. Creación de una base de satos aplicable a España. Universidad Politécnica de Valencia. 
Gallardo, A., Carlos, M., Bovea, M.D., Colomer, F.J., Albarrán, F., 2014. Analysis of refuse-derived fuel from the municipal solid waste reject fraction and its compliance with quality standards. J. Clean. Prod. 83, 118-125. https://doi.org/10.1016/j.jclepro.2014.07.085

Garcés, D., Díaz, E., Sastre, H., Ordóñez, S., González-LaFuente, J.M., 2016. Evaluation of the potential of different high calorific waste fractions for the preparation of solid recovered fuels. Waste Manag. 47, 164-173. https://doi.org/10.1016/j.wasman.2015.08.029

Gidarakos, E., Havas, G., Ntzamilis, P., 2006. Municipal solid waste composition determination supporting the integrated solid waste management system in the island of Crete. Waste Manag. 26, 668-679. https://doi.org/10.1016/j.wasman.2005.07.018

Glorius, T., 2014. Production and Use of Solid Recovered Fuels - Developments and Prospects. ZKG 9, 7280.

Grigorieff, A., Costa, J.F., Koppe, J., 2004. Quantifying the influence of grain top size and mass on a sample preparation protocol 74, 201-207. https://doi.org/10.1016/j.chemolab.2004.03.008

Hernández-Berriel, M. del C., Aguilar-Virgen, Q., Taboada-González, P., Lima-Morra, R., Eljaiek-Urzola, M., Márquez-Benavides, L., Buenrostro-Delgado, O., 2016. Generación y composición de los residuos sólidos urbanos en América latina y el caribe. Rev. Int. Contam. Ambient. 32, 11-22. https://doi.org/10.20937/RICA.2016.32.05.02

lacovidou, E., Hahladakis, J., Deans, I., Velis, C., Purnell, P., 2018. Technical properties of biomass and solid recovered fuel (SRF) co-fired with coal: Impact of on multi-dimensional resource recovery value. Waste Manag. 73, 535-545. https://doi.org/10.1016/j.wasman.2017.07.001

Lebersorger, S., Beigl, P., 2011. Municipal solid waste generation in municipalities: Quantifying impacts of household structure, commercial waste and domestic fuel. Waste Manag. 31, 1907-1915. https://doi.org/10.1016/j.wasman.2011.05.016

Lorber, K.E., Sarc, R., Aldrian, a., 2012. Design and quality assurance for solid recovered fuel. Waste Manag. Res. 30, 370-380. https://doi.org/10.1177/0734242X12440484

Márquez, M.Y., Ojeda, S., Hidalgo, H., 2008. Identification of behavior patterns in household solid waste generation in Mexicali's city: Study case. Resour. Conserv. Recycl. 52, 1299-1306. https://doi.org/10.1016/j.resconrec.2008.07.011

Maystre, L., Viret, F., 1995. A goal-oriented characterization of urban waste. Waste Manag. Res. 13, 207218. https://doi.org/10.1016/S0734-242X(95)90040-3

Mccauley-bell, B.P., Reinhart, D.R., Member, Z., Sfeir, R., Ryan, B.O.T., 1997. MUNICIPAL SOLID WASTE COMPOSITION STUDIES 8 By Pamela McCauley-Bell,! Debra R. Reinhart,Z Member, ASCE, Rala Sfeir,3 and Brigid O'Toole Ryan 4 1, 158-163.

Moura, J.M.B.M., Gohr Pinheiro, I., Carmo, J.L., 2018. Gravimetric composition of the rejects coming from the segregation process of the municipal recyclable wastes. Waste Manag. https://doi.org/10.1016/j.wasman.2018.01.011

Nasrullah, M., Hurme, M., Oinas, P., Hannula, J., Vainikka, P., 2017. Influence of input waste feedstock on solid recovered fuel production in a mechanical treatment plant. Fuel Process. Technol. 163, 35-44. https://doi.org/10.1016/j.fuproc.2017.03.034

Nasrullah, M., Vainikka, P., Hannula, J., Hurme, M., Kärki, J., 2014. Mass, energy and material balances of SRF production process. Part 1: SRF produced from commercial and industrial waste. Waste Manag. 34, 1398-1407. https://doi.org/10.1016/j.wasman.2014.03.011

Nasrullah, M., Vainikka, P., Hannula, J., Hurme, M., Oinas, P., 2016. Elemental balance of SRF production process: Solid recovered fuel produced from municipal solid waste. Waste Manag. Res. 34, 38-46. https://doi.org/10.1177/0734242X15615697

Ozcan, H.K., Guvenc, S.Y., Guvenc, L., Demir, G., 2016. Municipal solid waste characterization according to different income levels: A case study. Sustain. 8. https://doi.org/10.3390/su8101044 
Parizeau, K., Maclaren, V., Chanthy, L., 2006. Waste characterization as an element of waste management planning: Lessons learned from a study in Siem Reap, Cambodia. Resour. Conserv. Recycl. 49, 110128. https://doi.org/10.1016/j.resconrec.2006.03.006

Pehlken, A., Von Blottnitz, H., Pretz, T., 2000. Requirements for the sampling of residual waste - Approach to developing a new sampling model. Aufbereit. Tech. 41, 409-415.

Petersen, L., Minkkinen, P., Esbensen, K.H., 2005. Representative sampling for reliable data analysis: Theory of Sampling. Chemom. Intell. Lab. Syst. 77, 261-277. https://doi.org/10.1016/j.chemolab.2004.09.013

Qu, X., Li, Z., Xie, X., Sui, Y., Yang, L., Chen, Y., 2009. Survey of composition and generation rate of household wastes in Beijing, China. Waste Manag. 29, 2618-2624. https://doi.org/10.1016/j.wasman.2009.05.014

Rada, E.C., Ragazzi, M., 2014. Selective collection as a pretreatment for indirect solid recovered fuel generation. Waste Manag. 34, 291-297. https://doi.org/10.1016/j.wasman.2013.11.013

Republique Française, 2016. Arrêté du 23 mai 2016 relatif à la préparation des combustibles solides de récupération en vue de leur utilisation dans des installations relevant de la rubrique 2971 de la nomenclature des installations classées pour la protection de l'environnement. J. Off. Repub. Française.

Rotter, V.S., Kost, T., Winkler, J., Bilitewski, B., 2004. Material flow analysis of RDF-production processes. Waste Manag. 24, 1005-1021. https://doi.org/10.1016/j.wasman.2004.07.015

Rotter, V.S., Lehmann, A., Marzi, T., Möhle, E., Schingnitz, D., Hoffmann, G., 2011. New techniques for the characterization of refuse-derived fuels and solid recovered fuels. Waste Manag. Res. 29, 229-236. https://doi.org/10.1177/0734242X10364210

Runfola, J., Gallardo, A., 2010. Análisis de los factores que influyen en la generación y composición de los residuos sólidos urbanos a considerar para el diseño de un modelo de caracterización, in: 3 Simposio Iberoamericano De Ingenieria De Residuos. João Pessoa, Brasil.

Sarc, R., Lorber, K., Pomberger, R., Rogetzer, M., Sipple, E., 2014. Design, quality, and quality assurance of solid recovered fuels for the substitution of fossil feedstock in the cement industry. Waste Manag. Res. 32, 565-585. https://doi.org/10.1177/0734242X14536462

Sarc, R., Lorber, K.E., 2013. Production, quality and quality assurance of Refuse Derived Fuels (RDFs). Waste Manag. 33, 1825-1834. https://doi.org/10.1016/j.wasman.2013.05.004

SFS 5875, 2000. Solid Recovered Fuel - Quality Control System. Finnish Standards Association.

Suthar, S., Singh, P., 2015. Household solid waste generation and composition in different family size and socio-economic groups: A case study. Sustain. Cities Soc. 14, 56-63. https://doi.org/10.1016/j.scs.2014.07.004

Thanh, N.P., Matsui, Y., Fujiwara, T., 2010. Household solid waste generation and characteristic in a Mekong Delta city, Vietnam. J. Environ. Manage. 91, 2307-2321. https://doi.org/10.1016/j.jenvman.2010.06.016

UNE-EN 15359, 2012. Combustibles sólidos recuperados: Especificaciones y clases. AENOR, Asocición Española de Normalizaciónj y Certificación, Madrid.

UNE-EN 15415-1, 2012. Combustibles sólido recuperados: Determinación de la distribución de tamaño de partícula. Parte 1: Método del tamiz para partículas pequeñas. AENOR, Asocición Española de Normalizaciónj y Certificación, Madrid.

UNE-EN 15415-2, 2012. Combustibles sólidos recuperados: Deteminación de la distribución de tamaño de partícula. Parte 2: Método (manual) de la longitud máxima proyectada para particulas de grandes dimensiones. AENOR, Asocición Española de Normalizaciónj y Certificación, Madrid.

UNI 9903-1, 2004. Combustibili solidi non minerali ricavati da rifiuti (RDF) - Specifiche e classificazione (in Italian). UNI: Italian National Agency for Standardization, Milano, Italy. 
Velis, C.A., Longhurst, P.J., Drew, G.H., Smith, R., Pollard, S.J.T., 2010. Production and quality assurance of solid recovered fuels using Mechanical- Biological Treatment (MBT) of waste: a comprehensive assessment. Crit. Rev. Environ. Sci. Technolgy 40, 979-1105. https://doi.org/10.1080/10643380802586980

Velis, C., Wagland, S., Longhurst, P., Robson, B., Sinfield, K., Wise, S., Pollard, S., 2012. Solid recovered fuel: Influence of waste stream composition and processing on chlorine content and fuel quality. Environ. Sci. Technol. 46, 1923-1931. https://doi.org/10.1021/es2035653

Von Blottnitz, H., Pehlken, A., Pretz, T., 2002. The description of solid wastes by particle mass instead of particle size distributions. Resour. Conserv. Recycl. 34, 193-207. https://doi.org/10.1016/S09213449(01)00107-0

Zeng, Y., Trauth, K.M., Peyton, R.L., Banerji, S.K., 2005. Characterization of solid waste disposed at Columbia Sanitary Landfill in Missouri. Waste Manag. Res. 23, 62-71. https://doi.org/10.1177/0734242X05050995 


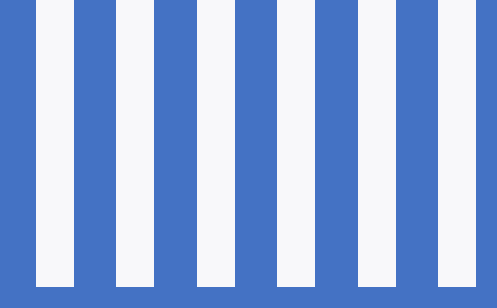

CAPÍTULO 5

METODOLOGÍAS APLICABLES AL MUESTREO

Y CARACTERIZACIÓN DE RECHAZOS 



\subsection{INTRODUCCIÓN}

De las conclusiones obtenidas en el capítulo anterior se puede extraer que el correcto muestreo y caracterización de los rechazos es un verdadero desafío, puesto que sus características y propiedades pueden depender de numerosas variables. Además, existe una serie de propiedades físicas que son responsables de parte del error de muestreo y tienen una gran influencia en el tamaño de muestra necesario. Todo esto debe contemplarse en el diseño de la metodología para el control de calidad de los rechazos, de manera que, tras la aplicación del plan de muestreo se obtengan muestras representativas.

En la actualidad existen diversas metodologías de muestreo y caracterización de RSU que se aplican y utilizan en diferentes países, las cuales tienen criterios de muestreo distintos que se adaptan a las condiciones de cada caso (Dahlén and Lagerkvist, 2008; Runfola, 2008). Para los CSR, la norma UNE-EN 15442 (2012) sobre métodos de muestreo y la norma UNE-EN 15359 (2012) sobre especificaciones y clases indican cómo realizar el muestreo de estos materiales. No obstante, la aplicación de los métodos existentes (tanto para RSU como para CSR) en el muestro y caracterización de rechazos requiere un gran esfuerzo en relación al tiempo, coste y mano de obra invertida (Rotter et al., 2011), puesto que supone trabajar con grandes cantidades de material.

Así pues, en la práctica, no existe un método específico para el muestreo y caracterización de rechazos, sino que se debe utilizar metodologías diseñadas para otros materiales. Las cuales no se adecuan a las características y naturaleza de las corrientes de rechazo generadas en las plantas de TMB, ni incluyen muchas de las variables anteriormente identificadas (Capítulo 4).

El objetivo del presente capítulo es analizar en profundidad las distintas técnicas estadísticas de muestreo y las metodologías existentes de muestreo y caracterización de RSU y CSR, así como los procedimientos estadísticos que son aplicables a los residuos y rechazos. La información obtenida servirá como punto de partida para el diseño de la metodología para el control de calidad de los rechazos.

Para ello, en primer lugar, se ha llevado a cabo una revisión de las diferentes técnicas estadísticas de muestreo y de las metodologías existentes de muestreo y caracterización de RSU y CSR. Esta ha permitido obtener los fundamentos que se requieren para el desarrollo de la nueva metodología como: criterios de muestreo existentes, métodos utilizados para el cálculo del número de muestras y tamaño de muestras, etc. De manera que, aquellas técnicas o métodos que se adaptan más a la naturaleza de los rechazos han servido de base para el diseño del plan de muestreo. Para ello se han revisado tanto normas o metodologías propuestas por diferentes organismos oficiales, como metodologías propuestas en diferentes trabajos de investigación. En segundo lugar, se ha realizado una revisión más teórica en relación a los procedimientos estadísticos que son aplicables a los residuos y rechazos. Los cuales permitirán extraer conclusiones sobre los datos obtenidos en los diferentes experimentos realizados en los capítulos posteriores. Por ejemplo, comprobar si los resultados obtenidos son representativos.

En la Figura 5.1 se muestra la estructura que sigue este capítulo. La información obtenida en cada uno de los apartados, junto con las variables identificadas en el capítulo 4, se utilizarán en los siguientes capítulos para el desarrollo del plan de muestreo de la metodología objeto de esta tesis. 


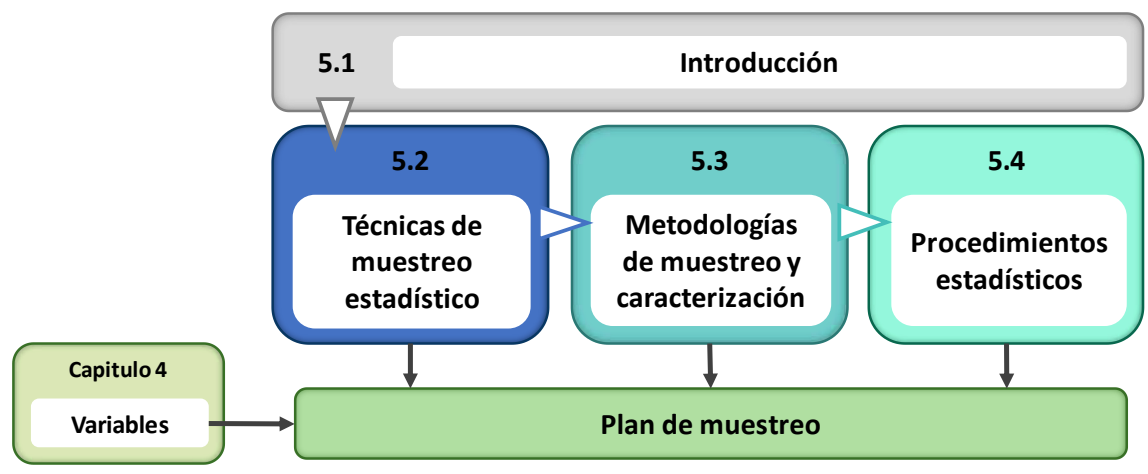

Figura 5.1 Estructura del capítulo 5

\subsection{TÉCNICAS DE MUESTREO ESTADISTICO}

La mayor parte de los estudios de caracterización de RSU utilizan el muestreo estadístico para obtener toda la información necesaria y, posteriormente, aplican diferentes procedimientos estadísticos para el análisis de los resultados obtenidos. Este tipo de estudios consisten en cuatro fases: información preliminar sobre la población a muestrear y sus características (variables influyentes); determinación del número de muestras; selección de muestras o muestreo, y validación de resultados (Runfola, 2008).

En estadística el muestreo es la técnica utilizada para la correcta selección de una muestra a partir de una población, existiendo dos métodos diferentes para ello: el muestreo aleatorio (que incorpora el azar en el proceso de selección) y el muestreo a juicio de experto.

En el caso del muestreo aleatorio, cuando además cumple con el principio fundamental de muestreo de que todos los elementos que forman parte de la población tienen la misma probabilidad de ser escogidos para formar parte de la muestra, este se le denomina probabilístico. Esto implica que la totalidad de la población que se va a evaluar es accesible para el muestreo, lo que muchas veces en el caso de los RSU o de los rechazos no es posible. Por otro lado, la selección de la herramienta de muestreo también es clave para asegurar que se puede tomar una muestra representativa, de manera que todos los tamaños de partícula presentes en el material tengan la misma probabilidad de ser cogidos.

Dentro del muestreo aleatorio existen diferentes técnicas para la selección de muestras que se utilizan en el campo de los RSU, las cuales se exponen a continuación:

- Muestreo aleatorio simple: en este caso las muestras son escogidas al azar de forma aleatoria, sin seguir ningún patrón, por lo que las muestras no están necesariamente distribuidas de forma equilibrada a lo largo de la población (Figura 5.2 (a)). Además, todos los elementos tienen la misma (pequeña) probabilidad de ser seleccionados como muestra. El muestreo aleatorio puede ser sin reposición de los elementos (cada elemento extraído queda descartado para la siguiente selección) o con reposición (los elementos que se seleccionan vuelven a la muestra, de forma que la población es idéntica en todas las extracciones).

- Muestreo estratificado: en este caso la población se divide en una serie de estratos en función de diferentes variables (como las que se han identificado en el capítulo 4). Las subpoblaciones que forman estos estratos tienen características diferentes entre sí, pero dentro de ellas los elementos tienen características similares, es decir, son homogéneos respecto a esas variables. Las muestras a seleccionar se distribuyen entre todos estos estratos, normalmente de forma aleatoria (Figura 5.2 (b)). Esta división puede ser proporcional (el número o tamaño de las muestras dentro de cada estrato es proporcional al tamaño del estrato dentro de la población) u óptima (se toman más elementos de aquellos estratos que tengan más variabilidad). Otra opción es coger el mismo número de muestras en cada estrato y, posteriormente, ponderar los resultados al tamaño del estrato. Este tipo de muestreo tiene como objetivo que todos los estratos de interés están representados en la muestra. Además, se sigue manteniendo que todos los elementos de la población tienen la misma probabilidad de ser elegidos. 
- Muestreo sistemático: en este caso las muestras se seleccionan de forma sistemática a intervalos regulares en relación a un momento o punto de referencia seleccionado al azar (para asegurarse que cada elemento tiene la misma probabilidad de ser muestreado). Las muestras están dispersas de forma regular en la población (Figura 5.2 (c)).

En el muestreo no probabilístico a juicio de experto no todos los elementos tienen la misma probabilidad de ser elegidos para formar la muestra. Este tipo de muestreo se basa en la experiencia de una persona (o grupo de personas) que tiene un conocimiento profundo del tema bajo estudio o tiene mucha experiencia en ese campo. La información aportada por este individuo es vital para la toma de decisiones y selección de la muestra. Esta selección, en el mejor de los casos, se puede llevar a cabo mediante una técnica parcialmente probabilística. La principal razón para elegir este tipo de técnica es que el muestro probabilístico de toda la población es prácticamente imposible o los recursos de tiempo y dinero no lo permiten. Por ello las muestras serán tomadas de subpoblaciones accesibles de la población total, no obstante, dentro de estas subpoblaciones el muestreo sí que se realizará con técnicas probabilísticas siempre que sea posible (Figura 5.2 (d)).

Otro tipo de muestreo no probabilístico es el errático o sin norma, en él la muestra se toma de cualquier forma, teniendo sólo en cuenta la comodidad en término de costes, tiempo o esfuerzo. Este tipo de muestreo es el menos recomendado (Figura 5.2 (e)).

Muestreo aleatorio simple (a)

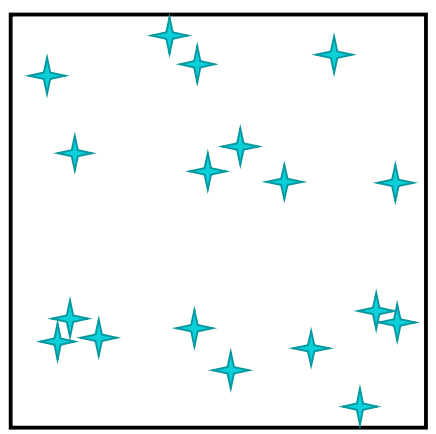

Muestreo a juicio de experto (d)

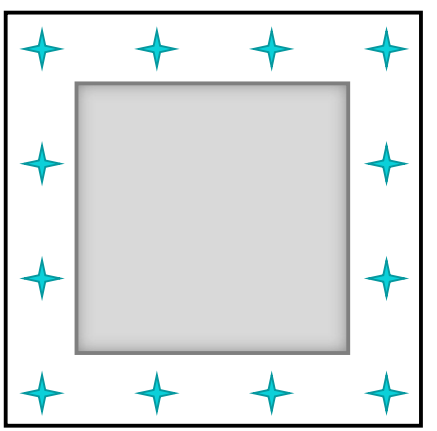

Muestreo aleatorio estratificado (b)

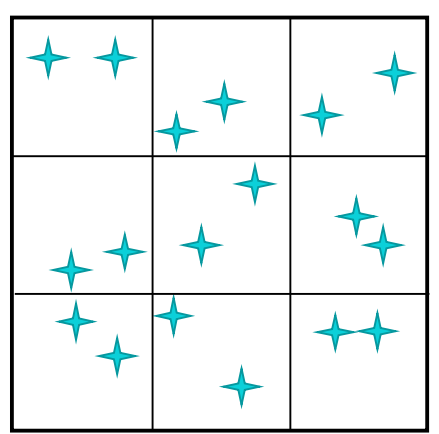

Muestreo errático o sin norma (e)
Muestreo sistemático (c)
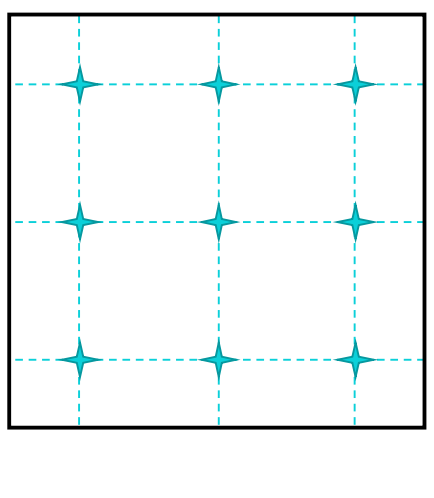

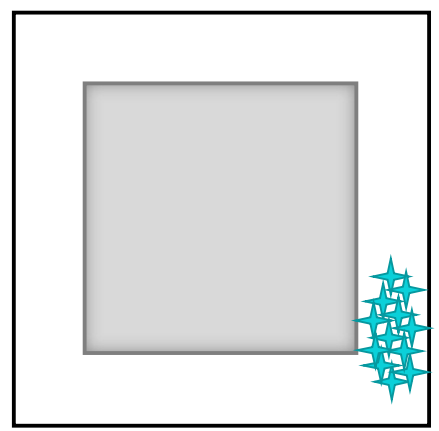

NOTA: La figura muestra los patrones de muestreo posibles cuando existe una variación espacial en un área de dos dimensiones. No obstante, los conceptos se aplican del mismo modo a otro tipo de variabilidad que pueda existir, por ejemplo, la temporal.

Figura 5.2 Patrones de muestreo para las diferentes técnicas de muestreo estadístico.

En el campo de los residuos, el muestreo estratificado es muy útil, sobre todo cuando se analizan un gran número de muestras seleccionadas en varias temporadas o condiciones, ya que pueden aportar información acerca de las variaciones existentes debido a la influencia de diferentes factores como la estacionalidad, tipo de población, nivel de renta, etc. (Runfola, 2008). Sin embargo, a medida que el número de muestras aumenta el coste del estudio o muestreo será mayor, lo que limita su utilización. 


\subsection{METODOLOGIAS PARA EL MUESTREO Y CARACTERIZACIÓN DE RSU Y CSR}

A continuación, se han revisado diferentes metodologías para el muestreo y caracterización de RSU y CSR. Las metodologías revisadas se han clasificado en: normas aplicables al muestreo y caracterización de residuos sólidos y CSR, metodologías propuestas por diferentes organismos oficiales y metodologías diseñadas en diferentes trabajos de investigación.

\subsubsection{Normas aplicables al muestreo y caracterización de RSU y CSR}

Dentro de las metodologías para el muestreo y caracterización de RSU y CSR existe una serie de normas que regulan los procedimientos de muestreo de los mismos, así como los métodos a seguir para la determinación de diferentes propiedades que permiten su caracterización. Por ejemplo, la composición física de los RSU o la determinación de los parámetros que definen la calidad de los $\mathrm{CSR}(\mathrm{PCl}, \mathrm{Cl}$ y $\mathrm{Hg})$.

\section{ASTM: D 5231-92}

La American Society for Testing and Materials (ASTM) desarrolló en 1992 un método estandarizado para determinar la composición de residuos sólidos municipales no procesados (ASTM D5231-92, 1992), cuya última reaprobación se realizó en el año 2016. Este método proporciona una secuencia de pasos para determinar la composición media de los RSU en base a la recolección y clasificación de un determinado número de muestras. La metodología incluye los procedimientos para la toma de muestras, la caracterización manual de las mismas, el registro de datos y la presentación de resultados. Además, también incluye recomendaciones sobre seguridad y equipo requerido para los análisis de composición.

Respecto al número de muestras necesarias, la norma incluye un método para su cálculo que está basado en la t de Student y en estadísticas históricas (medias y desviaciones estándar) sobre la composición de los residuos. El número de muestras (n) se calcula mediante la ecuación 5.1, en función de los componentes que van a ser separados y la precisión deseada:

$$
n=\left(\frac{t \cdot s}{e \cdot \bar{x}}\right)^{2}
$$

Dónde: $\mathrm{n}$ es el número de muestras necesarias; $\mathrm{t}$ es el estadístico de la $\mathrm{t}$ de Student correspondiente al nivel de confianza deseado; s es la desviación estándar estimada para la población (en porcentaje); e es el nivel deseado de precisión expresado como el máximo error permitido para la media (en tanto por uno), y $\bar{x}$ es la media estimada para la población (en porcentaje). La desviación estándar y la media estimada para la población son proporcionados por la norma a partir de una serie de datos históricos, aunque también pueden utilizarse datos propios de estudios pilotos.

Puesto que utilizando esta fórmula se obtiene una " $n$ " para cada material, un componente es elegido para regir la precisión de la caracterización (componente gobernante) y, por tanto, el número de muestras total a realizar. Esta es una de las críticas que se realizan a esta norma, puesto que no es factible utilizar un número diferente de muestras para cada componente $y$, por tanto, no todos los materiales estarán estimados con la misma precisión (Dahlén and Lagerkvist, 2008). Por otro lado, esta norma propone un periodo mínimo de muestreo de una semana (5-7 días) y un tamaño de muestra de al menos 91-136 kg. Además, también da otras recomendaciones como: usar las cargas de los vehículos de recogida de RSU para la toma de las muestras (eligiéndolos al azar y seleccionando una sola muestra por camión); realizar la división de muestra mediante conificación y posterior cuarteo, y clasificar los RSU de forma manual en un mínimo de 13 categorías o fracciones.

Uno de los principales problemas de esta norma es que los datos históricos proporcionados son muy antiguos (año 1972) y están referidos solo a los EEUU (Mccauley-bell et al., 1997; Sharma and McBean, 2007). Así pues, la composición de los residuos desde entonces ha podido sufrir numerosas variaciones, por lo que siempre será necesario realizar una experiencia piloto para determinar la media y la desviación estándar a la hora de utilizar la ecuación 5.1. Otro problema indicado en la literatura es que supone que los datos de composición de los RSU siguen una distribución Normal (Mccauley-bell et al., 1997), cuando realmente estos están sesgados positivamente y solo se puede asumir Normalidad con un número elevado 
de muestras, lo que en muchos casos es muy caro o económicamente inviable (Klee, 1993). Además, los métodos que se basan en que los datos siguen una distribución Normal no funcionan correctamente para componentes minoritarios o con una elevada variabilidad, puesto que la cantidad de muestras necesarias para su correcta estimación es demasiado grande (Sharma and McBean, 2007).

\section{Nordtest Method}

En Finlandia, Nordtest (Nordic Innovations Center) desarrollo en 1995 un método estándar para el muestreo y caracterización de RSU para los Países Escandinavos (NT ENVIR 001, 1995). Esta norma proporciona una metodología para la estimación de la tasa de generación de RSU y la composición de los mismos. La metodología incluye los procedimientos para la toma de muestras (diferenciando entre estimación de la tasa de generación y la composición), la caracterización manual de los componentes, la preparación de las muestras para la realización de análisis fiscos o químicos posteriores y la presentación de los resultados. Además, también incluye recomendaciones sobre seguridad y el equipamiento requerido.

En el caso de la determinación de la tasa de generación, el muestreo se realiza mediante el pesaje de la carga de un cierto número de camiones de recogida de RSU seleccionados aleatoriamente. El número total de camiones pesados debe representar al menos el 5\% de la población, es decir, la muestra debe corresponder a un $5 \%$ o más de la misma. El periodo de muestreo debe abarcar como mínimo una semana para evitar la variación existente entre los días de la semana, mientras que las variaciones estacionales (si existen) deben ser evitadas repitiendo el muestreo en diferentes estaciones del año.

En el caso del muestreo para el análisis de la composición física (o la realización de otros análisis físicos o químicos), también se utilizan cargas de vehículos de recogida para la toma de muestras y el periodo de muestreo será de al menos una semana. La metodología propone como tamaño total de muestra los residuos generados en una semana por al menos 100-200 hogares (aprox. entre 1 y 2,5 toneladas). Además, si se realiza un muestreo estratificado y la población a muestrear se divide en diferentes áreas o estratos en función del tipo de casa o municipio, tamaño del hogar, factores socio-económicos, etc., el tamaño total de muestra en cada área debe de corresponder a los residuos generados por 40-100 hogares. Cada una de estas muestras se tiene que dividir mediante conificación y posterior cuarteo hasta una muestra de tamaño menor, que se clasificará manualmente en 11 categorías para determinar su composición. No obstante, la norma no indica el tamaño específico de la muestra más pequeña a clasificar.

Por otro lado, la metodología también señala que con el tamaño total de muestra recomendado (residuos generados por 100-200 hogares) se obtendrá una muestra representativa de la población en general. Sin embargo, puede ser necesario obtener una precisión específica en la determinación de la composición de cierto componente o fracción (por ejemplo, una precisión del 10\% para el textil). En dicho caso, el número de hogares que conforman el tamaño total de muestra se determinará mediante la ecuación proporcionada por la norma ASTM (Ec.5.1), utilizando datos obtenidos de estudios preliminares. La utilización de esta ecuación tiene las limitaciones descritas anteriormente respecto a la Normalidad de los datos.

En cuanto a la preparación de muestras para el análisis en laboratorio, esta consiste en la reducción del tamaño de muestra mediante cuarteo u otros métodos de división. En el caso que el tamaño de partículas sea muy grande, recomienda la trituración del material antes del cuarteo. Por otra parte, si las muestras van a ser almacenadas deben ser secadas a 105 으 (en el caso de que las muestras contengan mercurio, la temperatura de secado debe reducirse a 70 으 para evitar su evaporación).

\section{Norma UNE-EN 14899: 2007}

La norma europea UNE-EN 14899 (2007) “Caracterización de residuos: Toma de muestras de residuos. Esquema para la preparación y aplicación de un plan de muestreo" fue publicada en España por la Asociación Española de Normalización y Certificación (AENOR) en 2007. La norma proporciona un esquema para el diseño y desarrollo de un plan de muestreo y describe el método de toma de muestras necesario para cumplir con el objetivo del programa de ensayo.

Esta norma divide el programa de ensayo en siete pasos clave, los cuales se desarrollan en la propia norma $y$ en los cinco informes técnicos que la complementan: UNE-CEN/TR 15310-1 IN (2008), UNE-CEN/TR 
15310-2 IN (2008), UNE-CEN/TR 15310-3 IN (2008), UNE-CEN/TR 15310-4 IN (2008) y UNE-CEN/TR 15310-5 IN (2008). Para llevar a cabo el muestreo, la norma hace referencia a la aplicación de los principios estadísticos contenidos en el primero de los informes técnicos, en el cual se proponen una serie de herramientas estadísticas para ello. Debido a la gran variedad de tipos de residuos que se pueden muestrear, así como los diversos escenarios y objetivos que puede tener un muestreo, el informe técnico no proporciona métodos específicos para cada caso.

Así pues, se trata de una norma muy amplia y extensa, la cual no define un uso específico para la caracterización de RSU, sino que está más orientada a las actividades industriales. Por lo que, a continuación, se va a realizar un breve resumen de los puntos más importantes de la misma.

Según la norma, el primer paso para el diseño del plan de muestreo es definir o especificar el objetivo del programa de ensayo, puesto que este determinará el nivel deseado de información y la fiabilidad deseada de los resultados del muestreo. Una vez el objetivo se ha definido, a partir del mismo de deben desarrollar las metas técnicas para su consecución. Dentro de las metas técnicas se debe:

- Definir la población o subpoblaciones que se van a muestrear.

- Evaluar su variabilidad tanto espacial (debida a las diferentes localizaciones físicas de las partículas del material) como temporal.

- Seleccionar el enfoque de muestreo (probabilístico o a juicio de experto).

- Identificar la escala, esta define la cantidad mínima de material por debajo del cual se considera que las variaciones son poco importantes.

- Elegir el parámetro estadístico requerido (por ejemplo: media, desviación estándar, percentil, mediana, etc.).

- $\quad$ Elegir el grado de fiabilidad que se considera aceptable en función del objetivo.

Algunas de estas metas técnicas deben transformarse en instrucciones prácticas, las cuales consideran los siguientes aspectos prácticos del muestreo:

- Elección del patrón de muestreo: el patrón de muestreo define dónde, cuándo y cómo se seleccionan las muestras. Este puede ser probabilístico, existiendo el aleatorio simple, el estratificado y el sistemático como se ha visto en el apartado anterior, o a juicio de experto.

- Utilización de muestras compuestas frente a muestras individuales: si se quiere obtener unos resultados fiables sobre el valor medio del parámetro que se quiere analizar, la norma recomienda el uso de muestras compuestas o combinadas antes que muestras individuales. Una muestra combinada es aquella que está formada por diferentes incrementos mezclados que permiten obtener el valor medio de una característica.

- Determinación del número requerido de incrementos y muestras: el muestreo probabilístico que propone la norma se basa en los mismos principios estadísticos que las normas descritas anteriormente, no obstante, las ecuaciones para el cálculo del número de incrementos y muestras son diferentes y mucho más complejas. Estas se pueden consultar en el anexo C del informe técnico UNE-CEN/TR 15310-1 IN (2008).

- Determinación de la fracción elemental y el tamaño de muestra: la fracción elemental o incremento es la cantidad de material que se obtiene a través de una única operación del dispositivo de muestro y que se junta con otros incrementos para formar una muestra combinada. El tamaño mínimo de muestra se determina a partir de la siguiente ecuación:

$$
M_{\text {sam }}=\frac{\pi}{6} \cdot d_{95}^{3} \cdot \rho \cdot g \cdot \frac{(1-p)}{c v^{2} \cdot p}
$$

Donde: $M_{\text {sam }}$ es la masa de la muestra en gramos; $d_{95}$ es el tamaño nominal superior de una partícula en $\mathrm{cm}$; $\rho$ es la densidad media de partícula de las partículas en $\mathrm{g} / \mathrm{cm}^{3}$; g el factor de corrección para la distribución en el tamaño de las partículas; $p$ es la fracción de las partículas con 
la característica especifica que se quiere evaluar (por ejemplo, un contaminante especifico), en $\mathrm{kg} / \mathrm{kg}$; cv es el coeficiente de variación, este valor es de 0,1 .

Así pues, para poder utilizar adecuadamente esta ecuación es necesario conocer o determinar todas estas características o factores relacionados con los residuos a muestrear.

Cabe señalar que muchos de estos parámetros son los utilizados en la ecuación de Gy para el cálculo del tamaño de muestra en materiales particulados en la Teoría de Muestreo, eso se debe a que esta fórmula es una adaptación de dicha ecuación.

Finalmente, destacar que la norma deja a las partes implicadas el diseño del plan de muestreo a seguir. Este diseño se realizará en función del objetivo que se quiere alcanzar e incluye: la determinación del número y tamaño de muestras, la elección del método de selección de muestras, la frecuencia con la que se realizará, los componentes o tipos de residuos a muestrear y la fiabilidad requerida.

\section{Norma UNE-EN 15359: 2012 y UNE-EN 15442: 2011}

Respecto al caso concreto de los CSR, también existe una serie de normas para su muestreo y caracterización que fueron desarrolladas por el Comité Europeo de Estandarización (CEN), en concreto por el comité técnico CEN/TC 343 - Solid Recovered Fuels, las cuales posteriormente fueron publicadas en España por AENOR.

En primer lugar, la norma UNE-EN 15359 (2012) “Combustibles sólidos recuperados: Especificaciones y clases" establece que, para poder clasificar un CSR y conocer su calidad en base a los tres parámetros que la definen ( $\mathrm{PCl}, \mathrm{Cl}$ y $\mathrm{Hg}$ ), el número mínimo de lotes a muestrear debe ser de 10 , siendo el tamaño máximo de un lote de 1.500 toneladas. Esta norma establece que un lote es una cantidad definida de CSR del cual se va a determinar su calidad. Para cada lote se debe realizar al menos una medición de las propiedades y los lotes deben estar repartidos a lo largo de todo un año (o del periodo que se quiera muestrear si es menor a un año). La norma también indica que el muestreo se debe realizar mediante una muestra combinada formada por diferentes incrementos y aplicando la norma UNE-EN 15442 (2012) "Combustibles sólidos recuperados: Métodos de muestreo".

Dicha norma específica los métodos de toma de muestras para los CSR. En ella se indica que el diseño del plan de muestreo debe comenzar con la identificación de los objetivos de la toma de muestras, ya que estos definirán el nivel de ensayos necesario (examen a fondo o ensayos de rutina), la fiabilidad deseada en los mismos y la frecuencia con la que se realizarán. Además, la técnica de muestreo que se adopte depende del tipo de CSR, del lugar de muestreo o la forma en la que el material se produce y del grado de heterogeneidad del material.

El desarrollo del plan de muestreo para CSR definido en esta norma está formado por varias etapas, las cuales se describen a continuación:

1. Definición del objetivo: el plan de muestreo debe cumplir los requisitos marcados por los objetivos.

2. Definición del lote y tamaño de lote: el lote se debe definir en base a la forma en la que el CSR ha sido producido, puesto que un lote es la cantidad de un material con unas mismas especificaciones y se ha producido de la misma manera. Identificando también la forma de las partículas que lo forman y el origen del mismo. Respecto al tamaño, el peso máximo es de 1.500 toneladas por lote (si el tamaño del lote es superior se debe dividir en sub-lotes).

3. Determinación del método de muestreo: este debe ser lo más representativo posible, en orden de preferencia estos son los métodos de toma de muestras a utilizar según la norma: mecánicamente de un flujo de caída; mecánicamente a partir de una cinta transportadora en movimiento; manualmente desde una cinta fija; manualmente desde un flujo de caída; de forma manual desde un vehículo; de una almacén temporal o pila estática.

4. Determinación del número de incrementos: la norma define incremento como la porción de material que se extrae con una única operación del dispositivo de muestreo. El número mínimo de incrementos por muestra combinada debe de ser de 24 . 
5. Determinación del tamaño mínimo de incremento y el tamaño mínimo de muestra: para ello la norma propone una serie de ecuaciones. A continuación, se muestra la más relevante de todas ellas, la utilizada para determinar el tamaño mínimo de muestra (Ec.5.3).

$$
m_{m}=\frac{\pi}{6 \cdot 10^{9}} \cdot d_{95}{ }^{3} \cdot f \cdot \lambda_{p} \cdot g \cdot \frac{(1-p)}{c v^{2} \cdot p}
$$

Donde: $\mathrm{m}_{m}$ es la masa del tamaño mínimo de muestra en $\mathrm{kg}$; $\mathrm{d}_{95}$ es el tamaño nominal superior de partícula en $\mathrm{mm}$; f es el factor forma en $\mathrm{mm}^{3} / \mathrm{mm}^{3} ; \lambda_{p}$ es la densidad media de partícula de las partículas en $\mathrm{kg} / \mathrm{m}^{3}$; g es el factor de corrección para la distribución de tamaño de las partículas; $\mathrm{p}$ es la fracción de las partículas con la característica especifica que se quiere evaluar (por ejemplo, un contaminante especifico), en $\mathrm{kg} / \mathrm{kg}$, y es igual a 0,1 ; cv es el coeficiente de variación, este valor es de 0,1 . La utilización de esta ecuación implica conocer con precisión las características del combustible, lo que en algunas ocasiones es complicado o costoso.

Cabe señalar que esta ecuación es prácticamente la misma que utiliza la norma UNE-EN 14899: 2007. No obstante, debido a la naturaleza particular de los CSR que normalmente son sólidos fibrosos, no granulares ni consistentes, la fórmula para el cálculo de tamaño de muestra necesita incluir el término del factor forma (f) y que corrige la no esfericidad. Por otro lado, y como ocurre en la norma anterior, muchos de los parámetros que incluye son los que aparecen en la ecuación de Gy, ya que es una adaptación de la misma.

6. Distribución de los incrementos sobre un lote: los incrementos deben tomarse dispersos por todo el lote (cada partícula del lote debe tener la misma probabilidad de terminar en la muestra). Los métodos de muestreo que se deben utilizar son, en orden de preferencia: el muestreo aleatorio estratificado (se toma un incremento en cada estrato en sitios diferentes) o el muestreo estratificado (se toma un incremento en cada estrato en el mismo sitio). Además, si el lote es estático, en cada ubicación se tomarán los incrementos de la parte superior, media e inferior de forma alterna.

Finalmente, el CEN también ha desarrollado diferentes normas donde se establecen los métodos a seguir para la determinación de las propiedades que permiten caracterizar los CSR y determinar su calidad.

\subsubsection{Metodologías de muestreo y caracterización de RSU propuestas por organismos oficiales}

Junto con las normas anteriores, también se han revisado algunas metodologías para la toma de muestra y caracterización de RSU propuestas por organismos oficiales europeos. Así como un protocolo para la toma de muestra, caracterización y análisis de RSU mezclados utilizado por la empresa Suez Advanced Solutions en España.

\section{SWA-Tool}

La Comisión Europea desarrolló en 2004 dentro del 5o Programa Marco una metodología estandarizada para el análisis de residuos sólidos, denominada SWA-Tool, en la que participaron varios países miembros. En ella se establecen una serie de recomendaciones y unos mínimos requisitos para el correcto muestreo y caracterización de los RSU a escala local o regional, sin embargo, no se ha convertido en un estándar europeo (Dahlén and Lagerkvist, 2008). Estas recomendaciones están recogidas en un manual de usuario bastante complejo de 57 páginas.

La metodología describe los procedimientos para el muestreo de los RSU mezclados, clasificación manual de sus componentes y análisis de los mismos para determinar su generación y composición. Asimismo, en los anexos, incluye también unas directrices para la presentación de los resultados teniendo en cuenta la precisión estadística, unas recomendaciones sobre seguridad a la hora de aplicar la metodología y una estimación del coste que supone el análisis de RSU.

Respecto a la toma de muestras, recomienda que se realice a nivel de contenedor. Además, indica que es fundamental evaluar los factores que influyen en la generación y composición de los RSU con el objetivo de 
llevar a cabo, si fuera necesario, un muestreo aleatorio estratificado. Algunos factores que incluye la metodología son: la estacionalidad, la estructura residencial (zona rural, suburbana, centro ciudad, etc.), el tamaño de contenedor, el sistema de recogida, el origen de los residuos, los factores socio-económicos o el día de recogida. Para cada uno de estos factores propone unos criterios de estratificación de la población. No obstante, con el fin de que el número de muestras no sea muy elevado, sugiere no dividir la población en más de 5 estratos.

En cuanto al tamaño mínimo de muestra, la metodología sugiere diferentes unidades de muestreo, estas pueden ser: un volumen especifico de contenedor (240, 1.100 o 3.200 litros); un peso específico de residuos (100 kg), o un número específico de personas que genera cierta cantidad de residuos (30 personas). De todas ellas, recomienda la utilización del volumen del contenedor como unidad de muestreo (teniendo en cuenta que esto no hace referencia al volumen de los residuos contenidos en el mismo). Cuando existen diferentes volúmenes de contenedor se debe escoger el más comúnmente usado.

La SWA-Tool propone realizar el cálculo del número de muestras o unidades de muestreo mediante la ecuación 5.1, utilizando datos de composición de residuos procedentes de estudios realizados con anterioridad, por lo que tiene las mismas limitaciones respecto a la Normalidad de los datos que la norma ASTM. Además, proporciona una tabla en la que se puede determinar fácilmente el número mínimo de muestras en función de diferentes coeficientes de variación para un nivel de confianza del 95\%.

En el caso de no disponer de datos previos para el cálculo del coeficiente de variación recomienda una serie de volúmenes totales de muestra: $45 \mathrm{~m}^{3}$ para residuos domiciliarios, $80 \mathrm{~m}^{3}$ para mezclas de residuos domiciliarios y comerciales y $100 \mathrm{~m}^{3}$ para residuos comerciales. De esta manera, conociendo el tamaño de muestra total y el tamaño de la unidad de muestreo, se puede obtener el número mínimo de muestras. Además, si la población se ha dividido en estratos, para residuos domésticos se debe cumplir que en cada estrato el número de unidades de muestreo (muestras) sea superior a 6 y que el tamaño total de muestra sea como mínimo de $6 \mathrm{~m}^{3}$. Para los residuos comerciales se debe cumplir que el número de unidades de muestreo por estrato sea de 15 y que el tamaño total de muestra sea de al menos $15 \mathrm{~m}^{3}$.

Esta metodología recomienda tres periodos de muestreo a lo largo de todo el año, puesto que la estratificación por estacionalidad debe ser siempre considerada, con una duración de al menos una semana y un tamaño mínimo de muestra total de $45 \mathrm{~m}^{3}$ para los residuos domiciliarios. Cada unidad de muestreo debe ser caracterizada manualmente por separado para determinar la composición, clasificando sus componentes en como mínimo 13 categorías principales, aunque existen otras categorías secundarias.

Finalmente, en cuanto a los costes del análisis de residuos, la SWA-Tool estima que para la etapa de planificación se necesita de 40 a 200 horas de trabajo y para la etapa de muestreo se necesita 6 horas para clasificar manualmente $100 \mathrm{~kg}$ de RSU por una persona.

Una de las limitaciones de esta metodología es que implica el muestreo de una gran cantidad de contenedores de RSU y su caracterización por separado, lo que supone un elevado coste y esfuerzo. Además, realizar la toma de muestras a nivel de contenedor supone la utilización de un vehículo especial para la recogida de los mismos y la distribución de contenedores sustitutos (Dahlén and Lagerkvist, 2008).

\section{Guidance on the Methodology for Waste Composition Analysis (Zero Waste Scotland)}

Zero Waste Scotland es una organización escocesa financiada por el gobierno de este país que en 2015 desarrollo una guía para el muestreo y caracterización de los RSU basada en la "National Methodology for Household Waste Composition Analysis in Scotland" (2008) de la Scottish Environment Protection Agency (SEPA).

La guía incluye las estrategias de muestreo que se han de seguir para el análisis de la composición de los RSU, los procedimientos para la clasificación de los mismos y las directrices para la presentación de los resultados. Por otra parte, establece algunos aspectos operativos como: la seguridad y el equipamiento necesario, o las obligaciones y responsabilidades de los agentes implicados en el muestreo y caracterización. Además, estima los costes que puede suponer la aplicación de la metodología. 
Al igual que la SWA-Tool, esta metodología especifica que existe una serie de factores que influyen en la variabilidad de la composición de los RSU y que se enumeran a continuación: factores socio-económicos, factores demográficos (por ejemplo, edad de la población), tipo de vivienda, estructura residencial (zona urbana, rural o mezclada), estacionalidad, climatología y factores relacionadas con el sistema de gestión de residuos. Estos se han de identificar y considerar a la hora de diseñar la estrategia de muestreo de manera que se pueda llevar a cabo un muestro aleatorio estratificado. Para cada uno de estos factores establece unas recomendaciones de estratificación. Además, propone dividir la población a muestrear en 4-5 estratos teniendo en cuenta, como mínimo, los factores socio-económicos, el tipo de vivienda y la estructura residencial.

Respecto al número y tamaño de muestras, dentro de cada estrato se debe tomar una muestra. Esta deberá tener un tamaño correspondiente a los RSU generados como mínimo por 50 viviendas distintas, las cuales se seleccionarán de manera aleatoria. Como unidad de muestreo se debe utilizar el volumen del contenedor donde cada vivienda deposita sus residuos, recomendando un volumen de contenedor de 240 litros. Si se trata de un bloque de pisos estos contenedores serán comunitarios y corresponderán a un cierto número de viviendas (habitadas).

Esta guía recomienda dos periodos de muestreo con el objetivo de considerar la estacionalidad, uno de ellos en primavera o principios de verano y otro en otoño o principios de invierno, así como evitar realizar el muestreo cuando ocurra un evento especial (por ejemplo, las fiestas populares). La duración de estos periodos debe tener en cuenta la frecuencia de recogida de los diferentes tipos de RSU de manera que se puedan obtener muestras de todos los tipos de residuos generados por los hogares. Las muestras se clasificarán en 17 categorías diferentes de forma manual para determinar su composición física.

Por último, respecto a los costes, la guía estima que de media llevar a cabo todo el proceso de muestreo y caracterización puede costar de 3.800 a 10.400 libras (sin IVA). Aunque este valor depende de muchos factores como: en número de hogares por muestra, el número de estratos en los que se divide la población, el tipo de residuos a caracterizar, la duración del periodo de muestreo, la necesidad de usar vehículos para recoger las muestras, etc.

\section{Protocolo de caracterización de la FORM procedente de la recogida selectiva de residuos municipales (Agencia de Residuos de Cataluña)}

Este protocolo ha sido desarrollado por la Agencia de Residuos de Cataluña (ARC) que pertenece al Dpto. de Territorio y Sostenibilidad de la Generalitat de Cataluña. Está diseñado para ser utilizado en las plantas de compostaje de la FORS y su objetivo es la caracterización de la FORM (fracción orgánica de los residuos municipales recogida selectivamente) para conocer su calidad. En él se incluyen los procedimientos para la toma de muestras y la caracterización manual de los componentes, así como recomendaciones respecto al equipamiento necesario y sobre seguridad (por ejemplo, la actuación frente a la aparición de residuos sanitarios de riesgo biológico). Sin embargo, no indica el número de muestras necesarias.

El protocolo considera como lote a muestrear la cantidad de FORM recogida por una determinada ruta y que es transportada a la PCFO. La toma de la muestra se debe realizar tras homogeneizar completamente el lote y haber eliminado los residuos voluminosos que pueda contener, de modo que, mediante sucesivos cuarteos se llegue a un tamaño de muestra aproximado de $250 \mathrm{~kg}$.

La clasificación de la FORS para determinar la composición se realizará de forma manual, esta tiene la finalidad de diferenciar entre la fracción compostable y la fracción de impropios. Dentro de la fracción de impropios, además, se recomienda la separación del material en 11 categorías más.

\section{Protocolo de toma de muestras caracterización y análisis de RSU (SUEZ Advanced Solutions)}

El protocolo tiene como objetivo la caracterización de los RSU recogidos de forma mezclada que entran a las plantas de TMB y ha sido desarrollado por Suez Advanced Solutions Spain. Este establece una serie de procedimientos para la toma de muestras, la caracterización manual de los componentes y la selección y preparación de las muestras para el análisis en laboratorio de diferentes propiedades químicas como 
humedad, poder calorífico, cenizas y análisis elemental. Además, también incluye recomendaciones de seguridad y de equipamiento necesario para su aplicación. Como en el caso anterior, tampoco indica el número de muestras necesarias.

El protocolo considera como lote a muestrear la cantidad de RSU recogidos en una ruta, que puede estar formado por la carga de uno o dos camiones con un peso total de aproximadamente 30 toneladas. Tras la homogeneización completa del lote y la eliminación de los elementos voluminosos, se procede a la toma de muestra mediante cuarteo. El peso mínimo de muestra recomendado es de $100 \mathrm{~kg}$ con un margen de error del $10 \%$. Esta muestra se clasificará manualmente para determinar la composición física, proponiendo como mínimo su clasificación en 13 categorías.

Respecto al procedimiento de selección y preparación de las muestras para el laboratorio, el protocolo establece que, una vez conocida la composición física de la muestra de $100 \mathrm{~kg}$, se tienen que recomponer dos muestras de $1 \mathrm{~kg}$ cada una. A continuación, las dos muestras deben ser troceadas a un tamaño de partícula menor de $30 \mathrm{~mm}$, que se enviarán al laboratorio para determinar la humedad. Junto con esas dos muestras también se recogerá una muestra de finos de $250 \mathrm{~g}$ (material menor de 2-3 mm).

Una vez secas, una de las muestras de un kg se guarda como referencia, mientras que la otra se triturara a un tamaño menor de $2 \mathrm{~mm}$ para la determinación de poder calorífico, cenizas y análisis elemental $(\mathrm{C}, \mathrm{H}, \mathrm{O}$, $\mathrm{N}, \mathrm{S}$ y $\mathrm{Cl}$ ). Sobre la muestra de finos también se determinará el contenido en cenizas.

\subsubsection{Metodologías de muestreo y caracterización propuestas por algunos investigadores}

Junto con las normas o metodologías expuestas en los puntos anteriores, algunos trabajos de investigación proponen mejoras a las mismas o diseñan nuevos procedimientos que también se han revisado. Estos se exponen a continuación.

Klee (1993, 1991) desarrollo una metodología computarizada denominada "PROTOCOL". Esta permite realizar los cálculos necesarios para determinar el número de muestra necesarias para la estimación de la cantidad y la composición de RSU que llegan da las instalaciones de tratamiento, eliminado los sesgos que las metodologías tradicionales suelen introducir. La metodología se basa en una serie de fórmulas complejas basadas en numerosos parámetros del muestreo (por ejemplo, el número de vehículos de recogida que llegan a planta, la carga de RSU media que llevan los camiones, la frecuencia de muestreo, el número total de horas de muestreo, etc.), junto con datos históricos sobre la composición de RSU (medias y desviaciones estándares). A partir de estos datos se estima el peso medio de la carga de los camiones que debe ser muestreado a la semana, así como el número de camiones necesario para alcanzarlo. Además, se calcula los intervalos de confianza sobre el peso medio de la carga en base a unos grados de libertad efectivos.

Respecto al tamaño de muestra recomienda, para RSU en bruto recomienda pesos de 91-136 kilos, mientras que para corrientes de residuos procesados cuyas partículas son pequeñas se puede utilizar la siguiente ecuación basada en el diámetro de las partículas:

$$
Y=X e^{0,146 X}
$$

Donde: $Y$ es el peso óptimo en libras; $X$ el tamaño de partícula característico del material (tamaño de luz de malla a través del cual pasa el 63,3\% del material) en pulgadas.

En cuanto al número de muestras, Klee plantea que las metodologías utilizadas tradicionalmente no son las adecuadas, puesto que se basan en el teorema del límite central y asumen que los datos de composición de un determinado componente siguen una distribución Normal. Sin embargo, esa asunción es solo justificable en las estimaciones de la cantidad de RSU generadas, pero no en los estudios de composición. En el caso de la composición los datos están limitados, ya que no hay componentes en los RSU que este por debajo del $0 \%$ o sean mayores a $100 \%$, lo que hace que su distribución tenga una asimetría positiva o, en el peor de los casos, tenga forma de J. Así pues, Klee establece que los datos de composición solo seguirán una 
distribución aproximadamente normal con un amplio número de muestras (mayor a 40), lo que en la caracterización de RSU es poco viable debido al gran coste económico que esto supone.

En su trabajo también habla sobre la variación estacional de los RSU, indicando que no es suficiente el muestreo de una única semana en todo el año. Para ello propone el cálculo computarizado de un número óptimo de semanas de muestro mediante la simulación de Monte Carlo. Por otro lado, debido a que los datos no siguen una distribución Normal, para el cálculo de los intervalos de confianza de los resultados de composición recomienda la trasformación logarítmica de los datos.

Sin embargo, esta metodología tiene una gran limitación, ya que basa sus cálculos en estadísticas sobre la composición de EE.UU. del año 1972, al igual que la norma ASTM. Por lo que sería necesario actualizar estos datos por nuevos más recientes (Mccauley-bell et al., 1997; Sharma and McBean, 2007).

Scott (1995) llevó a cabo un proyecto junto con la Agencia Internacional de la Energía (IEA), Dinamarca, Noruega, Países Bajos, Gran Bretaña y EE.UU, cuyo objetivo era armonizar los protocolos de muestreo y análisis de RSU destinados a la valorización energética. En primer lugar, se realizó una revisión de los protocolos para el análisis de la composición de los RSU que eran utilizados en los países participantes. Esta mostró que el tamaño del lote utilizado para la toma de muestras variaba desde las 0,5 a las 12 toneladas y el principal método para la división y sub-muestreo del lote era la conificación y el posterior cuarteo. En la mayoría de los países se llevaban a cabo dos o más periodos de muestreo, salvo en Gran Bretaña y EE.UU. La selección de los componentes se realizaba en la mayoría de los países de forma manual, aunque en países Bajos y Gran Bretaña se combinaba con medios mecánicos, clasificándolos en un rango de 8 a 19 categorías primarias.

La IEA recomienda planificar el muestreo considerando una serie de factores que influyen en la composición y generación de los RSU como: factores socioeconómicos, política de gestión de residuos, tipo de sistema de recolección, estacionalidad, uso de combustibles sólidos, turismo, tipo de residencia u otras características del área. Además, sugiere la utilización del muestreo estratificado, puesto que es el utilizado en la mayoría de las metodologías. En cuanto al cálculo del tamaño de muestra propone la utilización de la ecuación de Gy basada en las propiedades físicas del material, pero con una adaptación debido a que normalmente los RSU son elementos planos con solo dos dimensiones, por lo que el tamaño nominal (d) se eleva al cuadrado y no al cubo (Ec.5.5).

$$
M_{S}=\frac{C d^{2}}{s_{0}^{2}(F S E)}
$$

Donde: $M_{s}$ es la masa mínima de muestra, $C$ es la denominada "Constante de Muestreo" $\left(\mathrm{g} / \mathrm{cm}^{3}\right)$; $\mathrm{d}$ es el tamaño nominal superior de partícula $(\mathrm{cm})$, y $\mathrm{so}_{0}^{2}(\mathrm{FSE})$ la varianza del error fundamental de muestreo admitida o el nivel de incertidumbre deseado, en porcentaje.

A la hora de realizar la caracterización, la IEA sugirió la necesidad de llegar a un acuerdo en 9 categorías principales: residuos de cocina y jardinería, papel y cartón, plásticos, metales, textiles, otros combustibles, vidrio, otros no combustibles y finos. Estas categorías comunes facilitarán la comparación y el intercambio de información entre países, programas de investigación, etc.

McCauley-bell et al. (1997) desarrollaron también una metodología para el muestro y estudio de la composición de los RSU, así como un sistema computarizado para facilitar su implementación. La metodología se divide en cinco procesos secuenciales: planificación del estudio, plan de muestreo, selección del tamaño de muestra, muestreo e interpretación de los resultados.

En la planificación del estudio se debe definir el objetivo del muestreo, así como identificar las corrientes de RSU a muestrear y los factores que influyen sobre la variabilidad de estas corrientes. Esto permitirá diseñar el plan de muestreo y, si es necesario, estratificar la población a muestrear. Los factores a tener en cuenta son: la fuente generadora de los residuos (viviendas unifamiliares o multifamiliares, zonas rurales, urbanas, comerciales o industriales), factores demográficos (salario, edad, cultura, etc.), estacionalidad, turismo, eventos especiales y otras influencias económicas (aumento o bajada de paro, aumento o bajada en el 
precio de los materiales reciclables, etc.). En esta fase también se debe diseñar un plan de seguridad y salud.

En el plan de muestreo se deben calcular el número adecuado de muestras para que los resultados sean representativos, para ello se utilizará el método desarrollado por Klee (1991): PROTOCOL, pero con datos propios. En cuanto a la selección del tamaño de muestra, la metodología propone un mínimo de 91-136 kilos, al igual que Klee.

Los autores recomiendan realizar una fase de muestreo por estación y utilizar la carga de los camiones de recogida para la toma de muestras, los cuales se deben seleccionar de forma aleatoria, tomando una muestra de cada camión. Para ello, mediante el mezclado y cuarteo, se irá reduciendo el tamaño de la muestra hasta llegar al tamaño mínimo. Las categorías en las que se clasificarán los RSU dependerán del objetivo del estudio de caracterización, aunque se sugiere un mínimo de 33 categorías.

Petersen et al. (2005) desarrollaron un procedimiento para el muestreo y caracterización física y química de RSU, enfocado a los residuos que se destinan a incineración, el cual aplicaron a los RSU tratados en una incineradora sueca. Las muestras se tomaron a nivel de planta y cada unidad de muestreo correspondió a la carga de un camión de recogida. La campaña de muestreo tuvo una duración de 5 días de lunes a viernes, puesto que en estudios preliminares se había observado que el día de la semana no tenía influencia. De los 16 camiones de RSU que llegaban cada día a la incineradora, 5 se seleccionaron aleatoriamente para tomar una muestra de cada uno. Para ello, cada carga era depositada en una superficie plana y con ella se formaba una pila rectangular. La pila se dividió en 4 × 5 cuadrados y 10 fueron seleccionados al azar para coger una sub-muestra o incremento. El tamaño de las sub-muestras correspondía a todos los residuos que había dentro de un cuadrado de 0,5 $\mathrm{m} \times$ 0,5 $\mathrm{m}$ que se demarcó en el centro de cada uno de los cuadrados usando un marco de madera. Finalmente, las 10 sub-muestras se unían para formar la muestra combinada. Los pesos de las diferentes muestras tomadas a lo largo de la campaña de muestreo variaron de los 90 a los 189 kilos. Además, también se tomó una muestra diaria de residuos industriales. Las muestras fueron clasificadas manualmente en 3 categorías primarias (bio-combustibles, combustibles fósiles y materiales no combustibles) y en 12 categorías secundarias para conocer su composición física.

Respecto a la caracterización química, a partir del material ya clasificado y separado, se prepararon dos muestras de laboratorio para cinco componentes: biorresiduos, bio-combustibles bajo responsabilidad del productor (papel y envases de cartón), otros bio-combustibles, combustibles fósiles bajo responsabilidad del productor (envases de plástico) y otros combustibles fósiles. En el caso de los biorresiduos, todo el material de este tipo que había sido clasificado en el día era dividido por conificación y posterior cuarteo hasta aproximadamente un $1 \%$ (aprox. $5 \mathrm{~L}$ ) del total de biorresiduos clasificados ese día. Las muestras obtenidas se almacenaban en el congelador y al finalizar la campaña de muestreo fueron mezcladas y preparadas para el análisis químico. En el caso de los otros componentes, estos fueron almacenados por separado a lo largo de la semana de muestreo. Al finalizar la misma se procedió a su división por cuarteo hasta aproximadamente $20 \mathrm{~L}$ de muestra para cada uno de ellos y se prepararon para el análisis químico. Además, también se preparó una muestra de residuos industriales para su análisis. Estos análisis consistieron en la determinación de la materia seca, cenizas y poder calorífico.

Burnley et al. (2007) propusieron un protocolo para la toma y análisis de muestras con el objetivo de investigar el flujo total de RSU a partir de un trabajo realizado por la Agencia de Medioambiente de Inglaterra y Gales. Los tipos de RSU que incluía son: residuos domiciliarios, residuos de puntos limpios, residuos comerciales, basura de limpieza de las calles y residuos voluminosos. En el protocolo se definen una serie de variables que pueden influir en la generación de los RSU como: ubicación geográfica, factores demográficos y socioeconómicos, diferencias en la gestión de residuos, etc., que se utilizan para la estratificación de la población. Mediante la aplicación del método se determinó la composición general de los residuos sólidos municipales en Gales, clasificándolos en 38 categorías distintas.

En el caso de los residuos domiciliarios, 22 municipios de Gales se clasificaron en función de distintas variables relacionadas con el sistema de gestión de RSU y la ubicación geográfica. A continuación, se eligieron al azar cinco distritos diferentes en cada municipio y se realizó un análisis estadístico de los mismos en base a las variables de estratificación. Este tenía como objetivo evitar correlaciones y seleccionar 
los distritos y municipios que mejor representaban a Gales en su conjunto. Una vez identificados los mejores distritos donde hacer el muestreo, se seleccionaban 32 viviendas en cada uno para la toma de muestras. Además, para conocer las características de las viviendas en relación a factores demográficos y socioeconómicos, se envió una encuesta a aquellas que habían sido seleccionadas. En global se analizaron los residuos de 2778 viviendas de 9 municipios diferentes a través de cuatro campañas de muestreo, una por estación. Los datos obtenidos tras el muestreo se analizaron estadísticamente para conocer las relaciones significativas entre las variables de estratificación y los residuos producidos por hogar, para ello se utilizó principalmente el análisis de la varianza (ANOVA). Algunas de las relaciones estadísticamente significativas que se encontraron han sido comentadas en el capítulo 4 de la presente tesis.

Sharma y McBean (2007) diseñaron un método estadístico para estimar el número de muestras necesarias para la caracterización de residuos utilizando la información específica del sitio. Esta metodología se basa en que la media y la desviación estándar de los resultados obtenidos en el muestreo tienden a estabilizarse con el aumento del número de muestras, así como el intervalo de confianza disminuye su rango (lo que indica una mayor certeza en la estimación del valor real).

Se trata de un método iterativo, en el que el número de muestras requeridas va cambiando a lo largo del proceso de muestreo hasta alcanzar un criterio de convergencia, momento en el que se detienen el muestreo. Para ello se hace un seguimiento del proceso de muestreo y caracterización, que tiene como objetivo conocer en qué momento el cuadrado del coeficiente de variación de un componente (por ejemplo, el plástico film) se vuelve casi estable a pesar de realizar un muestro adicional. Lo que indica que una muestra más no proporcionará información adicional significativa, es decir, no reducirá el intervalo de confianza de la estimación. Basándose en su experiencia, los autores establecen una recomendación de un mínimo de 10 muestras.

En otro trabajo de investigación, los mismos autores, Sharma and McBean (2009) desarrollaron una estrategia alternativa para la estimación del número de muestras requeridas para el muestreo representativo de componentes que estan presentes en los residuos en porcentajes pequeños; puesto que su muestreo mediante las metodologias tradicionales requerían un número de muestras elevado. Esta estrategia se basa en la utilización de un tamaño (cantidad) de muestra mayor, lo que permite obtener resultados de composición más estables y, por tanto, reducir la desviación estandar y el coeficiente de variación. Como se ha visto anteriormente en la metodologia diseñada por estos autores (Sharma and McBean, 2007), el coeficiente de variación es el estadistico que se utilizada para el cálculo del número de muestras. Así pues, un coeficiente de variación menor y más estable (asociado a un tamaño de muestra mayor) supone un menor número de muestras para estos compuestos que se preserntan en porcentajes bajos.

Lebersorger y Schneider (2011), en su trabajo de investigación sobre la determinación del desperdicio alimentario, analizaron las limitaciones y problemas específicos de las metodologías utilizadas en diferentes estudios de composición de los residuos domiciliarios y las posibles soluciones o adaptaciones necesarias para su utilización en relación a los desperdicios alimentarios. Respecto a las categorías utilizadas, observaron que es necesaria una clasificación más detallada y elaborada. Asimismo, los estudios de composición proporcionan solo datos sobre el flujo analizado y no incluyen los alimentos eliminados por otras vías como: el compostaje doméstico, alcantarillado, recogida separada o alimentación a animales. Por otro lado, para la determinación de la cantidad de desperdicios alimentarios existentes en los residuos domiciliarios, el estudio sugiere que el muestreo se realice a nivel de hogar para evitar la descomposición de los mismos. También recomienda que la población a muestrear se estratifique en zonas rurales y urbanas, así como entre viviendas unifamiliares y multifamiliares, ya que tienen comportamientos diferentes. Además, la muestra no debe tamizarse antes de su clasificación y los residuos de alimentos envasados se clasificarán como restos de alimentos junto con su embalaje, sin separarlos.

Edjabou et al. (2015) presentan una nueva metodología de muestreo y caracterización de RSU, la cual aplicaron a 3 municipios daneses. Para ello, los municipios se estratificaron en 10 sub-áreas (estratos) en función del tipo de vivienda (unifamiliar y multifamiliar). El número de muestras fue de una por cada subárea (10 en total), las cuales se tomaron a nivel de contenedor de recogida. El tamaño total de cada una de 
estas muestras fue la generación de residuos de 100-200 hogares como recomienda la norma "Nordtest Method". Sin embargo, estas muestras no fueron divididas por cuarteo como indica la norma, sino que fueron tratadas como muestras únicas a la hora de su clasificación en los diferentes componentes. La clasificación se realizó mediante un enfoque escalonado de tres niveles, lo que facilita la comparación de datos de composición de RSU: el primer nivel corresponde a 10 categorías, el segundo a 36 y el tercero a 56.

Por otro lado, dentro de este trabajo de investigación, también se llevó a cabo un análisis estadístico de los resultados obtenidos tras el muestreo y caracterización, el cual tenía como objetivo estudiar si existían diferencias significativas entre los diferentes estratos y/o municipios. El análisis estadístico se realizó con los datos de composición en porcentaje. Esto permitió realizar las comparaciones evitando las variaciones de escala entre municipios o estratos, es decir, las variaciones debidas a que algunos municipios o estratos que generan más cantidades que otros. Sin embargo, como los datos de composición en porcentajes son "conjuntos de datos cerrados" (las proporciones de las fracciones individuales son positivas y suman una constante de 100) no seguían una distribución Normal, por lo que fue necesaria su transformación logarítmica antes de realizar los análisis estadísticos.

Sahimaa et al. (2015) desarrollaron un método para el estudio de la composición de los residuos domésticos. Para ello identificaron las buenas prácticas de diferentes metodologías de este tipo en Europa, revisaron varios estudios de composición finlandeses e identificaron las necesidades de información de las empresas regionales de gestión de RSU mediante encuestas y entrevistas. Según los autores, los factores clave de un buen estudio son: la estratificación, el muestreo, la caracterización y la adecuada presentación de los resultados.

Las estratificaciones se realizarán en función de las necesidades de información, recomendándose siempre la estratificación por tipo de área (urbana, rural, etc.) o el tamaño de la propiedad (si existen diferencias en el sistema de recogida en propiedades de tamaños distintos). Además, siempre que sea posible, se sugiere realizar de dos a cuatro periodos de muestreo a lo largo del año para evitar la estacionalidad. Otros factores de estratificación que incluyen los estudios revisados por los autores son: ubicación geográfica, diferencias socioeconómicas, tipo de propiedad o sistema de recolección.

Respecto al muestreo, este se debe realizar de forma separada para cada estrato y las muestras se tienen que tomar de los residuos recogidos por los camiones en el estrato correspondiente. La carga debe ser mezclada completamente para evitar posibles errores de agrupación y segregación tras haber eliminado los residuos voluminosos presentes. A continuación, se divide en pilas alargadas y planas sobre las que se realizará el submuestreo. Cada pila debe contener los residuos generados por 100-200 hogares. La masa mínima recomendada para cada submuestra en de 100 kilos y, al menos, 6 muestras deben ser recolectadas en cada estrato.

A la hora de la clasificación se puede utilizar un tamiz $(10-20 \mathrm{~mm})$ para eliminar las partículas finas y facilitar la separación. El material fino se clasificará en diferentes categorias en base a una evaluación visual. Las categorias de materiales deben estar definidas de una forma clara, recomendandose un sistema jerarquico de tres niveles con 11 categorias en el primero, 27 en el segundo y 38 en el tercero. Las cuales se basan en las necesidades de información expuestas por lo expertos en las encuestas.

Respecto a los CSR, Flamme and Geiping (2014, 2012), en sus trabajos de investigación revisaron y analizaron los estándares de calidad y requisitos para los combustibles sólidos recuperados, en concreto la norma UNE-EN 15359: 2012 y UNE-EN 15442: 2011 y la norma alemana RAL-GZ 724. Respecto a esta última, en ella se establecen los parámetros de calidad y valores límites que ha de cumplir un CSR en Alemania, así como el proceso de muestreo y análisis que se ha de seguir para la determinación de los mismos. Este incluye el muestreo, tratamiento de muestra en el laboratorio, método de análisis e interpretación de los resultados.

De acuerdo a la norma RAL-GZ 724, el muestreo se debe realizar mediante muestras combinadas de manera que se tengan en cuenta las variaciones entre periodos de producción. Cada una de ellas se compone de 25 incrementos de 5 litros, los cuales se tienen que recoger directamente de la cinta transportadora. Durante cada periodo de monitoreo de la calidad del CSR, el número total de muestras combinadas que se deben tomar es de 24 (21 para control interno y 3 para control externo) repartidas a lo 
largo del mismo. Una vez se han tomado todos los incrementos y se ha formado la muestra combinada, esta se debe mezclar y reducir de los 125 litros (25 incrementos de $5 \mathrm{~L}$ ) a dos submuestras de 10 litros que se trasladará al laboratorio (una para guardar como referencia y otra para analizar). Las 24 muestras son sometidas a un breve análisis respecto al contenido en humedad, poder calorífico, contenido en cloro y dos metales pesados relevantes. Además, 10 de esas muestras serán sometidas a unos análisis más extensos para determinar los valores límites de todos los parámetros de calidad (mediana y percentil 80). Si se excede algún valor límite, se analizarán otras 10 muestras de las 14 restantes para determinar dicho parámetro, volviéndose a comprobar los valores límites con los resultados de las 20 muestras analizadas en total.

Por su parte, Rotter et al (2011), presentaron una nueva técnica para la caracterización de los CSR mediante métodos de ensayo rápidos que se basan en el análisis de incineración y correlación. Estos ensayos rápidos minimizan los esfuerzos (económicos, de tiempo y mano de obra) que normalmente son necesarios para llevar a cabo los métodos de análisis estandarizados. Además, permiten determinar parámetros relevantes del combustible como: poder calorífico, humedad, cenizas y contenido en cloro. Según los autores, estas nuevas técnicas no pretenden remplazar los métodos estandarizados, sino que deben considerarse como una herramienta práctica de apoyo en la caracterización de los CSR.

Los ensayos rápidos propuestos son análisis indirectos en los que se analizan los gases de combustión generados en un incinerador a escala de laboratorio en los que se introduce 5 gramos de material. Además, con el objetivo de minimizar esfuerzos, estos ensayos consideran las correlaciones existentes entre los parámetros del combustible (por ejemplo, la relación existente entre el poder calorífico y la composición elemental) y utilizan diferentes fórmulas para la estimación de los mismos. Mediante un análisis de pérdida de masa se calcula el contenido en humedad y las cenizas. El cloro se determina mediante un análisis fotométrico tras el borboteo y absorción de la corriente de gas de combustión en un matraz de lavado (impinger). Para el análisis del poder calorífico, en primer lugar, se determina el contenido en carbono y oxígeno a partir del $\mathrm{CO}_{2}$ formado y el $\mathrm{O}_{2}$ presente en el flujo de entrada y en los gases de combustión mediante unas células de medición del infrarrojo no dispersivo (NDIR). Finalmente, usando las fórmulas apropiadas se estima el poder calorífico.

Por otro lado Lorber et al (2012), en su trabajo de investigación, proponen dos escenarios de control de calidad de dos tipos diferentes de CSR usados en cementeras, para ello se basan en las normas de CSR elaboradas por el CEN y las normas nacionales austriacas.

El primero de los CSR es utilizado en el quemador primario de las cementeras (mayor calidad), su producción es mayor de 40.000 toneladas al año y tiene un $d_{95}<30 \mathrm{~mm}$. El tamaño del lote corresponde a la cantidad de CSR producido durante un mes y, al menos, 10 muestras combinadas deben tomarse a lo largo de ese periodo (sugiere dos o tres muestras por semana que estén formadas por incrementos tomados en dos o tres días distintos). Estas muestras se tomarán por duplicado, una para el análisis y otra para guardar como referencia. El tamaño mínimo de muestra y el tamaño mínimo del incremento se calcula utilizando la norma CEN/TS 15442 y se recomienda que entre 6 y 10 incrementos formen cada muestra combinada. Para este escenario concreto esto supuso un tamaño de incremento de $0,5 \mathrm{~kg}$ y un tamaño de muestra de $3 \mathrm{~kg}$.

El segundo CSR es utilizado en el disco caliente de las cementeras (menos calidad), su producción es menor a 40.000 toneladas/año y tienen un $d_{95}<80 \mathrm{~mm}$. En este caso el tamaño de lote corresponde a 1.500 toneladas producidas, las cuales se deben dividir de forma aleatoria en 10 sub-lotes de un máximo de 150 toneladas. Se seleccionarán al azar 5 sub-lotes y en cada uno se tomarán dos muestras combinadas (una para análisis y otra para guardar como referencia). El tamaño mínimo de muestra y el tamaño mínimo de incrementos se calcula usando la norma CEN/TS 15442, proponiendo que deben utilizarse de 6 a 10 incrementos como mínimo para crear cada muestra. Para este escenario en concreto esto supuso un tamaño de incremento de 3,5 kg y un tamaño de muestra de $21 \mathrm{~kg}$, este aumento en el tamaño de muestra en comparación con el primer CSR es consecuencia del mayor tamaño de partícula.

Por último, junto con las metodologías analizadas anteriormente, algunos autores han realizado revisiones sobre los diferentes métodos para la caracterización y el muestreo de RSU. 
En este sentido, Dahlén y Lagerkvis (2008) realizaron una revisión de 20 métodos para el análisis de la composición de los RSU. En su trabajo concluyen, por un lado, que el procedimiento general de estos estudios sigue cuatro pasos:

1. Planificación y diseño

2. Muestreo y fraccionamiento de muestras (sub-muestreo)

3. Selección manual y clasificación de componentes

4. Evaluación y procesamiento de datos

Por otro, que los diferentes métodos se utilizan a nivel regional o nacional y que no existe ninguna norma internacional que funcione como estándar. Además, identifican los factores clave a considerar a la hora de realizar un estudio de composición, los cuales se enumeran a continuación:

- $\quad$ El número y tipos de estratos requeridos en función del objetivo del análisis.

- La ubicación del muestreo (es decir, a nivel de vivienda o contenedor, de carga de los vehículos de recogida) en función de si se necesita una visión del comportamiento de los hogares o una más general.

- $\quad$ El número mínimo de muestras y el tamaño de muestras.

- $\quad$ El número y tipo de componentes a clasificar.

Respecto al tamaño y número de muestra no obtuvieron una conclusión definitiva, no obstante, afirman que se puede tomar como regla general un número mínimo de 10 muestras por campaña y con un tamaño de 100 kilos o más cada una de ellas. Mientras que si se lleva a cabo un muestreo estratificado será necesario un mínimo de 5 muestras en cada estrato. Además, indican que es importante considerar las variaciones estacionales y cada periodo de muestreo debe cubrir al menos una semana completa. El método recomendado para dividir la muestra es mediante una pila plana alargada (o cinta transportadora) donde se realiza un corte perpendicular con dos planos paralelos. Asimismo, señalan que utilizar siempre las mismas categorías primarias para la clasificación de los RSU facilitaría la comparación entre estudios, las cuales deberían estar estrictamente definidas y limitadas a un máximo de 10.

Por su parte, Runfola (2008) realizó un análisis comparativo de 7 metodologías y normas para la caracterización de residuos y 11 casos prácticos. Tras la revisión, por un lado, concluyó que hay diferentes enfoques para determinar el número de muestras para la caracterización y que cada metodología aplica diferentes métodos estadísticos para ello. Por otro, que cada caso práctico utilizaba diferentes criterios para la determinación de este número, así como para la selección, toma y análisis de las muestras. Además, en la mayoría de los estudios de caracterización se asumía que los datos obtenidos seguían una distribución Normal.

\subsection{PROCEDIMIENTOS ESTADISTICOS}

Para abordar el diseño de la metodología para el control de calidad de los rechazos también ha sido necesario llevar a cabo una revisión de los procedimientos estadísticos aplicables a los residuos y rechazos, puesto que algunos de ellos han sido utilizados en el desarrollo de la misma. En concreto, permitirán extraer conclusiones sobre los datos obtenidos en los diferentes experimentos realizados en los capítulos posteriores. Por ejemplo, comprobar si los resultados obtenidos son representativos.

La estadística es una de las herramientas más usadas en la investigación científica y en ella se utilizan diferentes conceptos y métodos matemáticos para recopilar, organizar, resumir, analizar, interpretar o presentar datos o información numérica, de manera que se puedan extraer conclusiones sobre fenómenos relacionados con ellos. De forma simplificada, la estadística tiene dos usos principales:

- Descripción de la información (estadística descriptiva): permiten organizar y describir un conjunto de datos con el propósito de facilitar su uso e interpretación. Para ello se utilizan resúmenes numéricos y/o gráficos. 
- Realización de inferencias (inferencia estadística): consiste en la obtención de conclusiones acerca de las características de una población (realidad) a partir de muestras de la misma (datos obtenidos). Para ello se hacen estimaciones y/o contrastes de hipótesis y siempre existe una probabilidad de error o incertidumbre.

A continuación, se definen algunos términos estadísticos fundamentales. Además, se realizan algunas observaciones sobre los mismos debido a que, en el ámbito del muestreo y caracterización de residuos, la terminología utilizada no es exactamente la misma, lo que puede crear confusiones.

- Universo: es la totalidad de individuos o elementos en los cuales puede presentarse una determinada característica que quiere ser estudiada. En muchos casos es igual a la población y puede ser finito o infinito.

- Población: la población estadística es un conjunto de individuos o elementos que presentan determinadas características en común, las cuales quieren ser estudiadas para sacar ciertas conclusiones. Puede ser finita o infinita.

- Muestra: es un subconjunto de elementos de la población que se estudian para determinar cierta característica de la misma. Todas las muestras son subconjuntos de una población, pero no todas son representativas. Las muestras más representativas son las que se seleccionan aleatoriamente (al azar), de manera que cualquier elemento de la población tiene la misma probabilidad de formar parte de la muestra.

En el ámbito del muestreo y caracterización de residuos, una muestra se define como una cantidad (peso o volumen) de residuos representativa de una cantidad mayor y que se va a analizar para determinar cierta característica, obteniéndose un único dato a partir de la misma. Así pues, una muestra de residuos no está formada por varios elementos, sino que es un único elemento de la población.

Como consecuencia se obtiene el término de grupo de muestras. Un grupo de muestras está formado por varias muestras (elementos) que pertenecen a la misma población y que fueron seleccionados de la misma forma o bajo las mismas condiciones. En este sentido, el número de muestras hace referencia a la cantidad de muestras que componen un grupo y con el estudio de cada una de ellas se obtienen un conjunto de datos sobre la población. Así pues, en el campo de la caracterización de residuos, un grupo de muestras es lo que en estadística se considera una muestra formada por varios elementos de la población.

- Dato u observación: expresiones numéricas obtenidas como consecuencia de observar un elemento de la muestra o población en relación a la característica que se quieren estudiar.

En el campo del muestreo y caracterización de residuos, cada dato se obtiene de observar una única muestra, ya que esta no está formada por varios elementos, sino que es un único elemento.

- Conjunto de datos u observaciones: conjunto de expresiones numéricas que se obtiene de observar todos de los elementos de la muestra o población en relación a la característica que se quiere estudiar.

En el ámbito del muestreo y caracterización de residuos, un conjunto de datos se obtiene de observar todas las muestras que forman un grupo de muestras, las cuales pertenecen a la misma población y fueron tomadas del mismo modo o bajo las mismas condiciones.

- Parámetro: valor característico de la población, es decir, un valor numérico que describe una característica de la población. Los parámetros se estiman a partir de la información aportada por un grupo de muestras. Este valor es constante y suelen representarse con letras griegas.

- Estadígrafo o estadístico: valor característico de un grupo de muestras, es decir, un valor numérico que describe una característica del grupo. Se obtiene mediante manipulación algebraica del conjunto de datos obtenido a partir las muestras y son utilizados para estimar un parámetro. Este valor no es constante y depende de las muestras seleccionadas dentro del grupo, ya que en una población se pueden tomar distintos grupos de muestras cada uno con un valor característico diferente. Suele representarse con letras latinas. 
- Variable: es una característica que puede tomar diferentes valores, es decir, que varía de una muestra a otra del grupo o de un elemento a otro de la población.

\subsubsection{Estadística Descriptiva}

La estadística descriptiva es la técnica matemática que incluye la obtención, organización, presentación y descripción de un conjunto de datos o información con la finalidad de facilitar su uso. Para ello se apoya en tablas, gráficos o resúmenes numéricos. Además, incluye el cálculo de parámetros y estadísticos como las medidas de tendencia central o de dispersión.

A la hora de realizar un estudio de campo o una experimentación es indispensable disponer de una planificación en la que se indique el objetivo del estudio, la hipótesis de partida, las características o aspectos que se quieren estudiar, bajo qué condiciones se van a medir y cómo se van a tratar los datos. Asimismo, la identificación de los aspectos que se van a considerar como variables en el estudio es muy importante, puesto que el tipo de resumen numérico, representación gráfica y métodos de análisis dependerá del tipo de variable (Gallardo, 2000). Desde el punto de vista estadístico existen diferentes tipos de variables, estas se pueden clasificar en dos categorías principales, las que a su vez se pueden subdividir en otros dos tipos según el nivel de medida:

Variables cualitativas o categóricas, son las que miden una cualidad o característica y no se pueden medir numéricamente:

- Nominales: sus valores son nombres o códigos de las distintas categorías o niveles. Las cuales son mutuamente excluyentes y totalmente exhaustivas, por lo que los elementos clasificados en la misma categoría son equivalentes respecto a la variable que se está midiendo. No se pueden realizar operaciones matemáticas con ellas ni pueden ser ordenadas. Ejemplos: estacionalidad (primavera, verano, otoño o invierno), tipo de planta de TMB (manual o automática), forma de partícula (granular, copo, pelusa, ...), etc.

- Ordinales: sus valores son nombres o códigos de las distintas categorías o niveles de la variable. Es posible establecer una relación de orden entre estas categorías, ya que cada categoría tiene una posición relativa. La ordenación es la única operación matemática posible. Ejemplos: nivel de renta (bajo, medio, alto), tamaño de partícula (pequeño, mediano, grande), etc.

Variables cuantitativas o numéricas, son la que miden una cantidad, se expresan mediante valores numéricos y por lo tanto se pueden realizar operaciones matemáticas con ellas:

- Discreta: sus valores están condicionados y solo pueden adoptar los valores de un conjunto numérico dado, no pudiendo adoptar cualquier valor. Entre los valores potencialmente observables de una variable discreta existe una distancia o separación que resulta imposible de "completar", donde se encuentran los valores intermedios que la variable discreta no puede asumir. Normalmente una variable discreta aparece por conteo y solo toma valores enteros. Ejemplos: número de corrientes de rechazo $(1,2,3, \ldots)$.

- Continua: son aquellas que pueden asumir cualquier valor real dentro de un intervalo determinado. Una variable continua nunca puede ser medida con exactitud, ya que el valor observado está limitado por la precisión del equipo de medición, por lo que siempre existirá un error de medida. Los porcentajes pueden considerarse variables continuas, aunque pueden causar problemas en el análisis, por lo que se tienen que tener cuidado al analizar este tipo de datos. Ejemplos: tamaño nominal superior de partícula, densidad de partícula, porcentaje de cada componente o fracción de material, $\mathrm{PCl}$, contenido en $\mathrm{Cl}$ o $\mathrm{Hg}$, etc.

La descripción de las características y comportamientos de estas variables se puede llevar a cabo mediante tablas, gráficos y/o medidas resúmenes, los cuales permite simplificar la comprensión de los datos.

\subsubsection{Tablas y gráficos}

El uso de tablas y gráficos para describir los datos es fundamental en estadística y sirve como fase preliminar al empleo de resúmenes numéricos, que a su vez se completan con inferencias estadísticas. La representación gráfica de los datos hace visible sus características más importantes, aporta información 
sobre la estructura de los mismos y permite explorarlos para, por ejemplo, conocer su distribución o separar las tendencias generales de las desviaciones puntuales o datos atípicos. Según la variable estudiada se pueden utilizar diferentes técnicas:

- Representaciones de variables categóricas: tablas de frecuencia, diagrama de barras y diagrama de sectores.

- Representaciones de variables numéricas: diagrama de tallos y hojas, histograma, diagrama de dispersión y diagrama de caja y bigotes.

Actualmente existen programas informáticos de estadística que permiten aplicar estas técnicas y dibujar los gráficos correspondientes de forma sencilla. En la presente tesis se ha utilizado el programa de acceso libre $\mathrm{R}$ y su paquete $\mathrm{R}$ Commander. A continuación, se explican brevemente los gráficos de mayor interés en el análisis de datos aplicado al muestreo y caracterización de residuos y rechazos.

\section{Histograma}

El histograma es uno de los gráficos más utilizados para resumir un conjunto de datos y permite conocer diferentes características de los datos como: el rango de las observaciones, los valores máximos y mínimos, la forma de la distribución (si es aproximadamente simétrica o asimétrica), el número de picos o modas que tienen la distribución y la existencia de valores atípicos. De todas ellas, la función principal es conocer la forma de la distribución de la variable.

Un histograma es la representación gráfica de la distribución de frecuencias, es decir, el número de registros correspondientes a cada categoría. Su construcción se realiza a partir de la tabla de frecuencia para datos numéricos y para ello es necesario clasificar los datos en categorías o intervalos definidos por el investigador, lo que normalmente supone una pérdida de información para las variables continuas. A la hora de establecer los intervalos es importante tener en cuenta los siguientes aspectos (Gallardo, 2000):

- Los intervalos deben ser mutuamente excluyentes y exhaustivos, es decir, cada dato solo puede formar parte de un intervalo y todos los datos tienen un intervalo al que pertenecen.

- $\quad$ Deben ser iguales.

- El número de intervalos debe permitir la interpretación simple y completa de los datos. Algunos autores recomiendan la regla práctica de considerar un número de intervalos del orden de la raíz cuadrada del número de datos disponibles. En general, la división entre 6 y 15 intervalos suele ser adecuada.

Se trata de un gráfico que representa la densidad de los valores que se incluyen entre el límite superior e inferior del intervalo. Los histogramas se pueden construir a partir de las frecuencias absolutas o de las relativas. Las primeras permiten observar tendencias de una variable en un grupo de muestras o en la población, mientras que las últimas tienen una mayor utilidad a la hora de comparar las distribuciones de dos grupos de muestras o poblaciones distintas.

\section{Diagrama de caja y bigotes}

El diagrama de caja y bigotes permite representar gráficamente un conjunto de datos numéricos basándose en medidas robustas de posición y dispersión (mediana, cuartiles y rango intercuartil) de los mismos. Estos gráficos permiten comparar distribuciones de varios conjuntos de observaciones mostrando a simple vista su mediana, cuartiles y valores atípicos que pueden presentar. Además, también permite estudiar la simetría de la distribución.

Un diagrama de este tipo consiste en una caja rectangular que puede está alineada vertical u horizontalmente. Los lados más largos de esta caja representan el rango intercuartil del conjunto de datos, que es una medida de dispersión que indica la distancia entre el primer cuartil y el tercer cuartil (Figura 5.3). Esta caja está dividida por un segmento o línea que indica la posición de la mediana y su relación con los cuartiles primero y tercero, lo que aporta información sobre la distribución que siguen los datos. Si la mediana no está en el centro, la distribución no es simétrica. Además, cabe señalar que la mediana coincide con el segundo cuartil. 
Los bigotes son las líneas que se extienden desde la caja hasta los valores máximos y mínimos del conjunto de datos o hasta 1,5 veces el rango intercuartil (límite superior e inferior). La distancia a la que se encuentran los bigotes indica la variabilidad de los datos. Cuando algún dato se encuentra fuera de 1,5 veces el rango intercuartil significa que este dato es un valor atípico. Asimismo, aquellos que encuentren más allá de 3 veces el rango intercuartil se consideraran atípico severo.

A continuación se muestra cómo es un diagrama de este tipo (Figura 5.3) y cómo se construye lo que ayuda a entender su interpretación.

En primer lugar, hay que ordenar el conjunto de datos de menor a mayor de modo que se pueda calcular la mediana, el primer cuartil $\left(Q_{1}\right)$, el tercer cuartil $\left(Q_{3}\right)$ y el rango intercuartil (IQR) para poder dibujar la caja. En segundo lugar, se calculan los límites que permiten decidir si un dato es atípico o no:

- $\quad$ Límite inferior: $Q_{1}-1,5 \cdot I Q R$

- $\quad$ Límite superior: $Q_{3}+1.5 \cdot 1 Q R$

A continuación, se dibuja una escala que cubra todos los valores del conjunto de datos, en ella se dibuja la caja marcando la posición de los cuartiles y la mediana.

Partiendo del primer cuartil se dibuja una línea (bigote) que llega hasta el último dato del conjunto que este contenido dentro del límite inferior. Partiendo del tercer cuartil, se traza otra línea que llega hasta el último dato contenido dentro del límite superior. Así pues, los últimos valores del conjunto de datos que no son atípicos marcan los extremos de los bigotes (cuando no existan valores atípicos estos extremos coincidirán con los valores máximos y mínimo del conjunto).

Por último, se marca la posición de los valores atípicos, diferenciando los atípicos severos (fuera del rango de 3 veces el IQR).

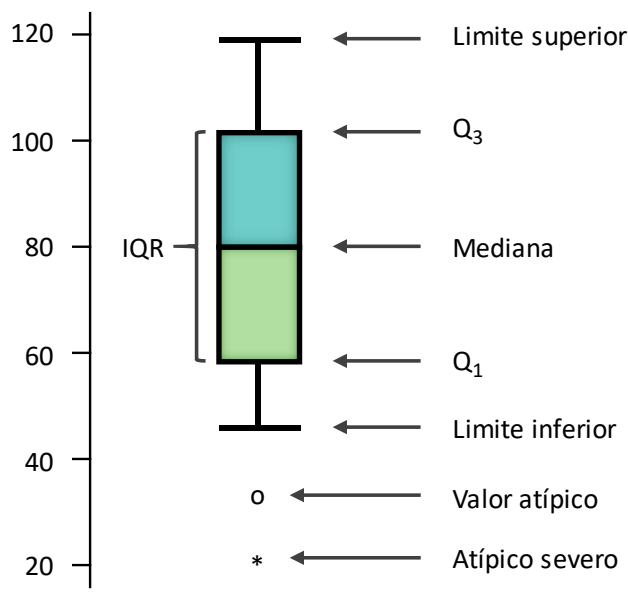

Figura 5.3 Diagrama de caja y bigotes

\subsubsection{Medidas resúmenes}

Las medidas resúmenes o resúmenes numéricos es una forma de resumir la información reduciéndola hasta solo una o dos cifras, tratando de preservar las características esenciales del grupo de muestras o de la población. Estos valores característicos se denominan parámetros cuando se trata de un resumen de la población o estadísticos si se trata del resumen de un grupo de muestras. Solo pueden ser aplicables a variables cuantitativas y permiten comparar conjuntos de datos y presentar los resultados de un estudio de una forma sencilla. Además, son utilizados en la inferencia estadística para comprobar si las diferencias existentes entre los valores característicos de distintos conjuntos de datos son significativas o se deben al azar.

En la actualidad existen programas informáticos de estadística que permiten calcular estos resúmenes numéricos fácilmente. Como se ha comentado anteriormente, en la presente tesis se ha utilizado el programa de acceso libre $\mathrm{R}$ y su paquete $\mathrm{R}$ Commander para el análisis estadístico de los datos. 
Las medidas resúmenes se pueden clasificar en tres grupos principales: medidas de posición, de dispersión y de forma. Además, dentro de las medidas de posición, se pueden diferenciar dos tipos diferentes: las medidas de tendencia central y las medidas de posición no central. Estos grupos, junto con las medidas resúmenes más importantes que se incluyen en los mismos, se definen a continuación.

\section{Medidas de posición central o tendencia central}

Las medidas de posición central indican el valor central alrededor del cual se distribuyen los datos e informan sobre el orden de magnitud de los mismos mediante un valor "típico" del conjunto. Las medidas de posición central más relevantes son la media aritmética o promedio, la mediana y la moda.

La media aritmética $(\mu \circ \bar{x})$ es la medida de posición más ampliamente utilizada en variables numéricas debido a sus propiedades matemáticas y a su vinculación con la distribución Normal.

La mediana (Me) puede utilizarse también para variables ordinales. Es una medida de posición robusta y no se ve afectada por valores atípicos, por lo que es importante cuando la distribución del conjunto de datos no es Normal.

La moda (Mo) es útil para conocer el valor más frecuente y puede utilizarse con variables nominales y ordinales.

Cuando los datos siguen una distribución aproximadamente simétrica (por ejemplo, una distribución Normal), la media aritmética y la mediana tienen valores similares. Por lo que ambos podrían utilizarse como medida de tendencia central, aunque es preferible utilizar la media ya que tiene un menor error de estimación respecto a la media poblacional.

Sin embargo, la media es muy sensible a valores atípicos y a distribuciones asimétricas o que sean distintas de la Normal, dejando de ser representativa del conjunto de datos. En estos casos debe utilizarse la mediana como medida de tendencia central, ya que así la estimación obtenida a partir de un grupo de muestras será más parecida al parámetro de la población.

Así pues, cuando la distribución de los datos no es simétrica, la media y la mediana difieren de la siguiente manera: si la distribución de los datos tiene una asimetría positiva (cola larga a la derecha) la media será mayor que la mediana; si tiene una asimetría negativa (cola larga a la izquierda) la media será menor a la mediana (Figura 5.4).
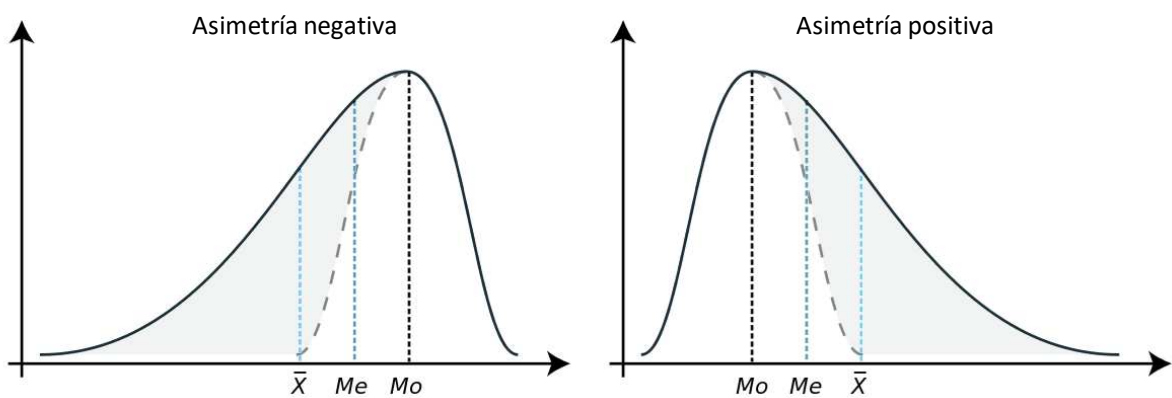

Figura 5.4 Posición de las medias de tendencia central en distribuciones asimétricas

\section{Medidas de posición no central}

Este tipo de medidas son otra forma de resumir la distribución de los datos, pero en este caso indican valores de posición distintos al central. Las medidas de posición no central más utilizadas son los cuartiles y los percentiles.

La mediana corresponde al percentil $50 \%\left(P_{50}\right)$ y al segundo cuartil $\left(Q_{2}\right)$. Otros percentiles importantes son el percentil $25 \%\left(P_{25}\right)$ y el $75 \%\left(P_{75}\right)$ que coinciden con el primer $\left(Q_{1}\right)$ y tercer cuartil $\left(Q_{3}\right)$ respectivamente. En este sentido, una forma de resumir toda la distribución del conjunto de datos es utilizando estas cinco medidas resúmenes: mínimo, primer cuartil, mediana, tercer cuartil y máximo. 


\section{Medidas de dispersión}

Las medidas de dispersión cuantifican la variabilidad o heterogeneidad de los datos. Estas aportan información de cómo se distribuyen los datos alrededor del valor central, es decir, de cómo de cerca se encuentran los datos entre ellos o de cómo de parecidos o diferentes son los datos obtenidos entre sí. Algunas medidas de dispersión para variables numéricas son el rango, el rango intercuartil, la desviación estándar, la varianza y el coeficiente de variación.

El rango considera solo los valores extremos (máximo y mínimo) por lo que es una medida sencilla de obtener. No obstante, es muy sensible a los valores atípicos y aporta muy poca información sobre las características del conjunto de datos.

El rango intercuartil o distancia intercuartil (IQR) corresponde a la distancia entre el primer y tercer cuartil, por lo que indica dónde se encuentran aproximadamente el $50 \%$ central de las observaciones. Esta medida de dispersión es muy robusta y no se ve afectada por los valores atípicos.

La desviación estándar $\left(\begin{array}{llll}\sigma & 0 & s\end{array}\right)$ y la varianza $\left(\sigma^{2} \quad a^{2}\right)$ son las medias de dispersión más utilizadas y representan la desviación de los resultados respecto a la media. La varianza tiene la limitación de que sus unidades están al cuadrado y por tanto no son las mismas que las de los datos, lo que no es interpretable en la práctica. Para evitarlo se usa la desviación estándar que se define como la raíz cuadrada de la varianza. Cabe señalar que la desviación estándar es muy sensible a la presencia de valores atípicos.

EL coeficiente de variación (CV) mide la dispersión de los datos de manera relativa y no dimensional, lo que permite una interpretación más objetiva y la comparación de la variabilidad de diferentes conjuntos de datos. Mediante el coeficiente de variación se puede conocer la homogeneidad de los datos: valores menores al 5\% indican una gran homogeneidad (menor dispersión y mayor representatividad), alrededor del $20 \%$ indican una homogeneidad moderada y por encima del $50 \%$ indican una gran heterogeneidad (pudiendo alcanzar valores superiores al 100\%).

\section{Medidas de forma}

Las medidas de forma permiten identificar y describir la forma en la que se reúnen los datos de acuerdo a su distribución de frecuencias, sin necesidad de construir un gráfico. Además, esto permite clasificarlos en un tipo concreto de distribución, lo que definirá las técnicas o pruebas a utilizar en el análisis estadístico de los mismos.

Para ello se analizan dos características de la distribución: la asimetría y la curtosis o apuntamiento. Los resúmenes numéricos que se utilizan son los coeficientes de asimetría (coeficiente de Pearson y coeficiente de asimetría de Fisher) y los coeficientes de apuntamiento (coeficiente de curtosis de Fisher).

La asimetría permite identificar si los datos se distribuyen de manera uniforme alrededor de la medida de posición central de la distribución (media aritmética), presentando las siguientes formas:

- Asimetría negativa o a la izquierda: la distribución presenta una menor cantidad de datos en la parte izquierda de la media, presentando un alargamiento o sesgo hacia la izquierda (cola larga). El valor de la media es menor al de la mediana y este a su vez es menor que la moda (Figura 5.4).

- Simétrica: la distribución presenta aproximadamente la misma cantidad de datos en los dos lados de la media. No tiene alargamiento y se representa por una curva Normal en forma de campana de Gauss. La media, la mediana y la moda son iguales.

- $\quad$ Asimetría positiva o a la derecha: la distribución presenta una menor cantidad de datos en la parte derecha de la media, presentando un alargamiento a la derecha. El valor de la media es mayor a la mediana y esta es mayor que la moda (Figura 5.4).

La curtosis o apuntamiento mide cómo de puntiaguda o achatada en una distribución en comparación con la distribución Normal, indicando cómo de concentrados están los datos en la región central de la distribución. Las formas que pueden presentarse son:

- $\quad$ Leptocúrtica: La distribución es puntiaguda, lo que indica una elevada concentración de datos. 
- $\quad$ Mesocúrtica: La concentración de datos es Normal.

- $\quad$ Planicúrta: La distribución es achatada, lo que indica una baja concentración de datos en el centro.

\subsubsection{Distribución de probabilidad}

La distribución de probabilidad describe las diferentes frecuencias relativas con las que aparecen los distintos valores de una población. Conocer la distribución de probabilidad de la población o del grupo de muestras es importante a la hora de realizar un estudio de campo o experimentación, ya que ayudará a que los resultados obtenidos sean fiables y define las técnicas a utilizar en la inferencia estadística para el análisis de los datos obtenidos. A continuación, se describen las distribuciones más importantes en el campo de los residuos.

\subsubsection{Distribución Normal}

La distribución Normal es la distribución de probabilidad más ampliamente utilizada en estadística, puesto que es la que aparece con más frecuencia en el comportamiento de los fenómenos reales, existiendo una gran cantidad de variables continuas que tienen esta distribución. Se caracteriza por su forma simétrica de campana de Gauss y se define por dos parámetros: la media (centro de la distribución) y la desviación típica (grado de dispersión). En una distribución Normal, el valor de la media, la mediana y la moda es el mismo.

Además, es una de las distribuciones más importantes, ya que la mayoría de los procedimientos de la inferencia estadística se basan en que las muestras han sido tomadas de una población Normal, es decir, requieren que el conjunto de datos se distribuya Normalmente.

Una propiedad característica de las poblaciones Normalmente distribuidas es que aproximadamente el $68 \%$ de sus valores se encuentran dentro del intervalo de \pm una desviación estándar de la media, entorno al 95\% caen dentro del intervalo de \pm dos desviaciones estándar y entorno al 99,7\% en el intervalo de \pm tres desviaciones estándar (Figura 5.5). Esto es una de sus principales ventajas puesto que, si a la media de una población Normal se le suma dos veces la desviación por un lado y se le resta dos desviaciones por otro, el $95 \%$ de los valores se encontrarán en el rango obtenido.

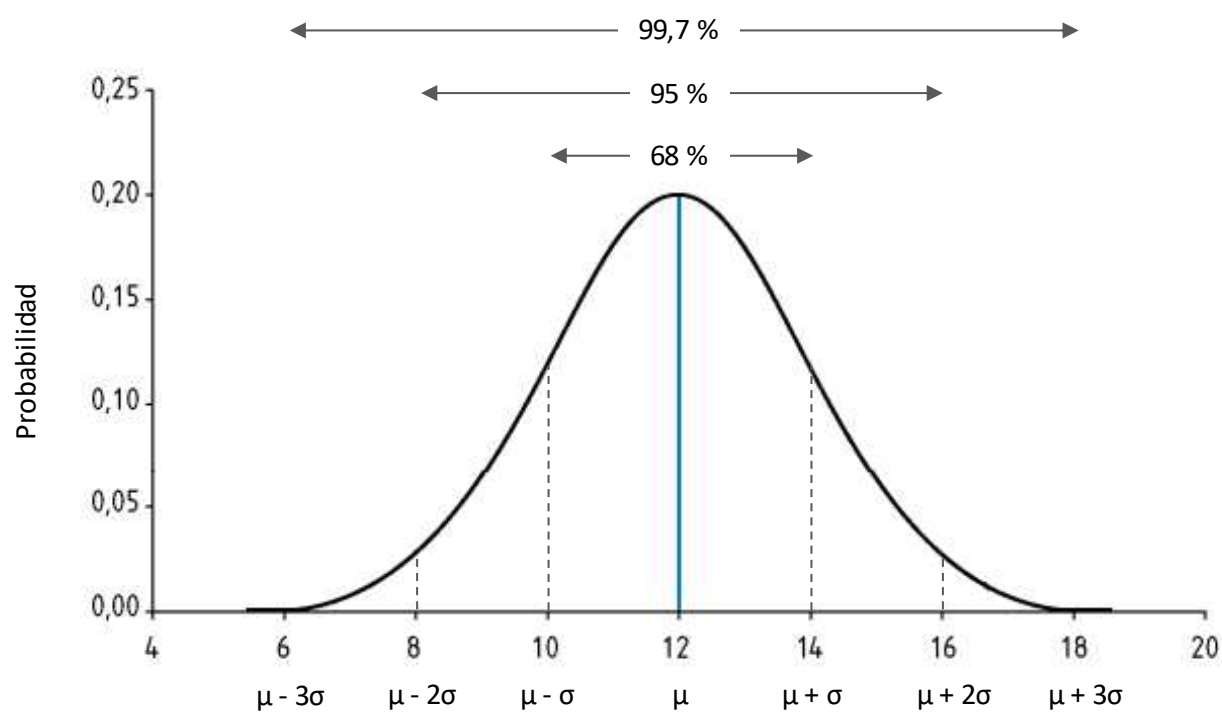

Figura 5.5 Distribución Normal de una población con media $(\mu)$ de 12 y deviación estándar $(\sigma)$ de 2

No obstante, los datos sobre composición de residuos tienen una distribución asimétrica positiva y solo siguen una distribución aproximadamente Normal con un número de muestras elevado (superior a 40) (Klee, 1993). Además, en los análisis ambientales en general, así como de las propiedades químicas de los residuos, habitualmente se observan también distribuciones de datos con una asimetría positiva debido a 
que no es posible obtener valores por debajo de un determinado umbral o valor límite (Edjabou et al., 2015; Flamme and Geiping, 2012). Por ejemplo, las concentraciones u otras características relacionadas con los residuos nunca pueden ser inferiores a cero, pero pueden aparecer cantidades ocasionalmente más altas de lo normal.

Para conocer si un conjunto de datos de una muestra sigue una distribución Normal existen técnicas estadísticas conocidas como pruebas de bondad de ajuste, las cuales están incluidas en los programas informáticos de estadística. Además, la representación gráfica de los datos mediante un histograma puede aportar una buena aproximación sobre la forma de la distribución.

\subsubsection{Distribución logaritmo-Normal}

Este tipo de distribución se caracteriza por tener una asimetría positiva o hacia la derecha, que como se ha visto es típica de los datos ambientales o de residuos. Es una aproximación de conveniencia, por lo que no siempre reflejará las asimetrías extremas que pueden darse en algunos tipos de datos, aunque generalmente proporciona una asunción aceptable.

En la Figura 5.6 se muestra un ejemplo de este tipo de distribución con una media de 3 y una desviación estándar de 2,4, en ella se pueden ver las implicaciones que supone la asimetría positiva. Por un lado, se observa que la media deja de ser representativa del conjunto de datos como medida de tendencia central, siendo más representativa la mediana. Por otro, se observa que más del $90 \%$ de la población se encuentra por debajo de $6\left(\mathrm{P}_{90}\right)$, mientras que para obtener el $99 \%\left(\mathrm{P}_{99}\right)$ de la población este valor se duplica a 12, esto es debido al alargamiento a la derecha que presenta la distribución.

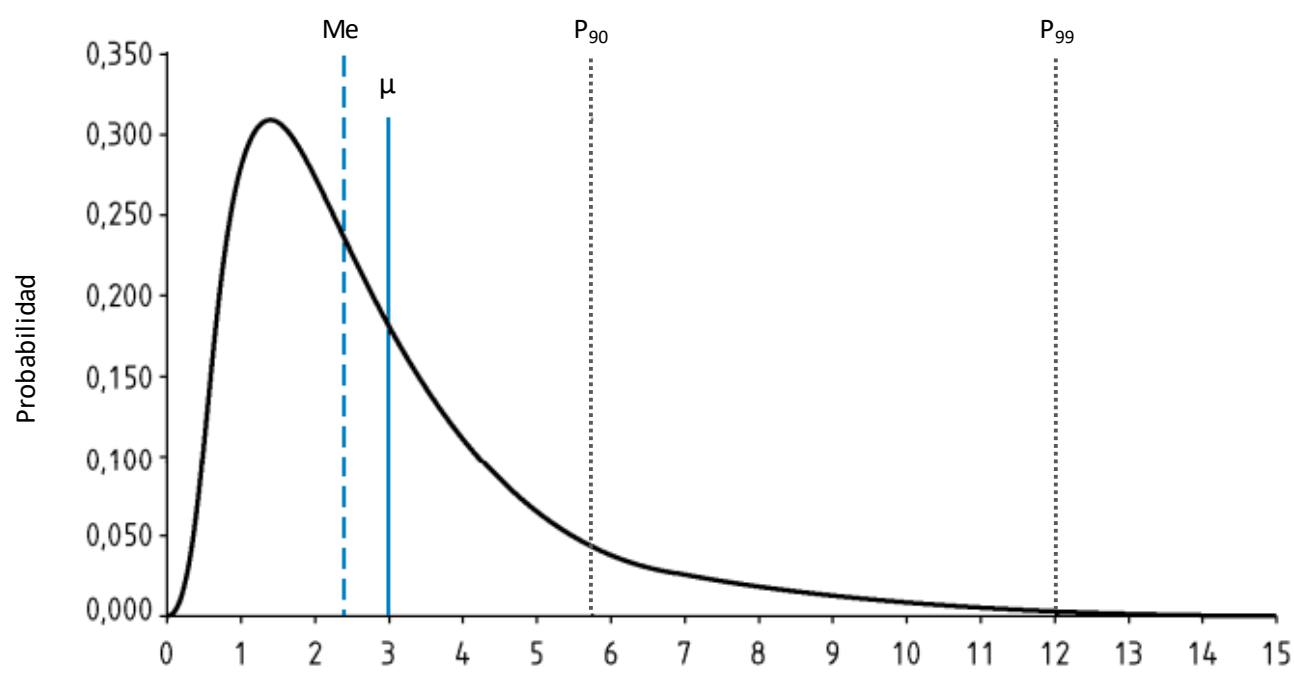

Figura 5.6 Distribución logaritmo-Norma de una población media $(\mu)$ de 3 y deviación estándar $(\sigma)$ de 2,4

No obstante, que los datos de residuos sigan esta distribución tiene una ventaja práctica, puesto que se pueden utilizar una serie de trasformaciones matemáticas (habitualmente logarítmicas) de forma que, tras su aplicación, los datos presentarán una distribución aproximadamente Normal, haciendo más sencillo su análisis estadístico.

\subsubsection{Transformación de las variables}

En estadística, la transformación de una variable puede solucionar problemas de asimetría, heterogeneidad de varianzas, no-linealidad o presencia de valores atípicos. Esto facilita su análisis puesto que permite utilizar técnicas estadísticas que se basan en que los datos siguen una distribución Normal. Así pues, los objetivos que se persiguen con esta transformación son cuatro:

- Hacer que la distribución de la variable se aproxime a una distribución Normal. 
- Reducir cualquier relación que pueda existir entre la media y la varianza (minimizando la heterogeneidad de varianza).

- Reducir la influencia de los valores atípicos.

- Hacer más lineal la relación entre variables mejorando los análisis de regresión.

Las transformaciones matemáticas que recomienda la estadística son diferentes en función del tipo de datos que se quieran transformar, las cuales se exponen a continuación. Estas transformaciones son funciones matemáticas que se aplicarán a todas las observaciones o datos de una variable.

- Transformación logarítmica: consiste en remplazar el valor de cada observación por su logaritmo. Para variables que presentan valores iguales a cero se debe sumar una constante a todas las observaciones y luego hacer la transformación. Es útil para datos de medida como tasas, concentraciones o relaciones.

- Transformación de raíz (potencia): consiste en sustituir el valor de cada observación por su raíz (cuadrada, cubica, etc.). Para variables que presentan valores iguales a cero se debe sumar una constante a todas las observaciones y luego hacer la transformación. Son útiles para conjuntos de datos de conteo que siguen una distribución de Poisson.

- Transformación arcoseno (angular): consiste en remplazar el valor de cado observación por el arcoseno de la raíz cuadrada del valor. Se usa para proporciones y porcentajes, si los datos son porcentajes primero deben convertirse en proporciones (dividirlos de 100).

- Transformación recíproca: consiste en sustituir cada observación por su reciproco. Es útil para variables que son tasas.

Así pues, las funciones matemáticas anteriores permiten transformar los datos en "Normales" cuando su distribución no es Normal, por ejemplo, si tienen una asimetría positiva moderada. No obstante, en el caso de que la desviación respecto a la distribución Normal sea muy grande (por ejemplo, tenga una asimetría extrema o en forma de J) no será posible hacer que los datos mejoren su distribución. Por lo que, siempre que se lleve a cabo una transformación de una variable, hay que comprobar que la distribución de la variable transformada ha cambiado y sigue aproximadamente una distribución Normal.

Respecto al caso de la composición física de los RSU, Klee (1993) y Edjabou et al. (2015) recomiendan llevar a cabo una transformación de datos antes de su análisis estadístico, ya que tienen una asimetría positiva. Esta asimetría es consecuencia de que los datos de composición expresados en porcentajes son un conjunto de datos cerrado, puesto que las proporciones en las que se encuentran las fracciones individuales siempre van a ser positivas y suman una constante de 100\% (Filzmoser and Hron, 2008).

En cuando a los parámetros que definen la calidad de los CSR, Flamme and Geiping (2012) descubrieron que al evaluar conjuntos de datos sobre el contenido en metales de los CSR, la mayoría de los resultados se encontraban en áreas de concentraciones bajas y de ahí se dispersaban unidireccionalmente hacia zonas de concentración más altas. Como resultado se obtenía una distribución de los datos logaritmo-Normal o con asimetría positiva. Esto es debido a que no es posible obtener datos por debajo de un determinado valor umbral, el cual coincide con el límite de detección del equipo. Respecto a los datos de poder calorífico y contenido en cloro, estos autores indican que generalmente presentan una distribución Normal cuando el número de observaciones es elevado. No obstante, cuando se determina la calidad de los CSR, la evaluación se basa generalmente en un pequeño conjunto de datos y, como consecuencia, los valores no suelen estar distribuidos Normalmente.

Así pues, en la presente tesis, se ha llevado a cabo la transformación de los datos a la hora de realizar los diferentes análisis estadísticos cuando los datos no siguen una distribución Normal. Esta transformación tiene como objetivo mejorar su distribución y transformarla en Normal, facilitando la aplicación de las diferentes técnicas de inferencia estadísticas. En el caso del análisis de la composición física y el contenido en cloro, debido a que los datos son porcentajes, se ha optado por la transformación arcoseno. Mientras que en el caso del $\mathrm{PCl}$ y el contenido en mercurio, debido a que se tratan de tasas y concentraciones, se ha utilizado la transformación logarítmica. 


\subsubsection{Inferencia estadística}

En la mayoría de las investigaciones resulta imposible estudiar una población o universo en su totalidad debido a que supondría un gran esfuerzo o a que no se puede acceder a todos los elementos que la forman. Por lo que, habitualmente, los estudios se realizan sobre un conjunto reducido de elementos o casos (muestras) y, mediante la inferencia, se establecen conclusiones sobre la población. Esto conlleva que solo una parte de la población es analizada y, por tanto, siempre existirá la posibilidad de cometer errores, teniéndose que asumir ese riesgo a la hora de tomar una decisión.

La inferencia estadística (o estadística analítica) es la parte de la estadística que incluye los métodos y procedimientos adecuados para que un investigador pueda deducir características y extraer conclusiones de una población a partir de los datos obtenidos de un grupo de muestras, las cuales debe ser seleccionadas de forma aleatoria. Para ello se utilizan estimaciones de parámetros y contrastes de hipótesis estadísticas, ambas técnicas siempre tendrán asociada una probabilidad de error o incertidumbre.

\subsubsection{Estimación de parámetros}

Como se ha explicado anteriormente, en estadística, un parámetro representa un valor característico de la población y es constante. El valor real de un parámetro solo se puede obtener a través de la observación de todos los elementos de la población, lo que en muchos casos es imposible o demasiado costoso. Como consecuencia, la única forma de poder hacer una estimación de un parámetro es a través de las muestras, obteniendo así un valor muestral o estadígrafo que será similar al valor del parámetro poblacional. La estimación de los parámetros se puede realizar de dos formas diferentes:

- Estimaciones puntuales: este tipo de estimaciones son las que proporcionan estadígrafos como la media, la mediana o la varianza, en la que simplemente atribuimos al parámetro poblacional el valor del estadígrafo correspondiente al grupo de muestras. Un problema de este tipo de estimación es que el valor del grupo de muestras difícilmente coincidirá con el parámetro poblacional. Por lo que, en la práctica no interesa solamente dar una estimación puntual, sino, además, dar un margen de error, el cual se puede definir como el intervalo en el que se espera encontrar el valor del parámetro.

- Estimación por intervalos de confianza: los intervalos de confianza se basan en añadir a un estimador puntual un margen de error teniendo en cuenta su distribución de probabilidad. Los intervalos establecen un rango de valores dentro del cual se encontraría el verdadero valor del parámetro con una cierta probabilidad o nivel de confianza. El nivel de confianza expresa la certeza de que el valor real está dentro del margen de error, es decir, del intervalo; se denota por 1- $\alpha$, donde $\alpha$ es el nivel de significación. Cabe señalar que contra mayor sea el nivel de confianza mayor será la amplitud del intervalo y, por tanto, la estimación será menos precisa (es decir, contra más estrecho es el intervalo de confianza más precisa es la estimación). Los valores más habituales para el nivel de confianza son 0,9, 0,95 o 0,99. Además, para utilizar los intervalos de confianza correctamente, es necesario que los datos (o los datos transformados) sigan una distribución Normal, aunque si el número de observaciones es muy grande también se puede usar de manera aproximada en poblaciones no Normales.

\subsubsection{Contraste de hipótesis}

Los contrastes de hipótesis engloban un conjunto de métodos o técnicas que pueden utilizarse con diferentes finalidades:

- Contrastes para un grupo de muestras: permiten ver si un parámetro toma un determinado valor de interés.

- Contrastes para dos o más grupos de muestras: permiten hacer comparaciones entre grupos de muestras para comparar si sus medias o varianzas son iguales (comparación de medias y varianzas respectivamente). Además, este enfoque es muy importante en el análisis de datos experimentales ya que permite conocer si las diferencias entre varios grupos son reales (es decir, no han aparecido como fruto del azar) y por tanto pertenecen a poblaciones distintas o si, por el contrario, las 
diferencias son tan pequeñas que se deben al azar y por tanto los grupos de muestras pertenecen a la misma población y son iguales.

- Contrastes de bondad de ajuste: permiten comprobar si un conjunto de datos sigue una distribución de probabilidad determinada.

Dentro de los contrastes de hipótesis, la hipótesis estadística es una proposición o enunciado acerca de una característica de la población que necesita ser probada. Esta nunca podrá ser aceptada de forma rotunda, ya que siempre existirá un cierto nivel de incertidumbre.

Un contraste de hipótesis es una regla de decisión que consta de dos hipótesis, la denominada hipótesis nula $\left(\mathrm{H}_{0}\right)$ y la hipótesis alternativa $\left(\mathrm{H}_{1}\right)$. La hipótesis nula es la hipótesis conservadora que representa lo conocido y se mantiene si no se demuestra lo contrario. La hipótesis alternativa representa un cambio, lo que se quiere probar o demostrar (usando una analogía, en un juicio la hipótesis nula sería ser inocente y la alternativa ser culpable, lo que se debe probar). A partir del contraste de hipótesis se pueden tomar dos decisiones:

- Aceptar $\mathrm{H}_{0}$ : esto ocurre cuando la información muestral no aporta las evidencias suficientes para poder rechazarla y decir que no se cumple.

- $\quad$ Rechazar la $H_{0}$ : ocurre cuando la información muestral aporta evidencias de que se debe aceptar la hipótesis alternativa, aunque siempre con una mínima incertidumbre o probabilidad de error.

En un contraste de hipótesis se pueden cometer dos tipos de errores:

- $\quad$ Error de tipo l: es el error cometido al rechazar la hipótesis nula cuando es cierta.

- $\quad$ Error de tipo II: es el error cometido al aceptar la hipótesis nula cuando es falsa.

De los dos tipos de error el tipo I es el más importante y el que provoca consecuencias más graves. El nivel de significación $(\alpha)$ es la probabilidad de cometer un error de tipo I, por lo que, siempre será un dato prefijado por el investigador a la hora de hacer un contraste y debe ser pequeño (normalmente $\alpha=0,1$, 0,05 o 0,01). Además, el resultado de los contrastes de hipótesis depende del nivel de significación al que se realice.

Los contrastes de hipótesis son una de las técnicas más utilizadas en el análisis de datos experimentales y las distintas técnicas o pruebas de significación que engloban pueden clasificarse en:

- Pruebas paramétricas: se llevan a cabo cuando los datos (o los datos transformados) siguen una distribución determinada, habitualmente la Normal; o cuando el número de observaciones es tan grande que la distribución se aproxima a la Normal.

- Pruebas no paramétricas: son independientes de la distribución de probabilidades que sigan los datos y no se ven afectadas por la misma, por lo que se utilizan cuando los datos no siguen una distribución Normal o el número de observaciones es muy pequeño.

- $\quad$ Test de bondad de ajuste: se utilizan para conocer si un conjunto de datos sigue una distribución determinada, por ejemplo, la Normal. Ayudan a decidir qué tipo de pruebas de significación son de aplicación al conjunto de datos.

Todas estas pruebas tienen asociado un nivel significación ( $\alpha$ ) que indica la probabilidad de cometer un error de tipo I, es decir, de que la decisión de rechazar la hipótesis nula sea incorrecta. De este se puede deducir el nivel de confianza (1- $\alpha$ ) que indica la probabilidad de que la decisión de rechazar la hipótesis nula $y$, por tanto, aceptar la alternativa sea correcta.

De entre los diferentes test estadísticos existentes, las comparaciones de medias y varianzas son dos tipos de prueba de significación muy utilizados en el análisis de datos experimentales en el ámbito de los RSU. Estos permiten conocer si las diferencias entre dos o más grupos de muestras son reales, es decir, no han aparecido como fruto del azar y por tanto pertenecen a poblaciones distintas; o si, por el contrario, se admite que las diferencias son tan pequeñas que sean fruto del azar y por tanto los grupos pertenecen a la misma población y son iguales. 
Así pues, las comparaciones de medias y varianzas se basan en estimar la probabilidad de obtener unas diferencias como las calculadas a partir de las muestras, bajo el supuesto de que estas han sido sacadas de la misma población. Si la probabilidad de obtener diferencias como las calculadas es muy pequeña, se acepta que las muestras corresponden a poblaciones distintas y que, además, estas diferencias son significativas (Gallardo, 2000). En este tipo de test la hipótesis nula es la que indica la no existencia de diferencias, mientras que la hipótesis alternativa es la que afirma que existen diferencias entre los grupos de muestras.

Por otro lado, a la hora de rechazar o aceptar la hipótesis nula, en los test estadísticos para el contraste de hipótesis se suele utilizar el valor crítico o p-valor, puesto que muchos programas informáticos dan este valor como salida. El p-valor se define como el nivel de significación mínimo a partir del cual Ho se puede rechazar (es decir, el valor límite para que un contraste sea significativo). Si el p-valor es menor que el nivel de significación elegido se rechaza $\mathrm{H}_{0}$. Así pues, el investigador decide si rechaza o acepta $\mathrm{H}_{0}$ en función del p-valor obtenido y el nivel de significación escogido. A nivel conceptual este valor hace referencia a la probabilidad de obtener por azar una diferencia tan grande o mayor de la observada, es decir, a la probabilidad de que las diferencias que existen sean debidas al azar.

En la actualidad existen programas informáticos de estadística que permiten aplicar los diferentes test o pruebas de forma sencilla. Como se ha comentado anteriormente, en la presente tesis se ha utilizado el programa de acceso libre $\mathrm{R}$ y su paquete $\mathrm{R}$ Commander para el análisis estadístico de los datos.

En los siguientes apartados se van a exponer, en primer lugar, los test de bondad de ajuste utilizados en la presente tesis, los cuales han permitido conocer si la distribución del conjunto de datos es Normal y, de este modo, elegir entre utilizar una prueba paramétrica o no paramétrica.

En segundo lugar, se muestran los test estadísticos para el contraste de hipótesis más utilizadas para variables numéricas en el campo de los residuos. En concreto los test utilizados para la comparación de dos o más de dos grupos de muestras, tanto paramétricas como no paramétricas.

\subsubsection{Test de bondad de ajuste}

Los test de bondad de ajuste comparan toda la distribución de probabilidad de la población y sirven para contrastar si la población que se está analizando sigue alguno de los modelos de probabilidad: Normal, Poisson, etc. Para ello comparan las frecuencias observadas en los grupos de muestras con las frecuencias teóricas de la distribución de probabilidad contrastada. La hipótesis nula indica que los valores siguen una determinada distribución y la hipótesis alternativa que no la siguen.

En el caso del análisis estadístico de datos numéricos en el campo de los residuos, lo más habitual es querer contrastar la distribución de probabilidad Normal para decidir si se utiliza posteriormente una prueba paramétrica o no paramétrica. Los test más utilizados para ello son:

- Test de Kolmogorov-Smirnov

- $\quad$ Test de Shapiro-Wilk

En ambos test, si el p-valor asociado al estadístico de contraste es menor al nivel de significación ( $\alpha$ ), se rechaza la hipótesis nula, por lo que se puede afirmar a cierto nivel de confianza (1- $\alpha$ ) que los datos de las muestras no sigue la distribución Normal.

\subsubsection{Test paramétricos para el contraste de hipótesis}

Los test paramétricos asumen que los datos siguen una determinada distribución de probabilidad, habitualmente una distribución Normal. Por lo que deben cumplirse algunas condiciones o supuestos para que el resultado tras su aplicación sea fiable.

En el caso de la presente tesis, estos test se utilizarán cuando los datos o los datos transformados sigan una distribución Normal, o cuando el número de observaciones es tan elevado que la distribución se aproxima a la Normal. 


\section{Test t: Comparación de medias de dos grupos de muestras}

A la hora de llevar a cabo la comparación de medias de dos grupos de muestras independientes, una de las pruebas más utilizadas es el test t de Student. La cual permite comprobar si las medias de los dos grupos son iguales, por lo que pertenecen a la misma población, o si por el contrario pertenecen a dos poblaciones distintas.

Para poder utilizar el test t de Student y obtener unos resultados fiables deben cumplirse dos supuestos, los cuales se deben comprobar antes de su aplicación:

- $\quad$ Supuesto de Normalidad: los datos deben de seguir una distribución Normal.

- $\quad$ Supuesto de homogeneidad de las varianzas u homoscedasticidad: las varianzas de los dos grupos de muestras son iguales.

El supuesto de Normalidad se comprueba mediante la aplicación de un test de bondad de ajuste como los expuestos anteriormente a cada grupo de muestras, por ejemplo, el de Shapiro-Wilk. En el caso del incumplimiento de la Normalidad, no se podrá utilizar el test t de Sudent y se deberá utilizar un test no paramétrico equivalente (punto 5.4.4.5).

El supuesto de homoscedasticidad se comprueba mediante la aplicación del test F para la comparación de dos varianzas, el cual se expone a continuación. En el caso de que no se cumpla, se debe utilizar una corrección del test $\mathrm{t}$ de Student denominada test $\mathbf{t}$ de Welch. Este se aplica únicamente cuando las varianzas son diferentes pero los datos sí que siguen distribuciones Normales.

Tanto para el test $t$ de Student como para el test $t$ de Welch, la hipótesis nula indica que las dos medias son iguales y la hipótesis alternativa que existen diferencias entre ellas y, por lo tanto, pertenecen a poblaciones distintas.

Tras la aplicación del test, si el p-valor asociado al estadístico de contraste es menor al nivel de significación $(\alpha)$, se rechaza la hipótesis nula, por lo que se puede afirmar a cierto nivel de confianza (1- $\alpha)$ que los grupos de muestras pertenecen a poblaciones distintas.

\section{Test F: Comparación de varianzas de dos grupos de muestras}

El test $\mathrm{F}$ de Snedecor es una prueba utilizada para la comparación de dos varianzas que permite conocer si las varianzas de dos grupos de muestras son iguales o no, es decir, si son homogéneas o no. Este test es muy importante a la hora de comprobar el supuesto de homocedasticidad que es necesario para la utilización de numerosos test paramétricos como el test t de Student.

La hipótesis nula indica que los dos grupos de muestras tienen varianzas iguales (son homocedásticos) y la alternativa indica que las varianzas son diferentes (son heterocedásticos).

Tras la aplicación del test, si el p-valor asociado al estadístico de contraste es menor al nivel de significación $(\alpha)$, se rechaza la hipótesis nula, por lo que se puede afirmar a cierto nivel de confianza (1- $\alpha)$ que las varianzas de los dos grupos muestras no son iguales.

\section{ANOVA: Comparación de más de dos grupos de muestras}

Una de las técnicas más utilizadas para los análisis de datos experimentales es el Análisis de la Varianza o ANOVA, el cual permite comparar más de dos medias pertenecientes a varios grupos de muestras y puede verse como una extensión del Test t. Para ello usa la denominada distribución F de Snedecor.

EI ANOVA es un método muy flexible que permite construir modelos estadísticos para el análisis de los datos experimentales de más de dos grupos de muestras ( $k$ grupos de muestras), cuyos valores ha sido medido en diferentes circunstancias (por ejemplo, en diferentes lugares o periodos de tiempo, con diferentes métodos, etc.). A estas circunstancias se les denomina factores y un ANOVA puede ser de uno o varios factores. Los factores son características que se controlan del experimento y de las que se quiere conocer su influencia en la respuesta o en los resultados obtenidos mediante la comparación de medias.

Para poder utilizar esta técnica y obtener unos resultados fiables se deben de cumplir tres supuestos, de los cuales, los dos últimos se deben comprobar a posteriori: 
- Las observaciones o datos deben ser independientes (cada dato ha sido medido en una muestra distinta).

- $\quad$ Supuesto de Normalidad: Los datos deben seguir una distribución Normal, lo que se traduce en que los residuos del modelo ANOVA siguen una distribución Normal.

- Supuesto de homogeneidad de las varianzas u homoscedasticidad: misma varianza para todos los grupos de muestras.

La Normalidad de los datos y de los residuos del modelo ANOVA se pueden comprobar de dos formas: a partir del grafico Q-Q Normal de los residuos o a partir el análisis de Normalidad de los residuos stunderizados del modelo mediante un test de bondad de ajuste como el de Shapiro-Wilk. En el caso de incumplimiento de la Normalidad, no se podrá utilizar el ANOVA y, por tanto, se deberá utilizar un test no paramétrico equivalente (punto 5.4.4.5).

El supuesto de homoscedasticidad se comprueba mediante la aplicación del test de Levene para la comparación de varianzas de más de dos grupos de muestras, el cual se expone a continuación. En el caso de que no se cumpla, se debe utilizar una corrección del ANOVA denominada ANOVA de Welch. Esta se aplica únicamente en los casos en que las varianzas entre los grupos de muestras no sean homogéneas, pero los residuos del modelo ANOVA sí que siguen una distribución Normal.

Para ambas pruebas, la hipótesis nula indica que $k$ número de grupos de muestras provienen de la misma población, siendo sus medias iguales. La hipótesis alternativa indica lo contrario, que las medias son diferentes y, por tanto, pertenecen a poblaciones distintas.

Tras la aplicación del ANOVA o el ANOVA de Welch, si el p-valor asociado al estadístico de contraste es menor al nivel de significación ( $\alpha$ ), se rechaza la hipótesis nula, por lo que se puede afirmar a cierto nivel de confianza (1- $\alpha$ ) que algunos de los grupos de muestras pertenecen a poblaciones distintas.

Sin embargo, este resultado solo hace referencia a que existen diferencias entre algunos grupos de muestras, pero no da información respecto a qué grupos son diferentes. Así pues, al rechazar la hipótesis nula y aceptar la alternativa es necesario aplicar posteriormente un test post hoc. Este tipo de test permite realizar comparaciones múltiples por parejas de las medias de cada uno de los grupos, de manera que se identifica entre qué conjuntos de datos se dan esas diferencias. Uno de los test post hoc comúnmente utilizados para el ANOVA es el de Tukey.

\section{Test Levene: Comparación de varianzas de más de dos grupos de muestras}

El test de Levene es una prueba que permite compara las varianzas de más de dos grupos de muestras para comprobar su homogeneidad. Este test es muy útil a la hora de comprobar el supuesto de homocedasticidad del ANOVA y ver si la varianza de los diferentes grupos son iguales o no. Puede utilizar como estadístico central la media o la mediana. Normalmente se recomienda el uso de la mediana ya que de esta forma el test es más robusto y no se ve afectado por la falta de Normalidad de los datos.

La hipótesis nula indica que existe homogeneidad de varianzas entre los distintos grupos de muestras (varianzas iguales), mientras que la alternativa indica que las varianzas son diferentes (no homogeneidad).

Tras la aplicación del test, si el p-valor asociado al estadístico de contraste es menor al nivel de significación $(\alpha)$, se rechaza la hipótesis nula, por lo que se puede afirmar a cierto nivel de confianza (1- $\alpha)$ que las varianzas de los distintos grupos de muestras no son iguales.

\subsubsection{Test no paramétricos para el contraste de hipótesis}

En el caso de que el número de datos sea muy pequeño o que no se cumpla el supuesto de que los datos siguen una distribución Normal se pueden utilizar los test no paramétricos, los cuales son análogos a los expuestos en el punto anterior. Los test no paramétricos se denominan también de distribución libre ya que son independientes de la distribución de probabilidades que sigan los datos, por lo que no se ven afectadas por la misma.

En estos test el contraste se realiza sobre las medianas, ya que este estadígrafo es más robusto y no se ve afectado por los valores atípicos o por la no Normalidad. 


\section{Test Wilcoxon: Comparación de dos grupos de muestras}

El test de los rangos con signo de Wilcoxon (o test $U$ de Mann-Whitney) es la prueba alternativa al test $t$ de Student para dos grupos de muestras independientes. Este permite comparar la mediana de dos grupos de muestras para conocer si las diferencias que se observan son reales y no han aparecido como fruto del azar, por lo que pertenecen a poblaciones distintas; o si, por el contrario, se admite que las diferencias son tan pequeñas que son fruto del azar, por lo que pertenecen a la misma población y son iguales.

La hipótesis nula indica que las medianas son iguales y la hipótesis alternativa que existen diferencias entre ellas y, por lo tanto, pertenecen a poblaciones distintas.

Tras la aplicación del test, si el p-valor asociado al estadístico de contraste es menor al nivel de significación $(\alpha)$, se rechaza la hipótesis nula, por lo que se puede afirmar a cierto nivel de confianza (1- $\alpha$ ) que los grupos de muestras pertenecen a poblaciones distintas.

\section{Test de Kruskal-Wallis: Comparación de medianas de más dos grupos de muestras}

El test de Kruskal-Wallis es la prueba alternativa al ANOVA de un factor para la comparación de medianas de más de dos grupos de muestras ( $k$ grupos de muestras). Permiten contrastar la hipótesis nula de que $k$ grupos provienen de la misma población y sus medianas son iguales, frente a la hipótesis alternativa de que las medianas son distintas.

Tras la aplicación del test, si el p-valor asociado al estadístico de contraste es menor al nivel de significación $(\alpha)$, se rechaza la hipótesis nula, por lo que se puede afirmar a cierto nivel de confianza (1- $\alpha$ ) que algunos de los grupos de muestras pertenecen a poblaciones distintas.

No obstante, este resultado solo indica que existen diferencias entre algunos grupos de muestras, pero no da información respecto a entre qué grupos se dan las mismas. Por lo que, en el caso de rechazar la hipótesis nula y aceptar la alternativa, será necesario aplicar posteriormente un test post hoc. Este realiza comparaciones múltiples por parejas de las medianas de cada una de los grupos, de manera que se identifica entre qué conjuntos de datos se dan esas diferencias. El test post hoc asociado al test de KruskalWallis es el test de Dunn.

\subsubsection{Procedimientos estadísticos aplicados en el diseño de la metodología de control de calidad de los rechazos}

Tras la revisión de los diferentes procedimientos estadísticos aplicables a los residuos, se va a resumir brevemente los utilizados en el diseño de la metodología para el control de calidad de los rechazos. Estos procedimientos permitirán analizar y extraer conclusiones sobre los datos obtenidos en los diferentes experimentos realizados.

En primer lugar, a la hora de hacer cualquier análisis estadístico, es importante tener el mayor número de datos u observaciones posibles. No obstante, en el caso de los rechazos, conseguir un elevado número de muestras aumenta el coste del estudio, por lo que hay que llegar a un equilibrio entre este número y el esfuerzo que ello supone. Así pues, se recomienda un mínimo de 10 muestras por grupo para poder aplicar los procedimientos estadísticos paramétricos (cuando se cumplan los supuestos) y al menos 6 para hacer cualquier tipo de análisis estadístico. Cuando el número de muestras sea menor de 10 siempre deberán utilizarse métodos no paramétricos.

Respecto a los procedimientos estadísticos utilizados en el desarrollo de la metodología para el control de calidad de los rechazos, en la Figura 5.7 se muestra el resumen en forma de árbol de decisión para la comparación de dos grupos de muestras. Mientras que la iError! No se encuentra el origen de la $r$ eferencia. se expone el árbol de decisión para la comparación de $k$ grupos de muestras. En ellos se indica los pasos seguidos en el análisis de los datos experimentales cuando se tienen 10 o más datos por grupo de muestra, así como los diferentes test estadísticos necesarios para llevarlos a cabo, tanto paramétricos como no paramétricos. 


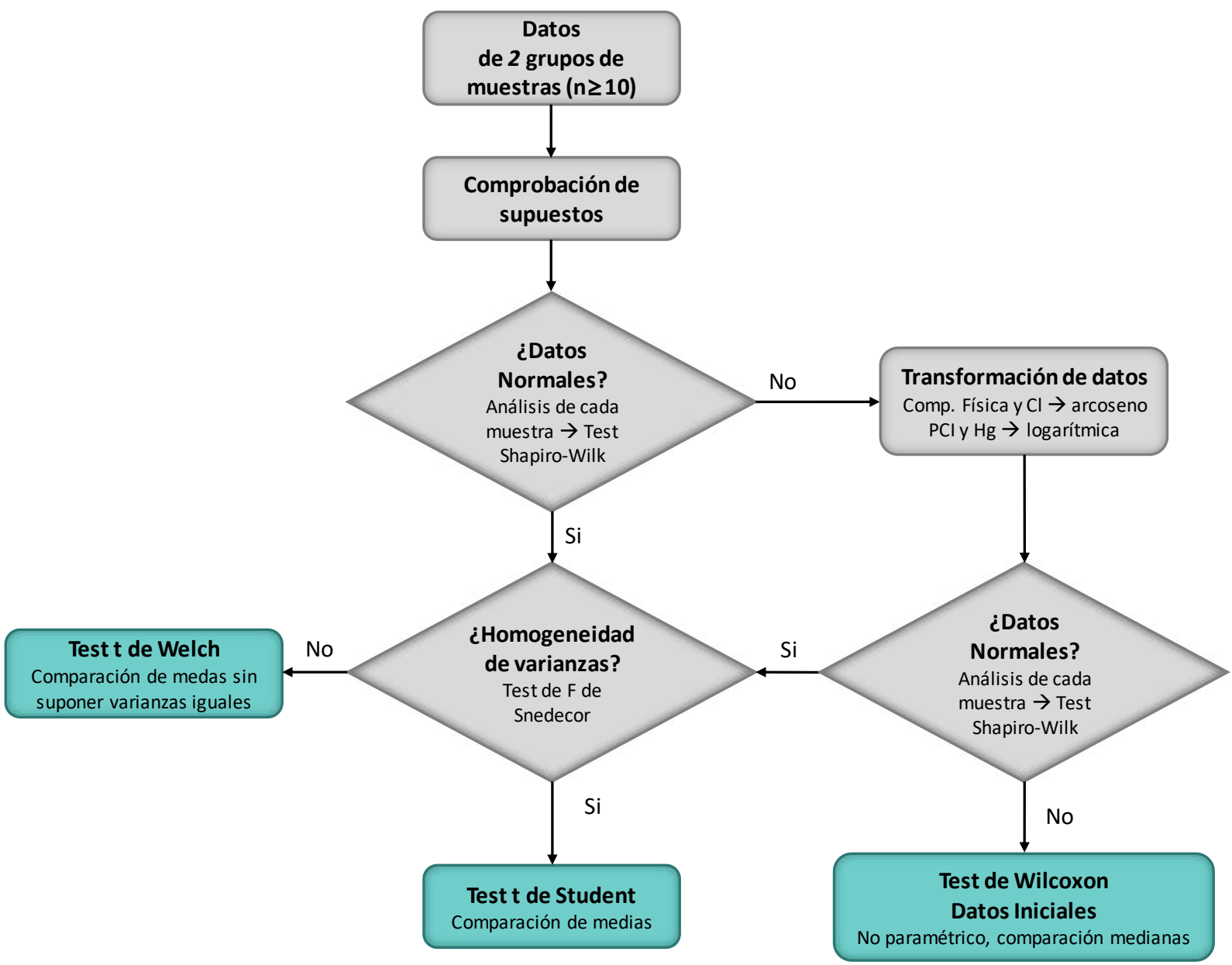

Figura 5.7 Procedimiento estadístico para la comparación de dos grupos de muestras para comprobar si pertenecen a la misma población (son iguales) cuando $\mathrm{n} \geq 10$ 


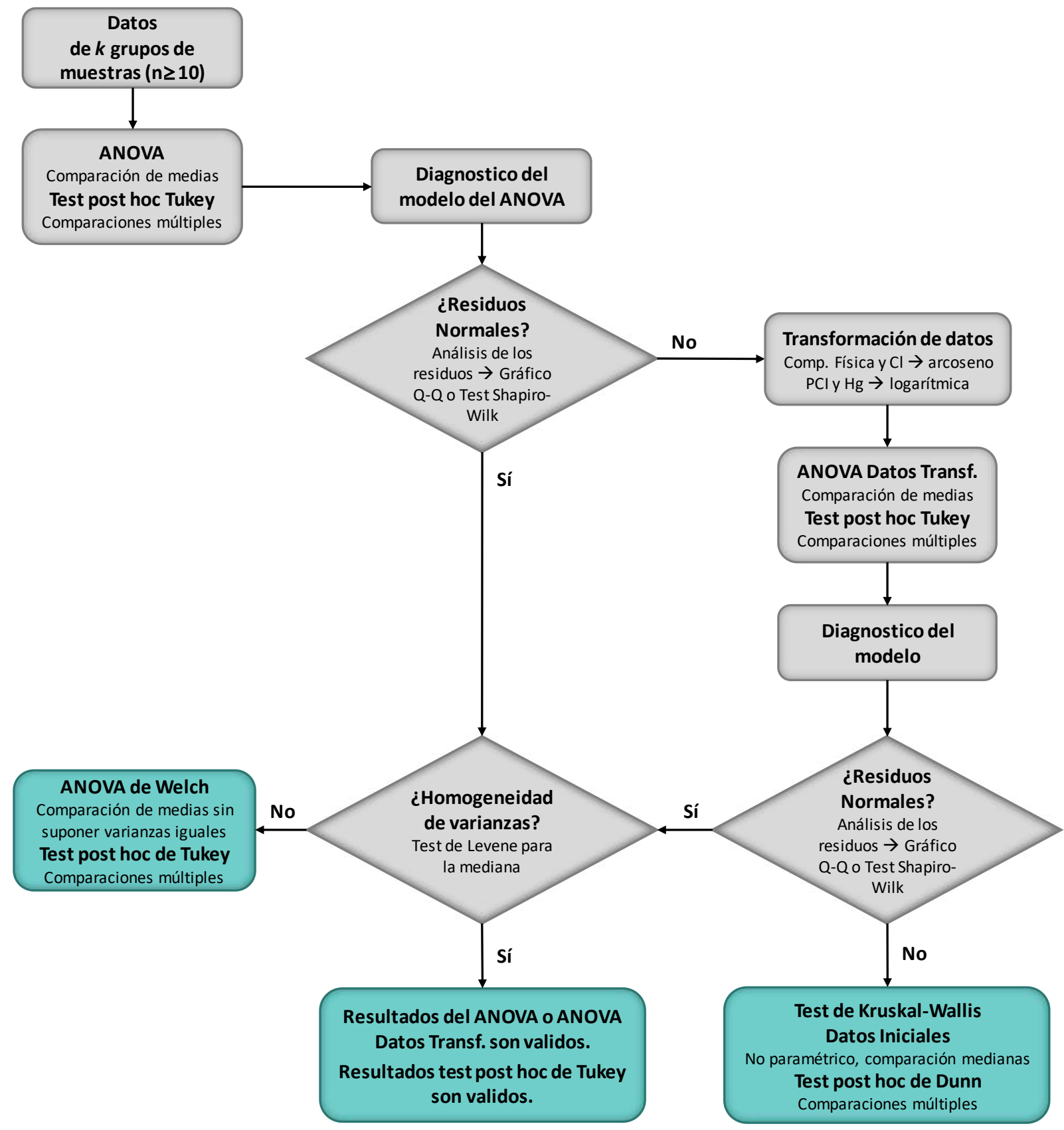

Figura 5.8 Procedimiento estadístico comparación de $k$ grupos de muestras para comprobar si pertenecen a la misma población (son iguales) cuando $n \geq 10$ 


\subsection{CONCLUSIONES}

En el presente capítulo se ha realizado una revisión sobre diferentes técnicas de muestreo estadístico y metodologías de muestreo y caracterización de RSU y CSR, así como de los procedimientos que son aplicables en el análisis estadístico de los datos experimentales de residuos y rechazos.

En estadística un muestreo es la técnica utilizada para la selección de una muestra a partir de una población, existiendo dos métodos para ello: el muestreo aleatorio probabilístico y el muestreo a juicio de experto (no probabilístico).

Dentro del muestreo aleatorio probabilístico existen tres técnicas diferentes: el muestreo aleatorio simple, el muestreo estratificado y el muestreo sistemático. De todos ellos, el muestro estratificado es muy útil en el campo de los RSU, puesto que permite analizar distintas muestras seleccionadas en varias temporadas o condiciones. Esto puede aportar información acerca de las variaciones existentes debido a la influencia de diferentes factores como estacionalidad, tipo de población, nivel de renta, etc.

El muestreo a juicio de experto también tiene una gran utilidad en el ámbito de los RSU o de los rechazos, puesto que en muchas ocasiones el muestreo de toda la población (como requieren las técnicas probabilísticas) es prácticamente imposible o los recursos no lo permiten. En estos casos, las muestran se tomarán de subpoblaciones accesibles en base a la información aportada por el experto.

Por otro lado, se han revisado un total de 26 metodologías para el muestreo y caracterización de RSU y CSR, de ellas cinco son normas, cuatro son metodologías propuestas por organismos oficiales y diecisiete son metodologías propuestas en trabajos de investigación.

Respecto a los RSU se han revisado un total de 20 normas y metodologías, de forma general se puede concluir que en la actualidad se han desarrollado una gran variedad de métodos distintos para llevar a cabo el muestreo y caracterización de estos materiales. Estos se aplican en cada región o país con diferentes criterios de muestreo y métodos para el cálculo de número y tamaño de muestras; los cuales se adaptan a las condiciones de cada caso y a la información que se quiere obtener a partir de su aplicación. Además, cabe señalar que, a nivel europeo, no se ha llegado a ningún consenso sobre el mejor método de muestreo y caracterización de RSU y no existe una metodología estandarizada; a pesar de que la Comisión Europea desarrolló su propia metodología con la colaboración de diferentes países miembros.

Para los RSU la mayoría de metodologías recomiendan la estratificación de la población a muestrear en función de una serie de factores que influyen en la variabilidad de la composición de los RSU (como los identificados en el capítulo 4). Esta estratificación permite aumentar la precisión del estudio, no obstante, un elevado número de estratos también supone un mayor coste, por lo que es necesario llegar a un equilibrio entre este número y el esfuerzo que ello supone. Algunas de las metodologías revisadas recomiendan la utilización de entre 4-5 estratos y, como mínimo, tener siempre en cuenta la estratificación por estacionalidad, realizando varios periodos de muestreo a lo largo del año. Además, con el objetivo de evitar la variabilidad que puede existir entre los días de la semana, también recomiendan que la duración de cada periodo de muestreo sea de al menos una semana.

En relación al número de muestras, algunas de las metodologías para RSU analizadas utilizan la formula proporcionada por la ASTM. Sin embargo, varios autores plantean que esta fórmula no es adecuada puesto que supone que los datos de residuos siguen una distribución Normal, cuando realmente tienen una distribución con asimetría positiva y solo se puede asumir Normalidad con un elevado número de muestras, mayor a 40 (lo que en la caracterización de RSU en muchos casos es inviable). Además, los métodos que se basan en que los datos son Normales no funcionan correctamente para componentes minoritarios con una elevada variabilidad, siendo necesario un número de muestras demasiado grande para su correcta estimación. Por otro lado, varias metodologías recomiendan realizar al menos 10 muestras, por lo que se puede tomar como regla general un mínimo de 10 muestras por periodo de muestreo. Asimismo, si se ha realizado un muestreo estratificado, también se debe tener en cuenta coger un mínimo de 6 muestras en cada estrato. 
En cuanto al tamaño de muestra, tampoco hay un consenso común entre las diferentes metodologías de RSU. Algunas utilizan adaptaciones de la ecuación de Gy para su cálculo y otras proponen diferentes pesos, los cuales van desde los $91 \mathrm{~kg}$ a $250 \mathrm{~kg}$, siendo el valor más típico el de $100 \mathrm{~kg}$. El método más utilizado para la división de muestra es la conificación y el posterior cuarteo. Mientras que las categorías en las que se clasifican manualmente los componentes de los RSU varia de 9 a 38, siendo necesaria la definición de unas categorías comunes para facilitar la comparación de estudios.

Respecto a los CSR se han revisado 2 normas de muestreo y caracterización y 4 metodologías propuestas en trabajos de investigación. Se puede observar que hay un menor número de metodologías para este tipo de materiales, esto se debe a que, a nivel europeo y desde 2011, existe una serie de estándares para el muestreo y análisis de estos combustibles.

En relación al número de muestras, tanto en las normas de los CSR como en la mayoría de trabajos de investigación, se recomienda un mínimo de 10 muestras en cada periodo de muestreo. Las cuales se tomarán de forma combinada, es decir tomando diferentes incrementos dispersos por todo el lote. En cuanto al tamaño de muestra, habitualmente se utiliza la fórmula propuesta por la norma UNE-EN 15442: 2011, la cual es una adaptación de la ecuación de Gy. En ella, debido que los CSR normalmente son sólidos fibrosos no granulares, se incluye un factor forma que corrige la no esfericidad.

Así pues, tras la revisión de las diferentes normas y metodologías existentes para el muestreo y caracterización de RSU y CSR se puede concluir que, a pesar de existir diferentes métodos, en la práctica ninguno de ellos es aplicable a los rechazos debido a la naturaleza de los mismos. Por un lado, los rechazos son un material un poco más homogéneo que los RSU mezclados. Por otro, están formados por componentes con diferentes tamaños de partícula, normalmente mayores de los que forman parte de un CSR (en especial en aquellos rechazos originados en las etapas de recuperación de materiales). Estas dos características hacen que, si se utilizaran las metodologías aplicadas a los RSU o a los CSR, en ambos casos sería necesario trabajar con cantidades muy grandes de material, lo que supondría un elevado coste económico, así como de mano de obra y tiempo invertido. Además, muchas de ellas no incluyen todas las variables identificadas en el capítulo 4.

Por último, también se ha realizado una revisión más teórica en cuanto a los procedimientos estadísticos aplicables a los residuos y rechazos. Los cuales se aplicarán en los siguientes capítulos para el diseño de la metodología de control de calidad de los rechazos.

La estadística es una de las herramientas más utilizadas en la investigación científica, así como en el análisis de datos experimentales en el área de los RSU, y tiene dos usos principales. El primero es la descripción de la información mediante la estadística descriptiva, la cual se encarga de organizar y describir un conjunto de datos para facilitar su interpretación. El segundo es la realización de inferencias mediante la inferencia estadística, la cual permite extraer conclusiones sobre la población a partir de los datos obtenidos a partir de muestras de la misma.

Dentro de la estadística descriptiva las variables se pueden clasificar en dos categorías principales, que a su vez se pueden dividir en otros dos tipos:

- Variables cualitativas o categóricas, que puede ser nominales u ordinales.

- Variables cuantitativas o numéricas, que pueden ser discretas o continuas.

Todas ellas aparecen o son utilizadas en el campo de los RSU y de los rechazos, algunos ejemplos serían: la estacionalidad (primavera, verano, otoño o invierno) y el tipo de planta de TMB (automática o manual) como variables nominales; el nivel de renta (bajo, medio, alto) y el tamaño de partícula (grande, mediano, pequeño) como ordinales; el número de corrientes de rechazos como discreta, o el $\mathrm{PCl}$ o el contenido en $\mathrm{Cl}$ como continuas.

La descripción de las características y comportamientos de estas variables se puede llevar a cabo mediante tablas, gráficos y/o medidas resúmenes. En el ámbito de los residuos los gráficos de mayor utilidad son los histogramas y los diagramas de cajas y bigotes. Respecto a las medidas resúmenes, las más útiles se exponen a continuación, clasificándolas en los diferentes tipos existentes: 
- Medidas de posición central o tendencia centras: media aritmética y mediana.

- $\quad$ Medidas de posición no central: cuartiles y percentiles.

- Medidas de dispersión: desviación estándar, varianza y coeficiente de variación.

- Medidas de forma: asimetría y curtosis.

Otra de las características clave a la hora de realizar análisis estadísticos es conocer la distribución de probabilidad de la población o de los grupos de muestras, puesto que ayuda a que los resultados obtenidos sean fiables y define las técnicas de la inferencia estadística a utilizar. En el campo de los residuos las dos distribuciones más relevantes son la Normal y la logaritmo-Normal.

La distribución Normal es una de las más importantes ya que la mayoría de los procedimientos de la inferencia estadística requieren que el conjunto de datos se distribuya Normalmente. No obstante, en los análisis ambientales en general, así como en las propiedades físico-químicas de los residuos, se observan distribuciones de datos no Normales con una asimetría positiva.

La distribución logaritmo-Normal se caracteriza por tener una asimetría positiva, típica de los datos ambientales o de residuos. Una de las ventajas de que los datos sigan esta distribución es que se les pueden aplicar una serie de transformaciones matemáticas, de forma que los valores presentarán una distribución aproximadamente Normal tras su aplicación, haciendo más fácil su análisis estadístico.

Estas transformaciones son diferentes en función del tipo de datos que se quieren transformar y se clasifican en: logarítmicas, de raíz, arcoseno o recíproca. Además, es importante resaltar que, siempre que se haga una transformación de una variable, hay que comprobar que la distribución de la variable transformada ha cambiado y sigue aproximadamente una distribución Normal.

En el caso de los RSU o los CSR, algunos autores recomiendan la transformación de los datos de composición física, $\mathrm{PCl}$, contenido en $\mathrm{Cl}$ o concentración en metales antes de su análisis estadístico. Por lo que, en la presente tesis, se ha llevado a cabo la transformación de dichos los datos a la hora de aplicar los diferentes procedimientos estadísticos cuando los datos no siguen una distribución Normal. En el caso de los análisis de la composición física y el contenido en cloro, debido a que los datos son porcentajes, se ha optado por la transformación arcoseno. Mientras que en el caso del PCl y el contenido en mercurio, debido a que se tratan de tasas y concentraciones, se ha utilizado la transformación logarítmica. Estas transformaciones facilitarán la aplicación de las diferentes técnicas de la inferencia estadística.

La inferencia estadística es la parte de la estadística que incluye las técnicas que permiten a un investigador extraer conclusiones de la población a partir de los datos obtenidos de las muestras. Para ello se utilizan estimaciones de parámetros (puntuales o por intervalos de confianza) y contrastes de hipótesis, ambas técnicas siempre tienen asociado una probabilidad de error o incertidumbre.

Los contrastes de hipótesis son muy utilizados en al análisis de datos experimentales y las distintas pruebas de significación que engloban puede clasificarse en:

- Pruebas paramétricas: requieren que los datos sigan una distribución determinada, habitualmente la Normal, o que el número de observaciones sea tan elevado que la distribución se aproxime a esta distribución.

- Pruebas no paramétricas: son utilizadas cuando el número de datos es muy pequeño o no se cumple el supuesto de que siguen una distribución Normal. Son pruebas independientes de la distribución y análogas a las paramétricas.

- Test de bondad de ajuste: se utilizan para contrastar si la población que se está analizando sigue algún tipo de modelo de distribución de probabilidad determinado (por ejemplo, la Normal). Ayudan a decidir si se aplicará a los datos una prueba paramétrica o no paramétrica.

De entre los diferentes test estadísticos, la comparación de medias y varianzas son dos tipos de pruebas de significación muy utilizados en el análisis de datos experimentales en el ámbito de los RSU y tienen un papel muy importante en los realizados en la presente tesis. Estas pruebas permiten contrastar dos o más grupos de muestras para comprobar si las diferencias que se dan entre ellos son reales, es decir, no han aparecido como fruto del azar y por tanto pertenecen a poblaciones distintas; o si, por el contrario, se admite que las 
diferencias son tan pequeñas que sean fruto del azar y, por tanto, los grupos pertenecen a la misma población y son iguales.

Finalmente, en base a la revisión de los test de bondad de ajuste y los test para la comparación de dos o más grupos de muestras (tanto paramétricas como no paramétricas) aplicables a los residuos, se ha desarrollado los procedimientos estadísticos que permitirán analizar y extraer conclusiones sobre los datos obtenidos en los diferentes experimentos realizados en el diseño de la metodología para el control de calidad de los rechazos. Estos procedimientos se han resumido en forma de árbol de decisión para facilitar su uso, los cuales se muestran en la Figura 5.7 y iError! No se encuentra el origen de la referencia.. A demás, se recomienda a la hora de realizar cualquier análisis estadístico un mínimo de 10 muestras para poder aplicar los procedimientos estadísticos paramétricos si se cumplen los supuestos. Cuando el número de muestras sea menor a 10 siempre se deberán utilizar métodos no paramétricos.

Así pues, la revisión de todas estas técnicas y métodos de muestreo y caracterización han permitido obtener los fundamentos y principios necesarios para el diseño del plan de muestreo de la metodología para el control de calidad de los rechazos. Mientras que la revisión de los procedimientos estadísticos de aplicación a los residuos y rechazos ha permitido obtener las herramientas necesarias para el análisis estadístico de los resultados obtenidos en los experimentos que se realizarán en los siguientes capítulos, de manera que se puedan extraer conclusiones a partir de los mismos.

\subsection{REFERENCIAS}

Agencia de Residuos de Cataluña, n.d. Protocol de caracterització de la FORM procedent de la recollida selectiva dels residus municipals. Generalitat de Cataluña, Dpto. de Territorio y Sostenibilidad, Barcelona, España.

ASTM D5231-92, 1992. Standard Test Method for Determination of the composition of Unprocessed Municipal solid Waste. ASTM: American Society for Testing and Materials, USA.

Burnley, S.J., Ellis, J.C., Flowerdew, R., Poll, a. J., Prosser, H., 2007. Assessing the composition of municipal solid waste in Wales. Resour. Conserv. Recycl. 49, 264-283. https://doi.org/10.1016/j.resconrec.2006.03.015

Dahlén, L., Lagerkvist, A., 2008. Methods for household waste composition studies. Waste Manag. 28, 1100-1112. https://doi.org/10.1016/j.wasman.2007.08.014

Edjabou, M.E., Jensen, M.B., Götze, R., Pivnenko, K., Petersen, C., Scheutz, C., Astrup, T.F., 2015. Municipal solid waste composition: Sampling methodology, statistical analyses, and case study evaluation. Waste Manag. 36, 12-23. https://doi.org/10.1016/j.wasman.2014.11.009

European Commision, 2004. Methodology for the Analysis of Solid Waste (SWA-Tool).

Filzmoser, P., Hron, K., 2008. Correlation Analysis for Compositional Data. Math. Geosci. 41, 905. https://doi.org/10.1007/s11004-008-9196-y

Flamme, S., Geiping, J., 2014. Quality assurance of solid recovered fuels (SRF). ZKG Int. 67, 54-57.

Flamme, S., Geiping, J., 2012. Quality standards and requirements for solid recovered fuels: a review. Waste Manag. Res. 30, 335-53. https://doi.org/10.1177/0734242X12440481

Gallardo, A., 2000. Metodología para el diseño de redes de recogida selectiva de RSU utilizando sistemas de información geográfica. Creación de una base de satos aplicable a España. Universidad Politécnica de Valencia.

Klee, A.J., 1993. New approaches to estimation of solid-waste quantity and composition. J. Environ. Eng. 119, 248-261.

Klee, A.J., 1991. PROTOCOL, a computerized solid waste quantity and composition estimation system. US EPA/600/2-91/005A. RREL, Cincinnati, Ohio, USA. 
Lebersorger, S., Schneider, F., 2011. Discussion on the methodology for determining food waste in household waste composition studies. Waste Manag. 31, 1924-1933. https://doi.org/10.1016/j.wasman.2011.05.023

Lorber, K.E., Sarc, R., Aldrian, a., 2012. Design and quality assurance for solid recovered fuel. Waste Manag. Res. 30, 370-380. https://doi.org/10.1177/0734242X12440484

Mccauley-bell, B.P., Reinhart, D.R., Member, Z., Sfeir, R., Ryan, B.O.T., 1997. MUNICIPAL SOLID WASTE COMPOSITION STUDIES 8 By Pamela McCauley-Bell,! Debra R. Reinhart,Z Member, ASCE, Rala Sfeir,3 and Brigid O'Toole Ryan 4 1, 158-163.

NT ENVIR 001, 1995. Nordtest method NT ENVIR 001. Solid waste, municipal: sampling and characterisation. Nordtest: Nordic Innovations Center, Finland.

Parfitt, J., Griffiths, P., Reid, T., 2015. Guidance on the Methodology for Waste Composition Analysis: Waste Composition Analysis For local authorities commissioning waste composition analysis of municipal waste. Zero Waste Scotland, Scotland.

Petersen, M.C., Berg, P.E.O., Rönnegård, L., 2005. Quality control of waste to incineration - Waste composition analysis in Lidköping, Sweden. Waste Manag. Res. 23, 527-533. https://doi.org/10.1177/0734242X05060710

Rotter, V.S., Lehmann, A., Marzi, T., Möhle, E., Schingnitz, D., Hoffmann, G., 2011. New techniques for the characterization of refuse-derived fuels and solid recovered fuels. Waste Manag. Res. 29, 229-236. https://doi.org/10.1177/0734242X10364210

Runfola, J.W., 2008. Análisis comparativo de los diferentes métodos de caracterización de residuos urbanos para su recolección selectiva en comunidades urbanas. Universidad Politecnica de Valencia. Dpto. de Ingeniería Hidráulica y Medio Ambiente, Valencia, España.

Sahimaa, O., Hupponen, M., Horttanainen, M., Sorvari, J., 2015. Method for residual household waste composition studies. Waste Manag. 46, 3-14. https://doi.org/10.1016/j.wasman.2015.08.032

Scott, P.E., 1995. The International Energy Agency's (IEA) work in harmonising sampling and analytical protocols related to municipal solid waste (MSW) conversion to energy. Biomass and Bioenergy 9, 415-439. https://doi.org/10.1016/0961-9534(95)00108-5

Sharma, M., McBean, E., 2009. Strategy for use of alternative waste sort sizes for characterizing solid waste composition. Waste Manag. Res. 27, 38-45. https://doi.org/10.1177/0734242X07082764

Sharma, M., McBean, E., 2007. A methodology for solid waste characterization based on diminishing marginal returns. Waste Manag. 27, 337-344. https://doi.org/10.1016/j.wasman.2006.02.007

Suez Advanced Solutions Spain, n.d. Protocolo de toma de muestra, caracterización y análisis de RSU. Suez Advanced Solutions Spain.

UNE-CEN/TR 15310-1 IN, 2008. Informe UNE. Caracterización de residuos: Muestreo de residuos. Parte 1: Orientación en la selección y aplicación de los criterios de muestreo bajo diversas condiciones. AENOR, Asocición Española de Normalizaciónj y Certificación, Madrid, España.

UNE-CEN/TR 15310-2 IN, 2008. Informe UNE. Caracterización de residuos: Muestreo de residuos. Parte 2: Orientación en técnicas de muestreo. AENOR, Asocición Española de Normalizaciónj y Certificación, Madrid, España.

UNE-CEN/TR 15310-3 IN, 2008. Informe UNE. Caracterización de residuos: Muestreo de residuos. Parte 3: Orientación en los procedimientos de submuestreo en campo. AENOR, Asocición Española de Normalizaciónj y Certificación, Madrid, España.

UNE-CEN/TR 15310-4 IN, 2008. Caracterización de residuos: Muestreo de residuos. Parte 4: Orientación en procedimientos para embalar, almacenar, conservar, transportar y entregar muestras. AENOR, Asocición Española de Normalizaciónj y Certificación, Madrid, España.

UNE-CEN/TR 15310-5 IN, 2008. Caracterización de residuos: Muestreo de residuos. Parte 5: Orientación en el proceso de definición del plan de muestreo. AENOR, Asocición Española de Normalizaciónj y Certificación, Madrid, España. 
UNE-EN 14899, 2007. Caracterización de residuos: Toma de muestras de residuos. Esquema para la preparación y aplicación de un plan de muestreo. AENOR, Asocición Española de Normalizaciónj y Certificación, Madrid, España.

UNE-EN 15359, 2012. Combustibles sólidos recuperados: Especificaciones y clases. AENOR, Asocición Española de Normalizaciónj y Certificación, Madrid.

UNE-EN 15442, 2012. Combustibles sólidos recuperados: Métodos de muestreo. AENOR, Asocición Española de Normalizaciónj y Certificación, Madrid. 

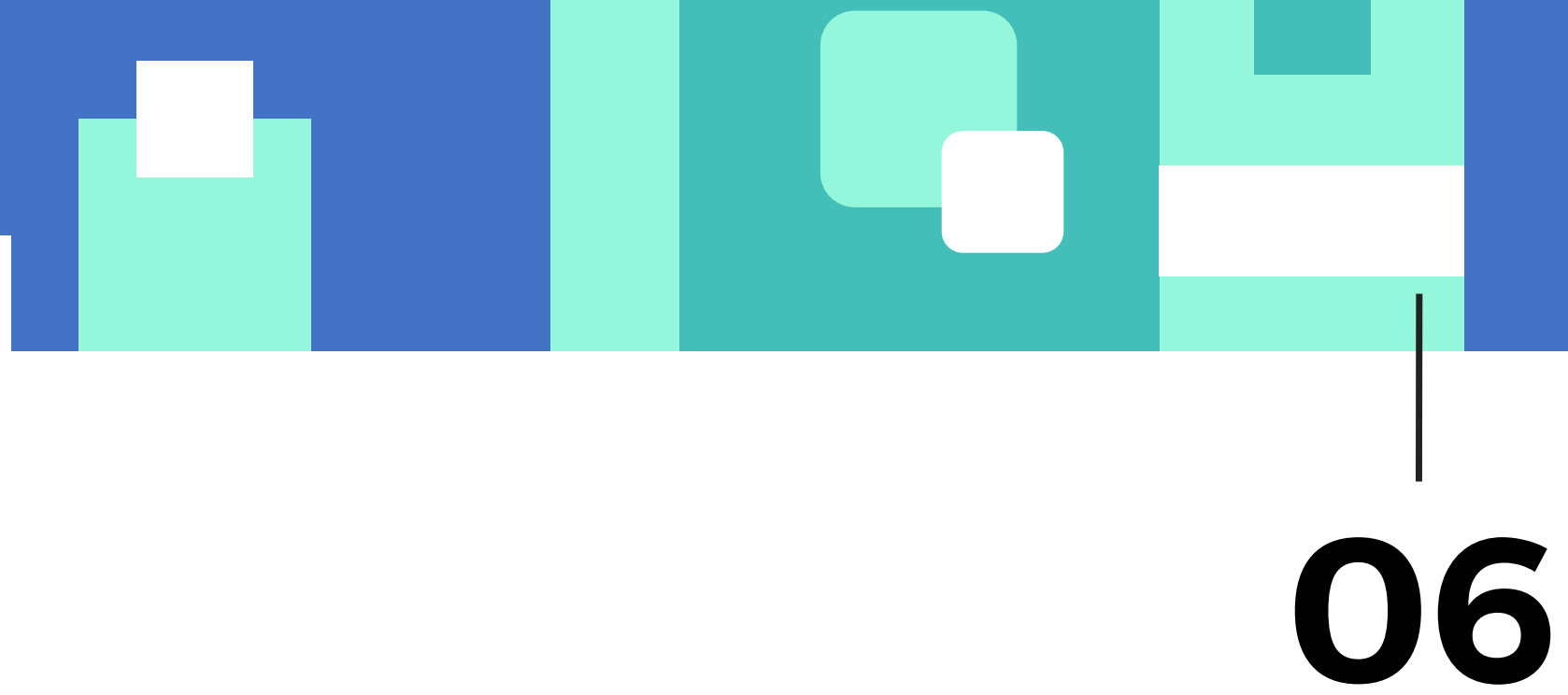

CAPÍTULO 6

DESARROLLO DEL PLAN DE MUESTREO PARA EL CONTROL DE CALIDAD DE LOS RECHAZOS 



\subsection{INTRODUCCIÓN}

Los rechazos generados en el TMB de RSU son mezclas heterogéneas de materiales, formados por distintos componentes que tienen un tamaño, forma y densidad de partículas muy variable. Como consecuencia, su correcto muestreo y caracterización es una de las partes fundamentales para el control de calidad de los mismos.

De acuerdo con la revisión realizada en el capítulo 4, los principales parámetros que definen la calidad de los CSR son el $\mathrm{PCl}$, el contenido en $\mathrm{Cl}$ y $\mathrm{Hg}$. Estos parámetros serán también los utilizados para el control de calidad de los rechazos mediante el análisis químico de varias muestras. Los resultados obtenidos de dichos análisis deben ser representativos y extrapolables, por lo que es necesario llevar a cabo un correcto muestreo y caracterización.

El proceso de muestreo y caracterización típico para los rechazos se divide en 4 etapas principales:

1. Muestreo

2. Preparación de muestra en el laboratorio

3. Medición del parámetro de interés

4. Evaluación de los resultados

El presente capítulo se centra en la primera de ellas y tiene como objetivo el diseño de un plan de muestreo para el control de calidad de los rechazos. Este se desarrolla en tres etapas:

- Etapa I: Determinación del tamaño de muestra. En esta etapa se propone una metodología para determinar el tamaño mínimo de muestra más adecuado a las características de cada corriente de rechazo. Dicha metodología se basa en las normativas existentes y se ajusta a las propiedades físicas de estos materiales. Cabe señalar que el tamaño de muestra hace referencia a los kilogramos de rechazo que se deben seleccionar en cada muestra.

- Etapa II: Determinación del número de muestras. En esta etapa se diseña una metodología para calcular el número mínimo de muestras necesarias para el muestreo de la producción anual de rechazo. Esta metodología se basa en la estratificación de la producción y en el número de corrientes distintas de rechazo que se generan en una planta.

- Etapa III: Directrices para el muestreo y la caracterización de los rechazos. En esta etapa se proponen una serie de recomendaciones que se deben tener en cuenta a la hora de aplicar el plan de muestreo y llevar a cabo la caracterización de los rechazos.

Finalmente se presentan tres casos de aplicación. En dos de ellos se aplica la metodología para la determinación del tamaño de muestra necesario para la caracterización y control de calidad de los rechazos generados en dos plantas de TMB. La primera es una planta de recuperación y compostaje donde se generan tres corrientes de rechazos susceptibles de ser transformadas en CSR. La segunda en una planta de biosecado y recuperación donde se generan otras tres corrientes de rechazo. El tercer caso consiste en la aplicación de la metodología para determinar el número mínimo de muestras en una planta de recuperación y compostaje de RSU mezclados para el control de calidad anual de sus rechazos.

En base a todo esto, el capítulo está estructurado según la Figura 6.1. En el apartado 6.2 se define el objetivo y alcance del plan de muestreo. En al apartado 6.3, se justifica la necesidad de una metodología propia para el muestreo de rechazos. En los apartados $6.4,6.5$ y 6.6 se desarrollan las tres etapas del plan de muestreo. Por último, en los apartados 6.7 y 6.8 se presentan los casos de aplicación para la determinación de tamaño de muestra y número de muestras respectivamente. Además, en dicha figura, se muestra también la información de partida necesaria para el diseño del plan de muestreo. 


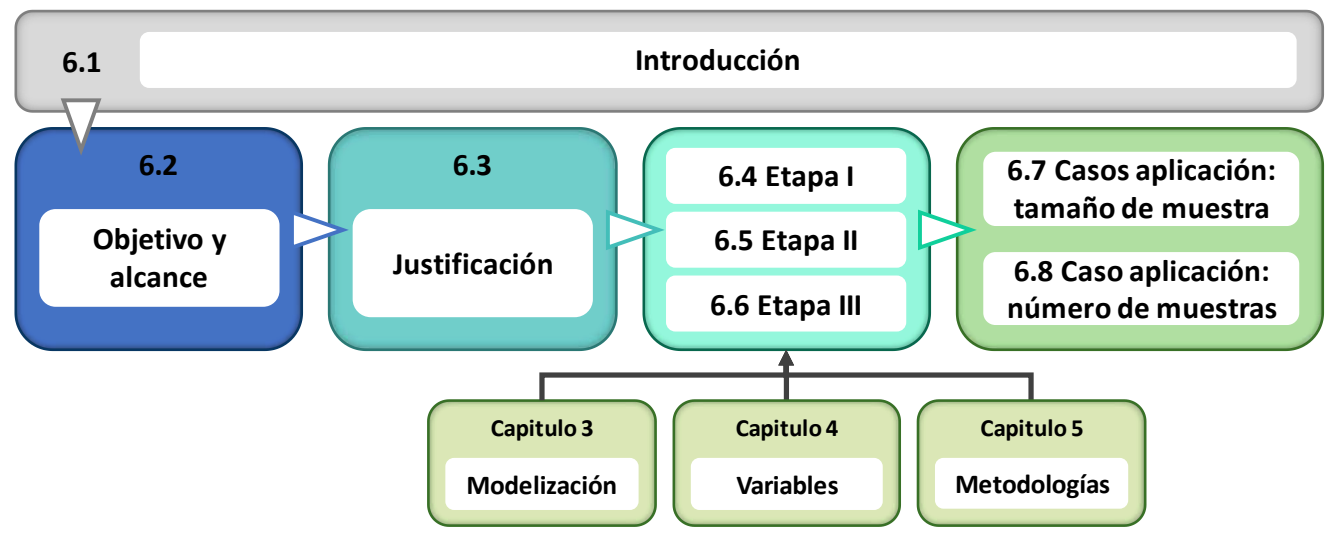

Figura 6.1. Estructura del Capítulo 6

\subsection{OBJETIVO Y ALCANCE DEL PLAN DE MUESTREO}

El diseño del plan de muestreo tiene como objetivo establecer un procedimiento sencillo para el control de calidad de los rechazos producidos anualmente en una planta TMB. Para ello es indispensable determinar el número y tamaño mínimo de muestra necesarios para una correcta caracterización de los rechazos, de forma que se obtenga un conjunto de muestras representativas que, tras un proceso de preparación, sirvan para medir los parámetros de control de calidad $(\mathrm{PCl}, \mathrm{Cl}$ y Hg$)$.

Las metodologías revisadas en el capítulo 5 han servido como base para el diseño del plan de muestreo, permitiendo obtener los fundamentos y principios necesarios para su desarrollo. No obstante, estas se han ajustado y adecuado a las características de los rechazos de las plantas de TMB.

El plan de muestreo tiene que tener en cuenta las siguientes consideraciones:

- Adaptarse a los diferentes tipos de plantas de TMB y sus rechazos.

- Considerar la variabilidad temporal que pueden sufrir las propiedades de los rechazos.

- Contemplar las propiedades físicas de los rechazos que pueden afectar al tamaño mínimo de muestra.

- Minimizar los costes económicos, la mano de obra y tiempo invertido, que supone la utilización de otras metodologías que no están adaptadas a la naturaleza de este tipo de materiales, como pueden ser la de los RSU o de los CSR.

El plan de muestreo se debe poder aplicar a los seis tipos de instalaciones de TMB modelizadas en el capítulo 3 y a las distintas alternativas de tratamiento que se dan en cada una de ellas, adaptándose a los diferentes rechazos generados en las mismas. Estos rechazos, como se ha visto en el capítulo 4, tienen unas propiedades distintas en función del tipo de instalación y el proceso de tratamiento (operaciones unitarias mecánicas utilizadas).

Así pues, en la Tabla 6.1 se exponen los distintos tipos de corrientes de rechazo a considerar, así como los procesos y plantas de TMB donde se generan, de forma que el plan de muestreo a diseñar se adapte y pueda aplicar a todas ellas. 
Tabla 6.1 Tipos de rechazos y plantas de TMB de RSU a considerar en el diseño del plan de muestreo

\begin{tabular}{|c|c|c|c|}
\hline Tipo de rechazo & $\begin{array}{l}\text { Proceso de tratamiento y grado de } \\
\text { automatización }\end{array}$ & $\begin{array}{l}\text { Tipos de planta } \\
\text { de TMB }\end{array}$ & Tipo de RSU \\
\hline $\begin{array}{l}\text { Rechazo de recuperación automática } \\
\text { (RRA) }\end{array}$ & $\begin{array}{l}\text { Recuperación automática de materiales } \\
\text { reciclables }\end{array}$ & \multirow{4}{*}{ PT, PRC, PRBC } & \multirow{12}{*}{$\begin{array}{c}\mathrm{RSU} \\
\text { mezclados }\end{array}$} \\
\hline $\begin{array}{l}\text { Rechazo de recuperación manual } \\
\text { (RRM) }\end{array}$ & $\begin{array}{l}\text { Recuperación manual de materiales } \\
\text { reciclables }\end{array}$ & & \\
\hline $\begin{array}{l}\text { Rechazo de afino primario del } \\
\text { bioestabilizado (RAB1) }\end{array}$ & Afino primario del material bioestabilizado & & \\
\hline $\begin{array}{l}\text { Rechazo de afino secundario del } \\
\text { bioestabilizado (RAB2) }\end{array}$ & $\begin{array}{l}\text { Afino secundario del material } \\
\text { bioestabilizado }\end{array}$ & & \\
\hline Rechazo fino de recuperación (RFR) & $\begin{array}{l}\text { Rechazo de la fracción fina de } \\
\text { recuperación de materiales reciclables }\end{array}$ & PT & \\
\hline $\begin{array}{c}\text { Rechazo de recuperación automática } \\
\text { del biosecado (RRA-BS) }\end{array}$ & $\begin{array}{l}\text { Recuperación automática de materiales } \\
\text { reciclables de la fracción seca del } \\
\text { biosecado }\end{array}$ & \multirow{4}{*}{ PBSR } & \\
\hline $\begin{array}{c}\text { Rechazo de recuperación manual del } \\
\text { biosecado (RRM-BS) }\end{array}$ & $\begin{array}{c}\text { Recuperación manual de materiales } \\
\text { reciclables de la fracción seca del } \\
\text { biosecado }\end{array}$ & & \\
\hline $\begin{array}{l}\text { Rechazo de afino primario del } \\
\text { biosecado (RABS1) }\end{array}$ & $\begin{array}{l}\text { Afino primario de la fracción húmeda del } \\
\text { biosecado }\end{array}$ & & \\
\hline $\begin{array}{c}\text { Rechazo de afino secundario del } \\
\text { biosecado (RABS2) }\end{array}$ & $\begin{array}{l}\text { Afino secundario del material } \\
\text { bioestabilizado }\end{array}$ & & \\
\hline $\begin{array}{l}\text { Rechazo de limpieza de la FORS } \\
\text { (RLFO) }\end{array}$ & $\begin{array}{c}\text { Limpieza y acondicionamiento inicial de la } \\
\text { fracción orgánica }\end{array}$ & \multirow{3}{*}{ PCFO, PBCFO } & \\
\hline $\begin{array}{l}\text { Rechazo de afino primario del } \\
\text { compost (RAC1) }\end{array}$ & Afino primario del compost & & \\
\hline $\begin{array}{l}\text { Rechazo de afino secundario compost } \\
\text { (RAC2) }\end{array}$ & Afino secundario del compost & & \\
\hline
\end{tabular}

En la presente tesis se ha considerado que las PRC y las PRBC generan los mismos tipos de corrientes de rechazo; y lo mismo ocurre con las PCFO y las PBCFO (Tabla 6.1). Esto se debe a que los rechazos generados en estas instalaciones tienen un origen, composición y características similares, por lo que se puede asumir que son iguales. Así pues, si el plan de muestreo es aplicable a las PRC y a las PCFO, también los será a las PRBC y a las PBCFO.

Respecto a la variabilidad temporal y estacional de las propiedades de los rechazos, es necesario considerar las variables identificadas en el capítulo 4 que determinan su composición y características a lo largo de un año. Muchos autores señalan la importancia de tener en cuenta este aspecto a hora la caracterizar residuos y CSR (Flamme and Geiping, 2014, 2012; Klee, 1993). Estas variables permitirán estratificar la población a muestrear como recomiendan la mayoría de las metodologías revisadas en el capítulo 5, lo que aumentará la precisión de plan de muestreo. Por lo tanto, tendrán una gran influencia en el número mínimo de muestras necesarias para que los resultados sean representativos de la producción anual de rechazo.

En el capítulo 4 también se han identificado una serie de propiedades físicas de los rechazos que son responsables de algunos errores de muestreo y tienen una gran influencia en el tamaño mínimo de muestra necesario. Estas son: la heterogeneidad del material (relacionada con la composición física), el tamaño y distribución del tamaño de partícula, la forma de partícula y la densidad de las partículas que forman el rechazo. Algunas de ellas dependen del tipo de residuos tratados en las plantas de TMB y del proceso de tratamiento llevados a cabo en las mismas (por ejemplo: heterogeneidad o el tamaño y forma de partícula). Otras son intrínsecas del propio material (por ejemplo, la densidad de partícula). 
La relación entre estas variables y el tamaño mínimo de muestra se basa en los aspectos geométricos del material involucrados en el muestreo y en cómo se distribuyen espacialmente las partículas en el lote de rechazos a muestrear, por lo que el plan de muestreo debe adaptarse a la naturaleza particular de los rechazos y contemplar estas propiedades, de forma que se llegue a un equilibrio entre el tamaño mínimo de muestra necesario y la representatividad de las mismas.

\subsection{JUSTIFICACIÓN DEL PLAN DE MUESTREO PARA RECHAZOS}

Tras la revisión realizada en el capítulo 5, se ha visto que existen diferentes normas y metodologías para el muestreo y caracterización de RSU y CSR. Su utilización supone trabajar con un número y tamaño de muestra muy elevado, lo que deriva en una gran carga de trabajo y un elevado coste económico, por lo que son inadecuadas para llevar a cabo el control de calidad de los rechazos.

Una de las dificultades respecto a la utilización de estas metodologías está relacionada con el grado de heterogeneidad. Los rechazos son un material más homogéneo que los RSU mezclados, puesto que ya han pasado por un proceso de tratamiento en el cual han sufrido, al menos, una clasificación por tamaño y se les han eliminado gran parte de los materiales reciclables. Sin embargo, son más heterogéneos que los CSR, ya que para la producción de estos combustibles son necesarias ciertas operaciones de acondicionamiento que homogeneizan el material final. Otra de las dificultades encontradas está relacionada con el tamaño de partícula, puesto que los rechazos están formados por componentes con tamaños de partícula muy variable y normalmente mayores que los que forman parte de un CSR. Todo ello hace que las metodologías existentes para RSU o CSR no se adapten a la naturaleza de los rechazos.

Por otro lado, algunas de las metodologías utilizadas para la caracterización de RSU tienen en cuenta la variabilidad que puede existir en la composición y características de los residuos, por lo que llevan a cabo una estratificación de la población (Burnley et al., 2007; Dahlén and Lagerkvist, 2008; Edjabou et al., 2015; European Commision, 2004; Lebersorger and Schneider, 2011; Mccauley-bell et al., 1997; Parfitt et al., 2015; Sahimaa et al., 2015; Scott, 1995). Sin embargo, no consideran las propiedades físicas que influyen en el tamaño de muestras. Por su parte, la norma UNE-EN 15442 (2012) "Combustibles sólidos recuperados: Métodos de muestreo", solo tiene en cuenta las propiedades físicas del material, pero no la variabilidad temporal que pueda existir.

Respecto al cálculo del número mínimo de muestras, algunas de las metodologías que utilizan fórmulas sencillas asumen que los datos siguen una distribución Normal (ASTM D5231-92, 1992; European Commision, 2004; NT ENVIR 001, 1995). Sin embargo, como se ha visto en el capítulo 5, Klee (1993) demostró que para la estimación de la composición de los residuos esta asunción no es correcta. Esto se debe a que este tipo de datos tiene una distribución con una asimetría positiva y solo se podrá asumir Normalidad si se toma un número elevado de muestras, lo que es extremadamente caro o económicamente inviable en el caso de los rechazos o los RSU en general. Además, los métodos que se basan en que los datos son Normales tampoco funcionan correctamente para componentes minoritarios o con una elevada variabilidad (Sharma and McBean, 2007); ni son adecuados para determinar los parámetros que definen la calidad del CSR, puesto que estos tampoco presentan una distribución normal o solo lo hacen cuando el número de observaciones es elevado (Flamme and Geiping, 2012). Por todo ello, el uso de estas metodologías no es apropiado para determinar el número de muestras necesarias para la caracterización de los rechazos.

En cuanto al tamaño mínimo de muestra, tampoco hay un criterio estandarizado. En el caso de los RSU cada metodología recomienda un peso o volumen mínimo necesario, el cual oscila alrededor de los $100 \mathrm{~kg}$. Mientras que para los CSR, la norma UNE-EN 15442 (2012) propone una fórmula para su cálculo en función de diferentes propiedades físicas del material. Sin embargo, esta fórmula no es completamente aplicable a materiales heterogéneos y con tamaños de partículas grandes (Aldrian et al., 2016), como ocurre con los rechazos del TMB cuyos tamaños y formas de partícula son mayores y mucho más variables que los de los CSR. Así pues, si se tomaran los pesos recomendados para los RSU o se aplicará directamente la norma de 
los CSR, sería necesario muestrear una gran cantidad de material, lo que supone un elevado coste económico, de tiempo y mano de obra.

Finalmente, es importante destacar que para poder realizar cualquier análisis de caracterización con precisión es necesario un procedimiento de muestreo apropiado (Scott, 1995), ya que el muestreo es crítico a la hora de obtener unos resultados representativos y fiables (Edjabou et al., 2015; Petersen et al., 2005). Además, los estudios de caracterización de rechazos suelen ser costosos y llevar mucho tiempo, por lo que es importante garantizar que el plan de muestreo utilizado sea eficiente, fiable, práctico y permita obtener unos datos válidos.

Por todo ello, queda justificado el desarrollo de un plan de muestreo que, basándose en las metodologías existentes para RSU y CSR, se adapte a la naturaleza particular de los rechazos y facilite su correcto muestreo y caracterización con los menores costes posibles. Dicho plan servirá para obtener una serie de muestras que serán utilizadas para el control de calidad de los rechazos. Esto permitirá producir un CSR de características conocidas, facilitando su valorización y comercialización.

\subsection{ETAPA I: DETERMINACIÓN DEL TAMAÑO DE MUESTRA MÍNIMO}

En esta etapa se propone una metodología para determinar el tamaño de muestra necesario para la caracterización de las corrientes de rechazo que se generan en una planta de TMB.

Esta metodología tiene como objetivo determinar el peso de muestra con el que se obtienen resultados representativos en el análisis de los parámetros que definen la calidad ( $\mathrm{PCl}, \mathrm{Cl}$ y $\mathrm{Hg}$ ). Sin embargo, a la hora de determinar el tamaño de muestra no se van a utilizar estos parámetros, si no que se van a utilizar datos de composición. Esto atiende a dos razones fundamentales:

- Facilitar la aplicación de la metodología, puesto que a nivel práctico es más sencillo realizar una caracterización física de los rechazos, que los análisis químicos necesarios para la determinación del $\mathrm{PCl}, \mathrm{Cl}$ y $\mathrm{Hg}$.

- Su utilización permite hacer una analogía entre el porcentaje de cierto componente en el rechazo con las diferentes concentraciones a las que se puede encontrar un analito en el mismo (Petersen et al., 2004). Por ejemplo, componentes que se encuentran en porcentajes pequeños como los residuos tóxicos y peligrosos (RTP) pueden representar analitos que se presenten en concentraciones de ppm, como el $\mathrm{Cl}$ o el $\mathrm{Hg}$. De esta forma, si una fracción que tiene un porcentaje pequeño está correctamente representada con el tamaño de muestra calculado, es razonable asumir que también lo estará un analito con una concentración baja.

La metodología propuesta comienza determinando el tamaño de muestra inicial a partir de la norma UNEEN 15442 (2012) de CSR, puesto que es la única que incluye las propiedades físicas del material. No obstante, como esta fórmula no se adapta completamente a las características de los rechazos se ha propuesto dividir sucesivamente este tamaño de muestra inicial. En cada nivel de división o submuestreo se lleva a cabo una caracterización, obteniéndose los datos de composición. Finalmente, los resultados para cada nivel se analizarán estadísticamente con el objetivo de determinar el tamaño de muestra mínimo con el que se obtienen resultados representativos. Los pasos en los que se ha dividido son los siguientes:

1. Cálculo del tamaño de muestra inicial

2. Definición de las fracciones a caracterizar

3. Procedimiento de división del tamaño de muestra inicial

4. Determinación del tamaño mínimo de muestra 


\subsubsection{Cálculo del tamaño de muestra inicial}

En primer lugar, se debe calcular el tamaño de muestra inicial. Para ello, se utiliza la ecuación que propone la norma UNE-EN 15442 (2012) “Combustibles sólidos recuperados: Métodos de muestreo" y que se expone a continuación:

$$
m_{m}=\frac{\pi}{6 \cdot 10^{9}} \cdot d_{95}{ }^{3} \cdot f \cdot \lambda_{p} \cdot g \cdot \frac{(1-p)}{c v^{2} \cdot p}
$$

Donde:

$m_{m}$ es la masa del tamaño de muestra inicial, en kg según se recibieron;

$d_{95}$ es el tamaño nominal superior de una partícula (una fracción másica del $95 \%$ de las partículas son más pequeñas que $d_{95}$ ), en $\mathrm{mm}$. Si los materiales no son granulares se puede usar $d_{95, l}$ (longitud máxima de una partícula de copos);

$f$ es el factor de forma, en $\mathrm{mm}^{3} / \mathrm{mm}^{3}$;

$\lambda_{p}$ es la densidad media de partícula de las partículas, en $\mathrm{kg} / \mathrm{m}^{3}$ según se reciba;

$g$ es el factor de corrección para la distribución en el tamaño de las partículas, es adimensional;

$p$ es la fracción de las partículas con una característica especifica (por ejemplo, un contaminante especifico), en $\mathrm{kg} / \mathrm{kg}$;

$c v$ es el coeficiente de variación, en tanto por uno.

Esta ecuación incluye el factor forma y el tamaño de partícula. El primero permite corregir la no esfericidad de los rechazos. El segundo es un parámetro fundamental para el muestreo representativo de materiales heterogéneos, como se ha visto en el capítulo 4. Además, también tienen en cuenta todas las propiedades físicas de los rechazos que se han identificado como influyentes en el tamaño mínimo de muestra en dicho capítulo (tamaño y distribución del tamaño de partícula, la forma de partícula y la densidad de las partículas).

Para el cálculo de $m_{m}$ es necesario conocer todos los parámetros que forman parte de la ecuación. En el caso de no conocerlos será necesario determinar su valor a partir de una muestra control. A continuación, se describe detalladamente como calcular el valor de cada uno de ellos.

\subsubsection{Determinación del tamaño nominal superior}

El tamaño nominal superior, d95, se determinará según lo especificado en la norma UNE-EN 15415-1 (2012) "Combustibles sólidos recuperados: Determinación de la distribución de partícula; Parte 1: Método del tamiz para partículas pequeñas" y en la norma UNE-EN 15415-2 (2012) "Combustibles sólidos recuperados: Determinación de la distribución de partícula; Parte 2: Método de la longitud máxima proyectada para partículas de grandes dimensiones", en el caso de partículas de grandes dimensiones y de forma irregular.

El método descrito por la norma UNE-EN 15414-1 (2012) consiste en someter a la muestra a un cribado a través de tamices, clasificando las partículas en clases de tamaño decrecientes. En los tamices superior e inferior no debe retenerse más del $5 \%$ del material en cada uno de ellos y la geometría de las aperturas debe ser circular o cuadrada. La masa mínima de muestra de ensayo debe ser de: $1 \mathrm{~kg}$ para materiales finos $\left(d_{95}<25 \mathrm{~mm}\right) ; 2 \mathrm{~kg}$ para materiales con un $\mathrm{d}_{95}$ de $25 \mathrm{~mm}$ a $150 \mathrm{~mm}$, y de $5 \mathrm{~kg}$ para materiales con un $\mathrm{d}_{95}$ mayor a $150 \mathrm{~mm}$. Si el contenido en humedad de la muestra es mayor a $20 \%$ se recomienda su secado al aire para prevenir que las partículas se peguen. En el caso que una partícula se pegue al orificio del tamiz, esta se deberá añadir a la fracción superior como si no hubiera pasado por el orificio. Finalmente, se pesa el material retenido sobre cada tamiz después del cribado con el tamiz de tamaño de apertura más pequeño. Los resultados se expresan como porcentaje en peso sobre el total. Además, todas las partículas mayores a $100 \mathrm{~mm}$ se deben separar manualmente y su tamaño se definirá como la longitud máxima de partícula mediante la norma UNE-EN 15415-2. 
La norma UNE-EN 15415-2 (2012) establece un método manual para la determinación de la longitud máxima proyectada $\left(d_{95,1}\right)$ para las partículas que tienen forma irregular y de grandes dimensiones, las cuales no pueden medirse con la norma anterior. Para el ensayo es necesario tomar una muestra de material que contenga 100 o más partículas o piezas (sin incluir filamentosas) que no pasen a través del tamiz definido como límite inferior. La norma indica que, normalmente, la cantidad de muestra para obtener más de 100 partículas está entre 3 y $15 \mathrm{~kg}$. Cada pieza se considera por separado, midiendo su longitud máxima proyectada, la cual se define como la mayor longitud proyectada sobre un plano (excluyendo los filamentos que sobresalen).

Para llevar a cabo el ensayo se ha de establecer un límite de tamaño inferior y otro superior, definiendo entre estos dos límites siete clases de tamaño de la misma anchura. De esta manera la muestra quedará dividida en: partículas finas (por debajo del límite inferior), siete clases de tamaños (entre los límites inferior y superior) y partículas grandes (por encima del límite superior). Una vez identificadas las dimensiones para los dos límites y las siete clases, se coge una muestra de peso conocido y se criba con un tamiz cuyo tamaño de apertura corresponda al límite inferior. Tras el tamizado se debe de cumplir que el número de piezas que no pasan al través del mismo sea mayor a 100. Cada una de estas piezas se coloca sobre una superficie plana, se mide su longitud máxima proyectada (sin deformar la pieza y excluyendo los filamentos) y se clasifica en la clase correspondiente. Finalmente se calcula el porcentaje en peso para las siete clases, las partículas finas, las partículas grandes y las filamentosas.

\subsubsection{Determinación del factor forma}

Como se ha comentado anteriormente, el factor forma $(f)$ se utiliza para corregir la no esfericidad que puede existir en materiales como los residuos, los rechazos o los CSR. Este factor describe la desviación de la forma de las partículas respecto a la forma de una esfera.

La norma UNE-EN 15442 (2012) establece que para materiales más o menos granulares y con un d95 menor a $50 \mathrm{~mm}$ no es necesaria su utilización, por lo que no hará falta determinarlo y se considerara que el factor forma es igual a 1. En el resto de casos se deberá calcular utilizando la ecuación 6.2. Además, de forma general, el factor forma aumenta si un material se tritura.

$$
f=\frac{V_{95}}{d_{95, l}{ }^{3}}
$$

Donde:

$f$ es el factor de forma, en $\mathrm{mm}^{3} / \mathrm{mm}^{3}$;

$V_{95}$ es el volumen de una partícula con forma de copo, en $\mathrm{mm}^{3}$. Hace referencia al volumen de la partícula más pequeña que se queda por encima del tamiz de $d_{95}$;

$d_{95, l}$ es la longitud máxima de una partícula de copos, en $\mathrm{mm}$. Hace referencia a la longitud máxima de la partícula más pequeña que se queda por encima del tamiz de $d_{95}$.

\subsubsection{Determinación de la densidad media de partícula}

La densidad media de partícula $\left(\lambda_{p}\right)$ designa la densidad de la fase sólida de un material sin tener en cuenta los huecos que hay entre las partículas del mismo, es decir, la relación entre la masa total de sólidos y el volumen de solidos de un material. Así pues, la densidad de partículas se centra solo en las partículas, por lo que no representa la densidad a granel de la muestra.

La norma UNE-EN 15442 (2012) no aporta indicaciones para su determinación, ni se ha encontrado otro tipo de normativa que permita el cálculo de este parámetro para rechazos, residuos o CSR. Por lo que, en la presente tesis, se ha desarrollado un método sencillo que consiste en determinar la masa y el volumen de un conjunto de partículas y a partir de estos datos calcular su densidad.

La determinación del volumen de partículas se basa en el principio de Arquímedes, por lo que el volumen de partícula se determina midiendo el volumen desalojado por los rechazos al sumergirlos en agua. Para 
ello se utilizará un recipiente que tenga marcas de graduación, lo que permitirá ver la variación del volumen. Además, este debe ser lo suficientemente grande como para poder sumergir la muestra.

Así pues, el método para determinar la densidad de partícula comienza con el llenando del recipiente que tiene las marcas de graduación con agua. Seguidamente se sumerge una capsula de porcelana vacía (donde posteriormente se introducirá la muestra) y se anota el volumen inicial ( $\left.V_{0}\right)$. A continuación, se pesa una porción de muestra $(\mathrm{m})$, que se coloca en la capsula tras haberla sacado del agua. Por último, se sumerge de nuevo en el recipiente la capsula de porcelana con la muestra, haciendo subir el volumen del agua (volumen desplazado por la muestra) y se anota el nuevo nivel $\left(\mathrm{V}_{1}\right)$. La densidad de partícula se calcula utilizando la siguiente ecuación:

$$
\lambda_{p}=\frac{m}{\left(V_{1}-V_{0}\right)} \cdot 10^{3}
$$

Donde:

$\lambda_{p}$ es la densidad media de partícula de las partículas, en $\mathrm{kg} / \mathrm{m}^{3}$ según se reciba;

$m$ es la masa de muestra que se sumerge, en $\mathrm{kg}$;

$V_{0}$ es el volumen inicial del recipiente en el que se ha introducido la capsula vacía, en I;

$V_{1}$ es el volumen en el recipiente tras sumergir la muestra, en I.

Se recomienda que la determinación de la densidad media de partícula se haga por triplicado y se tome el valor promedio.

En el caso que el material tenga una densidad menor que la del agua $\left(1,0 \mathrm{~g} / \mathrm{cm}^{3}\right)$, será necesario cubrir la capsula de porcelana y la muestra con tela metálica o algún tipo de tapa perforada, cuya luz de malla sea menor al diámetro de partícula de la muestra. Esto permitirá que el líquido entre en la capsula y evitará que el material flote al sumergirlo.

\subsubsection{Determinación del factor de corrección de distribución en el tamaño de partícula}

El factor de distribución $(g)$ describe el intervalo de tamaños de partículas existente en el material y corrige su distribución. Si las partículas tienen el mismo tamaño $g$ será igual a 1 . El valor de $g$ a utilizar se deduce a partir de la Tabla 6.2.

Este factor depende de la relación entre el tamaño nominal superior ( $d_{95}$ ) y el tamaño mínimo de partícula (do5). El tamaño mínimo de partícula es el diámetro a través del cual pasan el $5 \%$ de las partículas (es decir, una fracción másica del $5 \%$ de las partículas son más pequeñas que $d_{05}$ ) y se determina de la misma forma que el tamaño nominal superior.

Tabla 6.2 Factor de distribución $(g)$

\begin{tabular}{c|c}
\hline Relación $d_{95} / d_{05} *$ & $g$ \\
\hline$d_{95} / d_{05}>4$ & 0,25 \\
\hline $2 \leq d_{95} / d_{05} \leq 4$ & 0,50 \\
\hline $1 \leq d_{95} / d_{05}<2$ & 0,75 \\
\hline$d_{95} / d_{05}=1$ & 1 \\
\hline *Si los materiales no son granulares se puede usar $d_{95}$
\end{tabular}

En el caso de los rechazos, por lo general, hay una amplia distribución en el tamaño de las partículas, por lo que en muchos casos esta distribución resulta en un $g$ de 0,25 . Para materiales granulares con un tamaño de partícula similar, $g$ es generalmente 1 . 


\subsubsection{Determinación del factor $p$}

El factor $p$ se refiere a la fracción de las partículas con la característica especifica que se quiere evaluar (por ejemplo, un contaminante) en tanto por uno. La norma UNE-EN 15442 (2012) establece que si este factor no se conoce se deja por defecto el valor de 0,1.

\subsubsection{Coeficiente de variación}

El coeficiente de variación hace referencia al error fundamental de muestreo. El cual está relacionado con la heterogeneidad del material y corresponde al error mínimo que se genera en el muestreo de un material sólido. Además, tiene una influencia directa en el tamaño de muestra mínimo (Petersen et al., 2005).

Un valor típico que se suele adoptar para el cálculo del tamaño de muestras en el campo de los residuos es 0,1 (Pehlken et al., 2000). Asimismo, este valor también es el recomendado por la norma UNE-EN 15442 (2012).

\subsubsection{Definición de las fracciones a caracterizar}

En segundo lugar, es necesario definir las fracciones o categorías de residuos que se van a considerar a la hora de determinar el tamaño mínimo de muestra. Es importante que las fracciones consideradas incluyan componentes que se encuentren en diferentes porcentajes, ya que estos representarán a su vez sustancias químicas con distintas concentraciones. De esta forma se consigue que con el tamaño de muestra calculado se obtengan resultados representativos para analitos con concentraciones altas, medias o bajas.

Así pues, tras la revisión bibliográfica de varios trabajos de investigación sobre la caracterización de rechazos originados en el TMB y teniendo en cuenta la recomendación del párrafo anterior, se propone la división de los rechazos en 13 categorías o fracciones, las cuales se muestran en Tabla 6.3. Estas están basadas en las utilizadas en otros estudios, lo que facilitará la comparación de resultados.

Tabla 6.3 Fracciones de residuos consideradas

\begin{tabular}{|c|c|c|}
\hline Fracción & Descripción & Ejemplos típicos \\
\hline Fracción orgánica & $\begin{array}{l}\text { Cualquier tipo de residuo } \\
\text { biodegradable originado en las } \\
\text { cocinas domésticas, en cafeterías } \\
\text { y restaurantes y en jardines } \\
\text { domésticos o municipales. Otros } \\
\text { residuos biodegradables. }\end{array}$ & $\begin{array}{l}\text { Alimentos y comida (cocinados o no), restos de alimentos, } \\
\text { fruta, vegetales, peladuras, carne, pescado, huesos, espinas, } \\
\text { cascaras de moluscos, cascaras de frutos secos, bolsas de té, } \\
\text { posos de café, tapones de corcho natural, pañuelos, ramos de } \\
\text { flores, malas hierbas, hojas, ramas, césped, excrementos de } \\
\text { animales, papel de cocina o pañuelos muy sucios, etc. }\end{array}$ \\
\hline Papel/Cartón & $\begin{array}{l}\text { Cualquier tipo de papel o cartón, } \\
\text { limpio o parcialmente sucio. }\end{array}$ & $\begin{array}{c}\text { Revistas, periódicos, libros, sobres, folios, correspondencia, } \\
\text { apuntes, fotocopias, carpetas, folletos, bolsas de papel, trozos } \\
\text { de papel o cartón, servilletas, pañuelos, vasos de papel o } \\
\text { cartón, tickets, papel de envolver alimentos, papel de regalo, } \\
\text { cajas de galletas, cereales, etc. }\end{array}$ \\
\hline Plástico Film & $\begin{array}{l}\text { Cualquier tipo de plástico film o } \\
\text { flexible y bolsas de plástico, ya } \\
\text { sean o no envases. }\end{array}$ & $\begin{array}{c}\text { Bolsas de un solo uso, bolsas de basura, film de cocina, film } \\
\text { industrial, envoltorios y bolsas de aperitivos, bolsas de } \\
\text { congelados, etc. }\end{array}$ \\
\hline Plástico Rígido & $\begin{array}{c}\text { Cualquier tipo de plástico rígido } \\
\text { que sea un envase. }\end{array}$ & $\begin{array}{c}\text { Botellas de agua o refresco, botellas de productos de limpieza, } \\
\text { botellas de leche o aceite, envases de productos de belleza, } \\
\text { tubos de pasta de dientes, hueveras, tapas, tapones, } \\
\text { desodorantes roll-on, bandejas, envases de yogurt, pajitas de } \\
\text { bebidas, vasos, platos y cubiertos de plástico, etc. }\end{array}$ \\
\hline Textil & Cualquier tipo de residuo textil. & $\begin{array}{l}\text { Ropa, trapos, calcetines, medias, sacos o bolsas de tela, } \\
\text { retales, bayetas, trozos de tela, gorras, guantes, hilos o } \\
\text { cuerdas, alfombras, cortinas, sabanas, toallas, toallitas } \\
\text { húmedas, etc. }\end{array}$ \\
\hline
\end{tabular}




\begin{tabular}{|c|c|c|}
\hline Fracción & Descripción & Ejemplos típicos \\
\hline Metales & $\begin{array}{l}\text { Cualquier tipo residuo de metal o } \\
\text { chatarra. }\end{array}$ & $\begin{array}{l}\text { Latas de refresco y cerveza, latas de conservas, papel de } \\
\text { aluminio, envases de flan, aerosoles de desodorantes o laca, } \\
\text { bandejas de aluminio, envases de comida enlatada, cubiertos } \\
\text { de metal, sartenes u ollas, palos de escoba, clavos o tornillos, } \\
\text { tuberías de metal, candados, alambres, cadenas, chatarra, etc. }\end{array}$ \\
\hline Madera & $\begin{array}{l}\text { Cualquier tipo de residuo de } \\
\text { madera, tratado o no. }\end{array}$ & $\begin{array}{l}\text { Trozos de madera, partes de muebles, trozos de } \\
\text { conglomerado, cajas de fruta de madera, palillos chinos, palos } \\
\text { de helado, etc. }\end{array}$ \\
\hline Brik & $\begin{array}{l}\text { Residuos de envases mixtos, } \\
\text { normalmente de bebidas. }\end{array}$ & $\begin{array}{l}\text { Briks de leche o zumos, envases de batidos, envases de } \\
\text { tomate frito, envases de caldo o cremas precocinadas, } \\
\text { envases de patatas "Pringles", etc. }\end{array}$ \\
\hline Inertes & $\begin{array}{l}\text { Cualquier tipo de residuo inerte } \\
\text { de origen domiciliario, incluido } \\
\text { los materiales cerámicos. }\end{array}$ & $\begin{array}{l}\text { Escombros, piedras, ladrillos, tierras, macetas de arcilla, vajilla } \\
\text { de cerámica, decoraciones de cerámica, azulejos, jarrones, } \\
\text { tazas, etc. }\end{array}$ \\
\hline $\begin{array}{l}\text { Residuos Tóxicos } \\
\text { y Peligrosos (RTP) }\end{array}$ & $\begin{array}{l}\text { Cualquier tipo de residuo toxico } \\
\text { o peligroso de origen } \\
\text { domiciliario, incluido sus } \\
\text { envases. }\end{array}$ & $\begin{array}{l}\text { Baterías, pilas, mecheros, medicamentos y sus envases (llenos } \\
\text { o vacíos), jeringuillas, material médico, radiografías, } \\
\text { bolígrafos, cartuchos de tinta, botes de pintura, disolventes, } \\
\text { pegamentos, aceites mecánicos, productos fitosanitarios, } \\
\text { bombillas de bajo consumo, fluorescentes, etc. }\end{array}$ \\
\hline Vidrio & $\begin{array}{l}\text { Cualquier tipo de residuo de } \\
\text { vidrio, envase o no, y de } \\
\text { cualquier color. Incluye también } \\
\text { el cristal. }\end{array}$ & $\begin{array}{l}\text { Botellas de vidrio, botellines de cerveza o refresco, botellas de } \\
\text { zumo, trozos de vidrio, tarros de cristal, cristales, espejos, } \\
\text { bombillas incandescentes, vasos y jarras, etc. }\end{array}$ \\
\hline Otros & $\begin{array}{l}\text { Residuos que no puedan incluirse } \\
\text { en otras categorías como: } \\
\text { celulosa sanitaria, residuos de } \\
\text { aparatos eléctricos o } \\
\text { electrónicos, plásticos rígido no } \\
\text { envases, gomas y cueros, } \\
\text { productos multimaterial, calzado, } \\
\text { etc. }\end{array}$ & $\begin{array}{l}\text { Pañales, compresas, pequeños electrodomésticos, móviles, } \\
\text { periféricos de ordenadores, cargadores de móvil, cables, } \\
\text { juguetes eléctricos o electrónicos, juguetes, peluches, trozos } \\
\text { de corcho blanco, tarjetas de crédito, CDs, mangueras, } \\
\text { tuberías, cajas de fruta, macetas, marcos de plástico, gafas de } \\
\text { sol, perchas, guantes de látex, gomas, cuero, cinturones, } \\
\text { carteras y monederos, cámaras de bicicletas, globos, zapatos, } \\
\text { zapatillas, chanclas, etc. }\end{array}$ \\
\hline Finos & $\begin{array}{l}\text { Materiales muy finos, } \\
\text { normalmente con un tamaño } \\
\text { menor a } 30 \text { mm y cuya } \\
\text { separación es muy costosa. }\end{array}$ & - \\
\hline
\end{tabular}

\subsubsection{Procedimiento de división del tamaño de muestra inicial}

Una vez definido el tamaño de muestra inicial y las fracciones consideradas, la metodología propone un procedimiento de división de dicho tamaño para la obtención de las muestras de distintos pesos a caracterizar. Este procedimiento comprende los siguientes apartados:

\section{Selección del lote de la corriente de rechazo a muestrear}

Un lote se define como una cantidad específica de rechazo del cual se va a determinar una propiedad, que tiene unas mismas especificaciones y se ha producido del mismo modo. Este debe seleccionarse de la corriente de rechazo a muestrear y a partir del mismo se obtendrán las muestras de distintos pesos.

El tamaño mínimo de lote recomendado varía en función de los tipo de rechazo identificados en la Tabla 6.1, siendo de:

- 500 a 1.000 kg para rechazos originados en la etapa de recuperación de materiales: RRA, RRM, RRA-BS, RRM-BS y RRF.

- 20 a $10 \mathrm{~kg}$ para rechazos originados en la etapa de afino primario y limpieza de la FORS: RAB1, RABS1, RLFO y RAC1. 
- $\quad 10$ a 5 kg para rechazos originados en la etapa de afino secundario: RAB2, RABS2 Y RAC2.

Además, siempre se debe cumplir que el tamaño de lote sea al menos 4 veces el tamaño de muestra inicial, de modo que se pueda aplicar el procedimiento de división.

El método para la selección del lote de la corriente de rechazo debe de ser lo más representativo posible, de forma de que cada partícula de material tenga la misma probabilidad de ser incluida en el lote. Por lo que, siempre que sea posible y se tenga acceso a toda la población se debe realizar un muestreo probabilístico. En el caso de que esto no sea posible o los recursos no lo permitan, se debe optar por realizar un muestreo a juicio de experto sobre las subpoblaciones accesibles (por ejemplo, los rechazos generados en un periodo de tiempo determinado). No obstante, dentro de estas subpoblaciones, el muestro se llevará a cabo con técnicas probabilísticas.

Cuando el muestreo se realice a partir de una pila estática de rechazo, si es posible el lote se debe extraer mediante un muestreo aleatorio estratificado. Para ello, la pila se divide en tantos estratos o porciones como incrementos a tomar, siendo un incremento la cantidad de material que se recoge en una única operación de muestreo. La norma UNE-EN 15442 (2012) recomienda un mínimo de 24 incrementos por lote. A continuación, dentro de cada estrato en los que se ha dividido la pila se toma un incremento de forma aleatoria (Figura 6.2). Finalmente se juntan todos los incrementos para formar el lote.

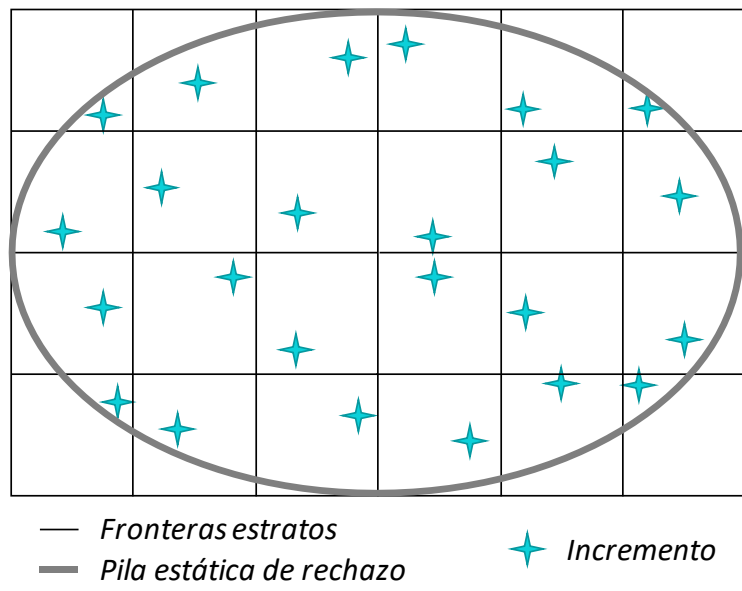

Figura 6.2 Muestreo estratificado en una pila de rechazo

En los casos que técnicamente no sea posible la estratificación de la pila, el material se homogeneiza por medios mecánicos (pala cargadora) y se toma la cantidad de material correspondiente al lote mediante un muestreo aleatorio simplificado. Para ello se seleccionan varios incrementos de diferentes puntos de la pila escogidos al azar y posteriormente se unen para formar el lote.

Si el muestreo se realiza directamente de la línea de producción, ya sea en una cinta transportadora o en un flujo de caída, el lote se extrae mediante un muestreo probabilístico sistemático. Para ello se toman varios incrementos a intervalos de tiempos fijos hasta obtener el lote.

Finalmente, el lote se deposita en una superficie limpia y pavimentada para continuar con el procedimiento de división del tamaño de muestra inicial.

\section{División del tamaño de muestra inicial y caracterización de las muestras}

Los pesos de las diferentes muestras se obtienen a partir de la división del tamaño de muestra inicial como se muestra en esquema de la Figura 6.3, cada uno de estos pesos corresponden a un nivel de división o submuestreo. El nivel uno (L1) corresponde al nivel donde cada muestra tiene un peso igual al tamaño inicial $\left(\mathrm{m}_{\mathrm{m}}\right)$ calculado en el punto 1 de la metodología (Ec.6.1). El nivel dos (L2) corresponde a un peso de muestra igual a la mitad de $\mathrm{m}_{\mathrm{m}}$. El nivel tres (L3) corresponde a un peso de un cuarto de $\mathrm{m}_{\mathrm{m}}$ y así sucesivamente. Se recomienda la división del tamaño de muestra inicial hasta el quinto o sexto nivel de submuestreo. 


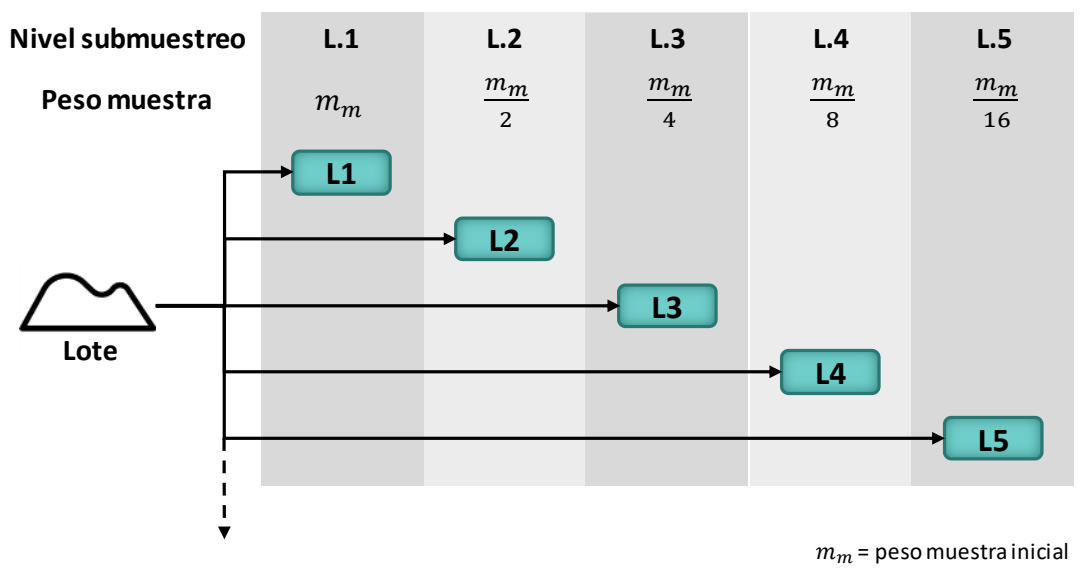

Figura 6.3 Esquema del procedimiento de división de tamaño de muestra inicial

Las diferentes muestras para cada nivel de submuestreo se tomarán del lote que se ha extraído de la corriente de rechazo a muestrear. Para ello, tras extender el lote, se procede del siguiente modo en función del tipo de rechazo con el que se esté trabajando:

- En los rechazos originados en la etapa de recuperación de materiales (RRA, RRM, RRA-BS, RRM-BS, RRF y RLFO) se deben de tomar varios incrementos de diferentes puntos del lote, los cuales se eligen de forma aleatoria, hasta alcanzar el peso de muestra correspondiente a cada nivel de submuestreo.

- En los rechazos originados en la etapa de afino primario y secundario (RAB1, RABS1, RAC1, RAB2, RABS2 y RAC2), debido a que el tamaño de lote es más manejable, mediante sucesivos cuarteos se obtienen las muestras de diferentes pesos para cada nivel.

Cada una de las muestras debe ser caracterizada por separado. Para ello la muestra se extiende sobre una superficie plana y se procede a la clasificación de los diferentes materiales en función de las fracciones definidas en el punto 2 de la metodología. Los materiales que se van seleccionando se depositan en los recipientes correspondientes $y$, una vez finalizada la separación, se determina el peso de cada fracción por separado. Los resultados se presentan como porcentaje en peso sobre el total de la muestra caracterizada.

Por otro lado, en base a las conclusiones del capítulo 5, se recomienda un mínimo de 10 muestras por nivel de submuestreo para poder aplicar los métodos estadísticos paramétricos en el siguiente punto de la metodología (si se cumplen los supuestos para su utilización). Este número se puede aumentar para mejorar los resultados del análisis estadístico siempre que el incremento en la carga de trabajo y/o coste sea asumible. Cuando el número de muestras por nivel sea menor de 10 siempre deberán utilizarse técnicas estadísticas no paramétricas.

\subsubsection{Determinación del tamaño mínimo de muestra}

Por último, una vez obtenidos los datos de composición física para los distintos niveles de submuestreo se procede a la determinación del tamaño de muestra para el control de la calidad de los rechazos con el que se obtienen resultados representativos. Para ello, mediante la comparación de los datos obtenidos en las caracterizaciones, se debe estudiar si existen diferencias en la composición de los rechazos en función del nivel de submuestreo.

Al nivel de submuestreo en el que aparecen las primeras diferencias se le denominará nivel crítico, puesto que los resultados obtenidos para el tamaño de muestra correspondiente al mismo dejan de ser representativos de la población de rechazo muestreada. El nivel de submuestreo que está por encima es el que marca el límite y, por tanto, el peso de muestra correspondiente a dicho nivel será el tamaño mínimo para el control de calidad de la corriente de rechazo analizada ( $\mathrm{mf}_{\mathrm{f}}$ ). 
La comparación de los datos de composición para cada nivel de su muestreo se realizará mediante un análisis estadístico, en concreto una comparación de medias de $k$ grupos de muestras. Esta técnica estadística permite analizar datos experimentales de más de dos grupos de muestras que se han medido en diferentes circunstancias, en este caso tienen distintos tamaños de muestra. De esta forma se puede identificar a qué nivel de submuestreo aparecen diferencias significativas en la composición de los rechazos y, por tanto, los resultados dejan de ser representativos. Los distintos métodos estadísticos que se deben aplicar se han explicado en el capítulo 5 de la presente tesis. Además, en la Figura 5.8 de dicho capítulo se resumen los procedimientos a seguir en un árbol de decisión.

Los análisis estadísticos se aplicarán a todas las fracciones caracterizadas y que se han definido en el punto 2 de la metodología. Como consecuencia se obtiene un tamaño de muestra diferente para cada componente o material. Así pues, el tamaño mínimo de muestra siempre será el más restrictivo de todos ellos, puesto que los parámetros de calidad $(\mathrm{PCl}, \mathrm{Cl}$ y $\mathrm{Hg}$ ) están repartidos en todos los materiales y, por lo tanto, todas las fracciones deben estar correctamente representadas en la muestra.

Cabe señalar que, debido a que se van a utilizar datos de composición física en porcentajes, cuando los datos no sigan una distribución normal deben de ser transformados como se ha indicado en el capítulo 5. Esta transformación matemática puede mejorar su distribución y facilitar la aplicación de las técnicas estadistas paramétricas.

\subsection{ETAPA II: DETERMINACIÓN DEL NÚMERO DE MUESTRAS}

En segundo lugar, dentro del plan de muestreo, es fundamental determinar el número de muestras necesarias para la caracterización de los rechazos, puesto que influirá en el coste del mismo y en la representatividad de los resultados obtenidos.

A continuación, se propone una metodología para la determinación del número de muestras mínimo necesarias para el control de calidad de la producción anual del rechazo de una planta de TMB. Dicha metodología se basa en dividir la población a muestrear en diferentes estratos en función de una serie de variables, las cuales son responsables de la variabilidad temporal de las propiedades de los rechazos y han sido identificadas en el capítulo 4 de la presente tesis.

Esta estratificación permite analizar muestras seleccionadas en diferentes periodos, por lo que el muestreo es mucho más representativo y posibilita tener en cuenta la variabilidad de las propiedades de los rechazos a lo largo del año. Además, como se ha visto en el capítulo 5, el muestreo estratificado mejora la precisión y veracidad de los resultados.

Los pasos en los que se divide la metodología propuesta son cuatro:

1. Determinación de las variables de estratificación

2. Determinación de los niveles de variación temporal

3. Identificación de las corrientes de rechazo a muestrear

4. Cálculo del número de muestras

\subsubsection{Determinación de las variables de estratificación}

En primer lugar, se deben determinar las variables que influyen en las propiedades físico-químicas de los rechazos y son responsables de su variabilidad temporal. Estas variables permitirán estratificar la producción anual de rechazos de la planta (población a muestrear) en lotes de rechazo con características similares (subpoblaciones o estratos). Dichos estratos se definen como partes mutuamente exclusivas o exhaustivas de la población a muestrear, cuyas características difieren del resto de los estratos.

El objetivo de esta estratificación es obtener muestras más homogéneas, puesto que la variación de las propiedades de los rechazos dentro de cada estrato es menor que la de la población en conjunto. Por lo 
tanto, mediante el muestreo de cada uno de los estratos se obtienen resultados representativos del total de la producción.

Para la identificación de las variables de estratificación será necesario realizar un estudio inicial de la planta de TMB que debe incluir: su modo de funcionamiento, tipo de RSU tratados, procesos llevados a cabo, tecnologías utilizadas, etc., así como un análisis de las influencias estacionales/climáticas y socioeconómicas que puedan existir respecto a su entorno y los municipios a los que da servicio.

En el capítulo 4 se han identificado todas las variables que influyen en la composición y propiedades de los rechazos. Estas se definen a continuación proponiendo una escala y/o unidades de medición, no obstante, estas pueden ser diferentes en función del contexto en el que se ubica la instalación. De todas ellas se deben de escoger como variables de estratificación las que afectan a los rechazos de la planta de TMB que se va a muestrear.

- Estacionalidad: variable cualitativa nominal relacionada con las diferencias que pueden darse en las propiedades de los rechazos en función de la época del año. Se compone de 4 categorías que corresponden con las estaciones del año: primavera, verano, otoño e invierno.

- Climatología: variable cualitativa nominal relacionada con las variaciones existentes en las propiedades de los rechazos en función del clima. Se da en zonas donde solo existen dos estaciones y está compuesta por dos categorías: estación lluviosa y estación seca.

- Área geográfica: variable cualitativa nominal relacionada con las diferencias que pueden darse en las características de los rechazos en función de la procedencia los RSU tratados en la instalación. Dentro de esta variable se diferencian dos categorías: zonas de interior y zonas de costa.

- Turismo: variable cualitativa nominal relacionada con las variaciones en las características de los rechazos debidas la movilidad de la población durante periodos vacacionales. Se compone de dos categorías: turismo estacional y turismo de fin de semana.

- Nivel de renta: variable cualitativa ordinal que hace referencia al nivel de ingresos de los ciudadanos que generan los RSU tratados en la planta y que puede afectar a las propiedades de los rechazos. Esta variable está formada por tres categorías: nivel de renta bajo, medio y alto.

- Modo de vida: variable cualitativa nominal relacionada con las variaciones de la característica de los rechazos como consecuencia de las diferencias en los hábitos de consumo de los ciudadanos a lo largo de la semana. Estos cambios en los hábitos suelen darse entre el fin de semana y el resto de días o por la celebración de mercado en días específicos. Dentro de esta variable se diferencian las siguientes categorías: día de mercado, fin de semana, días laborables.

- Tipo de población: variable cualitativa nominal relacionada con las diferencias que se dan en las propiedades de los rechazos en función del tipo de población que genera los residuos tratados en la planta. Se compone de cuatro categorías: zona rural, urbana, residencial y comercial.

- Nivel de urbanización: variable cualitativa nominal que hace referencia al tipo de viviendas existentes en la zona donde se originan los RSU que se tratan en la instalación y que puede influir en las propiedades de los rechazos. Dentro de esta variable se distinguen dos categorías: viviendas unifamiliares y edificios multifamiliares.

- Edad de la población: variable cualitativa nominal relacionada con el rango de edad de las personas que generan los RSU tratados en la planta y que puede afectar a las características de los rechazos. Dentro de esta variable se han considerado tres categorías: zonas jóvenes, zonas de media edad y zonas envejecidas.

- Frecuencia de recogida: variable cuantitativa discreta que indica el número de días a la semana que se recogen los residuos, sus unidades son núm. días/semana. Esta variable puede dar lugar a diferencias en las propiedades de los rechazos por la acumulación de residuos de varios días.

- Funcionamiento de la instalación: variable cualitativa discreta que indica el número de días que funciona la instalación de tratamiento, sus unidades son núm. días/semana. Está relacionada con las variaciones existentes en las características de los rechazos por la acumulación de RSU en el foso de descarga de la planta. 


\subsubsection{Determinación de los niveles de variación temporal}

La variabilidad temporal de las propiedades de los rechazos se puede dividir en tres niveles, los cuales hacen referencia a la variación que pueden sufrir estas propiedades a lo largo de un año. Cada nivel de variación temporal se puede dividir en varios estratos en función de las variables identificadas en el punto anterior.

A continuación, se definen los tres niveles considerados:

- Mensual: relacionado con la variación de las propiedades entre los diferentes meses del año, también se incluyen las variaciones estacionales. El número de estratos del nivel de variación mensual $\left(\mathrm{P}_{\mathrm{m}}\right)$ varía desde 1 (siempre existirá un periodo de muestreo al año) hasta un máximo de 12 (si se dan variaciones en todos los meses de año). Por ejemplo: si solo hay diferencias en agosto debido al turismo, el número de estratos será de $2\left(\mathrm{P}_{\mathrm{m}}=2\right)$. Si existen diferencias entre las estaciones, el número de estratos sería de 1 a $4\left(\mathrm{P}_{\mathrm{m}}=1,2,3\right.$ o 4). Si no hay diferencias, $\mathrm{P}_{\mathrm{m}}=1$.

- Semanal: hace referencia a la existencia de variaciones a lo largo de la semana. El número de estratos del nivel de variación semanal $\left(P_{s}\right)$ va desde un mínimo de 2 estratos a un máximo de 7, mientras que si no existe variación semanal no será necesario la división $\left(P_{s}=0\right)$. Por ejemplo: si hay diferencias entre el fin de semana y resto de días $\left(P_{s}=2\right)$.

- Diario: nivel relacionado con la existencia de variaciones a lo largo de un mismo día. Estas diferencias son consecuencia de la acumulación de los RSU en el foso de descarga de la planta, de manera que se forman capas de residuos con características distintas en función la de procedencia o ruta de los camiones de recogida. El número de estratos del nivel de variación diario $\left(\mathrm{P}_{\mathrm{d}}\right)$ va desde 2 a tantos estratos como capas de residuos diferentes haya en el foso. Si no existe variación diaria, no será necesario la división $\left(\mathrm{P}_{\mathrm{d}}=0\right)$.

En la Tabla 6.4 se exponen los niveles de variación temporal que se han considerado y las variables relacionadas con cada uno de ellos.

Tabla 6.4 Niveles de variación y variables identificadas en cada uno de ellos

\begin{tabular}{|c|c|c|}
\hline \multicolumn{3}{|c|}{ Nivel de variación temporal } \\
\hline Mensual & Semanal & Diario \\
\hline $\begin{array}{c}\text { Estacionalidad } \\
\text { Climatología } \\
\text { Turismo estacional } \\
\text { Nivel de urbanización (residuos } \\
\text { de jardinería) }\end{array}$ & $\begin{array}{l}\text { Turismo fin de semana } \\
\qquad \text { Modo de vida } \\
\text { Frecuencia de recogida } \\
\text { Funcionamiento instalación }\end{array}$ & $\begin{array}{l}\text { Área geográfica } \\
\text { Tipo de población } \\
\text { Nivel de renta } \\
\text { Nivel de urbanización } \\
\text { Edad de la población }\end{array}$ \\
\hline
\end{tabular}

Las variables incluidas en el nivel de variación mensual son las responsables de que existan diferencias en las propiedades de los rechazos en función de la época del año (estacionalidad y climatología), así como las que pueden dar lugar a variaciones entre los diferentes meses como consecuencia de la movilidad estacional de la población (turismo estacional) o de la generación de residuos de jardinería en zonas de viviendas unifamiliares (nivel de urbanización).

Las variables relacionadas con el nivel de variación semanal son las que dan lugar a diferencias en las características de los rechazos entre los distintos días de la semana. Estas variaciones ocurren principalmente entre el fin de semana y el resto de días como consecuencia de la movilidad de la población (turismo de fin de semana) o los cambios en los hábitos de consumo (modo de vida); aunque también puede deberse a la celebración de mercado en días concretos de la semana, a la frecuencia de recogida o al funcionamiento de la instalación.

Las variables incluidas en el nivel de variación diario corresponden a aquellas relacionadas con la procedencia u origen de los RSU tratados en la planta de TMB desde diferentes perspectivas: zonas de 
interior frente a zonas de costa (área geográfica); zonas rurales, urbanas, comerciales o industriales (tipo de población); zonas con ingresos altos, medio o bajos (nivel de renta); zonas con bloques multifamiliares frente a zonas de viviendas unifamiliares (nivel de urbanización), y barrios jóvenes o envejecidos (edad de la población). Estas variables pueden provocar variaciones diarias en las propiedades de los rechazos si las rutas de recogida pasan solo por determinadas zonas, de manera que al descargar los residuos en el foso de descarga se forman capas con características distintas.

Finalmente, en función del nivel de variación temporal, las variables y el valor que toma cada una de ellas se obtiene el número total de estratos en los que hay que dividir la producción anual de rechazo para el caso de estudio y que será necesario muestrear.

\subsubsection{Identificación de las corrientes de rechazo a muestrear}

La metodología considera las distintas corrientes de rechazo de una planta TMB que son susceptibles de ser transformadas en CSR (Tabla 6.1). Como se ha visto en el estado del arte es necesario muestrear los diferentes flujos de rechazo por separado, puesto que darán lugar a CSR de distintas calidades y especificaciones.

En este punto, en función del tipo de instalación y los procesos de tratamiento llevados a cabo, se determinarán las corrientes de rechazo a muestrear.

\subsubsection{Cálculo del número de muestras}

Una vez determinados los niveles de variación que afectan al caso de estudio y el número de corrientes que se tienen que muestrear se calculará el número mínimo de muestras, para ello se propone la ecuación 6.4:

$$
N M=\sum_{N C R=1}^{n}\left[\left(P_{m_{N C R}} \cdot 10\right)+\left(\left(P_{S_{N C R}}+P_{d_{N C R}}\right) \cdot 6\right)\right]
$$

Dónde:

NM es el número de muestras necesarias para el control de calidad de los rechazos;

NCR es el número corrientes de rechazo a muestrear;

$P_{m}$ es número de estratos para el nivel de variación mensual para cada corriente de rechazo identificada;

$P_{s}$ es número de estratos para el nivel de variación semanal para cada corriente de rechazo identificada;

$P_{d}$ es número de estratos para el nivel de variación diario para cada corriente de rechazo identificada.

A partir de las conclusiones obtenidas en el capítulo 5 y con el objetivo de que el muestreo sea representativo se recomienda tomar como mínimo 10 muestras para cada estrato del nivel de variación mensual y un mínimo de 6 muestras en cada estrato del nivel de variación semanal y diario.

La ecuación propuesta considera cada una de las corrientes de rechazo identificadas por separado, puesto que cada una de ellas puede estar afectada por unas variables de estratificación distintas y, por lo tanto, los estratos en los que haya que dividir su producción serán diferentes.

El número total de muestras se deben repartir en los diferentes estratos en los que se divida la producción anual de cada corriente de rechazo en función de los niveles de variación identificados.

Por otro lado, si se observan periodos cortos o puntuales donde pueda existir una variación atípica de las propiedades de los rechazos y se quiere considerar en el plan de muestreo, se deberá de estimar cual es el número de muestras necesario para ese periodo concreto. Algunos ejemplos de variaciones atípicas son las debidas a: días festivos, eventos deportivos, festivales, día de Nochevieja, día de Reyes, etc. 


\subsection{ETAPA III: DIRECTRICES PARA EL MUESTREO Y CARACTERIZACIÓN DE RECHAZOS}

En base a la experiencia adquirida durante el desarrollo de la tesis se han definido una serie de directrices para llevar a cabo el muestreo y caracterización de rechazos en plantas de TMB. Estas incluyen los siguientes aspectos: equipamiento de protección individual, material de trabajo, consideraciones para la programación de las caracterizaciones, localización y condiciones para realizar las caracterizaciones y casos especiales en la clasificación de los materiales.

\subsubsection{Equipamiento de protección individual}

Para llevar a cabo las caracterizaciones de forma segura y proporcionar una protección completa a las personas que realizan la caracterización, como mínimo, resulta imprescindible disponer de los siguientes equipamientos de protección individual:

- Calzado antideslizante y anticorte, de caña alta y con plantilla antiperforación.

- Guantes anticorte y guantes de látex.

- Casco, en el caso que la caracterización se realice en planta.

- Gafas de protección.

- Protectores auditivos (especialmente en espacios cerrados y con gran tránsito de vehículos).

- Mascarillas (con filtros para vapores orgánicos, gases ácidos, amoniaco y partículas de polvo).

- Ropa de trabajo adecuada (mono de trabajo, bata, etc.).

- Chalecos reflectantes, en el caso que la caracterización se realice en planta.

- Botiquín de primeros auxilios.

Además, siempre se seguirán las recomendaciones de seguridad dadas por la empresa.

\subsubsection{Equipamiento y material de trabajo}

Para poder realizar la toma de muestras y su caracterización con la calidad adecuada, como mínimo, es necesario disponer del siguiente equipamiento y material de trabajo:

- Pala mecánica: para realizar la manipulación inicial, la homogeneización y toma de la muestra en planta.

- Mesas de triaje, o en su defecto una superficie de suelo limpia, plana y pavimentada.

- Báscula de plataforma con una precisión mínima de 10 gramos.

- Número suficiente de recipientes (capazos, cubos, contenedores, etc.) de diferentes capacidades, tarados e identificados, para la clasificación de las diferentes fracciones.

- Lona de resistencia adecuada y no absorbente, en el caso que la caracterización se realice en el suelo y que este no este pavimentado, para evitar la contaminación de la muestra.

- Palas, azadas y otras herramientas para la manipulación de los residuos.

- Herramientas para cortar o abrir las bolsas.

- Cepillo para la limpieza del suelo.

- Cinta de plástico y conos señalizadores para delimitar el espacio de trabajo y para facilitar la toma de muestra cuando se realiza de forma estratificada.

- Imanes.

- Carpeta de trabajo con las hojas de campo.

- Cámara de fotos.

\subsubsection{Consideraciones para la programación de las caracterizaciones}

A la hora de programar la o las campañas de muestreo y caracterización, siempre se tendrá en cuenta la disponibilidad de los titulares o gestores de la planta de TMB donde se van a realizar las mismas, de manera que se minimicen las molestias que estas puedan ocasionar. 
Una vez calculado del número mínimo de muestras necesarias para cada una de las corrientes de rechazo, estas se repartirán entre los estratos en los que se ha dividido la producción anual de rechazo. Por lo que la programación temporal de las caracterizaciones se deberá realizar en función de esta división, de manera que todos los estratos se muestreen correctamente. Además, siempre que sea posible se intentará tomar al menos una muestra por día de la semana.

\subsubsection{Localización y condiciones para realizar las caracterizaciones}

Siempre que sea posible las caracterizaciones se realizarán en la planta de tratamiento, donde los titulares o gestores de las mismas deberán garantizar una zona acotada y señalizada para su realización. Esta deberá estar suficientemente iluminada y ventilada, evitando la circulación de maquinaria pesada por el lugar mientras se estén realizando las caracterizaciones.

Los rechazos a caracterizar se depositarán en una zona limpia y pavimentada para evitar la contaminación de la muestra y, preferiblemente, a cubierto para evitar las inclemencias meteorológicas. La descarga se realizará directamente sobre el pavimento (o lona si fuera necesaria) y nunca sobre un material absorbente.

La caracterización se llevará a cabo lo más rápido posible desde el momento de la llegada del material y preferentemente con luz natural.

\subsubsection{Casos especiales en la clasificación de los materiales}

A continuación, se exponen algunas consideraciones especiales que se deben tener en cuenta a la hora de clasificar los rechazos en las diferentes fracciones.

- Elementos compuestos por diferentes materiales: si pueden ser separados fácilmente, cada material será clasificado en su categoría específica correspondiente. Si por el contrario no se pueden separar, los materiales se clasificarán en base a su fracción mayoritaria.

- Envases llenos: si el contenido pesa más que el envase, todo el conjunto se clasificara en la categoría correspondiente al contenido. En este sentido Edjabou et al. (2015) observaron que la separación de los restos de comida de su envase no afectaba significativamente a los porcentajes obtenidos para la fracción orgánica o los envases, por lo que esta separación es innecesaria.

- Envases llenos de líquidos: por motivos de seguridad, no se abrirán los frascos, botes o envases llenos o semillenos de líquidos. Si el líquido no se puede identificar, el conjunto se clasificará en la categoría de Otros.

- Finos: si los materiales finos no tienen su propia categoría, estos se repartirán en el resto de categorías mediante una estimación visual de los materiales contenidos en los mismos.

- Aparición de un residuo sanitario de riesgo: en el caso de que durante la caracterización aparezca un residuo sanitario de riesgo biológico o un residuo cortante o punzante que pueda contener material biológico que suponga un riesgo de contagio grave (p. ej. una jeringuilla), se procederá a su separación depositándolo en un lugar seguro y visible. La caracterización se continuará con las máximas precauciones posibles. En el caso que aparezca de nuevo otro residuo de este tipo, la caracterización se interrumpirá dándose por finalizada.

\subsection{CASOS DE APLICACIÓN PARA DETERMINAR DEL TAMAÑO MÍNIMO DE MUESTRA (ETAPA I)}

Una vez desarrollada la metodología para la determinación del tamaño mínimo de muestra (Etapa I), esta ha sido aplicada a dos plantas de TMB diferentes. El objetivo es determinar el tamaño mínimo de muestra para el control de calidad de las diferentes corrientes de rechazo generadas en dichas instalaciones y que son susceptibles de ser transformados en CSR. 
A partir de los proyectos mencionados en la financiación de la presente tesis, en los que la doctoranda ha participado, se ha contado con la colaboración de la Planta de Recuperación y Compostaje de Onda (Castellón), donde se ha aplicado la metodología en dos épocas del año diferentes: primavera-verano (fase 1) y otoño-invierno (fase 2) con el objetivo de comprobar si el tamaño de muestra es diferente en función de la estacionalidad. Estos proyectos también han permitido tener acceso a la Planta de Biosecado y Recuperación de Cervera del Maestre (Castellón), donde se ha aplicado la metodología en un único periodo: primavera-verano.

Para la determinación el tamaño mínimo de muestra se van a seguir los cuatro puntos de la metodología propuesta:

1. Cálculo del tamaño de muestra inicial

2. Definición de las fracciones a caracterizar

3. Procedimiento de división del tamaño de muestra inicial

4. Determinación del tamaño mínimo de muestra

\subsubsection{Caso 1: Determinación del tamaño mínimo de muestra en la planta de recuperación y compostaje de Onda}

\subsubsection{Descripción de la planta}

La PRC de Onda (Figura 6.4) trata los RSU mezclados gestionados por el Consorcio de Residuos C2 (Zona Centro de la provincia de Castellón) procedentes de 46 municipios cuya población suma 364.947 habitantes. La capacidad de tratamiento de la instalación es de 120.000 t/año, sin embargo, en 2017 se trataron un total de 163.000 t de RSU mezclados.

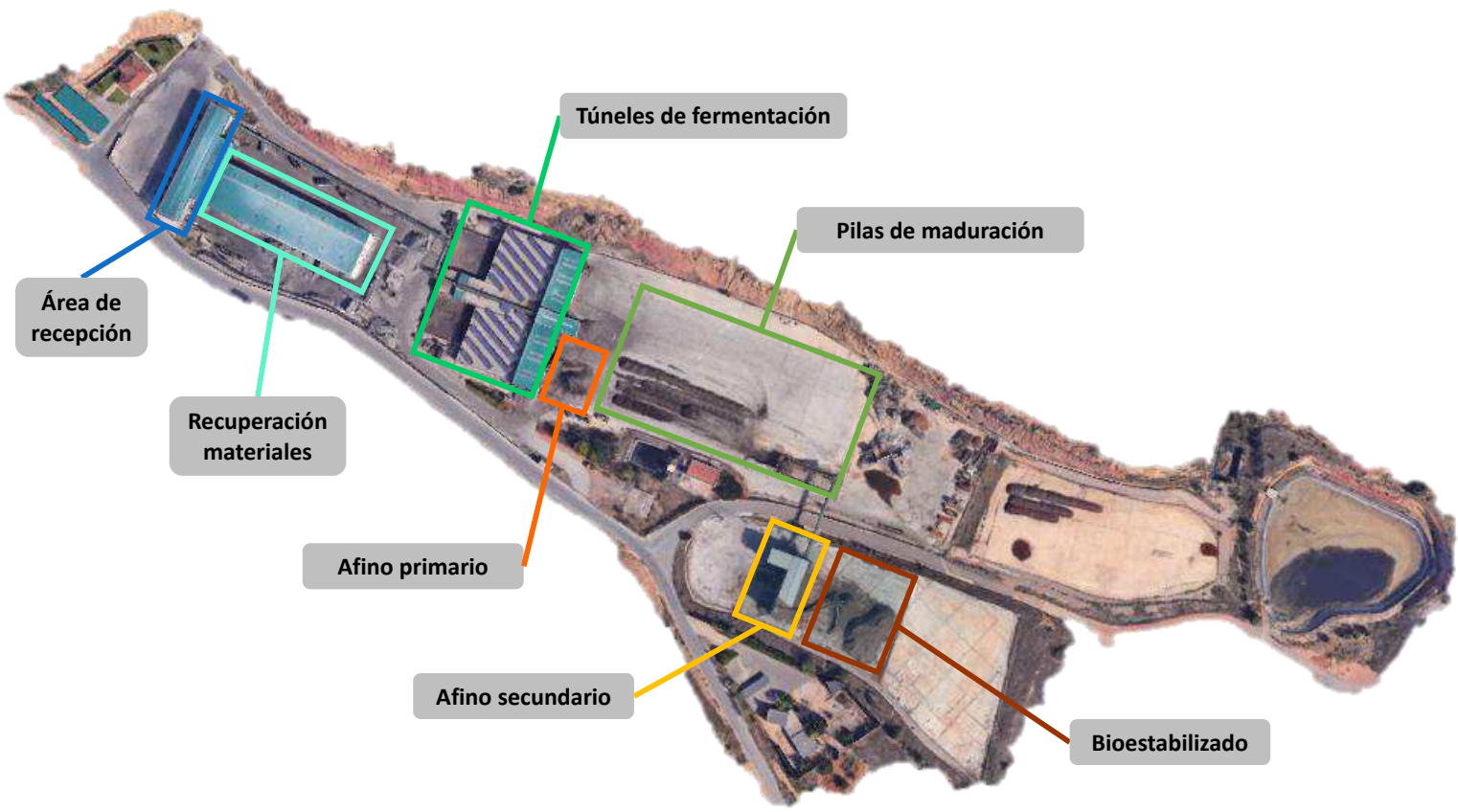

Figura 6.4 Planta de recuperación y compostaje de Onda

La recuperación de los materiales reciclables se realiza de forma mecánica y manual, separando: PET, PEAD, plástico mix, cartón, brik, metales férricos, metales no férricos y vidrio. La fracción orgánica de los residuos se destina a bioestabilización mediante túneles y posterior maduración en pilas, con una duración total del proceso de 8-9 semanas. 
En cuanto al balance de masas y respecto al material entrante, tras el tratamiento de los RSU se obtienen un flujo de materiales recuperados (5,5\%), un flujo de material bioestabilizado (4,7\%) y varias corrientes de rechazo (75,3\%). Las pérdidas del proceso (emisiones gaseosas y liquidas) suponen el $14,5 \%$ del material entrante.

Las corrientes de rechazo de las cuales se pueden obtener un CSR y que se han considerado para su estudio son (Figura 6.5):

- Rechazo de recuperación manual (RRM-O): generado en la etapa de recuperación de materiales, tras la separación de los materiales reciclables del rebose del trómel de pretratamiento, con un diámetro de partícula superior a $80 \mathrm{~mm}$.

- Rechazo de afino primario del bioestabilizado (RAB1-0): generado en el trómel intermedio de afino del material pre-bioestabilizado que procede de la fermentación en túneles, con un tamaño de partícula entre 80 y $30 \mathrm{~mm}$.

- Rechazo de afino secundario del bioestabilizado (RAB2-0): generado en la mesa densimétrica de afino final del bioestabilizado, con un tamaño de partícula entre 30 y $14 \mathrm{~mm}$.
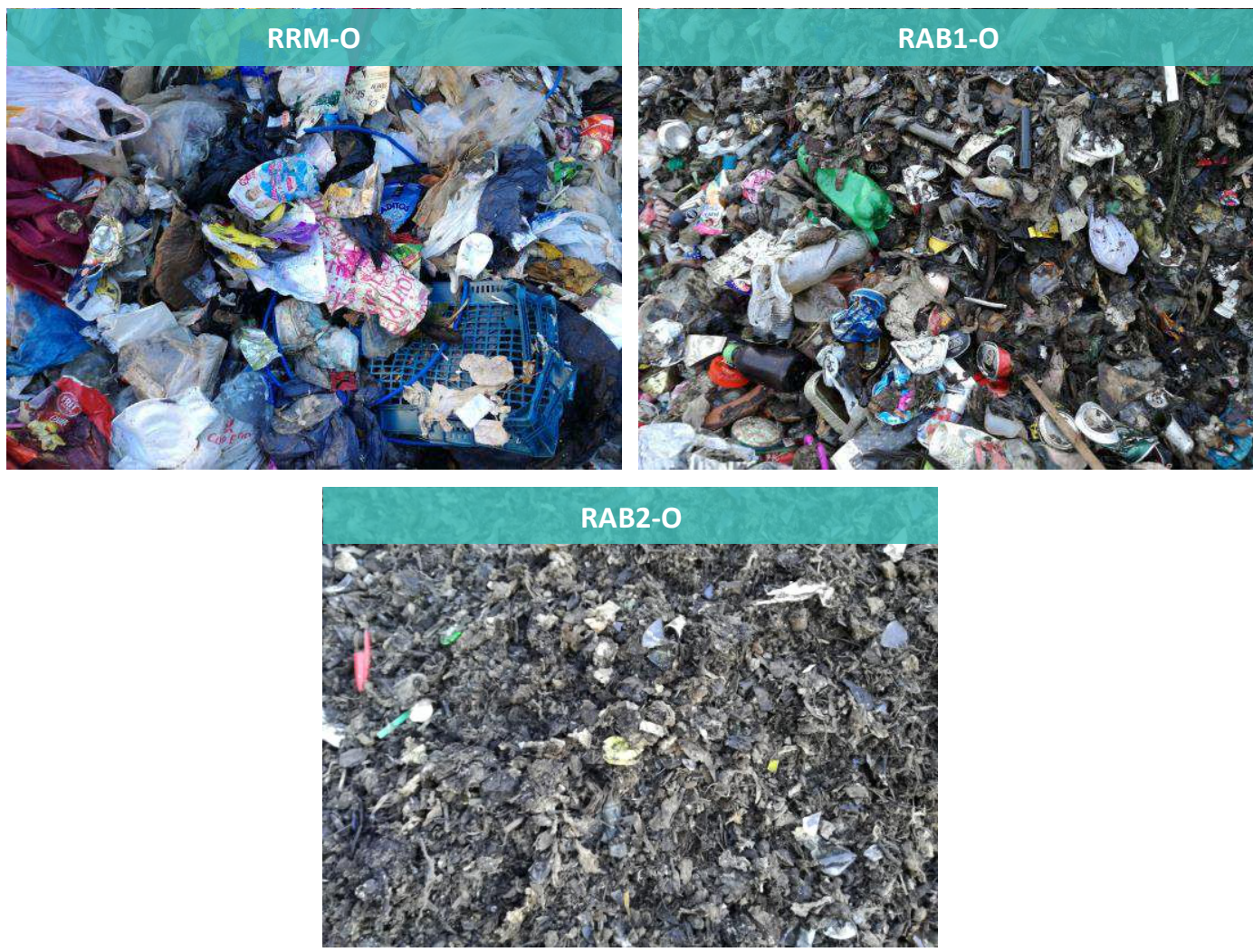

Figura 6.5 Rechazos generados en la planta de recuperación y compostaje de Onda

\subsubsection{Cálculo del tamaño de muestra inicial}

En primer lugar, siguiendo la metodología propuesta, se calculó el tamaño de muestra inicial para las tres corrientes de rechazo mediante la ecuación 6.1. Para ello, a partir de la muestra control, se determinaron todos los parámetros relacionados con las propiedades físicas de los rechazos que forman parte de dicha ecuación. El peso de las muestras control fue de aproximadamente $30 \mathrm{~kg}$ para el RRM-O, de $10 \mathrm{~kg}$ para el RAB1-O y de unos $5 \mathrm{~kg}$ para el RAB2-O. 


\section{Determinación del tamaño nominal superior y el tamaño mínimo de partícula}

En el caso del RRM-O, debido a que su diámetro de partícula es superior a $80 \mathrm{~mm}$, el tamaño nominal superior $\left(d_{95}\right)$ se determinó mediante la norma UNE-EN 15415-2. Para ello se tomó una muestra de 13,36 kg de material, se estableció como límite inferior de tamaño $70 \mathrm{~mm}$ y como superior $770 \mathrm{~mm}$ y se midió la longitud máxima de todas las partículas por encima límite inferior para su clasificación. El tamaño mínimo de partícula (do5) se determinó con la norma UNE-EN 15415-1 utilizando un conjunto de tamices. Las clases de tamaño consideradas y los resultados obtenidos se muestran en la Tabla 6.5. Además, en la Figura 6.6 se pueden ver las piezas que componen el $d_{95}$ y el $d_{05}$ para este rechazo.

Tabla 6.5 Tamaño nominal superior y tamaño mínimo de partícula del RRM-O

\begin{tabular}{|c|c|c|c|c|c|}
\hline $\begin{array}{c}\text { Clases de tamaño } \\
(\mathrm{mm})\end{array}$ & Peso (kg) & $\%$ en peso & $\begin{array}{c}\% \\
\text { acumulado }\end{array}$ & $d_{95,1}(m m)^{*}$ & $\mathrm{~d}_{05}(\mathrm{~mm})$ \\
\hline$>770$ & 0 & 0 & 0 & \multirow{12}{*}{570} & \multirow{12}{*}{20} \\
\hline $770-670$ & 0,49 & 3,75 & 3,75 & & \\
\hline $670-570$ & 0,12 & 0,92 & 4,66 & & \\
\hline $570-470$ & 0,36 & 2,75 & 7,42 & & \\
\hline $470-370$ & 0,34 & 2,60 & 10,02 & & \\
\hline $370-270$ & 2,45 & 18,73 & 28,75 & & \\
\hline $270-170$ & 2,19 & 16,74 & 45,49 & & \\
\hline 170- 70 & 1,34 & 10,24 & 55,73 & & \\
\hline $70-20$ & 4,96 & 37,92 & 93,65 & & \\
\hline $20-10$ & 0,42 & 3,21 & 96,87 & & \\
\hline$<10$ & 0,41 & 3,13 & 100 & & \\
\hline Filamentosas & 0,28 & 2,10 & - & & \\
\hline
\end{tabular}

${ }^{*} d_{95,1}:$ longitud máxima de proyectada para las partículas que tienen forma irregular y de grandes dimensiones.

En la Tabla 6.5 se puede observar que el tamaño de partícula predominante en el RRM-O se encuentra entre los 70-20 mm con un 37,92\% de las partículas (Figura 6.6), mientras que entre los tamaños de 370 y $20 \mathrm{~mm}$ se encuentran el $83,64 \%$ de las mismas. Como se ha comentado anteriormente, el RRM-O debería tener un diámetro de partícula superior a $80 \mathrm{~mm}$, puesto que su origen es el rebose de un trómel con esta luz de malla. No obstante, se observa que existen partículas por debajo de este tamaño que no han sido separadas correctamente. Esto se puede deber a diferentes motivos: velocidad de giro del trómel demasiado alta, flujo de entrada de material por encima de la capacidad de diseño del equipo, incorrecta apertura de las bolsas por el abrebolsas, formación de madejas de materiales que atrapan a partículas de pequeño tamaño o adhesión de las partículas como consecuencia de la humedad. 

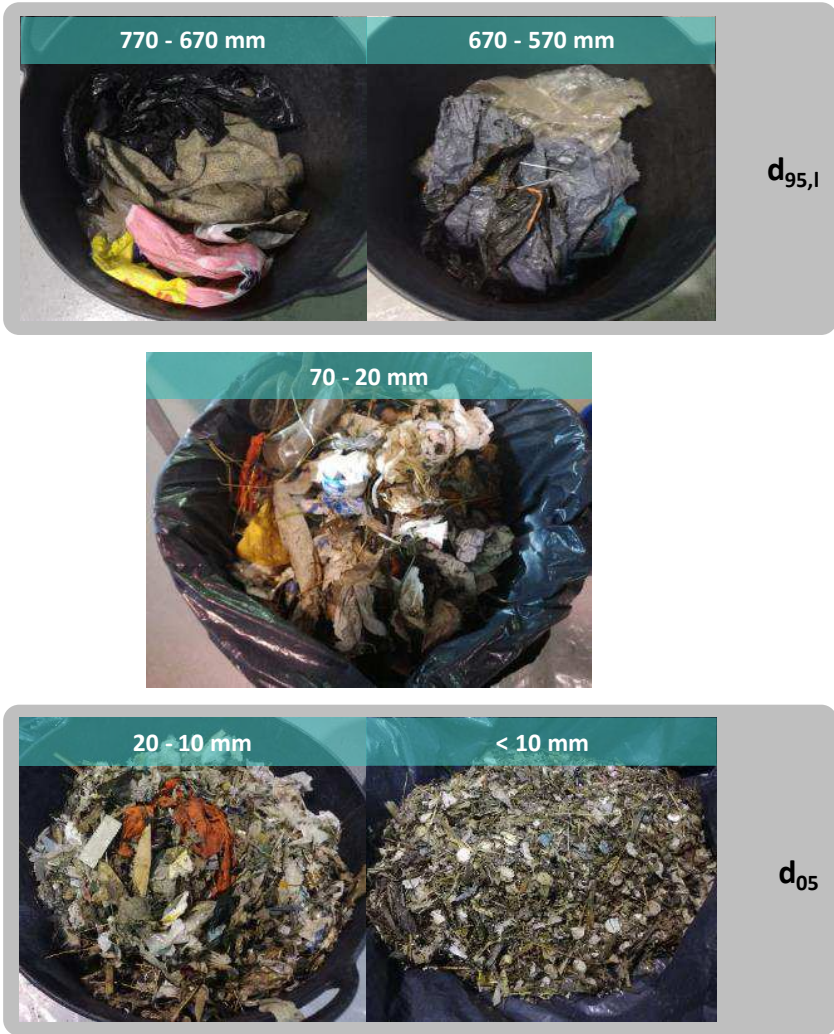

Figura 6.6 Tamaño nominal superior, tamaño mínimo de partícula y tamaño de partícula predominante en el RRM-O

Para las corrientes de rechazo RAB1-O y RAB2-O, el d 95 y el d05 se determinó utilizando la norma UNE-EN $15415-1$, puesto que tienen un diámetro de partícula entre $80-30 \mathrm{~mm}$ y $30-14 \mathrm{~mm}$ respectivamente. Para ello se tamizó aproximadamente $2 \mathrm{~kg}$ de material para cada rechazo. Tras el cribado se obtuvieron los resultados expuestos en la Tabla 6.6 para el RAB1-O y en la Tabla 6.7 para el RAB2-O.

Tabla 6.6 Tamaño nominal superior y tamaño mínimo de partícula del RAB1-O

\begin{tabular}{|c|c|c|c|c|c|}
\hline $\begin{array}{l}\text { Clases de tamaño } \\
(\mathrm{mm})\end{array}$ & Peso (kg) & $\%$ en peso & $\begin{array}{c}\% \\
\text { acumulado }\end{array}$ & $d_{95}(\mathrm{~mm})$ & $d_{05}(\mathrm{~mm})$ \\
\hline$>70$ & 0,11 & 5,19 & 5,19 & \multirow{5}{*}{70} & \multirow{5}{*}{5} \\
\hline $70-60$ & 0,18 & 8,58 & 13,77 & & \\
\hline $60-10$ & 1,57 & 75,02 & 88,78 & & \\
\hline $10-5$ & 0,11 & 5,13 & 93,92 & & \\
\hline$<5$ & 0,13 & 6,08 & 100 & & \\
\hline
\end{tabular}

El tamaño de partícula mayoritario en el RAB1-O se encuentra entre los 60-10 mm con un 75,02\% del material (Tabla 6.6), existiendo partículas con tamaños menores a los esperados según su origen (rebose de un trómel de $30 \mathrm{~mm}$ ), esto es debido a los mismos motivos explicados anteriormente. En la Figura 6.7 se muestran las partículas que componen el d95, el d05 y el rango de tamaño mayoritario para este rechazo. 

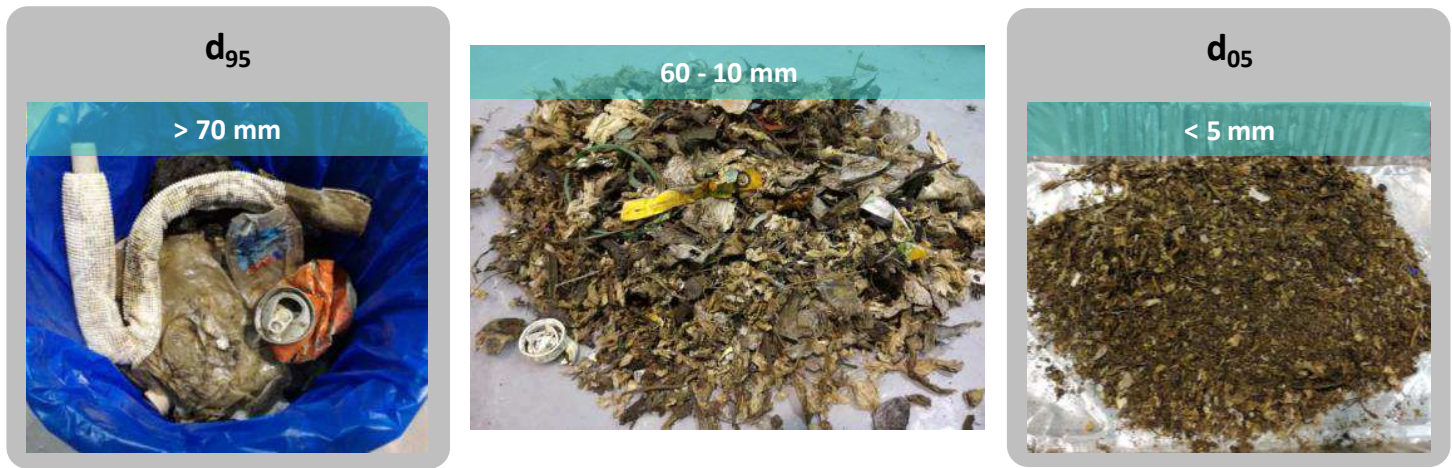

Figura 6.7 Tamaño nominal superior, tamaño mínimo de partícula y tamaño de partícula predominante en el RAB1-O

En la Tabla 6.7 se puede ver que el tamaño de partícula predominante en el RAB2-O es de $20-5 \mathrm{~mm}$ $(75,46 \%)$, con partículas menores al tamaño esperado $(30-14 \mathrm{~mm})$ debido a las razones anteriormente enumeradas. En la Figura 6.8 se pueden ver las partículas que componen el d95, el do5 y el rango de tamaño mayoritario para este rechazo.

Tabla 6.7 Tamaño nominal superior y tamaño mínimo de partícula del RAB2-O

\begin{tabular}{|c|c|c|c|c|c|}
\hline $\begin{array}{c}\text { Clases de tamaño } \\
(\mathrm{mm})\end{array}$ & Peso (kg) & $\%$ en peso & $\begin{array}{c}\% \\
\text { acumulado }\end{array}$ & $\mathrm{d}_{95}(\mathrm{~mm})$ & $d_{05}(\mathrm{~mm})$ \\
\hline$>\mathbf{3 0}$ & 0 & 0 & 0 & \multirow{5}{*}{20} & \multirow{5}{*}{1} \\
\hline $30-20$ & 0,17 & 8,23 & 8,23 & & \\
\hline $20-5$ & 1,57 & 75,46 & 83,69 & & \\
\hline $5-1$ & 0,26 & 12,40 & 96,09 & & \\
\hline$<1$ & 0,08 & 3,91 & 100 & & \\
\hline
\end{tabular}
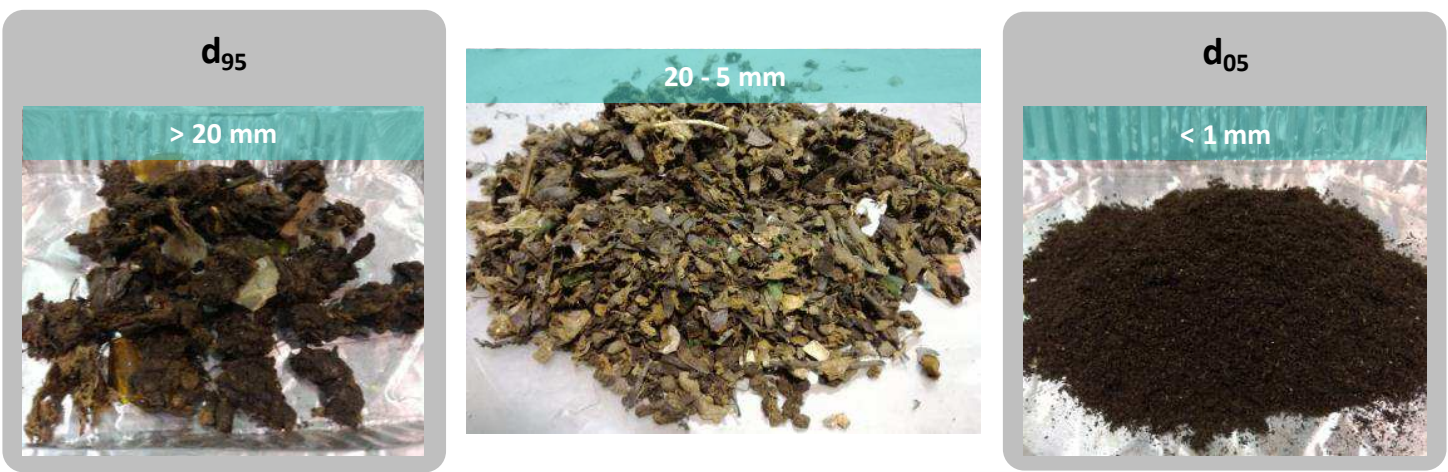

Figura 6.8 Tamaño nominal superior, tamaño mínimo de partícula y tamaño de partícula predominante en el RAB2-O

\section{Determinación del factor forma}

El factor forma $(f)$ se determinó mediante la ecuación 6.2. En la Tabla 6.8 se muestran los valores obtenidos para las tres corrientes de rechazo. 
Tabla 6.8 Factor forma del RRM-O, RAB1-O y RAB2-O

\begin{tabular}{c|c|c|c}
\hline Parámetro & RRM-O & RAB1-0 & RAB2-O \\
\hline $\mathbf{V}_{\mathbf{9 5}}\left(\mathbf{m m}^{\mathbf{3}}\right)$ & 826.500 & 120.000 & 15.750 \\
\hline $\mathbf{d}_{95, \mathbf{l}}(\mathbf{m m})$ & 570 & $160^{*}$ & $35^{*}$ \\
\hline $\boldsymbol{f}$ & 0,004 & 0,029 & 0,367 \\
\hline
\end{tabular}

* Los valores de $d_{95, l}$ se obtuvieron a partir de la longitud máxima de la partícula más pequeña que se quedó por encima del tamiz de $d_{95}$.

Como se observa en la tabla anterior, el RRM-O presenta el factor forma más pequeño, esto se debe a que la forma de las partículas de este rechazo se desvían en gran medida de una forma esférica, como se puede ver en la Figura 6.6. Mientras que el RAB2-O, debido a que sus partículas tienen una forma más regular (Figura 6.8), presenta el factor forma más próximo a 1.

\section{Determinación de la densidad media de partícula}

La densidad media de partícula $\left(\lambda_{p}\right)$ se determinó a partir de la ecuación 6.3 y mediante la aplicación del método desarrollado en la metodología a tal efecto, por triplicado (cuadriplicado en el caso del RRM-O). La cantidad de muestra a sumergir se obtuvo a partir de la muestra de control mediante cuarteo.

Para determinar el volumen de partícula de RRM-O, debido a que el tamaño de sus partículas no permitía utilizar un recipiente con marcas de graduación, el volumen desalojado se midió a partir del agua que rebosaba al sumergir el rechazo en un recipiente completamente lleno (Figura 6.9). Esta se recogió y posteriormente se midió su volumen con una probeta. Antes de introducir la muestra en el recipiente, los envases y bolsas presentes fueron agujerados para que el agua pudiera entrar en su interior y no quedaran huecos con aire.
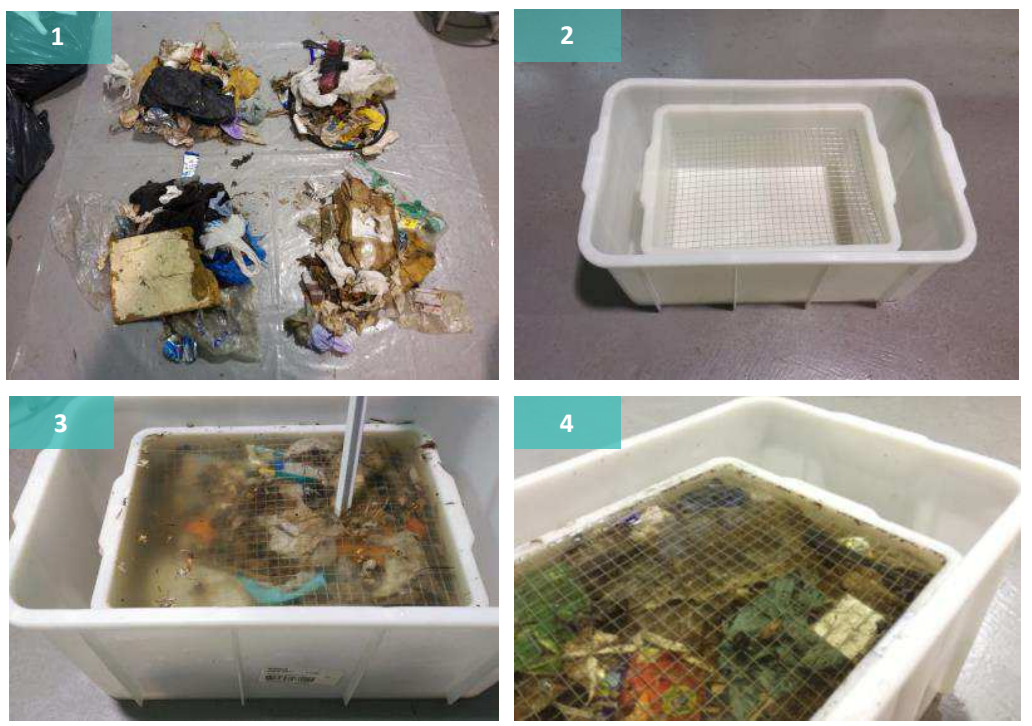

Figura 6.9 Determinación del volumen de partícula RRM-O: cuarteo de muestra control (1), recipiente (2) y muestra sumergida ( 3 y 4 )

En el caso del RAB1-O y el RAB2-O, para medir el volumen de partícula fue necesario diseñar un artilugio que se sumergió en una recipiente graduado, lo que permitió ver la variación de volumen al sumergir los rechazos (Figura 6.10). 

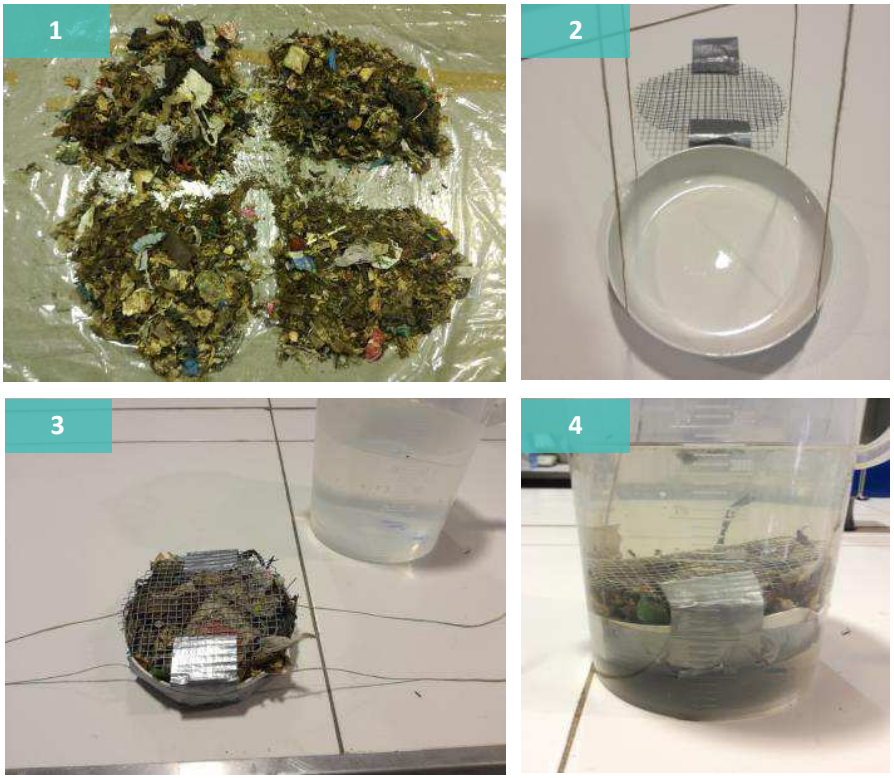

Figura 6.10 Determinación del volumen de partícula RAB1-O: cuarteo de muestra control (1), artilugio (2) y muestra preparada para sumergirla (3) y muestra sumergida (4)

La densidad media de partícula para las tres corrientes de rechazo de la PRC de Onda se muestra en la Tabla 6.9 .

Tabla 6.9 Densidad de partícula del RRM-O, RAB1-O y RAB2-O

\begin{tabular}{c|c|c|c}
\hline$\lambda_{\boldsymbol{p}}\left(\mathbf{k g} / \mathbf{m}^{\mathbf{3}}\right)$ & RRM-0 & RAB1-0 & RAB2-0 \\
\hline Replica 1 & 578,95 & 824,60 & 942,18 \\
\hline Replica 2 & 763,98 & 931,67 & 935,04 \\
\hline Replica 3 & 520,00 & 664,60 & 1020,88 \\
\hline Replica 4 & 568,77 & - & - \\
\hline Media & 607,92 & 806,96 & 966,03 \\
\hline CV (\%) & 17,63 & 16,66 & 4,93 \\
\hline
\end{tabular}

En la tabla anterior se puede observar que el rechazo con mayor densidad media de partícula es el RAB2-O, esto es debido a que este tipo de rechazo está formado principalmente por materia orgánica, trozos de vidrio e inertes, todos ellos materiales muy densos. El RRM-O es el que presenta una menor densidad de partícula ya que está formado por materiales menos densos como plásticos, papel, cartón, textil, madera, etc.

\section{Determinación del factor de distribución en el tamaño de partícula}

El factor de distribución $(g)$ se determinó a partir de la Tabla 6.2 de la metodología en función de la relación entre el tamaño nómina superior $\left(d_{95}\right)$ y el tamaño mínimo de partícula $\left(d_{05}\right)$. Para los tres rechazos analizados el factor de distribución es de 0,25 lo que indica que existe un amplio intervalo de tamaños de partículas en todos ellos.

\section{Determinación del factor $p$ y el coeficiente de variación}

Para estos dos parámetros se utilizaron los valores por defecto que propone la norma UNE-EN 15442 (2012), por lo que $p=0,1$ y $c v=0,1$. 


\section{Cálculo del tamaño de muestra inicial}

A partir de todos los parámetros determinados y la ecuación 6.1 se calculó el tamaño de muestra inicial $\left(\mathrm{m}_{\mathrm{m}}\right)$ para las tres corrientes de rechazo, los resultados obtenidos se muestran en la Tabla 6.10.

Tabla 6.10 Tamaño de muestra inicial para RRM-O, RAB1-O y RAB2-O

\begin{tabular}{c|c|c|c}
\hline Parámetro & RRM-O & RAB1-O & RAB2-0 \\
\hline $\mathbf{d}_{95}(\mathbf{m m})$ & 570 & 70 & 20 \\
\hline $\mathbf{d}_{95, \mathbf{l}}(\mathbf{m m})$ & 570 & 160 & 35 \\
\hline $\mathbf{d}_{05}(\mathbf{m m})$ & 20 & 5 & 1 \\
\hline $\mathbf{V}_{\mathbf{9 5}}\left(\mathbf{m m}^{3}\right)$ & 826.500 & 120.000 & 15.750 \\
\hline $\boldsymbol{f}\left(\mathbf{m m}^{\mathbf{3}} / \mathbf{m m}^{3}\right)$ & 0,004 & 0,029 & 0,367 \\
\hline$\lambda_{p}\left(\mathbf{k g} / \mathbf{m}^{3}\right)$ & 607,92 & 806,96 & 966,03 \\
\hline $\boldsymbol{g}$ & 0,25 & 0,25 & 0,25 \\
\hline $\boldsymbol{p}(\mathbf{k g} / \mathbf{k g})$ & 0,1 & 0,1 & 0,1 \\
\hline $\boldsymbol{c v}$ & 0,1 & 0,1 & 0,1 \\
\hline $\mathbf{m}_{\mathbf{m}}(\mathbf{k g})$ & 59,19 & 0,955 & 0,334 \\
\hline $\mathbf{m}_{\mathbf{m}}(\mathbf{k g})$ & $\mathbf{6 0}$ & $\mathbf{1}$ & $\mathbf{0 , 4}$ \\
\hline
\end{tabular}

* Valor redondeado al alza

En la Tabla 6.10 se observa que para cada rechazo se obtiene un tamaño de muestra inicial diferente. Esto se debe a que los rechazos tienen unas propiedades distintas en función del proceso de tratamiento donde se originan. Así pues, es fundamental determinar un tamaño mínimo de muestra específico para cada corriente de rechazo de forma que este se adapte sus propiedades y características.

\subsubsection{Definición de las fracciones a caracterizar}

Las fracciones de residuos que se han considerado para hacer las caracterizaciones son las propuestas por la metodología, con dos pequeñas excepciones para el RAB1-O y el RAB2-O.

Para el RRM-O los rechazos se han dividido en las 13 categorías mostradas en la Tabla 6.3. Mientras que en el caso de los rechazos de afino del bioestabilizado se han clasificado en 11 categorías, puesto que para el RAB1-O y el RAB2-O el papel/cartón (que estaba muy sucio y/o semidegradado) y los finos se incluyeron dentro de la fracción orgánica.

\subsubsection{Procedimiento de división del tamaño de muestra inicial}

Una vez calculado el tamaño de muestra inicial y definidas las fracciones a caracterizar se llevó a cabo la caracterización de los rechazos mediante el procedimiento propuesto en la metodología. Este se ha dividido en los siguientes puntos:

1. Programación temporal de las caracterizaciones

2. Selección del lote de la corriente de rechazo a muestrear

3. División de tamaño de muestra inicial y caracterización de las muestras

Por otro lado, cada día de trabajo se contabilizó el tiempo necesario para el muestreo y caracterización de cada una de las corrientes de rechazo, lo que ha permitido estimar las horas de trabajo de campo necesarias para la aplicación del procedimiento. Los resultados obtenidos respecto al tiempo invertido se comentarán en un punto específico al final del caso de estudio. 


\section{Programación temporal de las caracterizaciones}

El muestreo y caracterización de los rechazos generados en la PRC de Onda se ha llevado a cabo durante el año 2017. En la fase 1 la toma de muestras se ha realizado durante los meses de mayo y junio (primaveraverano), mientras que en la fase 2 se ha realizado durante los meses de noviembre y diciembre (otoñoinvierno). Dentro de cada fase, los días de muestreo y caracterización se han elegido repartidos durante los diferentes días de la semana (salvo los fines de semana), con el objetivo de minimizar las posibles variaciones diarias que puedan existir en la composición de los rechazos.

Cada día de muestreo un equipo de trabajo formado de 2 a 4 personas se desplazaba a la PRC de Onda con todo el equipamiento necesario para llevar a cabo la toma de muestras y su caracterización. A continuación, se muestra el calendario con la programación temporal de la fase 1 (Tabla 6.11) y de la fase 2 (Tabla 6.12). Las tablas también incluyen el número de muestras caracterizadas para cada nivel de submuestreo. En cada fase se han caracterizado como mínimo 10 muestras por corriente de rechazo y nivel de submuestreo, como indica la metodología, de forma que se puedan aplicar los métodos estadísticos paramétricos para la determinación del tamaño de mínimo de muestra (si se cumplen los supuestos para su utilización).

Cabe señalar que para el RAB1-O y el RAB2-O, debido a que el tamaño de lote recomendado es más manejable, el número total de muestras por nivel en cada periodo se ha duplicado a 20 con el objetivo de mejorar los resultados de los análisis estadísticos. Para ello, cada día de muestreo, se caracterizaban dos muestras por nivel. En el caso del RRM-O, durante tres días de la fase 1 también se caracterizaron dos muestras por nivel de submuestreo con el fin de aumentar el número de datos (Tabla 6.11). No obstante, esto supuso una gran carga de trabajo extra, por lo que en el segundo periodo se desechó la idea, tomando solo una muestra diaria por nivel (Tabla 6.12).

Tabla 6.11 Programación temporal y número de muestras para la fase 1 en la PRC de Onda

\begin{tabular}{|c|c|c|c|c|}
\hline \multirow{2}{*}{ Día semana } & \multirow{2}{*}{ Fecha } & \multicolumn{3}{|c|}{ Núm. de muestras por nivel de submuestrec } \\
\hline & & RRM-O & RAB1-O & RAB2-O \\
\hline \multirow{2}{*}{ Lunes } & $29 / 05 / 2017$ & 1 & 2 & 2 \\
\hline & $19 / 06 / 2017$ & 2 & 2 & 2 \\
\hline \multirow{2}{*}{ Martes } & $30 / 05 / 2017$ & 1 & 2 & 2 \\
\hline & $20 / 06 / 2017$ & 1 & 2 & 2 \\
\hline \multirow{2}{*}{ Miércoles } & $31 / 05 / 2017$ & 1 & 2 & 2 \\
\hline & $07 / 06 / 2017$ & 1 & 2 & 2 \\
\hline \multirow{2}{*}{ Jueves } & $01 / 06 / 2017$ & 2 & 2 & 2 \\
\hline & 08/06/2017 & 1 & 2 & 2 \\
\hline \multirow{2}{*}{ Viernes } & $26 / 05 / 2017$ & 2 & 2 & 2 \\
\hline & 02/06/2017 & 1 & 2 & 2 \\
\hline \multicolumn{2}{|c|}{$\begin{array}{c}\text { Total muestras por nivel de } \\
\text { submuestreo }\end{array}$} & 13 & 20 & 20 \\
\hline
\end{tabular}


Tabla 6.12 Programación temporal y número de muestras para la fase 2 en la PRC de Onda

\begin{tabular}{|c|c|c|c|c|}
\hline \multirow{2}{*}{ Día semana } & \multirow{2}{*}{ Fecha } & \multicolumn{3}{|c|}{ Núm. de muestras por nivel de submuestreo } \\
\hline & & RRM-O & RAB1-0 & RAB2-O \\
\hline \multirow{2}{*}{ Lunes } & $20 / 11 / 2017$ & 1 & 2 & 2 \\
\hline & $04 / 12 / 2017$ & 1 & 2 & 2 \\
\hline \multirow{2}{*}{ Martes } & $21 / 11 / 2017$ & 1 & 2 & 2 \\
\hline & $28 / 11 / 2017$ & 1 & 2 & 2 \\
\hline \multirow{2}{*}{ Miércoles } & $22 / 11 / 2017$ & 1 & 2 & 2 \\
\hline & $13 / 12 / 2017$ & 1 & 2 & 2 \\
\hline \multirow{2}{*}{ Jueves } & $23 / 11 / 2017$ & 1 & 2 & 2 \\
\hline & $30 / 11 / 2017$ & 1 & 2 & 2 \\
\hline \multirow{2}{*}{ Viernes } & $24 / 11 / 2017$ & 1 & 2 & 2 \\
\hline & $01 / 12 / 2017$ & 1 & 2 & 2 \\
\hline \multicolumn{2}{|c|}{$\begin{array}{c}\text { Total muestras por nivel de } \\
\text { submuestreo }\end{array}$} & 10 & 20 & 20 \\
\hline
\end{tabular}

\section{Selección del lote de la corriente de rechazo a muestrear}

La selección del lote de la corriente de rechazo se llevó a cabo mediante un muestreo a juicio de experto sobre los rechazos accesibles de las tres corrientes de rechazo analizadas, puesto que no se pudo tener acceso a la cantidad total generada diariamente. Los rechazos accesibles son aquellos generados durante las horas previas al momento del muestreo, los cuales se disponen en pilas estáticas. La extracción del lote a partir de dichas pilas se realizó con técnicas probabilísticas mediante un muestreo aleatorio simple.

En el caso del RRM-O, cada día de muestreo la pila fue homogeneizada por los operarios de la planta mediante una pala mecánica. A continuación, utilizando la misma maquinaria, se seleccionaron varios incrementos de material en diferentes puntos escogidos aleatoriamente. Los incrementos se unieron para formar el lote (Figura 6.11) cuyo tamaño fue de aproximadamente $1.000 \mathrm{~kg}$.

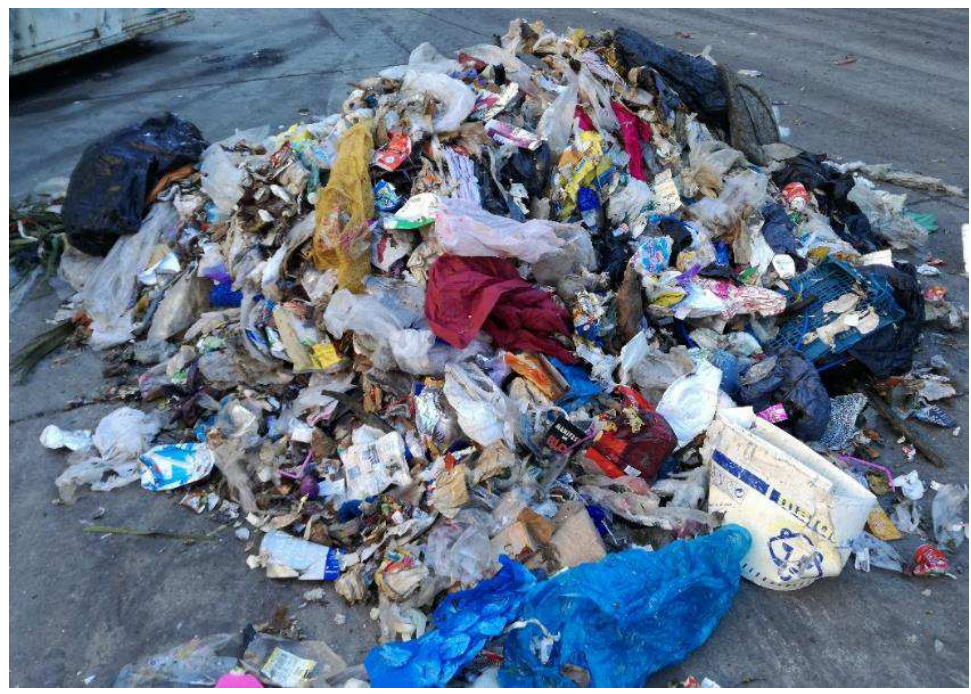

Figura 6.11 Lote de RRM-O

Para el RAB1-O y el RAB2-O, debido a que el material es más homogéneo y el tamaño de lote necesario menor, el muestreo del rechazo accesible se realizó tomando varios incrementos de forma aleatoria de la 
pila con una pala manual. Los diferentes incrementos se juntaron para formar el lote, cuyo tamaño fue de aproximadamente $15 \mathrm{~kg}$ para el RAB1-O y de $5 \mathrm{~kg}$ para el RAB-O, como indica la metodología. En la Figura 6.12 se muestra un ejemplo de pilas de rechazo para ambas corrientes, de ellas se extrajo el lote correspondiente a ese día.
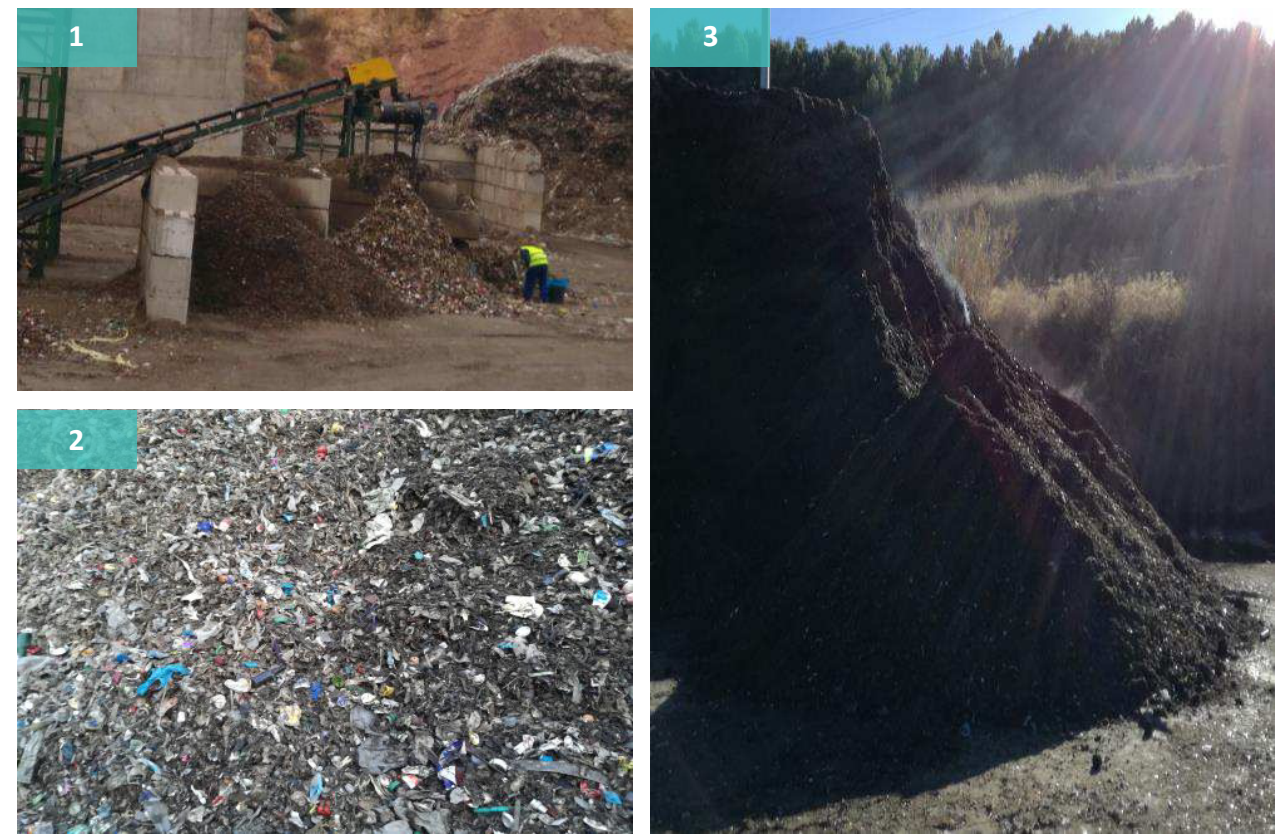

Figura 6.12 Pila de RAB1-O (1 y 2); pila de RAB2-O (3)

\section{División de tamaño de muestra inicial y caracterización de las muestras}

Los pesos de los diferentes niveles de submuestreo para las tres corrientes de rechazo se obtuvieron a partir de la división del tamaño de muestra inicial $\left(\mathrm{m}_{\mathrm{m}}\right)$ siguiendo el esquema propuesto por la metodología (Figura 6.3). A continuación, se explica cómo se llevaron a cabo esta división y las caracterizaciones para cada uno de los rechazos analizados.

En el caso del RRM-O, las caracterizaciones se realizaron en la propia planta de tratamiento, por lo que cada día de muestreo el lote se depositó en una superficie limpia y pavimentada. Los pesos de muestra utilizados en cada nivel de submuestreo aparecen en la Figura 6.13.

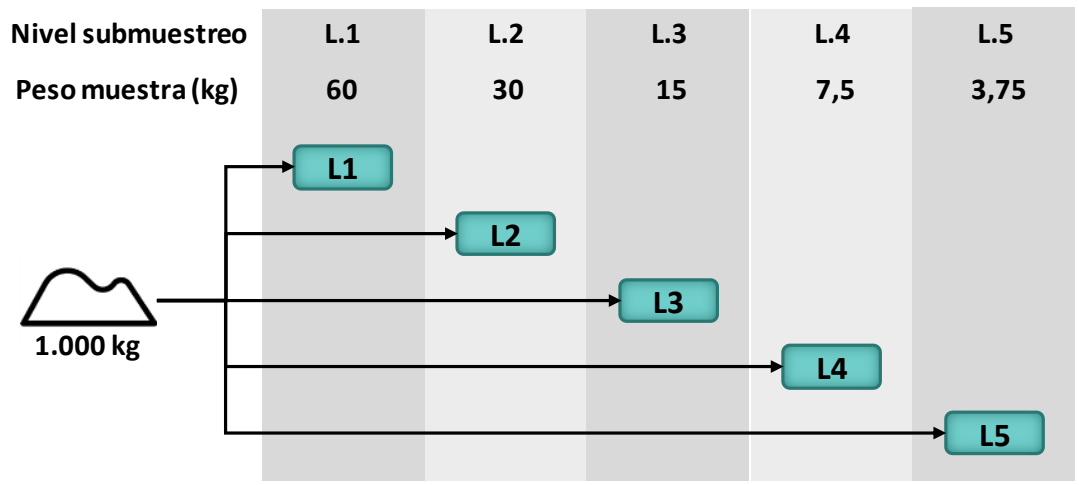

Figura 6.13 Esquema de procedimiento de división del tamaño de muestra inicial del RRM-O

Las muestras para cada nivel de submuestreo se obtuvieron tomando varios incrementos en diferentes puntos del lote mediante una pala manual. Los incrementos se introducían en un cubo de 100 litros que, una vez lleno, se pesaba y se extendía en la zona de caracterización (Figura 6.14). Esta operación se repitió 
las veces necesarias para conseguir el peso de muestra correspondiente al nivel de submuestreo a caracterizar.

La caracterización consistió en la clasificación del material en las 13 categorías definidas. Los materiales se iban seleccionando y depositando en los recipientes correspondientes, los cuales estaban identificados y tarados a tal efecto (Figura 6.14).
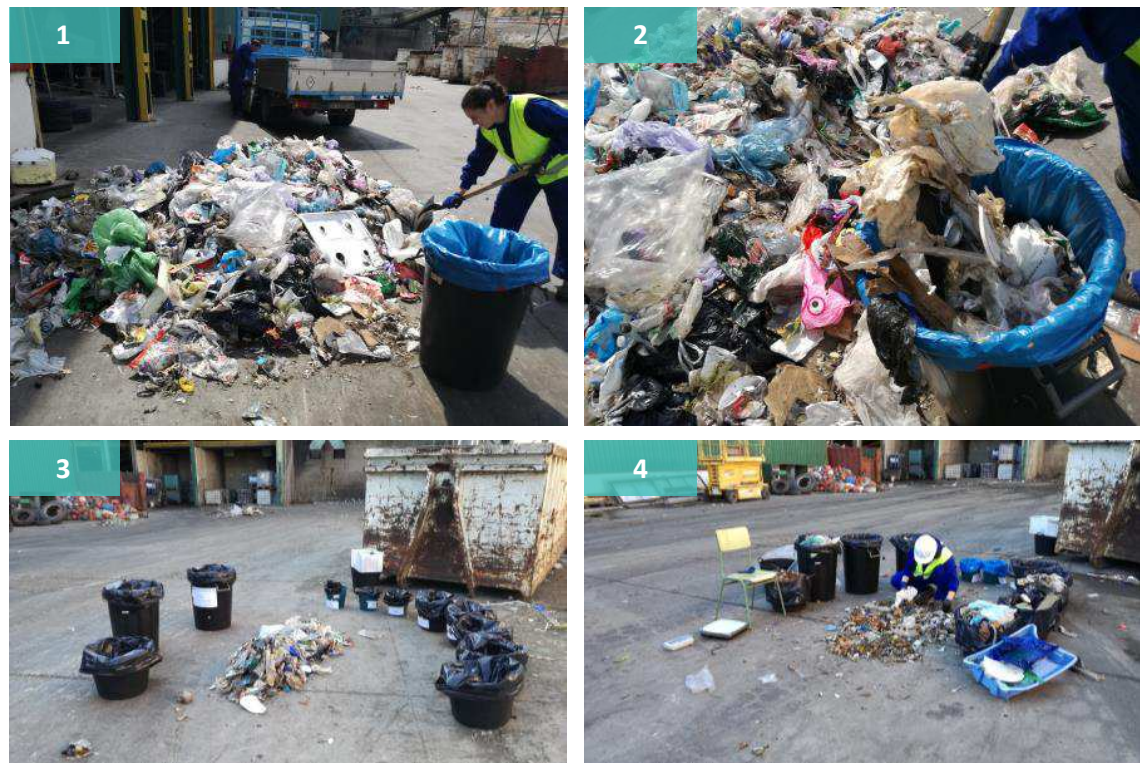

Figura 6.14 Toma de muestras ( 1 y 2 ) y caracterización (3 y 4) del RRM-O

Al finalizar la separación y clasificación, se determinó el peso de cada fracción por separado en una báscula de plataforma con una precisión de 10 gramos y se anotaron los pesos obtenidos en las hojas de campo. En la Figura 6.15 se muestran varias fotos de algunas de las fracciones caracterizadas para el RRM-O.
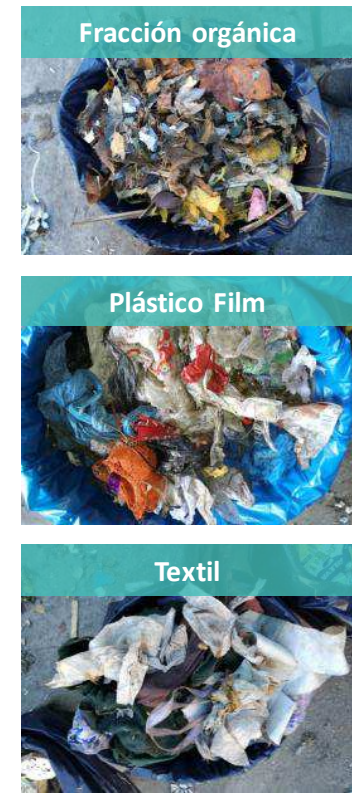
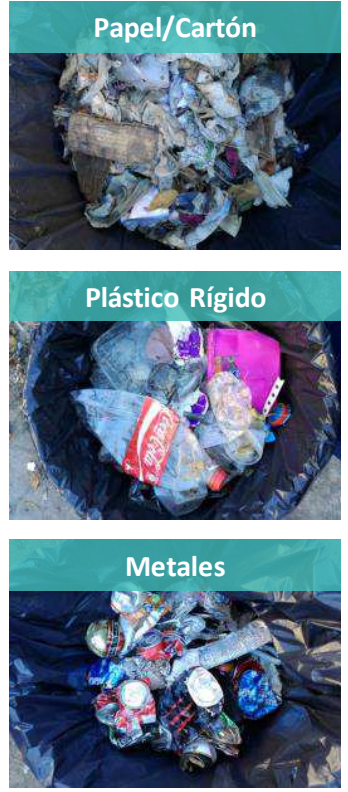
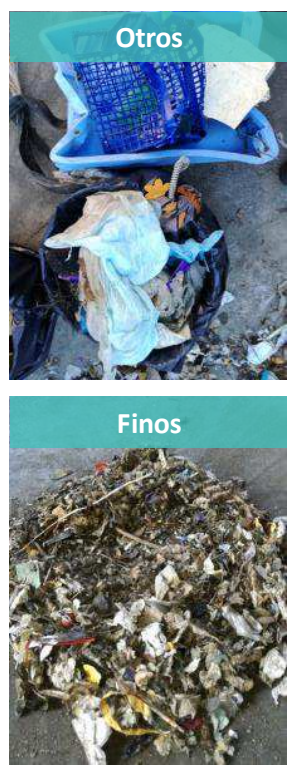

Figura 6.15 Fracciones separadas del RRM-O

Respecto al RAB1-O y el RAB2-O, puesto que el tamaño del lote es más pequeño y manejable, al finalizar la jornada se procedía a la selección de los lotes que se trasladaban al laboratorio del grupo de investigación INGRES en la Universitat Jaume I para su caracterización. Los pesos de muestra utilizados en cada nivel de submuestreo se muestran en la Figura 6.16 para el RAB1-O y en la Figura 6.17 para el RAB2-O. 


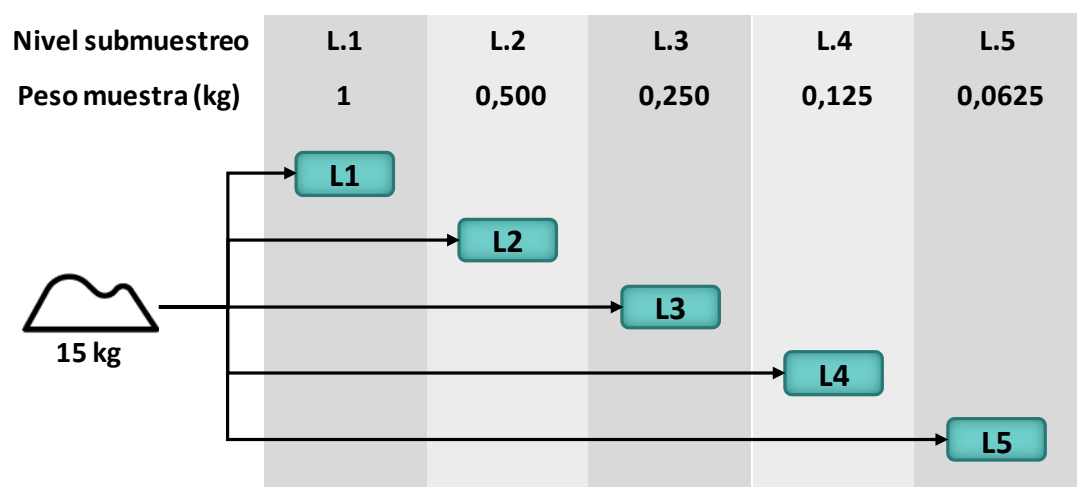

Figura 6.16 Esquema de procedimiento de división del tamaño de muestra inicial del RAB1-O

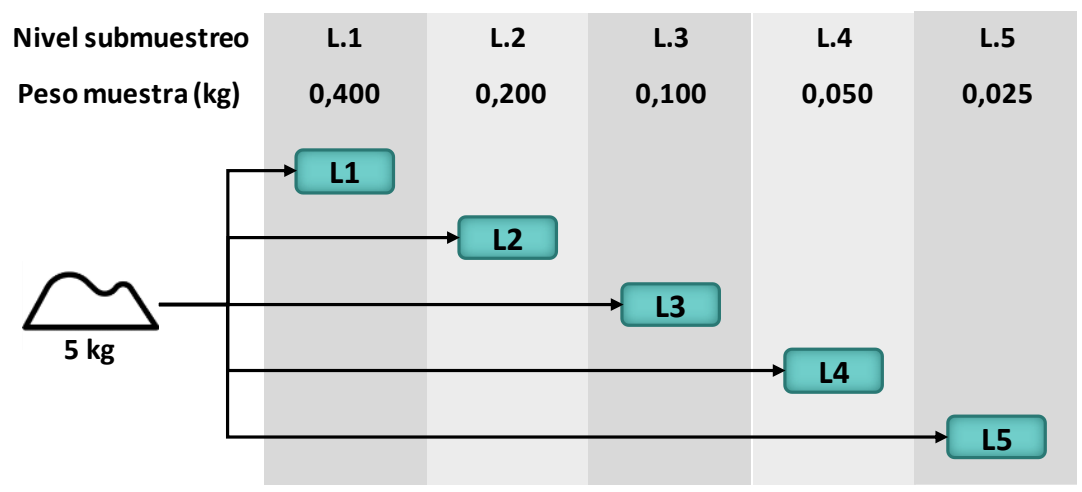

Figura 6.17 Esquema de procedimiento de división del tamaño de muestra inicial del RAB2-O

Las muestras de cada nivel de submuestreo se obtuvieron mediante el cuarteo del lote. La caracterización de estos rechazos fue realizada por dos personas que extendieron la muestra sobre una mesa limpia, clasificándola en las 11 categorías (Figura 6.18).
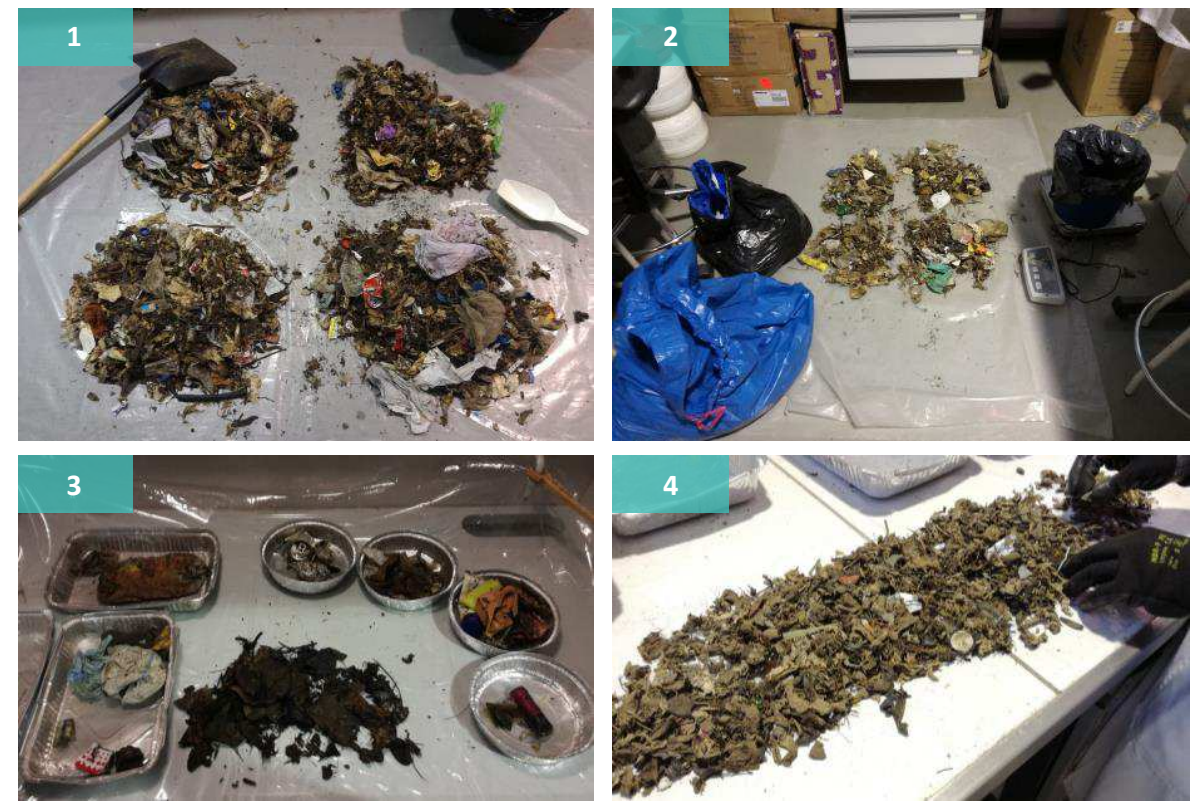

Figura 6.18 Cuarteo y caracterización del RAB1-O (1, 2 y 3), caracterización RAB2-O (4) 
Al finalizar se determinó el peso de cada fracción por separado en una balanza con una precisión de 0,01 gramos y se anotaron los pesos obtenidos en las hojas de campo. En la Figura 6.19 y Figura 6.20 se muestran varias fotos de algunas de las fracciones caracterizadas para el RAB1-O y RAB2-O respectivamente.
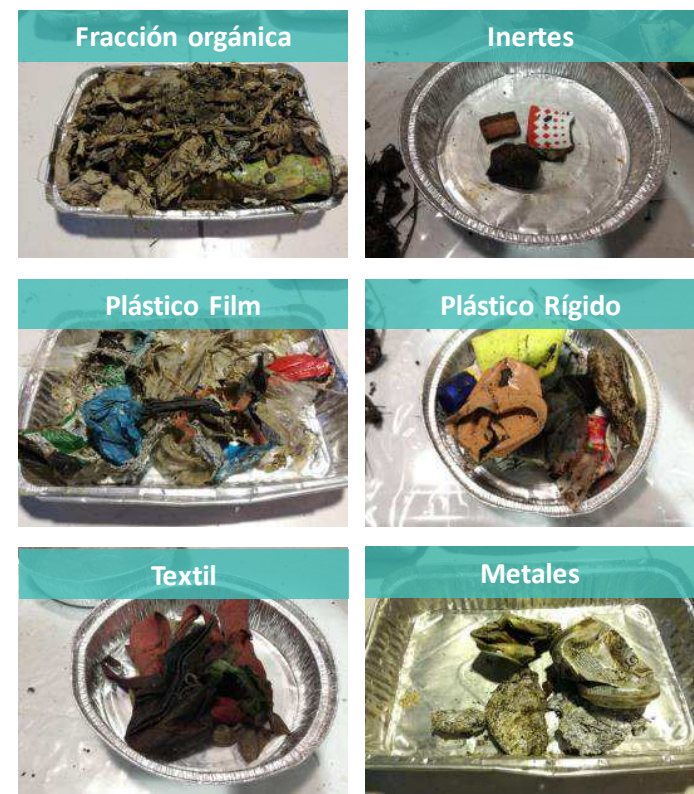

Figura 6.19 Fracciones separadas del RAB1-O
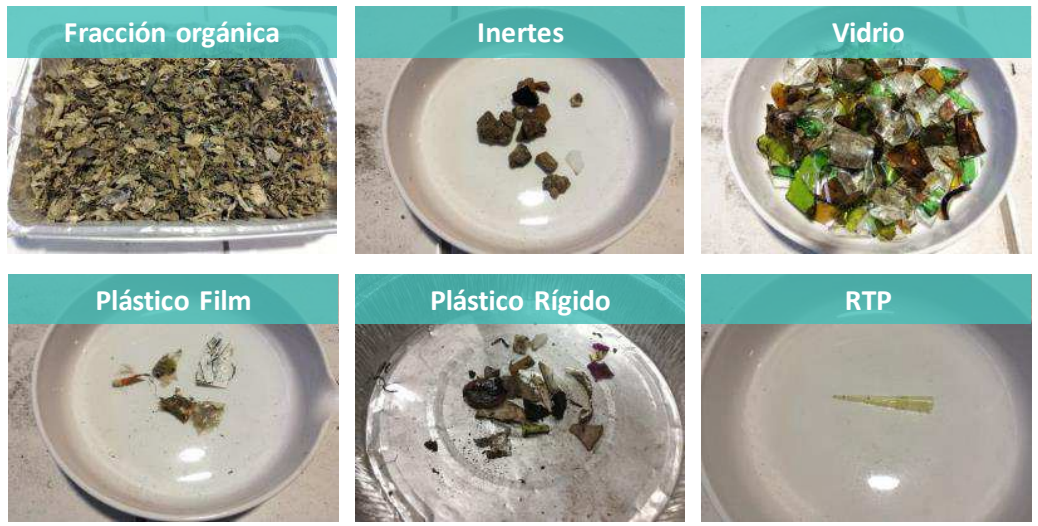

Figura 6.20 Fracciones separadas del RAB2-O

\subsubsection{Determinación del tamaño mínimo de muestra}

Una vez obtenidos los datos de composición para cada día, fase y nivel de submuestreo se ha procedido a la determinación del tamaño mínimo de muestra con el que se obtienen resultados representativos para cada corriente de rechazo. Para ello, se debe analizar si existen diferencias significativas en la composición de los rechazos en función del nivel de submuestreo. La metodología propone una serie de procedimientos estadísticos para llevar a cabo este análisis.

En primer lugar, para cada fracción de la composición, se ha realizado una comparación de medias mediante un ANOVA y se comprobaron los supuestos de Normalidad y de homocedasticidad (comparación de varianzas). Los datos de las fracciones cuyos residuos del ANOVA fueron no Normales se transformaron (transformación arcoseno) con el objetivo de mejorar su distribución. A continuación, se ha aplicado de 
nuevo el ANOVA a los datos transformados y se volvieron a comprobar los dos supuestos. En función de los supuestos cumplidos la comparación se ha realizado con una prueba estadística u otra:

- $\quad$ ANOVA (paramétrico): cuando se cumplen ambos supuestos, haya sido necesario transformar los datos o no.

- $\quad$ ANOVA de Welch (paramétrico): cuando los residuos del modelo sí que son Normales, pero las varianzas son diferentes. Puede haber sido necesario transformar los datos o no.

- Test de Kruskal-Wallis (no paramétrico): cuando el supuesto de Normalidad no se cumple en ninguno de los dos casos, es decir con los datos sin transformar o con los datos transformados.

Por último, para aquellas fracciones donde se han obtenido diferencias estadísticamente significativas en función del nivel de submuestreo, se han realizado los test post-hoc correspondientes con el objetivo de conocer entre que niveles se dan estas diferencias (Tukey para el ANOVA y Dunn para el test de KruskallWallis). Esto ha permitido identificar cual es el nivel de submuestreo crítico en el que los resultados dejan de ser representativos, determinando de este modo el tamaño mínimo de muestra $\left(m_{f}\right)$.

Todos los análisis estadísticos se realizaron con el programa de acceso libre $\mathrm{R}$ y su paquete $\mathrm{R}$ Commander, el nivel de confianza utilizado ha sido del $95 \%(\alpha=0,05)$.

A continuación, se exponen los resultados de las caracterizaciones de las tres corrientes de rechazo, así como resultados de los análisis estadísticos.

\section{Determinación del tamaño mínimo de muestra para el RRM-O}

Como se ha visto en la programación temporal, para esta corriente de rechazo el número de muestras por nivel de submuestreo fue de 13 en la primera fase y de 10 en la segunda. Los tamaños de muestra para cada nivel son los indicadas en la Figura 6.13, mientas que los pesos medios de muestra obtenidos tras la caracterizaciones se exponen en la Tabla 6.13. La cantidad total de RRM-O muestreada y caracterizada fue de $1.533,74 \mathrm{~kg}$ en la fase 1 y de $1.175,53 \mathrm{~kg}$ en la fase 2.

Tabla 6.13 Peso medio de muestra por nivel de submuestreo para el RRM-O

\begin{tabular}{|c|c|c|c|c|c|c|c|c|c|c|}
\hline \multirow{3}{*}{ Peso de muestra (kg) } & \multicolumn{10}{|c|}{ Nivel Submuestreo } \\
\hline & \multicolumn{2}{|c|}{ L1 (60 kg) } & \multicolumn{2}{|c|}{ L2 (30 kg) } & \multicolumn{2}{|c|}{ L3 (15 kg) } & \multicolumn{2}{|c|}{ L4 (7,5 kg) } & \multicolumn{2}{|c|}{ L5 (3,75 kg) } \\
\hline & $\bar{x}$ & s & $\bar{x}$ & s & $\bar{x}$ & s & $\bar{x}$ & s & $\bar{x}$ & s \\
\hline Fase 1 & 60,20 & 3,06 & 30,10 & 1,54 & 15,43 & 0,56 & 8,01 & 0,79 & 4,25 & 0,49 \\
\hline Fase 2 & 59,87 & 0,53 & 30,24 & 0,88 & 15,34 & 0,37 & 7,83 & 0,47 & 4,26 & 0,37 \\
\hline
\end{tabular}

A continuación, se exponen los resultados obtenidos tras las caracterizaciones en ambas fases, Tabla 6.14 y Tabla 6.15 respectivamente. En ellas se muestra la composición media para los cinco niveles de submuestreo, así como su desviación estándar. 
Tabla 6.14 Composición media por nivel de submuestreo para el RRM-O, fase 1

\begin{tabular}{|c|c|c|c|c|c|c|c|c|c|c|}
\hline \multirow{3}{*}{$\begin{array}{c}\text { Composición (\%) } \\
\text { Fracción }\end{array}$} & \multicolumn{10}{|c|}{ Nivel Submuestreo } \\
\hline & \multicolumn{2}{|c|}{ L1 (60 kg) } & \multicolumn{2}{|c|}{ L2 (30 kg) } & \multicolumn{2}{|c|}{ L3 (15 kg) } & \multicolumn{2}{|c|}{ L4 (7,5 kg) } & \multicolumn{2}{|c|}{ L5 (3,75 kg) } \\
\hline & $\bar{x}$ & s & $\bar{x}$ & s & $\bar{x}$ & s & $\bar{x}$ & s & $\bar{x}$ & s \\
\hline Fracción orgánica & 18,81 & 6,60 & 19,86 & 6,89 & 17,65 & 6,92 & 19,05 & 5,59 & 19,81 & 9,20 \\
\hline Papel/Cartón & 14,06 & 4,52 & 14,47 & 6,35 & 15,36 & 4,64 & 16,85 & 8,55 & 20,23 & 11,42 \\
\hline Plástico Film & 11,50 & 1,82 & 11,56 & 2,55 & 11,19 & 2,99 & 12,01 & 2,74 & 9,75 & 4,46 \\
\hline Plástico Rígido & 11,49 & 1,86 & 10,93 & 3,30 & 11,24 & 4,29 & 13,41 & 5,59 & 14,23 & 5,54 \\
\hline Textil & 9,27 & 4,70 & 9,86 & 3,28 & 10,67 & 7,66 & 9,07 & 5,94 & 4,36 & 3,82 \\
\hline Metales & 3,78 & 1,07 & 3,24 & 1,35 & 3,37 & 1,32 & 3,89 & 1,32 & 5,43 & 3,37 \\
\hline Madera & 3,49 & 1,69 & 3,14 & 2,46 & 3,19 & 3,02 & 2,34 & 2,75 & 4,98 & 5,13 \\
\hline Brik & 1,72 & 0,38 & 1,65 & 0,71 & 1,47 & 0,91 & 2,47 & 1,21 & 2,14 & 1,74 \\
\hline Inertes & 1,16 & 1,10 & 2,24 & 1,88 & 1,17 & 1,05 & 1,11 & 1,88 & 1,30 & 2,75 \\
\hline RTP & 0,65 & 0,77 & 0,61 & 0,73 & 0,28 & 0,46 & 0,25 & 0,45 & 0,13 & 0,33 \\
\hline Vidrio & 0,65 & 0,36 & 0,60 & 0,38 & 0,77 & 0,53 & 0,95 & 1,08 & 1,25 & 1,02 \\
\hline Otros & 10,87 & 2,75 & 11,78 & 2,72 & 14,02 & 3,63 & 10,05 & 4,99 & 9,35 & 3,66 \\
\hline Finos & 12,53 & 14,10 & 10,08 & 10,00 & 9,61 & 8,70 & 8,54 & 5,20 & 7,04 & 3,41 \\
\hline
\end{tabular}

Tabla 6.15 Composición media por nivel de submuestreo para el RRM-O, fase 2

\begin{tabular}{|c|c|c|c|c|c|c|c|c|c|c|}
\hline \multirow{3}{*}{$\begin{array}{c}\text { Composición (\%) } \\
\text { Fracción }\end{array}$} & \multicolumn{10}{|c|}{ Nivel Submuestreo } \\
\hline & \multicolumn{2}{|c|}{ L1 (60 kg) } & \multicolumn{2}{|c|}{ L2 (30 kg) } & \multicolumn{2}{|c|}{ L3 (15 kg) } & \multicolumn{2}{|c|}{ L4 (7,5 kg) } & \multicolumn{2}{|c|}{ L5 (3,75 kg) } \\
\hline & $\bar{x}$ & s & $\bar{x}$ & s & $\bar{x}$ & s & $\bar{x}$ & s & $\bar{x}$ & s \\
\hline Fracción orgánica & 22,01 & 3,18 & 18,65 & 3,50 & 19,80 & 3,71 & 19,48 & 4,93 & 14,70 & 5,95 \\
\hline Papel/Cartón & 18,56 & 4,23 & 20,91 & 6,00 & 21,19 & 4,56 & 20,44 & 4,59 & 22,97 & 5,71 \\
\hline Plástico Film & 11,73 & 1,40 & 11,43 & 2,07 & 11,41 & 1,08 & 14,07 & 7,01 & 12,39 & 5,33 \\
\hline Plástico Rígido & 10,00 & 1,62 & 10,14 & 1,21 & 11,33 & 2,82 & 9,72 & 4,31 & 12,21 & 5,78 \\
\hline Textil & 7,49 & 2,71 & 7,05 & 3,17 & 5,81 & 2,35 & 4,53 & 3,56 & 7,59 & 5,24 \\
\hline Metales & 3,48 & 1,18 & 3,46 & 1,25 & 2,47 & 0,54 & 2,22 & 0,97 & 4,23 & 2,57 \\
\hline Madera & 2,31 & 1,18 & 2,44 & 1,49 & 2,68 & 2,15 & 4,26 & 3,22 & 1,78 & 1,58 \\
\hline Brik & 1,58 & 0,32 & 1,77 & 0,72 & 1,84 & 0,52 & 1,59 & 0,73 & 2,69 & 1,34 \\
\hline Inertes & 0,82 & 0,68 & 0,61 & 0,69 & 1,74 & 2,00 & 0,89 & 1,87 & 1,04 & 1,56 \\
\hline RTP & 1,17 & 0,88 & 1,07 & 1,68 & 0,49 & 0,25 & 0,59 & 0,62 & 1,47 & 2,19 \\
\hline Vidrio & 1,02 & 0,60 & 0,94 & 0,46 & 1,13 & 0,90 & 1,73 & 1,59 & 1,61 & 1,35 \\
\hline Otros & 14,47 & 2,27 & 15,94 & 8,94 & 14,66 & 5,51 & 13,79 & 5,61 & 12,86 & 6,42 \\
\hline Finos & 5,35 & 2,79 & 5,58 & 3,31 & 5,46 & 2,94 & 6,70 & 2,88 & 4,48 & 2,10 \\
\hline
\end{tabular}


Los estadísticos de contraste y p-valores obtenidos tras la aplicación de los diferentes test a las 13 fracciones de residuos se muestran en la Tabla 6.16 para la fase 1 y en la Tabla 6.17 para la fase 2. Cabe señalar que las pruebas utilizadas para comprobar los supuestos de Normalidad y homocedasticidad aparecen en primer lugar para favorecer la comprensión del procedimiento estadístico. No obstante, en la práctica estos se comprueban a posteriori de la realización del ANOVA.

Tabla 6.16 Análisis estadístico RRM-0, fase 1

\begin{tabular}{|c|c|c|c|c|c|c|c|c|}
\hline \multirow{3}{*}{$\begin{array}{c}\text { Test estadístico } \\
\text { Tipo de prueba } \\
\text { Fracción }\end{array}$} & \multirow{2}{*}{\multicolumn{2}{|c|}{$\begin{array}{c}\text { Test de Shapiro-Wilk } \\
\text { Bondad de ajuste: } \\
\text { Normalidad }\end{array}$}} & \multirow{2}{*}{\multicolumn{2}{|c|}{$\begin{array}{l}\text { Test de Levene } \\
\text { Comparación de } \\
\text { varianzas }\end{array}$}} & \multirow{2}{*}{\multicolumn{2}{|c|}{$\begin{array}{c}\text { ANOVA / ANOVA de } \\
\text { Welch } \\
\text { Comparación de } \\
\text { medias }\end{array}$}} & \multirow{2}{*}{\multicolumn{2}{|c|}{$\begin{array}{c}\text { Test de Kuskal-Wallis } \\
\text { Comparación de } \\
\text { medianas }\end{array}$}} \\
\hline & & & & & & & & \\
\hline & $\mathbf{w}$ & p-valor & $\mathbf{F}$ & p-valor & $\mathbf{F}$ & p-valor & H & p-valor \\
\hline Fracción orgánica & 0,983 & 0,532 & 1,205 & 0,318 & 0,208 & 0,933 & - & - \\
\hline Papel/Cartón & 0,891 & $<0,001$ & - & - & - & - & 4,368 & 0,358 \\
\hline Plástico Film & 0,986 & 0,673 & 2,727 & 0,037 & 0,601 & 0,665 & - & - \\
\hline Plástico Rígido* & 0,971 & 0,134 & 2,520 & 0,051 & 1,370 & 0,255 & - & - \\
\hline Textil* & 0,985 & 0,633 & 2,087 & 0,094 & 3,717 & 0,009 & - & - \\
\hline Metales & 0,827 & $<0,001$ & - & - & - & - & 5,755 & 0,218 \\
\hline Madera* & 0,974 & 0,183 & 3,054 & 0,023 & 0,958 & 0,445 & - & - \\
\hline Brik & 0,973 & 0,162 & 4,339 & 0,004 & 1,581 & 0,207 & - & - \\
\hline Inertes & 0,720 & $<0,001$ & - & - & - & - & 8,665 & 0,070 \\
\hline RTP & 0,746 & $<0,001$ & - & - & - & - & 15,231 & 0,004 \\
\hline Vidrio* & 0,975 & 0,212 & 3,758 & 0,009 & 0,477 & 0,752 & - & - \\
\hline Otros & 0,964 & 0,054 & 1,765 & 0,148 & 3,214 & 0,019 & - & - \\
\hline Finos & 0,704 & $<0,001$ & - & - & - & - & 0,761 & 0,944 \\
\hline
\end{tabular}

* Fracciones en las que la transformación de los datos ha mejorado su distribución, aproximándola a la Normal y permitiendo usar pruebas paramétricas con los datos transformados.

Tabla 6.17 Análisis estadístico RRM-O, fase 2

\begin{tabular}{|c|c|c|c|c|c|c|c|c|}
\hline \multirow{3}{*}{$\begin{array}{c}\text { Test estadístico } \\
\text { Tipo de prueba } \\
\text { Fracción }\end{array}$} & \multirow{2}{*}{\multicolumn{2}{|c|}{$\begin{array}{c}\text { Test de Shapiro-Wilk } \\
\text { Bondad de ajuste: } \\
\text { Normalidad }\end{array}$}} & \multirow{2}{*}{\multicolumn{2}{|c|}{$\begin{array}{l}\text { Test de Levene } \\
\text { Comparación de } \\
\text { varianzas }\end{array}$}} & \multirow{2}{*}{\multicolumn{2}{|c|}{$\begin{array}{c}\text { ANOVA / ANOVA de } \\
\text { Welch } \\
\text { Comparación de } \\
\text { medias }\end{array}$}} & \multirow{2}{*}{\multicolumn{2}{|c|}{$\begin{array}{c}\text { Test de Kuskal-Wallis } \\
\text { Comparación de } \\
\text { medianas }\end{array}$}} \\
\hline & & & & & & & & \\
\hline & $\mathbf{w}$ & p-valor & $\mathbf{F}$ & p-valor & $\mathbf{F}$ & p-valor & $\mathbf{H}$ & p-valor \\
\hline Fracción orgánica & 0,981 & 0,581 & 1,532 & 0,209 & 3,725 & 0,011 & - & - \\
\hline Papel/Cartón & 0,970 & 0,235 & 0,296 & 0,879 & 0,972 & 0,433 & - & - \\
\hline Plástico Film & 0,699 & $<0,001$ & - & - & - & - & 0,596 & 0,964 \\
\hline Plástico Rígido & 0,904 & 0,001 & - & - & - & - & 3,512 & 0,476 \\
\hline Textil* & 0,984 & 0,740 & 1,223 & 0,315 & 1,648 & 0,179 & - & - \\
\hline Metales & 0,972 & 0,289 & 6,490 & $<0,001$ & 3,639 & 0,021 & - & - \\
\hline Madera* & 0,972 & 0,277 & 1,744 & 0,157 & 1,756 & 0,154 & - & - \\
\hline Brik & 0,950 & 0,034 & - & - & - & - & 5,482 & 0,241 \\
\hline
\end{tabular}




\begin{tabular}{c|c|c|c|c|c|c|c|c}
\hline Inertes & 0,739 & $<0,001$ & - & - & - & - & 5,479 & 0,242 \\
\hline RTP & 0,718 & $<0,001$ & - & - & - & - & 3,202 & 0,525 \\
\hline Vidrio* & 0,967 & 0,175 & 2,951 & 0,030 & 0,352 & 0,840 & - & - \\
\hline Otros & 0,835 & $<0,001$ & - & - & - & - & 1,688 & 0,793 \\
\hline Finos & 0,888 & $<0,001$ & - & - & - & - & 5,104 & 0,277 \\
\hline
\end{tabular}

* Fracciones en las que la transformación de los datos ha mejorado su distribución, aproximándola a la Normal y permitiendo usar pruebas paramétricas con los datos transformados.

Respecto a la fase 1, los resultados obtenidos tras el análisis estadístico del RRM-O indican que existen diferencias significativas en el porcentaje de textil, RTP y Otros entre los distintos niveles de submuestreo, puesto que el $p$-valor obtenido en la comparación de medias o medianas para estas fracciones es menor a 0,05 (Tabla 6.16). Así pues, se puede afirmar con una confianza del $95 \%$ que el porcentaje de estos materiales en el RRM-O es diferente en función del tamaño de muestra y, por lo tanto, los resultados obtenidos a cierto nivel de submuestreo dejan de ser representativos de la población de rechazo muestreada. En cuanto a la fase 2, estas diferencias se dan para la fracción orgánica y los metales ( $p$-valor < 0,05) (Tabla 6.17).

Para el resto de fracciones de la fase 1 y fase 2 no se han encontrado diferencias estadísticamente significativas en función del nivel de submuestreo, ya que los p-valores obtenidos son mayores que 0,05. Esto indica que el porcentaje de estos materiales es el mismo para todos los tamaños de muestra del RRM0 , es decir, que los resultados son representativos incluso con el nivel de submuestreo más bajo. Por lo que el tamaño mínimo de muestra para estas fracciones es el correspondiente al L5: 3,75 kg.

Finalmente, en la Tabla 6.18 (fase 1) y Tabla 6.19 (fase 2) se muestran los resultados de los test post hoc realizados a las fracciones que presentan diferencias significativas en función del nivel de submuestreo. Así como el nivel de submuestreo crítico identificado y el tamaño mínimo de muestra para el RRM-O determinado a partir de estos resultados ( $\mathrm{m} f \mathrm{RRM}-\mathrm{O})$.

Tabla 6.18 Test post hoc RRM-O, fase 1

\begin{tabular}{|c|c|c|c|c|c|c|}
\hline \multirow{3}{*}{$\begin{array}{c}\text { Fracción } \\
\text { Test post hoc } \\
\text { Comparaciones }\end{array}$} & \multicolumn{2}{|c|}{ Textil* } & \multicolumn{2}{|c|}{ RTP } & \multicolumn{2}{|c|}{ Otros } \\
\hline & \multicolumn{2}{|c|}{ Tukey } & \multicolumn{2}{|c|}{ Dunn } & \multicolumn{2}{|c|}{ Tukey } \\
\hline & $t$ & p-valor & z & p-valor & $\mathbf{t}$ & p-valor \\
\hline L1 - L2 & $-0,012$ & 0,998 & $-0,156$ & 0,876 & $-0,633$ & 0,969 \\
\hline L1 - L3 & $-0,012$ & 0,998 & 1,788 & 0,123 & $-2,201$ & 0,193 \\
\hline L2 - L3 & 0,000 & 1,000 & 1,944 & 0,104 & $-1,569$ & 0,523 \\
\hline L1 - L4 & 0,011 & 0,998 & 2,121 & 0,085 & 0,576 & 0,978 \\
\hline L2 - L4 & 0,023 & 0,972 & 2,277 & 0,076 & 1,209 & 0,746 \\
\hline L3 - L4 & 0,023 & 0,974 & 0,333 & 0,821 & 2,778 & 0,055 \\
\hline L1 - L5 & 0,109 & 0,039 & 3,005 & 0,013 & 1,066 & 0,823 \\
\hline L2 - L5 & 0,121 & 0,016 & 3,161 & 0,016 & 1,698 & 0,443 \\
\hline L3 - L5 & 0,121 & 0,017 & 1,216 & 0,320 & 3,267 & 0,015 \\
\hline L4 - L5 & 0,098 & 0,080 & 0,884 & 0,471 & 0,489 & 0,989 \\
\hline Nivel crítico & \multicolumn{2}{|c|}{ L5 (3,75 kg) } & \multicolumn{2}{|c|}{ L5 (3,75 kg) } & \multicolumn{2}{|c|}{ L5 (3,75 kg) } \\
\hline $\begin{array}{l}\mathrm{m}_{\mathrm{f}} \text { RRM-O } \\
\text { Fase } 1(\mathrm{Kg})\end{array}$ & \multicolumn{2}{|c|}{7,5} & \multicolumn{2}{|c|}{7,5} & \multicolumn{2}{|c|}{7,5} \\
\hline
\end{tabular}


* Test aplicado a los datos transformados

Tabla 6.19 Test post hoc RRM-O, fase 2

\begin{tabular}{|c|c|c|c|c|}
\hline \multirow{3}{*}{$\begin{array}{c}\text { Fracción } \\
\text { Test post hoc } \\
\text { Comparaciones }\end{array}$} & \multicolumn{2}{|c|}{ Fracción Orgánica } & \multicolumn{2}{|c|}{ Metales } \\
\hline & \multicolumn{2}{|c|}{ Tukey } & \multicolumn{2}{|c|}{ Tukey } \\
\hline & $\mathbf{t}$ & p-valor & $\mathbf{t}$ & p-valor \\
\hline L1 - L2 & 1,717 & 0,434 & 0,030 & 1,000 \\
\hline L1 - L3 & 1,128 & 0,791 & 1,538 & 0,544 \\
\hline L2 - L3 & $-0,588$ & 0,976 & 1,508 & 0,563 \\
\hline L1 - L4 & 1,295 & 0,696 & 1,917 & 0,323 \\
\hline L2 - L4 & $-0,422$ & 0,993 & 1,887 & 0,339 \\
\hline L3 - L4 & 0,166 & 1,000 & 0,379 & 0,996 \\
\hline L1 - L5 & 3,736 & 0,005 & $-1,145$ & 0,782 \\
\hline L2 - L5 & 2,019 & 0,274 & $-1,175$ & 0,765 \\
\hline L3 - L5 & 2,608 & 0,086 & $-2,683$ & 0,073 \\
\hline L4 - L5 & 2,441 & 0,123 & $-3,062$ & 0,029 \\
\hline Nivel crítico & \multicolumn{2}{|c|}{ L5 $(3,75$ kg) } & \multicolumn{2}{|c|}{$\operatorname{L} 5(3,75 \mathrm{~kg})$} \\
\hline $\begin{array}{l}\mathrm{m}_{\mathrm{f}} \text { RRM-O } \\
\text { Fase } 2(\mathrm{Kg})\end{array}$ & \multicolumn{2}{|c|}{7,5} & \multicolumn{2}{|c|}{7,5} \\
\hline
\end{tabular}

Los resultados de las comparaciones múltiples de la Tabla 6.18 y Tabla 6.19 muestran que, para ambas fases y dichas fracciones, las diferencias se dan entre el nivel de submuestreo $L 5$ y el resto de niveles. En el caso de la fase 1 , el porcentaje de textil obtenido con el nivel de submuestreo $L 5$ es diferente al obtenido en el nivel L1, L2 y L3; el porcentaje de RTP es diferente entre el nivel L5 y los niveles L1 y L2, y para el porcentaje de Otros las diferencias se dan entre el L5 y el L3. En todas estas comparaciones el p-valor obtenido es menor a 0,05 (Tabla 6.18). Respecto a la fase 2, el porcentaje de fracción orgánica obtenido con el nivel de submuestreo L5 es diferente al obtenido con el L1, mientras que para los metales las diferencias se dan ente el L5 y el L4 ( $p$-valor <0,05) (Tabla 6.19).

Así pues, por una parte, se puede concluir que el nivel crítico para el RRM-O es el L5 en ambas fases, ya que los resultados obtenidos para el peso de muestra correspondiente a ese nivel de submuestreo $(3,75 \mathrm{~kg}) \mathrm{no}$ son representativos para todas las fracciones estudiadas. Por otro, que el tamaño mínimo de muestra para el control de calidad del RRM-O es de 7,5 kg (L4). Esto supone una reducción del 87,5\% en el peso de muestra necesario respecto al tamaño de muestra inicial $(60 \mathrm{~kg}$ ) y, por tanto, una disminución muy importante en el coste y la carga de trabajo en comparación a la utilización de otras metodologías que no están adaptadas a los rechazos, como pueden ser las de los RSU o CSR. Además, se ha observado que el tamaño mínimo de muestra no se ve afectado por la estacionalidad, ya que se ha obtenido el mismo peso para ambas fases del estudio.

Por último, los pesos de muestra determinados también pueden ser utilizados para determinar la composición física de los rechazos mediante un muestreo aleatorio simple. En Tabla 6.20 se presentan los tamaños mínimos de muestra necesarios para el RRM-O. En función del periodo y fracciones que interese conocer, el peso de muestra a utilizar será diferente. Por ejemplo, si se quiere determinar el textil, los RTP y los Otros en el periodo de primavera-verano será necesario tomar una muestra de al menos 7,5 kg, mientras que si se quiere conocer el porcentaje de estas fracciones en otoño-invierno la muestra debe tener un tamaño mínimo de 3,75 kg. En el caso de la fracción orgánica y los metales ocurre lo contrario, para primavera verano se necesitan al menos $3,75 \mathrm{~kg}$, mientras que para otoño-invierno se necesita un 
mínimo de 7,5 kg. Para la determinación del resto de materiales el tamaño de muestra necesario es de 3,75 kg en ambas épocas del año. Finalmente, si se quiere conocer la composición global será necesario coger el tamaño más restrictivo de 7,5 kg como mínimo.

Tabla 6.20 Tamaño mínimo de muestra para el RRM-O

\begin{tabular}{|c|c|c|c|c|c|}
\hline \multirow[b]{2}{*}{ Fracción } & \multicolumn{2}{|c|}{$m_{f}(k g)$} & \multirow[b]{2}{*}{ Fracción } & \multicolumn{2}{|c|}{$m_{f}(k g)$} \\
\hline & $\begin{array}{c}\text { Primavera- } \\
\text { verano }\end{array}$ & $\begin{array}{c}\text { Otoño- } \\
\text { invierno }\end{array}$ & & $\begin{array}{c}\text { Primavera- } \\
\text { verano }\end{array}$ & $\begin{array}{l}\text { Otoño- } \\
\text { invierno }\end{array}$ \\
\hline \multirow{2}{*}{ Textil } & \multirow{6}{*}{7,5} & \multirow{6}{*}{3,75} & Papel/Cartón & \multirow{8}{*}{3,75} & \multirow{8}{*}{3,75} \\
\hline & & & Plástico Film & & \\
\hline & & & Plástico Rígido & & \\
\hline & & & Madera & & \\
\hline & & & Brik & & \\
\hline & & & Inertes & & \\
\hline Fracción orgánica & \multirow{2}{*}{3,75} & \multirow{2}{*}{7,5} & Vidrio & & \\
\hline Metales & & & Finos & & \\
\hline
\end{tabular}

\section{Determinación de tamaño mínimo de muestra para el RAB1-O}

El número de caracterizaciones por nivel de submuestreo para esta corriente de rechazo fue de 20 para la fase 1 y 20 más para la fase 2. Los tamaños de muestra para cada nivel se han indicado en la Figura 6.16, mientras que los pesos medios de muestra obtenidos tras las caracterizaciones se exponen en la Tabla 6.21. En total se muestrearon y caracterizaron $41,55 \mathrm{~kg}$ de RAB1-O en la primera fase y 40,27 kg en la segunda.

Tabla 6.21 Peso medio de muestra por nivel de submuestreo para el RAB1-O

\begin{tabular}{|c|c|c|c|c|c|c|c|c|c|c|}
\hline \multirow{3}{*}{ Peso de muestra (kg) } & \multicolumn{10}{|c|}{ Nivel Submuestreo } \\
\hline & \multicolumn{2}{|c|}{ L1 (1 kg) } & \multicolumn{2}{|c|}{ L2 $(0,500 \mathrm{~kg})$} & \multicolumn{2}{|c|}{ L3 $(0,250 \mathrm{~kg})$} & \multicolumn{2}{|c|}{ L4 (0,125 kg) } & \multicolumn{2}{|c|}{ L5 (0,065 kg) } \\
\hline & $\bar{x}$ & s & $\bar{x}$ & s & $\bar{x}$ & s & $\bar{x}$ & s & $\bar{x}$ & s \\
\hline Fase 1 & 1,091 & 0,115 & 0,523 & 0,017 & 0,257 & 0,010 & 0,132 & 0,007 & 0,075 & 0,008 \\
\hline Fase 2 & 1,034 & 0,037 & 0,525 & 0,014 & 0,259 & 0,006 & 0,129 & 0,006 & 0,066 & 0,001 \\
\hline
\end{tabular}

A continuación, se exponen los resultados obtenidos en las caracterizaciones de la fase 1 (Tabla 6.22) y de la fase 2 (Tabla 6.23). En las tablas se muestra la composición media y desviación estándar para los cinco niveles de submuestreo.

Tabla 6.22 Composición media por nivel de submuestreo para el RAB1-O, fase 1

\begin{tabular}{|c|c|c|c|c|c|c|c|c|c|c|}
\hline \multirow{3}{*}{$\begin{array}{c}\text { Composición (\%) } \\
\text { Fracción }\end{array}$} & \multicolumn{10}{|c|}{ Nivel Submuestreo } \\
\hline & \multicolumn{2}{|c|}{ L1 (1 kg) } & \multicolumn{2}{|c|}{ L2 (0,500 kg) } & \multicolumn{2}{|c|}{ L3 (0,250 kg) } & \multicolumn{2}{|c|}{ L4 (0,125 kg) } & \multicolumn{2}{|c|}{ L5 (0,065 kg) } \\
\hline & $\bar{x}$ & s & $\bar{x}$ & s & $\bar{x}$ & s & $\bar{x}$ & s & $\bar{x}$ & $\mathbf{s}$ \\
\hline Fracción orgánica & 61,13 & 9,65 & 65,48 & 9,10 & 61,77 & 13,57 & 58,75 & 15,72 & 62,10 & 21,33 \\
\hline Plástico Film & 2,74 & 1,50 & 3,21 & 2,35 & 3,34 & 3,65 & 2,40 & 3,18 & 2,96 & 3,84 \\
\hline Plástico Rígido & 7,05 & 4,11 & 6,45 & 4,70 & 8,19 & 5,94 & 8,45 & 7,86 & 9,63 & 11,31 \\
\hline Textil & 1,01 & 0,95 & 1,92 & 2,24 & 1,44 & 2,04 & 1,15 & 3,25 & 0,15 & 0,65 \\
\hline
\end{tabular}




\begin{tabular}{|c|c|c|c|c|c|c|c|c|c|c|}
\hline \multirow{3}{*}{$\begin{array}{c}\text { Composición (\%) } \\
\text { Fracción }\end{array}$} & \multicolumn{10}{|c|}{ Nivel Submuestreo } \\
\hline & \multicolumn{2}{|c|}{ L1 (1 kg) } & \multicolumn{2}{|c|}{ L2 (0,500 kg) } & \multicolumn{2}{|c|}{ L3 (0,250 kg) } & \multicolumn{2}{|c|}{ L4 (0,125 kg) } & \multicolumn{2}{|c|}{ L5 (0,065 kg) } \\
\hline & $\bar{x}$ & $s$ & $\bar{x}$ & $s$ & $\bar{x}$ & s & $\bar{x}$ & s & $\bar{x}$ & s \\
\hline Metales & 4,04 & 5,17 & 2,90 & 3,12 & 4,10 & 5,64 & 3,83 & 7,39 & 8,13 & 10,98 \\
\hline Madera & 0,96 & 1,82 & 1,32 & 2,72 & 0,94 & 2,88 & 0,86 & 3,17 & 1,01 & 4,51 \\
\hline Brik & 0,30 & 0,53 & 0,08 & 0,37 & 1,22 & 4,46 & 0,89 & 2,78 & 0,00 & 0,00 \\
\hline Inertes & 8,39 & 8,91 & 5,27 & 7,15 & 2,51 & 4,10 & 3,67 & 6,01 & 3,15 & 5,61 \\
\hline RTP & 0,91 & 1,59 & 0,99 & 2,85 & 0,90 & 3,05 & 0,86 & 2,25 & 0,09 & 0,36 \\
\hline Vidrio & 11,27 & 5,12 & 11,50 & 5,73 & 11,62 & 11,06 & 18,82 & 12,03 & 12,59 & 13,26 \\
\hline Otros & 2,19 & 3,22 & 0,87 & 1,36 & 3,96 & 9,14 & 0,32 & 1,03 & 0,20 & 0,90 \\
\hline
\end{tabular}

Tabla 6.23 Composición media por nivel de submuestreo para el RAB1-O, fase 2

\begin{tabular}{|c|c|c|c|c|c|c|c|c|c|c|}
\hline \multirow{3}{*}{$\begin{array}{c}\text { Composición (\%) } \\
\text { Fracción }\end{array}$} & \multicolumn{10}{|c|}{ Nivel Submuestreo } \\
\hline & \multicolumn{2}{|c|}{ L1 (1 kg) } & \multicolumn{2}{|c|}{ L2 (0,500 kg) } & \multicolumn{2}{|c|}{ L3 (0,250 kg) } & \multicolumn{2}{|c|}{ L4 (0,125 kg) } & \multicolumn{2}{|c|}{ L5 $(0,065 \mathrm{~kg})$} \\
\hline & $\bar{x}$ & s & $\bar{x}$ & s & $\bar{x}$ & s & $\bar{x}$ & s & $\bar{x}$ & s \\
\hline Fracción orgánica & 66,59 & 11,36 & 69,71 & 8,72 & 62,28 & 18,63 & 67,08 & 21,08 & 78,38 & 12,74 \\
\hline Plástico Film & 2,04 & 1,18 & 2,19 & 1,81 & 2,26 & 3,06 & 2,63 & 2,93 & 3,78 & 7,59 \\
\hline Plástico Rígido & 5,04 & 3,02 & 5,14 & 3,46 & 7,09 & 8,42 & 4,69 & 4,21 & 3,42 & 6,23 \\
\hline Textil & 1,66 & 2,23 & 1,66 & 2,55 & 1,53 & 2,58 & 1,79 & 3,64 & 2,18 & 5,02 \\
\hline Metales & 3,40 & 2,64 & 3,37 & 3,16 & 1,77 & 2,98 & 1,10 & 2,38 & 0,32 & 0,76 \\
\hline Madera & 1,52 & 1,63 & 0,91 & 2,41 & 1,96 & 7,61 & 4,18 & 12,98 & 0,00 & 0,00 \\
\hline Brik & 0,59 & 2,19 & 0,12 & 0,54 & 0,00 & 0,00 & 2,65 & 6,79 & 0,00 & 0,00 \\
\hline Inertes & 4,56 & 4,55 & 3,82 & 5,36 & 1,95 & 3,25 & 0,51 & 1,24 & 0,36 & 1,41 \\
\hline RTP & 0,82 & 1,21 & 0,39 & 0,69 & 0,63 & 2,59 & 0,63 & 1,62 & 0,40 & 1,05 \\
\hline Vidrio & 10,39 & 5,46 & 11,48 & 5,47 & 17,73 & 17,12 & 8,36 & 11,10 & 10,45 & 8,64 \\
\hline Otros & 3,39 & 5,54 & 1,20 & 2,16 & 2,80 & 7,18 & 6,38 & 20,55 & 0,72 & 2,57 \\
\hline
\end{tabular}

En la Tabla 6.24 y Tabla 6.25 se presentan los estadísticos de contraste y p-valores obtenidos tras la aplicación de los diferentes test a cada fracción de residuos, para la fase 1 y 2 respectivamente. En dichas tablas también se puede observar que, para todas las fracciones salvo el plástico rígido de la fase 1 , se han tenido que utilizar test no paramétricos, ya que los residuos del ANOVA no eran Normales ni tampoco se ha podido mejorar su distribución mediante la transformación de los datos. 
Tabla 6.24 Análisis estadístico RAB1-O, fase 1

\begin{tabular}{|c|c|c|c|c|c|c|c|c|}
\hline Test estadístico & \multirow{2}{*}{\multicolumn{2}{|c|}{$\begin{array}{c}\text { Test de Shapiro-Wilk } \\
\text { Bondad de ajuste: } \\
\text { Normalidad }\end{array}$}} & \multirow{2}{*}{\multicolumn{2}{|c|}{$\begin{array}{c}\text { Test de Levene } \\
\text { Comparación de } \\
\text { varianzas }\end{array}$}} & \multirow{2}{*}{\multicolumn{2}{|c|}{$\begin{array}{c}\text { ANOVA / ANOVA de } \\
\text { Welch }\end{array}$}} & \multirow{2}{*}{\multicolumn{2}{|c|}{$\begin{array}{c}\text { Test de Kuskal-Wallis } \\
\text { Comparación de } \\
\text { medianas }\end{array}$}} \\
\hline Tipo de prueba & & & & & & & & \\
\hline Fracción & $\mathbf{w}$ & p-valor & $\mathbf{F}$ & p-valor & $\mathbf{F}$ & p-valor & H & p-valor \\
\hline Fracción orgánica & 0,964 & 0,008 & - & - & - & - & 3,686 & 0,450 \\
\hline Plástico Film & 0,740 & $<0,001$ & - & - & - & - & 5,217 & 0,266 \\
\hline Plástico Rígido* & 0,984 & 0,248 & 5,515 & $<0,001$ & 0,129 & 0,971 & - & - \\
\hline Textil & 0,905 & $<0,001$ & - & - & - & - & 31,073 & $<0,001$ \\
\hline Metales & 0,659 & $<0,001$ & - & - & - & - & 8,302 & 0,081 \\
\hline Madera & 0,785 & $<0,001$ & - & - & - & - & 22,193 & $<0,001$ \\
\hline Brik & 0,357 & $<0,001$ & - & - & - & - & 9,307 & 0,054 \\
\hline Inertes & 0,265 & $<0,0010$ & - & - & - & - & 12,551 & 0,014 \\
\hline RTP & 0,754 & $<0,001$ & - & - & - & - & 21,517 & $<0,001$ \\
\hline Vidrio & 0,402 & $<0,001$ & - & - & - & - & 8,914 & 0,063 \\
\hline Otros & 0,863 & $<0,001$ & - & - & - & - & 23,699 & $<0,001$ \\
\hline
\end{tabular}

* Fracciones en las que la transformación de los datos ha mejorado su distribución, aproximándola a la Normal y permitiendo usar pruebas paramétricas con los datos transformados.

Tabla 6.25 Análisis estadístico RAB1-O, fase 2

\begin{tabular}{|c|c|c|c|c|c|c|c|c|}
\hline Test estadístico & \multirow{2}{*}{\multicolumn{2}{|c|}{$\begin{array}{c}\text { Test de Shapiro-Wilk } \\
\text { Bondad de ajuste: } \\
\text { Normalidad }\end{array}$}} & \multirow{2}{*}{\multicolumn{2}{|c|}{$\begin{array}{c}\text { Test de Levene } \\
\text { Comparación de } \\
\text { varianzas }\end{array}$}} & \multirow{2}{*}{\multicolumn{2}{|c|}{$\begin{array}{c}\text { ANOVA / ANOVA de } \\
\text { Welch } \\
\begin{array}{c}\text { Comparación de } \\
\text { medias }\end{array}\end{array}$}} & \multirow{2}{*}{\multicolumn{2}{|c|}{$\begin{array}{c}\text { Test de Kuskal-Wallis } \\
\text { Comparación de } \\
\text { medianas }\end{array}$}} \\
\hline Tipo de prueba & & & & & & & & \\
\hline Fracción & $\mathbf{w}$ & p-valor & $\mathbf{F}$ & p-valor & $\mathbf{F}$ & p-valor & H & p-valor \\
\hline Fracción orgánica & 0,931 & $<0,001$ & - & - & - & - & 10,992 & 0,027 \\
\hline Plástico Film & 0,435 & $<0,001$ & - & - & - & - & 1,012 & 0,908 \\
\hline Plástico Rígido & 0,800 & $<0,001$ & - & - & - & - & 12,128 & 0,016 \\
\hline Textil & 0,641 & $<0,001$ & - & - & - & - & 14,101 & 0,007 \\
\hline Metales & 0,846 & $<0,001$ & - & - & - & - & 36,227 & $<0,001$ \\
\hline Madera & 0,247 & $<0,001$ & - & - & - & - & 17,779 & 0,001 \\
\hline Brik & 0,354 & $<0,001$ & - & - & - & - & 8,725 & 0,068 \\
\hline Inertes & 0,729 & $<0,001$ & - & - & - & - & 37,934 & $<0,001$ \\
\hline RTP & 0,380 & $<0,001$ & - & - & - & - & 22,065 & $<0,001$ \\
\hline Vidrio & 0,795 & $<0,001$ & - & - & - & - & 9,129 & 0,060 \\
\hline Otros & 0,221 & $<0,001$ & - & - & - & - & 19,979 & 0,001 \\
\hline
\end{tabular}


Los resultados obtenidos para el RAB1-O en la fase 1 muestran que existen diferencias significativas en el porcentaje de textil, madera, inertes, RTP y Otros entre los diferentes niveles de submuestreo, ya que el pvalor obtenido en los contrastes de medianas son menores a 0,05 (Tabla 6.24). Por lo tanto, se puede afirmar con una confianza del $95 \%$ que el porcentaje de estos materiales en el RAB1-O es distinto en función del tamaño de muestra utilizado para su determinación, por lo que los resultados obtenidos para cierto nivel de submuestreo no son representativos de la población de rechazo muestreada. En el caso de la fase 2, existen un mayor número de fracciones en las que se dan estas diferencias: fracción orgánica, plástico rígido, textil, metales, madera, inertes, RTP y Otros; con p-valores en el contraste de medianas menores a 0,05.

Para el resto de fracciones no se han encontrado diferencias significativas ( $p$-valor $>0,05$ ), por lo que su porcentaje no varía en función del nivel de submuestreo. Para estas fracciones el tamaño mínimo de muestra necesario sería el correspondiente al nivel de submuestreo más bajo (L5), con 0,065 kg.

Por último, en la Tabla 6.26 para la fase 1 y en la Tabla 6.27 y Tabla 6.28 para la fase 2, se exponen los resultados de los test post hoc realizados a las fracciones donde existen diferencias significativas, así como el nivel crítico identificado y el tamaño mínimo de muestra para el RAB1-O determinado en base a estos resultados ( $\left.m_{f} R A B 1-O\right)$.

Tabla 6.26 Test post hoc RAB1-O, fase 1

\begin{tabular}{|c|c|c|c|c|c|c|c|c|c|c|}
\hline \multirow{3}{*}{$\begin{array}{c}\text { Fracción } \\
\text { Test post hoc } \\
\text { Comparaciones }\end{array}$} & \multicolumn{2}{|c|}{ Textil } & \multicolumn{2}{|c|}{ Madera } & \multicolumn{2}{|c|}{ Inertes } & \multicolumn{2}{|c|}{ RTP } & \multicolumn{2}{|c|}{ Otros } \\
\hline & \multicolumn{2}{|c|}{ Dunn } & \multicolumn{2}{|c|}{ Dunn } & \multicolumn{2}{|c|}{ Dunn } & \multicolumn{2}{|c|}{ Dunn } & \multicolumn{2}{|c|}{ Dunn } \\
\hline & Z & p-valor & Z & p-valor & z & p-valor & Z & p-valor & Z & p-valor \\
\hline L1 - L2 & $-0,614$ & 0,539 & $-0,057$ & 0,954 & 1,294 & 0,279 & 2,217 & 0,067 & 1,817 & 0,099 \\
\hline L1 - L3 & 1,153 & 0,311 & 1,612 & 0,153 & 2,787 & 0,027 & 2,963 & 0,010 & 1,792 & 0,091 \\
\hline L2 - L3 & 1,767 & 0,110 & 1,669 & 0,159 & 1,492 & 0,271 & 0,746 & 0,506 & $-0,026$ & 0,980 \\
\hline L1 - L4 & 3,002 & 0,007 & 3,099 & 0,005 & 2,625 & 0,029 & 3,413 & 0,003 & 3,865 & 0,001 \\
\hline L2 - L4 & 3,616 & 0,001 & 3,156 & 0,005 & 1,331 & 0,305 & 1,196 & 0,331 & 2,048 & 0,068 \\
\hline L3 - L4 & 1,849 & 0,107 & 1,488 & 0,171 & $-0,161$ & 0,969 & 0,450 & 0,653 & 2,073 & 0,076 \\
\hline L1 - L5 & 4,038 & $<0,001$ & 3,483 & 0,002 & 2,894 & 0,038 & 4,349 & $<0,001$ & 4,204 & $<0,001$ \\
\hline L2 - L5 & 4,652 & $<0,001$ & 3,540 & 0,004 & 1,600 & 0,274 & 2,133 & 0,066 & 2,387 & 0,042 \\
\hline L3 - L5 & 2,885 & 0,008 & 1,872 & 0,123 & 0,108 & 0,914 & 1,386 & 0,276 & 2,412 & 0,053 \\
\hline L4 - L5 & 1,036 & 0,334 & 0,384 & 0,779 & 0,269 & 0,985 & 0,937 & 0,436 & 0,339 & 0,816 \\
\hline Nivel crítico & \multicolumn{2}{|c|}{ L4 (0,125 kg) } & \multicolumn{2}{|c|}{ L4 $(0,125 \mathrm{~kg})$} & \multicolumn{2}{|c|}{ L3 $(0,250 \mathrm{~kg})$} & \multicolumn{2}{|c|}{ L3 $(0,250 \mathrm{~kg})$} & \multicolumn{2}{|c|}{ L4 (0,125 kg) } \\
\hline $\begin{array}{l}\mathrm{m}_{\mathrm{f}} \text { RAB1-O } \\
\text { Fase } 1(\mathrm{Kg})\end{array}$ & \multicolumn{2}{|c|}{0,250} & \multicolumn{2}{|c|}{0,250} & \multicolumn{2}{|c|}{0,500} & \multicolumn{2}{|c|}{0,500} & \multicolumn{2}{|c|}{0,250} \\
\hline
\end{tabular}


Tabla 6.27 Test post hoc RAB1-O, fase 2 (fracción orgánica, plástico rígido, textil y metales)

\begin{tabular}{|c|c|c|c|c|c|c|c|c|}
\hline Fracción & \multicolumn{2}{|c|}{ Fracción Orgánica } & \multicolumn{2}{|c|}{ Plástico Rígido } & \multicolumn{2}{|c|}{ Textil } & \multicolumn{2}{|c|}{ Metales } \\
\hline Test post hoc & \multicolumn{2}{|c|}{ Dunn } & \multicolumn{2}{|c|}{ Dunn } & \multicolumn{2}{|c|}{ Dunn } & \multicolumn{2}{|c|}{ Dunn } \\
\hline Comparaciones & Z & p-valor & $\mathbf{Z}$ & p-valor & $\mathbf{Z}$ & p-valor & $\mathbf{Z}$ & p-valor \\
\hline L1 - L2 & $-0,779$ & 0,545 & 0,120 & 0,905 & 0,994 & 0,457 & 0,292 & 0,770 \\
\hline L1 - L3 & 0,185 & 0,853 & 0,512 & 0,869 & 2,208 & 0,091 & 2,430 & 0,030 \\
\hline L2 - L3 & 0,965 & 0,478 & 0,393 & 0,868 & 1,214 & 0,375 & 2,138 & 0,046 \\
\hline L1 - L4 & $-1,281$ & 0,334 & 0,900 & 0,737 & 2,846 & 0,022 & 4,023 & $<0,001$ \\
\hline L2 - L4 & $-0,501$ & 0,685 & 0,780 & 0,726 & 1,852 & 0,128 & 3,731 & $<0,001$ \\
\hline L3 - L4 & $-1,466$ & 0,357 & 0,387 & 0,776 & 0,638 & 0,582 & 1,593 & 0,139 \\
\hline L1 - L5 & $-2,730$ & 0,032 & 3,020 & 0,025 & 3,182 & 0,015 & 4,710 & $<0,001$ \\
\hline L2 - L5 & $-1,951$ & 0,170 & 2,900 & 0,019 & 2,188 & 0,072 & 4,418 & $<0,001$ \\
\hline L3 - L5 & $-2,916$ & 0,035 & 2,508 & 0,040 & 0,974 & 0,412 & 2,280 & 0,038 \\
\hline L4 - L5 & $-1,450$ & 0,294 & 2,121 & 0,085 & 0,336 & 0,737 & 0,687 & 0,547 \\
\hline Nivel crítico & \multicolumn{2}{|c|}{ L5 (0,065 kg) } & \multicolumn{2}{|c|}{ L5 (0,065 kg) } & \multicolumn{2}{|c|}{ L4 (0,125 kg) } & \multicolumn{2}{|c|}{ L3 $(0,250$ kg) } \\
\hline $\begin{array}{l}\mathrm{m}_{\mathrm{f}} \text { RAB1-O } \\
\text { Fase } 1(\mathrm{Kg})\end{array}$ & \multicolumn{2}{|c|}{0,125} & \multicolumn{2}{|c|}{0,125} & \multicolumn{2}{|c|}{0,250} & \multicolumn{2}{|c|}{0,500} \\
\hline
\end{tabular}

Tabla 6.28 Test post hoc RAB1-O, fase 2 (madera, inertes, RTP y otros)

\begin{tabular}{|c|c|c|c|c|c|c|c|c|}
\hline Fracción & \multicolumn{2}{|c|}{ Madera } & \multicolumn{2}{|c|}{ Inertes } & \multicolumn{2}{|c|}{ RTP } & \multicolumn{2}{|c|}{ Otros } \\
\hline Test post hoc & \multicolumn{2}{|c|}{ Dunn } & \multicolumn{2}{|c|}{ Dunn } & \multicolumn{2}{|c|}{ Dunn } & \multicolumn{2}{|c|}{ Dunn } \\
\hline Comparaciones & Z & p-valor & Z & p-valor & Z & p-valor & Z & p-valor \\
\hline L1 - L2 & 1,440 & 0,214 & 1,785 & 0,106 & 2,198 & 0,070 & 1,695 & 0,180 \\
\hline L1 - L3 & 2,470 & 0,034 & 3,339 & 0,002 & 3,877 & 0,001 & 3,073 & 0,011 \\
\hline L2 - L3 & 1,030 & 0,379 & 1,554 & 0,150 & 1,679 & 0,186 & 1,378 & 0,280 \\
\hline L1 - L4 & 1,499 & 0,223 & 4,836 & $<0,001$ & 3,690 & 0,001 & 2,881 & 0,013 \\
\hline L2 - L4 & 0,059 & 0,953 & 3,051 & 0,005 & 1,491 & 0,194 & 1,186 & 0,295 \\
\hline L3 - L4 & $-0,971$ & 0,368 & 1,497 & 0,149 & $-0,187$ & 1,000 & $-0,192$ & 0,848 \\
\hline L1 - L5 & 4,041 & 0,001 & 5,239 & $<0,001$ & 3,761 & 0,001 & 4,148 & $<0,001$ \\
\hline L2 - L5 & 2,600 & 0,047 & 3,454 & 0,002 & 1,562 & 0,197 & 2,453 & 0,035 \\
\hline L3 - L5 & 1,571 & 0,233 & 1,900 & 0,096 & $-0,116$ & 1,000 & 1,075 & 0,314 \\
\hline L4 - L5 & 2,542 & 0,037 & 0,403 & 0,687 & 0,071 & 0,943 & 1,267 & 0,293 \\
\hline Nivel crítico & \multicolumn{2}{|c|}{ L3 $(0,250 \mathrm{~kg})$} & \multicolumn{2}{|c|}{ L3 $(0,250 \mathrm{~kg})$} & \multicolumn{2}{|c|}{ L3 $(0,250 \mathrm{~kg})$} & \multicolumn{2}{|c|}{ L3 $(0,250 \mathrm{~kg})$} \\
\hline $\begin{array}{l}m_{f} \text { RAB1-O } \\
\text { Fase } 2(\mathrm{Kg})\end{array}$ & \multicolumn{2}{|c|}{0,500} & \multicolumn{2}{|c|}{0,500} & \multicolumn{2}{|c|}{0,500} & \multicolumn{2}{|c|}{0,500} \\
\hline
\end{tabular}


Los resultados de las comparaciones múltiples de dichas fracciones para la fase 1 (Tabla 6.26) muestran que existen diferencias estadísticamente significativas entre los niveles de submuestreo L3, L4 y L5 y el resto, aunque para cada fracción estas diferencias se dan entre unos niveles u otros:

- $\quad$ Textil: el porcentaje obtenido con el nivel de submuestreo L4 es distinto al obtenido con el L1 y L2. Para el L5 las diferencias se dan entre este nivel y el L1, L2 y L3.

- $\quad$ Madera: los porcentajes de los niveles L4 y L5 son diferentes a los obtenidos en L1 y L2.

- $\quad$ Inertes y RTP: las diferencias en los porcentajes de ambas fracciones se dan entre los niveles L3, L4 y L5 con L1.

- $\quad$ Otros: el porcentaje obtenido para L4 es distinto al de L1. Para L5 las diferencias se dan entre este nivel y el L1 y L2.

En el caso de la fase 2 (Tabla 6.27 y Tabla 6.28), las diferencias significativas también se dan entre los niveles de submuestreo L3, L4 y L5 con el resto. Los resultados por fracciones se enumeran a continuación:

- $\quad$ Fracción orgánica: el porcentaje obtenido con el nivel L5 es distinto al obtenidos con el L1 y L2.

- $\quad$ Plástico rígido: las diferencias se dan entre el nivel L5 y los niveles L1, L2 y L3.

- $\quad$ Textil: los porcentajes obtenidos en los niveles L4 y L5 son diferentes a los obtenidos en L1.

- $\quad$ Metales: el porcentaje de esta fracción para L3 y L4 es distinto al obtenido con L1 y L2. Para L5 las diferencias se dan entre este nivel y L1, L2 y L3.

- $\quad$ Madera: existen diferencias entre el porcentaje obtenido con el nivel L3 y el obtenido con L1. Respecto a L5, los resultados para este nivel son distintos a los de L1, L2 y L4.

- $\quad$ Inertes: el porcentaje del nivel L3 es diferentes al obtenido con L1. Los porcentajes de L4 y L5 también son distintos a los obtenidos con L1 y L2.

- $\quad$ RTP: Las diferencias se dan entre los niveles L3, L4 y L5 y el nivel L1.

- $\quad$ Otros: El porcentaje de esta fracción para L3 y L4 es distinto al obtenido para L1. Para L5 las diferencias se dan entre este nivel con L1 y L2.

En todas estas comparaciones el p-valor obtenido es menor a 0,05.

En las tablas anteriores también se puede ver que, en función de la fracción analizada, se han obtenido tamaños de muestra distintos. Por lo tanto, como indica la metodología, el tamaño de muestra para el control de calidad de los rechazos debe ser el más restrictivo de todos ellos para que todas las fracciones estén correctamente representadas, puesto que los parámetros de calidad $(\mathrm{PCl}, \mathrm{Cl}$ y $\mathrm{Hg}$ ) están repartidos en todos los materiales.

Así pues, se puede concluir que el nivel crítico más restrictivo para el RAB1-O en ambas fases es el L3, puesto que los resultados obtenidos para el peso de muestra correspondiente a ese nivel de submuestreo $(0,250 \mathrm{~kg})$ no son representativos para todas las fracciones estudiadas. Por lo tanto, el tamaño mínimo de muestra para el control de calidad del RAB1-O es de 0,5 kg (L2). Esto supone que, tras la aplicación de la metodología propuesta, el peso de muestra necesario se ha reducido a la mitad respecto al tamaño de muestra inicial $(1 \mathrm{~kg})$, minimizando el coste económico y la carga de trabajo en comparación al uso de otras metodologías. Además, el tamaño mínimo de muestra es el mismo para las dos fases del estudio, por lo que no se ve afectado por la estacionalidad.

Finalmente, en la Tabla 6.29 se presentan los tamaños mínimos de muestra necesarios para la determinación de la composición física del RAB1-O. El peso de muestra será diferente en función del periodo y de la fracción que se quiera conocer, este se tomará mediante un muestreo aleatorio simple. Si se quiere determinar la composición global se deben tomar $0,5 \mathrm{~kg}$. 
Tabla 6.29 Tamaño mínimo de muestra para el RAB1-O

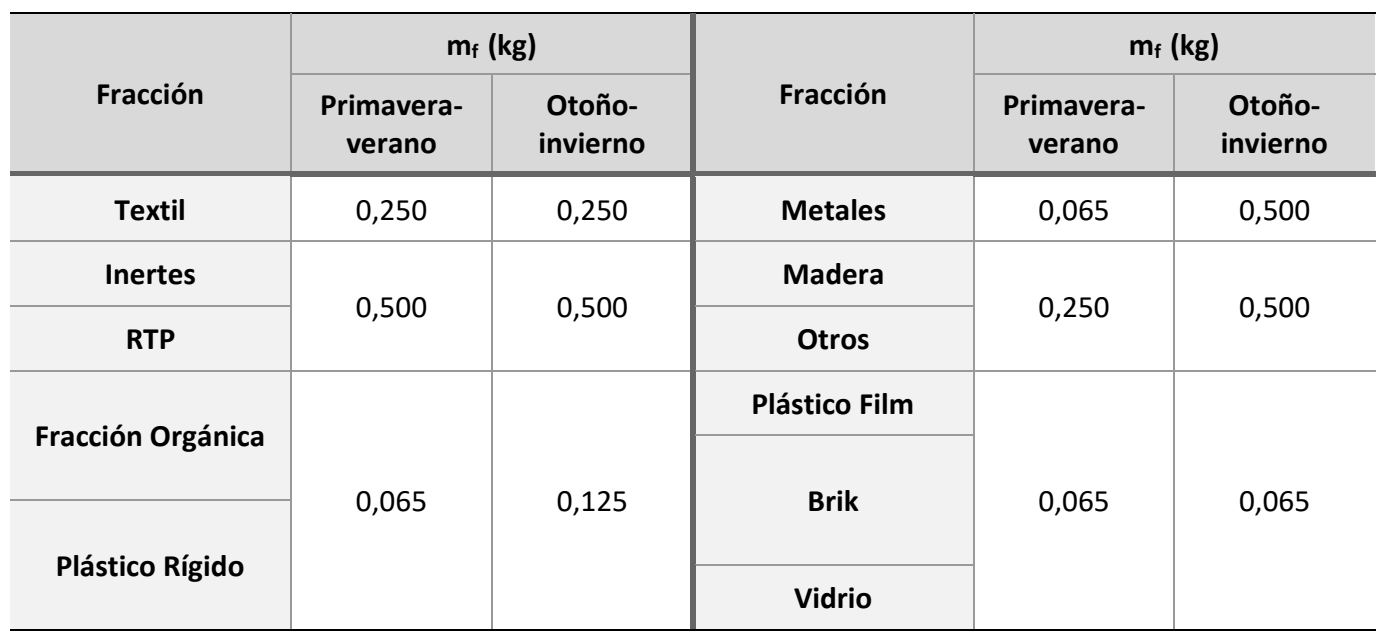

\section{Determinación del tamaño mínimo de muestra para el RAB2-O}

Para esta corriente de rechazo el número de caracterizaciones realizadas por nivel de submuestreo fue de 20 en la primera fase y de otras 20 en la segunda. Los tamaños de muestra para cada nivel son los indicados en la Figura 6.17, mientras que los pesos medios de muestra obtenidos tras las caracterizaciones se exponen en la Tabla 6.30. En total se muestrearon y caracterizaron 16,04 kg de RAB2-O en la fase 1 y 15,87 kg durante la fase 2.

Tabla 6.30 Peso medio de muestra por nivel de submuestreo para el RAB2-O

\begin{tabular}{|c|c|c|c|c|c|c|c|c|c|c|}
\hline \multirow{3}{*}{ Peso de muestra (kg) } & \multicolumn{10}{|c|}{ Nivel Submuestreo } \\
\hline & \multicolumn{2}{|c|}{ L1 $(0,400 \mathrm{~kg})$} & \multicolumn{2}{|c|}{ L2 $(0,200 \mathrm{~kg})$} & \multicolumn{2}{|c|}{ L3 $(0,100 \mathrm{~kg})$} & \multicolumn{2}{|c|}{$\mathrm{L} 4(0,050 \mathrm{~kg})$} & \multicolumn{2}{|c|}{ L5 $(0,025 \mathrm{~kg})$} \\
\hline & $\bar{x}$ & s & $\bar{x}$ & s & $\bar{x}$ & $\mathbf{s}$ & $\bar{x}$ & s & $\bar{x}$ & s \\
\hline Fase 1 & 0,409 & 0,007 & 0,206 & 0,003 & 0,106 & 0,004 & 0,054 & 0,002 & 0,027 & 0,001 \\
\hline Fase 2 & 0,405 & 0,005 & 0,204 & 0,003 & 0,105 & 0,003 & 0,053 & 0,002 & 0,026 & 0,001 \\
\hline
\end{tabular}

A continuación, se presentan los resultados obtenidos en las caracterizaciones realizadas para ambas fases, Tabla 6.31 y Tabla 6.32 respectivamente. En ellas se muestra la composición media para los cinco niveles de submuestreo, así como su desviación estándar.

Tabla 6.31 Composición media por nivel de submuestreo para el RAB2-O, fase 1

\begin{tabular}{|c|c|c|c|c|c|c|c|c|c|c|}
\hline \multirow{3}{*}{$\begin{array}{c}\text { Composición (\%) } \\
\text { Fracción }\end{array}$} & \multicolumn{10}{|c|}{ Nivel Submuestreo } \\
\hline & \multicolumn{2}{|c|}{ L1 (0,400 kg) } & \multicolumn{2}{|c|}{ L2 (0,200 kg) } & \multicolumn{2}{|c|}{ L3 (0,100 kg) } & \multicolumn{2}{|c|}{ L4 (0,050 kg) } & \multicolumn{2}{|c|}{ L5 $(0,025 \mathrm{~kg})$} \\
\hline & $\bar{x}$ & s & $\bar{x}$ & s & $\bar{x}$ & s & $\bar{x}$ & s & $\bar{x}$ & s \\
\hline Fracción orgánica & 66,81 & 7,15 & 64,07 & 8,38 & 64,96 & 7,75 & 61,54 & 13,29 & 66,48 & 13,06 \\
\hline Plástico Film & 0,50 & 0,52 & 0,36 & 0,29 & 0,34 & 0,25 & 0,27 & 0,29 & 0,29 & 0,35 \\
\hline Plástico Rígido & 1,30 & 0,55 & 1,68 & 0,83 & 1,70 & 1,45 & 2,09 & 2,16 & 1,47 & 2,00 \\
\hline Textil & 0,07 & 0,18 & 0,00 & 0,00 & 0,06 & 0,15 & 0,06 & 0,21 & 0,03 & 0,09 \\
\hline Metales & 0,39 & 0,63 & 0,38 & 0,75 & 0,43 & 1,68 & 0,31 & 0,90 & 0,23 & 0,79 \\
\hline Madera & 0,16 & 0,31 & 0,22 & 0,69 & 0,00 & 0,00 & 0,09 & 0,42 & 0,00 & 0,00 \\
\hline
\end{tabular}




\begin{tabular}{|c|c|c|c|c|c|c|c|c|c|c|}
\hline \multirow{3}{*}{$\begin{array}{c}\text { Composición (\%) } \\
\text { Fracción }\end{array}$} & \multicolumn{10}{|c|}{ Nivel Submuestreo } \\
\hline & \multicolumn{2}{|c|}{ L1 (0,400 kg) } & \multicolumn{2}{|c|}{ L2 (0,200 kg) } & \multicolumn{2}{|c|}{ L3 (0,100 kg) } & \multicolumn{2}{|c|}{ L4 (0,050 kg) } & \multicolumn{2}{|c|}{ L5 (0,025 kg) } \\
\hline & $\bar{x}$ & s & $\bar{x}$ & s & $\bar{x}$ & s & $\bar{x}$ & s & $\bar{x}$ & s \\
\hline Brik & 0,00 & 0,00 & 0,00 & 0,00 & 0,00 & 0,00 & 0,00 & 0,00 & 0,00 & 0,00 \\
\hline Inertes & 3,57 & 3,37 & 3,81 & 2,58 & 5,93 & 4,67 & 3,91 & 5,40 & 3,85 & 5,58 \\
\hline RTP & 0,05 & 0,15 & 0,09 & 0,27 & 0,00 & 0,00 & 0,03 & 0,13 & 0,01 & 0,06 \\
\hline Vidrio & 27,15 & 7,10 & 29,31 & 6,84 & 26,59 & 7,59 & 31,66 & 12,61 & 27,64 & 12,93 \\
\hline Otros & 0,00 & 0,02 & 0,09 & 0,31 & 0,00 & 0,00 & 0,04 & 0,17 & 0,00 & 0,00 \\
\hline
\end{tabular}

Tabla 6.32 Composición media por nivel de submuestreo para el RAB2-O, fase 2

\begin{tabular}{|c|c|c|c|c|c|c|c|c|c|c|}
\hline \multirow{2}{*}{$\begin{array}{c}\text { Composición (\%) } \\
\text { Fracción }\end{array}$} & \multicolumn{10}{|c|}{ Nivel Submuestreo } \\
\hline & \multicolumn{2}{|c|}{ L1 (0,400 kg) } & \multicolumn{2}{|c|}{$\mathrm{L} 2(0,200 \mathrm{~kg})$} & \multicolumn{2}{|c|}{ L3 $(0,100 \mathrm{~kg})$} & \multicolumn{2}{|c|}{ L4 (0,050 kg) } & \multicolumn{2}{|c|}{ L5 (0,025 kg) } \\
\hline Fracción orgánica & 67,68 & 7,13 & 68,70 & 7,30 & 63,69 & 7,15 & 64,27 & 10,61 & 65,30 & 9,19 \\
\hline Plástico Rígido & 0,87 & 0,39 & 1,26 & 0,81 & 1,57 & 1,38 & 1,34 & 1,49 & 1,38 & 3,07 \\
\hline Textil & 0,01 & 0,05 & 0,03 & 0,07 & 0,00 & 0,00 & 0,07 & 0,28 & 0,11 & 0,49 \\
\hline Metales & 0,33 & 0,94 & 0,04 & 0,12 & 0,10 & 0,23 & 0,17 & 0,55 & 0,00 & 0,00 \\
\hline Inertes & 3,13 & 1,74 & 3,13 & 2,68 & 4,09 & 3,42 & 2,18 & 2,90 & 2,70 & 4,35 \\
\hline RTP & 0,11 & 0,45 & 0,03 & 0,10 & 0,01 & 0,02 & 0,00 & 0,00 & 0,13 & 0,48 \\
\hline Vidrio & 27,43 & 6,04 & 26,32 & 6,06 & 29,93 & 6,90 & 29,39 & 13,25 & 30,08 & 10,81 \\
\hline Otros & 0,10 & 0,18 & 0,15 & 0,43 & 0,09 & 0,18 & 0,05 & 0,18 & 0,00 & 0,01 \\
\hline
\end{tabular}

Los estadísticos de contraste y p-valores obtenidos tras la aplicación de los diferentes test estadísticos a las fracciones de residuos se exponen en la Tabla 6.33 (fase 1) y Tabla 6.34 (fase 2). En dichas tablas, además, se puede observar que, para todas las fracciones salvo la fracción orgánica y el vidrio, se han utilizado test no paramétricos debido a que los residuos del ANOVA no fueron Normales ni tampoco se pudo mejorar su distribución transformando los datos. Además, cabe destacar que en la fase 1 para la fracción brik no se pudieron realizar los análisis estadísticos ya que los valores obtenidos para este material en todas las caracterizaciones fueron de $0 \%$ (Tabla 6.31). 
Tabla 6.33 Análisis estadístico RAB2-O, fase 1

\begin{tabular}{|c|c|c|c|c|c|c|c|c|}
\hline Test estadístico & \multirow{2}{*}{\multicolumn{2}{|c|}{$\begin{array}{c}\text { Test de Shapiro-Wilk } \\
\text { Bondad de ajuste: } \\
\text { Normalidad }\end{array}$}} & \multirow{2}{*}{\multicolumn{2}{|c|}{$\begin{array}{c}\text { Test de Levene } \\
\text { Comparación de } \\
\text { varianzas }\end{array}$}} & \multirow{2}{*}{\multicolumn{2}{|c|}{$\begin{array}{c}\text { ANOVA / ANOVA de } \\
\text { Welch } \\
\begin{array}{c}\text { Comparación de } \\
\text { medias }\end{array}\end{array}$}} & \multirow{2}{*}{\multicolumn{2}{|c|}{$\begin{array}{c}\text { Test de Kuskal-Walli } \\
\text { Comparación de } \\
\text { medianas }\end{array}$}} \\
\hline Tipo de prueba & & & & & & & & \\
\hline Fracción & w & p-valor & $\mathbf{F}$ & p-valor & $\mathbf{F}$ & p-valor & H & p-valor \\
\hline Fracción orgánica & 0,987 & 0,416 & 3,474 & 0,011 & 0,743 & 0,568 & - & - \\
\hline Plástico Film & 0,706 & $<0,001$ & - & - & - & - & 5,979 & 0,201 \\
\hline Plástico Rígido & 0,846 & $<0,001$ & - & - & - & - & 5,129 & 0,274 \\
\hline Textil & 0,453 & $<0,001$ & - & - & - & - & 9,822 & 0,044 \\
\hline Metales & 0,349 & $<0,001$ & - & - & - & - & 14,216 & 0,007 \\
\hline Madera & 0,368 & $<0,001$ & - & - & - & - & 13,712 & 0,008 \\
\hline Brik & - & - & - & - & - & - & - & - \\
\hline Inertes & 0,810 & $<0,001$ & - & - & - & - & 7,164 & 0,128 \\
\hline RTP & 0,360 & $<0,001$ & - & - & - & - & 13,577 & 0,009 \\
\hline Vidrio & 0,990 & 0,668 & 4,238 & 0,003 & 0,812 & 0,524 & - & - \\
\hline Otros & 0,253 & $<0,001$ & - & - & - & - & 3,661 & 0,454 \\
\hline
\end{tabular}

Tabla 6.34 Análisis estadístico RAB2-O, fase 2

\begin{tabular}{|c|c|c|c|c|c|c|c|c|}
\hline Test estadístico & \multirow{2}{*}{\multicolumn{2}{|c|}{$\begin{array}{c}\text { Test de Shapiro-Wilk } \\
\text { Bondad de ajuste: } \\
\text { Normalidad }\end{array}$}} & \multirow{2}{*}{\multicolumn{2}{|c|}{$\begin{array}{c}\text { Test de Levene } \\
\text { Comparación de } \\
\text { varianzas }\end{array}$}} & \multirow{2}{*}{\multicolumn{2}{|c|}{$\begin{array}{c}\text { ANOVA / ANOVA de } \\
\text { Welch } \\
\begin{array}{c}\text { Comparación de } \\
\text { medias }\end{array}\end{array}$}} & \multirow{2}{*}{\multicolumn{2}{|c|}{$\begin{array}{c}\text { Test de Kuskal-Wallis } \\
\text { Comparación de } \\
\text { medianas }\end{array}$}} \\
\hline Tipo de prueba & & & & & & & & \\
\hline Fracción & $\mathbf{w}$ & p-valor & $\mathbf{F}$ & p-valor & $\mathbf{F}$ & p-valor & H & p-valor \\
\hline Fracción orgánica & 0,983 & 0,208 & 0,893 & 0,471 & 1,344 & 0,259 & - & - \\
\hline Plástico Film & 0,823 & $<0,001$ & - & - & - & - & 10,763 & 0,029 \\
\hline Plástico Rígido & 0,416 & $<0,001$ & - & - & - & - & 5,202 & 0,267 \\
\hline Textil & 0,196 & $<0,001$ & - & - & - & - & 4,969 & 0,291 \\
\hline Metales & 0,275 & $<0,001$ & - & - & - & - & 22,426 & $<0,001$ \\
\hline Madera & 0,266 & $<0,001$ & - & - & - & - & 5,688 & 0,224 \\
\hline Brik & 0,077 & $<0,001$ & - & - & - & - & 6,818 & 0,146 \\
\hline Inertes & 0,804 & $<0,001$ & - & - & - & - & 9,576 & 0,050 \\
\hline RTP & 0,255 & $<0,001$ & - & - & - & - & 5,126 & 0,275 \\
\hline Vidrio & 0,976 & 0,063 & 3,781 & 0,007 & 1,013 & 0,410 & - & - \\
\hline Otros & 0,470 & $<0,001$ & - & - & - & - & 9,884 & 0,042 \\
\hline
\end{tabular}


Respecto a la fase 1, los resultados obtenidos para el análisis estadístico del RAB2-O muestran la existencia de diferencias significativas en el porcentaje de textil, metales, madera y RTP entre los niveles de submuestreo. Para la fase 2 estas diferencias se dan en el plástico film, los metales y los Otros. El p-valor obtenido en la comparación de medias o medianas para estas fracciones es menor a 0,05 (Tabla 6.33 y Tabla 6.34). Así pues, se puede afirmar con una confianza del 95\% que, en función del tamaño de muestra, el porcentaje de estos materiales en el RAB2-O es diferente $y$, por tanto, los resultados obtenidos para cierto nivel de submuestreo dejan de ser representativos de la población de rechazo muestreada.

Para el resto de fracciones de la fase 1 y 2 no se han encontrado diferencias estadísticamente significativas ( $p$-valor $>0,05$ ), por lo que su porcentaje no varía en función del nivel de submuestreo y los resultados son representativos para todos los tamaños de muestra estudiados. Así pues, el tamaño mínimo de muestra para estas fracciones corresponde al nivel de submuestreo más bajo (L5) con 0,025 kg.

Por último, en la Tabla 6.35 y Tabla 6.36 se muestran los resultados de los test post hoc realizados a aquellas fracciones en las que existen diferencias en función del nivel de submuestreo, para la fase 1 y 2 respectivamente. En ellas también se indica el nivel de submuestreo crítico y el tamaño mínimo de muestra para el RAB2-O determinado a partir de estos resultados ( $\left.m_{f} R A B 2-0\right)$.

Tabla 6.35 Test post hoc RAB2-O, fase 1

\begin{tabular}{|c|c|c|c|c|c|c|c|c|}
\hline Fracción & \multicolumn{2}{|c|}{ Textil } & \multicolumn{2}{|c|}{ Metales } & \multicolumn{2}{|c|}{ Madera } & \multicolumn{2}{|c|}{ RTP } \\
\hline Test post hoc & \multicolumn{2}{|c|}{ Dunn } & \multicolumn{2}{|c|}{ Dunn } & \multicolumn{2}{|c|}{ Dunn } & \multicolumn{2}{|c|}{ Dunn } \\
\hline Comparaciones & Z & p-valor & Z & p-valor & $\mathbf{z}$ & p-valor & $\mathbf{z}$ & p-valor \\
\hline L1 - L2 & 2,840 & 0,045 & 0,359 & 0,799 & 1,481 & 0,231 & 1,748 & 0,201 \\
\hline L1 - L3 & 1,457 & 0,362 & 2,529 & 0,038 & 3,078 & 0,010 & 3,269 & 0,011 \\
\hline L2 - L3 & $-1,382$ & 0,334 & 2,170 & 0,060 & 1,597 & 0,221 & 1,521 & 0,257 \\
\hline L1 - L4 & 2,249 & 0,082 & 2,292 & 0,055 & 2,518 & 0,039 & 2,752 & 0,020 \\
\hline L2 - L4 & $-0,591$ & 0,693 & 1,933 & 0,089 & 1,036 & 0,429 & 1,004 & 0,450 \\
\hline L3 - L4 & 0,791 & 0,613 & $-0,237$ & 0,812 & $-0,561$ & 0,639 & $-0,517$ & 0,757 \\
\hline L1 - L5 & 2,324 & 0,101 & 2,891 & 0,038 & 3,078 & 0,021 & 2,781 & 0,027 \\
\hline L2 - L5 & $-0,516$ & 0,673 & 2,532 & 0,057 & 1,597 & 0,276 & 1,033 & 0,502 \\
\hline L3 - L5 & 0,866 & 0,644 & 0,362 & 0,897 & 0,000 & 1,000 & $-0,488$ & 0,695 \\
\hline L4 - L5 & 0,075 & 0,940 & 0,599 & 0,784 & 0,560 & 0,719 & 0,029 & 0,977 \\
\hline Nivel crítico & \multicolumn{2}{|c|}{ L2 $(0,200 \mathrm{~kg})$} & \multicolumn{2}{|c|}{ L3 $(0,100 \mathrm{~kg})$} & \multicolumn{2}{|c|}{ L3 $(0,100$ kg) } & \multicolumn{2}{|c|}{ L3 $(0,100$ kg) } \\
\hline $\begin{array}{l}\mathrm{m}_{\mathrm{f}} \text { RAB2-O } \\
\text { Fase } 1(\mathrm{Kg})\end{array}$ & \multicolumn{2}{|c|}{0,400} & \multicolumn{2}{|c|}{0,200} & \multicolumn{2}{|c|}{0,200} & \multicolumn{2}{|c|}{0,200} \\
\hline
\end{tabular}


Tabla 6.36 Test post hoc RAB2-O, fase 2

\begin{tabular}{|c|c|c|c|c|c|c|}
\hline Fracción & \multicolumn{2}{|c|}{ Plástico Film } & \multicolumn{2}{|c|}{ Metales } & \multicolumn{2}{|c|}{ Otros } \\
\hline Test post hoc & \multicolumn{2}{|c|}{ Dunn } & \multicolumn{2}{|c|}{ Dunn } & \multicolumn{2}{|c|}{ Dunn } \\
\hline Comparaciones & z & p-valor & Z & p-valor & Z & p-valor \\
\hline L1 - L2 & 0,357 & 1,000 & 2,442 & 0,037 & 1,426 & 0,308 \\
\hline L1 - L3 & 0,439 & 1,000 & 2,601 & 0,031 & 1,030 & 0,433 \\
\hline L2 - L3 & 0,082 & 0,935 & 0,159 & 0,874 & $-0,397$ & 0,692 \\
\hline L1 - L4 & 0,617 & 1,000 & 3,593 & 0,002 & 2,110 & 0,174 \\
\hline L2 - L4 & 0,259 & 0,994 & 1,152 & 0,356 & 0,684 & 0,549 \\
\hline L3 - L4 & 0,177 & 0,955 & 0,993 & 0,401 & 1,080 & 0,467 \\
\hline L1 - L5 & 2,898 & 0,038 & 4,455 & $<0,001$ & 2,947 & 0,032 \\
\hline L2 - L5 & 2,540 & 0,055 & 2,014 & 0,088 & 1,521 & 0,321 \\
\hline L3 - L5 & 2,459 & 0,046 & 1,855 & 0,106 & 1,917 & 0,184 \\
\hline L4 - L5 & 2,281 & 0,056 & 0,862 & 0,432 & 0,837 & 0,503 \\
\hline Nivel crítico & \multicolumn{2}{|c|}{ L5 $(0,025 \mathrm{~kg})$} & \multicolumn{2}{|c|}{ L2 $(0,200 \mathrm{~kg})$} & \multicolumn{2}{|c|}{ L5 (0,025 kg) } \\
\hline $\begin{array}{l}m_{f} \text { RAB2-O } \\
\text { Fase } 2(\mathrm{Kg})\end{array}$ & \multicolumn{2}{|c|}{0,050} & \multicolumn{2}{|c|}{0,400} & \multicolumn{2}{|c|}{0,050} \\
\hline
\end{tabular}

Las comparaciones múltiples para la fase 1 (Tabla 6.35) muestran diferencias significativas en dichas fracciones entre los niveles de submuestreo L2, L3, L4 y L5 y el nivel L1, aunque en función del material estas diferencias se dan para unos niveles u otros. En el caso del textil, el porcentaje de este material obtenido con el nivel de submuestreo L2 es distinto al obtenido con L1. Para los metales, los porcentajes obtenidos con L3 y L5 son diferentes al obtenido en L1. Respecto a la madera y los RTP, las diferencias en los porcentajes de ambas fracciones se dan entre los niveles de submuestreo L3, L4 y L5 y el nivel L1. En todas estas las comparaciones el p-valor obtenido es menor a 0,05.

En cuanto a la fase 2, los resultados de la Tabla 6.36 también muestran que existen diferencias estadísticamente significativas entre los niveles L2, L3, L4 y L5 y el nivel L1, aunque para cada fracción las diferencias se dan entre unos niveles u otros. En el caso del plástico film, el porcentaje obtenido con el nivel L5 es distinto al del L1 y L3. Respecto a los metales, las diferencias en los porcentajes se dan entre los niveles $L 2, L 3, L 4$ y $L 5$ respecto a $L 1$. Por último, el porcentaje de Otros obtenido en el nivel de submuestreo L5 es distinto al de L1. En todas las comparaciones el p-valor obtenido es menor a 0,05.

Por otra parte, como se observa en las tablas anteriores, en función de cada fracción se ha obtenido un tamaño de muestra mínimo diferente. Como indica la metodología, el tamaño de muestra será el más restrictivo de todos ellos, de forma que todas las fracciones estén correctamente representadas.

Así pues, se puede concluir que el nivel crítico más restrictivo para el RAB2-O en ambas fases es el L2, por lo que los resultados obtenidos para el peso de muestra correspondiente a este nivel de submuestreo $(0,200$ $\mathrm{kg}$ ) no son representativos para todas las fracciones. Esto significa que el tamaño de mínimo de muestra necesario para el control de calidad del RAB2-O es de 0,400 kg (L1). Además, este peso es el mismo en ambas fases, por lo que el tamaño de muestra no está afectado por la estacionalidad.

Por último, cabe señalar que en el caso del RAB2-O el tamaño de mínimo de muestra determinado con la metodología propuesta coincide con el tamaño de muestra inicial calculado a partir de la norma UNE-EN 15442 (2012) para los CSR. Esto es debido a que el rechazo de afino secundario es un material con un 
tamaño de partícula más regular, lo que hace que la fórmula propuesta por la norma funcione adecuadamente.

Finalmente, en la Tabla 6.40 se presentan los tamaños mínimos de muestra necesarios para la determinación de la composición física del RAB2-O, los cuales se tienen de tomar mediante un muestreo aleatorio simple. El peso de muestra será diferente en función del periodo y de la fracción que se quiera conocer. Si se quiere determinar la composición global se deben tomar 0,4 kg.

Tabla 6.37 Tamaño mínimo de muestra para el RAB2-O

\begin{tabular}{|c|c|c|c|c|c|}
\hline \multirow[b]{2}{*}{ Fracción } & \multicolumn{2}{|c|}{$m_{f}(k g)$} & \multirow[b]{2}{*}{ Fracción } & \multicolumn{2}{|c|}{$m_{f}(k g)$} \\
\hline & $\begin{array}{c}\text { Primavera- } \\
\text { verano }\end{array}$ & $\begin{array}{c}\text { Otoño- } \\
\text { invierno }\end{array}$ & & $\begin{array}{c}\text { Primavera- } \\
\text { verano }\end{array}$ & $\begin{array}{l}\text { Otoño- } \\
\text { invierno }\end{array}$ \\
\hline Textil & 0,400 & 0,025 & Fracción Orgánica & \multirow{6}{*}{0,025} & \multirow{6}{*}{0,025} \\
\hline Metales & 0,200 & 0,400 & Plástico Rígido & & \\
\hline Madera & \multirow{2}{*}{0,200} & \multirow{2}{*}{0,025} & \multirow{2}{*}{ Brik } & & \\
\hline RTP & & & & & \\
\hline Plástico Film & \multirow{2}{*}{0,025} & \multirow{2}{*}{0,050} & Inertes & & \\
\hline Otros & & & Vidrio & & \\
\hline
\end{tabular}

\subsubsection{Relación entre el tamaño de muestra y tamaño de partícula de los rechazos de la PRC de Onda}

Klee (1993) estableció en su trabajo de investigación que para residuos procesados existe una relación entre el tamaño de muestra y el tamaño de partícula del material. A partir de los datos obtenidos en el caso estudiado se ha comprobado si existe algún tipo de relación entre el tamaño de partícula de los rechazos $\left(d_{95}\right)$ y el peso de muestra necesario.

Así pues, en la Figura 6.21 se muestra el diagrama de dispersión para los tamaños de muestra de cada rechazo $\left(\mathrm{m}_{\mathrm{f}}\right)$ en relación al $\mathrm{d}_{95}$. El mejor ajuste se ha obtenido con una curva exponencial, cuya ecuación y valor de $\mathrm{R}^{2}$ también se presentan en la figura.

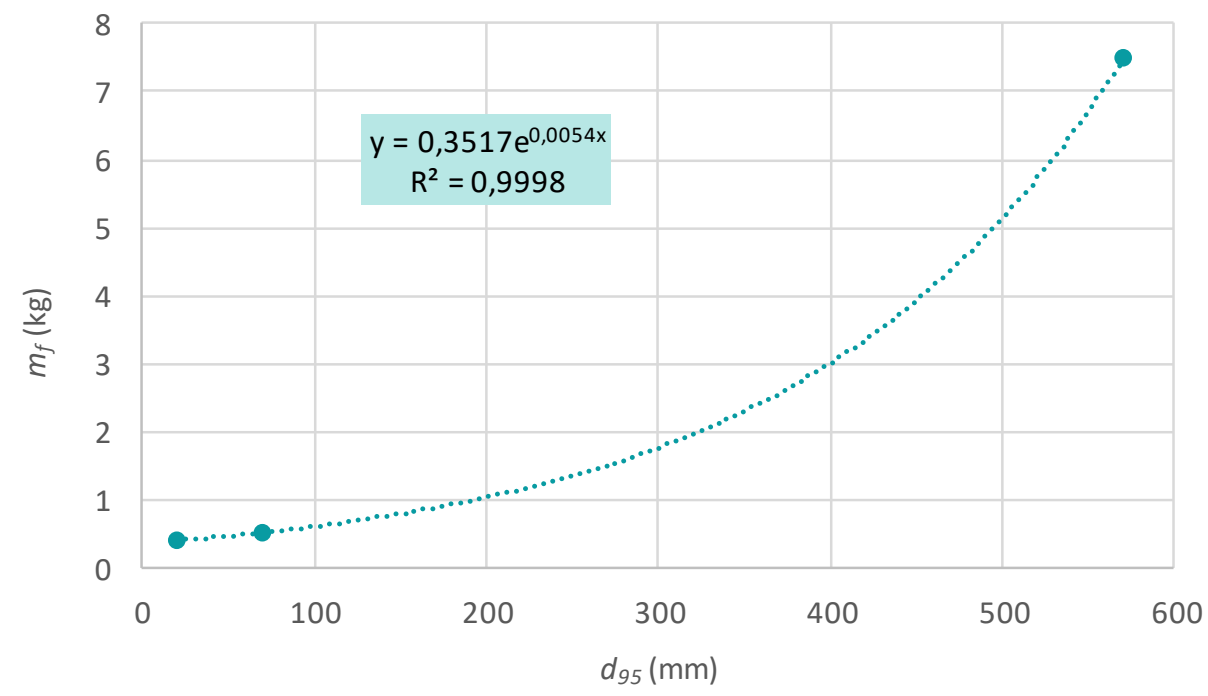

Figura 6.21 Ajuste ecuación del tamaño de muestra de la PRC de Onda 
A partir del ajuste se obtiene la siguiente ecuación:

$$
m_{f}(P R C-O)=0,3517 e^{0,0054 \cdot d_{95}}
$$

Donde $m_{f}(P R C-O)$ es el tamaño mínimo de muestra en kg para cierta corriente de rechazo de la PRC de Onda y d95 es el tamaño nominal superior de partícula en $\mathrm{mm}$ de dicha corriente.

Esta ecuación es muy útil si el proceso de tratamiento de la instalación cambiara y aparecieran nuevas corrientes de rechazo con un tamaño de partícula diferente, puesto que, conociendo el tamaño nominal superior del nuevo rechazo, permite calcular el peso de muestra necesario para su caracterización sin tener que aplicar de nuevo toda la metodología.

\subsubsection{Cálculo de los tiempos invertidos en el procedimiento de división de muestra y caracterización en la PRC de Onda.}

A continuación, se muestra el cálculo del tiempo empleado en el procedimiento de división de muestra y caracterización para el caso de la PRC de Onda.

\section{Rechazo de recuperación manual de la PRC de Onda (RRM-O)}

El tiempo total invertido en el muestreo y caracterización de este rechazo para determinar el tamaño de muestra mínimo fue de 38,25 horas para la fase 1 y 26,25 horas para la fase 2 . Este trabajo, como se ha comentado anteriormente, fue realizado por un equipo formado de 2 a 4 personas en función del día.

En la Tabla 6.38 se indica el tiempo medio necesario por persona para el muestreo y caracterización de $1 \mathrm{~kg}$ de RRM-O, así como el tiempo medio que se necesitaría para la caracterización de cada uno de los niveles de submuestreo y para el procedimiento de división y caracterización completo.

Tabla 6.38 Tiempo invertido para el muestreo y caracterización de RRM-O

\begin{tabular}{c|c|c}
\hline \multirow{2}{*}{ Cantidad RRM-O } & \multicolumn{2}{c}{ Tiempo necesario } \\
\cline { 2 - 3 } & h/persona & min/persona \\
\hline $\mathbf{1} \mathbf{~ k g}$ & 0,06 & 3,69 \\
\hline L1 (60 kg) & 3,69 & 221,40 \\
\hline L2 (30 kg) & 1,85 & 110,70 \\
\hline L3 (15 kg) & 0,92 & 55,35 \\
\hline L4 (7,5 kg) & 0,46 & 27,68 \\
\hline L5 (3,75 kg) & 0,23 & 13,84 \\
\hline $\begin{array}{c}\text { Procedimiento de división y } \\
\text { caracterización (116,25 kg) }\end{array}$ & 7,15 & 428,96 \\
\hline
\end{tabular}

Como se observa en la tabla anterior, se ha determinado que una persona tarda casi 4 minutos en caracterizar un kilogramo de RRM-O. Por lo que, para poder aplicar el procedimiento propuesto por la metodología, son necesarias algo más de 7 horas de trabajo de una persona para la toma de muestras y caracterización de todos los niveles de submuestreo.

Por otro lado, se puede comparar el tiempo necesario para la caracterización de este rechazo si se utilizara el tamaño de muestra de $60 \mathrm{~kg}$ calculado a partir de la norma del CSR ( $m_{m}$ RRM-O), con el determinado a partir de la metodología de 7,5 kg ( $\left.m_{f} R R M-0\right)$. Así pues, en el caso de utilizar el peso de $60 \mathrm{~kg}$ sería necesario invertir 3 horas y 40 minutos de trabajo de una persona, mientras que para 7,5 kg serían necesario 27 minutos. Esto supone un ahorro del 87,5\% en el tiempo invertido, con todas las ventajas económicas que esto conlleva. 
Rechazo de afino primario del bioestabilizado de la PRC de Onda (RAB1-O)

El tiempo total invertido en el muestreo y caracterización de este rechazo para la determinación del tamaño de muestra mínimo fue de 11,25 horas en la fase 1 y de 11,42 horas en la fase 2 . Este trabajo siempre fue realizado por un equipo formado por dos personas.

En la Tabla 6.39 se muestra el tiempo medio necesario por persona para el muestreo y caracterización de 1 kg de RAB1-O (que coincide con el nivel de submuestreo L1), para la caracterización del resto de niveles y para el procedimiento de división y caracterización completo.

Tabla 6.39 Tiempo invertido para el muestreo y caracterización de RAB1-O

\begin{tabular}{c|c|c}
\hline \multirow{2}{*}{ Cantidad RAB1-O } & \multicolumn{2}{|c}{ Tiempo necesario } \\
\cline { 3 - 3 } & h/persona & min/persona \\
\hline L1 (1 kg) & 0,47 & 27,95 \\
\hline L2 (0,500 kg) & 0,23 & 13,97 \\
\hline L3 (0,250 kg) & 0,12 & 6,99 \\
\hline L4 (0,125 kg) & 0,06 & 3,49 \\
\hline L5 (0,065 kg) & 0,03 & 1,82 \\
\hline $\begin{array}{c}\text { Procedimiento de división y } \\
\text { caracterización (1,940 kg) }\end{array}$ & 0,90 & 54,22 \\
\hline
\end{tabular}

En la tabla anterior se puede ver que de media una persona necesita 28 minutos para caracterizar un kilogramo de RAB1-O. Este tiempo es mucho mayor comparado con el del RRM-O debido a que el tamaño de partícula del RAB1-O es más pequeño, lo que hace que la separación de las diferentes fracciones sea mucho más laboriosa. No obstante, el tiempo total necesario para la aplicación del procedimiento de división de muestra y caracterización por una persona es de 54 minutos, menos que para el RRM-O, ya que la cantidad de muestra en cada nivel de submuestreo es mucho menor.

Por otro parte, el tiempo necesario para la caracterización de este rechazo por una persona si se utilizará el tamaño de muestra de $1 \mathrm{~kg}$ calculado con la norma del CSR ( $m_{m}$ RAB1-O) sería de 28 minutos. Mientras que, si se utiliza el tamaño de muestra de $0,500 \mathrm{~kg}$ determinado con la metodología ( $\mathrm{m}_{\mathrm{f}} \mathrm{RAB1}-\mathrm{O}$ ), este tiempo se reduce a la mitad con 14 minutos, lo que supone un ahorro importante en el tiempo invertido y por tanto en el coste de la caracterización.

\section{Rechazo de afino secundario del bioestabilizado de la PRC de Onda (RAB2-O)}

Para la determinación del tamaño de muestra mínimo de este rechazo fue necesario invertir un total de 9,67 horas en la fase 1 y un total de 10,75 horas en la fase 2 . Este trabajo siempre fue realizado por un equipo formado por 2 personas.

En la Tabla 6.40 se expone el tiempo medio necesario por una persona para el muestreo y caracterización de $1 \mathrm{~kg}$ de RAB2-O, para los diferentes niveles de submuestreo y para el procedimiento de división y caracterización completo. En ella se observa que una persona necesita 71 minutos para caracterizar un kilogramo de RAB2-O, duplicándose el tiempo en relación al RAB1-O. Esto es consecuencia del menor tamaño de partícula de este rechazo, que hace que su separación sea aún más laboriosa. En cuanto al tiempo total necesario para la aplicación de procedimiento propuesto en la metodología, una persona necesita 55 minutos para la toma de muestras y caracterización de todos los niveles de submuestreo. Este valor coincide con el del RAB1-O a pesar de que la cantidad de muestra en cada nivel para el RAB2-O es menor, esto se debe a que se necesita más tiempo para la caracterización de este rechazo al tener un tamaño de partícula más pequeño. 
Tabla 6.40 Tiempo invertido para el muestreo y caracterización de RAB2-O

\begin{tabular}{c|c|c}
\hline \multirow{2}{*}{ Cantidad RAB2-O } & \multicolumn{2}{|c}{ Tiempo necesario } \\
\cline { 2 - 3 } & h/persona & min/persona \\
\hline $\mathbf{1} \mathbf{~ k g}$ & 1,19 & 71,62 \\
\hline L1 (0,400 kg) & 0,48 & 28,65 \\
\hline L2 (0,200 kg) & 0,24 & 14,32 \\
\hline L3 (0,100 kg) & 0,12 & 7,16 \\
\hline L4 (0,050 kg) & 0,06 & 3,58 \\
\hline L5 (0,025 kg) & 0,03 & 1,79 \\
\hline $\begin{array}{c}\text { Procedimiento de división y } \\
\text { caracterización (0,775 } \mathbf{~ g g})\end{array}$ & 0,93 & 55,50 \\
\hline
\end{tabular}

Así pues, en el caso del RAB2-O, el tamaño de muestra calculado con la norma del CSR y el determinado con la metodología coinciden, por lo que para los dos casos se necesitarían cerca de 28 minutos de media para caracterizar el peso de $0,400 \mathrm{~kg}$ correspondiente al nivel de submuestreo L1 por una persona.

\subsubsection{Caso 2: Determinación del tamaño mínimo de muestra en la planta de biosecado y recuperación de Cervera del Maestre}

\subsubsection{Descripción de la planta}

La PBSR de Cervera (Figura 6.22) es la única instalación de este tipo que existe en España y en ella se tratan los RSU mezclados gestionados por el Consorcio del Residuos C1 (Consorci Castelló Nord) procedentes de 49 municipios cuya población suma 114.420 habitantes. Su capacidad de tratamiento es de 160.000 t/año y en el año 2018 se trataron un total de 75.840 t de RSU mezclados.

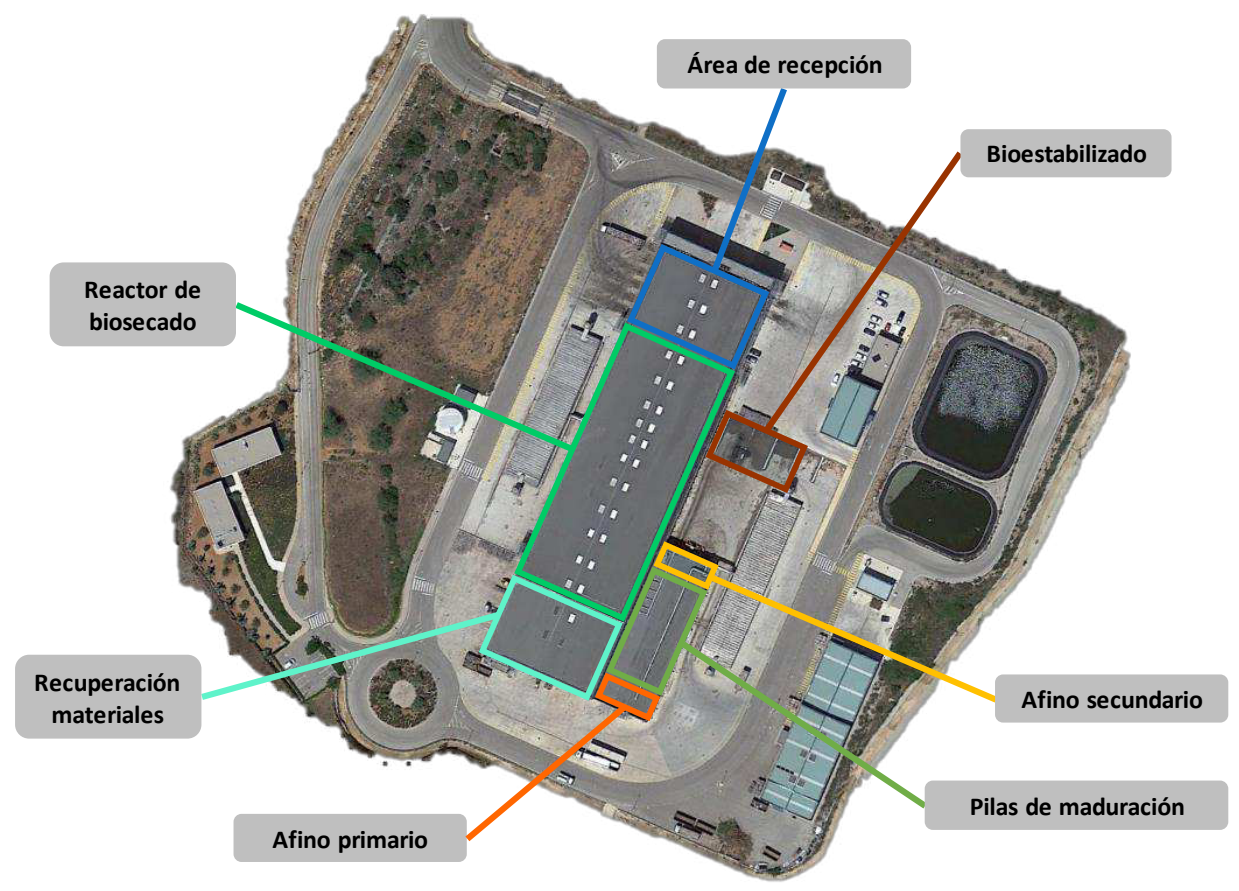

Figura 6.22 Planta de biosecado y recuperación de Cervera del Maestre 
En esta instalación los RSU mezclados son sometidos directamente a un proceso de biosecado durante 14 días, tras el cual se separa la fracción seca (fracción no biodegradable) de la húmeda (fracción orgánica). La recuperación de los materiales reciclables de la fracción seca se realiza de forma mecánica y manual, separando: PET, PEAD, plástico film, plástico mix, papel/cartón, brik, madera y metales férricos. La fracción húmeda se destina a maduración en pilas.

En cuanto al balance de masas y respecto al material entrante, tras el tratamiento de los RSU se obtiene un flujo de materiales recuperados (9,82\%), un flujo de material bioestabilizado $(3,56 \%)$ y varias corrientes de rechazo (45,47\%). Las pérdidas del proceso (emisiones gaseosas y líquidas) suponen el 41,15\% del material.

Las corrientes de rechazo que pueden ser transformadas en un CSR y se han considerado para su estudio son (Figura 6.23):

- Rechazo de recuperación manual del biosecado (RRM-BS-C): generado en la etapa de recuperación de materiales del biosecado, tras la separación de los materiales reciclables del rebose del trómel que separa la fracción seca de la húmeda. Con un diámetro de partícula superior a $80 \mathrm{~mm}$.

- Rechazo de afino primario del biosecado (RABS1-C): generado en el trómel de afino primario de la fracción húmeda del biosecado antes de su maduración en pilas, con un tamaño de partícula entre 80 y $25 \mathrm{~mm}$.

- Rechazo de afino secundario del biosecado (RABS2-C): generado en el trómel de afino final del material biosecado tras su maduración, con un tamaño de partícula entre 25 y $8 \mathrm{~mm}$.
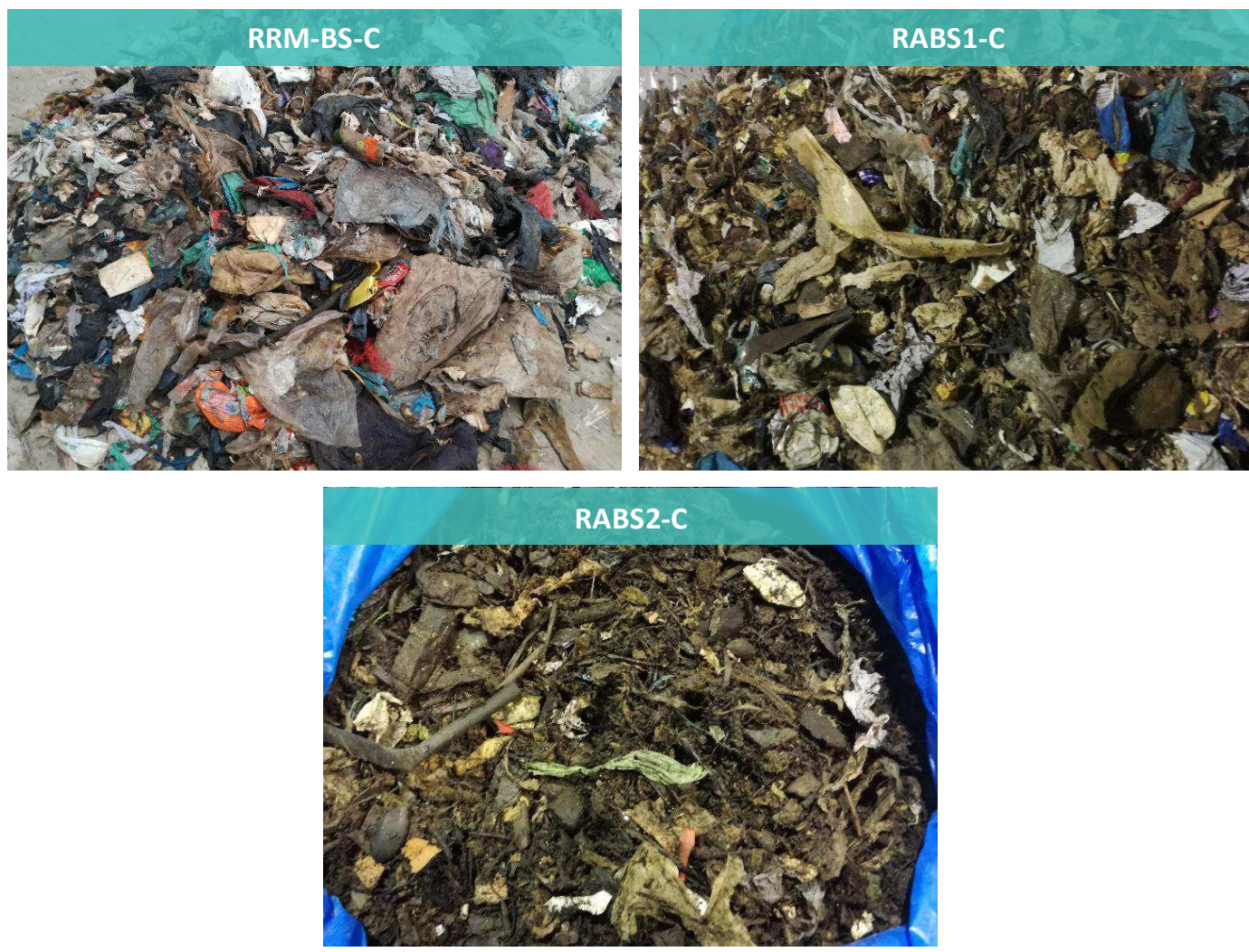

Figura 6.23 Rechazos generados en la planta de biosecado y recuperación de Cervera

\subsubsection{Cálculo del tamaño de muestra inicial}

En primer lugar, se calculó el tamaño de muestra inicial para las tres corrientes de rechazo mediante la ecuación 6.1. Para ello, se determinaron todos los parámetros relacionados con las propiedades físicas del 
material a partir de la muestra control. El peso de las muestras control fue de unos $30 \mathrm{~kg}$ para el RRM-BS-C, de $10 \mathrm{~kg}$ para el RABS1-C y de $5 \mathrm{~kg}$ para el RABS2-C.

\section{Determinación del tamaño nominal superior y el tamaño mínimo de partícula}

EL tamaño nominal superior ( $\mathrm{d}_{95}$ ) del RRM-BS-C se determinó a partir de la norma UNE-EN 15415-2 mediante la medición de la longitud máxima de partícula, puesto que el diámetro de partícula del material es mayor a $80 \mathrm{~mm}$. De acuerdo con la norma se utilizó una muestra de 13,19 kg y se estableció $70 \mathrm{~mm}$ como límite inferior de tamaño y $770 \mathrm{~mm}$ como superior. El tamaño mínimo de partícula (do5) se ha determinado con la norma UNE-EN 15415-1 mediante una serie de tamices. En la Tabla 6.41 se muestran las clases de tamaño consideradas entre estos niveles y los resultados obtenidos. Además, en la Figura 6.24 se pueden ver las partícula que componen el $d_{95}$ y el $d_{05}$ para este rechazo.

Tabla 6.41 Tamaño nominal superior y tamaño mínimo de partícula del RRM-BS-C

\begin{tabular}{|c|c|c|c|c|c|}
\hline $\begin{array}{c}\text { Clases de tamaño } \\
(\mathrm{mm})\end{array}$ & Peso (kg) & $\%$ en peso & $\begin{array}{c}\% \\
\text { acumulado }\end{array}$ & $d_{95,1}(\mathrm{~mm})^{*}$ & $\mathrm{~d}_{05}(\mathrm{~mm})$ \\
\hline$>770$ & 0 & 0 & 0 & \multirow{13}{*}{470} & \multirow{13}{*}{30} \\
\hline $770-670$ & 0 & 0 & 0 & & \\
\hline $670-570$ & 0,07 & 0,54 & 0,54 & & \\
\hline $570-470$ & 0,59 & 4,55 & 5,08 & & \\
\hline $470-370$ & 1,53 & 11,79 & 16,87 & & \\
\hline $370-270$ & 2,21 & 17,03 & 33,90 & & \\
\hline $270-170$ & 2,33 & 17,95 & 51,85 & & \\
\hline $170-70$ & 1,01 & 7,78 & 59,63 & & \\
\hline $70-30$ & 4,51 & 34,75 & 94,38 & & \\
\hline $30-20$ & 0,32 & 2,47 & 96,84 & & \\
\hline $20-10$ & 0,20 & 1,54 & 98,38 & & \\
\hline$<10$ & 0,21 & 1,62 & 100 & & \\
\hline Filamentosas & 0,21 & 1,59 & - & & \\
\hline
\end{tabular}

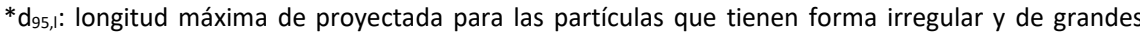
dimensiones.

En la Tabla 6.41 se puede ver que el tamaño de partícula predominante en el RRM-BS-C se encuentra entre los $70-30 \mathrm{~mm}$ con un $34,75 \%$ de la partículas (Figura 6.24), mientras que entre los tamaños de 470 y $30 \mathrm{~mm}$ se encuentra el $89,29 \%$ de las mismas. Como se ha comentado anteriormente, el RRM-BS-C debería tener un diámetro de partícula superior a $80 \mathrm{~mm}$, puesto que su origen es el rebose de un trómel con esa luz de malla. Sin embargo, se observa que existen partículas por debajo de este tamaño que no han sido separadas correctamente. Esto se puede deber a diferentes motivos: velocidad de giro del trómel demasiado alta, flujo de entrada de material por encima de la capacidad de diseño del equipo, incorrecta apertura de las bolsas por el abrebolsas, formación de madejas de materiales que atrapan a partículas de pequeño tamaño o adhesión de las partículas como consecuencia de la humedad. 

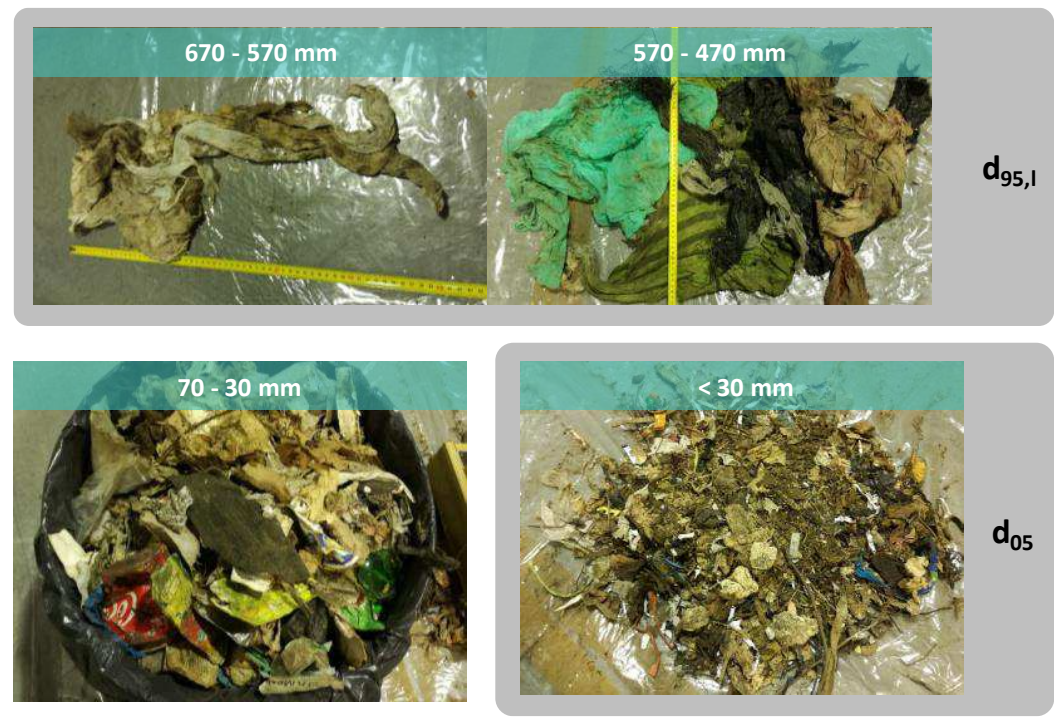

Figura 6.24 Tamaño nominal superior, tamaño mínimo de partícula y tamaño de partícula predominante en el RRM-BSC

En cuanto al RABS1-C y al RABS2-C, el d95 y el do5 se determinó utilizando la norma UNE-EN 15415-1, dado que su diámetro de partícula está entre $80-25 \mathrm{~mm}$ y $25-8 \mathrm{~mm}$ respectivamente. Para ello se tamizó aproximadamente $2 \mathrm{~kg}$ de material para cada rechazo. Tras el cribado se obtuvieron los resultados expuestos en la Tabla 6.42 para el RABS1-C y en la Tabla 6.43 para el RABS2-C.

Tabla 6.42 Tamaño nominal superior y tamaño mínimo de partícula del RABS1-C

\begin{tabular}{|c|c|c|c|c|c|}
\hline $\begin{array}{l}\text { Clases de tamaño } \\
(\mathrm{mm})\end{array}$ & Peso (kg) & $\%$ en peso & $\begin{array}{c}\% \\
\text { acumulado }\end{array}$ & $d_{95}(\mathrm{~mm})$ & $d_{05}(\mathrm{~mm})$ \\
\hline$>60$ & 0,03 & 1,25 & 1,25 & \multirow{7}{*}{50} & \multirow{7}{*}{1} \\
\hline $60-50$ & 0,14 & 5,82 & 7,07 & & \\
\hline $50-30$ & 0,62 & 25,78 & 32,85 & & \\
\hline $30-10$ & 0,97 & 40,33 & 73,18 & & \\
\hline $10-5$ & 0,25 & 10,40 & 83,58 & & \\
\hline $5-1$ & 0,28 & 11,56 & 95,14 & & \\
\hline$<1$ & 0,12 & 4,86 & 100 & & \\
\hline
\end{tabular}

El tamaño de partícula mayoritario en el RABS1-C se encuentra entre los 30-10 mm con un 40,33\% del material (Tabla 6.42), por lo que una gran parte de las partículas tienen un tamaño menor al esperado según su origen (rebose de un trómel de $25 \mathrm{~mm}$ ). Esto podría deberse a las razones explicadas anteriormente. En la Figura 6.25 se muestran las partículas que componen el d95, el do5 y el rango de tamaño mayoritario para este rechazo. 

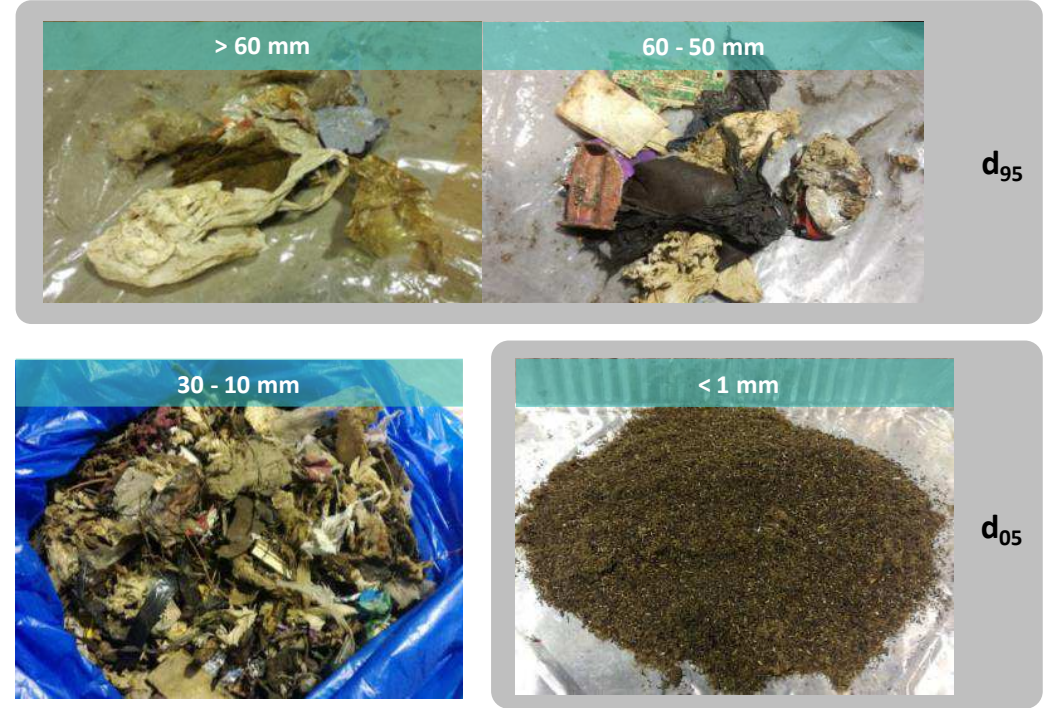

Figura 6.25 Tamaño nominal superior, tamaño mínimo de partícula y tamaño de partícula predominante en el RABS1-C

En la Tabla 6.43 se puede ver que el tamaño de partícula predominante en el RABS2-C es de $20-10 \mathrm{~mm}$ $(38,90 \%)$ y que el rechazo presenta partículas menores al tamaño esperado (25-8 $\mathrm{mm}$ ), los posibles motivos se han enumerado anteriormente. En la Figura 6.26 se pueden ver las partículas que componen el $d_{95}$, el $d_{05}$ y el rango de tamaño mayoritario para este rechazo.

Tabla 6.43 Tamaño nominal superior y tamaño mínimo de partícula del RABS2-C

\begin{tabular}{|c|c|c|c|c|c|}
\hline $\begin{array}{l}\text { Clases de tamaño } \\
(\mathrm{mm})\end{array}$ & Peso (kg) & $\%$ en peso & $\begin{array}{c}\% \\
\text { acumulado }\end{array}$ & $\mathrm{d}_{95}(\mathrm{~mm})$ & $\mathrm{d}_{05}(\mathrm{~mm})$ \\
\hline$>20$ & 0,06 & 2,80 & 2,80 & \multirow{5}{*}{20} & \multirow{5}{*}{1} \\
\hline $20-10$ & 0,85 & 38,90 & 41,70 & & \\
\hline $10-5$ & 0,63 & 28,85 & 70,55 & & \\
\hline $5-1$ & 0,50 & 23,03 & 93,58 & & \\
\hline$<1$ & 0,14 & 6,42 & 100 & & \\
\hline
\end{tabular}
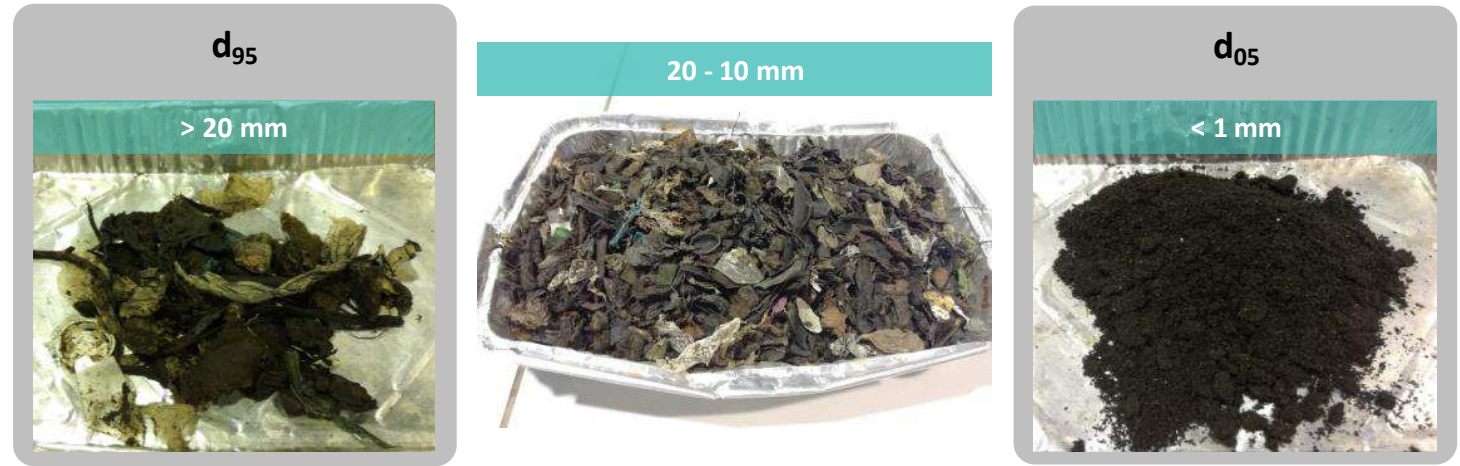

Figura 6.26 Tamaño nominal superior, tamaño mínimo de partícula y tamaño de partícula predominante en el RABS2-C 


\section{Determinación del factor forma}

El factor forma $(f)$ se determinó mediante la ecuación 6.2. Los valores obtenidos para las tres corrientes de rechazo se exponen en la Tabla 6.44 .

Tabla 6.44 Factor forma del RRM-BS-C, RABS1-C y RABS2-C

\begin{tabular}{c|c|c|c}
\hline Parámetro & RRM-BS-C & RABS1-C & RABS2-C \\
\hline $\mathbf{V}_{\mathbf{9 5}}\left(\mathbf{m m}^{3}\right)$ & 705.000 & 150.000 & 3.927 \\
\hline $\mathbf{d}_{95, \mathbf{l}}(\mathbf{m m})$ & 470 & $100 *$ & $25^{*}$ \\
\hline $\boldsymbol{f}$ & 0,007 & 0,150 & 0,251 \\
\hline
\end{tabular}

*Los valores de $d 95$, I se obtuvieron a partir de la longitud máxima de la partícula más pequeña que se quedó por encima del tamiz de d95.

En la tabla anterior se puede ver que el RRM-BS-C es el rechazo que presenta un valor menor debido a que la forma de sus partículas se desvían en gran medida de una esfera (Figura 6.24). Por el contrario, el RABS2$C$ es el que presenta un factor forma más cercano a 1, puesto que las partículas de este rechazo tienen una forma más regular (Figura 6.26).

\section{Determinación de la densidad media de partícula}

La densidad media de partícula $\left(\lambda_{p}\right)$ se determinó a partir de la ecuación 6.3 y mediante la aplicación por triplicado del método desarrollado en la metodología a tal efecto.

Para determinar el volumen de partícula se siguió el mismo procedimiento que en el primer caso de aplicación, el cual se muestra en Figura 6.9 para el rechazo de recuperación de materiales (RRM-BS-C) y en la Figura 6.10 para los rechazos de afino (RABS1-C y RABS2-C).

La densidad media de partícula para las tres corrientes de rechazo de la PBSR de Cervera se muestra en la Tabla 6.45 .

Tabla 6.45 Densidad de partícula del RRM-BS-C, RABS1-C y RABS-C

\begin{tabular}{c|c|c|c}
\hline$\lambda_{p}\left(\mathrm{~kg} / \mathrm{m}^{3}\right)$ & RRM-BS-C & RABS1-C & RABC2-C \\
\hline Replica 1 & 617,78 & 977,14 & 1070,67 \\
\hline Replica 2 & 731,62 & 841,78 & 1154,29 \\
\hline Replica 3 & 691,30 & 900,53 & 1191,86 \\
\hline Media & 680,23 & 906,48 & 1138,94 \\
\hline CV (\%) & 8,49 & 7,49 & 5,45 \\
\hline
\end{tabular}

Como se observa en la tabla anterior, el rechazo con mayor densidad de partícula es el RABS2-C, esto se debe a que este tipo de rechazo está formado principalmente por más densos como: materia orgánica, vidrio e inertes. El RRM-BS-C es el que presenta una menor densidad de partícula, ya que está formado por materiales menos densos como: plásticos, papel, cartón, textil, etc.

\section{Determinación del factor de distribución en el tamaño de partícula}

El factor de distribución $(g)$ se determinó a partir de la Tabla 6.2 de la metodología, en función de la relación entre el tamaño nominal superior $\left(d_{95}\right)$ y el tamaño mínimo de partícula $\left(d_{05}\right)$. Para los tres rechazos analizados el factor de distribución es de 0,25 lo que indica que existe un amplio intervalo de tamaños de partículas en todos ellos. 


\section{Determinación del factor $p$ y el coeficiente de variación}

Para estos dos parámetros se utilizaron los valores que por defecto propone la norma UNE-EN 15442 (2012), por lo que $p=0,1$ y $c v=0,1$.

\section{Cálculo del tamaño de muestra inicial}

Finalmente, a partir de todos los parámetros determinados y la ecuación 6.1 se calculó el tamaño de muestra inicial $\left(\mathrm{m}_{\mathrm{m}}\right)$. Los resultados obtenidos se muestran en la Tabla 6.46.

Tabla 6.46 Tamaño de muestra inicial para RRM-BS-C, RABS1-C y RABS2-C

\begin{tabular}{c|c|c|c}
\hline Parámetro & RRM-BS-C & RABS1-C & RABS2-C \\
\hline$d_{95}(\mathbf{m m})$ & 470 & 50 & 20 \\
\hline$d_{95,1}(\mathbf{m m})$ & 470 & 100 & 25 \\
\hline$d_{05}(\mathbf{m m})$ & 30 & 1 & 1 \\
\hline $\mathbf{V}_{\mathbf{9 5}}\left(\mathbf{m m}^{3}\right)$ & 705.000 & 150.000 & 3.927 \\
\hline $\boldsymbol{f}\left(\mathbf{m m}^{\mathbf{3}} / \mathbf{m m}^{\mathbf{3}}\right)$ & 0,007 & 0,150 & 0,251 \\
\hline$\lambda_{\boldsymbol{p}}\left(\mathbf{k g} / \mathbf{m}^{3}\right)$ & 680,23 & 906,48 & 1138,94 \\
\hline $\boldsymbol{g}$ & 0,25 & 0,25 & 0,25 \\
\hline $\boldsymbol{p}(\mathbf{k g} / \mathbf{k g})$ & 0,1 & 0,1 & 0,1 \\
\hline $\boldsymbol{c v}$ & 0,1 & 0,1 & 0,1 \\
\hline $\mathbf{m}_{\mathbf{m}}(\mathbf{k g})$ & 56,50 & 2,002 & 0,270 \\
\hline $\mathbf{m}_{\mathbf{m}}(\mathbf{k g})$ & $\mathbf{6 0}$ & $\mathbf{2}$ & $\mathbf{0 , 3 0 0}$ \\
\hline
\end{tabular}

* Valor redondeado al alza

En la tabla anterior se observa que para cada rechazo se obtiene un peso de muestra inicial distinto. Esto es consecuencia de que, en función del proceso de tratamiento donde se originan, los rechazos tienen unas propiedades diferentes. Por lo tanto, es indispensable determinar un tamaño mínimo de muestra específico para cada corriente de rechazo de forma que este se adapte a sus propiedades.

\subsubsection{Definición de las fracciones a caracterizar}

Las fracciones que se han considerado a la hora de hacer las caracterizaciones son las propuestas por la metodología, con dos excepciones para el RABS1-C y el RABS2-C.

Para el RRM-BS-C el material se ha dividido en las 13 categorías mostradas en la Tabla 6.3. En el caso de los rechazos de afino, el papel/cartón (que estaba muy sucio y semidegradado) y los finos se incluyeron en la fracción orgánica, por lo que estos rechazos se han clasificado en 11 fracciones.

\subsubsection{Procedimiento de división del tamaño de muestra inicial}

Tras calcular del tamaño de muestra inicial y definir las fracciones a caracterizar, se procedió a la caracterización de los rechazos siguiendo el procedimiento propuesto por la metodología y que se ha dividido en tres pasos:

1. Programación temporal de las caracterizaciones

2. Selección del lote de la corriente de rechazo a muestrear

3. División de tamaño de muestra inicial y caracterización de las muestras 
Además, como en el primer caso de aplicación, cada día de trabajo se contabilizo el tiempo necesario para el muestreo y caracterización de cada corriente de rechazo.

\section{Programación temporal de las caracterizaciones}

El muestreo y caracterización de los rechazos generados en la PBSR de Cervera se ha realizado en un único periodo que se llevó a cabo durante el mes de junio de 2018. Los días de muestreo y caracterización se han elegido repartidos durante los diferentes días de la semana (salvo los fines de semana) de forma que se eviten las variaciones diarias que puedan existir en la composición de los rechazos.

Durante dicho periodo se han caracterizado 10 muestras por corriente de rechazo y nivel de submuestreo como indica la metodología, de forma que se puedan aplicar los métodos estadísticos paramétricos a los datos obtenidos.

Por otro lado, con el objetivo de optimizar el tiempo y aprovechar los viajes a la planta, la programación de las caracterizaciones se ha diseñado de forma que, cada uno de los días en los que se iba a la instalación, se caracterizaban los rechazos generados en dos días diferentes. Por ejemplo, el primer viernes del periodo de muestreo se caracterizaban los rechazos generados el jueves y el propio viernes. Para ello se pidió la colaboración de la empresa, de manera que ellos se han encargado de recoger y almacenar los lotes de las tres corrientes de rechazo correspondiente a los días que no se iba a la planta, los cuales se caracterizaban al día siguiente.

Cada día de muestreo en la instalación, un equipo de trabajo formado por 3 personas se desplazaba a las PBSR de Cervera con todo el equipo necesario para llevar a cabo la toma de muestras y su caracterización (Figura 6.27). En la Tabla 6.47, se muestra el calendario con la programación temporal, en ella se indica el número de muestras caracterizadas por nivel de submuestreo y los días en los que el equipo de trabajo se desplazó a la planta.

Tabla 6.47 Programación temporal y número de muestras en la PBSR de Cervera

\begin{tabular}{c|c|c|c|c}
\hline \multirow{2}{*}{ Día semana } & \multirow{2}{*}{ Fecha } & \multicolumn{3}{c}{ Núm. de muestras por nivel de submuestreo } \\
\cline { 3 - 5 } & & RRM-BS-C & RABS1-C & RAB2-C \\
\hline \multirow{3}{*}{ Lunes } & $11 / 06 / 2018$ & 1 & 1 & 1 \\
\cline { 2 - 5 } & $18 / 06 / 2018^{*}$ & 1 & 1 & 1 \\
\hline \multirow{3}{*}{ Martes } & $12 / 06 / 2018^{*}$ & 1 & 1 & 1 \\
\cline { 2 - 5 } & $19 / 06 / 2018$ & 1 & 1 & 1 \\
\hline \multirow{3}{*}{ Miércoles } & $13 / 06 / 2018$ & 1 & 1 & 1 \\
\cline { 2 - 5 } & $20 / 06 / 2018^{*}$ & 1 & 1 & 1 \\
\hline \multirow{2}{*}{ Jueves } & $07 / 06 / 2018$ & 1 & 1 & 1 \\
\cline { 2 - 5 } & $14 / 06 / 2018 *$ & 1 & 1 & 1 \\
\hline \multirow{2}{*}{ Viernes } & $08 / 06 / 2018^{*}$ & 1 & 1 & 1 \\
\cline { 2 - 5 } & $15 / 06 / 2018$ & 1 & 1 & 1 \\
\hline Total muestras por nivel de & 10 & 10 & 10 \\
\hline
\end{tabular}

* Día de caracterización en planta 


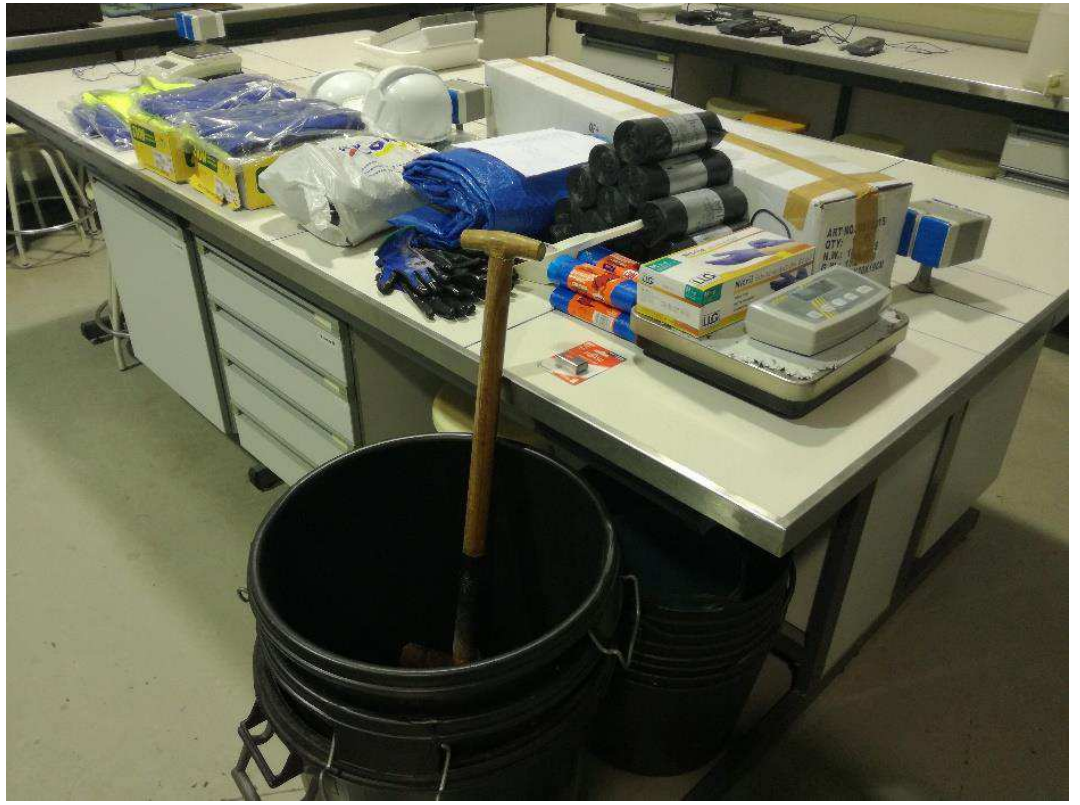

Figura 6.27 Material y equipamiento para realizar las caracterizaciones

\section{Selección del lote de la corriente de rechazo a muestrear}

La selección del lote de la corriente de rechazo se realizó mediante un muestreo a juicio de experto sobre los rechazos accesibles de las tres corrientes de rechazo analizadas, ya que no se tenía acceso a la cantidad total generada diariamente. Los rechazos accesibles corresponden a los generados durante las horas previas al muestreo, los cuales se disponen en pilas estáticas. El lote se seleccionó a partir de estas pilas mediante un muestreo aleatorio simple.

En el caso del RRM-BS-C, la pila fue homogeneizada con una pala mecánica por los operarios de la planta. A continuación, con la propia pala se cogían varios incrementos de material en distintos puntos escogidos aleatoriamente. Los incrementos se unieron para formar el lote cuyo tamaño fue de aproximadamente 500 kg (Figura 6.28).
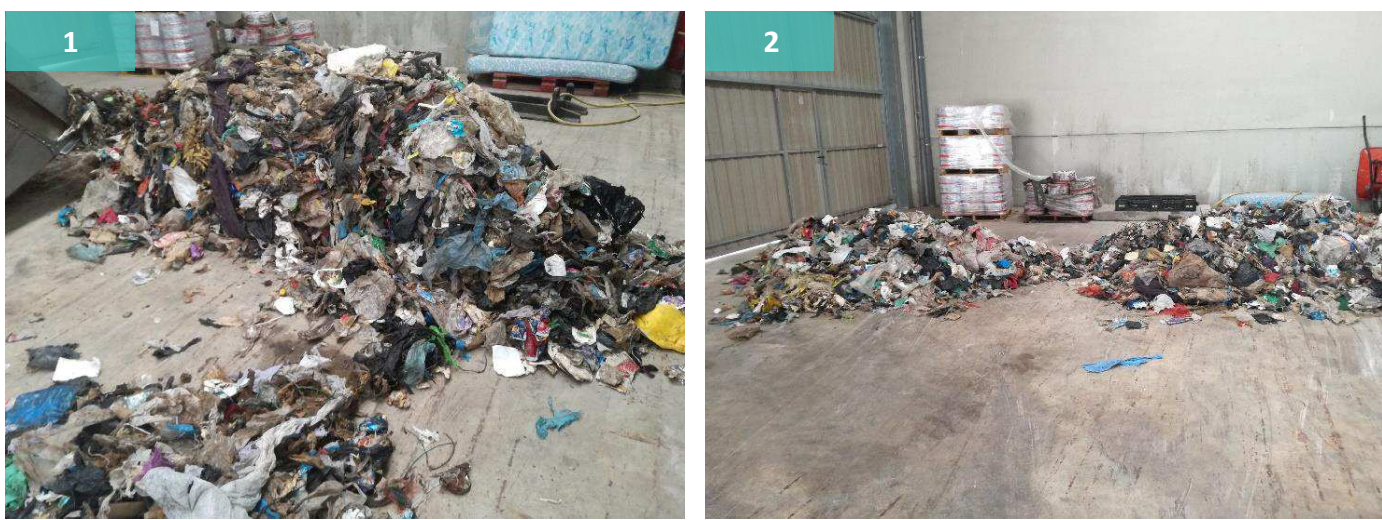

Figura 6.28 Pala mecánica depositando un lote de RRM-BS-C (1); lotes de RRM-BS-C de dos días (2)

Para el RABS1-C y el RABS2-C, debido a que el material era más homogéneo y el tamaño de lote necesario menor, el muestreo de los rechazos accesibles se realizó tomando varios incrementos de forma aleatoria de la pila con una pala manual. Los incrementos se juntaron para formar el lote, cuyo tamaño fue de aproximadamente $10 \mathrm{~kg}$ para el RABS1-C y de $5 \mathrm{~kg}$ para el RABS-2, como indica la metodología. La selección del lote para estos dos rechazos siempre fue realizada por los operarios de la planta, puesto que por motivos de seguridad el equipo de trabajo no tenía acceso a la nave de afino y maduración. 


\section{División de tamaño de muestra inicial y caracterización de las muestras}

Los pesos de muestra para los distintos niveles de submuestreo se obtuvieron a partir de la división del tamaño de muestra inicial $\left(\mathrm{m}_{\mathrm{m}}\right)$ siguiendo el esquema propuesto en la metodología (Figura 6.3).

Las caracterizaciones para el RRM-BS-C se realizaron en la propia planta de tratamiento. Cada lote correspondiente a un día de muestreo era depositado en una superficie limpia, pavimentada y a cubierto proporcionada por la empresa. Los pesos de muestra utilizados para cada nivel de submuestreo se muestran en la Figura 6.29.

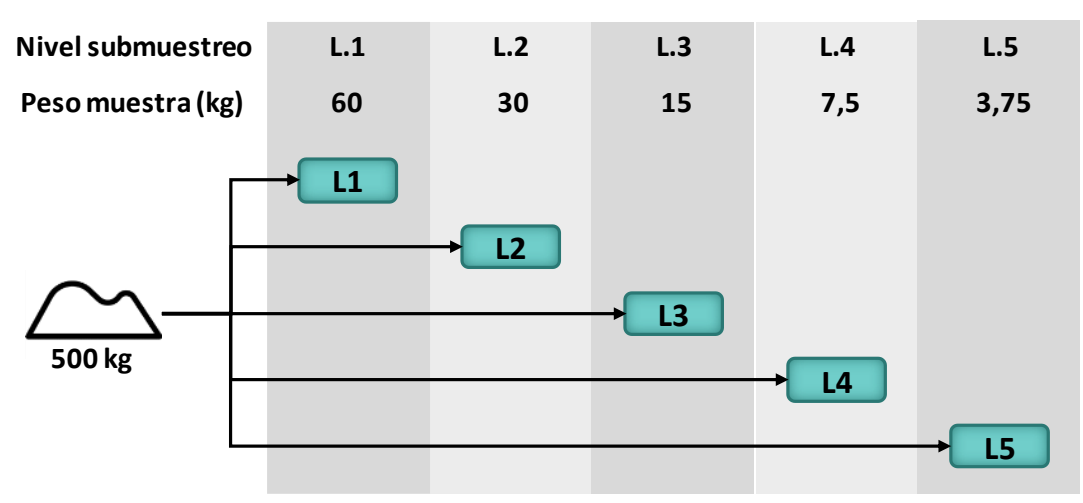

Figura 6.29 Esquema de procedimiento de división del tamaño de muestra inicial del RRM-BS-C

Las muestras para cada nivel de submuestreo se obtuvieron de la misma forma que en el primer caso de aplicación. Para ello se tomaron varios incrementos en diferentes puntos del lote mediante una pala manual hasta alcanzar el peso de muestra correspondiente al nivel de submuestreo a caracterizar. El material se depositó en la zona de caracterización para su clasificación en las 13 categorías (Figura 6.30).
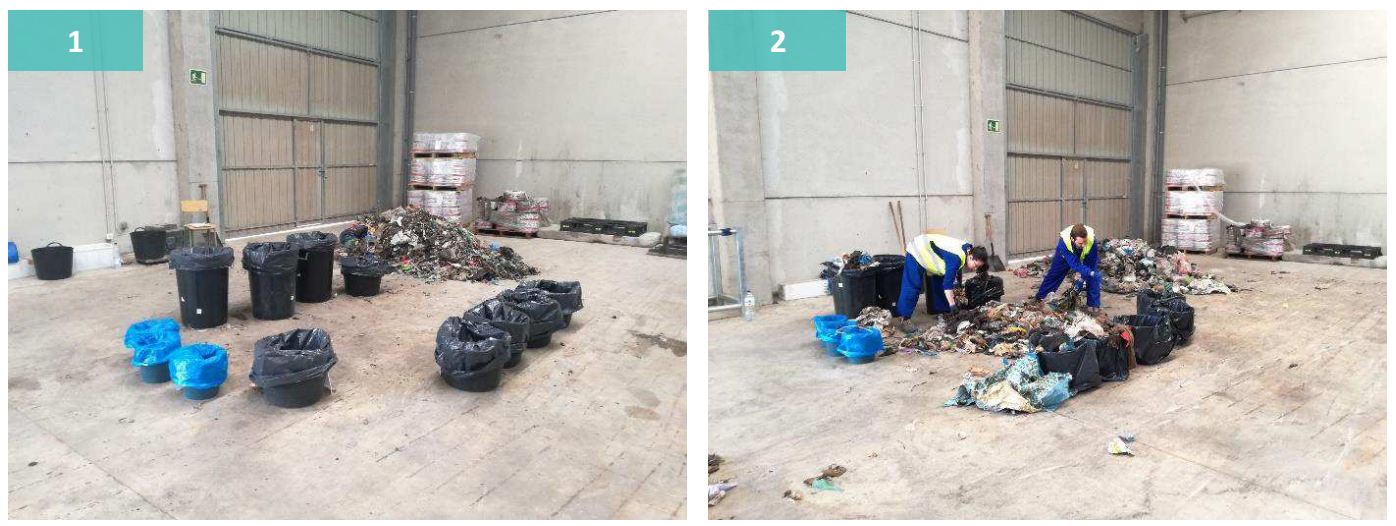

Figura 6.30 Zona de caracterización (1) y caracterización (2) del RRM-BS-C

Al finalizar la separación y clasificación, se determinó el peso de cada fracción por separado en una báscula de plataforma con una precisión de 10 gramos y se anotaron los pesos obtenidos en las hojas de campo. En la Figura 6.31 se muestran varias fotos de algunas de las fracciones caracterizadas para el RRM-BS-C. 

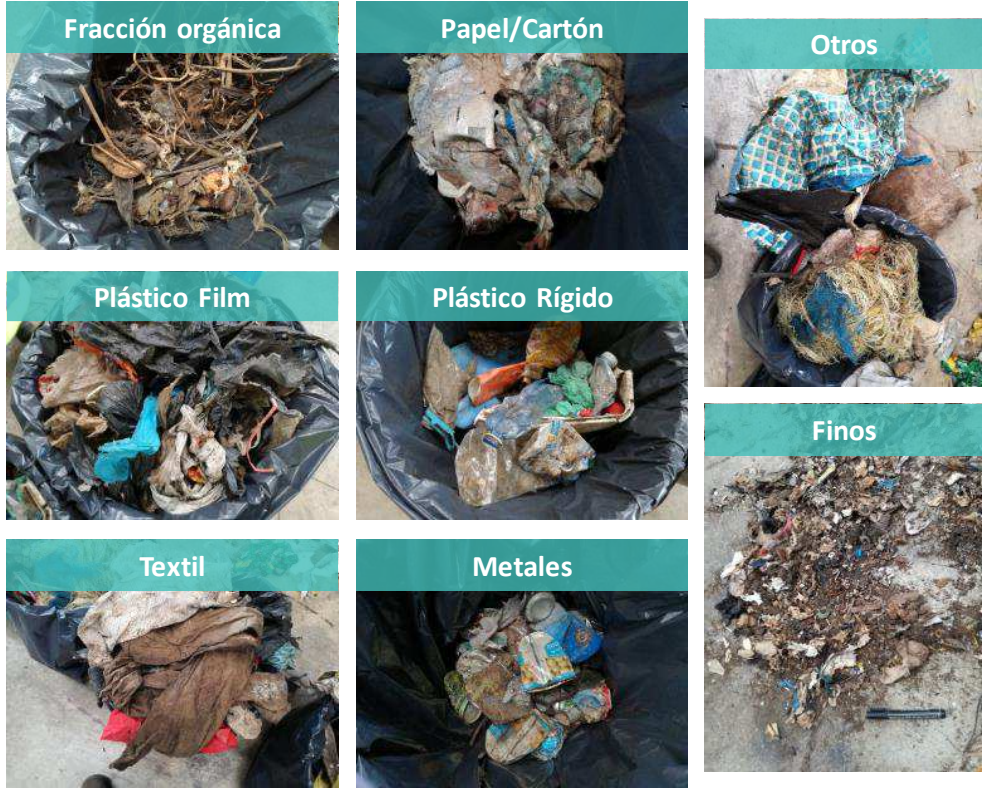

Figura 6.31 Fracciones separadas del RRM-BS-C

Respecto al RABS1-O y el RABS2-O, debido a que su tamaño de lote es más manejable, al finalizar la jornada se seleccionaban los lotes que se trasladaban al laboratorio del grupo de investigación INGRES para su caracterización. Los pesos de muestra utilizados en cada nivel de submuestreo se presentan en la Figura 6.32 para el RABS1-C y en la Figura 6.33 para el RABS2-C.

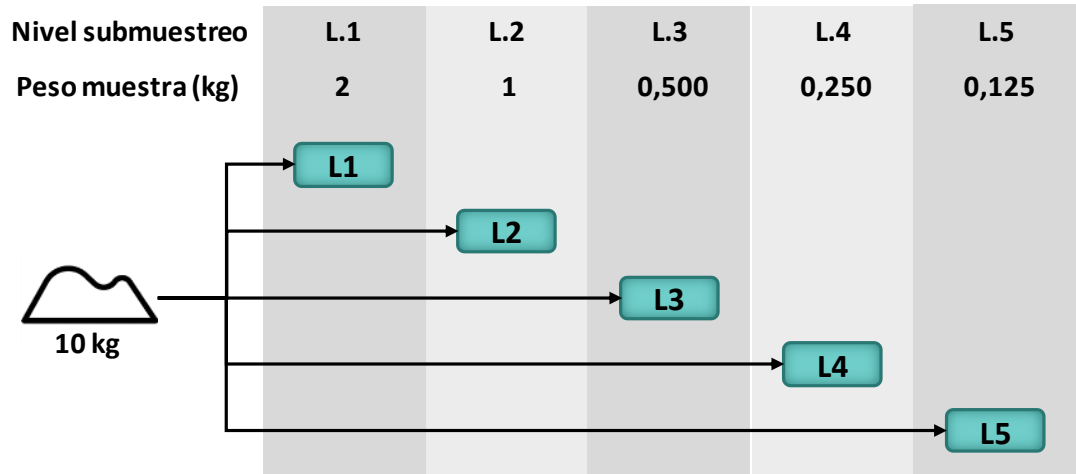

Figura 6.32 Esquema de procedimiento de división del tamaño de muestra inicial del RABS1-C

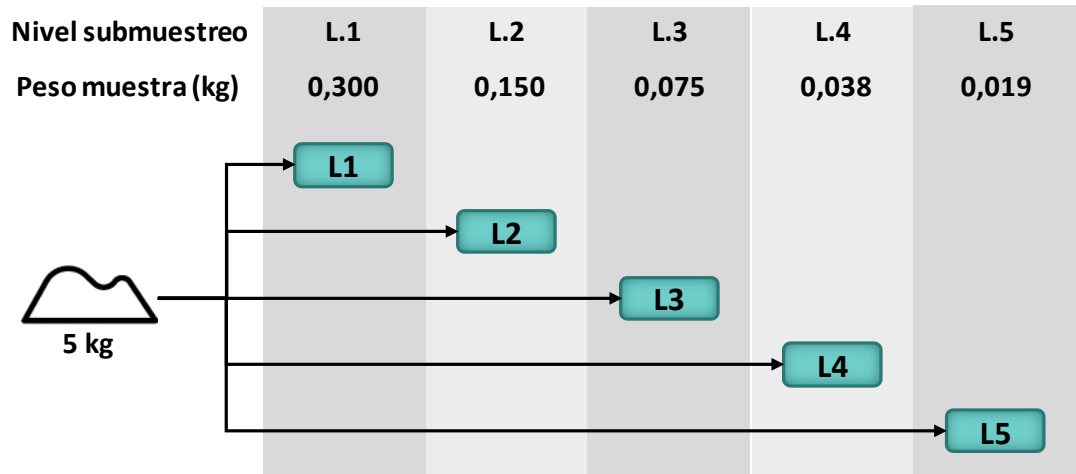

Figura 6.33 Esquema de procedimiento de división del tamaño de muestra inicial del RABS2-C 
Las muestras para cada nivel de submuestreo se obtuvieron por cuarteo. La caracterización del rechazo fue realizada por dos personas que extendieron la muestra sobe una mesa de trabajo limpia para su clasificación en las 11 categorías (Figura 6.34).
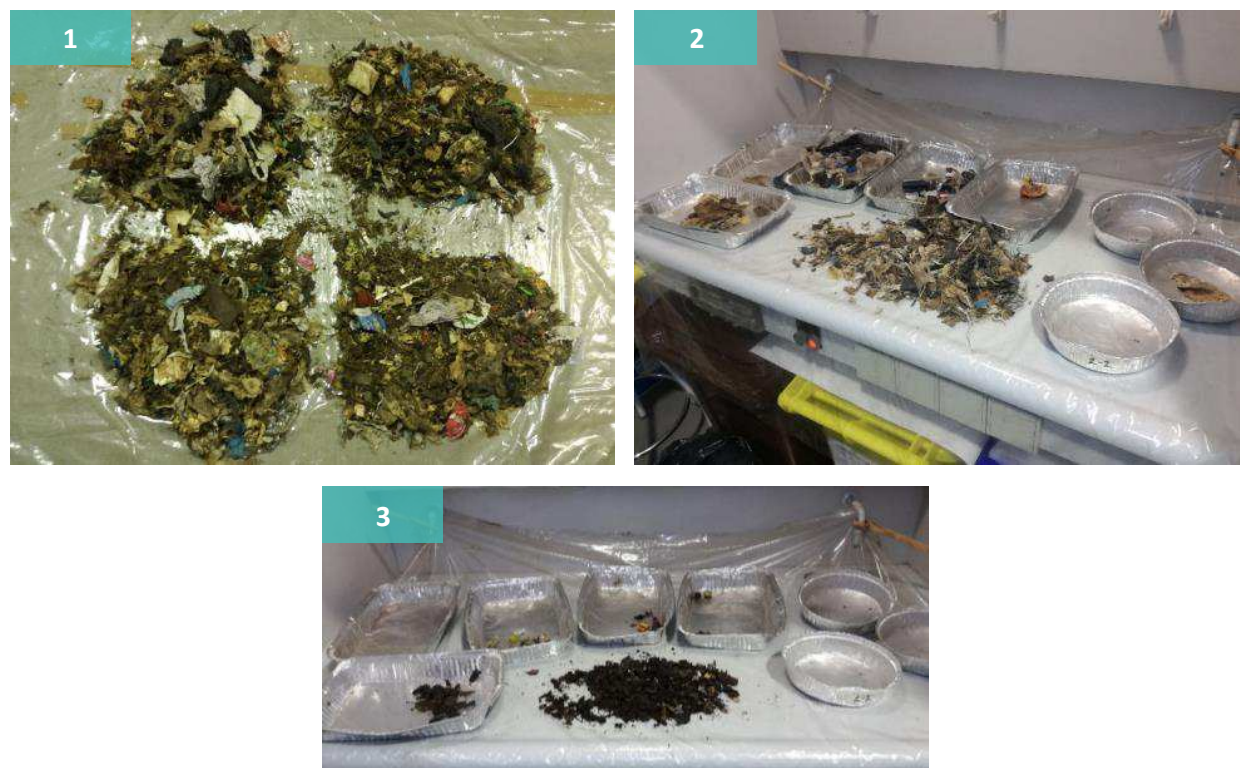

Figura 6.34 Cuarteo y caracterización del RABS1-C (1 y 2), caracterización RABS2-C (3)

Al finalizar se determinó el peso de cada fracción por separado en una balanza con una precisión de 0,01 gramos y se anotaron los pesos obtenidos en las hojas de campo. En la Figura 6.35 y Figura 6.36 se muestran varias fotos de algunas de las fracciones caracterizadas para el RABS1-C y RABS2-C respectivamente.
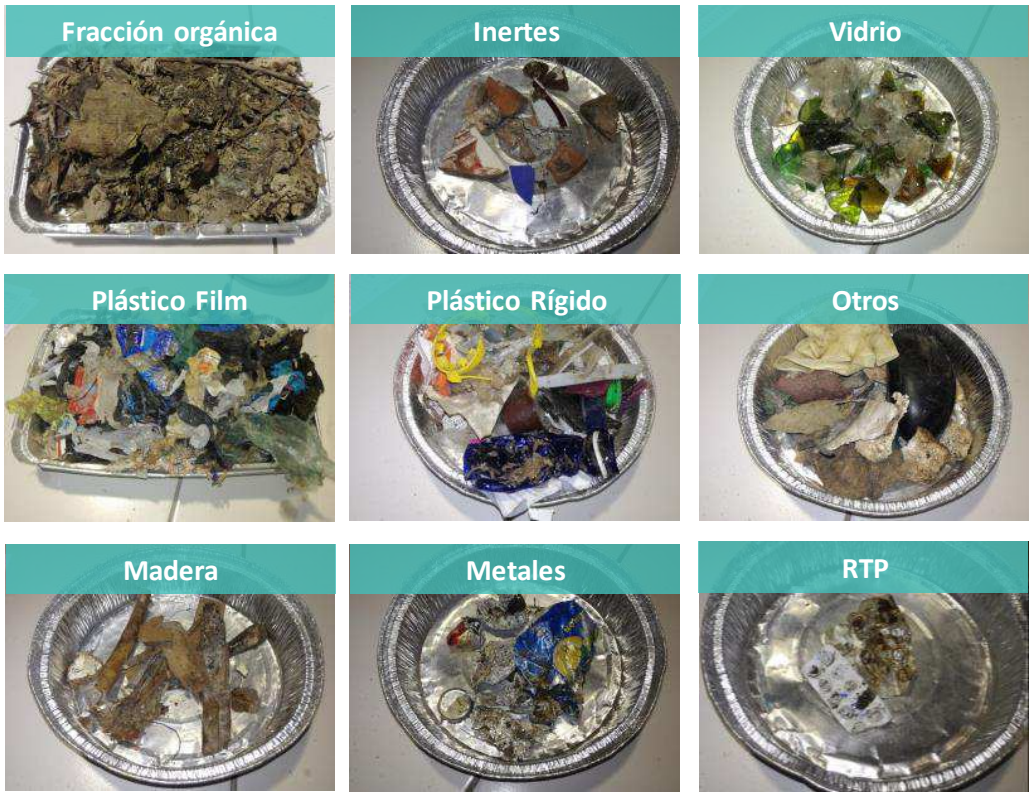

Figura 6.35 Fracciones separadas del RABS1-C 

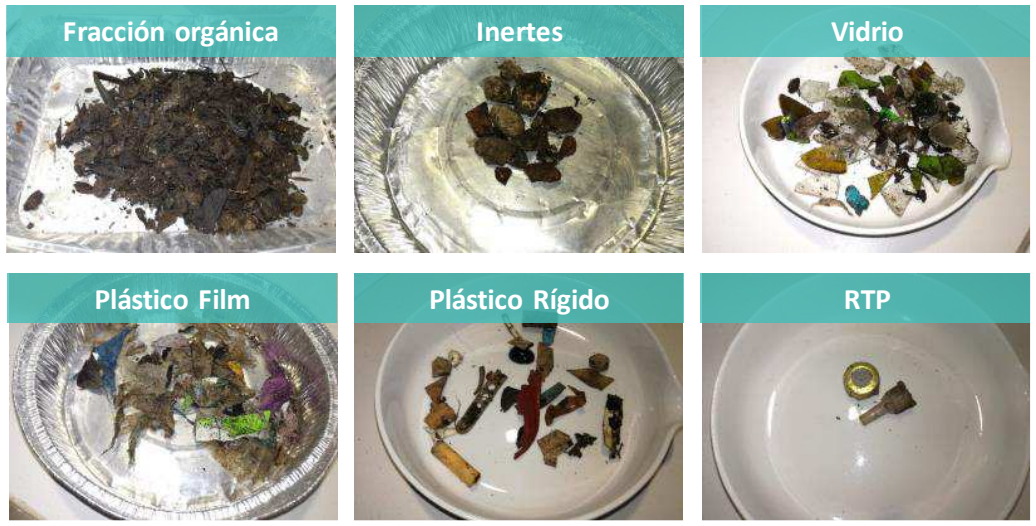

Figura 6.36 Fracciones separadas del RABS2-C

\subsubsection{Determinación del tamaño mínimo de muestras}

A partir de los datos de composición se ha procedido a determinar el tamaño mínimo de muestra con el que se obtienen resultados representativos para cada corriente de rechazo. Para ello se ha analizado si existen diferencias significativas en la composición de los rechazos en función del nivel de submuestreo. La metodología propone una serie de procedimientos estadísticos para llevar a cabo este análisis, los cuales también han sido utilizados en el primer caso de aplicación.

Todos los análisis estadísticos se realizaron con el programa de acceso libre $\mathrm{R}$ y su paquete $\mathrm{R}$ Commander, el nivel de confianza utilizado ha sido del $95 \%(\alpha=0,05)$. A continuación, se exponen los resultados de las caracterizaciones de las tres corrientes de rechazo.

\section{Determinación del tamaño mínimo de muestra para el RRM-BS-C}

Los tamaños de las muestras para cada nivel se han indicado en la Figura 6.29, mientras que los pesos medios de muestra obtenidos tras las caracterizaciones se presentan en la Tabla 6.48. En total se muestrearon y caracterizaron $1.179,93 \mathrm{~kg}$ de RRM-BS-C.

Tabla 6.48 Peso medio de muestra por nivel de submuestreo para el RRM-BS-C

\begin{tabular}{|c|c|c|c|c|c|c|c|c|c|c|}
\hline & \multicolumn{10}{|c|}{ Nivel Submuestreo } \\
\hline & \multicolumn{2}{|c|}{ L1 (60 kg) } & \multicolumn{2}{|c|}{ L2 (30 kg) } & \multicolumn{2}{|c|}{ L3 (15 kg) } & \multicolumn{2}{|c|}{ L4 (7,5 kg) } & \multicolumn{2}{|c|}{ L5 (3,75 kg) } \\
\hline & $\bar{x}$ & $\mathbf{s}$ & $\bar{x}$ & $\mathbf{s}$ & $\bar{x}$ & $\mathbf{s}$ & $\bar{x}$ & s & $\bar{x}$ & s \\
\hline Peso de muestra (kg) & 60,07 & 1,12 & 30,53 & 1,19 & 15,53 & 0,37 & 7,82 & 0,27 & 4,04 & 0,23 \\
\hline
\end{tabular}

En la Tabla 6.49 se exponen los resultados obtenidos en las caracterizaciones realizadas. En ella se muestra la composición media para los cinco niveles de submuestreo, así como su desviación estándar.

Tabla 6.49 Composición media por nivel de submuestreo para el RRM-BS-C

\begin{tabular}{|c|c|c|c|c|c|c|c|c|c|c|}
\hline \multirow{3}{*}{$\begin{array}{c}\text { Composición (\%) } \\
\text { Fracción }\end{array}$} & \multicolumn{10}{|c|}{ Nivel Submuestreo } \\
\hline & \multicolumn{2}{|c|}{ L1 (60 kg) } & \multicolumn{2}{|c|}{ L2 (30 kg) } & \multicolumn{2}{|c|}{ L3 (15 kg) } & \multicolumn{2}{|c|}{ L4 (7,5 kg) } & \multicolumn{2}{|c|}{ L5 (3,75 kg) } \\
\hline & $\bar{x}$ & s & $\bar{x}$ & s & $\bar{x}$ & s & $\bar{x}$ & $\mathbf{s}$ & $\bar{x}$ & s \\
\hline Fracción orgánica & 6,18 & 3,57 & 5,77 & 4,00 & 5,45 & 4,34 & 6,97 & 8,25 & 5,47 & 7,14 \\
\hline Papel/Cartón & 23,43 & 3,37 & 23,80 & 3,45 & 24,53 & 3,68 & 27,64 & 8,05 & 23,31 & 11,08 \\
\hline Plástico Film & 12,23 & 2,61 & 12,46 & 2,56 & 14,40 & 3,87 & 12,85 & 2,66 & 12,93 & 5,67 \\
\hline Plástico Rígido & 10,28 & 1,62 & 10,95 & 2,53 & 10,96 & 3,49 & 11,61 & 3,84 & 12,00 & 4,38 \\
\hline
\end{tabular}




\begin{tabular}{|c|c|c|c|c|c|c|c|c|c|c|}
\hline \multirow{3}{*}{$\begin{array}{c}\text { Composición (\%) } \\
\text { Fracción }\end{array}$} & \multicolumn{10}{|c|}{ Nivel Submuestreo } \\
\hline & \multicolumn{2}{|c|}{ L1 (60 kg) } & \multicolumn{2}{|c|}{ L2 (30 kg) } & \multicolumn{2}{|c|}{ L3 (15 kg) } & \multicolumn{2}{|c|}{ L4 (7,5 kg) } & \multicolumn{2}{|c|}{ L5 (3,75 kg) } \\
\hline & $\bar{x}$ & s & $\bar{x}$ & s & $\bar{x}$ & s & $\bar{x}$ & s & $\bar{x}$ & s \\
\hline Textil & 12,18 & 2,93 & 11,52 & 3,43 & 8,79 & 4,51 & 8,88 & 3,94 & 9,50 & 5,37 \\
\hline Metales & 4,87 & 1,52 & 4,61 & 2,25 & 5,28 & 2,87 & 5,13 & 2,20 & 6,07 & 3,19 \\
\hline Madera & 2,88 & 0,32 & 4,24 & 1,85 & 4,30 & 1,84 & 3,69 & 2,31 & 3,65 & 3,84 \\
\hline Brik & 2,49 & 0,55 & 2,98 & 0,68 & 3,06 & 1,51 & 3,36 & 2,11 & 3,27 & 1,69 \\
\hline Inertes & 2,91 & 2,12 & 1,51 & 1,61 & 1,79 & 2,05 & 0,74 & 1,21 & 1,37 & 2,59 \\
\hline RTP & 0,31 & 0,19 & 0,31 & 0,27 & 0,39 & 0,43 & 0,44 & 0,64 & 0,58 & 1,29 \\
\hline Vidrio & 1,26 & 1,06 & 0,67 & 0,67 & 1,52 & 1,67 & 0,83 & 1,02 & 1,67 & 2,00 \\
\hline Otros & 17,17 & 4,04 & 17,80 & 6,79 & 15,32 & 4,87 & 14,12 & 6,82 & 16,08 & 7,60 \\
\hline Finos & 3,81 & 5,47 & 3,39 & 4,11 & 4,22 & 5,87 & 3,73 & 3,02 & 4,11 & 7,36 \\
\hline
\end{tabular}

Los estadísticos de contraste y los p-valores obtenidos tras la aplicación de los diferentes test a las 13 fracciones de residuos se muestran en la Tabla 6.50. Las pruebas utilizadas para comprobar los supuestos de Normalidad y homocedasticidad aparecen en primer lugar para favorecer la comprensión del procedimiento estadístico. No obstante, en la práctica estos se comprueban a posteriori de la realización del ANOVA.

Tabla 6.50 Análisis estadístico RRM-BS-C

\begin{tabular}{c|c|c|c|c|c|c|c|c}
\hline Test estadístico & \multicolumn{2}{|c|}{ Test de Shapiro-Wilk } & \multicolumn{2}{|c|}{ Test de Levene } & \multicolumn{2}{c|}{$\begin{array}{c}\text { ANOVA / ANOVA de } \\
\text { Welch }\end{array}$} & Test de Kuskal-Wallis \\
\hline Tipo de prueba & \multicolumn{2}{|c|}{$\begin{array}{c}\text { Bondad de ajuste: } \\
\text { Normalidad }\end{array}$} & \multicolumn{2}{|c|}{$\begin{array}{c}\text { Comparación de } \\
\text { varianzas }\end{array}$} & \multicolumn{2}{c}{$\begin{array}{c}\text { Comparación de } \\
\text { medias }\end{array}$} & \multicolumn{2}{c}{$\begin{array}{c}\text { Comparación de } \\
\text { medianas }\end{array}$} \\
\hline Fracción & W & p-valor & F & p-valor & F & p-valor & H & p-valor \\
\hline Fracción orgánica & 0,647 & $<0,001$ & - & - & - & - & 3,453 & 0,485 \\
\hline Papel/Cartón & 0,925 & 0,004 & - & - & - & - & 1,913 & 0,752 \\
\hline Plástico Film & 0,972 & 0,268 & 3,185 & 0,022 & 0,542 & 0,707 & - & - \\
\hline Plástico Rígido* & 0,962 & 0,105 & 0,773 & 0,549 & 0,296 & 0,879 & - & - \\
\hline Textil & 0,976 & 0,412 & 1,027 & 0,404 & 1,450 & 0,233 & - & - \\
\hline Metales* & 0,969 & 0,210 & 1,336 & 0,271 & 0,466 & 0,761 & - & - \\
\hline Madera & 0,716 & $<0,001$ & - & - & - & - & 5,471 & 0,242 \\
\hline Brik* & 0,979 & 0,496 & 3,250 & 0,020 & 0,956 & 0,451 & - & - \\
\hline Inertes* & 0,955 & 0,053 & 0,091 & 0,985 & 2,255 & 0,078 & - & - \\
\hline RTP & 0,716 & $<0,001$ & - & - & - & - & 2,611 & 0,625 \\
\hline Vidrio* & 0,971 & 0,264 & 1,618 & 0,186 & 0,901 & 0,471 & - & - \\
\hline
\end{tabular}

* Fracciones en las que la transformación de los datos ha mejorado su distribución, aproximándola a la Normal y permitiendo usar pruebas paramétricas con los datos transformados. 
Como se puede observar en la Tabla 6.50, los resultados obtenidos tras el análisis estadístico del RRM-BS-C indican que no existen diferencias significativas en el porcentaje de ninguna fracción entre los diferentes niveles de submuestreo, puesto que todos los p-valores obtenidos en las comparaciones de medias o medianas son mayores a 0,05 . Esto indica que el porcentaje de todos los componentes es el mismo para los cinco tamaños de muestra analizados, es decir, que los resultados son representativos incluso con el nivel de submuestreo más bajo.

Así pues, para el RRM-BS-C no se ha identificado el nivel crítico para ninguna fracción de entre los cinco niveles de submuestreo estudiados. Por lo que, se puede concluir que el tamaño mínimo de muestra para el control de calidad del RRM-BS-C es de 3,75 kg (mf RRM-BS-C), correspondiente al nivel L5. Este peso podría reducirse si se estudiaran niveles de submuestreo más pequeños que permitieran determinar el nivel crítico.

Mediante la aplicación de la metodología se ha conseguido reducir el peso de muestra necesario en un $93,75 \%$ respecto al tamaño de muestra inicial (60 kg). Esto supone una disminución muy importante en el coste económico y carga de trabajo en comparación a las metodologías de RSU o CSR que no están adaptadas a los rechazos.

Finalmente, en la Tabla 6.51, se presentan los tamaños mínimos de muestra para para la determinación de la composición física del RRM-BS-C. El peso de muestra necesario es igual para todas las fracciones y se tomará mediante un muestreo aleatorio simple.

Tabla 6.51 Tamaño mínimo de muestra para el RRM-BS-C

\begin{tabular}{|c|c|c|c|}
\hline Fracción & $m_{f}(k g)$ & Fracción & $m_{f}(k g)$ \\
\hline Fracción Orgánica & \multirow{6}{*}{3,75} & Brik & \multirow{6}{*}{3,75} \\
\hline Plástico Film & & Inertes & \\
\hline Plástico Rígido & & & \\
\hline Textil & & & \\
\hline Metales & & Vidrio & \\
\hline Madera & & Otros & \\
\hline
\end{tabular}

\section{Determinación del tamaño mínimo de muestra para el RABS1-C}

Los tamaños de muestra para cada nivel de submuestreo se indican en la Figura 6.32, mientras que los pesos medios de muestra obtenidos tras las caracterizaciones se exponen en la Tabla 6.52. En total se muestrearon y caracterizaron 40,04 kg de RABS1-C.

Tabla 6.52 Peso medio de muestra por nivel de submuestreo para el RABS1-C

\begin{tabular}{|c|c|c|c|c|c|c|c|c|c|c|}
\hline & \multicolumn{10}{|c|}{ Nivel Submuestreo } \\
\hline & \multicolumn{2}{|c|}{ L1 (2 kg) } & \multicolumn{2}{|c|}{ L2 (1 kg) } & \multicolumn{2}{|c|}{ L3 $(0,500 \mathrm{~kg})$} & \multicolumn{2}{|c|}{ L4 (0,250 kg) } & \multicolumn{2}{|c|}{ L5 $(0,125 \mathrm{~kg})$} \\
\hline & $\bar{x}$ & $\mathbf{s}$ & $\bar{x}$ & $\mathbf{s}$ & $\bar{x}$ & $\mathbf{s}$ & $\bar{x}$ & s & $\bar{x}$ & $\mathbf{s}$ \\
\hline Peso de muestra (kg) & 2,040 & 0,028 & 1,052 & 0,023 & 0,527 & 0,017 & 0,258 & 0,006 & 0,127 & 0,001 \\
\hline
\end{tabular}

A continuación, en la Tabla 6.53 se presentan los resultados obtenidos en las caracterizaciones, donde se muestra la composición media y desviación estándar para los cinco niveles de submuestreo. 
Tabla 6.53 Composición media por nivel de submuestreo para el RABS1-C

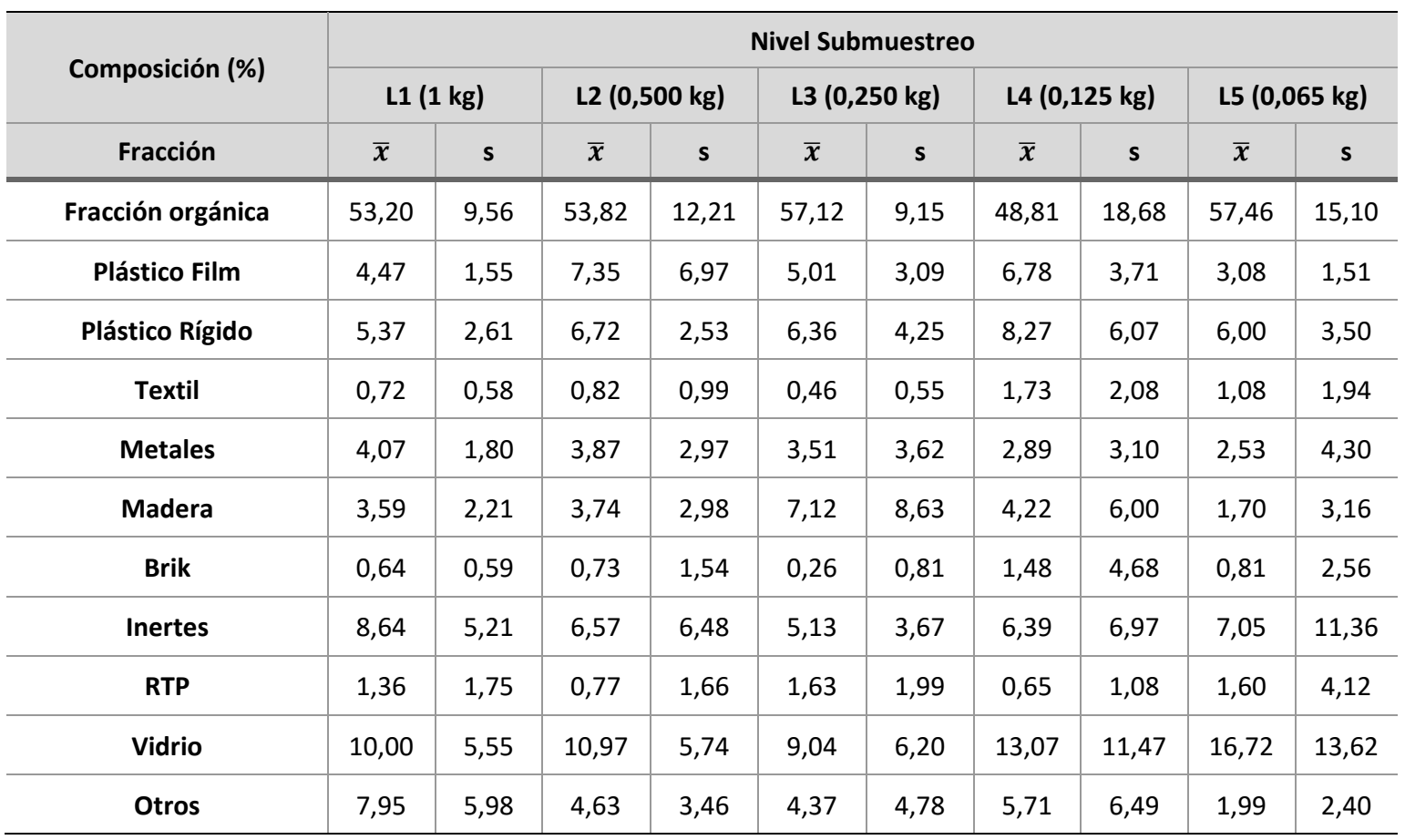

En la Tabla 6.54 se exponen los estadísticos y p-valores obtenidos tras la aplicación de los diferentes test cada fracción.

Tabla 6.54 Análisis estadístico RABS1-C

\begin{tabular}{|c|c|c|c|c|c|c|c|c|}
\hline \multirow{3}{*}{$\begin{array}{c}\text { Test estadístico } \\
\text { Tipo de prueba } \\
\text { Fracción }\end{array}$} & \multirow{2}{*}{\multicolumn{2}{|c|}{$\begin{array}{c}\text { Test de Shapiro-Wilk } \\
\text { Bondad de ajuste: } \\
\text { Normalidad }\end{array}$}} & \multirow{2}{*}{\multicolumn{2}{|c|}{$\begin{array}{l}\text { Test de Levene } \\
\text { Comparación de } \\
\text { varianzas }\end{array}$}} & \multirow{2}{*}{\multicolumn{2}{|c|}{$\begin{array}{c}\text { ANOVA / ANOVA de } \\
\text { Welch } \\
\begin{array}{c}\text { Comparación de } \\
\text { medias }\end{array}\end{array}$}} & \multirow{2}{*}{\multicolumn{2}{|c|}{$\begin{array}{c}\text { Test de Kuskal-Wallis } \\
\text { Comparación de } \\
\text { medianas }\end{array}$}} \\
\hline & & & & & & & & \\
\hline & $\mathbf{w}$ & p-valor & $\mathbf{F}$ & p-valor & $\mathbf{F}$ & p-valor & H & p-valor \\
\hline Fracción orgánica & 0,960 & 0,092 & 1,037 & 0,399 & 0,682 & 0,608 & - & - \\
\hline Plástico Film & 0,644 & $<0,001$ & - & - & - & - & 8,334 & 0,080 \\
\hline Plástico Rígido* & 0,983 & 0,683 & 2,754 & 0,039 & 0,484 & 0,747 & - & - \\
\hline Textil* & 0,955 & 0,056 & 1,266 & 0,297 & 0,856 & 0,498 & - & - \\
\hline Metales* & 0,970 & 0,239 & 2,232 & 0,081 & 1,359 & 0,263 & - & - \\
\hline Madera & 0,829 & $<0,001$ & - & - & - & - & 7,944 & 0,094 \\
\hline Brik & 0,366 & $<0,001$ & - & - & - & - & 9,942 & 0,041 \\
\hline Inertes & 0,821 & $<0,001$ & - & - & - & - & 5,065 & 0,281 \\
\hline RTP & 0,529 & $<0,001$ & - & - & - & - & 6,808 & 0,146 \\
\hline Vidrio & 0,954 & 0,052 & 5,578 & 0,001 & 0,752 & 0,567 & - & - \\
\hline Otros & 0,769 & $<0,001$ & - & - & - & - & 12,643 & 0,013 \\
\hline
\end{tabular}

* Fracciones en las que la transformación de los datos ha mejorado su distribución, aproximándola a la Normal y permitiendo usar pruebas paramétricas con los datos transformados. 
Los resultados obtenidos para le RABS1-C muestran que existen diferencias significativas en el porcentaje de brik y de Otros entre los diferentes niveles de submuestreo, ya que los p-valores obtenidos en la comparación de medianas son menores a 0,05 (Tabla 6.54). Por lo tanto, se puede afirmar con una confianza del 95\% que el porcentaje de estos materiales en el RABS1-C es distinto en función del tamaño de muestra utilizado para su determinación, por lo que los resultados obtenidos a cierto nivel de submuestreo no son representativos de la población de rechazo muestreada.

Para el resto de fracciones no se han encontrado diferencias significativas ( $p$-valor $>0,05$ ), por lo que su porcentaje no varía en función del nivel de submuestreo. Por tanto, para estas fracciones el tamaño mínimo de muestra necesario sería el correspondiente al nivel de submuestreo más bajo (L5), con 0,065 kg.

Por último, en la Tabla 6.55 se exponen los resultados de los test post hoc realizados a las fracciones en las que existen diferencias significativas, así como el nivel crítico identificado y el tamaño mínimo de muestra determinado para el RABS1-C en base a estos resultados (mf RABS1-C).

Tabla 6.55 Test post hoc RABS1-C

\begin{tabular}{c|c|c|c|c}
\hline Fracción & \multicolumn{2}{|c|}{ Brik } & \multicolumn{2}{c}{ Otros } \\
\hline Test post hoc & \multicolumn{2}{|c}{ Dunn } & \multicolumn{2}{c}{ Dunn } \\
\hline Comparaciones & Z & p-valor & Z & p-valor \\
\hline L1 - L2 & 1,591 & 0,279 & 1,534 & 0,208 \\
\hline L1 - L3 & 2,585 & 0,097 & 2,117 & 0,171 \\
\hline L2 - L3 & 0,994 & 0,640 & 0,583 & 0,700 \\
\hline L1 - L4 & 2,526 & 0,038 & 1,818 & 0,173 \\
\hline L2 - L4 & 0,935 & 0,500 & 0,284 & 0,777 \\
\hline L3 - L4 & $-0,060$ & 1,000 & $-0,299$ & 0,850 \\
\hline L1 - L5 & 2,546 & 0,055 & 3,506 & 0,005 \\
\hline L2 - L5 & 0,955 & 0,566 & 1,972 & 0,162 \\
\hline L3 - L5 & $-0,040$ & 1,000 & 1,389 & 0,236 \\
\hline L4 - L5 & 0,020 & 0,984 & 1,688 & 0,183 \\
\hline Nivel crítico & L4 (0,250 kg) & L5 (0,125 kg) \\
\hline mf RABS1-C (kg) & $\mathbf{0 , 5 0 0}$ & $\mathbf{0 , 2 5 0}$ \\
\hline
\end{tabular}

Las comparaciones múltiples entre los diferentes niveles de submuestreo para las fracciones de brik y Otros (Tabla 6.55) muestran que existen diferencias estadísticamente significativas entre los niveles $L 4$ y $L 5$ y el nivel L1. En el caso del brik, el porcentaje obtenido con el nivel de submuestreo L4 es distinto al obtenido con L1, mientras que para los Otros, el porcentaje de L5 es diferente al obtenido con L1. Para ambas comparaciones el p-valor obtenido es menor a 0,05.

Por otra parte, como se puede ver en la tabla anterior, para cada una de las fracciones se ha obtenido un tamaño de muestra mínimo diferente. Por lo que, como indica la metodología, el tamaño mínimo de muestra debe ser el más restrictivo de los dos, de forma que todas las fracciones estén correctamente representadas, puesto que los parámetros de calidad $(\mathrm{PCl}, \mathrm{Cl}$ y $\mathrm{Hg}$ ) están repartidos en todos los materiales.

Así pues, se puede concluir que el nivel crítico más restrictivo para el RABS1-C es el L4 y, por tanto, los resultados obtenidos para el peso de muestra correspondiente a ese nivel $(0,250 \mathrm{~kg})$ no son representativos de todas las fracciones. Esto significa que, el tamaño mínimo de muestra para el control de la calidad del RABS1-C es de 0,500 kg (L3). Por tanto, tras la aplicación de la metodología el peso de muestra necesario se 
ha reducido a un cuarto respecto al tamaño de muestra inicial $(2 \mathrm{~kg})$, minimizando el coste económico y la carga de trabajo en comparación a otras metodologías.

Finalmente, en la Tabla 6.56, se presentan los tamaños mínimos de muestra para para la determinación de la composición física del RABS1-C, estos se deben tomar mediante un muestreo aleatorio simple. El peso de muestra será diferente en función de la fracción que se quiera conocer. Si se quiere determinar la composición global se deben tomar $0,5 \mathrm{~kg}$.

Tabla 6.56 Tamaño mínimo de muestra para el RABS1-C

\begin{tabular}{|c|c|c|c|}
\hline Fracción & $m_{f}(k g)$ & Fracción & $m_{f}(k g)$ \\
\hline \multirow{4}{*}{ Brik } & \multirow{4}{*}{0,500} & Fracción Orgánica & \multirow{9}{*}{0,065} \\
\hline & & Plástico Rígido & \\
\hline & & Plástico Film & \\
\hline & & Textil & \\
\hline \multirow{5}{*}{ Otros } & \multirow{5}{*}{0,250} & Metales & \\
\hline & & Madera & \\
\hline & & Inertes & \\
\hline & & RTP & \\
\hline & & Vidrio & \\
\hline
\end{tabular}

\section{Determinación del tamaño mínimo de muestra para el RABS2-C}

Los tamaños de muestra para cada nivel de submuestreo son los indicados en la Figura 6.33, mientras que los pesos medios de muestra obtenidos tras las caracterizaciones se pueden ver en la Tabla 6.57. En total se muestrearon y caracterizaron $5,92 \mathrm{~kg}$ de RABS2-C.

Tabla 6.57 Peso medio de muestra por nivel de submuestreo para el RABS2-C

\begin{tabular}{|c|c|c|c|c|c|c|c|c|c|c|}
\hline & \multicolumn{10}{|c|}{ Nivel Submuestreo } \\
\hline & \multicolumn{2}{|c|}{ L1 (0,300 kg) } & \multicolumn{2}{|c|}{ L2 (0,150 kg) } & \multicolumn{2}{|c|}{ L3 (0,075 kg) } & \multicolumn{2}{|c|}{ L4 (0,038 kg) } & \multicolumn{2}{|c|}{ L5 (0,019 kg) } \\
\hline & $\bar{x}$ & $s$ & $\bar{x}$ & s & $\bar{x}$ & $\mathbf{s}$ & $\bar{x}$ & $s$ & $\bar{x}$ & $\mathbf{s}$ \\
\hline Peso de muestra (kg) & 0,305 & 0,006 & 0,153 & 0,002 & 0,077 & 0,001 & 0,038 & 0,000 & 0,019 & 0,000 \\
\hline
\end{tabular}

A continuación, en la Tabla 6.58, se presenta la composición media para los cinco niveles de submuestreo obtenida en las caracterizaciones realizadas, así como su desviación estándar.

Tabla 6.58 Composición media por nivel de submuestreo para el RABS2-C

\begin{tabular}{|c|c|c|c|c|c|c|c|c|c|c|}
\hline \multirow{3}{*}{$\begin{array}{c}\text { Composición (\%) } \\
\text { Fracción }\end{array}$} & \multicolumn{10}{|c|}{ Nivel Submuestreo } \\
\hline & \multicolumn{2}{|c|}{ L1 (0,300 kg) } & \multicolumn{2}{|c|}{ L2 (0,150 kg) } & \multicolumn{2}{|c|}{ L3 (0,075 kg) } & \multicolumn{2}{|c|}{ L4 (0,038 kg) } & \multicolumn{2}{|c|}{ L5 (0,019 kg) } \\
\hline & $\bar{x}$ & $\mathbf{s}$ & $\bar{x}$ & $\mathbf{s}$ & $\bar{x}$ & $\mathbf{s}$ & $\bar{x}$ & s & $\bar{x}$ & $\mathbf{s}$ \\
\hline Fracción orgánica & 60,12 & 10,00 & 65,32 & 6,54 & 60,84 & 13,55 & 62,47 & 14,93 & 66,46 & 14,23 \\
\hline Plástico Film & 1,91 & 0,69 & 2,05 & 0,84 & 2,06 & 0,90 & 1,65 & 1,25 & 2,27 & 2,37 \\
\hline Plástico Rígido & 2,70 & 1,40 & 2,85 & 1,64 & 4,15 & 4,12 & 2,64 & 1,47 & 2,49 & 1,32 \\
\hline Textil & 0,10 & 0,11 & 0,05 & 0,07 & 0,05 & 0,12 & 0,04 & 0,13 & 0,00 & 0,00 \\
\hline
\end{tabular}




\begin{tabular}{|c|c|c|c|c|c|c|c|c|c|c|}
\hline \multirow{3}{*}{$\begin{array}{c}\text { Composición (\%) } \\
\text { Fracción }\end{array}$} & \multicolumn{10}{|c|}{ Nivel Submuestreo } \\
\hline & \multicolumn{2}{|c|}{ L1 (0,300 kg) } & \multicolumn{2}{|c|}{ L2 (0,150 kg) } & \multicolumn{2}{|c|}{ L3 (0,075 kg) } & \multicolumn{2}{|c|}{ L4 (0,038 kg) } & \multicolumn{2}{|c|}{ L5 (0,019 kg) } \\
\hline & $\bar{x}$ & s & $\bar{x}$ & s & $\bar{x}$ & s & $\bar{x}$ & s & $\bar{x}$ & s \\
\hline Metales & 0,70 & 0,78 & 0,91 & 0,97 & 0,30 & 0,51 & 0,02 & 0,07 & 0,23 & 0,72 \\
\hline Madera & 0,03 & 0,09 & 0,27 & 0,52 & 0,00 & 0,00 & 0,38 & 1,19 & 0,00 & 0,00 \\
\hline Brik & 0,02 & 0,05 & 0,02 & 0,05 & 0,00 & 0,00 & 0,00 & 0,00 & 0,00 & 0,00 \\
\hline Inertes & 12,64 & 7,57 & 7,02 & 6,67 & 11,64 & 11,47 & 9,77 & 9,43 & 4,16 & 6,95 \\
\hline RTP & 0,39 & 0,76 & 0,17 & 0,33 & 0,13 & 0,29 & 0,00 & 0,00 & 0,00 & 0,00 \\
\hline Vidrio & 20,02 & 5,56 & 19,94 & 5,55 & 20,09 & 7,13 & 22,60 & 12,74 & 21,74 & 13,55 \\
\hline Otros & 1,38 & 0,98 & 1,41 & 1,64 & 0,74 & 0,81 & 0,44 & 0,32 & 2,65 & 7,66 \\
\hline
\end{tabular}

Los estadísticos de contraste y los p-valores obtenidos tras la aplicación de los diferentes test a cada fracción se exponen en la Tabla 6.59.

Tabla 6.59 Análisis estadístico RABS2-C

\begin{tabular}{|c|c|c|c|c|c|c|c|c|}
\hline \multirow{3}{*}{$\begin{array}{c}\text { Test estadístico } \\
\text { Tipo de prueba } \\
\text { Fracción }\end{array}$} & \multirow{2}{*}{\multicolumn{2}{|c|}{$\begin{array}{c}\text { Test de Shapiro-Wilk } \\
\text { Bondad de ajuste: } \\
\text { Normalidad }\end{array}$}} & \multirow{2}{*}{\multicolumn{2}{|c|}{$\begin{array}{c}\text { Test de Levene } \\
\text { Comparación de } \\
\text { varianzas }\end{array}$}} & \multirow{2}{*}{\multicolumn{2}{|c|}{$\begin{array}{c}\text { ANOVA / ANOVA de } \\
\text { Welch } \\
\begin{array}{c}\text { Comparación de } \\
\text { medias }\end{array} \\
\end{array}$}} & \multirow{2}{*}{\multicolumn{2}{|c|}{$\begin{array}{l}\text { Test de Kuskal-Wallis } \\
\text { Comparación de } \\
\text { medianas }\end{array}$}} \\
\hline & & & & & & & & \\
\hline & $\mathbf{w}$ & p-valor & $\mathbf{F}$ & p-valor & $\mathbf{F}$ & p-valor & H & p-valor \\
\hline Fracción orgánica & 0,979 & 0,526 & 1,863 & 0,134 & 0,509 & 0,729 & - & - \\
\hline Plástico Film & 0,775 & $<0,001$ & - & - & - & - & 2,093 & 0,719 \\
\hline Plástico Rígido* & 0,966 & 0,153 & 1,024 & 0,405 & 0,563 & 0,691 & - & - \\
\hline Textil & 0,641 & $<0,001$ & - & - & - & - & 10,411 & 0,034 \\
\hline Metales & 0,748 & $<0,001$ & - & - & - & - & 25,196 & $<0,001$ \\
\hline Madera & 0,261 & $<0,001$ & - & - & - & - & 6,524 & 0,163 \\
\hline Brik & 0,324 & $<0,001$ & - & - & - & - & 3,063 & 0,547 \\
\hline Inertes* & 0,975 & 0,378 & 0,251 & 0,908 & 2,655 & 0,045 & - & - \\
\hline RTP & 0,612 & $<0,001$ & - & - & - & - & 6,722 & 0,151 \\
\hline Vidrio* & 0,963 & 0,122 & 2,651 & 0,045 & 0,052 & 0,995 & - & - \\
\hline Otros & 0,208 & $<0,001$ & - & - & - & - & 12,062 & 0,017 \\
\hline
\end{tabular}

* Fracciones en las que la transformación de los datos ha mejorado su distribución, aproximándola a la Normal y permitiendo usar pruebas paramétricas con los datos transformados.

Como se observa en la tabla anterior, los resultados obtenidos para el análisis estadístico del RABS2-C muestran la existencia de diferencias significativas en el porcentaje de textil, metales, inertes y Otros en función del nivel de submuestreo. Puesto que los p-valores obtenidos en la comparación de medias o medianas para estas fracciones es menor a 0,05 (Tabla 6.59). Así pues, se puede afirmar con una confianza del $95 \%$ que, en función del tamaño de muestra, el porcentaje de estos materiales en el RABS2-C es diferente $y$, por tanto, los resultados obtenidos dejan de ser representativos de la población de rechazo muestreada a cierto nivel de submuestreo. 
Para el resto de fracciones no se han encontrado diferencias estadísticamente significativas ( $p$-valor $>0,05$ ), por lo que su porcentaje no varía en función del nivel de submuestreo y los resultados son representativos para todos los tamaños de muestra estudiados. Así pues, el tamaño mínimo de muestra para estas fracciones corresponde al nivel de submuestreo más bajo (L5) con 0,019 kg.

Por último, en la Tabla 6.60 se muestran los resultados de los test post hoc realizados a aquellas fracciones en las que existen diferencias en función del nivel de submuestreo. En ellas también se indica el nivel crítico y el tamaño mínimo de muestra determinado a partir de los resultados ( $m_{f} R A B S 2-C$ ).

Tabla 6.60 Test post hoc RABS2-C

\begin{tabular}{|c|c|c|c|c|c|c|c|c|}
\hline Fracción & \multicolumn{2}{|c|}{ Textil } & \multicolumn{2}{|c|}{ Metales } & \multicolumn{2}{|c|}{ Inertes* } & \multicolumn{2}{|c|}{ Otros } \\
\hline Test post hoc & \multicolumn{2}{|c|}{ Dunn } & \multicolumn{2}{|c|}{ Dunn } & \multicolumn{2}{|c|}{ Tukey } & \multicolumn{2}{|c|}{ Dunn } \\
\hline Comparaciones & Z & p-valor & Z & p-valor & $\mathbf{t}$ & p-valor & Z & p-valor \\
\hline L1 - L2 & 0,974 & 0,471 & $-0,242$ & 0,899 & 1,355 & 0,659 & 0,431 & 0,667 \\
\hline L1 - L3 & 1,889 & 0,147 & 1,889 & 0,098 & 0,588 & 0,976 & 1,369 & 0,285 \\
\hline L2 - L3 & 0,915 & 0,450 & 2,131 & 0,066 & $-0,767$ & 0,939 & 0,938 & 0,435 \\
\hline L1 - L4 & 2,287 & 0,111 & 3,519 & 0,001 & 0,831 & 0,920 & 1,969 & 0,163 \\
\hline L2 - L4 & 1,313 & 0,379 & 3,762 & 0,002 & $-0,524$ & 0,985 & 1,538 & 0,248 \\
\hline L3 - L4 & 0,398 & 0,691 & 1,631 & 0,147 & 0,243 & 0,999 & 0,600 & 0,609 \\
\hline L1 - L5 & 2,904 & 0,037 & 3,309 & 0,002 & 3,028 & 0,032 & 3,077 & 0,021 \\
\hline L2 - L5 & 1,929 & 0,179 & 3,552 & 0,002 & 1,673 & 0,460 & 2,646 & 0,041 \\
\hline L3 - L5 & 1,014 & 0,517 & 1,421 & 0,194 & 2,440 & 0,123 & 1,708 & 0,219 \\
\hline L4 - L5 & 0,617 & 0,597 & $-0,210$ & 0,834 & 2,197 & 0,199 & 1,108 & 0,383 \\
\hline Nivel crítico & \multicolumn{2}{|c|}{ L5 (0,019 kg) } & \multicolumn{2}{|c|}{ L4 (0,038 kg) } & \multicolumn{2}{|c|}{ L5 (0,019 kg) } & \multicolumn{2}{|c|}{ L5 (0,019 kg) } \\
\hline$m_{f}$ RABS2-C (Kg) & \multicolumn{2}{|c|}{0,038} & \multicolumn{2}{|c|}{0,075} & \multicolumn{2}{|c|}{0,038} & \multicolumn{2}{|c|}{0,038} \\
\hline
\end{tabular}

* Test aplicado a los datos transformados

Los resultados de las comparaciones múltiples para dichas fracciones (Tabla 6.60) muestran diferencias significativas entre los niveles de submuestreo L4 y L5 con los niveles L1 y L2, aunque en función de la fracción estas diferencias se dan para unos niveles u otros. En el caso del textil y los inertes, el porcentaje obtenido con el nivel de submuestreo L5 es diferente al obtenido con L1 para ambas fracciones. Respecto a los metales, los porcentajes obtenidos con L4 y L5 son distintos a los obtenidos con L1 y L2. Para los Otros, las diferencias se dan entre el nivel $L 5$ y los niveles $L 1$ y $L 2$. En todas estas las comparaciones el $p$-valor obtenido es menor a 0,05 (Tabla 6.60).

Por otro lado, como se observa en la tabla anterior, se ha obtenido un tamaño de muestra mínimo diferente en función de la fracción. Como indica la metodología, el tamaño de muestra será el más restrictivo de todos ellos, de forma que todas las fracciones este correctamente representadas.

Así pues, se puede concluir que el nivel crítico más restrictivo para el RABS2-C es el L4, por lo que los resultados obtenidos para el peso de muestra correspondiente a este nivel de submuestreo $(0,038 \mathrm{~kg}) \mathrm{no}$ son representativos para todas las fracciones. Esto significa que el tamaño de mínimo de muestra necesario para el control de calidad del RABS2-C es de 0,075 kg (L3) por lo que, mediante la aplicación de la metodología, el peso mínimo de muestra se ha reducido a un cuarto respecto al inicial de 0,3 kg, reduciendo el coste y carga de trabajo para la caracterización de este rechazo.

Finalmente, en la Tabla 6.61, se presentan los tamaños mínimos de muestra para para la determinación de la composición física del RABS2-C. El peso de muestra será diferente en función de la fracción que se quiera 
conocer y este se tomará mediante un muestreo aleatorio simple. Si se quiere determinar la composición global se deben tomar $0,075 \mathrm{~kg}$.

Tabla 6.61 Tamaño mínimo de muestra para el RABS2-C

\begin{tabular}{|c|c|c|c}
\hline \multirow{2}{*}{ Fracción } & $\mathbf{m}_{\mathbf{f}}(\mathbf{k g})$ & Fracción & \multirow{2}{*}{$\mathbf{m}_{\mathbf{f}}(\mathbf{k g})$} \\
\hline \multirow{2}{*}{ Metales } & & Fracción orgánica & \multirow{2}{*}{} \\
\cline { 3 - 3 } & 0,075 & Plástico Rígido & \multirow{2}{*}{} \\
\cline { 3 - 3 } & & Plástico Film & \multirow{2}{*}{0,019} \\
\cline { 1 - 2 } Textil & & Madera & \\
\cline { 1 - 2 } Inertes & \multirow{2}{*}{0,038} & Brik & \\
\cline { 1 - 2 } Otros & & RTP & \\
\hline
\end{tabular}

\subsubsection{Relación entre el tamaño de muestra y tamaño de partícula de los rechazos de la PBSR de Cervera}

Como en el primer caso de aplicación, con los datos obtenidos para la PBSR de Cervera para las tres corrientes de rechazos se ha comprobado si existe una relación entre el peso de muestra necesario y tamaño de partícula de los rechazos (d $\left.d_{95}\right)$.

En la Figura 6.37 se presenta el diagrama de dispersión para los tamaños de muestra de cada rechazo ( $\mathrm{m}_{\mathrm{f}}$ ) en relación a su d95. El mejor ajuste se ha obtenido con una curva exponencial, la ecuación de ajuste y el valor de $\mathrm{R}^{2}$ obtenido se muestran también en la figura.

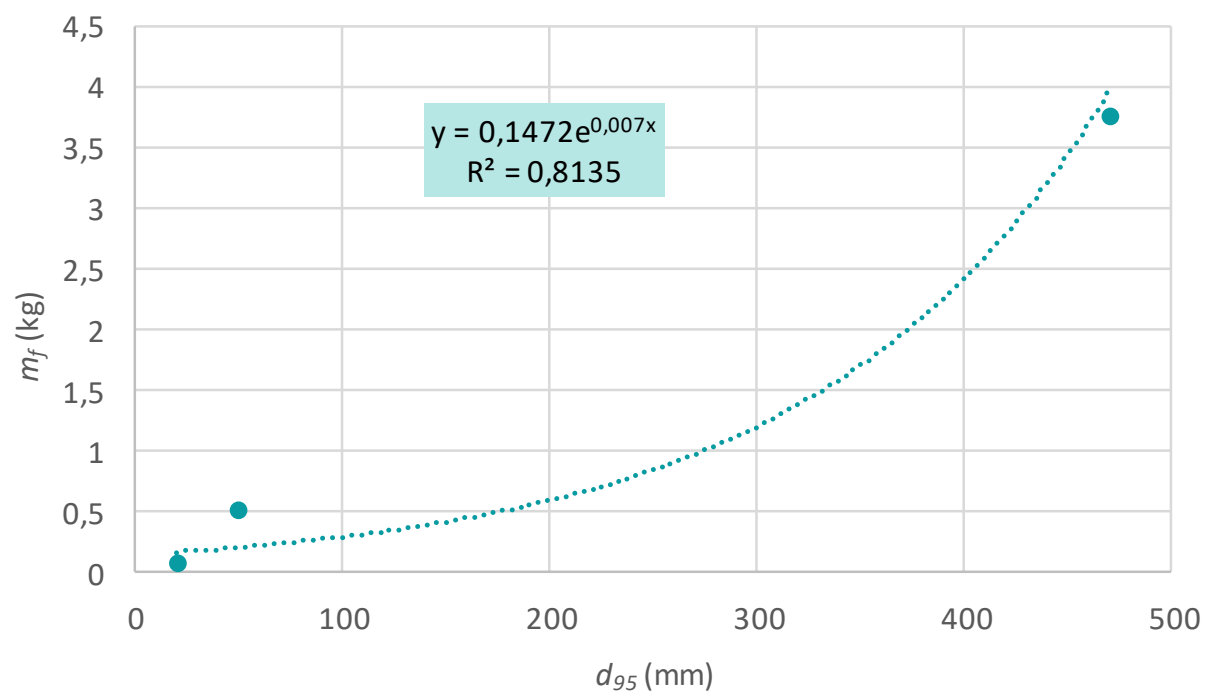

Figura 6.37 Ajuste ecuación del tamaño de muestra de la PBSR de Cervera

A partir del ajuste se obtiene la siguiente ecuación:

$$
m_{f}(P B S R-C)=0,1472 e^{0,007 \cdot d_{95}}
$$

Donde $\mathrm{m}_{\mathrm{f}}$ (PBSR-C) es el tamaño mínimo de muestra en kg para cierta corriente de rechazo de la PBSR de Cervera y $d_{95}$ es el tamaño nominal superior de partícula en $\mathrm{mm}$ de dicha corriente. 
Esta ecuación tiene una gran utilidad si el proceso de tratamiento de la instalación cambiara y se generaran nuevas corrientes de rechazo con un tamaño de partícula distinto, puesto que permitiría calcular el peso de muestra necesario para su caracterización sin tener que aplicar de nuevo toda la metodología para su determinación.

\subsubsection{Cálculo de los tiempos invertidos en el procedimiento de división de muestra y caracterización en la PBSR de Cervera.}

A continuación, se muestra el cálculo del tiempo empleado en el procedimiento de división de muestra y caracterización para el caso de la PBSR de Cervera.

\section{Rechazo de recuperación manual del biosecado de la PBSR de Cervera Onda (RRM-BS-C)}

El tiempo total invertido en el muestreo y caracterización de este rechazo para determinar el tamaño mínimo de muestra fue de 22,34 horas. Este trabajo fue realizado por un equipo formado por 3 personas.

En la Tabla 6.62 se indica el tiempo medio necesario por persona para el muestreo y caracterización de $1 \mathrm{~kg}$ de RRM-BS-C, así como el tiempo medio que se necesitaría para la caracterización de cada uno de los niveles de submuestreo y para el procedimiento de división y caracterización completo.

Tabla 6.62 Tiempo necesario para el muestreo y caracterización de RRM-BS-C

\begin{tabular}{c|c|c}
\hline \multirow{2}{*}{ Cantidad RRM-BS-C } & \multicolumn{2}{|c}{ Tiempo necesario } \\
\cline { 2 - 3 } & h/persona & min/persona \\
\hline $\mathbf{1} \mathbf{~ k g}$ & 0,06 & 3,40 \\
\hline L1 (60 kg) & 3,40 & 204,29 \\
\hline L2 (30 kg) & 1,70 & 102.14 \\
\hline L3 (15 kg) & 0,85 & 51,07 \\
\hline L4 (7,5 kg) & 0,43 & 25,54 \\
\hline L5 (3,75 kg) & 0,21 & 12,77 \\
\hline $\begin{array}{c}\text { Procedimiento de división y } \\
\text { caracterización (116,25 kg) }\end{array}$ & 6,60 & 395,80 \\
\hline
\end{tabular}

Como se observa en la tabla anterior, se ha estimado que una persona tarda 3 minutos y medio en caracterizar un kilogramo de RRM-BS-C por lo que, para poder aplicar el procedimiento propuesto por la metodología, son necesarias 6 horas y media de trabajo de una persona para la toma de muestras y caracterización de todos los niveles de submuestreo.

Por otro lado, en base a los resultados obtenidos, se puede comparar el tiempo necesario para la caracterización de este rechazo si se utilizara el tamaño de muestra de $60 \mathrm{~kg}$ calculado a partir de la norma del CSR ( $m_{m}$ RRM-BS-C), con el determinado a partir de la metodología de 3,75 kg (mf RRM-BS-C). Así pues, en el caso de utilizar el peso de $60 \mathrm{~kg}$ sería necesario invertir 3 horas y 24 minutos de trabajo de una persona, mientras que para 3,75 kg serían necesarios 13 minutos, lo que supone una disminución de un $93,75 \%$ en el tiempo medio invertido, con todas las ventajas económicas que esto conlleva.

\section{Rechazo de afino primario del biosecado de la PBSR de Cervera (RABS1-C)}

El tiempo total invertido en el muestreo y caracterización de este rechazo para la determinación del tamaño de muestra mínimo fue de 11,25 horas. Este trabajo siempre fue realizado por un equipo formado por dos personas.

En la Tabla 6.63 se expone al tiempo medio necesario por una persona para el muestreo y caracterización de $1 \mathrm{Kg}$ de RABS1-O, para la caracterización de cada uno de los niveles de submuestreo y para el procedimiento de división y caracterización completo. 
Tabla 6.63 Tiempo necesario para el muestreo y caracterización de RABS1-C

\begin{tabular}{c|c|c}
\hline \multirow{2}{*}{ Cantidad RABS1-C } & \multicolumn{2}{|c}{ Tiempo necesario } \\
\cline { 2 - 3 } & h/persona & min/persona \\
\hline $\mathbf{1} \mathbf{~ k g}$ & 0,37 & 22,49 \\
\hline $\mathbf{L 1}(\mathbf{2} \mathbf{~ k g})$ & 0,75 & 44,98 \\
\hline L2 (1 kg) & 0,37 & 22,49 \\
\hline L3 (0,500 kg) & 0,19 & 11,25 \\
\hline $\mathbf{L 4}(\mathbf{0 , 2 5 0} \mathbf{~ k g )}$ & 0,09 & 5,62 \\
\hline $\mathbf{L 5}(\mathbf{0 , 1 2 5} \mathbf{~ k g )}$ & 0,05 & 2,81 \\
\hline $\begin{array}{c}\text { Procedimiento de división y } \\
\text { caracterización (3,875 kg) }\end{array}$ & 1,45 & 87,15 \\
\hline
\end{tabular}

En la tabla anterior se puede ver que de media una persona necesita 22 minutos y medio para caracterizar un kilogramo de RABS1-C. Este tiempo es mucho mayor en comparación al del RRM-BS-C debido a que el tamaño de partícula del RABS1-C es más pequeño, haciendo que la separación de las diferentes fracciones sea mucho más laboriosa. No obstante, el tiempo total necesario para la aplicación del procedimiento de división de muestra y caracterización por una persona es de 87 minutos, ya que la cantidad de muestra en cada nivel de submuestreo es mucho menor que para el RRM-BS-C.

Por otro parte, si se utilizará el tamaño de muestra de $2 \mathrm{~kg}$ calculado con la norma del CSR ( $m \mathrm{~m}$ RABS1-C), el tiempo necesario para la caracterización de este rechazo por una persona sería de 45 minutos, mientras que este tiempo se reduce a un cuarto (11 minutos) si se utiliza el tamaño de muestra de 0,500 $\mathrm{kg}$ determinado con la metodología ( $\mathrm{m} f \mathrm{RABS1}-\mathrm{C}$ ). Esto supone un ahorro importante en el tiempo invertido y por tanto en el coste de la caracterización.

\section{Rechazo de afino secundario del biosecado de la PBSR de Cervera (RABS2-C)}

Para la determinación del tamaño de muestra mínimo de este rechazo fue necesario invertir un total de 4,50 horas y este trabajo siempre fue realizado por un equipo formado por 2 personas.

En la Tabla 6.64 se muestra el tiempo medio necesario por una persona para el muestreo y caracterización de $1 \mathrm{~kg}$ de RABS2-C, para los diferentes niveles de submuestreo y para el procedimiento de división y caracterización completo.

Tabla 6.64 Tiempo necesario para el muestreo y caracterización de RABS2-C

\begin{tabular}{c|c|c}
\hline \multirow{2}{*}{ Cantidad RABS2-C } & \multicolumn{2}{|c}{ Tiempo necesario } \\
\cline { 2 - 3 } & h/persona & min/persona \\
\hline $\mathbf{1} \mathbf{~ K g}$ & 1,31 & 78,50 \\
\hline L1 (0,300 kg) & 0,39 & 23,55 \\
\hline L2 (0,150 kg) & 0,20 & 11,78 \\
\hline L3 (0,075 kg) & 0,10 & 5,89 \\
\hline L4 (0,038 kg) & 0,05 & 2,94 \\
\hline L5 (0,019 kg) & 0,02 & 1,48 \\
\hline $\begin{array}{c}\text { Procedimiento de división y } \\
\text { caracterización (0.582 kg) }\end{array}$ & 0,76 & 45,63 \\
\hline
\end{tabular}


En la Tabla 6.64 se observa que una persona necesita 78 minutos y medio para caracterizar un kilogramo de RABS2-O, lo que supone más del triple de tiempo que para caracterizar la misma cantidad de RABS1-C. Esto es debido a que el tamaño de partícula de este rechazo es mucho menor y por tanto su separación es aún más laboriosa. En cuanto al tiempo total necesario para la aplicación de procedimiento propuesto en la metodología, una persona necesita 45 minutos para la toma de muestras y caracterización de todos los niveles de submuestreo. Este valor es más pequeño que el del RABS1-C ya que la cantidad de muestra en cada nivel es mucho menor.

Finalmente, si se utilizara el tamaño de muestra de 0,300 $\mathrm{kg}$ calculado con la norma del CSR (mm RABS2-C), el tiempo necesario para la caracterización de este rechazo por una persona sería de 23 minutos y medio. En cambio, si se usa el tamaño de 0,075 kg determinado con la metodología (mf RABS2-C), el tiempo necesario se reduce a 6 minutos, es decir casi cuatro veces menos, lo que minimiza también el coste económico de su caracterización.

\subsection{CASO DE APLICACIÓN PARA DETERMINAR DEL NÚMERO DE MUESTRAS (ETAPA II)}

En este punto se presenta la aplicación de la metodología para determinar el número de muestras necesarias para el control de calidad los rechazos producidos a lo largo de un año a la planta de recuperación y compostaje de Onda. Esta instalación ha sido descrita anteriormente en el primer caso de aplicación. Además, la metodología se ha validado a partir de los datos de composición y humedad obtenidos en los diferentes estratos y corrientes de rechazo.

\subsubsection{Determinación del número de muestras}

Para la determinación del número de muestras necesarias para el control de calidad de los rechazos que se generan en la PRC se han seguido los cuatro pasos propuestos en la metodología:

1. Determinación de las variables de estratificación

2. Determinación de los niveles de variación temporal

3. Identificación de las corrientes de rechazo a muestrear

4. Cálculo del número de muestras

\subsubsection{Determinación de las variables de estratificación}

Siguiendo la metodología propuesta se han estudiado las variables que influyen en la composición y las propiedades de los rechazos generados en la PRC de Onda y que son responsables de su variabilidad temporal. Para ello se contactó con los responsables de la instalación con el objetivo de obtener toda la información preliminar necesaria.

Así pues, tras la reunión con los responsables de la instalación y el análisis de su funcionamiento, se descartó cualquier variación debida a la procedencia de los residuos y con la posible formación de capas con características diferentes en el foso de descarga. Esto se debe a que los RSU, una vez son recogidos en los diferentes pueblos y rutas, se trasladan a la estación de transferencia donde se mezclan antes de su transporte a la planta de tratamiento. Tampoco existen diferencias en función del día de la semana.

Respecto a las variaciones entre los diferentes meses, los responsables de la planta indicaron que:

- Para los rechazos generados en la etapa mecánica de recuperación de materiales y en el afino primario del material pre-bioestabilizado existen variaciones en las propiedades de los rechazos en función de la estacionalidad, puesto que estas corrientes están afectadas por la variación de la composición de los RSU entrantes en las diferentes épocas del año.

- Para los rechazos generados en el afino final del material bioestabilizado no se ha detectado ninguna variación en sus propiedades a lo largo de año. Esto se debe a que el bioestabilizado es un 
material mucho más homogéneo tras pasar por el proceso de maduración y no se ve afectado por la composición de los RSU entrantes.

- El turismo no influye en las propiedades de los rechazos ni en el funcionamiento de la planta, a pesar que la instalación se ubica en una zona turística en la época de verano. Esto se debe a que en ella se reciben RSU de municipios que aumentan su población en verano (Benicassim), pero también de otros que la disminuyen (Castellón de la Plana).

Como conclusión del estudio inicial se ha determinado que la estacionalidad es la única variable de estratificación para los rechazos originados en las etapas de recuperación de materiales y de afino primario, mientras que para los rechazos generados en el afino secundario no se ha identificado ninguna variable de estratificación.

\subsubsection{Determinación de los niveles de variación temporal}

Una vez identificadas las variables de estratificación se determinan los niveles de variación y los estratos en los que hay que dividir la producción anual de rechazo y que será necesario muestrear.

A partir de la Tabla 6.65 se obtiene que los rechazos generados en la etapa de recuperación de materiales y afino primario de la PRC están afectados solo por el nivel de variación mensual. La existencia de este nivel implica la división de la producción entre 1 y 12 estratos. En el caso de la instalación estudiada, dado que la variable de estratificación identificada para estos rechazos es la estacionalidad, se ha decidido dividir la producción anual de los mismos en dos estratos: uno correspondiente a las estaciones de primavera-verano y otro a las estaciones otoño-invierno $\left(P_{m}=2\right)$. Las cuatro estaciones del año se han agrupado de esta forma por su similitud, puesto que en el área del Mediterráneo no hay una gran variación entre la primavera y el verano ni entre el otoño y el invierno, como indicaron Gallardo et al. (2018) para esta misma zona.

En el caso de los rechazos de afino secundario la estratificación de la producción anual a la hora de determinar el número de muestras no es necesaria, existiendo un único periodo de muestreo que corresponde a todo el año $\left(P_{m}=1\right)$.

Además, en la PRC de Onda ninguna corriente de rechazo está afectado por el nivel de variación semanal $\left(P_{s}=0\right)$ ni por el diario $\left(P_{d}=0\right)$.

Tabla 6.65 Niveles de variación y variables identificadas para el RRM-O y RAB1-O

\begin{tabular}{c|c|c}
\hline & Nivel de variación temporal \\
\hline Mensual & Semanal & Diario \\
\hline Estacionalidad & Turismo fin de semana & Área geográfica \\
Climatología & Modo de vida & Tipo de población \\
Turismo estacional & Frecuencia de recogida & Nivel de renta \\
de jardinería) & Funcionamiento instalación & Nivel de urbanización \\
\hline
\end{tabular}

\subsubsection{Identificación de las corrientes de rechazo a muestrear}

Respecto a las diferentes corrientes de rechazo a muestrear, en función de tipo de instalación y los procesos de tratamiento llevados a cabo, en la PRC de Onda se han identificado tres flujos de rechazo que pueden ser transformadas en un CSR y cuyas propiedades son distintas desde el punto de vista de su calidad:

- Rechazo de recuperación manual (RRM-O).

- $\quad$ Rechazo de afino primario del bioestabilizado (RAB1-O)

- $\quad$ Rechazo de afino secundario del bioestabilizado (RAB2-O)

Estas corrientes se han descrito en el primer caso de aplicación. 


\subsubsection{Cálculo del número de muestras}

Finalmente, mediante la ecuación 6.4 propuesta por la metodología, se ha calculado el número mínimo de muestras necesarias para el control de la calidad de la producción anual de los tres rechazos (Tabla 6.66 y ecuación 6.5):

Tabla 6.66 Determinación del número de muestras mínimo de la PRC de Onda

\begin{tabular}{c|c|c|c|c|c}
\hline Rechazo & $\mathbf{P}_{\mathrm{m}}$ & $\mathbf{P}_{\mathrm{s}}$ & $\mathbf{P}_{\mathrm{d}}$ & NCR & NM \\
\hline RRM-O & 2 & 0 & 0 & 1 & $\mathbf{2 0}$ \\
\hline RAB1-0 & 2 & 0 & 0 & 2 & $\mathbf{2 0}$ \\
\hline RAB2-0 & 1 & 0 & 0 & 3 & $\mathbf{1 0}$ \\
\hline TOTAL PRC de Onda & - & - & - & - & $\mathbf{5 0}$ \\
\hline
\end{tabular}

$\boldsymbol{N} \boldsymbol{M}_{\boldsymbol{P R C}-\boldsymbol{O}}=[(2 \cdot 10)+((0+0) \cdot 6)]+[(2 \cdot 10)+((0+0) \cdot 6)]+[(1 \cdot 10)+((0+0) \cdot 6)]=\mathbf{5 0}$

Como se observa en la Tabla 6.66, para el control de calidad de los tres rechazos producido en la PRC de Onda es necesario tomar un mínimo de 50 muestras en total al año. Estas muestras deben estar repartidas en los estratos en los que se divide la producción anual de cada corriente de rechazo: para el RRM-O y el RAB1-O son necesarias al menos 10 muestras en el periodo de primavera-verano y otras 10 en el periodo de otoño-invierno. Para el RAB2-O son necesarias un mínimo de 10 muestras que se tomarán a lo largo de todo el año (único estrato).

\subsubsection{Validación de la metodología para la determinación del número de muestras}

En este apartado se presenta la validación de la metodología para el cálculo del número mínimo de muestras. Por un lado, se va a comprobar que las tres corrientes de rechazo son diferentes y, por otro, que la producción anual de rechazo se tiene que dividir en los estratos considerados para cada rechazo.

Para la validación se han utilizado los datos de composición y humedad obtenidos para las tres corrientes de rechazo de la PRC de Onda en 2017 (caso 1 de aplicación), puesto que la fase 1 corresponde al estrato de primavera-verano y la fase 2 al de otoño invierno. El número mínimo de muestras necesarias determinado a partir de la metodología es de 10 por estrato. Sin embargo, en 2017 el número muestras tomadas por fase en algunos rechazos es superior a 10. Así pues, para aquellos rechazos en los que se tiene más de una caracterización por día de muestreo, solo se han seleccionado los datos correspondientes a la primera muestra del día.

Respecto al tamaño de muestra, se han escogido los datos correspondientes al peso mínimo de muestra determinado en el primer caso de aplicación $(\mathrm{mf})$ para cada una de las corrientes de la PRC de Onda: 7,5 kg para el RRM-O, 0,5 kg para el RAB1-O y 0,4 kg para el RAB2-O.

Los datos de humedad se han obtenido también a partir de las caracterizaciones realizadas en 2017, puesto que cada día de muestreo se determinaba la humedad de las tres corrientes de rechazo mediante el método de secado en estufa a $105^{\circ} \mathrm{C}$, el cual está definido en la norma UNE-EN 15414-3 (2011).

\subsubsection{Justificación de la diferenciación de las tres corrientes de rechazo}

En la PRC de Onda existen tres corrientes de rechazo que son susceptibles de producir CSR y cuyas propiedades son distintas desde el punto de vista de su calidad. 
EI RRM-O está compuesto principalmente por fracción orgánica y papel/cartón con valores alrededor del 20\% para ambas fracciones (Tabla 6.67). Por detrás de estos materiales se encuentran el plástico film, el plástico rígido y los Otros con porcentajes entre el 10-15\%. Las fracciones que se encuentran en menor proporción son el vidrio, inertes y RTP. Respecto a la humedad, el valor medio del RRM-O para la fase 1 es de $25,95 \%$ y para la fase 2 es de $31,70 \%$ (Tabla 6.67).

El RAB1-O está compuesto por un $60-70 \%$ de fracción orgánica debido a que esta corriente de rechazo se origina en la etapa biológica de tratamiento (Tabla 6.70). El siguiente material mayoritario es el vidrio con valores entre el 9 y $12 \%$ según la fase. La tercera fracción en importancia es el plástico rígido seguido por los metales y los inertes. Los materiales minoritarios son el brik y los RTP. En cuanto a la humedad, el RAB1-O presenta unos valores más altos en comparación con el RRM-O, con un $28,81 \%$ en la fase 1 y un $38,75 \%$ en la fase 2 (Tabla 6.70). Esto se debe a que esta corriente de rechazo es generada en el afino intermedio del material pre-bioestabilizado, el cual procede directamente de los túneles de compostaje, por lo que tienen una humedad muy elevada.

EI RAB2-O debido a que también se origina en la etapa biológica de tratamiento está compuesto principalmente por fracción orgánica, en torno a un 66\% (Tabla 6.73). En segundo lugar, se encuentra el vidrio con porcentajes también muy altos, entre el 27 y $29 \%$. Esto se debe a que a que el vidrio presente en los RSU se va rompiendo en las diferentes etapas de tratamiento en fragmentos pequeños con diámetros entre 30 y $14 \mathrm{~mm}$, que corresponden al tamaño de partícula de este rechazo. Los porcentajes obtenidos para el resto de fracciones han sido muy pequeños. Respecto a la humedad, el RAB2-O es el rechazo que presenta unos valores más bajos entre 11 y 16\% (Tabla 6.73). Esto es debido a que esta corriente procede del afino final del material bioestabilizado que ya ha madurado, por lo que ha perdido gran parte del agua que contenía.

Así pues, la existencia de estas diferencias de composición y humedad entre los tres rechazos justifican su distinción a la hora de llevar a cabo el control de calidad de los mismos, puesto que darán lugar a CSR de distintas calidades y especificaciones como se ha visto en el estado del arte.

\subsubsection{Justificación de la estratificación}

Los estratos en los que se tiene que dividir la producción anual del RRM-O y del RAB1-O son dos, mientras que para el RAB2-O la estratificación de la producción anual no es necesaria y solo existe un único estrato que corresponde a todo el año.

A continuación, se va a comprobar mediante un contraste de medias si existen diferencias en las propiedades (composición y humedad) del RRM-O y el RAB1-O entre los dos estratos (primavera-verano y otoño-invierno). Esto permitirá verificar si la estratificación propuesta es correcta. En el caso del RAB2-O también se ha realizado esta comprobación puesto que se dispone de los datos para las dos fases del primer caso de aplicación. No obstante, para esta corriente su producción no se tiene que estratificar y, por lo tanto, no deben de existir diferencias entre los estratos.

Para comprobar si existen diferencias estadísticamente significativas se van a seguir los procedimientos propuestos en el capítulo 5 de la presente tesis para la comparación de dos grupos de muestras (Figura 5.7). En primer lugar, para cada fracción, se ha comprobado el supuesto de Normalidad y de homocedasticidad (comparación de varianzas) para los datos de ambos estratos. Aquellos datos que no seguían una distribución Normal fueron transformados (trasformación arcoseno). A continuación, se volvió a comprobar si los datos transformados cumplían los dos supuestos. Finalmente, en función de los supuestos cumplidos, la comparación se realizó mediante un test u otro:

- Test $\mathrm{t}$ de Student (paramétrico): Cuando se cumplen ambos supuestos, haya sido necesario transformar los datos o no.

- $\quad$ Test t de Welch (paramétrico): Cuando los datos son Normales, pero las varianzas son diferentes. Puede haber sido necesario transformar los datos o no.

- Test de Wilcoxon (no paramétrico): Cuando el supuesto de Normalidad no se cumple en ninguno de los dos casos, es decir con los datos sin transformar o con los datos transformados. 
Todos los análisis estadísticos se realizaron con el programa de acceso libre $\mathrm{R}$ y su paquete $\mathrm{R}$ Commander, el nivel de confianza utilizado ha sido del $95 \%(\alpha=0,05)$.

A continuación, se exponen los datos de composición y humedad que se han analizado estadísticamente para las tres corrientes de rechazo, así como de los resultados del análisis estadístico.

\section{Justificación de la estratificación del RRM-O}

En la Tabla 6.67 se muestran los datos de composición y humedad media, así como su desviación estándar, para los dos estratos en los que se ha dividido la producción anual de RRM-O (fase 1 y fase 2).

Tabla 6.67 Composición y humedad del RRM-O, fase 1 y fase 2

\begin{tabular}{|c|c|c|c|c|}
\hline Composición RRM-O (\%) & \multicolumn{2}{|c|}{$\begin{array}{c}\text { Fase } 1 \\
\text { (primavera-verano) }\end{array}$} & \multicolumn{2}{|c|}{$\begin{array}{c}\text { Fase } 2 \\
\text { (otoño-invierno) }\end{array}$} \\
\hline NM & \multicolumn{2}{|c|}{10} & \multicolumn{2}{|c|}{10} \\
\hline $\mathrm{m}_{\mathrm{f}}(\mathrm{kg})$ & \multicolumn{2}{|c|}{7,5} & \multicolumn{2}{|c|}{7,5} \\
\hline Fracción & $\bar{x}$ & s & $\bar{x}$ & $\mathbf{s}$ \\
\hline Fracción orgánica & 19,40 & 6,05 & 19,48 & 4,93 \\
\hline Papel/Cartón & 17,91 & 9,14 & 20,44 & 4,59 \\
\hline Plástico Film & 11,08 & 2,33 & 14,07 & 7,01 \\
\hline Plástico Rígido & 12,72 & 5,95 & 9,72 & 4,31 \\
\hline Textil & 9,58 & 6,39 & 4,53 & 3,56 \\
\hline Metales & 4,19 & 1,32 & 2,22 & 0,97 \\
\hline Madera & 1,85 & 1,49 & 4,26 & 3,22 \\
\hline Brik & 2,29 & 1,26 & 1,59 & 0,73 \\
\hline Inertes & 1,12 & 1,99 & 0,89 & 1,87 \\
\hline RTP & 0,26 & 0,52 & 0,59 & 0,62 \\
\hline Vidrio & 0,98 & 1,19 & 1,73 & 1,59 \\
\hline Otros & 11,18 & 5,09 & 13,79 & 5,61 \\
\hline Finos & 7,45 & 3,87 & 6,70 & 2,88 \\
\hline Humedad (\%) & 25,95 & 5,00 & 31,70 & 4,05 \\
\hline
\end{tabular}

Como se observa en la tabla anterior, a priori se podría decir que existen diferencias para algunas fracciones y el contenido en humedad en función de fase. No obstante, es importante saber si estas diferencias son estadísticamente significativas y corroborar que no han aparecido como fruto del azar.

En la Tabla 6.68 se muestran los resultados obtenidos tras la aplicación de los diferentes test estadísticos para la comprobación de los supuestos de Normalidad y homocedasticidad, mientras que en la Tabla 6.69 se exponen los resultados de los test estadísticos para la comparación de medias o medianas entre las dos fases. En ellas se indica el estadístico de contraste y el p-valor obtenido en cada prueba. 
Tabla 6.68 Análisis estadístico RRM-O: comprobación de supuestos

\begin{tabular}{|c|c|c|c|c|c|c|}
\hline \multirow{4}{*}{$\begin{array}{c}\text { Tipo de prueba } \\
\text { Fracción }\end{array}$} & \multicolumn{4}{|c|}{ Test de Shapiro-Wilk } & \multirow{3}{*}{\multicolumn{2}{|c|}{$\begin{array}{c}\text { Test de F } \\
\text { Comparación de } \\
\text { varianzas }\end{array}$}} \\
\hline & \multicolumn{4}{|c|}{ Bondad de ajuste: Normalidad } & & \\
\hline & \multicolumn{2}{|c|}{ Fase 1} & \multicolumn{2}{|c|}{ Fase 2} & & \\
\hline & w & p-valor & w & p-valor & $\mathbf{F}$ & p-valor \\
\hline Fracción orgánica & 0,963 & 0,824 & 0,986 & 0,989 & 0,880 & 0,131 \\
\hline Papel/Cartón & 0,960 & 0,788 & 0,919 & 0,353 & 0,854 & 0,064 \\
\hline Plástico Film & 0,958 & 0,762 & 0,680 & $<0,001$ & - & - \\
\hline Plástico Rígido & 0,725 & 0,002 & 0,899 & 0,215 & - & - \\
\hline Textil & 0,896 & 0,196 & 0,883 & 0,141 & 3,220 & 0,096 \\
\hline Metales & 0,947 & 0,633 & 0,942 & 0,571 & 1,876 & 0,363 \\
\hline Madera* & 0,906 & 0,252 & 0,943 & 0,592 & 0,416 & 0,208 \\
\hline Brik & 0,902 & 0,233 & 0,900 & 0,218 & 2,963 & 0,121 \\
\hline Inertes & 0,559 & $<0,001$ & 0,550 & $<0,001$ & - & - \\
\hline RTP & 0,601 & $<0,001$ & 0,814 & 0,021 & - & - \\
\hline Vidrio* & 0,921 & 0,367 & 0,949 & 0,656 & 0,988 & 0,986 \\
\hline Otros & 0,922 & 0,374 & 0,880 & 0,131 & 0,821 & 0,778 \\
\hline Finos & 0,882 & 0,138 & 0,854 & 0,064 & 1,808 & 0,391 \\
\hline Humedad & 0,894 & 0,186 & 0,931 & 0,457 & 1,520 & 0,543 \\
\hline
\end{tabular}

* Fracciones en las que la transformación de los datos ha mejorado su distribución, aproximándola a la Normal y permitiendo usar pruebas paramétricas con los datos transformados.

Tabla 6.69 Análisis estadístico RRM-O: comparación de medias entre las dos fases

\begin{tabular}{c|c|c|c|c|}
\hline Test estadístico & \multicolumn{2}{|c|}{$\begin{array}{c}\text { Test t de Student / } \\
\text { Test t de Welch }\end{array}$} & \multicolumn{2}{|c}{ Test de Wilcoxon } \\
\hline Tipo de prueba & \multicolumn{2}{c|}{$\begin{array}{c}\text { Comparación de } \\
\text { medias }\end{array}$} & \multicolumn{2}{c}{$\begin{array}{c}\text { Comparación de } \\
\text { medianas }\end{array}$} \\
\hline Fracción & $\mathbf{t}$ & $\mathbf{p}$-valor & $\mathbf{W}$ & $\mathbf{p}$-valor \\
\hline Fracción orgánica & $-0,034$ & 0,974 & - & - \\
\hline Papel/Cartón & $-0,785$ & 0,443 & - & - \\
\hline Plástico Film & - & - & 41 & 0,529 \\
\hline Plástico Rígido & - & - & 66 & 0,248 \\
\hline Textil & 2,181 & 0,043 & - & - \\
\hline Metales & 3,806 & 0,001 & - & - \\
\hline Madera* & 1,854 & 0,080 & - & - \\
\hline Brik & 1,519 & 0,146 & - & - \\
\hline Inertes & - & - & 63 & 0,341 \\
\hline RTP & - & - & 21 & 0,031 \\
\hline Vidrio* & $-1,358$ & 0,191 & - & - \\
\hline
\end{tabular}




\begin{tabular}{c|c|c|c|c}
\hline Otros & $-1,090$ & 0,290 & - & - \\
\hline Finos & 0,495 & 0,627 & - & - \\
\hline Humedad & $-2,827$ & 0,011 & - & - \\
\hline
\end{tabular}

* Fracciones en las que la transformación de los datos ha mejorado su distribución, aproximándola a la Normal y permitiendo usar pruebas paramétricas con los datos transformados.

Los resultados obtenidos tras el análisis estadístico del RRM-O indican que existen diferencias significativas en el porcentaje de textil, metales y RTP entre las dos fases, puesto que el p-valor obtenido en la comparación de medias o medianas para estos materiales es menor a 0,05 (Tabla 6.69). Así pues, se puede afirmar con una confianza del 95\% que en función de la estación del año el porcentaje de estas fracciones varía. Para el textil y los metales, los mayores porcentajes se dan en la fase 1 (primavera-verano). En el caso de los textiles, esta diferencia puede estar relacionada con la presencia de una mayor cantidad de ropa en los RSU debido a la limpieza de armarios que se realiza habitualmente durante dicha época del año. En cuanto a los metales, la mayor cantidad de esta fracción en la primera fase puede deberse al aumento del consumo de refrescos durante primavera-verano. Para los RTP, los mayores porcentajes se dan en la fase 2 (otoño-invierno). Dentro de esta categoría se encuentran residuos como medicamentos y sus envases, los cuales pueden presentarse en mayor cantidad en los RSU durante esta época del año debido los constipados y gripes típicas de la misma.

Los resultados presentados la Tabla 6.69 también muestran que existen diferencias estadísticamente significativas en el contenido de humedad entre las fase 1 y 2 ( $p$-valor $<0,050$ ). Por lo que se puede afirmar con una confianza del $95 \%$ que la humedad del RRM-O es menor en primavera-verano que en otoñoinvierno y, por tanto, varía en función de la época del año. Estas diferencias pueden deberse, por un lado, a al aumento del contenido en papel/cartón en la fase 2, puesto que esta fracción acumula más humedad. Por otro lado, a que en la fase 1 la temperatura ambiental en Castellón en mucho más alta que en la fase 2. Esto favorece que haya una mayor evaporación del agua que contienen los RSU del foso de descarga de la PRC y, por tanto, disminuye su humedad y la de los rechazos. En este sentido, Garcés et al. (2016) observaron en su estudio que el contenido en humedad de los rechazos está muy influenciado por las condiciones atmosféricas y las condiciones de almacenamiento.

Así pues, se puede concluir que la estratificación de la producción anual del RRM-O en función de la estacionalidad a la hora de determinar el número de muestras es correcta.

\section{Justificación de la estratificación del RAB1-O}

Los datos de composición y humedad media para los dos estratos en los que se ha dividido la producción anual de RAB1-O (fase 1 y 2) se exponen en la Tabla 6.70, junto con la desviación estándar de los mismos. Como en el caso del RRM-O, es importante conocer si las diferencias que se pueden observar a priori son estadísticamente significativas, es decir, si son reales o han aparecido como fruto del azar.

Tabla 6.70 Composición y humedad del RAB1-O, fase 1 y fase 2

\begin{tabular}{|c|c|c|c|c|}
\hline Composición RAB1-O (\%) & \multicolumn{2}{|c|}{$\begin{array}{c}\text { Fase } 1 \\
\text { (primavera-verano) }\end{array}$} & \multicolumn{2}{|c|}{$\begin{array}{c}\text { Fase } 2 \\
\text { (otoño-invierno) }\end{array}$} \\
\hline NCR & \multicolumn{2}{|c|}{10} & \multicolumn{2}{|c|}{10} \\
\hline$m_{f}(k g)$ & \multicolumn{2}{|c|}{0,500} & \multicolumn{2}{|c|}{0,500} \\
\hline Fracción & $\bar{x}$ & $\mathbf{s}$ & $\bar{x}$ & $\mathbf{s}$ \\
\hline Fracción orgánica & 63,57 & 11,26 & 69,89 & 10,41 \\
\hline Plástico Film & 3,67 & 2,31 & 2,08 & 1,68 \\
\hline Plástico Rígido & 7,82 & 5,98 & 6,96 & 3,76 \\
\hline
\end{tabular}




\begin{tabular}{|c|c|c|c|c|}
\hline Composición RAB1-O (\%) & \multicolumn{2}{|c|}{$\begin{array}{c}\text { Fase } 1 \\
\text { (primavera-verano) }\end{array}$} & \multicolumn{2}{|c|}{$\begin{array}{c}\text { Fase } 2 \\
\text { (otoño-invierno) }\end{array}$} \\
\hline NCR & \multicolumn{2}{|c|}{10} & \multicolumn{2}{|c|}{10} \\
\hline$m_{f}(k g)$ & \multicolumn{2}{|c|}{0,500} & \multicolumn{2}{|c|}{0,500} \\
\hline Fracción & $\bar{x}$ & s & $\bar{x}$ & s \\
\hline Textil & 2,56 & 2,81 & 1,14 & 1,30 \\
\hline Metales & 4,18 & 3,68 & 4,31 & 3,61 \\
\hline Madera & 1,91 & 3,77 & 0,14 & 0,24 \\
\hline Brik & 0,00 & 0,00 & 0,24 & 0,76 \\
\hline Inertes & 5,42 & 6,03 & 2,58 & 4,04 \\
\hline RTP & 0,01 & 0,02 & 0,42 & 0,57 \\
\hline Vidrio & 9,70 & 6,41 & 11,56 & 5,86 \\
\hline Otros & 1,16 & 1,54 & 0,70 & 0,86 \\
\hline Humedad (\%) & 28,81 & 7,41 & 38,75 & 6,59 \\
\hline
\end{tabular}

Los resultados obtenidos para el análisis estadístico de los datos de composición y humedad se muestran en la Tabla 6.71 (comprobación de supuestos) y en la Tabla 6.72 (comparación de medias o medianas). En ellas se indica el estadístico de contraste y el p-valor obtenido en cada prueba. En el caso de la fracción de brik no se pudo comprobar la normalidad en la fase 1 porque todos los valores obtenidos para esa fase fueron de $0 \%$ (Tabla 6.70).

Tabla 6.71 Análisis estadístico RAB1-O: comprobación de supuestos

\begin{tabular}{|c|c|c|c|c|c|c|}
\hline \multirow{3}{*}{$\begin{array}{l}\text { Test estadístico } \\
\text { Tipo de prueba }\end{array}$} & \multicolumn{4}{|c|}{ Test de Shapiro-Wilk } & \multicolumn{2}{|c|}{ Test de $\mathbf{F}$} \\
\hline & \multicolumn{4}{|c|}{ Bondad de ajuste: Normalidad } & \multirow{2}{*}{\multicolumn{2}{|c|}{$\begin{array}{l}\text { Comparación de } \\
\text { varianzas }\end{array}$}} \\
\hline & \multicolumn{2}{|c|}{ Fase 1} & \multicolumn{2}{|c|}{ Fase 2} & & \\
\hline Fracción & $\mathbf{w}$ & p-valor & w & p-valor & $\mathbf{F}$ & p-valor \\
\hline Fracción orgánica & 0,861 & 0,078 & 0,877 & 0,120 & 1,171 & 0,818 \\
\hline Plástico Film* & 0,894 & 0,189 & 0,960 & 0,785 & 0,735 & 0,654 \\
\hline Plástico Rígido & 0,916 & 0,324 & 0,950 & 0,674 & 2,536 & 0,182 \\
\hline Textil* & 0,982 & 0,977 & 0,888 & 0,163 & 1,634 & 0,476 \\
\hline Metales & 0,854 & 0,065 & 0,913 & 0,302 & 1,038 & 0,957 \\
\hline Madera & 0,561 & $<0,001$ & 0,662 & $<0,001$ & - & - \\
\hline Brik & - & - & 0,366 & 0,000 & - & - \\
\hline Inertes* & 0,913 & 0,304 & 0,886 & 0,154 & 1,813 & 0,389 \\
\hline RTP & 0,366 & $<0,001$ & 0,710 & 0,001 & - & - \\
\hline Vidrio & 0,898 & 0,211 & 0,901 & 0,224 & 1,196 & 0,794 \\
\hline Otros & 0,786 & 0,010 & 0,776 & 0,007 & - & - \\
\hline Humedad & 0,956 & 0,736 & 0,937 & 0,516 & 1,261 & 0,736 \\
\hline
\end{tabular}

* Fracciones en las que la transformación de los datos ha mejorado su distribución, aproximándola a la Normal y permitiendo usar pruebas paramétricas con los datos transformados. 
Tabla 6.72 Análisis estadístico RAB1-O: comparación de medias entre las dos fases

\begin{tabular}{c|c|c|c|c}
\hline Test estadístico & \multicolumn{2}{|c|}{$\begin{array}{c}\text { Test t de Student / } \\
\text { Test t de Welch }\end{array}$} & \multicolumn{2}{c}{ Test de Wilcoxon } \\
\hline Tipo de prueba & \multicolumn{2}{|c|}{$\begin{array}{c}\text { Comparación de } \\
\text { medias }\end{array}$} & \multicolumn{2}{c}{$\begin{array}{c}\text { Comparación de } \\
\text { medianas }\end{array}$} \\
\hline Fracción & $\mathbf{t}$ & $\mathbf{p}$-valor & $\mathbf{W}$ & p-valor \\
\hline Fracción orgánica & $-1,303$ & 0,209 & - & - \\
\hline Plástico Film* & 2,001 & 0,061 & - & - \\
\hline Plástico Rígido & 0,388 & 0,703 & - & - \\
\hline Textil* & 1,443 & 0,166 & - & - \\
\hline Metales & $-0,082$ & 0,935 & - & - \\
\hline Madera & - & - & 63 & 0,313 \\
\hline Brik & - & - & 45 & 0,368 \\
\hline Inertes* & 1,043 & 0,311 & - & - \\
\hline RTP & - & - & 23 & 0,019 \\
\hline Vidrio & $-0,676$ & 0,508 & - & - \\
\hline Otros & - & - & 48 & 0,908 \\
\hline Humedad & $-3,172$ & 0,005 & - & - \\
\hline
\end{tabular}

* Fracciones en las que la transformación de los datos ha mejorado su distribución, aproximándola a la Normal y permitiendo usar pruebas paramétricas con los datos transformados.

Tras el análisis estadístico del RAB1-O, los resultados muestran que existen diferencias significativas en el porcentaje de RTP entre las dos fases, ya que el p-valor obtenido en menor a 0,05 (Tabla 6.72). Por lo que se puede afirmar con una confianza del 95\% que en función de la estación del año el porcentaje de esta fracción varía, siendo menor en la fase 1 (primavera-verano) que en la fase 2 (otoño-invierno). Esta diferencia, como se ha visto anteriormente, puede estar relacionada con el mayor consumo de medicamentos durante otoño e invierno debido a los constipados típicos de esa época del año.

Respecto a la humedad, los resultados de la Tabla 6.72 indican que existen diferencias en estadísticamente significativas en el porcentaje de humedad entre la fase 1 y 2 ( $p$-valor $<0,05$ ). Así pues, se puede afirmar con una confianza del $95 \%$ que la humedad del RAB1-O es mayor en otoño-invierno que en primaveraverano. Estas diferencias pueden deberse a la diferencia de temperatura ambiental entre las dos épocas del año, así como al mayor contenido en fracción orgánica en el RAB1-O en la segunda fase, que acumula mayor humedad.

Por todo ello, se puede concluir que la estratificación de la producción anual de RAB1-O en función de la estacionalidad también es correcta.

\section{Justificación de la estratificación del RAB2-O}

A continuación se exponen los datos de composición y humedad media del RAB2-O, junto con sus desviaciones estándar, para la fase 1 y fase 2 (Tabla 6.73). Como se ha comentado anteriormente, para esta corriente de rechazo no es necesario dividir su producción anual, por lo que es importante conocer si estadísticamente las dos fases son iguales. 
Tabla 6.73 Composición y humedad del RAB2-O, fase 1 y fase 2

\begin{tabular}{c|c|c|c|c}
\hline \multirow{2}{*}{ Composición RAB1-O (\%) } & \multicolumn{2}{c|}{ Fase 1 } & \multicolumn{2}{c}{ Fase 2 } \\
(primavera-verano) & \multicolumn{2}{c}{ (otoño-invierno) } \\
\hline m $_{\text {f }(\mathbf{g g})}$ & \multicolumn{2}{|c|}{10} & \multicolumn{2}{c}{0,400} \\
\hline Fracción & \multicolumn{2}{|c|}{0,400} & $\bar{x}$ & $\mathbf{s}$ \\
\hline Fracción orgánica & 66,65 & 7,04 & 66,46 & 7,21 \\
\hline Plástico Film & 0,38 & 0,24 & 0,22 & 0,16 \\
\hline Plástico Rígido & 1,37 & 0,70 & 0,87 & 0,40 \\
\hline Textil & 0,08 & 0,25 & 0,00 & 0,00 \\
\hline Metales & 0,26 & 0,40 & 0,13 & 0,19 \\
\hline Madera & 0,08 & 0,16 & 0,02 & 0,07 \\
\hline Brik & 0,00 & 0,00 & 0,01 & 0,03 \\
\hline Inertes & 3,75 & 2,98 & 3,07 & 1,73 \\
\hline RTP & 0,07 & 0,20 & 0,03 & 0,06 \\
\hline Vidrio & 27,34 & 6,49 & 29,10 & 5,96 \\
\hline Otros & 0,01 & 0,03 & 0,09 & 0,14 \\
\hline Humedad (\%) & 11,00 & 4,94 & 15,89 & 7,68 \\
\hline & & & &
\end{tabular}

Los resultados obtenidos para el análisis estadístico de los datos de composición y humedad se presentan en la Tabla 6.74 (comprobación de supuestos) y Tabla 6.75 (comparación de medias o medianas). En ellas se indica el estadístico de contraste y el p-valor obtenido en cada prueba. En el caso de la fracción de brik no se pudo comprobar la normalidad en la fase 1 porque todos los valores obtenidos para esa fase fueron de 0\% (Tabla 6.73).

Tabla 6.74 Análisis estadístico RAB2-O: comprobación de supuestos

\begin{tabular}{|c|c|c|c|c|c|c|}
\hline \multirow{4}{*}{$\begin{array}{c}\text { Tipo de prueba } \\
\text { Fracción }\end{array}$} & \multicolumn{4}{|c|}{ Test de Shapiro-Wilk } & \multirow{3}{*}{\multicolumn{2}{|c|}{$\begin{array}{c}\text { Test de } \mathbf{F} \\
\text { Comparación de } \\
\text { varianzas }\end{array}$}} \\
\hline & \multicolumn{4}{|c|}{ Bondad de ajuste: Normalidad } & & \\
\hline & \multicolumn{2}{|c|}{ Fase 1} & \multicolumn{2}{|c|}{ Fase 2} & & \\
\hline & $\mathbf{w}$ & p-valor & $\mathbf{w}$ & p-valor & $\mathbf{F}$ & p-valor \\
\hline Fracción orgánica & 0,944 & 0,603 & 0,973 & 0,921 & 0,953 & 0,944 \\
\hline Plástico Film & 0,898 & 0,211 & 0,953 & 0,709 & 2,179 & 0,262 \\
\hline Plástico Rígido & 0,935 & 0,497 & 0,898 & 0,209 & 3,064 & 0,111 \\
\hline Textil & 0,385 & $<0,001$ & 0,366 & $<0,001$ & - & - \\
\hline Metales* & 0,898 & 0,209 & 0,860 & 0,076 & 1,827 & 0,383 \\
\hline Madera & 0,614 & $<0,001$ & 0,366 & $<0,001$ & - & - \\
\hline Brik & - & - & 0,366 & $<0,001$ & - & - \\
\hline Inertes* & 0,898 & 0,206 & 0,915 & 0,317 & 1,468 & 0,577 \\
\hline RTP & 0,422 & $<0,001$ & 0,523 & $<0,001$ & - & - \\
\hline
\end{tabular}




\begin{tabular}{|c|c|c|c|c|c|c|}
\hline \multirow{4}{*}{$\begin{array}{c}\text { Tipo de prueba } \\
\text { Fracción }\end{array}$} & \multicolumn{4}{|c|}{ Test de Shapiro-Wilk } & \multicolumn{2}{|c|}{ Test de $\mathbf{F}$} \\
\hline & \multicolumn{4}{|c|}{ Bondad de ajuste: Normalidad } & \multirow{2}{*}{\multicolumn{2}{|c|}{$\begin{array}{c}\text { Comparación de } \\
\text { varianzas }\end{array}$}} \\
\hline & \multicolumn{2}{|c|}{ Fase 1} & \multicolumn{2}{|c|}{ Fase 2} & & \\
\hline & w & p-valor & w & p-valor & $\mathbf{F}$ & p-valor \\
\hline Vidrio & 0,963 & 0,824 & 0,953 & 0,706 & 1,186 & 0,804 \\
\hline Otros & 0,366 & $<0,001$ & 0,704 & 0,001 & - & - \\
\hline Humedad & 0,956 & 0,745 & 0,944 & 0,597 & 0,413 & 0,204 \\
\hline
\end{tabular}

* Fracciones en las que la transformación de los datos ha mejorado su distribución, aproximándola a la Normal y permitiendo usar pruebas paramétricas con los datos transformados.

Tabla 6.75 Análisis estadístico RAB2-O: comparación de medias entre las dos fases

\begin{tabular}{c|c|c|c|c|}
\hline Test estadístico & \multicolumn{2}{|c|}{$\begin{array}{c}\text { Test t de Student / } \\
\text { Test t de Welch }\end{array}$} & \multicolumn{2}{c}{ Test de Wilcoxon } \\
\hline Tipo de prueba & \multicolumn{2}{c|}{$\begin{array}{c}\text { Comparación de } \\
\text { medias }\end{array}$} & \multicolumn{2}{c}{$\begin{array}{c}\text { Comparación de } \\
\text { medianas }\end{array}$} \\
\hline Fracción & $\mathbf{t}$ & p-valor & W & p-valor \\
\hline Fracción orgánica & 0,059 & 0,954 & - & - \\
\hline Plástico Film & 1,782 & 0,092 & - & - \\
\hline Plástico Rígido & 1,963 & 0,065 & - & - \\
\hline Textil & - & - & 61,5 & 0,234 \\
\hline Metales & 0,800 & 0,434 & - & - \\
\hline Madera* & - & - & 60,5 & 0,280 \\
\hline Brik & - & - & 45 & 0,368 \\
\hline Inertes & 0,575 & 0,573 & - & - \\
\hline RTP & - & - & 54 & 0,728 \\
\hline Vidrio* & $-0,634$ & 0,534 & - & - \\
\hline Otros & - & - & 34 & 0,124 \\
\hline Humedad & $-1,695$ & $-1,695$ & - & - \\
\hline
\end{tabular}

* Fracciones en las que la transformación de los datos ha mejorado su distribución, aproximándola a la Normal y permitiendo usar pruebas paramétricas con los datos transformados.

En el caso de RAB2-O, los resultados del análisis estadístico muestran que no existen diferencias significativas en función de la fase para ninguna fracción, ya que todos los $p$-valor obtenidos son mayores a 0,05 (Tabla 6.75). Así pues, se puede afirmar que la época del año no influye en su composición.

En cuanto a la humedad, tampoco se han observado diferencias estadísticamente significativas entre las dos fases ( $p$-valor $>0,05$ ) (Tabla 6.75). Esto es consecuencia de que este material ya está completamente seco y estabilizado.

Por lo tanto, se puede concluir que la propuesta de no estratificar la producción de este rechazo en función de la estacionalidad es correcta, puesto que sus propiedades no cambian en función de la época del año. 


\subsection{CONCLUSIONES}

El plan de muestreo para el control de calidad de los rechazos desarrollado en el presente capitulo está formado por tres etapas: la primera es la determinación del tamaño mínimo de muestra, la segunda es la determinación del número de muestras necesarias y la tercera son las directrices para el correcto muestreo y caracterización de los rechazos.

En la primera etapa se propone y desarrolla una metodología para determinar el tamaño mínimo de muestra más adecuado a las características de las diferentes corrientes de rechazo que se generan en una planta de TMB. En la actualidad no existe ninguna que se adapte a la naturaleza de este material. Partiendo de un tamaño de muestra inicial, se propone un procedimiento de división de dicho tamaño que permite obtener datos de composición de los rechazos para diferentes pesos de muestra (niveles de submuestreo). Los resultados obtenidos para cada nivel se comparan estadísticamente de forma que se determina el tamaño de muestra mínimo con el que se obtienen resultados representativos. Esta metodología está formada por 4 pasos donde se expone el procedimiento que se debe seguir para su aplicación a cualquier planta de TMB.

En la segunda etapa se propone y desarrolla una metodología para el cálculo del número mínimo de muestras necesarias para el control de calidad de la producción anual de rechazo de una planta de TMB. Esta metodología se basa en la estratificación de la producción anual de rechazo en diferentes estratos en función de unos niveles de variación (mensual, semanal y diario), los cuales están relacionados con las variables responsables de la variabilidad temporal de las propiedades de los rechazos. La metodología se divide en cuatro pasos donde se describe el procedimiento para su aplicación a cualquier instalación de este tipo. Finalmente, se propone una fórmula que permite calcular de forma sencilla el número mínimo de muestras que se repartirán entre los estratos en los que se divide la producción.

Por último, el plan de muestreo también incluye una serie de recomendaciones que se deben de tener en cuenta a la hora de llevar a cabo del muestreo y caracterización de los rechazos en plantas de TMB. Estas incluyen aspectos como: equipamiento de protección individual, material de trabajo, consideraciones para la programación de las caracterizaciones, localización y condiciones para realizar las caracterizaciones y casos especiales en la clasificación de los materiales.

El plan de muestreo desarrollado puede aplicarse a cualquier tipo de planta de TMB, adaptándose a las características específicas de la instalación donde vaya a ser implementado. Mediante su aplicación se consigue obtener el tamaño y el número de muestras necesarias para llevar a cabo el control y seguimiento de calidad de sus rechazos, lo que facilitará la transformación de dichos rechazos en un CSR fiable, comercializable y que cumpla los estándares definidos por la normativa europea para estos combustibles.

Por otra parte, en este capítulo se presenta la aplicación de la metodología para la determinación del tamaño de muestra (primera etapa del plan de muestreo) en la planta de recuperación y compostaje de Onda y en la planta de biosecado y recuperación de Cervera del Maestre.

De forma general se puede concluir que esta metodología ha podido ser implementada completamente en las dos plantas de TMB, adaptándose a los diversos tipos de rechazos generados en cada una de ellas y permitiendo determinar el tamaño mínimo de muestra necesario para su control de calidad. En base a los resultados obtenidos en los dos casos de aplicación, se ha comprobado que los pesos de muestra determinados mediante la metodología propuesta son menores a los que se obtienen a partir de la norma de muestreo de los CSR (tamaño de muestra inicial) o a los recomendados en la mayoría de las metodologías de RSU (100 kg), las cuales no se ajustan a las propiedades específicas de los rechazos. Por lo tanto, su aplicación y utilización en el control de calidad de esos materiales permite minimizar el coste y la carga de trabajo necesarios. Además, estos pesos de muestra también pueden ser utilizados para determinar la composición física de los rechazos.

Respecto a la PRC de Onda, para el rechazo de recuperación de materiales y aplicando la norma UNE-EN 15442 (2012) de CSR, se obtiene que serían necesarios un mínimo $60 \mathrm{~kg}$ para el control de calidad. Tras la aplicación de metodología este tamaño se reduce a $7,5 \mathrm{~kg}$, lo que supone una disminución del $87,5 \%$. En el caso del rechazo de afino primario del bioestabilizado, el tamaño de muestra según norma sería de $1 \mathrm{~kg}$, el cual se reduce a la mitad con un peso mínimo de 0,5 kg. Para el rechazo de afino secundario el tamaño calculado mediante la norma de CSR coincide con el tamaño de muestra determinado: 0,4 kg. 
En cuanto a la PBSR de Cervera, para el rechazo de recuperación de materiales del biosecado, aplicando la norma de los CSR sería necesario un peso mínimo de $60 \mathrm{~kg}$ para el control de su calidad. No obstante, una vez aplicada la metodología propuesta este tamaño se reduce a $3,75 \mathrm{~kg}$, disminuyendo en un $93,75 \%$. En el caso del rechazo de afino primario del biosecado, el peso calculado según norma es de $2 \mathrm{~kg}$, el cual se reduce a un cuarto con un tamaño mínimo de $0,5 \mathrm{~kg}$. Para el rechazo de afino secundario del biosecado el tamaño se reduce un cuarto pasando de $0,3 \mathrm{~kg}$ a $0,075 \mathrm{~kg}$.

Tras la aplicación de la metodología a las dos plantas de TMB se ha observado que existen diferencias entre los tamaños mínimos de muestra necesarios para la caracterización de los rechazos en función del tipo de instalación. Esto se debe a que el proceso de tratamiento y las tecnologías utilizadas en cada planta son muy diferentes y, como consecuencia, los rechazos generados tienen una composición y características distintas (por ejemplo, tamaños de partícula diferentes). Por tanto, a la hora de implementar la metodología, es necesario estudiar cada instalación y corriente de rechazo por separado.

Adicionalmente, se ha establecido que existe una relación exponencial entre el tamaño de partícula (d95) de los rechazos y el peso mínimo de muestra determinado $\left(\mathrm{mf}_{\mathrm{f}}\right)$ en las dos plantas estudiadas. Esto ha permitido obtener dos ecuaciones, una para cada instalación, a partir de las cuales se puede calcular el tamaño de muestra necesario para el control de calidad de cualquier otra corriente de rechazo que se genere en las mismas sin tener que aplicar de nuevo toda la metodología.

Por otra parte, también se ha calculado el tiempo invertido en el procedimiento de división de muestra y caracterización de cada una de las corrientes de rechazo estudiadas, el cual depende de tamaño de muestra de cada nivel de submuestreo y del tamaño de partícula del material. A partir de estos datos se ha realizado una comparación entre el tiempo necesario para la caracterización de los seis rechazos analizados si se utiliza el tamaño de muestra determinado a partir de la metodología propuesta, o si se utiliza el peso de muestra calculado con la norma del CSR. Esto ha confirmado el ahorro de en tiempo que supone la utilización de los tamaños determinados respecto al uso de otras metodologías que no están adaptadas a la naturaleza de los rechazos, con todas las ventajas económicas que esto conlleva. Por ejemplo, en el caso del rechazo de recuperación de la PRC de Onda esto supondría un ahorro de 3 horas y 13 minutos de trabajo y en el rechazo de recuperación de materiales del Cervera de otras 3 horas y 11 minutos.

Respecto a la metodología propuesta para determinar el número de muestras necesarias para el control de calidad de la producción anual de rechazo (segunda etapa del plan de muestreo) también se ha realizado un caso de aplicación a la PRC de Onda. A partir de la información proporcionada por los responsables de la empresa se determinó que existen tres rechazos distintos susceptibles de convertirse en CSR. Además de que, para el rechazo de recuperación de materiales y el de afino primario del bioestabilizado, la producción debe dividirse en dos estratos en función de la estacionalidad (nivel de variación mensual), mientras que para el rechazo de afino secundario del bioestabilizado no existe estratificación. Con estos datos se determinó que era necesario tomar al menos 50 muestras al año para el control de calidad de los tres rechazos de la PRC de Onda: 20 para el de recuperación de materiales, 20 para el de afino primario y 10 para el de afino secundario. Estas muestras se deben de repartir entre los estratos en los que se divide la producción anual de cada corriente de rechazo.

Una vez determinado el número mínimo de muestras se procedió a validar la metodología. Respecto a la identificación y diferenciación de los tres rechazos, se ha observado que cada uno de ellos tiene una composición y humedad distinta. En cuanto a la estratificación, en base a los resultados obtenidos se puede concluir que es correcta.

Finalmente, los resultados obtenidos experimentalmente han servido a las empresas responsables de las plantas de TMB para conocer las características de sus rechazos y las posibilidades de producir un CSR a partir de los mismo. Por otra parte, también han servido para llevar a cabo los 4 proyectos de investigación mencionados en el apartado de financiación.

\subsection{REFERENCIAS}

Aldrian, A., Sarc, R., Pomberger, R., Lorber, K.E., Sipple, E.M., 2016. Solid recovered fuels in the cement industry - Semi-automated sample preparation unit as a means for facilitated practical application. Waste Manag. Res. 34, 254-264. https://doi.org/10.1177/0734242X15622816 
ASTM D5231-92, 1992. Standard Test Method for Determination of the composition of Unprocessed Municipal solid Waste. ASTM: American Society for Testing and Materials, USA.

Burnley, S.J., Ellis, J.C., Flowerdew, R., Poll, a. J., Prosser, H., 2007. Assessing the composition of municipal solid waste in Wales. Resour. Conserv. Recycl. 49, 264-283. https://doi.org/10.1016/j.resconrec.2006.03.015

Dahlén, L., Lagerkvist, A., 2008. Methods for household waste composition studies. Waste Manag. 28, 1100-1112. https://doi.org/10.1016/j.wasman.2007.08.014

Edjabou, M.E., Jensen, M.B., Götze, R., Pivnenko, K., Petersen, C., Scheutz, C., Astrup, T.F., 2015. Municipal solid waste composition: Sampling methodology, statistical analyses, and case study evaluation. Waste Manag. 36, 12-23. https://doi.org/10.1016/j.wasman.2014.11.009

European Commision, 2004. Methodology for the Analysis of Solid Waste (SWA-Tool).

Flamme, S., Geiping, J., 2014. Quality assurance of solid recovered fuels (SRF). ZKG Int. 67, 54-57.

Flamme, S., Geiping, J., 2012. Quality standards and requirements for solid recovered fuels: a review. Waste Manag. Res. 30, 335-53. https://doi.org/10.1177/0734242X12440481

Gallardo, A., Carlos, M., Colomer, F.J., Edo-Alcón, N., 2018. Analysis of the waste selective collection at drop-off systems: Case study including the income level and the seasonal variation. Waste Manag. Res. 36, 30-38. https://doi.org/10.1177/0734242X17733539

Garcés, D., Díaz, E., Sastre, H., Ordóñez, S., González-LaFuente, J.M., 2016. Evaluation of the potential of different high calorific waste fractions for the preparation of solid recovered fuels. Waste Manag. 47, 164-173. https://doi.org/10.1016/j.wasman.2015.08.029

Klee, A.J., 1993. New approaches to estimation of solid-waste quantity and composition. J. Environ. Eng. $119,248-261$.

Lebersorger, S., Schneider, F., 2011. Discussion on the methodology for determining food waste in household waste composition studies. Waste Manag. 31, 1924-1933. https://doi.org/10.1016/j.wasman.2011.05.023

Mccauley-bell, B.P., Reinhart, D.R., Member, Z., Sfeir, R., Ryan, B.O.T., 1997. MUNICIPAL SOLID WASTE COMPOSITION STUDIES 8 By Pamela McCauley-Bell,! Debra R. Reinhart,Z Member, ASCE, Rala Sfeir,3 and Brigid O'Toole Ryan 4 1, 158-163.

NT ENVIR 001, 1995. Nordtest method NT ENVIR 001. Solid waste, municipal: sampling and characterisation. Nordtest: Nordic Innovations Center, Finland.

Parfitt, J., Griffiths, P., Reid, T., 2015. Guidance on the Methodology for Waste Composition Analysis: Waste Composition Analysis For local authorities commissioning waste composition analysis of municipal waste. Zero Waste Scotland, Scotland.

Pehlken, A., Von Blottnitz, H., Pretz, T., 2000. Requirements for the sampling of residual waste - Approach to developing a new sampling model. Aufbereit. Tech. 41, 409-415.

Petersen, L., Dahl, C.K., Esbensen, K.H., 2004. Representative mass reduction in sampling - A critical survey of techniques and hardware. Chemom. Intell. Lab. Syst. 74, 95-114. https://doi.org/10.1016/j.chemolab.2004.03.020

Petersen, L., Minkkinen, P., Esbensen, K.H., 2005. Representative sampling for reliable data analysis: Theory of Sampling. Chemom. Intell. Lab. Syst. 77, 261-277. https://doi.org/10.1016/j.chemolab.2004.09.013

Sahimaa, O., Hupponen, M., Horttanainen, M., Sorvari, J., 2015. Method for residual household waste composition studies. Waste Manag. 46, 3-14. https://doi.org/10.1016/j.wasman.2015.08.032

Scott, P.E., 1995. The International Energy Agency's (IEA) work in harmonising sampling and analytical protocols related to municipal solid waste (MSW) conversion to energy. Biomass and Bioenergy 9, 415-439. https://doi.org/10.1016/0961-9534(95)00108-5

Sharma, M., McBean, E., 2007. A methodology for solid waste characterization based on diminishing marginal returns. Waste Manag. 27, 337-344. https://doi.org/10.1016/j.wasman.2006.02.007 
UNE-EN 15414-3, 2011. Combustibles Sólidos Recuperados: Determinación del contenido en humedad por el método de secado en estufa. Parte 3: Humedad de la muestra para análisis general. AENOR, Asocición Española de Normalizaciónj y Certificación, Madrid.

UNE-EN 15415-1, 2012. Combustibles sólido recuperados: Determinación de la distribución de tamaño de partícula. Parte 1: Método del tamiz para partículas pequeñas. AENOR, Asocición Española de Normalizaciónj y Certificación, Madrid.

UNE-EN 15415-2, 2012. Combustibles sólidos recuperados: Deteminación de la distribución de tamaño de partícula. Parte 2: Método (manual) de la longitud máxima proyectada para particulas de grandes dimensiones. AENOR, Asocición Española de Normalizaciónj y Certificación, Madrid.

UNE-EN 15442, 2012. Combustibles sólidos recuperados: Métodos de muestreo. AENOR, Asocición Española de Normalizaciónj y Certificación, Madrid. 

$\begin{array}{llll}0 & 0 & 0 & 0 \\ 0 & 0 & 0 & 0 \\ 0 & 0 & 0 & 0\end{array}$

CAPÍTULO 7

PREPARACIÓN DE MUESTRAS DE RECHAZO

EN EL LABORATORIO PARA EL ANÁLISIS DE LOS PARÁMETROS DE CALIDAD 



\subsection{INTRODUCCIÓN}

Dentro del proceso de control de calidad de los rechazos, tras la selección de la muestra en la planta de TMB, es necesario analizar en el laboratorio los parámetros que definen su calidad como CSR. Estos se han identificado en el capítulo 4 de la presente tesis y son el poder calorífico inferior ( $\mathrm{PCl}$ ), el contenido en cloro (Cl) y el contenido en mercurio (Hg). Para ello es indispensable transformar la muestra tomada en la propia planta de tratamiento en una muestra de laboratorio, sobre la que se realizarán los análisis químicos necesarios para determinar dichos parámetros.

En la química analítica moderna, los equipos de medición requieren una masa de muestra para el análisis muy pequeña (menor o igual a un gramo) y con un diámetro de partícula por debajo un $1 \mathrm{~mm}$, por lo que es necesario reducir la muestra inicial tomada en la planta de tratamiento a una muestra de laboratorio con un tamaño adecuado. En el caso de los rechazos, esta etapa es de suma importancia debido a su gran heterogeneidad, puesto que los resultados analíticos obtenidos se refieren a una cantidad muy pequeña de material que debe ser representativa del material original. Por ejemplo, en la Figura 7.1 se observa la diferencia de tamaño entre la muestra tomada en planta y la muestra de análisis para el $\mathrm{PCl}$.
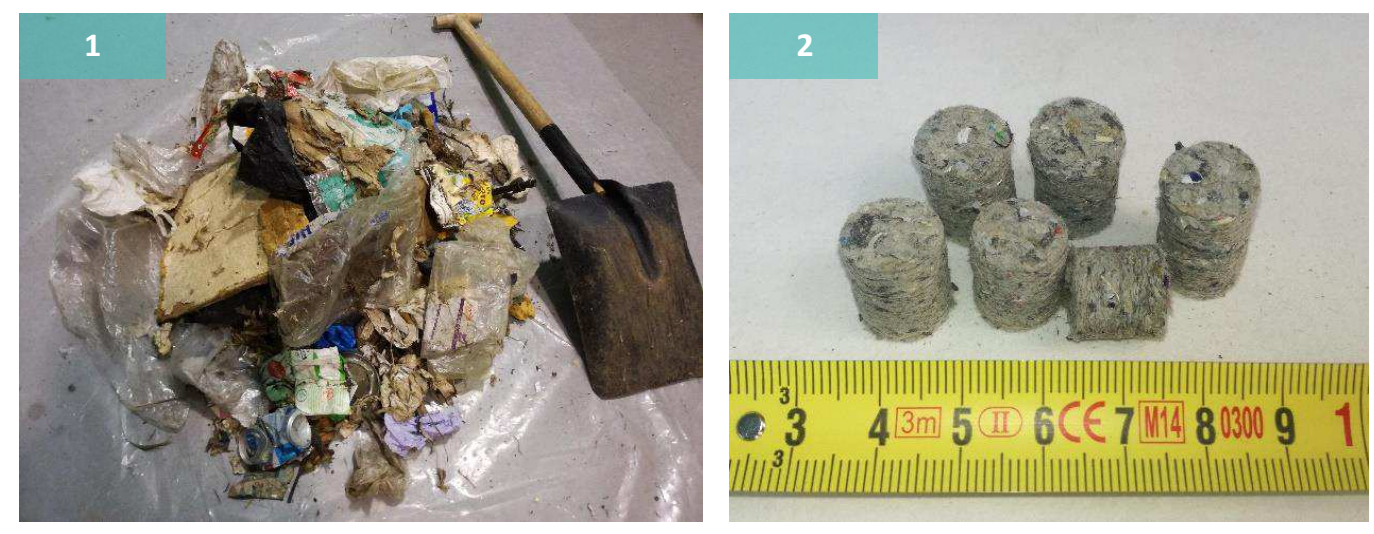

Figura 7.1 Muestra tomada en una planta de TMB (1); pellets de 1 gramo para el análisis del PCI

Cabe señalar que, a pesar de llevar a cabo una correcta preparación de muestra de laboratorio, todavía pueden aparecer variaciones en la composición de las diferentes muestras de análisis y, como consecuencia, los resultados obtenidos pueden ser distintos. Por ejemplo, si una partícula de PVC entra en la muestra a analizar, esta afectará al resultado del análisis de $\mathrm{Cl}$, obteniéndose un valor superior al real y que no es representativo de rechazo original del que se tomó la muestra. Por lo que, los valores individuales nunca serán utilizados para evaluar la calidad del rechazo, si no que será necesario analizar diferentes réplicas de una misma muestra de manera que se obtenga un valor medio que se comparará con el valor límite (Flamme and Geiping, 2014, 2012).

Respecto a la normativa existente para la preparación de muestras de laboratorio, los CSR cuentan con una norma específica para ello, se trata de la norma UNE-EN 15443 (2011) "Combustibles sólidos recuperados: Métodos para la preparación de la muestra de laboratorio". En ella se especifican los procedimientos necesarios para la reducción de las muestras combinadas a muestras de laboratorio. No obstante, Aldrian et al. (2016) observaron que para CSR muy heterogéneos y con tamaños de partícula elevados, como podrían ser los rechazos del TMB, esta norma no es adecuada; puesto que en su trabajo de investigación, con el tamaño de muestra de laboratorio que determinaron a partir de dicha norma, no obtuvieron resultados representativos. Por otro lado, la norma recomienda que se lleve a cabo una primera reducción del tamaño de partícula de la totalidad de la muestra original a un tamaño de $30 \mathrm{~mm}$ (o un diámetro lo más parecido posible) para su posterior división. Sin embargo, en el caso de los rechazos esto requiere mucho trabajo (sobre todo cuando no se dispone de una trituradora industrial), ya que los tamaños mínimos de muestra necesarios son elevados $y$, por tanto, es necesario triturar una gran cantidad de material. Además, la 
reducción de tamaño para materiales muy heterogéneos y con un alto contenido en plástico, como los rechazos del TMB, con frecuencia es más complejo y requiere un gran esfuerzo (Rotter et al., 2011; Smidt et al., 2008). Por todo ello, esta norma no es aplicable a los rechazos del TMB.

Así pues, el objetivo principal del presente capítulo es establecer un método de preparación de muestras para el análisis de los parámetros de calidad en los rechazos de plantas de TMB. Para ello, en primer lugar, se ha propuesto un procedimiento para la preparación de muestra de laboratorio aplicable al control de calidad de los rechazos. En él se describen las distintas etapas que conforman la preparación de muestras y los métodos que se deben utilizar en cada una de ellas.

En segundo lugar, se ha determinado el tamaño de muestra de laboratorio con el que se obtienen resultados representativos en los análisis de $\mathrm{PCl}$, cloro y mercurio. Para ello se ha analizado una muestra de referencia y 15 muestras de laboratorio de distintos pesos, las cuales se obtienen mediante diferentes procedimientos de preparación de muestra, en concreto de división mediante cuarteo y de reducción de tamaño de partícula mediante corte.

Finalmente, se ha determinado el tiempo óptimo para el correcto secado de las muestras de rechazo. Para ello se han estudiado cuatro tipos de rechazo con origen y composición distinta y tres corrientes intermedias del TMB, monitorizando su proceso de secado. Además, el material de cada rechazo fue dividido en varias categorías de tamaño diferentes con el objetivo de conocer si hay diferencias en el tiempo de secado en función del tamaño de partícula.

La estructura que sigue el capítulo se presenta en la Figura 7.2, así como la información de partida necesaria para el desarrollo del mismo.

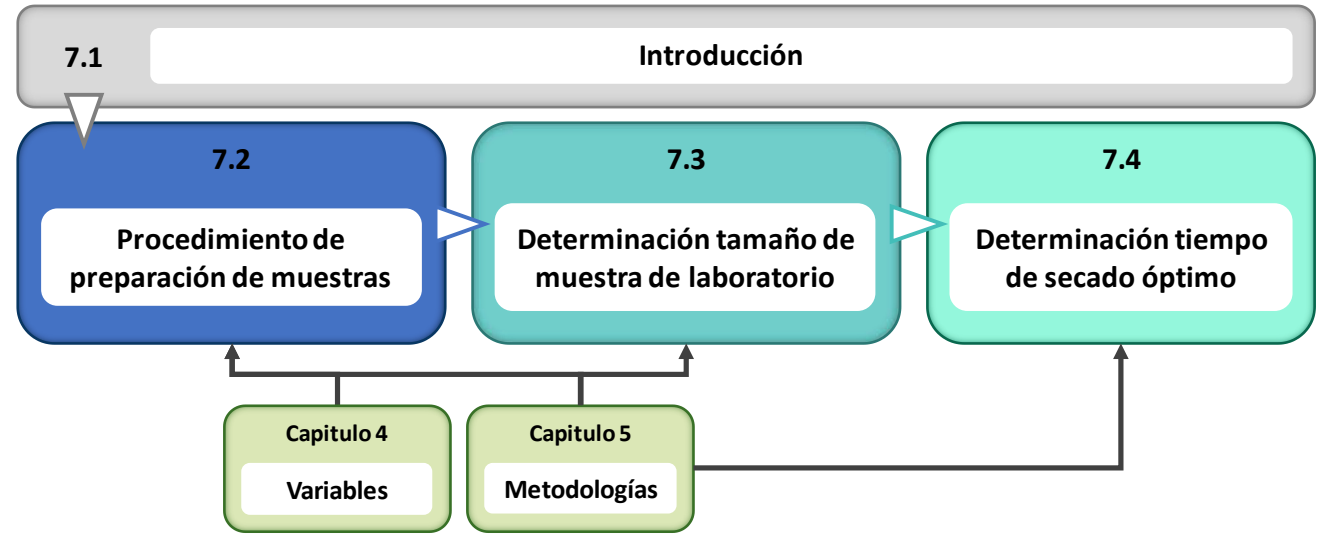

Figura 7.2 Estructura del Capítulo 7

\subsection{PROCEDIMIENTO PARA LA PREPARACIÓN DE MUESTRA PARA EL CONTROL DE CALIDAD DE LOS RECHAZOS DE LAS PLANTAS DE TMB}

Según la norma UNE-EN 15443 (2011) en una correcta preparación de muestra se deben cumplir tres requisitos:

- La composición de la muestra seleccionada in situ no se modifica significativamente durante los diferentes pasos.

- La muestra de laboratorio obtenida satisface las necesidades de las técnicas de análisis que vayan a realizarse.

- Cada partícula de la muestra original tiene la misma probabilidad de ser incluida en la muestra de laboratorio.

El objetivo de este apartado es proponer un procedimiento que cumpla con los requisitos anteriores y que permita obtener muestras de laboratorio representativas, el cual se ha dividido en dos etapas: 
- Recomposición de una muestra inicial representativa

- Preparación de muestra de laboratorio

\subsubsection{Recomposición de una muestra inicial representativa}

Esta etapa tiene como objetivo la obtención de una muestra de menor tamaño a partir de la muestra tomada de la corriente de rechazo en planta sin perder representatividad. Esto facilitará la preparación de muestras de laboratorio en la segunda etapa, puesto que no será necesario trabajar con cantidades de materiales tan grandes. Para ello se propone un procedimiento muy sencillo que está basado en la metodología utilizada por la empresa Suez Advanced Solutions Spain para la caracterización de RSU y que ha sido revisada en el capítulo 5.

Así pues, una vez seleccionada la muestra en planta, esta se clasificará manualmente para determinar su composición en las 13 categorías definidas en el capítulo 6 (Tabla 6.3). A continuación, se recompondrá una muestra de $2 \mathrm{~kg}$. Los materiales para cada fracción se deben seleccionar de aleatoriamente, de forma que cada partícula tenga la misma probabilidad de ser incluida en la muestra. Además, este procedimiento cumple el requisito de que la composición de la muestra seleccionada in situ no se modifica.

Cabe señalar que, para aquellos rechazos cuyo tamaño mínimo de muestra sea menor a dos kilogramos no será necesario realizar esta recomposición, sino que la propia muestra se utilizara en la siguiente etapa.

\subsubsection{Preparación de muestra de laboratorio}

Esta etapa tiene como objetivo obtener una muestra final de laboratorio a partir de la muestra recompuesta de $2 \mathrm{~kg}$, se ha dividido en los siguientes pasos:

1. Reducción de tamaño de partícula mediante corte, trituración o molienda

2. Homogeneización y mezclado

3. División de la muestra

4. Secado

5. Eliminación de materiales no combustibles

6. Trituración final

El objetivo de la reducción del tamaño de partícula es disminuir el d d $_{5}$ del material y, por tanto, su heterogeneidad de constitución (como se ha visto en el capítulo 4), haciendo la muestra más homogénea. De esta manera se consigue reducir el tamaño de la muestra sin perder representatividad. Para ello se pueden utilizar diferentes métodos o procedimientos:

- Trituración/molienda: consiste en triturar o moler las piezas grandes del rechazo mediante la utilización de una trituradora o molino.

- Corte: consiste en disminuir el tamaño de las partículas de forma manual con tijeras.

- Trituración o corte por congelación: procedimiento recomendable para materiales con un contenido muy elevado en plástico. Consiste en congelar la muestra sumergiéndola durante 10 minutos en nitrógeno líquido, para posteriormente triturarla/cortarla con un equipo apropiado o romperla manualmente con un martillo. Además, este procedimiento se puede mejorar congelando la muestra antes de la utilización del nitrógeno líquido y/o mezclado hielo seco $\left(\mathrm{CO}_{2}\right.$ en estado sólido) con la muestra a la hora de introducir el material en el equipo de trituración o corte (Riber et al., 2007).

La homogeneización tiene como objetivo minimizar la heterogeneidad de distribución (capitulo 4), la cual es consecuencia de la distribución espacial de las partículas en la muestra de forma segregada o estratificada en función de su tamaño o densidad. El mezclado del material se puede realizar de forma mecánica o manual. 
La finalidad de la división de muestra es disminuir la masa de la muestra una vez se ha llevado a cabo la reducción del tamaño de partícula y el mezclado del material, de forma que se obtenga una muestra más pequeña pero que, a su vez, sea representativa. Para lograrlo se pueden utilizar diferentes métodos o procedimientos:

- División manual por cuarteo: consiste en distribuir la muestra formando un círculo sobre una superficie plana y limpia, mediante una pala se mezcla el material y se le da forma de cono. A continuación, se divide el montón en cuatro cuartos de la misma forma y tamaño. Finalmente se descartan dos cuartos opuestos y se mezcla adecuadamente el resto de la muestra. Esta secuencia se repite hasta alcanzar el tamaño de muestra de laboratorio necesario.

- Divisor de rifle: se trata de una caja con un número par de canales adyacentes (normalmente 16 o más), cuya anchura debe ser al menos 3 veces el d95 del material, de forma que este pase a través de los mismos sin formar puentes. Cada uno de estos canales conducen a dos depósitos receptores diferentes. El material se esparce uniformemente a lo largo de la línea centran de los canales, separándolo en dos submuestras. Uno de los depósitos se descarta y el proceso se repite hasta alcanzar el tamaño de muestra requerido.

- Divisor rotatorio: consisten en una tolva de alimentación cuya boquilla giratoria vierte la muestra sobre una serie de tolvas radiales que desembocan en dos depósitos receptores diferentes. Otra configuración que puede darse es que la boquilla sea fija, mientras que los depósitos radiales sean los que roten. La dimensión de la boquilla debe ser al menos tres veces el d95 del material.

- División mediante pila longitudinal o en banda: en este método, toda la muestra se esparce en una superficie limpia y plana, mezclándose completamente. Mediante una pala se distribuye uniformemente el material a lo largo de una banda formando una pila, cuya relación entre la longitud y la anchura debe de ser mayor o igual a 10:1. Para tomar la muestra de laboratorio se seleccionan varios incrementos a lo largo de la longitud de la pila de forma aleatoria. Estos incrementos se delimitan con dos placas perpendiculares a la pila, retirando todo el material entre ellas. Las dos placas se colocan siempre a la misma distancia para que todos los incrementos tengan el mismo tamaño.

- División por paleo alternativo: la muestra se divide paleando todo el material de forma alternativa en dos pilas diferentes. A continuación, se elige aleatoriamente una pila y la otra se descarta. Este procedimiento se repite tantas veces como sea necesario para alcanzar el tamaño de muestra requerido.

El tamaño de muestra de laboratorio que se debe alcanzar en este paso es uno de los principales aspectos en la preparación de la muestra. En el apartado 7.3 se propone una metodología para su determinación.

Tras la división, se debe proceder al secado de la muestra de laboratorio obtenida, la cual es representativa del material original. La finalidad del secado es eliminar toda el agua que contiene el rechazo y que puede interferir en los análisis posteriores, puesto que todos ellos se realizan sobre materia seca. La técnica de secado se debe seleccionar con el fin de minimizar las pérdidas de compuestos volátiles y los cambios en las propiedades de los materiales (por ejemplo, el fundido del plástico), además de evitar el riesgo de autoignición del material.

A continuación, se deben eliminar los materiales no combustibles con el objetivo de facilitar el triturado final del material, así como el análisis químico de la muestra. Esta separación se llevará a cabo de forma manual extendiendo toda la muestra sobre una superficie limpia. El peso de los materiales no combustibles separados debe quedar registrados con el objetivo de que se pueda calcular los resultados analíticos en relación al material combustible, así como al total del material.

El último paso de la preparación de muestra de laboratorio consiste en la trituración final del material a un tamaño de partícula menor a un milímetro, o menos si la técnica analítica lo requiere. Para ello se pueden utilizar cualquiera de los procedimientos descritos anteriormente para la reducción de tamaño. De esta forma se obtiene la muestra de laboratorio que es representativa de la muestra de rechazo original y que satisface las necesidades de las técnicas analíticas que vayan a utilizarse. A partir de la misma se obtendrán las diferentes muestras de análisis para la determinación de los parámetros que definen la calidad $(\mathrm{PCl}, \mathrm{Cl}$ y $\mathrm{Hg})$. 
Cabe señalar que en algunas ocasiones, por razones técnicas, económicas o prácticas puede necesitarse varios pasos de preparación de muestra (Riber et al., 2007), cada uno de ellos incluirán siempre la reducción de tamaño de partícula, la homogeneización y la división de muestra.

\subsection{DETERMINACIÓN DEL TAMAÑO DE MUESTRA DE LABORATORIO}

El objetivo que persigue este apartado es, por un lado, la determinación del tamaño de muestra de laboratorio que se debe alcanzar utilizado en el procedimiento de preparación de muestra. Por otro lado, establecer los procedimientos de reducción del tamaño de partícula y división de muestra más adecuados para lograr dicho tamaño.

\subsubsection{Metodología experimental}

La metodología para la consecución del objetivo de ese apartado se divide en los siguientes puntos:

1. Diseño de las muestras de rechazo artificial

2. Reducción del tamaño de partícula

3. Diseño del experimento

4. Análisis químico de los parámetros de calidad

5. Determinación del tamaño de muestra de laboratorio

\subsubsection{Diseño de las muestras de rechazo artificial}

El tipo de rechazo que se ha decidido analizar para determinar el tamaño de muestra corresponde al generado en la etapa de recuperación de materiales de una planta TMB, puesto que en esta corriente es donde la diferencia entre el tamaño mínimo de muestra y el peso de muestra de análisis es mayor y, por tanto, más difícil es obtener una muestra de laboratorio representativa. Además, estos rechazos son muy heterogéneos y están formados por diferentes materiales (mayoritariamente papel/cartón, diferentes tipos de plásticos, materia orgánica y textil) con un alto grado de suciedad.

Para poder determinar el tamaño de muestra de laboratorio se han diseñado una serie muestras de rechazo artificiales a partir de la mezcla de componentes o materiales "limpios" utilizando una composición real de referencia, la cual fue publicada por Gallardo et al. (2014) y corresponde a un rechazo de recuperación de una PRC española. La utilización de materiales limpios permite que las muestras de partida tengan la misma composición y propiedades (por ejemplo, mismos tipos de plásticos, fracción orgánica, etc.). Como consecuencia, tras aplicar los procedimientos de reducción de tamaño de partícula y división de muestra, los resultados obtenidos para cada tamaño de muestra de laboratorio podrán ser comparados estadísticamente, de forma que si existen diferencias significativas se pueda afirmar que estas se deben a que la muestra de laboratorio obtenida no es representativa. Esto no sería posible en si se usaran muestras reales, puesto que la variabilidad de los resultados analíticos puede ser bastante alta debido a la propia heterogeneidad de los rechazos (Sarc and Lorber, 2013), siendo incluso mayor a la variabilidad introducida por procedimiento de preparación. Además, esta estrategia también fue adoptada por Petersen et al. (2004) a la hora de comparar diferentes métodos para la reducción de masa y por Schwarzböck et al. (2016) para estudiar el efecto de la preparación de muestra en la determinación del contenido en biomasa de los CSR.

La composición de referencia usada para formar las muestras de rechazo artificial se muestra en la Tabla 7.1, así como los materiales limpios utilizados para cada una de las fracciones. Estas muestras deberán de tener un peso de $2 \mathrm{~kg}$, que corresponde al de la muestra recompuesta de la primera etapa de la preparación de muestras para el control de calidad de los rechazos. 
Tabla 7.1 Composición de referencia para el diseño de las muestras de rechazo artificial (Gallardo et al., 2014) y materiales limpios utilizados

\begin{tabular}{|c|c|c|c|}
\hline \multicolumn{2}{|c|}{ Fracción } & $\begin{array}{l}\text { Composición } \\
\text { (\%) }\end{array}$ & Residuos limpios utilizados \\
\hline \multicolumn{2}{|c|}{ Fracción orgánica } & 16,84 & Pan (30\%), restos de sandía (30\%) y restos de poda $(40 \%)$ \\
\hline \multicolumn{2}{|c|}{ Papel/Cartón } & 32,15 & $\begin{array}{l}\text { Cartón grueso }(33 \%) \text {, cartón fino }(6 \%) \text {, papel absorbente } \\
(10 \%) \text {, folios }(33 \%) \text {, periódico }(10 \%) \text { y folletos }(8 \%)\end{array}$ \\
\hline \multirow{6}{*}{ Plásticos } & PEBD & 12,17 & $\begin{array}{l}\text { Bolsas de basura, bolsas de un solo uso, bolsas } \\
\text { transparentes y otras bolsas de PEBD }\end{array}$ \\
\hline & PET & 3,06 & Botellas de agua \\
\hline & PEAD & 2,40 & Botellas de leche y tapones \\
\hline & PP & 1,05 & Bolsas de PP, tapas, tapones y enveses rígidos de PP \\
\hline & PS & 1,01 & $\begin{array}{l}\text { Envases de yogurt, envases de queso fresco y cucharas de } \\
\text { un solo uso }\end{array}$ \\
\hline & Otros & 2,47 & $\begin{array}{l}\text { Perchas, juguetes, pinzas, polietileno expandido, trozos de } \\
\text { plástico no identificados }\end{array}$ \\
\hline \multicolumn{2}{|c|}{ Textil } & 7,91 & Retales de camisas, toallitas y cinturón de tela \\
\hline \multirow{3}{*}{ Metales } & Férricos & 3,28 & Latas atún, muelles y alambre \\
\hline & No férricos & 0,81 & Latas de refresco \\
\hline & Papel Al & 0,30 & Bolas de papel de aluminio \\
\hline \multicolumn{2}{|c|}{ Madera } & 3,25 & Trozos de madera de una carpintería \\
\hline \multicolumn{2}{|c|}{ Brik } & 2,03 & Envases de brik \\
\hline \multicolumn{2}{|c|}{ Inertes } & 1,42 & Piedras y tierra \\
\hline \multicolumn{2}{|c|}{ RTP } & 0,15 & Medicamentos y sus envases \\
\hline \multicolumn{2}{|c|}{ Vidrio } & 1,13 & Trozos de vidrio \\
\hline \multicolumn{2}{|c|}{ Celulosa sanitaria } & 4,23 & Pañales y compresas \\
\hline \multicolumn{2}{|c|}{ Zapatos } & 1,41 & Chancleta \\
\hline \multicolumn{2}{|c|}{ Goma y cuero } & 0,60 & Cinturón y guantes de látex \\
\hline \multicolumn{2}{|c|}{ Otros } & 2,29 & $\begin{array}{c}\text { Cargador móvil, auriculares, estropajo, peluche, espuma, } \\
\text { alfombrilla ratón }\end{array}$ \\
\hline
\end{tabular}

El tamaño nominal superior de las muestras artificiales tiene que ser lo más parecido posible a los de una muestra real. Para comprobarlo se determinará el d95 mediante la norma UNE-EN 15415-2 (2012).

\subsubsection{Reducción del tamaño de partícula}

Los rechazos generados en la etapa de recuperación son materiales muy heterogéneos con un amplio rango de tamaños de partícula que, como se ha visto en el capítulo 6, pueden ir desde los $570 \mathrm{~mm}$ (d95) hasta los 20 $\mathrm{mm}\left(\mathrm{d}_{05}\right)$, mientras que el tamaño de partícula predominante se encuentra alrededor de los $70 \mathrm{~mm}$. Como consecuencia, antes de llevar a cabo la división de muestra es necesario reducir su tamaño de partícula para que el material sea más homogéneo, de esta forma se consigue disminuir el peso de muestra sin perder representatividad.

Para determinar el tamaño de muestra de laboratorio se ha decidido reducir el diámetro de las partículas de las muestras artificiales a dos d95 diferentes antes de su división: 
- $\quad 30 \mathrm{~mm}$, puesto que corresponde con el diámetro de partícula recomendado por la norma UNE-EN 15443 (2011) de los CSR para la primera reducción de tamaño.

- $60 \mathrm{~mm}$, puesto que es un tamaño intermedio con el que solo será necesario cortar las partículas de más grandes, lo que supone un ahorro de tiempo y esfuerzo.

El corte de las muestras se realizará mediante tijeras.

\subsubsection{Diseño del experimento}

Para determinar el tamaño de muestra se ha diseñado un experimento que permite obtener muestras de laboratorio de diferentes pesos, el cual se expone en la Figura 7.3. En esta figura se puede observar que para obtener todas las muestras de laboratorio es necesario diseñar cuatro muestras de rechazo artificiales (MA1, MA2, MA3 y MA4). Cada una de estas muestras artificiales se somete a diferentes procedimientos de reducción de tamaño de partícula mediante corte y división de muestra mediante cuarteo, de forma que se obtiene una muestra de referencia y 15 muestra de laboratorio de diferentes pesos.

En el caso de la MA1 no se aplicará ningún procedimiento de reducción de tamaño de partícula ni de división de muestra, por lo que los $2 \mathrm{~kg}$ formaran la muestra de laboratorio CNL1. Esta muestra se considera como la muestra patrón o de referencia, puesto que los resultados que se obtengan a partir de la misma serán totalmente representativos ya que no sufren ningún cuarteo. Los resultados analíticos sobre los parámetros de calidad obtenidos para el resto de muestras de laboratorio se compararán con esta muestra con el objetivo de comprobar si son representativas o no.

Las muestras MA2, MA3 y MA4 han sido cortas y cuarteadas del siguiente modo (Figura 7.3):

- Las muestras de laboratorio CNL2, CNL3, CNL4, CNL5 y CNL6 se obtendrán mediante sucesivos cuarteos a partir de la MA2, que no sufre ninguna reducción de tamaño de partícula.

- Las muestras de laboratorio C60L2, C6OL3, C60L4, C60L5 y C60L6 se obtendrán mediante sucesivos cuarteos a partir de la MA3, que ha sufrido una reducción del tamaño de partícula a un diámetro de $60 \mathrm{~mm}$.

- Las muestras de laboratorio C30L2, C30L3, C30L4, C30L5 Y C30L6 se obtendrán mediante sucesivos cuarteos a partir de la MA4, que ha sufrido una reducción del tamaño de partícula a un diámetro de $30 \mathrm{~mm}$. 


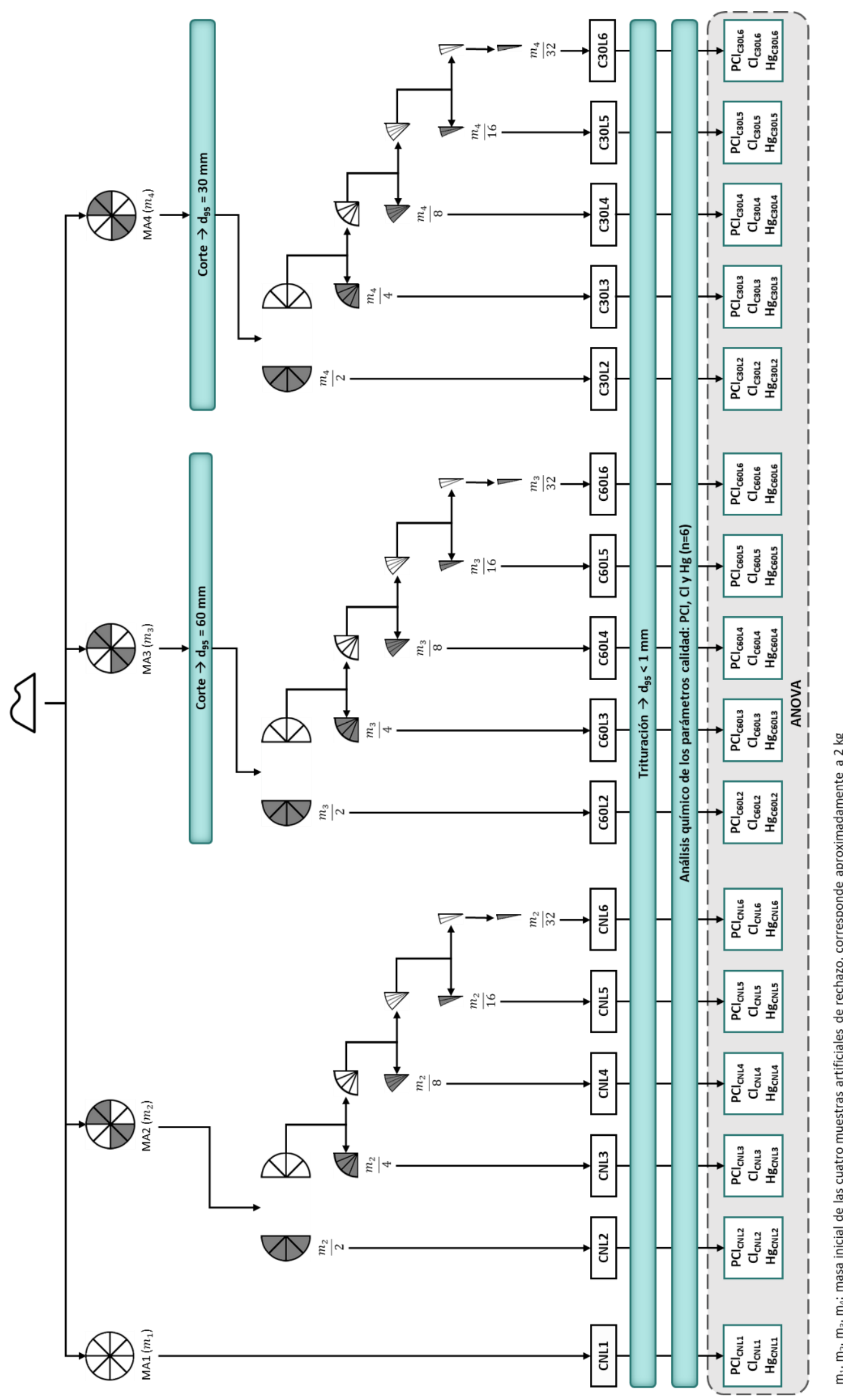

Figura 7.3 Diseño del experimento para la determinación del tamaño de muestra de laboratorio 
En la Tabla 7.2 se expone un cuadro resumen con las combinaciones de procedimientos de reducción de tamaño de partícula y división de muestra que se van a analizar, así como las características de la muestra de referencia y de las 15 muestras de laboratorio que se obtendrán tras llevar a cabo el experimento.

Tabla 7.2 Procedimientos de preparación de muestra en el laboratorio estudiados y muestras obtenidas

\begin{tabular}{|c|c|c|c|c|c|}
\hline \multirow{2}{*}{$\begin{array}{l}\text { Muestra } \\
\text { de rechazo } \\
\text { artificial }\end{array}$} & \multicolumn{2}{|c|}{ Procedimientos de preparación de muestra } & \multicolumn{2}{|c|}{ Características de la muestra } & \multirow{2}{*}{$\begin{array}{l}\text { Id. } \\
\text { Muestra de } \\
\text { laboratorio }\end{array}$} \\
\hline & $\begin{array}{l}\text { Reducción tamaño } \\
\text { partícula }\end{array}$ & División de muestra & $d_{95}(\mathrm{~mm})$ & $\begin{array}{l}\text { Peso tras la } \\
\text { división (kg) }\end{array}$ & \\
\hline MA1 & - & - & $d_{950}$ & $m_{1}$ & CNL1 (Ref.) \\
\hline \multirow{5}{*}{ MA2 } & - & 1 cuarteo & $d_{950}$ & $m_{2} / 2$ & CNL2 \\
\hline & - & $\begin{array}{l}2 \text { cuarteos } \\
\text { sucesivos }\end{array}$ & $d_{950}$ & $m_{2} / 4$ & CNL3 \\
\hline & - & $\begin{array}{l}3 \text { cuarteos } \\
\text { sucesivos }\end{array}$ & $d_{950}$ & $m_{2} / 8$ & CNL4 \\
\hline & - & $\begin{array}{l}4 \text { cuarteos } \\
\text { sucesivos }\end{array}$ & $d_{950}$ & $m_{2} / 16$ & CNL5 \\
\hline & - & $\begin{array}{l}5 \text { cuarteos } \\
\text { sucesivos }\end{array}$ & $d_{950}$ & $m_{2} / 32$ & CNL6 \\
\hline \multirow{5}{*}{ MA3 } & $\begin{array}{c}\text { Corte con tijera a } 60 \\
\mathrm{~mm}\end{array}$ & 1 cuarteo & 60 & $m_{3} / 2$ & C60L2 \\
\hline & $\begin{array}{l}\text { Corte con tijera a } 60 \\
\mathrm{~mm}\end{array}$ & $\begin{array}{l}2 \text { cuarteos } \\
\text { sucesivos }\end{array}$ & 60 & $m_{3} / 4$ & C60L3 \\
\hline & $\begin{array}{l}\text { Corte con tijera a } 60 \\
\mathrm{~mm}\end{array}$ & $\begin{array}{l}3 \text { cuarteos } \\
\text { sucesivos }\end{array}$ & 60 & $m_{3} / 8$ & C60L4 \\
\hline & $\begin{array}{l}\text { Corte con tijera a } 60 \\
\mathrm{~mm}\end{array}$ & $\begin{array}{l}4 \text { cuarteos } \\
\text { sucesivos }\end{array}$ & 60 & $m_{3} / 16$ & C60L5 \\
\hline & $\begin{array}{l}\text { Corte con tijera a } 60 \\
\mathrm{~mm}\end{array}$ & $\begin{array}{l}5 \text { cuarteos } \\
\text { sucesivos }\end{array}$ & 60 & $m_{3} / 32$ & C60L6 \\
\hline \multirow{5}{*}{ MA4 } & $\begin{array}{l}\text { Corte con tijera a } 30 \\
\mathrm{~mm}\end{array}$ & 1 cuarteo & 30 & $m_{4} / 2$ & C30L2 \\
\hline & $\begin{array}{c}\text { Corte con tijera a } 30 \\
\mathrm{~mm}\end{array}$ & $\begin{array}{l}2 \text { cuarteos } \\
\text { sucesivos }\end{array}$ & 30 & $m_{4} / 4$ & C30L3 \\
\hline & $\begin{array}{l}\text { Corte con tijera a } 30 \\
\mathrm{~mm}\end{array}$ & $\begin{array}{l}3 \text { cuarteos } \\
\text { sucesivos }\end{array}$ & 30 & $m_{4} / 8$ & C30L4 \\
\hline & $\begin{array}{l}\text { Corte con tijera a } 30 \\
\mathrm{~mm}\end{array}$ & $\begin{array}{l}4 \text { cuarteos } \\
\text { sucesivos }\end{array}$ & 30 & $m_{4} / 16$ & C30L5 \\
\hline & $\begin{array}{c}\text { Corte con tijera a } 30 \\
\mathrm{~mm}\end{array}$ & $\begin{array}{l}5 \text { cuarteos } \\
\text { sucesivos }\end{array}$ & 30 & $m_{4} / 32$ & C30L6 \\
\hline
\end{tabular}

$m_{1}, m_{2}, m_{3}, m_{4}$ : masa inicial de las cuatro muestras artificiales de rechazo, corresponde aproximadamente a $2 \mathrm{~kg}$

d95o: tamaño nominal superior de la muestra artificial de rechazo

Cabe señalar que la división por cuarteo de MA2, MA3 y MA4 se realizará de tal forma que el material que se descarta en cada cuarteo se vuelva a homogeneizar y cuartear para obtener la siguiente muestra de laboratorio de menor tamaño (en lugar de desecharlo) (Figura 7.4). De esta manera las muestras artificiales se aprovecharán al máximo. 


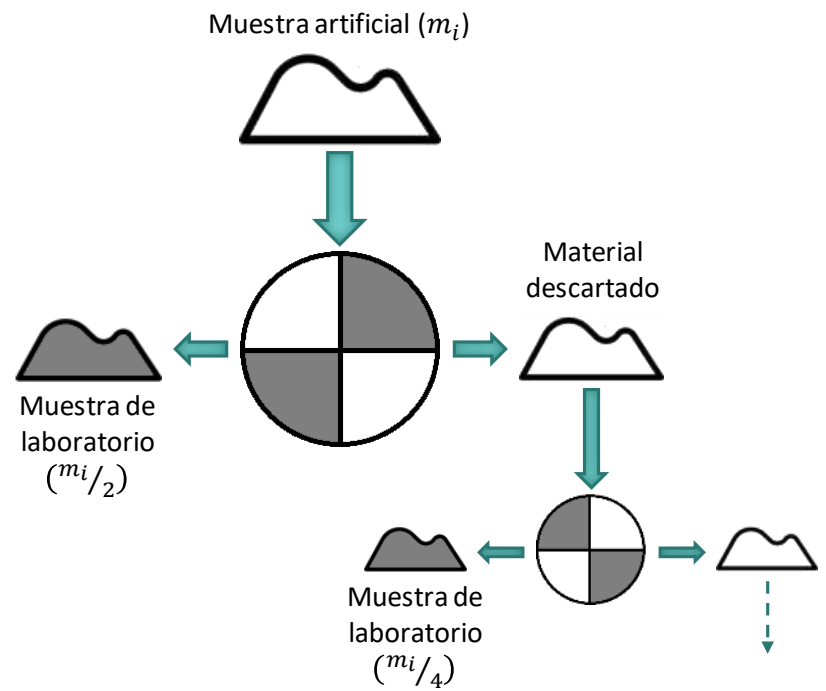

Figura 7.4 División de muestra por cuarteos sucesivos

Finalmente, una vez se obtiene la muestra de referencia y las 15 muestras de laboratorio, se debe continuar con los siguientes pasos de la preparación de muestra antes del análisis químico: el secado, eliminación de materiales no combustibles y trituración final. Estos pasos son idénticos para todas ellas y se describen a continuación.

Las muestras se han secado siguiendo el método propuesto por la norma UNE-EN 15414-3 (2011) "Combustibles sólidos recuperados: Determinación del contenido en humedad por el método de secada en estufa. Parte 3: Humedad de la muestra para análisis general”, determinando al mismo tiempo la humedad. Este método consiste en el secado de la muestra a una temperatura de $105^{\circ} \mathrm{C}$. Para ello se ha utilizado una estufa de desecación marca CARBOLITE y varias bandejas de aluminio o porcelana donde se introducía la muestra (Figura 7.5). El contenido en humedad se calcula por diferencia de peso entre la muestra antes y después del secado.

Tras el secado y antes de la trituración de las muestras se deben de separar manualmente las fracciones no combustibles (metales, inertes, vidrio y parte de la fracción RTP y Otros que corresponden a materiales no combustibles) para poder analizar los parámetros de calidad. El peso de los mismos deberá ser registrado para calcular los resultados analíticos en relación al material total.

Una vez eliminado el material no combustible se ha procedido a la trituración final de las muestras a un tamaño de partícula menor de $1 \mathrm{~mm}$ mediante un molino de corte marca RETSCH modelo SM-2000 (Figura 7.5). De esta forma se consigue la muestra de laboratorio final de la cual se tomarán las diferentes muestras de análisis o alícuotas para determinar el $\mathrm{PCl}, \mathrm{Cl}$ y $\mathrm{Hg}$.
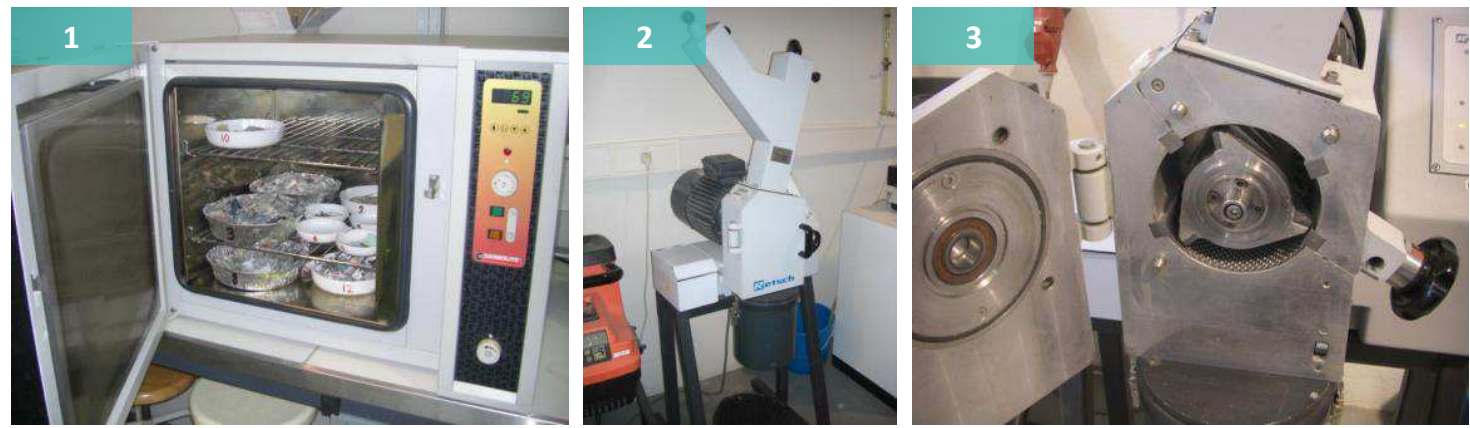

Figura 7.5 Estufa CARBOLITE para el secado (1) y molino de corte RETSCH modelo SM-2000 (2 y 3) 


\subsubsection{Análisis químico de los parámetros de calidad}

Los análisis químicos necesarios para determinar los parámetros que definen la calidad de los rechazos $(\mathrm{PCl}$, $\mathrm{Cl}$ y $\mathrm{Hg}$ ) se han llevado a cabo en el laboratorio del grupo de investigación INGRES de la Universitat Jaume I y en el Servicio Central de Instrumentación Científica (SCIC) de la misma universidad. Para cada parámetro se analizarán 6 réplicas por muestra, al igual que se realizó en los diferentes experimentos del Proyecto QUOVADIS (2008) para la validación de los métodos de medición de los parámetros de calidad de los CSR.

\section{Poder calorífico}

El poder calorífico de las diferentes muestras se ha determinado mediante una bomba calorimétrica y un calorímetro isoperibólico PARR modelo 1261 siguiendo el método definido por la norma UNE-EN 15400 (2011) "Combustibles sólidos recuperados: Determinación del poder calorífico". Este consiste en quemar una porción de aproximadamente 1 gramo de muestra en una bomba calorimétrica, con una presión elevada de oxígeno y bajo condiciones específicas. Como resultado se obtiene el valor de poder calorífico superior (PCS) que, conociendo la humedad y contenido en hidrógeno, se transforma en el poder calorífico inferior (PCI).

Debido a la baja densidad de los rechazos estos se deben analizar en forma de pastilla. Esta se coloca en la bomba calorimétrica junto con el hilo de ignición (conectado a los electrodos de la bomba y tocando la pastilla) y se le añaden $10 \mathrm{ml}$ de $\mathrm{KOH} \mathrm{0,2} \mathrm{M} \mathrm{que} \mathrm{se} \mathrm{usan} \mathrm{como} \mathrm{disolución} \mathrm{captadora} \mathrm{en} \mathrm{la} \mathrm{determinación} \mathrm{del}$ cloro. La bomba se cierra y se carga con oxígeno a una presión de $30 \mathrm{~atm}$. Posteriormente, se introduce en el calorímetro sumergiéndola en un baño de agua para la estabilización de su temperatura y se comienza con el análisis (Figura 7.6).
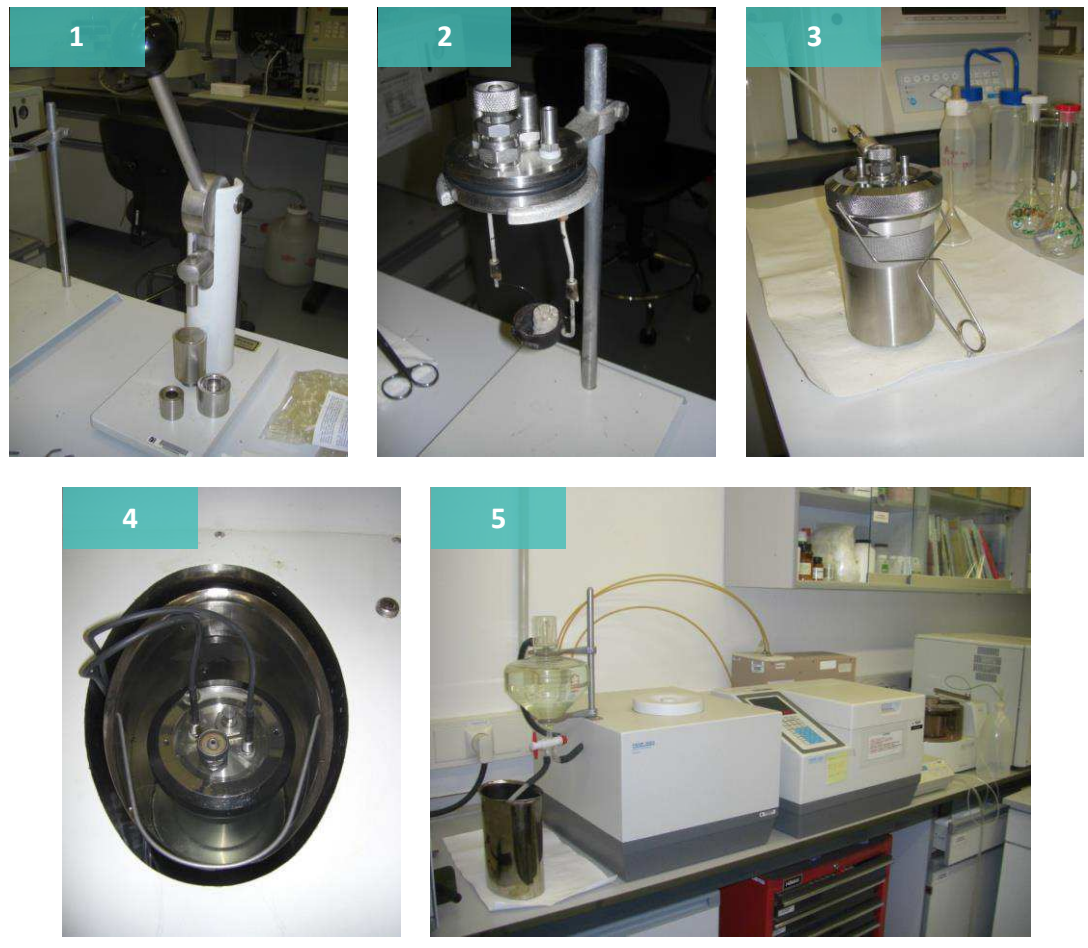

Figura 7.6 Prensa de pastillas (1), pastilla con el hilo de ignición (2), llenado de la bomba con $\mathrm{O}_{2}(3)$, bomba sumergida (4) y calorímetro isoperibólico (5)

El valor de hidrogeno necesario para el cálculo del PCl a partir de los valores de PCS se ha determinado mediante el método descrito por la norma UNE-EN 15407 (2011) "Combustibles sólidos recuperados: Métodos para la determinación del contenido en carbono $(\mathrm{C})$, hidrógeno $(\mathrm{H})$ y nitrógeno $(\mathrm{N})$ ". Este se basa en la oxidación completa de la muestra, transformando todos los elementos en gases productos de la combustión y que se detectan mediante distintos procedimientos instrumentales. Para ello se ha utilizado un

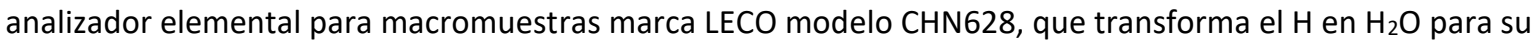


detección mediante espectrometría infrarroja (Figura 7.7). La cantidad de muestra que se introduce en cada análisis es de $150 \mathrm{mg}$.

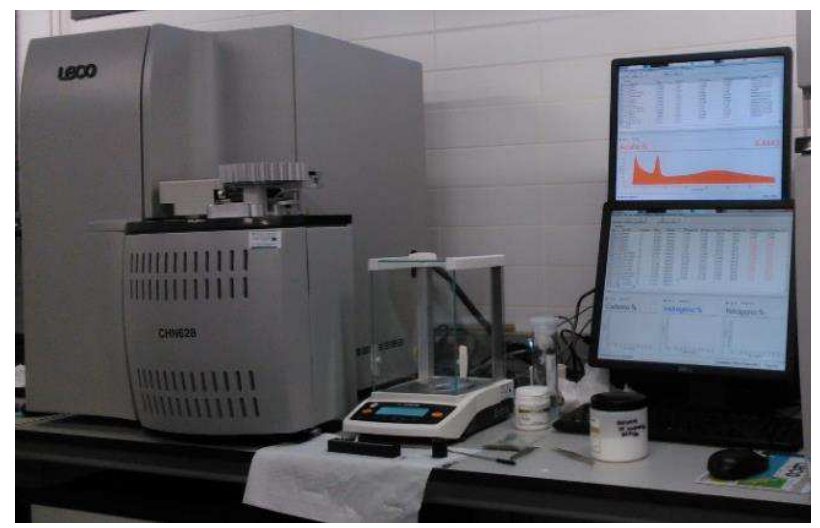

Figura 7.7 Analizador elemental LECO CHN628

\section{Contenido en cloro}

El contenido en cloro se ha determinado siguiendo el método descrito por las normas UNE-EN 15408 (2011) "Combustibles sólidos recuperados: Métodos para la determinación del contenido en azufre (S), cloro (Cl), flúor (F) y bromo (Br)" y UNE-EN ISO 10304-1 (2009) “Calidad del agua: Determinación de aniones disueltos por cromatografía de iones en fase líquida. Parte 1: Determinación de bromuro, cloruro, fluoruro, nitrato, nitrito, fosfato y sulfato.", el cual se divide en dos etapas:

- Oxidación de la muestra mediante combustión en una bomba calorimétrica: el cloro se convierte en cloruros y se absorbe en la disolución de absorción (KOH 0,2M).

- Análisis de los cloruros en la disolución mediante cromatografía iónica en fase líquida. El equipo utilizado ha sido un Cromatógrafo iónico DIONEX modelo DX-120 para muestras líquidas con una columna para aniones IonPac AS9-HC (Figura 7.8).

La primera etapa se realiza a la vez que se determina el poder calorífico. Para ello se añaden $10 \mathrm{ml}$ de la disolución de absorción en la bomba calorimétrica y se espera 10 minutos tras finalizar el análisis, de esta forma todos los cloruros quedarán atrapados en la disolución. Trascurrido el tiempo se abre la bomba y se recupera la disolución diluyéndola en un matraz aforado de $100 \mathrm{ml}$ utilizando agua ultrapura.

La segunda etapa consiste en el análisis por cromatografía iónica en fase líquida de la disolución obtenida. Este método separa los diferentes aniones presentes en la disolución utilizando una resina de intercambio aniónico como fase estacionaria (columna) y $\mathrm{Na}_{2} \mathrm{CO}_{3}$ como eluyente o fase móvil. Los aniones separados se miden utilizando una célula de conductividad eléctrica. Los resultados se obtienen un $\mathrm{mg} / \mathrm{l}$, posteriormente, se transforman en porcentaje en peso.

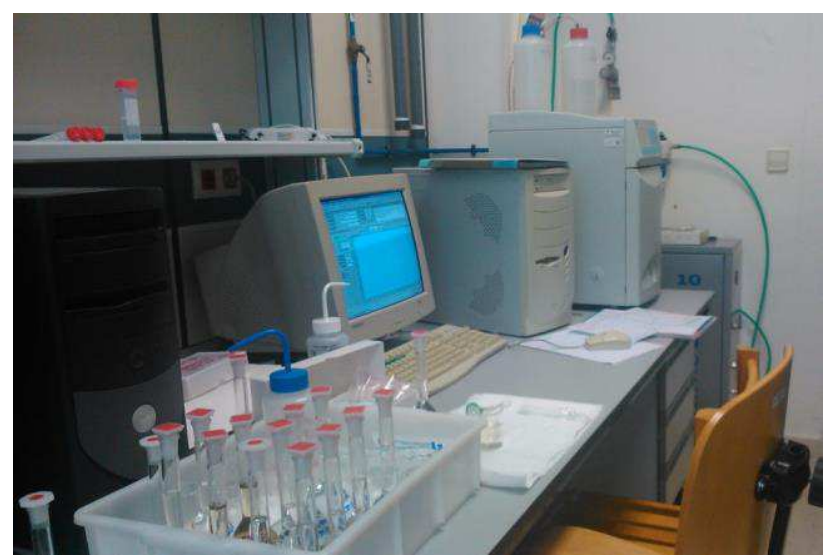

Figura 7.8 Soluciones preparadas para su análisis y cromatógrafo iónico DIONEX DX-120 


\section{Contenido de mercurio}

El contenido en mercurio de las diferentes muestras se ha determinado mediante el procedimiento definido en la norma UNE-EN 15411 (2011) “Combustibles sólidos recuperados. Método para la determinación del contenido en oligoelementos ( $\mathrm{As}, \mathrm{Ba}, \mathrm{Be}, \mathrm{Cd}, \mathrm{Co}, \mathrm{Cr}, \mathrm{Cu}, \mathrm{Hg}, \mathrm{Mo}, \mathrm{Mn}, \mathrm{Ni}, \mathrm{Pb}, \mathrm{Sb}, \mathrm{Se}, \mathrm{Tl}, \mathrm{V}$ y $\mathrm{Zn}$ )". De las diferentes técnicas propuestas en esta norma para el análisis de mercurio, se ha utilizado el análisis directo según el método EPA 7473 "Mercury in solids and solutions by thermal decomposition, amalgamation, and atomic absorption spectrophotometry" (US EPA, 2007). Este se basa en la descomposición térmica de la muestra, amalgamación en oro y posterior determinación mediante espectrometría de absorción atómica. Para ello se ha utilizado un analizador avanzado de mercurio marca LECO modelo AMA-254 (Figura 7.9). Este equipo es un espectrómetro de absorción atómica diseñado exclusivamente para la determinación de mercurio en muestras sólidas y líquidas sin necesidad de tratamientos químicos previos. La cantidad de muestra que se introduce en cada análisis es de aproximadamente $50 \mathrm{mg}$. Además, junto con la muestra, se introduce una pequeña cantidad de alúmina calcinada para evitar que los plásticos presentes en la muestra se quemen muy rápido y formen humos negros, los cuales interfieren en la medición.

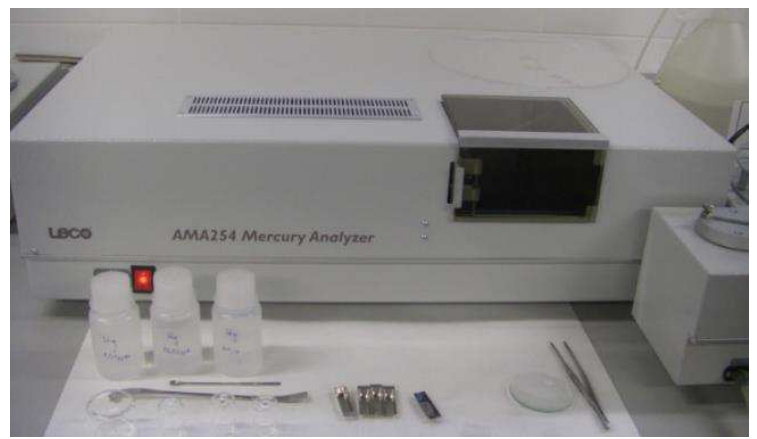

Figura 7.9 Analizador de mercurio LECO AMA-254

\subsubsection{Determinación del tamaño de muestra de laboratorio}

Por último, una vez obtenidos los datos de $\mathrm{PCl}, \mathrm{Cl}$ y $\mathrm{Hg}$ de la muestra de referencia y las 15 muestras de laboratorio, se procederá a la determinación del tamaño de muestra. Para ello, se estudiarán si existen diferencias significativas entre la muestra de referencia (CNL1) y el resto de muestras de laboratorio. Estas comparaciones tienen como objetivo identificar a qué nivel de división de muestra (número de cuarteos) los resultados de los parámetros de calidad dejan de ser representativos para cada procedimiento de reducción de tamaño de partícula estudiado (sin corte, corte a $60 \mathrm{~mm}$ y corte a $30 \mathrm{~mm}$ ).

El nivel de división de muestra donde aparezcan las primeras diferencias corresponde al nivel crítico, puesto que los resultados obtenidos para ese tamaño de muestra de laboratorio dejan de ser representativos de la población de rechazo muestreada (muestra de referencia). Por lo tanto, el nivel de división de muestra que esté por encima marcará el límite del número de cuarteos necesarios, determinado el peso mínimo de muestra de laboratorio con el que se obtienen resultados representativos $\left(\mathrm{m}_{\mathrm{L}}\right)$ para los tres procedimientos de reducción de tamaño de partícula.

La comparación de los datos se realizará mediante un análisis estadístico, en concreto mediante una comparación de medias de $k$ grupos de muestras. A través de esta técnica se puede conocer si las diferencias entre la muestra de referencia y cada una de las otras muestras de laboratorio son reales o si, por el contrario, las diferencias son tan pequeñas que se considera que se deben al azar. De esta forma se puede identificar el nivel de división de muestra donde aparecen diferencias estadísticamente significativas para los parámetros de calidad y, por tanto, el número de cuarteos al que las muestras de laboratorio obtenidas dejan de ser representativas.

Los métodos estadísticos que se deben aplicar para llevar a cabo esta comparación se han explicado en el capítulo 5 de la presente tesis, los cuales están resumidos en forma de árbol de decisión en la Figura 5.8 del mismo. Como se recomienda en dicho capitulo y debido a que para cada muestra de laboratorio se obtienen 6 datos por parámetro, se deberán utilizar solo las técnicas no paramétricas. 
Los datos utilizados para el análisis estadístico corresponden a los resultados sobre muestra húmeda, de esta forma se tienen en cuenta las variaciones en el contenido de humedad que pueden darse entre las muestras de laboratorio.

Por otro lado, debido a que los análisis estadísticos se aplican a los tres parámetros que definen la calidad, se obtienen un peso de muestra para cada parámetro. Por lo tanto, el tamaño de muestra de laboratorio para determinar la calidad global de los rechazos siempre será el más restrictivo de todos ellos.

\subsubsection{Resultados}

\subsubsection{Diseño de las muestras artificiales de rechazo}

Como se ha comentado en la metodología, para llevar a cabo la experimentación se diseñaron cuatro muestras artificiales de rechazo de $2 \mathrm{~kg}$ (MA1, MA2, MA3 y MA4), cuyo peso corresponde al de la muestra recompuesta de la primera etapa de la preparación de muestras para el control de calidad de los rechazos. En la Tabla 7.3 se presentan los pesos de los diferentes materiales utilizados para cada una de ellas y la composición final obtenida para las mismas. Por otro lado, en la Figura 7.10 y Figura 7.11 se muestran, respectivamente, algunas fotos de los materiales limpios utilizados y de las cuatro muestras de rechazo diseñadas.

Tabla 7.3 Peso y composición de las cuatro muestras diseñadas

\begin{tabular}{|c|c|c|c|c|c|c|c|c|c|}
\hline \multirow{2}{*}{\multicolumn{2}{|c|}{ Fracción }} & \multicolumn{4}{|c|}{ Peso muestras diseñadas (Kg) } & \multicolumn{4}{|c|}{ Composición muestras diseñadas (\%) } \\
\hline & & MA1 & MA2 & MA3 & MA4 & MP1 & MP2 & MP3 & MP4 \\
\hline \multicolumn{2}{|c|}{ Fracción orgánica } & 0,337 & 0,337 & 0,337 & 0,335 & 16,77 & 16,76 & 16,76 & 16,70 \\
\hline \multicolumn{2}{|c|}{ Papel/Cartón } & 0,644 & 0,643 & 0,644 & 0,644 & 32,02 & 31,97 & 31,99 & 32,05 \\
\hline \multirow{6}{*}{ Plásticos } & PEBD & 0,250 & 0,251 & 0,250 & 0,251 & 12,46 & 12,45 & 12,45 & 12,48 \\
\hline & PET & 0,062 & 0,063 & 0,062 & 0,062 & 3,09 & 3,11 & 3,08 & 3,10 \\
\hline & PEAD & 0,048 & 0,049 & 0,048 & 0,048 & 2,41 & 2,43 & 2,40 & 2,39 \\
\hline & PP & 0,025 & 0,026 & 0,026 & 0,025 & 1,26 & 1,29 & 1,28 & 1,25 \\
\hline & PS & 0,021 & 0,021 & 0,021 & 0,021 & 1,03 & 1,03 & 1,03 & 1,04 \\
\hline & Otros & 0,050 & 0,050 & 0,050 & 0,050 & 2,50 & 2,49 & 2,49 & 2,49 \\
\hline \multicolumn{2}{|c|}{ Textil } & 0,160 & 0,160 & 0,160 & 0,160 & 7,95 & 7,95 & 7,95 & 7,96 \\
\hline \multirow{3}{*}{ Metales } & Férricos & 0,066 & 0,066 & 0,066 & 0,066 & 3,27 & 3,27 & 3,27 & 3,28 \\
\hline & No férricos & 0,013 & 0,013 & 0,013 & 0,013 & 0,63 & 0,63 & 0,62 & 0,63 \\
\hline & Papel Al & 0,006 & 0,006 & 0,006 & 0,006 & 0,31 & 0,31 & 0,31 & 0,30 \\
\hline \multicolumn{2}{|c|}{ Madera } & 0,066 & 0,066 & 0,065 & 0,066 & 3,27 & 3,27 & 3,25 & 3,27 \\
\hline \multicolumn{2}{|c|}{ Brik } & 0,043 & 0,042 & 0,042 & 0,041 & 2,13 & 2,11 & 2,09 & 2,07 \\
\hline \multicolumn{2}{|c|}{ Inertes } & 0,029 & 0,029 & 0,029 & 0,029 & 1,42 & 1,44 & 1,42 & 1,43 \\
\hline \multicolumn{2}{|c|}{ RTP } & 0,003 & 0,004 & 0,003 & 0,004 & 0,17 & 0,17 & 0,17 & 0,18 \\
\hline \multicolumn{2}{|c|}{ Vidrio } & 0,023 & 0,023 & 0,023 & 0,023 & 1,12 & 1,13 & 1,14 & 1,13 \\
\hline \multicolumn{2}{|c|}{ Celulosa sanitaria } & 0,076 & 0,076 & 0,076 & 0,076 & 3,78 & 3,77 & 3,78 & 3,79 \\
\hline \multicolumn{2}{|c|}{ Zapatos } & 0,030 & 0,030 & 0,031 & 0,030 & 1,48 & 1,51 & 1,54 & 1,52 \\
\hline \multicolumn{2}{|c|}{ Goma y cuero } & 0,013 & 0,013 & 0,014 & 0,013 & 0,66 & 0,63 & 0,68 & 0,66 \\
\hline \multicolumn{2}{|c|}{ Otros } & 0,046 & 0,046 & 0,046 & 0,046 & 2,27 & 2,29 & 2,29 & 2,28 \\
\hline \multicolumn{2}{|c|}{ TOTAL } & 2,010 & 2,012 & 2,012 & 2,008 & 100 & 100 & 100 & 100 \\
\hline
\end{tabular}



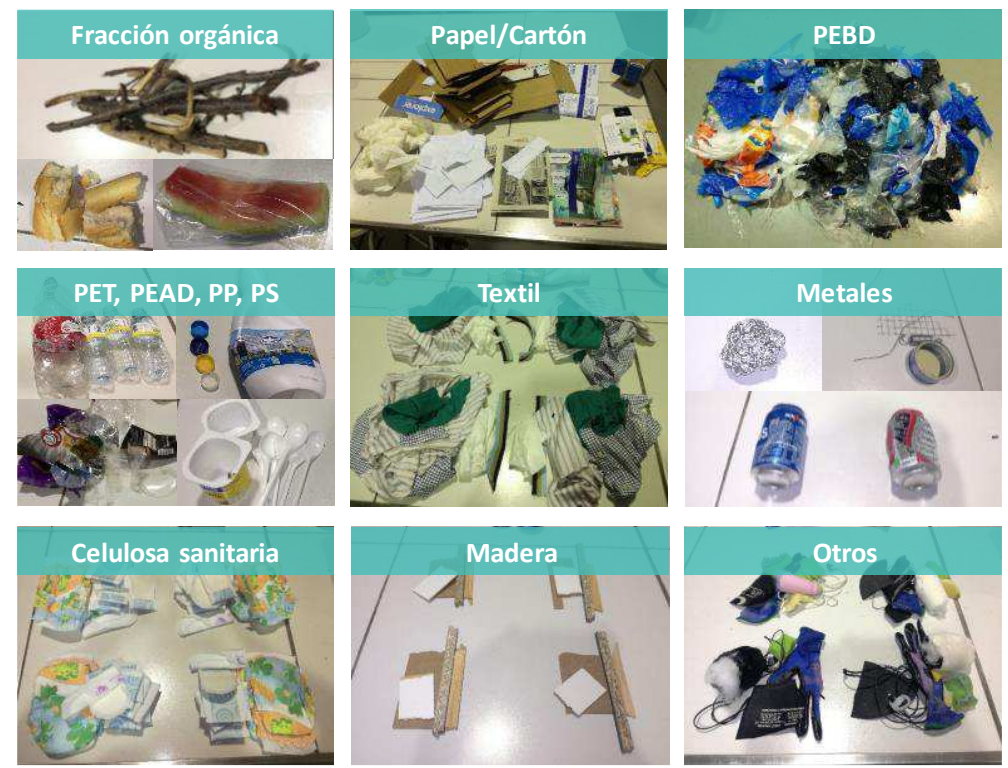

Figura 7.10 Materiales vírgenes utilizados en el diseño de las muestras

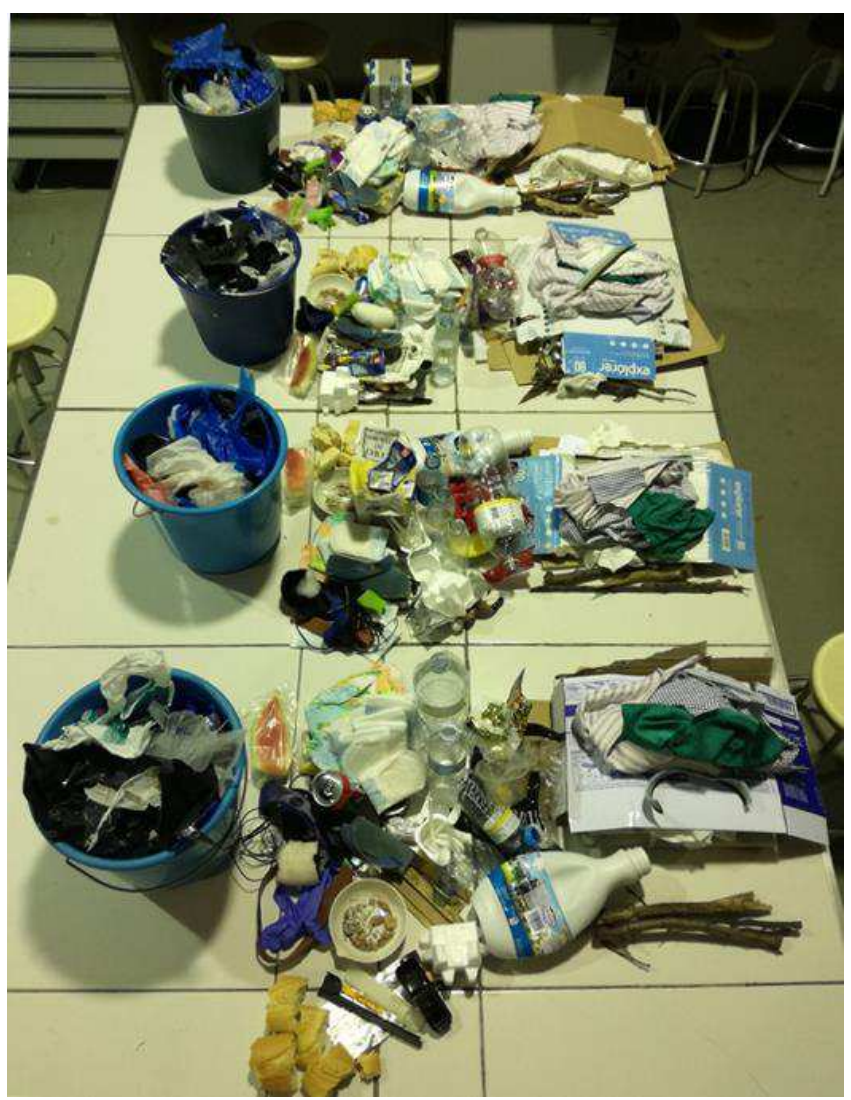

Figura 7.11 Muestras de rechazo diseñadas

Finalmente, se ha determinado el tamaño nominal superior de las muestras diseñadas con el objetivo de comprobar si es similar al de una muestra real de rechazo. Las clases de tamaño consideradas y los resultados obtenidos para una de ellas se exponen en la Tabla 7.4. Además, en la Figura 7.12 se pueden ver las piezas que componen el d95 para dicha muestra. 
Tabla 7.4 Tamaño nominal superior y tamaño mínimo de partícula de las muestras artificiales

\begin{tabular}{|c|c|c|c|c|}
\hline $\begin{array}{c}\text { Clases de } \\
\text { tamaño }(\mathrm{mm})\end{array}$ & Peso (g) & $\%$ en peso & $\begin{array}{c}\% \\
\text { acumulado }\end{array}$ & $\begin{array}{c}d_{95, I} \\
(\mathrm{~mm})^{*}\end{array}$ \\
\hline$>770$ & - & - & - & \multirow{10}{*}{570} \\
\hline $770-670$ & - & - & - & \\
\hline $670-570$ & 108,15 & 5,39 & 5,38 & \\
\hline $570-470$ & 86,63 & 4,32 & 9,68 & \\
\hline $470-370$ & 50,19 & 2,50 & 12,18 & \\
\hline $370-270$ & 509,59 & 25,39 & 37,50 & \\
\hline $270-170$ & 324,07 & 16,15 & 53,61 & \\
\hline $170-70$ & 75,81 & 3,78 & 57,38 & \\
\hline$<70$ & 857,59 & 42,74 & 100 & \\
\hline Filamentosas & 5,39 & 0,27 & - & \\
\hline
\end{tabular}

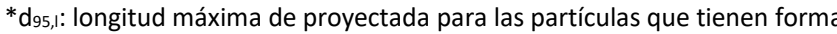
irregular y de grandes dimensiones.
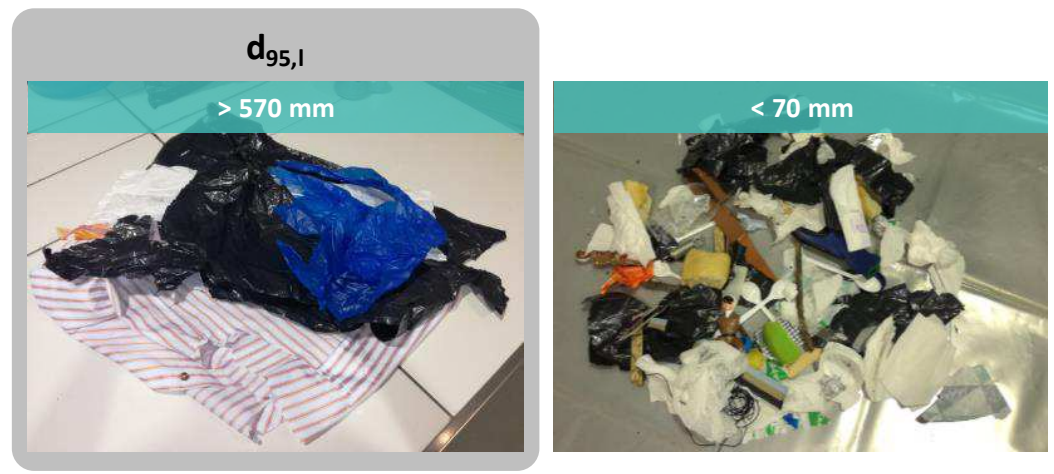

Figura 7.12 Tamaño nominal superior y tamaño de partícula predominante en las muestras artificiales de rechazo

Como se puede ver en la tabla anterior, las muestras de rechazo artificiales tienen un tamaño nominal superior de partícula de $570 \mathrm{~mm}$, valor muy parecido a los obtenidos para los rechazos de recuperación de materiales de la PRC de Onda (570 mm) y PBSR de Cervera $(470 \mathrm{~mm}$ ) que se han estudiado en el capítulo 6. Además, en la Tabla 7.4 también se observa que el tamaño de partícula predominante es menor a $70 \mathrm{~mm}$, dato que también coincide con los obtenidos para dichas plantas de TMB. Esto justifica que las muestras de rechazo diseñadas son muy similares a las de un rechazo real generado en la etapa de recuperación de materiales de una planta TMB.

\subsubsection{Reducción del tamaño de partícula}

Una vez diseñadas las cuatro muestras artificiales se procedió a reducir el tamaño de partícula de la MA3 y MA4 a un diámetro de $60 \mathrm{~mm}$ y $30 \mathrm{~mm}$, respectivamente. En la Figura 7.13 se puede ver el aspecto que tiene la muestra MA2, la cual no ha sido sometida a ningún procedimiento de corte, y de las muestras MA3 (60 $\mathrm{mm}$ ) y MA4 (30 mm) antes de su división por cuarteo. 

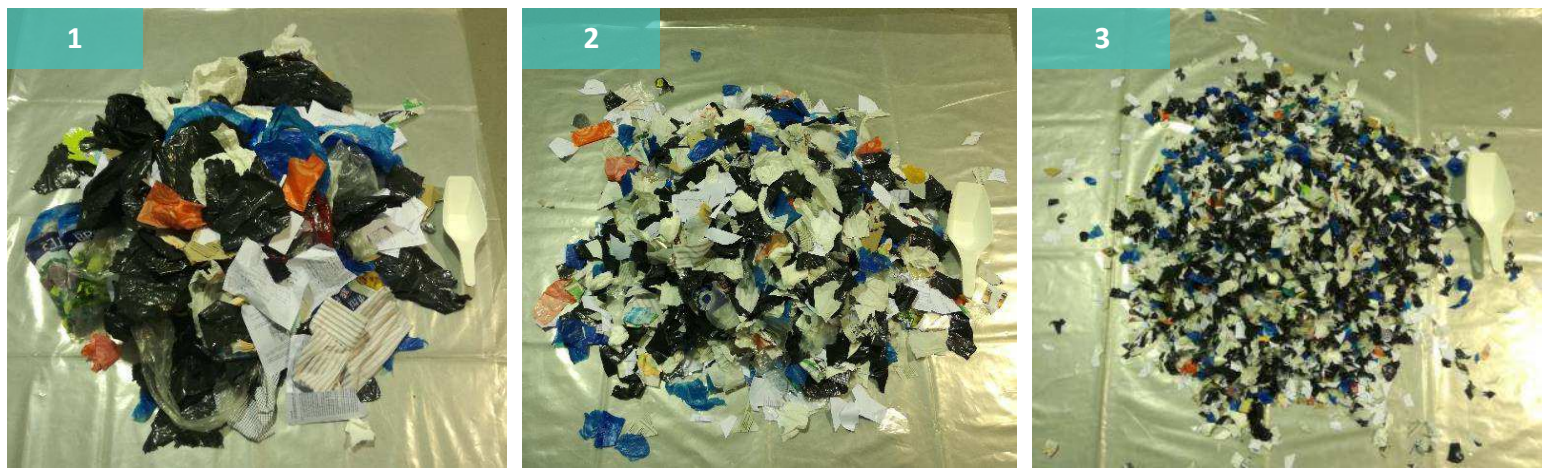

Figura 7.13 Tamaños de partícula antes de la división por cuarteo: MA2 (1), MA3 (2) y MA4 (3)

En la figura anterior se puede observar que con la reducción del tamaño de partícula se consigue que las muestras artificiales sean mucho más homogéneas. Como consecuencia, al disminuir el tamaño de muestra mediante la división por cuarteo, las muestras de laboratorio obtenidas pierden menos representatividad respecto a la muestra original. Además, como se puede ver al comparar la MA3 $(60 \mathrm{~mm})$ frente a la MA4 (30 $\mathrm{mm}$ ), a medida que el tamaño de partícula se reduce esta homogeneidad aumenta. Por lo tanto, es razonable asumir que con el corte a $30 \mathrm{~mm}$ se puedan obtener muestras de laboratorio representativas de menor tamaño.

\subsubsection{Obtención de las muestras de laboratorio}

A partir del experimento diseñado en la metodología y mediante las combinaciones de procedimientos expuestos en la Tabla 7.2 para las cuatro muestras artificiales, se han obtenido la muestra de referencia y las 15 muestras de laboratorio de diferentes pesos. A continuación, se muestra las características de las muestras obtenidas.

\section{Muestra de referencia: CNL1}

La muestra CNL1 corresponde a la MA1, la cual no ha sufrido ningún procedimiento de preparación de muestra puesto que es la de referencia y su peso corresponde a 2,010 kg. Esta muestra tienen un aspecto muy similar al de la MA2 que se puede ver en la Figura 7.13 (1).

\section{Muestras CNL2, CNL3, CNL4, CNL5 y CNL6}

Las muestras CNL2, CNL3, CNL4, CNL5 y CNL6 se obtuvieron mediante sucesivos cuarteos a partir de MA2 (Figura 7.13 (1)). Las características de estas muestras antes de la trituración final a $1 \mathrm{~mm}$ se presentan en la Tabla 7.5. A continuación de dicha tabla también se presentan una serie de figuras con los cuarteos realizados y las muestras obtenidas en cada uno de ellos.

Tabla 7.5 Características de las muestras de laboratorio CNL2, CNL3, CNL4, CNL5 Y CNL6

\begin{tabular}{|c|c|c|c|c|}
\hline \multirow{2}{*}{$\begin{array}{l}\text { Id. Muestra de } \\
\text { laboratorio }\end{array}$} & \multicolumn{2}{|c|}{ Procedimientos de preparación de muestra } & \multicolumn{2}{|c|}{ Características de la muestra } \\
\hline & $\begin{array}{c}\text { Reducción tamaño } \\
\text { partícula inicial }\end{array}$ & División de muestra & $d_{95}(\mathrm{~mm})$ & $\begin{array}{l}\text { Peso tras la } \\
\text { división }(\mathrm{kg})\end{array}$ \\
\hline CNL2 & - & 1 cuarteo & \multirow{5}{*}{570} & 1,010 \\
\hline CNL3 & - & $\begin{array}{l}2 \text { cuarteos } \\
\text { sucesivos }\end{array}$ & & 0,508 \\
\hline CNL4 & - & $\begin{array}{l}3 \text { cuarteos } \\
\text { sucesivos }\end{array}$ & & 0,254 \\
\hline CNL5 & - & $\begin{array}{l}4 \text { cuarteos } \\
\text { sucesivos }\end{array}$ & & 0,126 \\
\hline CNL6 & - & $\begin{array}{l}5 \text { cuarteos } \\
\text { sucesivos }\end{array}$ & & 0,069 \\
\hline
\end{tabular}



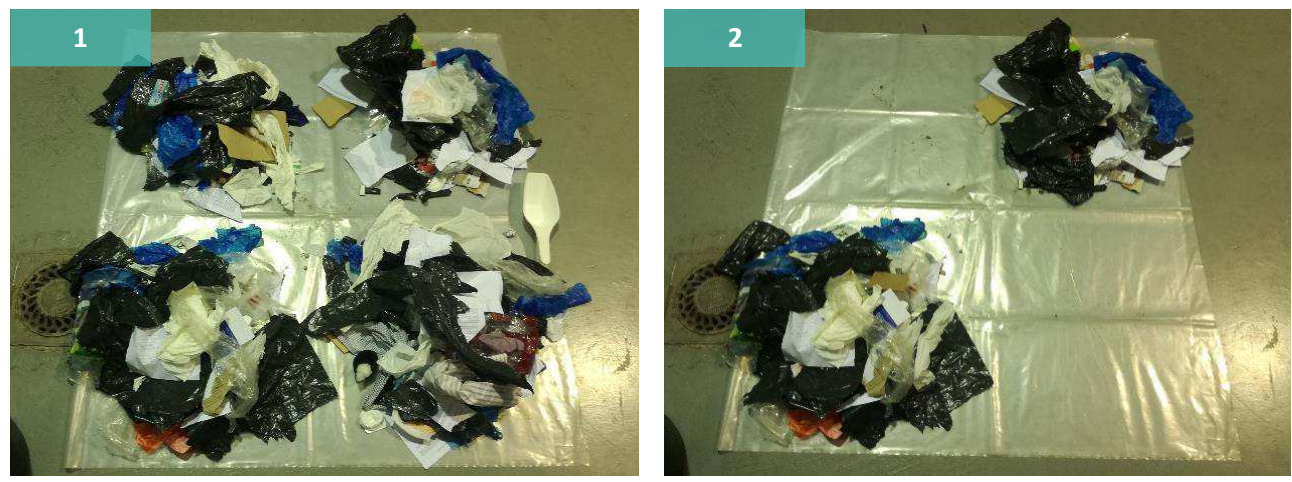

Figura 7.14 CNL2: Primer cuarteo (1) y muestra obtenida (2)
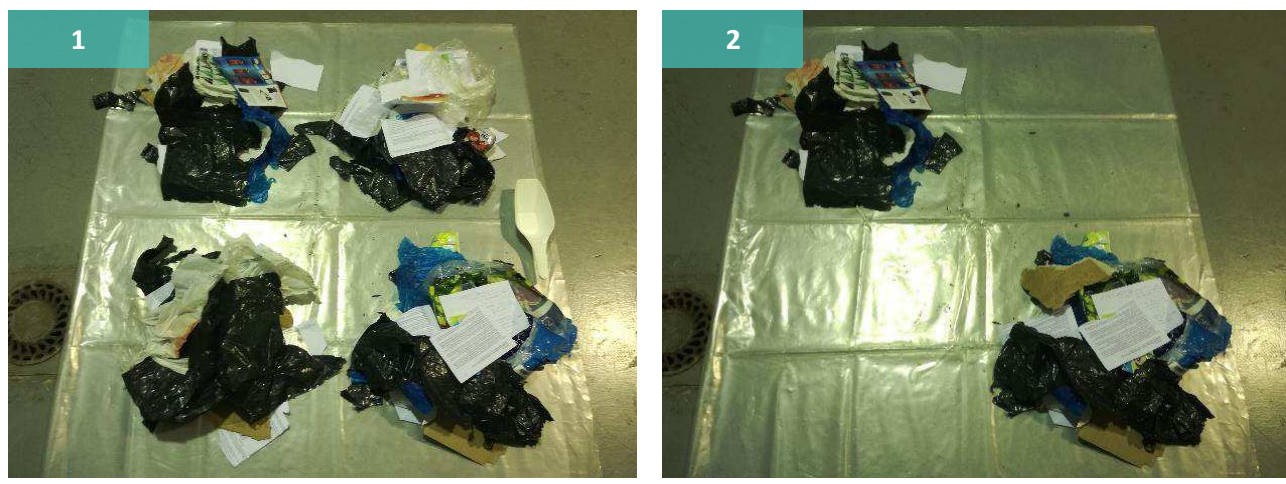

Figura 7.15 CNL3: Segundo cuarteo (1) y muestra obtenida (2)
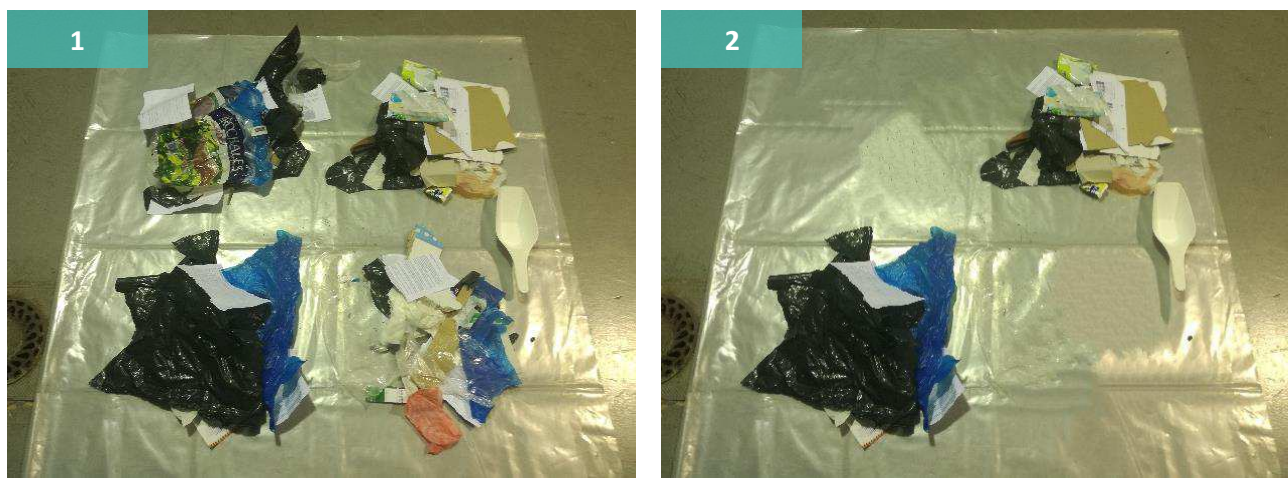

Figura 7.16 CNL4: Tercer cuarteo (1) y muestra obtenida (2)
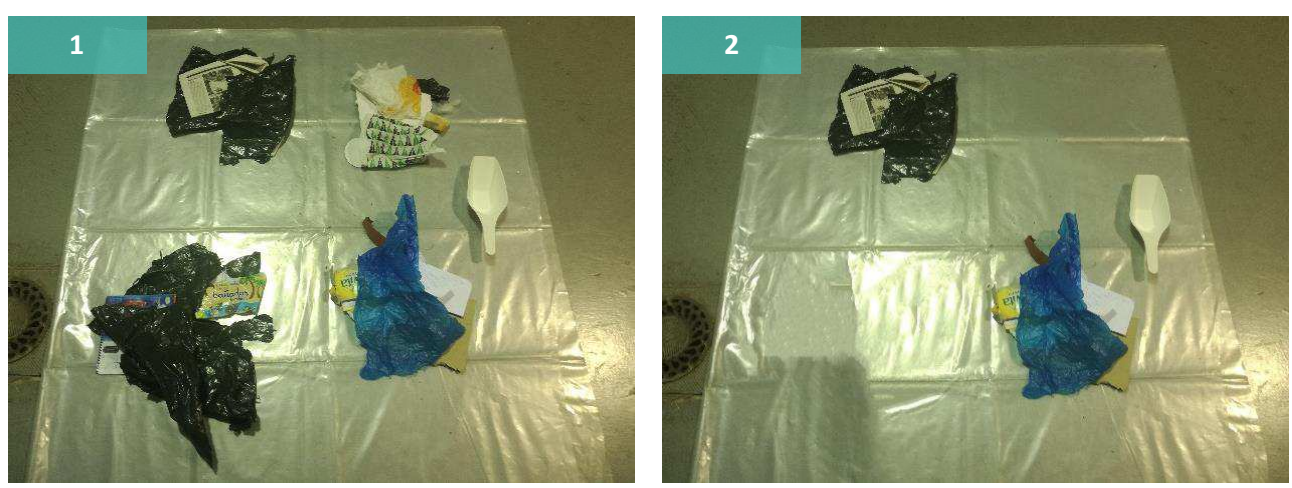

Figura 7.17 CNL5: Cuarto cuarteo (1) y muestra obtenida (2) 

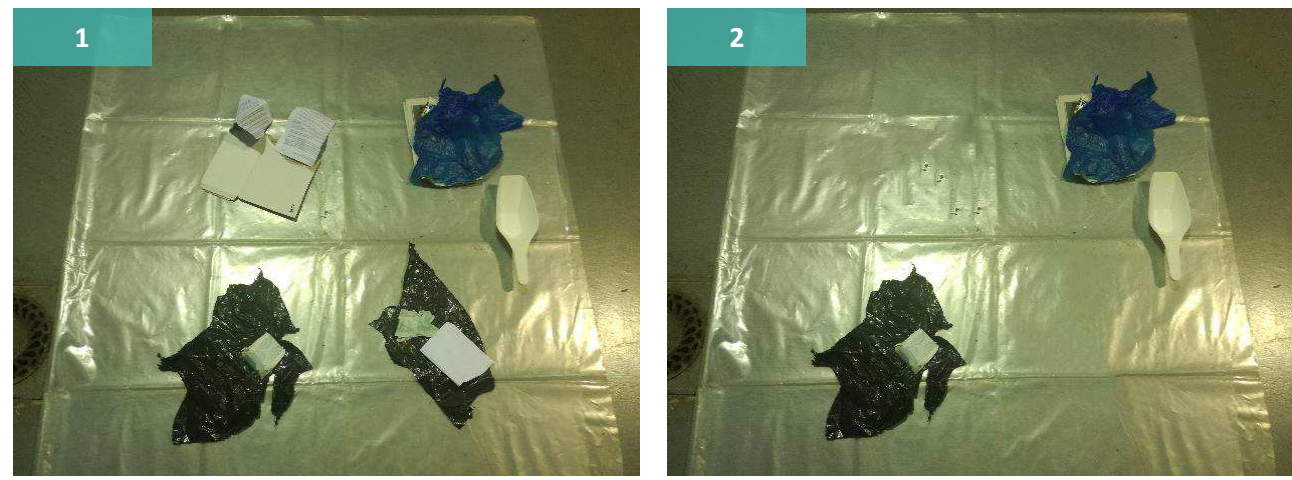

Figura 7.18 CNL6: Quinto cuarteo (1) y muestra obtenida (2)

\section{Muestras C60L2, C60L3, C6OL4, C6OL5 y C6OL6}

Las muestras C60L2, C60L3, C60L4, C60L5 y C60L6 se obtuvieron mediante sucesivos cuarteos a partir de MA3 (Figura 7.13 (2)). Las características de estas muestras de laboratorio antes de su trituración final a $1 \mathrm{~mm}$ se presentan en la Tabla 7.6. A continuación de la misma también se muestran varias figuras con los cuarteos realizados y las distintas muestras obtenidas en cada uno de ellos.

Tabla 7.6 Características de las muestras de laboratorio C60L2, C60L3, C60L4, C60L5 Y C60L6

\begin{tabular}{|c|c|c|c|c|}
\hline \multirow{2}{*}{$\begin{array}{l}\text { Id. Muestra de } \\
\text { laboratorio }\end{array}$} & \multicolumn{2}{|c|}{ Procedimientos de preparación de muestra } & \multicolumn{2}{|c|}{ Características de la muestra } \\
\hline & $\begin{array}{c}\text { Reducción tamaño } \\
\text { partícula inicial }\end{array}$ & División de muestra & $d_{95}(\mathrm{~mm})$ & $\begin{array}{l}\text { Peso tras la } \\
\text { división (kg) }\end{array}$ \\
\hline C60L2 & Corte con tijera a $60 \mathrm{~mm}$ & 1 cuarteo & \multirow{5}{*}{60} & 1,001 \\
\hline C60L3 & Corte con tijera a $60 \mathrm{~mm}$ & $\begin{array}{l}2 \text { cuarteos } \\
\text { sucesivos }\end{array}$ & & 0,505 \\
\hline C60L4 & Corte con tijera a $60 \mathrm{~mm}$ & $\begin{array}{l}3 \text { cuarteos } \\
\text { sucesivos }\end{array}$ & & 0,252 \\
\hline C60L5 & Corte con tijera a $60 \mathrm{~mm}$ & $\begin{array}{l}4 \text { cuarteos } \\
\text { sucesivos }\end{array}$ & & 0,129 \\
\hline C60L6 & Corte con tijera a $60 \mathrm{~mm}$ & $\begin{array}{l}5 \text { cuarteos } \\
\text { sucesivos }\end{array}$ & & 0,067 \\
\hline
\end{tabular}
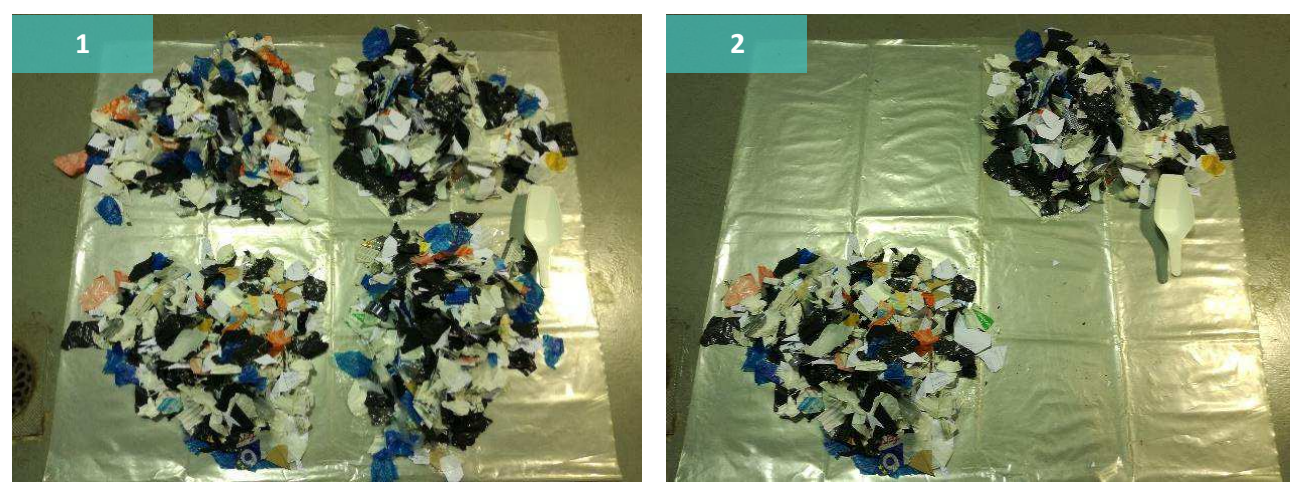

Figura 7.19 C60L2: Primer cuarteo (1) y muestra obtenida (2) 


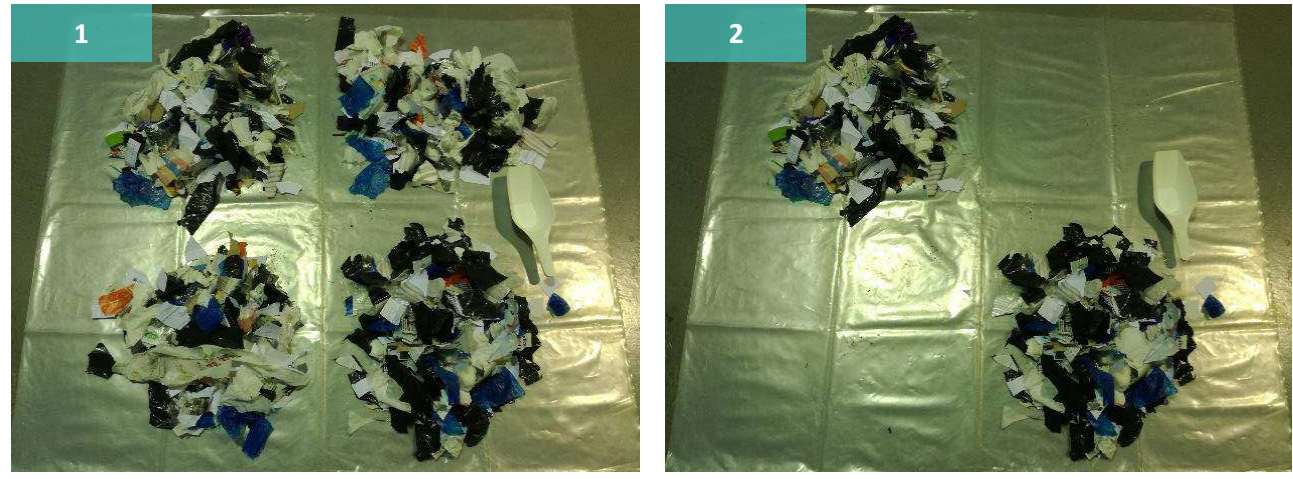

Figura 7.20 C60L3: Segundo cuarteo (1) y muestra obtenida (2)
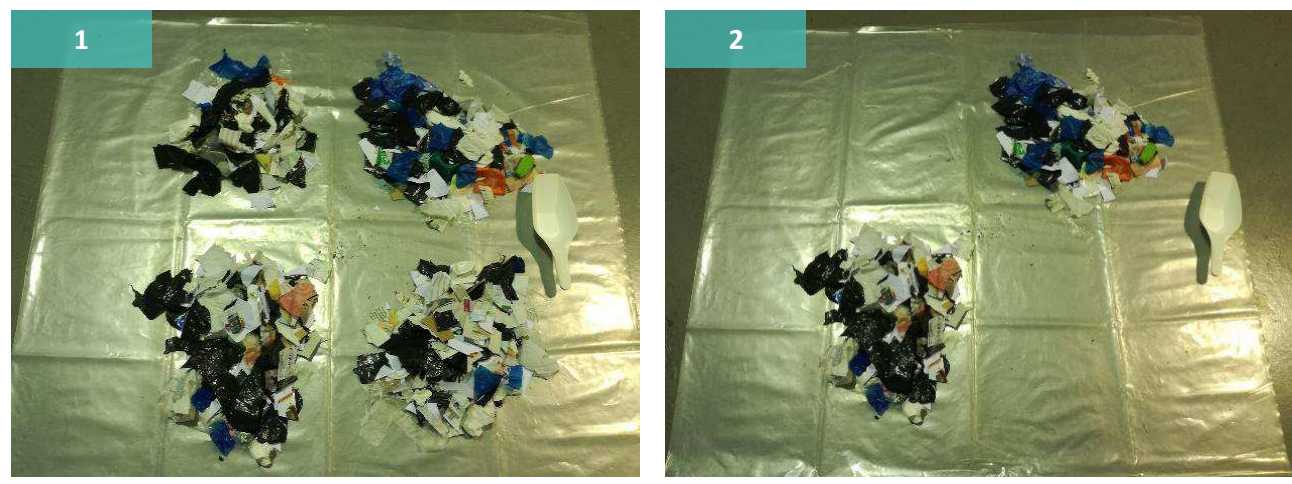

Figura 7.21 C60L4: Tercer cuarteo (1) y muestra obtenida (2)
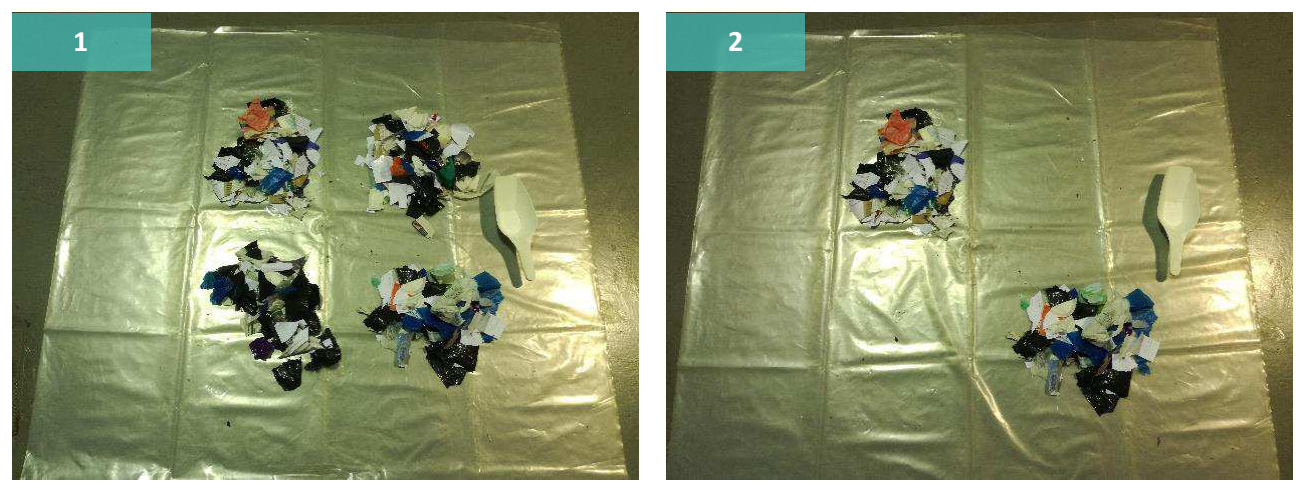

Figura 7.22 C60L5: Cuarto cuarteo (1) y muestra obtenida (2)
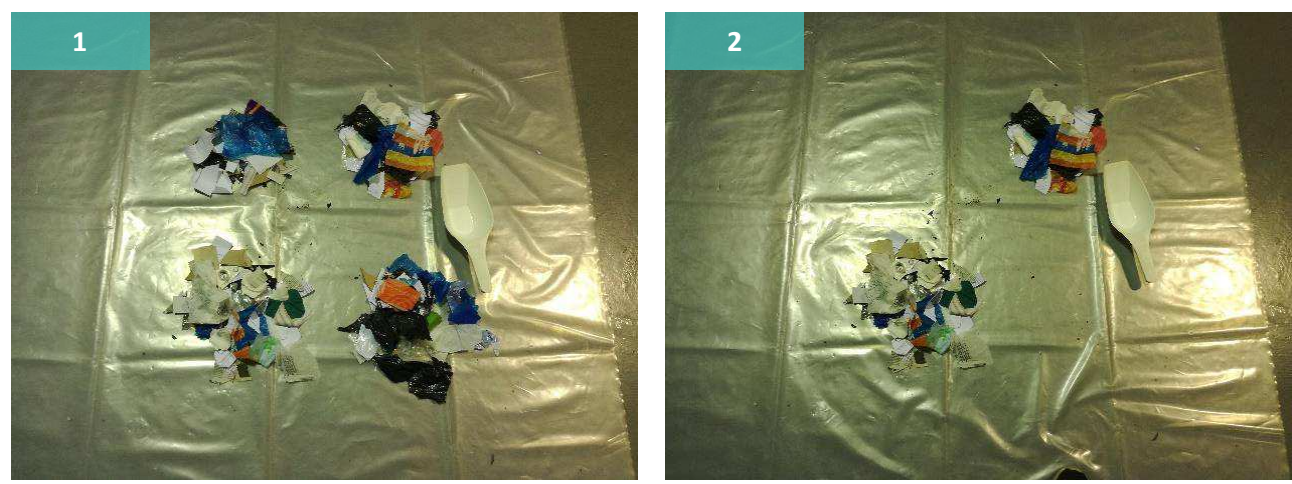

Figura 7.23 C60L6: Quinto cuarteo (1) y muestra obtenida (2) 


\section{Muestras C3OL2, C3OL3, C3OL4, C3OL5 y C3OL6}

Las muestras de laboratorio C30L2, C30L3, C30L4, C30L5 Y C30L6 se obtuvieron mediante sucesivos cuarteos a partir de MA4 (Figura 7.13 (3)). En la Tabla 7.7 se exponen las características de estas muestras de laboratorio antes de su trituración final a $1 \mathrm{~mm}$. Seguidamente se presentan una serie de figuras con los cuarteos realizados y las distintas muestras obtenidas en cada uno de ellos.

Tabla 7.7 Características de las muestras de laboratorio C30L2, C30L3, C30L4, C30L5 Y C30L6

\begin{tabular}{|c|c|c|c|c|}
\hline \multirow{2}{*}{$\begin{array}{l}\text { Id. Muestra de } \\
\text { laboratorio }\end{array}$} & \multicolumn{2}{|c|}{ Procedimientos de preparación de muestra } & \multicolumn{2}{|c|}{ Características de la muestra } \\
\hline & $\begin{array}{c}\text { Reducción tamaño } \\
\text { partícula inicial }\end{array}$ & División de muestra & $d_{95}(\mathrm{~mm})$ & $\begin{array}{l}\text { Peso tras la } \\
\text { división (kg) }\end{array}$ \\
\hline C30L2 & Corte con tijera a $30 \mathrm{~mm}$ & 1 cuarteo & \multirow{5}{*}{30} & 1,004 \\
\hline C30L3 & Corte con tijera a $30 \mathrm{~mm}$ & $\begin{array}{l}2 \text { cuarteos } \\
\text { sucesivos }\end{array}$ & & 0,503 \\
\hline C30L4 & Corte con tijera a $30 \mathrm{~mm}$ & $\begin{array}{l}3 \text { cuarteos } \\
\text { sucesivos }\end{array}$ & & 0,250 \\
\hline C30L5 & Corte con tijera a $30 \mathrm{~mm}$ & $\begin{array}{l}4 \text { cuarteos } \\
\text { sucesivos }\end{array}$ & & 0,128 \\
\hline C30L6 & Corte con tijera a $30 \mathrm{~mm}$ & $\begin{array}{l}5 \text { cuarteos } \\
\text { sucesivos }\end{array}$ & & 0,066 \\
\hline
\end{tabular}
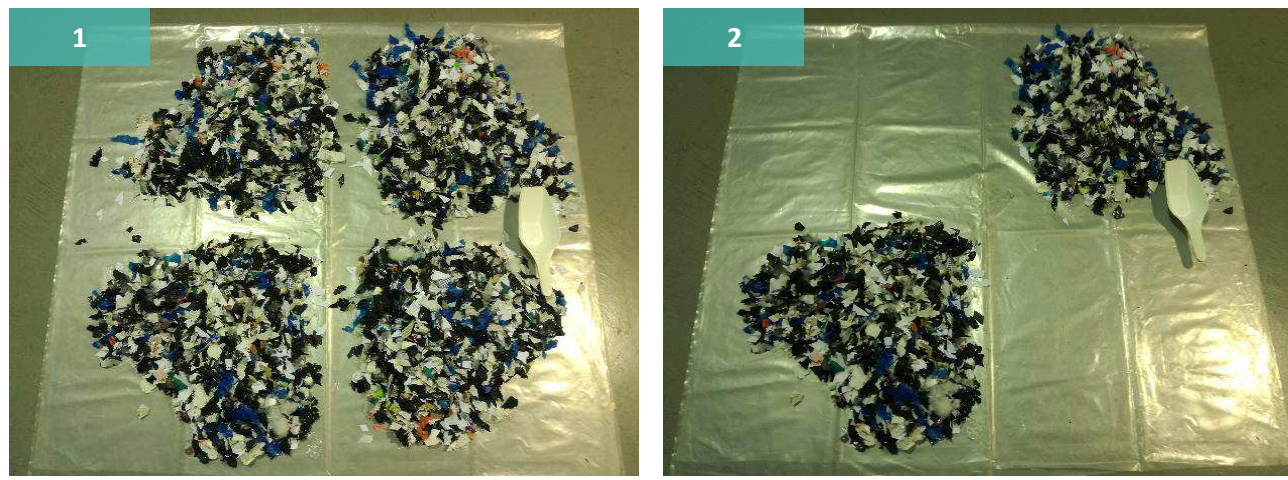

Figura 7.24 C30L2: Primer cuarteo (1) y muestra obtenida (2)
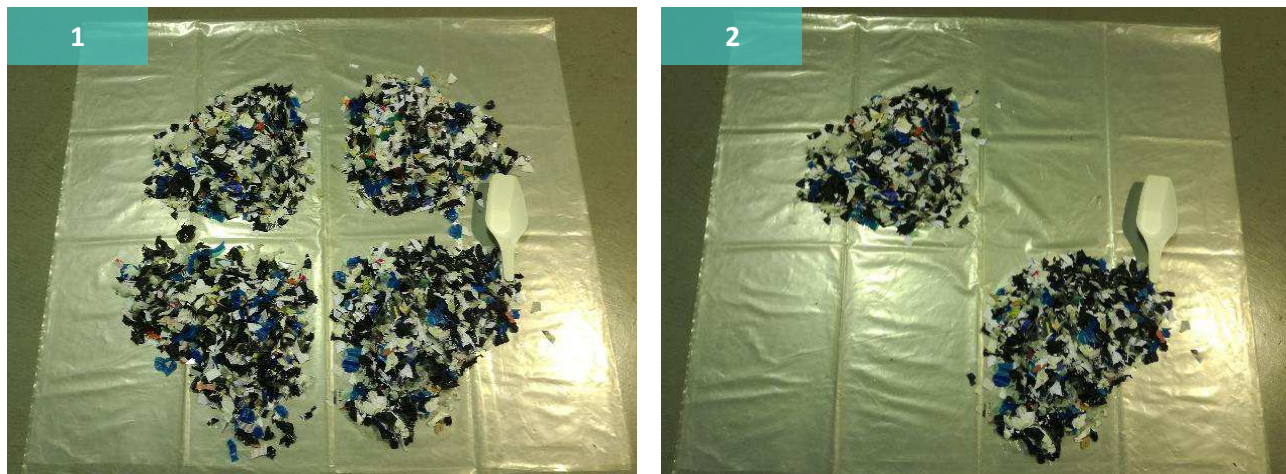

Figura 7.25 C30L3: Segundo cuarteo (1) y muestra obtenida (2) 

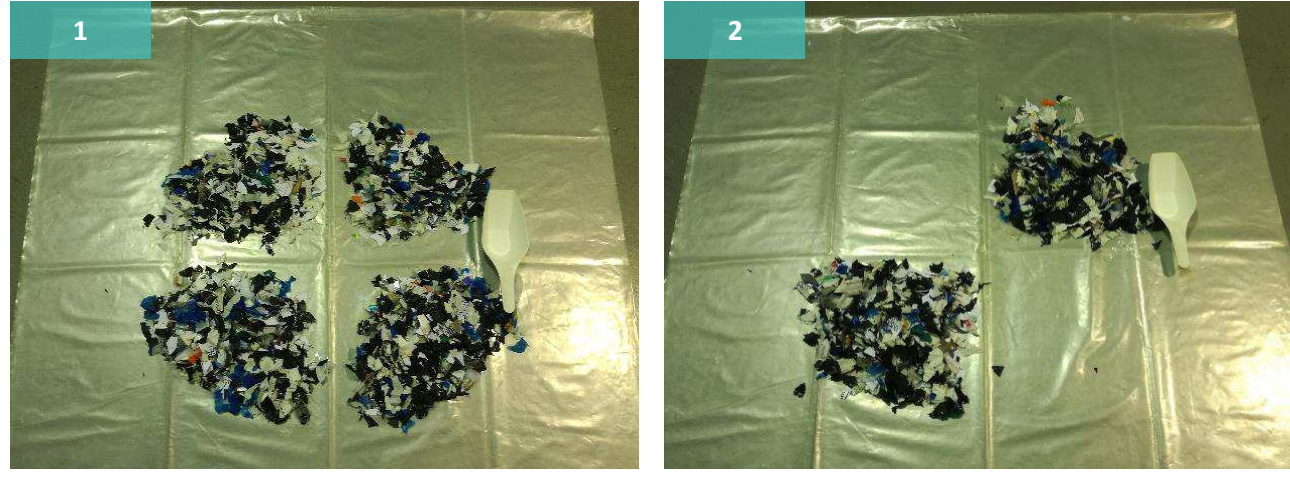

Figura 7.26 C30L4: Tercer cuarteo (1) y muestra obtenida (2)
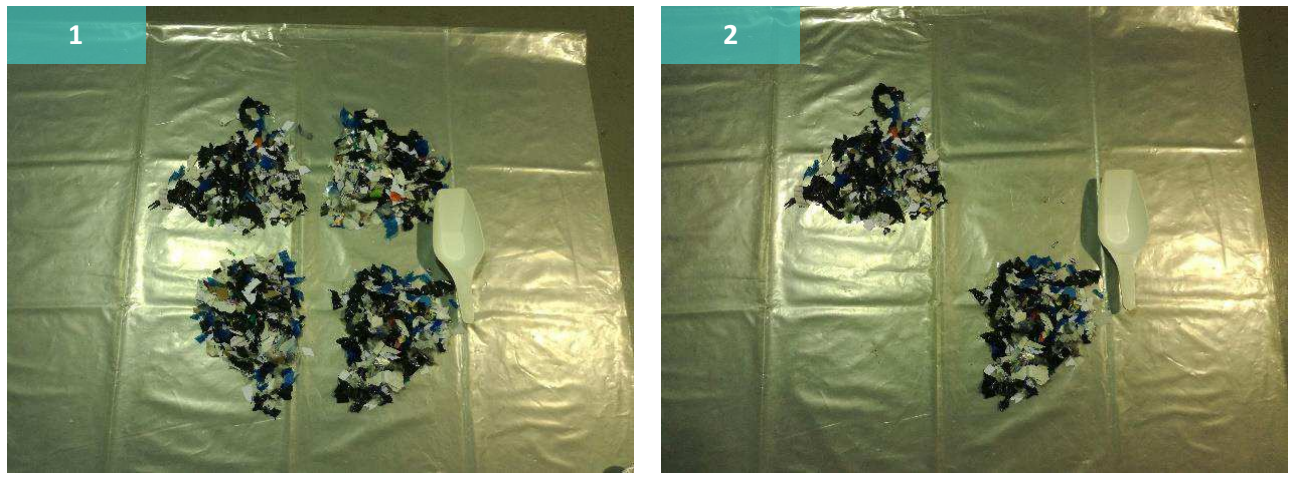

Figura 7.27 C30L5: Cuarto cuarteo (1) y muestra obtenida (2)
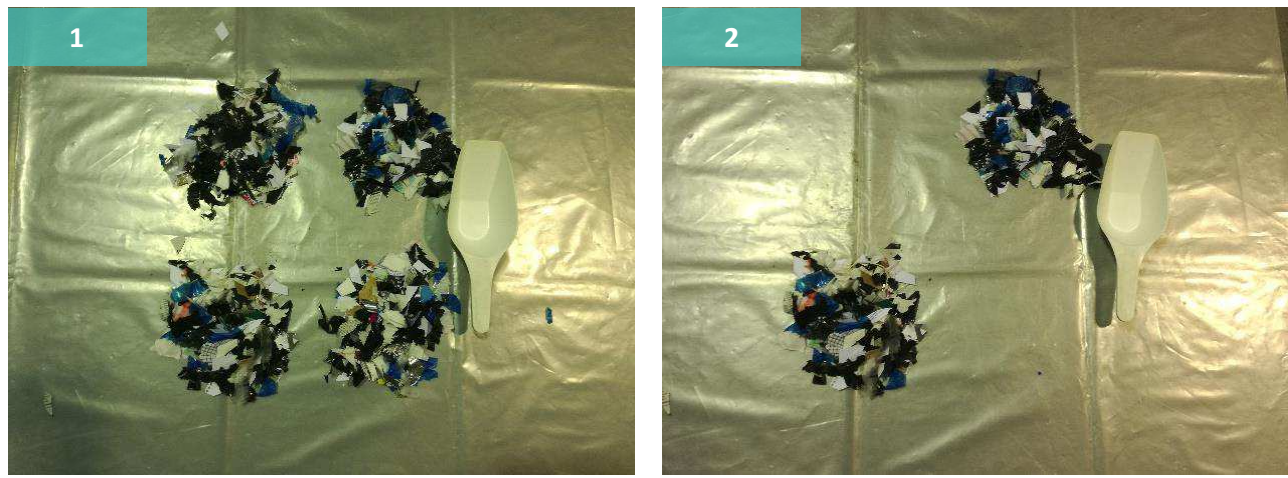

Figura 7.28 C30L6: Quito cuarteo (1) y muestra obtenida (2)

\section{Secado, eliminación de material no combustible y trituración final a $1 \mathrm{~mm}$}

Una vez obtenida la muestra de referencia y las 15 muestras de laboratorio mediante los diferentes procedimientos, se procedió a su secado y determinación de la humedad mediante la norma UNE-EN 154143 (2011). En la Tabla 7.9 se expone la humedad de cada una de las muestras de laboratorio estudiadas.

Tras el secado y antes de la trituración final se eliminó el material no combustible de las muestras que corresponde a: metales, inertes, vidrio y parte de la fracción RTP y parte de la fracción Otros (Figura 7.29). 


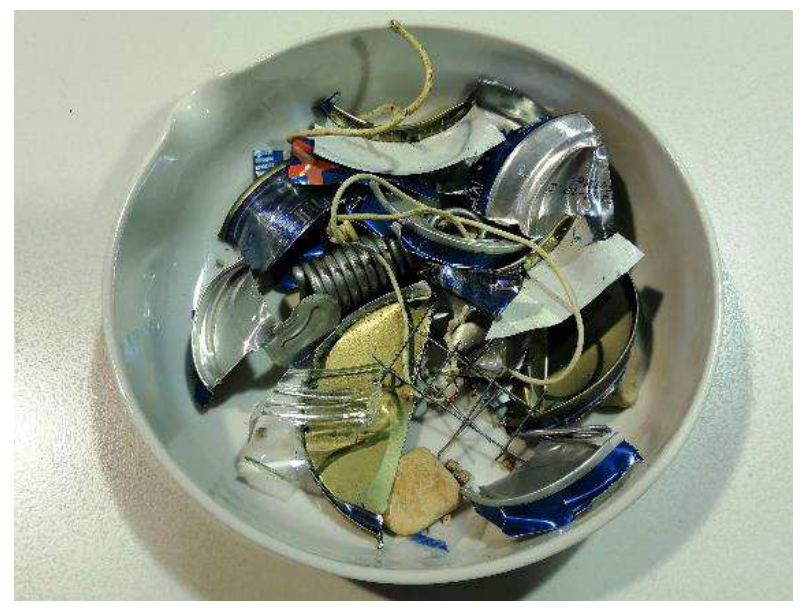

Figura 7.29 Fracción no combustible eliminada de la muestra de laboratorio C60L2

Los porcentajes de fracción no combustible obtenidos para la muestra de referencias y las 15 muestras de laboratorio se exponen en la Tabla 7.8.

Tabla 7.8 Porcentaje de fracción no combustible de las muestra de referencia y las 15 muestras de laboratorio

\begin{tabular}{c|c|c|c}
\hline Muestra & $\begin{array}{c}\text { Fracción no } \\
\text { combustible (\%) }\end{array}$ & Muestra & $\begin{array}{c}\text { Fracción no } \\
\text { combustible (\%) }\end{array}$ \\
\cline { 1 - 2 } CNL1 (Ref.) & 7,39 & C60L4 & 4,60 \\
\cline { 1 - 2 } CNL2 & 10,98 & C60L5 & 11,84 \\
\hline CNL3 & 5,47 & C60L6 & 2,69 \\
\hline CNL4 & 2,58 & C3OL2 & 9,33 \\
\hline CNL5 & 0,00 & C30L3 & 4,68 \\
\hline CNL6 & 0,86 & C30L4 & 2,89 \\
\hline C60L2 & 8,73 & C30L5 & 2,92 \\
\hline C60L3 & 3,92 & C30L6 & 3,30 \\
\hline
\end{tabular}

El porcentaje de fracción no combustible de la muestra de referencia es de 7,39\%, mientras que para el resto de muestras de laboratorio los porcentajes van desde el 11,84\% (C60L5) al 0\% (CNL5). Las diferencias que se observan se deben a un reparto desigual de los materiales no combustibles a la hora de realizar la división de muestra por cuarteo.

Por último, dado que todos los análisis necesarios para determinar los parámetros de calidad requieren un tamaño de partícula de $1 \mathrm{~mm}$, las muestras se trituraron a dicho tamaño con un molino de corte. De esta forma se consiguen las muestras de laboratorio finales, de las cuales se tomarán alícuotas para determinar el $\mathrm{PCl}, \mathrm{Cl}$ y $\mathrm{Hg}$. En la Figura 7.30 se puede ver parte del material obtenido para cada muestra de laboratorio. En ella se observa a simple vista que algunas muestras de laboratorio podrían ser diferentes y, por lo tanto, no representativas. Por ejemplo, la CNL5 tiene un color distinto. No obstante, esto se comprobará con el análisis estadístico de los resultados obtenidos para los parámetros de calidad. 


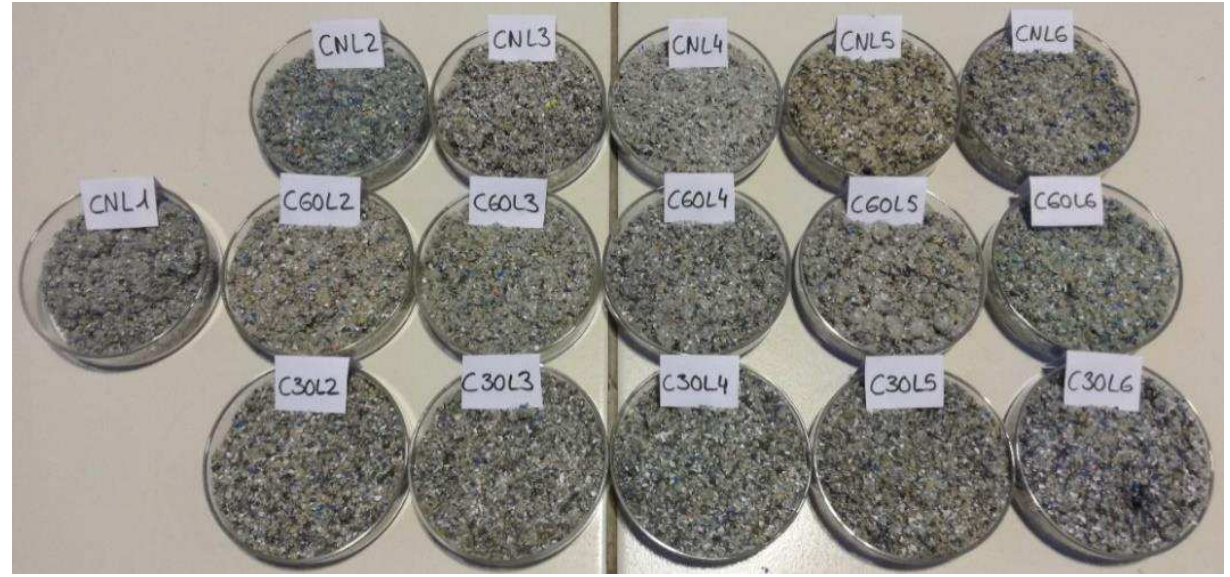

Figura 7.30 Muestras de laboratorio tras su trituración final a $1 \mathrm{~mm}$

\subsubsection{Análisis de los parámetros de calidad}

Los resultados de $\mathrm{PCl}$, contenido en $\mathrm{Cl}$ y contenido en $\mathrm{Hg}$ (media y desviación estándar) para la muestra de referencia y las 15 muestras de laboratorio obtenidas se presentan en la Tabla 7.9, así como la humedad de cada una de ellas. Estos resultados se expresan en relación al material total y sobre muestra húmeda (smh).

Tabla 7.9 Humedad, $\mathrm{PCl}$, contenido en $\mathrm{Cl}$ y en $\mathrm{Hg}$ de la muestra de referencia y las 15 muestras de laboratorio

\begin{tabular}{|c|c|c|c|c|c|c|c|}
\hline \multirow{2}{*}{$\begin{array}{l}\text { Id. Muestra } \\
\text { Laboratorio }\end{array}$} & \multirow{2}{*}{$\begin{array}{l}\text { Humedad } \\
\text { (\%) }\end{array}$} & \multicolumn{2}{|c|}{$\mathrm{PCl}$ smh (MJ/kg) } & \multicolumn{2}{|c|}{$\mathrm{Cl} \operatorname{smh}(\%)$} & \multicolumn{2}{|c|}{ Hg smh (ppm) } \\
\hline & & $\bar{x}$ & s & $\bar{x}$ & s & $\bar{x}$ & s \\
\hline CNL1 (Ref.) & 5,77 & 18,89 & 0,42 & 0,18 & 0,03 & 0,011 & 0,001 \\
\hline CNL2 & 3,93 & 18,43 & 0,26 & 0,12 & 0,01 & 0,007 & 0,000 \\
\hline CNL3 & 19,12 & 18,83 & 0,54 & 0,14 & 0,01 & 0,008 & 0,001 \\
\hline CNL4 & 3,72 & 17,18 & 0,09 & 0,09 & 0,00 & 0,008 & 0,001 \\
\hline CNL5 & 3,47 & 20,84 & 0,23 & 0,80 & 0,09 & 0,015 & 0,003 \\
\hline CNL6 & 3,24 & 17,21 & 0,48 & 0,08 & 0,01 & 0,014 & 0,001 \\
\hline C60L2 & 7,20 & 17,83 & 0,33 & 0,17 & 0,01 & 0,009 & 0,002 \\
\hline C60L3 & 16,50 & 16,94 & 0,26 & 0,16 & 0,02 & 0,006 & 0,001 \\
\hline C60L4 & 3,60 & 21,17 & 0,39 & 0,09 & 0,00 & 0,012 & 0,005 \\
\hline C60L5 & 3,97 & 17,45 & 0,16 & 0,09 & 0,00 & 0,010 & 0,002 \\
\hline C60L6 & 3,69 & 18,99 & 0,37 & 0,10 & 0,02 & 0,013 & 0,001 \\
\hline C30L2 & 5,88 & 18,34 & 0,16 & 0,13 & 0,02 & 0,009 & 0,002 \\
\hline C30L3 & 5,78 & 19,53 & 0,46 & 0,14 & 0,02 & 0,012 & 0,003 \\
\hline C30L4 & 19,17 & 16,08 & 0,21 & 0,13 & 0,02 & 0,009 & 0,001 \\
\hline C30L5 & 9,14 & 19,00 & 0,43 & 0,07 & 0,01 & 0,012 & 0,002 \\
\hline C30L6 & 2,95 & 21,88 & 0,62 & 0,06 & 0,01 & 0,011 & 0,001 \\
\hline
\end{tabular}

Como se observa en la tabla anterior, la humedad de la muestra de laboratorio de referencia (CNL1) es del $5,77 \%$, mientras que para el resto de muestras los valores van desde el 2,95\% (C30L6) al 19,17\% (C30L4). Esta gran variabilidad se debe a un reparto desigual de la fracción orgánica al realizar la división por cuarteo, en 
concreto de los restos de sandía que son los que aportan la humedad. Por otro lado, para casi todas las muestras, los valores obtenidos se encuentran por debajo de los hallados en la literatura para un rechazo de recuperación de materiales real (Bessi et al., 2016; Di Lonardo et al., 2016; Edo-Alcón et al., 2016; Gallardo et al., 2014; Sever Akdağ et al., 2016) debido a que se trata de muestras diseñadas a partir de materiales limpios y secos.

Respecto al poder calorífico, el valor medio para la muestra de referencia es de $18,89 \mathrm{MJ} / \mathrm{kg}$, mientras que el $\mathrm{PCl}$ para las otras muestras oscila entre el 16,08 MJ/kg de la C30L4 al 21,88 MJ/kg de la C30L6 (Tabla 7.9). Esta variabilidad se debe a que cada tipo de material presente en el rechazo tienen su propio $\mathrm{PCl}$, por ejemplo: 11,13 MJ/kg para el papel/cartón, 11,77 MJ/kg para la fracción orgánica, 30,07 MJ/kg para los plásticos rígidos, 34,94 MJ/kg para el film o 16,45 MJ/kg para el textil (Edo-Alcón, 2012). Por lo que, tras la división por cuarteo, las muestras de laboratorio tienen poderes caloríficos diferentes en función de cómo se hayan repartido los distintos materiales. Por otra parte, los valores obtenidos son muy parecidos a los de un rechazo de recuperación de materiales de una planta de TMB real, cuyo PCl puede encontrarse entre los 11 y los 19 MJ/kg (smh) (Bessi et al., 2016; Edo-Alcón et al., 2016; Gallardo et al., 2014; Sever Akdağ et al., 2016).

El contenido en cloro medio de la muestra de referencia (CNL1) es del 0,18\%. Para el resto de muestras de laboratorio el valor más alto se da en la CNL5 con 0,80\% y el mínimo en la C30L6 con 0,06\%. Al igual que ocurre con el $\mathrm{PCl}$, esta variabilidad es debida a que el contenido en cloro de cada material presente en el rechazo es distinto, por ejemplo: un 0,44\% para el papel/cartón, un 0,05\% para el PET, 0,12\% para el PEAD, un $38,4 \%$ para el PVC, un 0,46\% para el plástico film o un 0,72 \% para el textil (Gallardo et al., 2015) . Por lo tanto, en base a la composición obtenida para cada muestra tras la división por cuarteo, el porcentaje de cloro en la muestra será diferente. El contenido en cloro se encuentra en casi todos los casos un poco por debajo a los hallados en la literatura para un rechazo de recuperación real con porcentajes entre el 0,2 y el 0,8\% (smh) (Bessi et al., 2016; Di Lonardo et al., 2016; Edo-Alcón et al., 2016; Gallardo et al., 2014; Sever Akdağ et al., 2016).

En cuanto al contenido en $\mathrm{Hg}$, el valor medio para la muestra de referencia es de 0,011 ppm, mientras que los valores para el resto de muestras de laboratorio van desde 0,006 (C60L3) a 0,015 ppm (CNL5). Cabe señalar que estas concentraciones se encuentran por debajo de las que se darían en un rechazo real (Bessi et al., 2016; Di Lonardo et al., 2016; Edo-Alcón et al., 2016). Esto es debido a que las muestras se han diseñado a partir de material limpio que no contiene mercurio, puesto que normalmente la existencia de este metal pesado en los rechazos está asociado a la presencia de RTP como pilas o bombillas de bajo consumo que contaminan el material. Por otro lado, como en el caso del $\mathrm{PCl}$ y el $\mathrm{Cl}$, las variaciones respecto a la concentración de $\mathrm{Hg}$ entre las diferentes muestras son consecuencia de la distribución de los materiales que contienen mercurio a la hora de realizar la división por cuarteo.

Así pues, a priori se podría decir que, para algunas muestras de laboratorio, existen diferencias en los resultados obtenidos para los parámetros que definen la calidad de los rechazos en comparación con la muestra de referencia CNL1. No obstante, es importante conocer si estas diferencias son estadísticamente significativas y, por lo tanto, dichas muestras de laboratorio no son representativas.

\subsubsection{Determinación del tamaño de muestra de laboratorio}

Una vez obtenidos los datos de los análisis químicos de los parámetros de calidad $(\mathrm{PCl}, \mathrm{Cl}$ y $\mathrm{Hg}$ ) para la muestra de referencia y las 15 muestras de laboratorio, se ha procedido a la determinación del tamaño de muestra de laboratorio con el que se obtienen resultados representativos para cada procedimiento de reducción de tamaño de partícula. Para ello se debe analizar si existen diferencias significativas entre los resultados obtenidos para la muestra de referencia y los resultados del resto de muestras de laboratorio.

En primer lugar, para cada parámetro de calidad se ha realizado una comparación de medianas entre la muestra de referencia (CNL1) y las 15 muestras de restantes mediante técnicas no paramétricas: Test de Kruskal-Wallis y posterior comparación múltiple con el test post hoc de Dunn. De esta manera se ha podido identificar, para cada uno de los procedimientos de reducción de tamaño de partícula, el nivel de división crítico en el cual aparecen diferencias significativas respecto a la muestra de referencia y, por tanto, el número de cuarteos al que las muestras de laboratorio dejan de ser representativas. El nivel de división de 
muestra que esté por encima determinara el tamaño de muestra de laboratorio necesario ( $\mathrm{m} \mathrm{L})$ para cada procedimiento de reducción de tamaño de partícula.

A continuación, se exponen los resultados de los análisis estadísticos y de los tamaños de muestra de laboratorio determinados para cada uno de los parámetros de forma individual, así como para el análisis de la calidad global.

\section{$\mathrm{PCl}$}

Los resultados obtenidos tras la comparación de medianas mediante el Test de Kruskal-Wallis para el PCl muestran que existen diferencias estadísticamente significativas entre la muestra de referencia (CNL1) y algunas de las muestras de laboratorio estudiadas, puesto que se ha obtenido un p-valor mucho menor de 0,05 (H: 89,280; p-valor: 1,351·10-12). Por lo que se puede afirmar con una confianza del 95\%, que el PCl de ciertas muestras de laboratorio es distinto al de la muestra de referencia y, por tanto, los resultados obtenidos para algunos tamaños de muestra y procedimientos de reducción de tamaño de partícula no son representativos.

Para conocer entre qué muestras de laboratorio se dan estas diferencias se aplicó el test post hoc de Dunn. Los resultados obtenidos para las comparaciones entre CNL1 y el resto de muestras de laboratorio se presentan en la Tabla 7.10, así como el nivel de división de muestra crítico identificado para cada procedimiento de reducción de diámetro de partícula y el tamaño de muestra de laboratorio determinado en cada caso.

Tabla 7.10 Test post hoc para los resultados de $\mathrm{PCl}$

\begin{tabular}{|c|c|c|c|c|c|c|}
\hline \multirow{2}{*}{$\begin{array}{l}\text { Id. Muestra de } \\
\text { laboratorio }\end{array}$} & \multicolumn{2}{|c|}{ Características de la muestra } & \multicolumn{2}{|c|}{$\begin{array}{l}\text { Comparación CNL1 } \\
\text { - muestras de lab. }\end{array}$} & \multirow{2}{*}{$\begin{array}{c}\text { Nivel de } \\
\text { división } \\
\text { crítico }\end{array}$} & \multirow{2}{*}{$\begin{array}{c}\mathrm{m}_{\mathrm{L}} \mathrm{PCl} \\
(\mathrm{kg})\end{array}$} \\
\hline & $d_{95}(\mathrm{~mm})$ & $\begin{array}{c}\text { Peso de } \\
\text { muestra (kg) }\end{array}$ & Z & p-valor & & \\
\hline CNL1 (Ref.) & 570 & 2,010 & - & - & - & - \\
\hline CNL2 & \multirow{5}{*}{570} & 1,010 & 0,788 & 0,528 & \multirow{5}{*}{ CNL4 } & \multirow{5}{*}{$1,000^{*}$} \\
\hline CNL3 & & 0,508 & 0,073 & 0,958 & & \\
\hline CNL4 & & 0,254 & 2,518 & 0,033 & & \\
\hline CNL5 & & 0,126 & $-1,513$ & 0,208 & & \\
\hline CNL6 & & 0,069 & 2,539 & 0,033 & & \\
\hline C60L2 & \multirow{5}{*}{60} & 1,001 & 1,606 & 0,188 & \multirow{5}{*}{ C60L3 } & \multirow{5}{*}{1,000} \\
\hline C60L3 & & 0,505 & 2,860 & 0,016 & & \\
\hline C60L4 & & 0,252 & $-1,772$ & 0,145 & & \\
\hline C60L5 & & 0,129 & 1,938 & 0,115 & & \\
\hline C60L6 & & 0,067 & $-0,176$ & 0,898 & & \\
\hline C30L2 & \multirow{5}{*}{30} & 1,004 & 0,902 & 0,479 & \multirow{5}{*}{ C30L4 } & \multirow{5}{*}{0,500} \\
\hline C30L3 & & 0,503 & $-0,808$ & 0,518 & & \\
\hline C30L4 & & 0,250 & 3,430 & 0,003 & & \\
\hline C30L5 & & 0,128 & $-0,176$ & 0,890 & & \\
\hline C30L6 & & 0,066 & $-2,093$ & 0,084 & & \\
\hline
\end{tabular}

${ }^{*} \mathrm{~m}_{\mathrm{L}}$ correspondiente al procedimiento que incluye el corte a $60 \mathrm{~mm}$. puesto que no es lógico que al reducir el tamaño de partícula aumente el peso de muestra necesario, se ha escogido el peso más restrictivo de los dos. 
En el caso de no llevar a cabo una reducción inicial del tamaño de partícula, los resultados de las comparaciones múltiples (Tabla 7.10) muestran que, cuando la MA2 de $2 \mathrm{~kg}$ se divide mediante cuarteo hasta los 0,250 kg (CNL4) o hasta los 0,065 kg (CNL6), aparecen diferencias significativas en el PCl obtenido respecto a la muestra de referencia ( $p$-valores $<0,05$ ). Por lo tanto, para dichos tamaños de muestra de laboratorio, los resultados de este parámetro dejan de ser representativos de la población muestreada. Así pues, el nivel de división crítico más restrictivo para este procedimiento de reducción de diámetro de partícula corresponde al de la muestra CNL4, en la que se realizan 3 cuarteos sucesivos.

Cuando el proceso de preparación de muestra de laboratorio incluye la reducción inicial del tamaño de partícula a $60 \mathrm{~mm}$, los resultados expuestos en la Tabla 7.10 muestran que existen diferencias significativas en los valores de $\mathrm{PCl}$ entre la muestra de referencia y la muestra de laboratorio $\mathrm{C} 60 \mathrm{~L} 3$, cuyo peso corresponde a $0,500 \mathrm{~kg}$ ( $\mathrm{p}$-valor $<0,05)$. Así pues, los resultados obtenidos para ese peso de muestra de laboratorio ya no son representativos y, por lo tanto, el nivel de división crítico para ese procedimiento corresponde al de la muestra C60L3 en la que se realizan 2 cuarteos sucesivos.

En el caso de que la muestra de laboratorio se prepare llevando a cabo una reducción inicial del tamaño de partícula a $30 \mathrm{~mm}$, los resultados de las comparaciones múltiples indican que existen diferencias significativas en el PCl obtenido para la muestra de laboratorio C30L4 $(0,250 \mathrm{~kg})$ respecto a la muestra de referencia ( $p$ valor $<0,05$ ) (Tabla 7.10). Por lo que, para este peso de muestra de laboratorio, los resultados dejan de ser representativos. El nivel de división crítico para este procedimiento corresponde al de la muestra C30L4 en la que se realizan 3 cuarteos sucesivos.

A partir de la identificación de todos los niveles de división críticos se ha determinado el tamaño de muestra de laboratorio necesario para analizar el $\mathrm{PCl}$ en los rechazos para cada procedimiento de reducción de tamaño de partícula. Por un lado, cuando no se lleva a cabo una reducción inicial del tamaño de partícula, el tamaño de muestra de laboratorio $\left(m_{\mathrm{L}}\right)$ puede disminuirse a un cuarto mediante cuarteo, pasando de $2 \mathrm{~kg}$ a $0,500 \mathrm{~kg}$. En el caso de que se realice una reducción inicial del tamaño de partícula a un diámetro mayor o igual a $60 \mathrm{~mm}$, el tamaño de muestra de laboratorio puede disminuirse a la mitad mediante cuarteo, pasando de $2 \mathrm{~kg}$ a $1 \mathrm{~kg}$. Cabe señalar que, debido a que no es lógico que al reducir el tamaño de partícula a $60 \mathrm{~mm}$ se obtenga un peso de muestra necesario mayor que cuando no se reduce el diámetro de partícula, se ha decidido escoger el más restrictivo de los dos $\left(\mathrm{m}_{\mathrm{L}}=1 \mathrm{~kg}\right.$ ) para ambos casos (Tabla 7.10). Por otro lado, si se realiza una reducción inicial del tamaño de partícula a $30 \mathrm{~mm}$, el tamaño de muestra de laboratorio se puede disminuir a los 0,500 kg mediante dos cuarteos sucesivos sin que se pierda representatividad.

\section{Contenido en $\mathrm{Cl}$}

Los resultados obtenidos tras la comparación de medianas para el cloro indican que existen diferencias estadísticamente significativas entre la muestra de referencia (CNL1) y algunas de las muestras de laboratorio estudiadas, puesto que el p-valor obtenido en el Test de Kruskal-Wallis es mucho menor a 0,05 (H: 86,647; pvalor $4,169 \cdot 10^{-12}$ ). Así pues, se puede afirmar con una confianza del $95 \%$ que el contenido en cloro de ciertas muestras de laboratorio es distinto al de la muestra de referencia, por lo que los resultados obtenidos para algunos pesos de muestra y procedimiento de reducción de tamaño de partícula no son representativos.

Con el objetivo de conocer entre qué muestras se dan estas diferencias se ha aplicado el test post hoc de Dunn. En la Tabla 7.11 se presentan los resultados obtenidos para las comparaciones múltiples entre CNL1 y el resto de muestras de laboratorio, el nivel de división de muestra crítico identificado para cada procedimiento de reducción del diámetro de partícula y el tamaño de muestra determinado en cada caso. 
Tabla 7.11 Test post hoc para los resultados de $\mathrm{Cl}$

\begin{tabular}{|c|c|c|c|c|c|c|}
\hline \multirow{2}{*}{$\begin{array}{l}\text { Id. Muestra de } \\
\text { laboratorio }\end{array}$} & \multicolumn{2}{|c|}{ Características de la muestra } & \multicolumn{2}{|c|}{$\begin{array}{l}\text { Comparación CNL1 } \\
\text { - muestras de lab. }\end{array}$} & \multirow{2}{*}{$\begin{array}{l}\text { Nivel de } \\
\text { división } \\
\text { crítico }\end{array}$} & \multirow{2}{*}{$\begin{array}{r}\mathrm{m}_{\mathrm{L}} \mathrm{Cl} \\
(\mathrm{kg})\end{array}$} \\
\hline & $d_{95}(\mathrm{~mm})$ & $\begin{array}{c}\text { Peso de } \\
\text { muestra (kg) }\end{array}$ & Z & p-valor & & \\
\hline CNL1 (Ref.) & 570 & 2,010 & - & - & - & - \\
\hline CNL2 & \multirow{5}{*}{570} & 1,010 & 1,896 & 0,129 & \multirow{5}{*}{ CNL4 } & \multirow{5}{*}{0,500} \\
\hline CNL3 & & 0,508 & 1,047 & 0,398 & & \\
\hline CNL4 & & 0,254 & 2,891 & 0,014 & & \\
\hline CNL5 & & 0,126 & $-0,839$ & 0,496 & & \\
\hline CNL6 & & 0,069 & 4,052 & 0,001 & & \\
\hline C60L2 & \multirow{5}{*}{60} & 1,001 & $-0,062$ & 0,967 & \multirow{5}{*}{ C60L4 } & \multirow{5}{*}{0,500} \\
\hline C60L3 & & 0,505 & 0,187 & 0,881 & & \\
\hline C60L4 & & 0,252 & 3,140 & 0,008 & & \\
\hline C60L5 & & 0,129 & 3,223 & 0,007 & & \\
\hline C60L6 & & 0,067 & 2,881 & 0,014 & & \\
\hline C30L2 & \multirow{5}{*}{30} & 1,004 & 1,554 & 0,206 & \multirow{5}{*}{ C30L5 } & \multirow{5}{*}{0,250} \\
\hline C30L3 & & 0,503 & 1,067 & 0,390 & & \\
\hline C30L4 & & 0,250 & 1,285 & 0,302 & & \\
\hline C30L5 & & 0,128 & 4,290 & $<0,001$ & & \\
\hline C30L6 & & 0,066 & 4,725 & $<0,001$ & & \\
\hline
\end{tabular}

En la tabla anterior se puede ver que, en el caso de no realizar una reducción inicial del tamaño de partícula, existen diferencias significativas en el porcentaje de $\mathrm{Cl}$ entre la muestra de referencia (CNL1) y las muestras de laboratorio CNL4 y CNL6, cuyos pesos corresponden a $0,250 \mathrm{~kg}$ y $0,065 \mathrm{~kg}$ respectivamente ( $p$-valor $<0,05$ ). Por lo que, para este procedimiento el nivel de división crítico más restrictivo corresponde a la muestra CNL4.

En el caso de que la preparación de muestra incluya la reducción inicial del tamaño de partícula a $60 \mathrm{~mm}$, los resultados de las comparaciones múltiples indican que, cuando se divide la muestra artificial de rechazo por debajo de los 0,250 kg, las muestras de laboratorio obtenidas dejan de ser representativas (C60L4, C60L5 y C60L6). Puesto que el contenido en $\mathrm{Cl}$ obtenido para dichas muestras es significativamente diferente al obtenido para la muestra de referencia ( $p$-valor $<0,05$ ) (Tabla 7.11). Así pues, el nivel de división crítico más restrictivo para este procedimiento de reducción del diámetro de partícula corresponde a la muestra C60L4.

Cuando las muestras de laboratorio se preparan llevando a cabo una reducción del tamaño de partícula a 30 $\mathrm{mm}$, los resultados de las comparaciones expuestos en la Tabla 7.11 muestran que existen diferencias significativas en el contenido en Cl para las muestras de laboratorio C30L5 (0,125 kg) y C30L6 $(0,065 \mathrm{~kg})$ respecto a la muestra de referencia ( $p$-valor $<0,05)$. Por lo que el nivel de división crítico más restrictivo para este procedimiento corresponde a la muestra C30L5.

Una vez identificados todos los niveles de división críticos se ha determinado el tamaño de muestra de laboratorio necesario para analizar el contenido en cloro de los rechazos para cada procedimiento de reducción de tamaño de partícula. Por una parte, cuando no se realiza una reducción inicial del tamaño de partícula o esta se hace a un $d_{95}$ de $60 \mathrm{~mm}$, el tamaño de muestra de laboratorio ( $\mathrm{m}_{\mathrm{L}}$ ) puede disminuirse 
desde los $2 \mathrm{~kg}$ a los 0,500 kg mediante dos cuarteos sucesivos. Mientras que, cuando el tamaño de partícula se reduce a los $30 \mathrm{~mm}$, el tamaño de muestra de laboratorio puede ser menor sin perder representatividad, de $0,250 \mathrm{~kg}$.

\section{Contenido en $\mathrm{Hg}$}

Los resultados de la comparación de medianas para el Hg mediante el Test de Kruskal-Wallis muestran que existen diferencias significativas entre la muestra de referencia y algunas muestras de laboratorio, puesto que el $\mathrm{p}$-valor obtenido es muy pequeño y menor a $0,05\left(\mathrm{H}: 72,262 ; \mathrm{p}\right.$-valor $\left.1,761 \cdot 10^{-9}\right)$. Por lo que se puede afirmar con una confianza del $95 \%$, que el contenido en $\mathrm{Hg}$ para ciertas muestras de laboratorio es distinto al de la muestra de referencia y, por tanto, los resultados obtenidos para algunos tamaños de muestra y procedimientos de reducción de tamaño de partícula no son representativos.

Para conocer entre qué muestras de laboratorio se dan estas diferencias se aplicó el test pos hoc de Dunn. Los resultados obtenidos se presentan en la Tabla 7.12, junto con el nivel de división de muestra crítico identificado para cada procedimiento de reducción de diámetro de partícula y el tamaño de muestra determinado en cada caso.

Tabla 7.12 Test post hoc para los resultados de $\mathrm{Hg}$

\begin{tabular}{|c|c|c|c|c|c|c|}
\hline \multirow{2}{*}{$\begin{array}{l}\text { Id. Muestra de } \\
\text { laboratorio }\end{array}$} & \multicolumn{2}{|c|}{ Características de la muestra } & \multicolumn{2}{|c|}{$\begin{array}{l}\text { Comparación CNL1 } \\
\text { - muestras de lab. }\end{array}$} & \multirow{2}{*}{$\begin{array}{c}\text { Nivel de } \\
\text { división } \\
\text { crítico }\end{array}$} & \multirow{2}{*}{$\begin{array}{c}\mathrm{m}_{\mathrm{L}} \mathrm{Hg} \\
(\mathrm{kg})\end{array}$} \\
\hline & $d_{95}(\mathrm{~mm})$ & $\begin{array}{c}\text { Peso de } \\
\text { muestra (kg) }\end{array}$ & $\mathbf{z}$ & p-valor & & \\
\hline CNL1 (Ref.) & 570 & 2,010 & - & - & - & - \\
\hline CNL2 & \multirow{5}{*}{570} & 1,010 & 3,399 & 0,005 & \multirow{5}{*}{ CNL2 } & \multirow{5}{*}{2,000} \\
\hline CNL3 & & 0,508 & 2,124 & 0,096 & & \\
\hline CNL4 & & 0,254 & 2,456 & 0,051 & & \\
\hline CNL5 & & 0,126 & $-1,316$ & 0,301 & & \\
\hline CNL6 & & 0,069 & $-1,420$ & 0,263 & & \\
\hline C60L2 & \multirow{5}{*}{60} & 1,001 & 1,959 & 0,128 & \multirow{5}{*}{ C60L3 } & \multirow{5}{*}{1,000} \\
\hline C60L3 & & 0,505 & 3,523 & 0,004 & & \\
\hline C60L4 & & 0,252 & 0,249 & 0,877 & & \\
\hline C60L5 & & 0,129 & 1,109 & 0,382 & & \\
\hline C60L6 & & 0,067 & $-0,891$ & 0,492 & & \\
\hline C30L2 & \multirow{5}{*}{30} & 1,004 & 1,689 & 0,192 & \multirow{5}{*}{-} & \multirow{5}{*}{0,065} \\
\hline C30L3 & & 0,503 & 0,218 & 0,895 & & \\
\hline C30L4 & & 0,250 & 1,523 & 0,232 & & \\
\hline C30L5 & & 0,128 & $-0,145$ & 0,931 & & \\
\hline C30L6 & & 0,066 & 0,114 & 0,933 & & \\
\hline
\end{tabular}

Como se observa en la tabla anterior, en el caso de no llevar a cabo una reducción inicial del tamaño de partícula, los resultados de las comparaciones múltiples indican que, cuando la muestra artificial de $2 \mathrm{~kg}$ se divide a 1 kg (CNL2), aparecen diferencias significativas en la concentración de Hg respecto a la muestra de 
referencia ( $p$-valor $<0,05$ ). Por lo tanto, el nivel de división crítico para este procedimiento corresponde con el de la muestra CNL2.

Si la preparación de muestra de laboratorio incluye la reducción inicial del diámetro de partícula a $60 \mathrm{~mm}$, los resultados expuestos en la Tabla 7.12 muestran que existen diferencias en el contenido en $\mathrm{Hg}$ entre la muestra de referencia y la muestra de laboratorio C60L3, cuyo peso corresponde a 0,500 kg ( $p$-valor $<0,05$ ). Por lo que, para dicho tamaño de partícula, el nivel crítico de división corresponde al de la muestra C60L3.

En el caso de que la preparación de muestra incluya la reducción del diámetro a $30 \mathrm{~mm}$, los resultados de las comparaciones múltiples indican que todas las muestras de laboratorio estudiadas son representativas. Puesto que no existen diferencias entre la concentración de $\mathrm{Hg}$ de la muestra de referencias y el resto de muestras de laboratorio de distintos tamaños ( $p$-valor $>0,05$ ) (Tabla 7.12). Así pues, para este procedimiento no existe un nivel crítico de división.

A partir de la identificación de todos los niveles críticos se ha determinado el tamaño de muestra de laboratorio necesario para analizar el contenido en $\mathrm{Hg}$ en los rechazos para cada procedimiento de reducción de tamaño de partícula. Por un lado, cuando no exista una reducción inicial del tamaño de partícula, la muestra de laboratorio corresponderá a la muestra de $2 \mathrm{~kg}$ recompuesta de la primera etapa de la preparación de muestras para el control de calidad de los rechazos, puesto que se ha observado que si esta se cuartea para disminuir su peso los resultados dejan de ser representativos. Por otro lado, si se realiza una reducción inicial a un $d_{95}$ de $60 \mathrm{~mm}$, el tamaño de muestra de laboratorio $\left(\mathrm{m}_{\mathrm{L}}\right)$ se puede disminuir a la mitad mediante cuarteo sin perder representatividad, pasando de $2 \mathrm{~kg}$ a $1 \mathrm{~kg}$, mientras que si esta reducción de tamaño se hace a un $d_{95}$ de $30 \mathrm{~mm}$ el tamaño de muestra de laboratorio puede ser mucho más pequeño, de $0,065 \mathrm{~kg}$.

\section{Calidad global}

Como se ha visto anteriormente, el tamaño de muestra de laboratorio con el que se obtienen resultados representativos es diferente en función del parámetro de calidad que se quiera analizar. Por lo que, si se quiere llevar a cabo el control de calidad de los rechazos teniendo en cuenta todos ellos, el tamaño de muestra de laboratorio necesario será siempre el más restrictivo de los tres (Tabla 7.13).

Tabla 7.13 Tamaños de muestra de laboratorio necesarias para el control de calidad de los rechazos

\begin{tabular}{c|c|c|c|c}
\hline $\begin{array}{c}\text { Tamaño de muestra } \\
\text { de laboratorio }(\mathbf{k g})\end{array}$ & PCI & Cl & Hg & $\begin{array}{c}\text { Calidad } \\
\text { Global }\end{array}$ \\
\hline CN & 1,000 & 0,500 & 2,000 & $\mathbf{2 , 0 0 0}$ \\
\hline C60 & 1,000 & 0,500 & 1,000 & $\mathbf{1 , 0 0 0}$ \\
\hline C30 & 0,500 & 0,250 & 0,065 & $\mathbf{0 , 5 0 0}$ \\
\hline
\end{tabular}

Así pues, para determinar la calidad global de un rechazo es necesaria una muestra de laboratorio de $2 \mathrm{~kg}$ si no se lleva a cabo ninguna reducción inicial del tamaño de partícula (CN), que corresponde con la muestra recompuesta de la primera etapa de la preparación de muestras; una muestra de $1 \mathrm{~kg}$ si el d95 de la muestra inicial se reduce a $60 \mathrm{~mm}$ antes de la división por cuarteo (C60), o una muestra de 0,500 kg si el d95 de la muestra inicial se reduce a $30 \mathrm{~mm}$ antes de la división mediante dos cuarteos sucesivos (C30). Cabe señalar que a medida que se reduce el tamaño de partícula, el tamaño de muestra de laboratorio con el que se obtienen resultados representativos es menor.

En la tabla anterior también se observa que, para parámetros que están presentes en todos los materiales como el $\mathrm{PCl}$ o el $\mathrm{Cl}$, si la preparación de muestra no incluye ningún paso de reducción de tamaño de partícula, el tamaño de muestra con el que se obtienen resultados representativos se puede disminuir a 1 y 0,500 kg respectivamente. Sin embargo, para aquellos parámetros como el Hg que se encuentran en concentraciones mucho más bajas y que están presente en materiales muy específicos (pilas y bombillas de bajo consumo), el tamaño de muestra de laboratorio necesario es mayor, de $2 \mathrm{~kg}$. No obstante, mediante la reducción del $d_{95}$ de los materiales antes de la división de muestra este efecto puede disminuirse. 


\subsection{DETERMINACIÓN DEL TIEMPO ÓPTIMO DE SECADO}

La preparación de muestra de laboratorio incluye el secado de las mismas. Este tiene como finalidad eliminar el agua que contienen el material y que puede interferir en los análisis posteriores, por lo que es importante conseguir un secado total del rechazo. Además, los análisis de los parámetros de calidad siempre se realizan sobre muestra seca y, por lo tanto, es fundamental determinar la humedad adecuadamente.

El objetivo que persigue el presente apartado es establecer un tiempo óptimo de secado para muestras de rechazo. Para ello se han estudiado siete corrientes diferentes de materiales de dos plantas de TMB con origen y composición distintas, monitorizando su proceso de secado.

\subsubsection{Metodología experimental}

A continuación, se muestra la metodología experimental utilizada. Incluye la descripción de las diferentes corrientes de materiales estudiadas y del proceso de monitorización del secado.

\subsubsection{Corrientes de materiales estudiadas}

A la hora de determinar el tiempo de secado óptimo se han estudiado siete corrientes de materiales con composiciones y tamaños de partícula distintos, lo que permitirá conocer si existen diferencias en el tiempo de secado en función de la composición y/o diámetro de partícula.

Estas siete corrientes se originan en dos plantas de TMB diferentes, ambas ubicadas en la Comunidad Valenciana: la planta de recuperación y compostaje de Onda (Castellón) y la planta de recuperación y compostaje de Guadassuar (Valencia). A continuación, se describen cada una de estas plantas y las corrientes analizadas en ellas.

La PRC de Onda se ha descrito en primer caso de aplicación del capítulo 6 de la presente tesis. En ella la recuperación de materiales se realiza de forma mecánica y manual y la fracción orgánica se bioestabiliza mediante túneles. Tras el proceso se originan tres corrientes de rechazo susceptibles de ser transformadas en un CSR: el rechazo de recuperación manual, el rechazo de afino primario del bioestabilizado y el rechazo de afino secundario del bioestabilizado. De ellos, se van a estudiar solo los dos primeros:

- Rechazo de recuperación manual (RRM-O): generado en la etapa de recuperación de materiales, tras la separación de los materiales reciclables del rebose del trómel de pretratamiento, con un diámetro de partícula superior a $80 \mathrm{~mm}$.

- Rechazo de afino primario del bioestabilizado (RAB1-O): generado en el trómel intermedio de afino del material pre-bioestabilizado que procede de la fermentación en túneles, con un tamaño de partícula entre 80 y $30 \mathrm{~mm}$.

La PRC de Guadassuar trata los RSU mezclados que gestiona el Consorci de Residus Ribera i Valldigna (Plan Zonal de Residuos 5, Área de Gestión V4), procedentes de 54 municipios cuya población atendida suma 325.000 habitantes. La capacidad de tratamiento de la instalación es de 155.000 t/año y en el año 2015 se trataron 129.566 t de RSU mezclados. En esta instalación la recuperación de materiales se realiza de forma automática, separando: PET, PEAD, plástico mix, cartón, brik, metales férricos y metales no férricos. La fracción orgánica se destina a bioestabilización en nave cerrada.

Tras el tratamiento se generan cuatro corrientes de rechazo susceptibles de ser transformadas en CSR: dos en la recuperación de materiales, una en el afino primario del material bioestabilizado y otra en el afino secundario. De ellas se van a estudiar las originadas en la recuperación de materiales:

- Rechazo pesado de recuperación automática (RRAP-G): generado en la etapa de recuperación de materiales, formado por el material del rebose del trómel doble de pretratamiento (primer tramo $60 \mathrm{~mm}$, segundo tramo $90 \mathrm{~mm}$ ) y que no es separado por aspiración por la línea de recuperación de envases, con un diámetro de partícula de mayor de $90 \mathrm{~mm}$. 
- Rechazo ligero de recuperación automática (RRAL-G): generado en la etapa de recuperación de materiales al final de la línea de recuperación de envases, con un diámetro de partícula mayor a $70 \mathrm{~mm}$.

Además, en esta instalación también se han estudiado tres corrientes intermedias del proceso de tratamiento:

- Hundido 1 del pretratamiento (H60-G): flujo formado por el primer hundido del trómel doble de pretratamiento, con un tamaño de partícula menor a $60 \mathrm{~mm}$. Este flujo es destinado a compostaje.

- Hundido 2 del pretratamiento (H6090-G): flujo formado por el segundo hundido del trómel doble de pretratamiento, con un tamaño de partícula entre 60 y $90 \mathrm{~mm}$. Este flujo es destinado a compostaje tras la eliminación de los metales.

- Hundido del trómel recuperación (H70-G): flujo formado por el hundido del trómel existente en la etapa de recuperación de envases, con un tamaño de partícula menor a $70 \mathrm{~mm}$. Este flujo es destinado a compostaje.

En la Figura 7.31 se muestran el esquema de tratamiento de la etapa mecánica de la PRC de Guadassuar, en ella se indica el origen de las diferentes corrientes de materiales estudiadas:

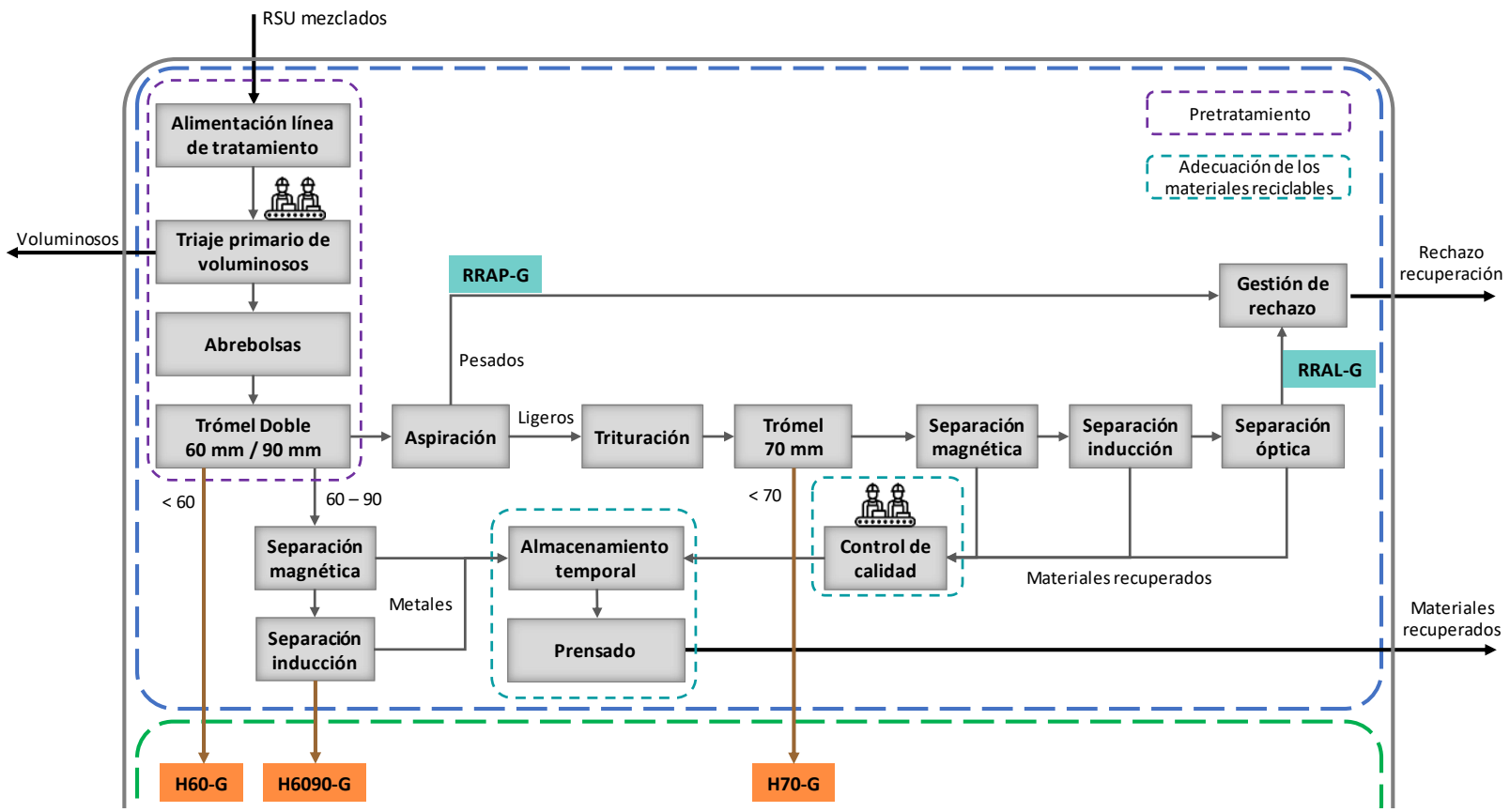

Figura 7.31 Esquema de tratamiento de las etapas mecánicas (pretratamiento y recuperación de materiales) de la PRC de Guadassuar

Con el objetivo de conocer si el tiempo de secado depende del diámetro de partícula, cada corriente se divide en diferentes categorías en función del tamaño de partícula. Para ello el material disponible para cada una de corrientes de material se tamizó con cribas de distintas luces de malla, dividiéndolo en las categorías en la Tabla 7.14 y determinando su distribución de tamaño de partícula. 
Tabla 7.14 Clases de tamaños consideradas para la determinación del tiempo óptimo de secado

\begin{tabular}{c|c}
\hline Corriente & $\begin{array}{c}\text { Categorías de tamaño } \\
(\mathbf{m m})\end{array}$ \\
\hline \multirow{2}{*}{ RRM-O } \\
RRAP-G & $<10$ \\
\cline { 2 - 2 } & $10-30$ \\
\cline { 2 - 2 } RRAL-G & $30-70$ \\
\hline \multirow{2}{*}{ RAB1-O } & $>70$ \\
\hline $\begin{array}{c}\text { H60-G } \\
\text { H6090-G } \\
\text { H70-G }\end{array}$ & $<70$ \\
\cline { 2 - 2 } & $<10$ \\
\hline
\end{tabular}

Finalmente, con el objetivo de conocer si el tiempo de secado varía en función de la composición, se ha caracterizado el material de cada una de las categorías de tamaños en los que se divide las siete corrientes, calificándolo en 12 fracciones.

\subsubsection{Monitorización del proceso de secado}

Para la monitorización del proceso de secado las muestras se reparten en tres bandejas de aluminio, previamente etiquetadas y taradas. En general, para todas las corrientes, la cantidad de material colocado en cada una de las bandejas fue de 150 gramos para la categoría de tamaño mayor de $70 \mathrm{~mm}$; 100 gramos para las categorías entre 70 y $10 \mathrm{~mm}$, y 50 gramos para la categoría menor de $10 \mathrm{~mm}$. Sin embargo, en el caso del RRAL-G, debido a que tiene una densidad muy baja, solo se han colocado 50 gramos de material por bandeja para todas las categorías de tamaño en las que se divide esta corriente.

A continuación, las bandejas se pesan en una balanza con precisión de 0,01 gramos para conocer el peso inicial del material en cada una de ellas y se introducen en una cámara climática marca DYCOMETAL modelo CCK-25/300 a una temperatura de $105^{\circ} \mathrm{C}$ (Figura 7.32), comenzando de esta forma el proceso de secado. Para la monitorización de dicho proceso, las muestras se han sometido a un periodo de secado de 24 horas. Durante las 8 primeras las muestras se pesan cada hora, finalmente, se dejan toda la noche y se vuelven a pesar al día siguiente, tras 24 horas de secado.

Todos los pesos obtenidos en la monitorización se han registrado en una hoja de campo diseñada a tal efecto. Esto ha permitido determinar la variación de masa debido a la pérdida de agua y, por lo tanto, determinar el tiempo óptimo de secado.

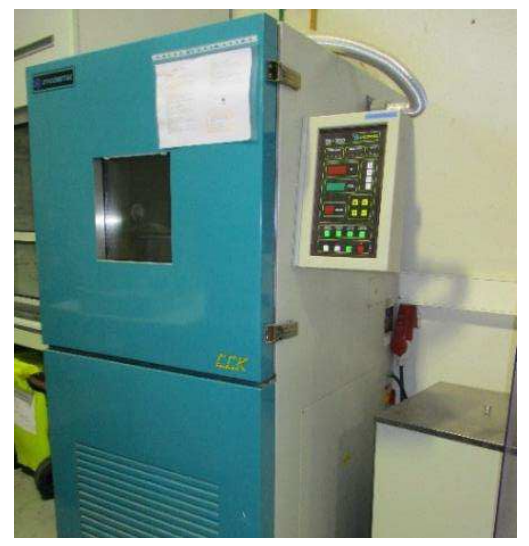

Figura 7.32 Cámara climática DYCOMETAL CCK-25/300 


\subsubsection{Resultados}

A continuación, se presentan los resultados obtenidos para las siete corrientes de materiales estudiadas en relación a su composición, distribución de tamaño de partícula y determinación del tiempo de secado. Los datos obtenidos en la monitorización del proceso de secado para las diferentes categorías de tamaño estudiadas se muestran en forma de gráfico. En dicho grafico se representa la variación de la masa inicial (en porcentaje) a lo largo del tiempo de secado. Cuando el porcentaje de la masa inicial se estabiliza, el proceso de secado a finalizado y el porcentaje alcanzado corresponde a la materia seca de la muestra.

Finalmente se presenta un resumen de los tiempos óptimos de secado determinados en función del tipo de rechazo, tamaño de partícula y materiales principales que los componen.

\subsubsection{Rechazo de recuperación manual de la PRC de Onda (RRM-O)}

EI RRM-O se genera en la etapa de recuperación de materiales de la PRC de Onda tras la separación de los materiales reciclables del rebose del trómel de pretratamiento. Las bandejas utilizadas en la monitorización del proceso de secado para cada categoría de tamaño se muestran en la Figura 7.33.

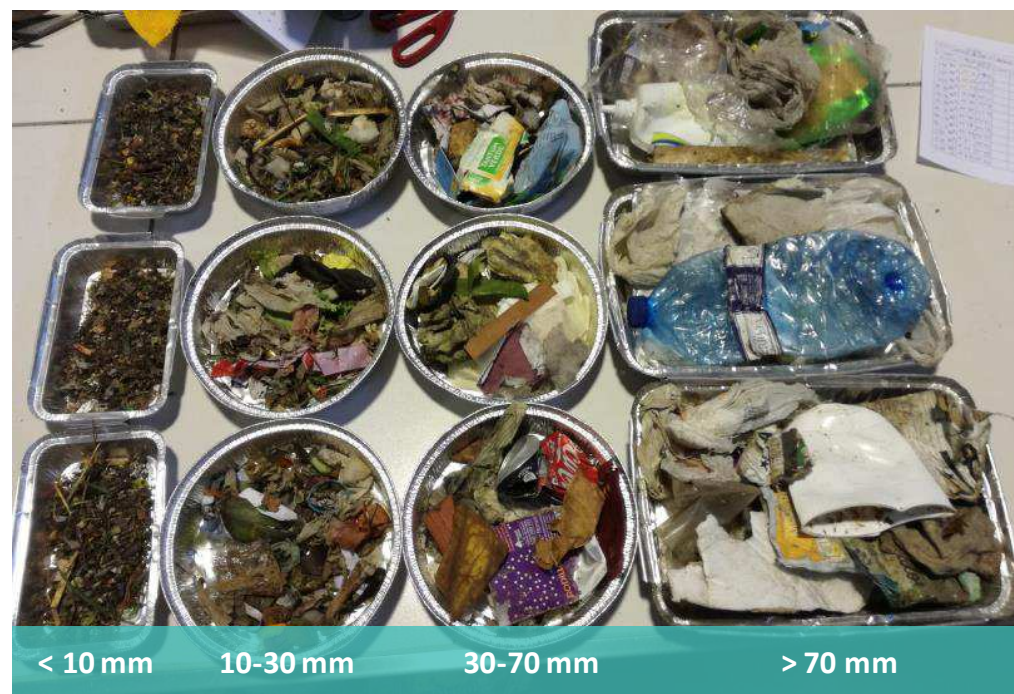

Figura 7.33 Bandejas de RRM-O para la monitorización del proceso de secado

Este rechazo está compuesto principalmente por papel/cartón $(27,37 \%)$ plástico rígido $(26,51 \%)$ y fracción orgánica $(11,38 \%)$, mientras que los materiales minoritarios son los RTP $(0,86 \%)$ y la madera $(1,34 \%)$. El tamaño de partícula predominante para este rechazo es el de mayor de $70 \mathrm{~mm}$, con un 53,72\% de las partículas, seguido por el de 30-70 mm, con un 29,38\% (Tabla 7.15). La distribución del tamaño de partícula y composición se muestra en la Tabla 7.15.

Tabla 7.15 Distribución del tamaño de partícula y composición del RRM-O

\begin{tabular}{c|c|c|c|c|c}
\hline Tamaño de partícula (mm) & $<\mathbf{1 0}$ & $\mathbf{1 0 - 3 0}$ & $\mathbf{3 0 - 7 0}$ & $>\mathbf{7 0}$ & TOTAL \\
\hline $\begin{array}{c}\text { Distribución de tamaño de } \\
\text { partícula (\%) }\end{array}$ & 4,34 & 12,57 & 29,38 & 53,72 & 100,00 \\
\hline Material & \multicolumn{5}{|c|}{ COMPOSICIÓN (\%) } \\
\hline Materia orgánica & 65,85 & 32,07 & 15,30 & 0,00 & 11,38 \\
\hline Papel/Cartón & 9,01 & 25,48 & 35,13 & 25,08 & 27,38 \\
\hline Plástico Film & 0,18 & 1,39 & 2,00 & 9,22 & 5,72 \\
\hline Plástico Rígido & 1,64 & 1,25 & 12,99 & 41,82 & 26,51 \\
\hline
\end{tabular}




\begin{tabular}{|c|c|c|c|c|c|}
\hline Tamaño de partícula (mm) & $<10$ & $10-30$ & $30-70$ & $>70$ & TOTAL \\
\hline Material & \multicolumn{5}{|c|}{ COMPOSICIÓN (\%) } \\
\hline Textil & 0,00 & 0,13 & 0,24 & 7,11 & 3,90 \\
\hline Metales & 0,00 & 2,46 & 13,25 & 0,00 & 4,20 \\
\hline Madera & 0,36 & 0,42 & 2,29 & 1,11 & 1,34 \\
\hline Brik & 0,00 & 0,26 & 4,26 & 9,07 & 6,15 \\
\hline Inertes & 1,76 & 1,12 & 9,73 & 0,00 & 3,08 \\
\hline RTP & 0,00 & 4,52 & 1,00 & 0,00 & 0,86 \\
\hline Vidrio & 20,25 & 29,41 & 0,00 & 0,00 & 4,57 \\
\hline Otros & 0,96 & 1,50 & 3,81 & 6,60 & 4,89 \\
\hline
\end{tabular}

Respecto a la determinación del tiempo de secado del RRM-O, en la Figura 7.34 se puede observar que en función del tamaño de partícula el tiempo que tarda en estabilizarse el porcentaje de la masa inicial es diferente, siendo menor a medida que el tamaño de partícula disminuye. Para este rechazo, las partículas con un diámetro mayor de $70 \mathrm{~mm}$, que están compuestas principalmente por plástico rígido y papel/cartón, necesitan 6 horas para su secado. Las partículas entre $70-30 \mathrm{~mm}$, formadas mayoritariamente por papel/cartón y materia orgánica, y las partículas entre $30-10 \mathrm{~mm}$, compuestas por materia orgánica, vidrio y papel/cartón, necesitan 4 horas para que el porcentaje de la masa inicial se estabilice. Para las partículas menores de $10 \mathrm{~mm}$ y que se componen fundamentalmente de materia orgánica, se necesitan de 2 a 3 horas.

En cuanto a la relación entre el tiempo de secado y la composición, se puede concluir que para este rechazo las categorías de tamaño con una elevada cantidad de papel/cartón y plástico rígido necesitan mayor tiempo de secado que las que están compuestas principalmente por materia orgánica. Esto puede deberse a que, por un lado, el papel/cartón es un material capaz de absorber gran cantidad de humedad del ambiente o de los residuos que le rodean (por ejemplo, materia orgánica). Por otro lado, a que los plásticos rígidos para este rechazo normalmente corresponden a envases como botellas que contienen restos de líquidos y que son más difíciles de evaporar por la propia forma del envase.

Por último, en la Figura 7.34, también se puede ver que cuando el porcentaje de la masa inicial se estabiliza las partículas que se encuentran entre los $30-10 \mathrm{~mm}$ son la que mayor humedad tienen, (50\% humedad y $50 \%$ de materia seca), seguidas por las que tienen un diámetro por debajo de $10 \mathrm{~mm}$ (40\% de humedad y $60 \%$ materia seca). Ambas categorías de tamaño son las más rápidas en secarse. Por el contrario, las partículas cuyo tamaño se encuentra por encima de los $70 \mathrm{~mm}$ y que tienen una humedad menor ( $24 \%$ humedad y $76 \%$ materia seca) son las que más tiempo necesitan. Por lo tanto, se puede decir que un mayor contenido en humedad en el material no supone un mayor tiempo de secado.

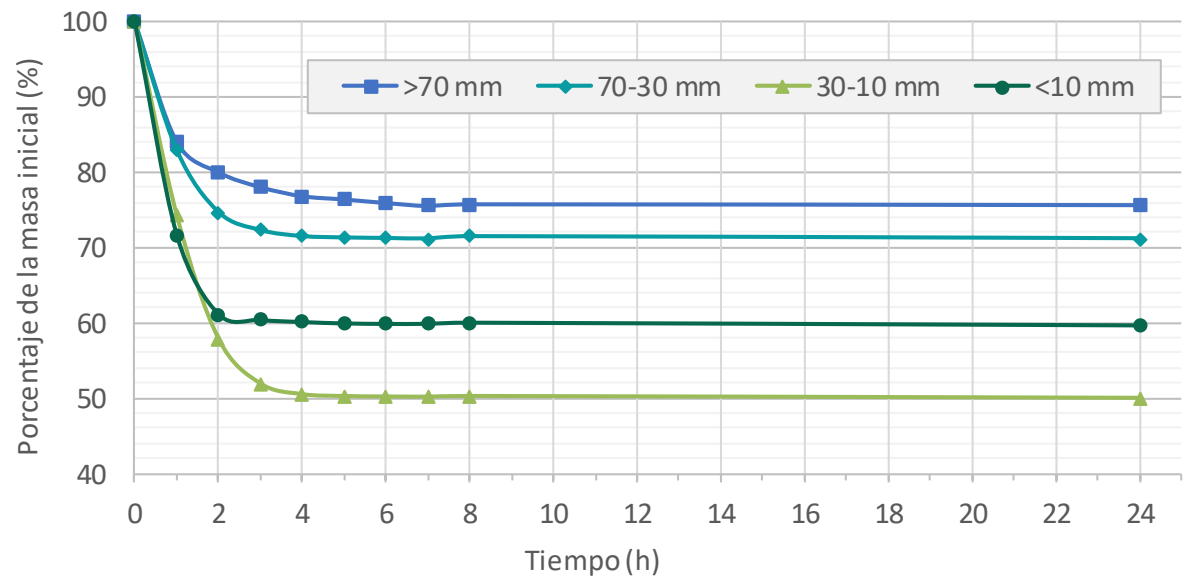

Figura 7.34 Variación del porcentaje de masa inicial del RRM-O a lo largo del tiempo de secado 


\subsubsection{Rechazo de afino primario del bioestabilizado de la PRC de Onda (RAB1-O)}

El RAB1-O se genera en el trómel intermedio de afino del material pre-bioestabilizado que procede de la fermentación en túneles en la PRC de Onda. Las bandejas utilizadas en la monitorización del proceso de secado para cada categoría de tamaño se muestran en la Figura 7.35.

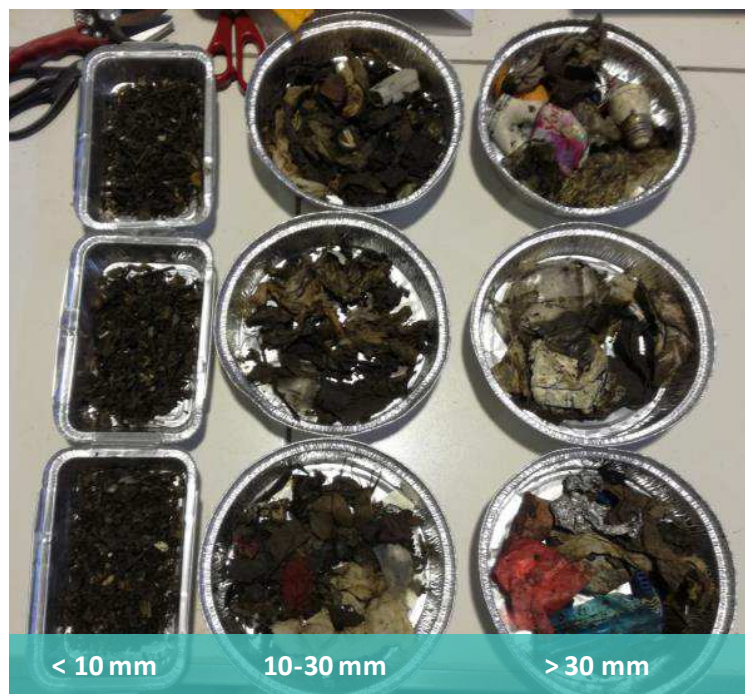

Figura 7.35 Bandejas de RAB1-O para la monitorización del proceso de secado

Este rechazo, debido a que se origina en una etapa biológica del tratamiento, está compuesto principalmente por materia orgánica, con un $27,10 \%$, seguido por papel/cartón, con un $16,33 \%$ y plástico rígido, con un $12,26 \%$. Los RTP son el cuarto material mayoritario, con un $12,26 \%$. Los materiales que se encuentran en menor porcentaje son la madera $(2,14 \%)$, textil $(1,89 \%)$ y brik $(0,00 \%)$. Respecto al tamaño de partícula, el $62,20 \%$ de las partículas se encuentran por encima de los $30 \mathrm{~mm}$ y el $31,10 \%$ entre los $10-30 \mathrm{~mm}$ (Tabla 7.16). La distribución del tamaño de partícula y composición se muestra en la Tabla 7.16.

Tabla 7.16 Distribución del tamaño de partícula y composición del RAB1-O

\begin{tabular}{|c|c|c|c|c|}
\hline Tamaño de partícula (mm) & $<10$ & $10-30$ & $>\mathbf{3 0}$ & TOTAL \\
\hline $\begin{array}{l}\text { Distribución de tamaño de } \\
\text { partícula (\%) }\end{array}$ & 6,71 & 31,10 & 62,20 & 100,00 \\
\hline Material & \multicolumn{4}{|c|}{ COMPOSICIÓN (\%) } \\
\hline Materia orgánica & 69,60 & 36,58 & 17,77 & 27,10 \\
\hline Papel/Cartón & 15,46 & 32,38 & 8,40 & 16,33 \\
\hline Plástico Film & 0,04 & 1,54 & 4,53 & 3,30 \\
\hline Plástico Rígido & 0,99 & 9,70 & 16,68 & 13,46 \\
\hline Textil & 0,23 & 0,08 & 2,97 & 1,89 \\
\hline Metales & 0,16 & 2,01 & 9,20 & 6,36 \\
\hline Madera & 0,16 & 0,30 & 3,27 & 2,14 \\
\hline Brik & 0,00 & 0,00 & 0,00 & 0,00 \\
\hline Inertes & 1,81 & 0,00 & 11,96 & 7,56 \\
\hline RTP & 0,00 & 0,00 & 19,71 & 12,26 \\
\hline Vidrio & 11,43 & 17,40 & 0,00 & 6,18 \\
\hline Otros & 0,13 & 0,00 & 5,51 & 3,43 \\
\hline
\end{tabular}


Respecto a la determinación del tiempo de secado del RAB1-O, en la Figura 7.36 se puede ver que las partículas con un tamaño mayor a $30 \mathrm{~mm}$ y cuyos componentes mayoritarios son los RTP, la materia orgánica, el plástico rígido y los inertes necesitan $3-4$ horas para que el porcentaje de la masa inicial se estabilice. En el caso de las partículas con un tamaño intermedio de 30 a 10 mm (formadas por materia orgánica, papel/cartón y vidrio principalmente) el tiempo necesario es de 4 horas; mientras que para fracciones con tamaños menores a $10 \mathrm{~mm}$ y compuestas fundamentalmente por materia orgánica se necesitan 3 horas para su secado.

En base a los resultados obtenidos se puede ver que en este caso no existe una gran variabilidad en el tiempo de secado en función del tamaño o de la composición. No obstante, cabe señalar que la fracción de rechazo que más tiempo de secado necesita $(30-10 \mathrm{~mm}$ ) coincide con la que mayor porcentaje de papel/cartón contiene.

Por otro lado, en la Figura 7.36 se puede ver que las categorías de tamaño correspondientes a las partículas más pequeñas son las que presentan una mayor humedad cuando el porcentaje de masa se estabiliza, con valores de $49 \%$ humedad y $51 \%$ de materia seca para las partículas entre 30 y $10 \mathrm{~mm}$ y de $47 \%$ de humedad y $53 \%$ de materia seca para las menores a $10 \mathrm{~mm}$. No obstante, el tiempo de secado para estas categorías de tamaño es prácticamente el mismo que para las partículas mayores de $30 \mathrm{~mm}$ que tienen una menor humedad (31\%).

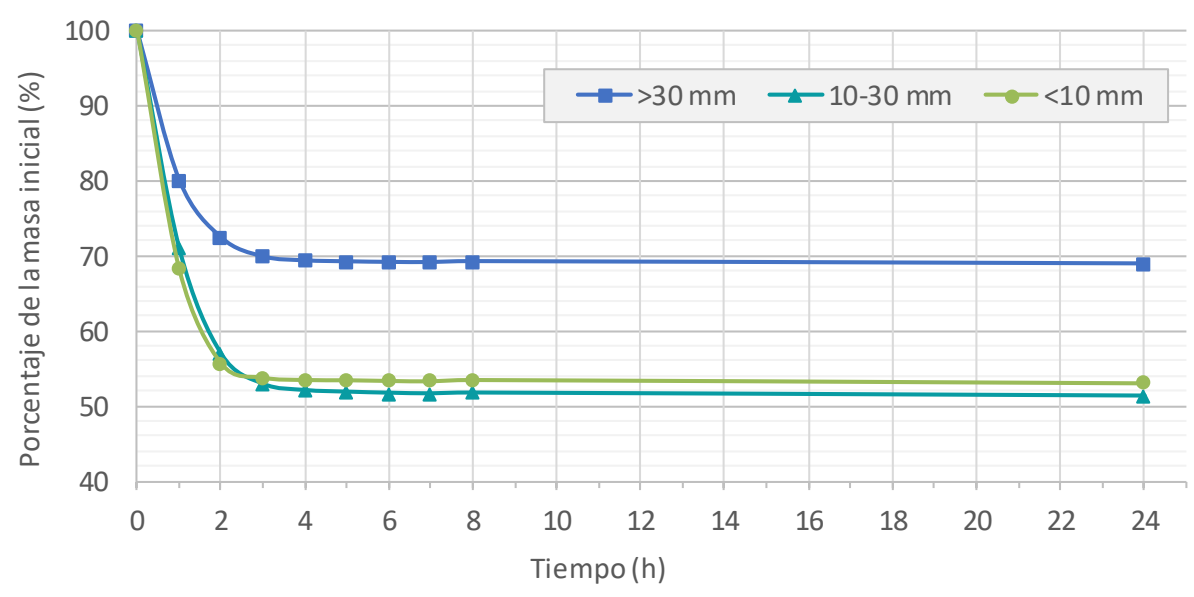

Figura 7.36 Variación del porcentaje de masa inicial del RAB1-O a lo largo del tiempo de secado

\subsubsection{Rechazo pesado de recuperación automática de la PRC de Guadassuar (RRAP-G)}

EI RRAP-G se genera en la etapa de recuperación de materiales de la PRC de Guadassuar, está formado por el material del rebose del trómel doble de pretratamiento que no es separado por aspiración por la línea de recuperación de envases. Las bandejas utilizadas en la monitorización del proceso de secado para cada categoría de tamaño se muestran en la Figura 7.37. 


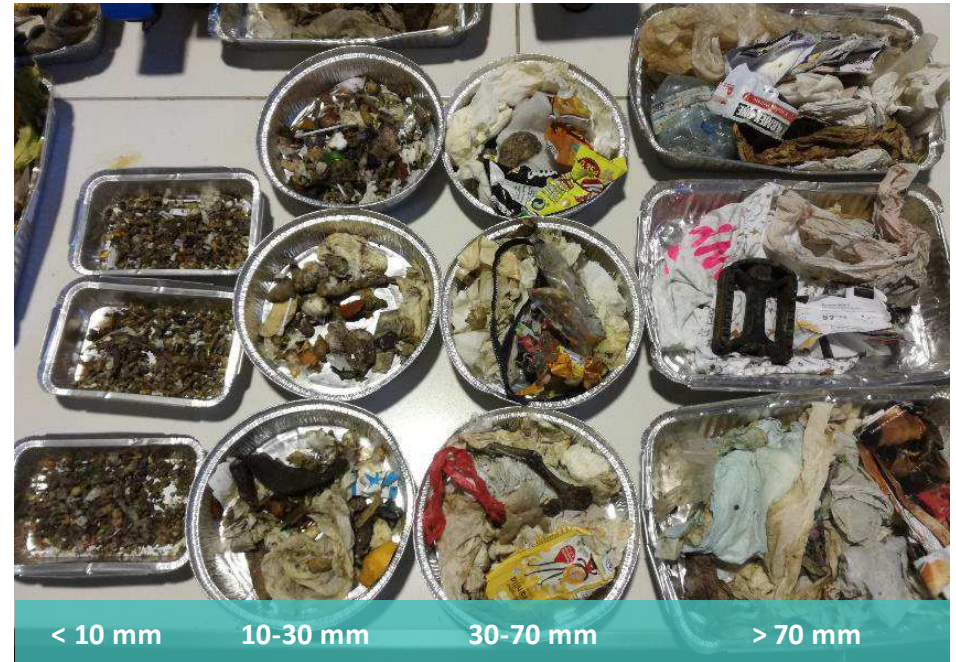

Figura 7.37 Bandejas de RRAP-G para la monitorización del proceso de secado

Este rechazo está compuesto en su mayor parte por papel/cartón $(33,89 \%)$, materia orgánica $(14,53 \%)$ y plástico rígido $(13,41 \%)$, seguido por el plástico film y el textil con valores alrededor del $11,50 \%$. Los materiales minoritarios son el vidrio $(0,43 \%)$ y los inertes $(0,03 \%)$, mientras que el brik y los RTP no están presentes. Los tamaños de partícula predominantes para este rechazo son el mayor de $70 \mathrm{~mm}$, con un $38,65 \%$ de las partículas, y el de $30-70 \mathrm{~mm}$, con un 43,45\%. (Tabla 7.17). La distribución del tamaño de partícula y composición se muestra en la Tabla 7.17.

Tabla 7.17 Distribución del tamaño de partícula y composición del RRAP-G

\begin{tabular}{|c|c|c|c|c|c|}
\hline Tamaño de partícula (mm) & $<10$ & $10-30$ & $30-70$ & $>70$ & TOTAL \\
\hline $\begin{array}{l}\text { Distribución de tamaño de } \\
\text { partícula (\%) }\end{array}$ & 3,37 & 14,53 & 43,45 & 38,65 & 100,00 \\
\hline Material & \multicolumn{5}{|c|}{ COMPOSICIÓN (\%) } \\
\hline Materia orgánica & 88,56 & 62,23 & 5,75 & 0,00 & 14,53 \\
\hline Papel/Cartón & 4,30 & 23,58 & 44,78 & 28,09 & 33,89 \\
\hline Plástico Film & 0,19 & 0,32 & 15,05 & 12,53 & 11,44 \\
\hline Plástico Rígido & 0,04 & 2,26 & 8,74 & 24,00 & 13,41 \\
\hline Textil & 0,00 & 7,96 & 1,81 & 24,73 & 11,50 \\
\hline Metales & 0,00 & 0,94 & 3,83 & 0,00 & 1,80 \\
\hline Madera & 0,06 & 0,00 & 17,56 & 0,00 & 7,63 \\
\hline Brik & 0,00 & 0,00 & 0,00 & 0,00 & 0,00 \\
\hline Inertes & 0,79 & 0,00 & 0,00 & 0,00 & 0,03 \\
\hline RTP & 0,00 & 0,00 & 0,00 & 0,00 & 0,00 \\
\hline Vidrio & 6,07 & 1,52 & 0,00 & 0,00 & 0,43 \\
\hline Otros & 0,00 & 1,19 & 2,47 & 10,65 & 5,36 \\
\hline
\end{tabular}

Respecto a la determinación del tiempo de secado del RRAP-G, como se puede ver en la Figura 7.38, existen diferencias en el tiempo que tarda en estabilizarse el porcentaje de la masa inicial en función del tamaño de partícula, siendo menor a medida que la granulometría de las partículas disminuye. En este sentido, las partículas con un tamaño superior a $70 \mathrm{~mm}$ y que se componen principalmente de papel/cartón, plástico 
rígido y textil necesitan entre 7 y 8 horas para secarse completamente. Las partículas con un diámetro entre $70-30 \mathrm{~mm}$, formadas mayoritariamente por papel/cartón, metales y plástico film, necesitan 6 - 7 horas para que el porcentaje de la masa se estabilice. En el caso de partículas con diámetros entre $30-10 \mathrm{~mm}$, compuestas por materia orgánica y papel/cartón, el tiempo necesario es de $5-6$ horas. Mientras que, para las partículas pequeñas con un tamaño inferior a $10 \mathrm{~mm}$ y que están constituidas en su mayor parte por materia orgánica y vidrio, se necesitan $2-3$ horas.

En cuanto a la relación entre el tiempo de secado y la composición, para este rechazo se observa que las categorías de tamaño con mayor cantidad de papel/cartón y plástico rígido necesitan más tiempo de secado respecto a las que están formadas mayoritariamente por materia orgánica, al igual que ocurre para el RRMO.

Finalmente, en la Figura 7.38 también se puede ver que, cuando el porcentaje de la masa inicial se estabiliza, las partículas con un diámetro de 30 a $10 \mathrm{~mm}$ son las que mayor humedad presentan con un 58\% (42\% de materia seca), sin embargo, esta categoría de tamaño es la segunda más rápida en secarse ( 5 - 6 horas). Por el contrario, las partículas con tamaños superiores a los $70 \mathrm{~mm}$ y que tienen la humedad más baja (28\%) son las que más tiempo de secado necesitan (7 - 8). Así pues, se puede afirmar que un mayor tiempo de secado no está asociado a un mayor contenido en humedad del material.

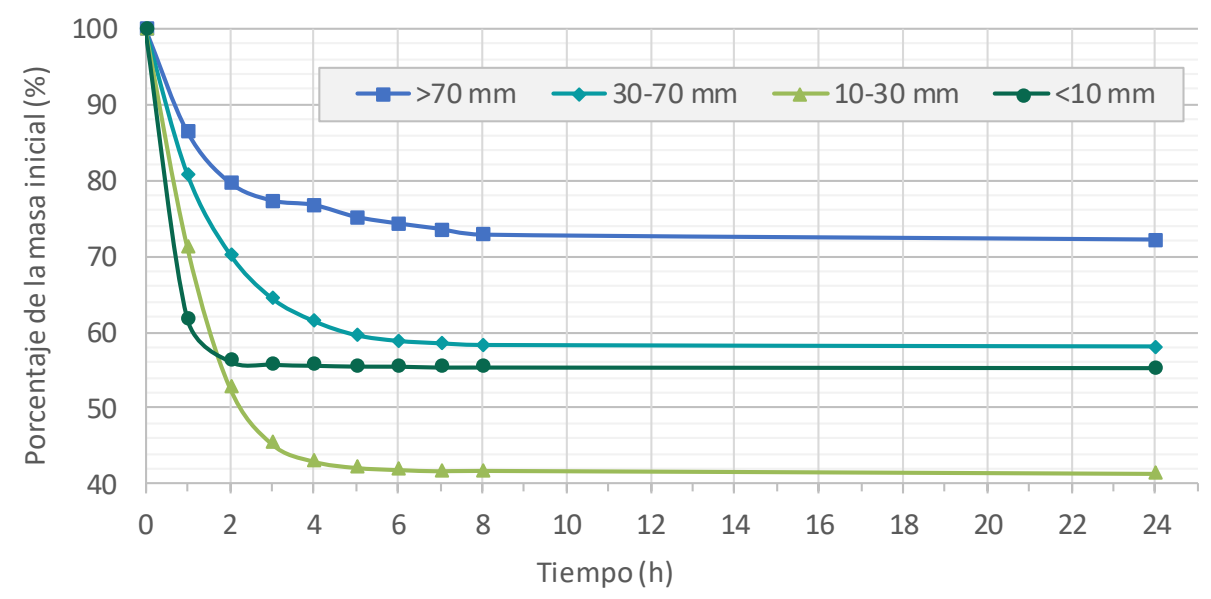

Figura 7.38 Variación del porcentaje de masa inicial del RRAP-G a lo largo del tiempo de secado

\subsubsection{Rechazo ligero de recuperación automática de la PRC de Guadassuar (RRAL-G)}

EI RRAL-G se genera en la etapa de recuperación de materiales de la PRC de Guadassuar, al final de la línea de recuperación de envases. Las bandejas utilizadas en la monitorización del proceso de secado para cada categoría de tamaño se muestran en la Figura 7.39. 


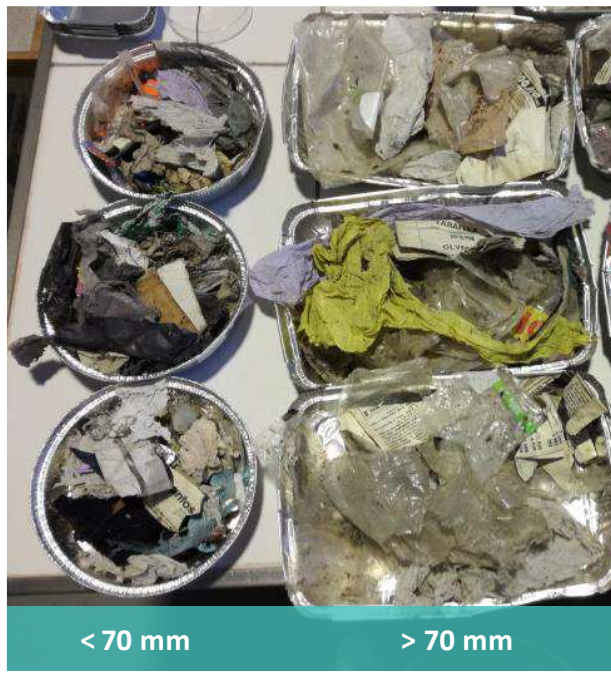

Figura 7.39 Bandejas de RRAL-G para la monitorización del proceso de secado

Este rechazo, debido a que se origina tras todo el proceso de recuperación de envases, está formado principalmente por plástico film (40,38\%) y papel/cartón (20,39\%), seguidos por el plástico rígido y el textil con valores de aproximadamente el $16 \%$ para ambos. El resto de materiales son Otros (3,93\%), materia orgánica $(2,23 \%)$ y RTP $(0,30 \%)$. El tamaño de partícula predominante es menor a $70 \mathrm{~mm}$ con un $60,78 \%$ (Tabla 7.18). La distribución del tamaño de partícula y composición se muestra en la Tabla 7.18.

Tabla 7.18 Distribución del tamaño de partícula y composición del RRAL-G

\begin{tabular}{|c|c|c|c|}
\hline Tamaño de partícula (mm) & $<70$ & $>70$ & TOTAL \\
\hline $\begin{array}{c}\text { Distribución de tamaño de } \\
\text { partícula (\%) }\end{array}$ & 60,78 & 39,22 & 100,00 \\
\hline Material & \multicolumn{3}{|c|}{ COMPOSICIÓN (\%) } \\
\hline Materia orgánica & 3,66 & 0,00 & 2,23 \\
\hline Papel/Cartón & 22,92 & 16,46 & 20,39 \\
\hline Plástico Film & 24,48 & 65,01 & 40,38 \\
\hline Plástico Rígido & 23,35 & 5,37 & 16,30 \\
\hline Textil & 19,00 & 12,57 & 16,48 \\
\hline Metales & 0,00 & 0,00 & 0,00 \\
\hline Madera & 0,00 & 0,00 & 0,00 \\
\hline Brik & 0,00 & 0,00 & 0,00 \\
\hline Inertes & 0,00 & 0,00 & 0,00 \\
\hline RTP & 0,49 & 0,00 & 0,30 \\
\hline Vidrio & 0,00 & 0,00 & 0,00 \\
\hline Otros & 6,09 & 0,59 & 3,93 \\
\hline
\end{tabular}

Respecto a la determinación del tiempo de secado del RRAL-G, se ha observado que existen diferencias en el tiempo necesario para que el porcentaje de la masa inicial se estabilice en función de la granulometría de las partículas (Figura 7.40). En este sentido, para las partículas con tamaños mayores de $70 \mathrm{~mm}$ necesitan 5 horas, mientras que para tamaños menores a $70 \mathrm{~mm}$ este tiempo se reduce a 2 horas. 
El tiempo necesario para el secado de este rechazo es menor en comparación al de los otros dos rechazos de recuperación de materiales estudiados (RRM-O y RRAP-G), sobre todo para las partículas de tamaños elevados. Esto puede deberse a que el RRAL-G se origina tras la recuperación de los envases a partir de la fracción ligera de los RSU que ha sido separada por aspiración y, como consecuencia, los materiales que componen esta corriente están menos sucios.

En cuanto a la relación entre el tiempo de secado y la composición, la categoría de tamaño mayor a $70 \mathrm{~mm}$, que está formada principalmente por bolsas de plástico film, necesita un tiempo de secado mayor que la categoría menor a $70 \mathrm{~mm}$ y que está formada por una mezcla de plástico film, plástico rígido no envase, papel/cartón y textil. Esta diferencia en el tiempo de secado puede deberse a la acumulación de líquidos o humedad en el interior de las bolsas de plástico film de la fracción del rechazo con un mayor tamaño de partícula, lo que dificulta el secado de las mismas.

Por último, en la Figura 7.40 se puede ver que, cuando el porcentaje de la masa inicial se estabiliza, la humedad para las dos muestras es muy similar (30\% humedad y 70\% materia seca), por lo que la variación en el tiempo de secado se deben a las diferencias en su composición y tamaño de partícula.

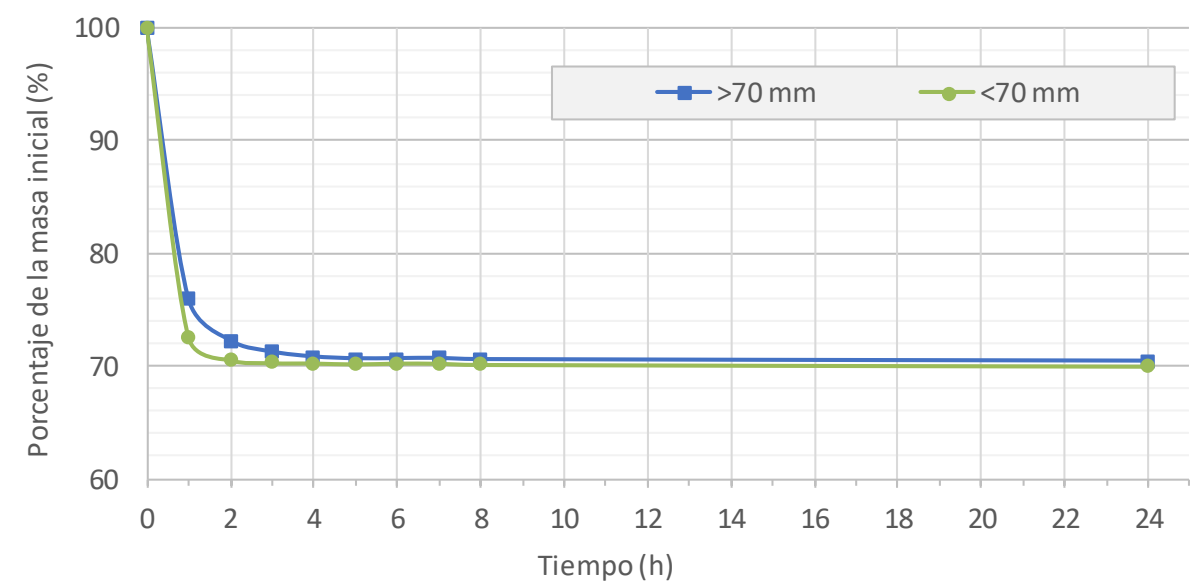

Figura 7.40 Variación del porcentaje de masa inicial del RRAL-G a lo largo del tiempo de secado

\subsubsection{Hundido 1 del pretratamiento de la PRC de Guadassuar (H60-G)}

El H60-G es una corriente intermedia del tratamiento de la PRC de Guadassuar, está formada por el primer hundido del trómel doble de pretratamiento y su destino es el compostaje. Las bandejas utilizadas en la monitorización del proceso de secado para cada categoría de tamaño se muestran en la Figura 7.41.

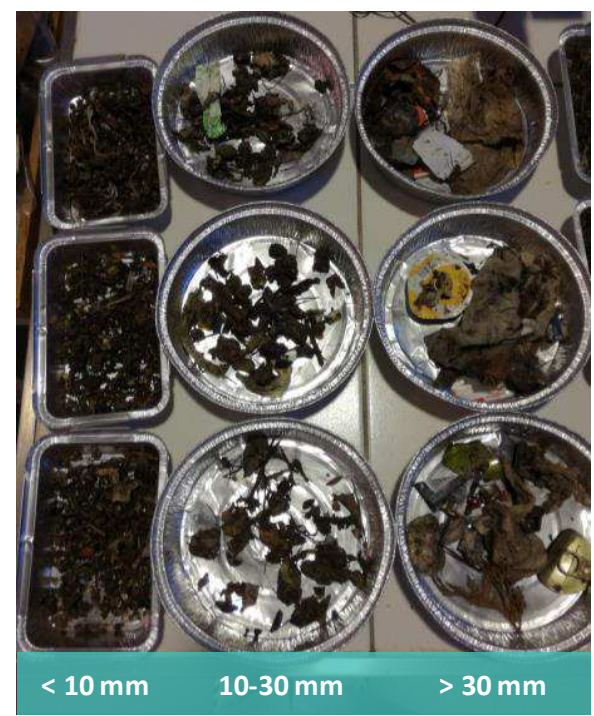

Figura 7.41 Bandejas de H60-G para la monitorización del proceso de secado 
El H60-G está compuesto por un 74,84\% de materia orgánica debido a que su destino es el compostaje. El vidrio, el papel/cartón y el plástico rígido son los otros materiales mayoritarios, pero con porcentajes mucho menores, entre el $8-6 \%$. Respecto al tamaño de partícula, el 53,53\% de las partículas se encuentran entre los 10 - $30 \mathrm{~mm}$ y el 29,26\% por debajo de $10 \mathrm{~mm}$ (Tabla 7.19). La distribución del tamaño de partícula y composición se muestra en la Tabla 7.19.

Tabla 7.19 Distribución del tamaño de partícula y composición del H60-G

\begin{tabular}{|c|c|c|c|c|}
\hline Tamaño de partícula (mm) & $<10$ & $10-30$ & $>30$ & TOTAL \\
\hline $\begin{array}{c}\text { Distribución de tamaño de } \\
\text { partícula (\%) }\end{array}$ & 29,26 & 53,53 & 17,21 & 100,00 \\
\hline Material & \multicolumn{4}{|c|}{ COMPOSICIÓN (\%) } \\
\hline Materia orgánica & 83,27 & 87,09 & 22,43 & 74,84 \\
\hline Papel/Cartón & 1,73 & 7,01 & 14,89 & 6,82 \\
\hline Plástico Film & 0,00 & 0,56 & 3,12 & 0,84 \\
\hline Plástico Rígido & 0,70 & 5,34 & 18,05 & 6,17 \\
\hline Textil & 0,64 & 0,00 & 0,37 & 0,25 \\
\hline Metales & 0,00 & 0,00 & 9,31 & 1,60 \\
\hline Madera & 0,00 & 0,00 & 0,00 & 0,00 \\
\hline Brik & 0,00 & 0,00 & 0,00 & 0,00 \\
\hline Inertes & 2,46 & 0,00 & 0,00 & 0,72 \\
\hline RTP & 0,00 & 0,00 & 0,00 & 0,00 \\
\hline Vidrio & 11,20 & 0,00 & 25,54 & 7,67 \\
\hline Otros & 0,00 & 0,00 & 6,28 & 1,08 \\
\hline
\end{tabular}

Respecto a la determinación del tiempo de secado, para esta corriente intermedia de tratamiento también se ha encontrado que a mayor tamaño de partícula, el tiempo que tarda en estabilizarse el porcentaje de la masa inicial aumenta (Figura 7.42). En el caso de las partículas con diámetros por encima de los $70 \mathrm{~mm}$, compuestas por una mezcla de vidrio, materia orgánica, plástico rígido y papel/cartón, se necesitan 7 horas para su completo secado. Las partículas con un tamaño intermedio entre $30-10 \mathrm{~mm}$, que están formadas principalmente por materia orgánica y una pequeña parte de papel/cartón y plástico rígido, necesitan 5 horas para que el porcentaje de masa se estabilice. Las partículas de rechazo de menor tamaño (por debajo de 10 $\mathrm{mm}$ ) y que se componen fundamentalmente de fracción orgánica y una pequeña parte de vidrio, necesitan solo 2 horas.

En cuanto a la relación del tiempo de secado y la composición, se observa que, las clases de tamaño donde el plástico rígido y el papel/cartón forman parte de los componentes mayoritarios, necesitan más tiempo para su secado en comparación a las que están compuestas principalmente por materia orgánica, al igual que ocurría con el RRM-O y el RRAP-G.

Finalmente, en la Figura 7.42 se puede ver que, cuando se estabiliza el porcentaje de masa inicial, todas las categorías de tamaño de partícula tienen una humedad muy alta (entre el 55 y el $45 \%$ ) debido a que esta corriente se originan el pretratamiento y tienen como destino el compostaje. Sin embargo, a pesar de que todas ellas presentan más o menos la misma humedad, existen variaciones en el tiempo de secado como consecuencia de las diferencias existentes en su tamaño de partícula y composición. 


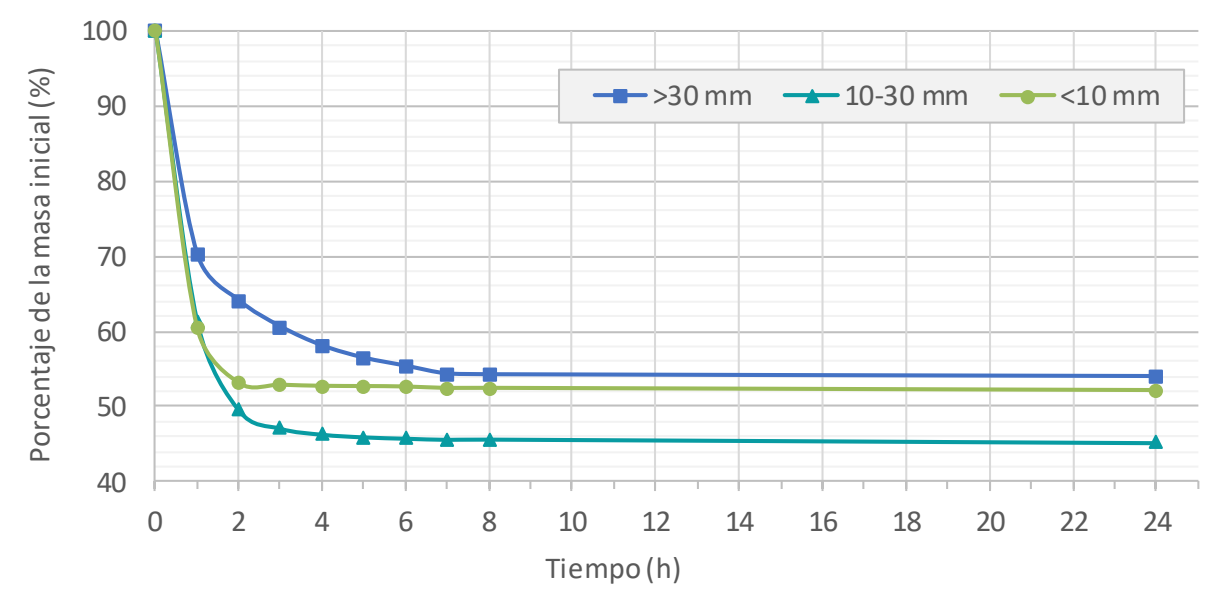

Figura 7.42 Variación del porcentaje de masa inicial del H60-G a lo largo del tiempo de secado

\subsubsection{Hundido 2 del pretratamiento de la PRC de Guadassuar (H6090-G)}

El H6090-G es una corriente intermedia del tratamiento de la PRC de Guadassuar, está formada por el segundo hundido del trómel doble de pretratamiento y su destino es el compostaje. Las bandejas utilizadas en la monitorización del proceso de secado para cada categoría de tamaño se muestran en la Figura 7.43.

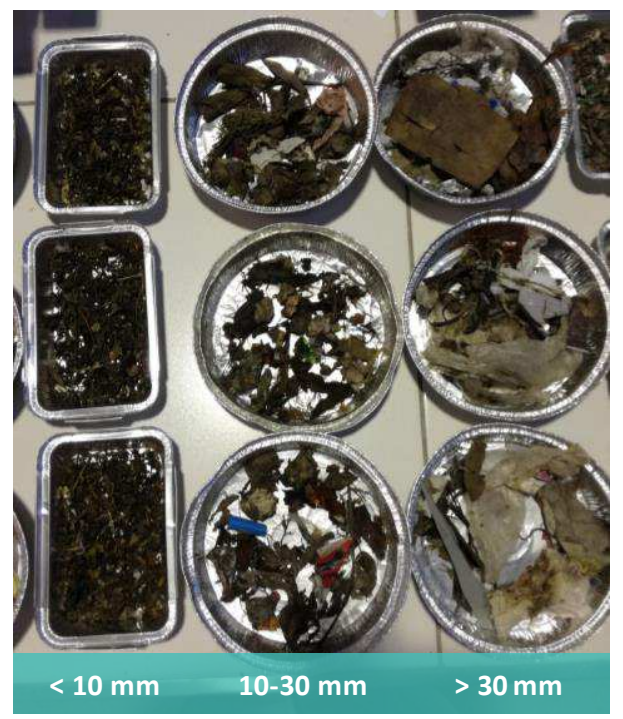

Figura 7.43 Bandejas de H6090-G para la monitorización del proceso de secado

El H6090-G también tiene como destino el compostaje, no obstante, el material predominante es el papel/cartón con un $35,86 \%$, seguido por la materia orgánica (26,78\%) y el plástico rígido (15,85\%). Esto es consecuencia a que el $61,07 \%$ de sus partículas se encuentran por encima de los $30 \mathrm{~mm}$ (Tabla 7.20) y, por tanto, la presencia de materia orgánica es menor. Los metales y el vidrio suponen alrededor del $5 \%$, mientras que el resto de materiales se encuentran en porcentajes menores al $2 \%$. La distribución del tamaño de partícula y composición se muestra en la Tabla 7.20. 
Tabla 7.20 Distribución del tamaño de partícula y composición del H6090-G

\begin{tabular}{|c|c|c|c|c|}
\hline Tamaño de partícula (mm) & $<10$ & $10-30$ & $>30$ & TOTAL \\
\hline $\begin{array}{l}\text { Distribución de tamaño de } \\
\text { partícula (\%) }\end{array}$ & 10,14 & 28,79 & 61,07 & 100,00 \\
\hline Material & \multicolumn{4}{|c|}{ COMPOSICIÓN (\%) } \\
\hline Materia orgánica & 79,26 & 47,78 & 8,16 & 26,78 \\
\hline Papel/Cartón & 8,69 & 24,54 & 45,70 & 35,86 \\
\hline Plástico Film & 0,25 & 3,37 & 9,89 & 7,04 \\
\hline Plástico Rígido & 1,56 & 3,46 & 24,06 & 15,85 \\
\hline Textil & 1,07 & 1,96 & 1,88 & 1,82 \\
\hline Metales & 0,00 & 0,78 & 7,90 & 5,05 \\
\hline Madera & 0,00 & 0,00 & 0,00 & 0,00 \\
\hline Brik & 0,00 & 0,00 & 0,00 & 0,00 \\
\hline Inertes & 1,54 & 1,14 & 0,00 & 0,49 \\
\hline RTP & 0,00 & 0,00 & 2,41 & 1,47 \\
\hline Vidrio & 7,64 & 16,96 & 0,00 & 5,66 \\
\hline Otros & 0,00 & 0,00 & 0,00 & 0,00 \\
\hline
\end{tabular}

Respecto a la determinación del tiempo de secado del H6090-G, en la Figura 7.44 se observa que las partículas con un tamaño mayor a $30 \mathrm{~mm}$ (cuyos componentes principales son el papel/cartón y el plástico rígido) y las partículas menores a $10 \mathrm{~mm}$ (formadas en su mayor parte por materia orgánica) necesitan dos horas para que el porcentaje de la masa inicial se estabilice. En el caso de la fracción de partículas con un tamaño intermedio entre $10-30 \mathrm{~mm}$ (compuestas por materia orgánica y papel cartón) el tiempo necesario es de 3 horas. Así pues, en base a estos resultados, se puede decir que para esta corriente intermedia del tratamiento no existe una gran variabilidad en el tiempo de secado en función el tamaño de partícula o de la composición. Además, tampoco se cumple que las categorías de tamaño con mayor porcentaje de plástico rígido y papel/cartón sean las que mayor tiempo de secado necesitan, como ocurre con algunos de los rechazos estudiados.

Por otra parte, cabe destacar que la humedad de las diferentes categorías de tamaño es bastante elevada, con valores entre $45 \%$ y $55 \%$ cuando el porcentaje de masa se estabiliza (Figura 7.44). Esto se debe a que esta corriente intermedia del tratamiento tiene como destino el compostaje. Los valores de humedad obtenidos son similares a los del H60-G, sin embargo, en el caso del H6090-G el tiempo de secado es mucho menor. Esto puede estar relacionado con que el H60-G está formado por el primer hundido del trómel de pretratamiento, donde la presencia de materia orgánica es muy elevada, mientras que el H6090-G está formado por el segundo hundido del trómel de pretratamiento, donde el porcentaje de materia orgánica es menor y los materiales están menos sucios, lo que favorece su secado. 


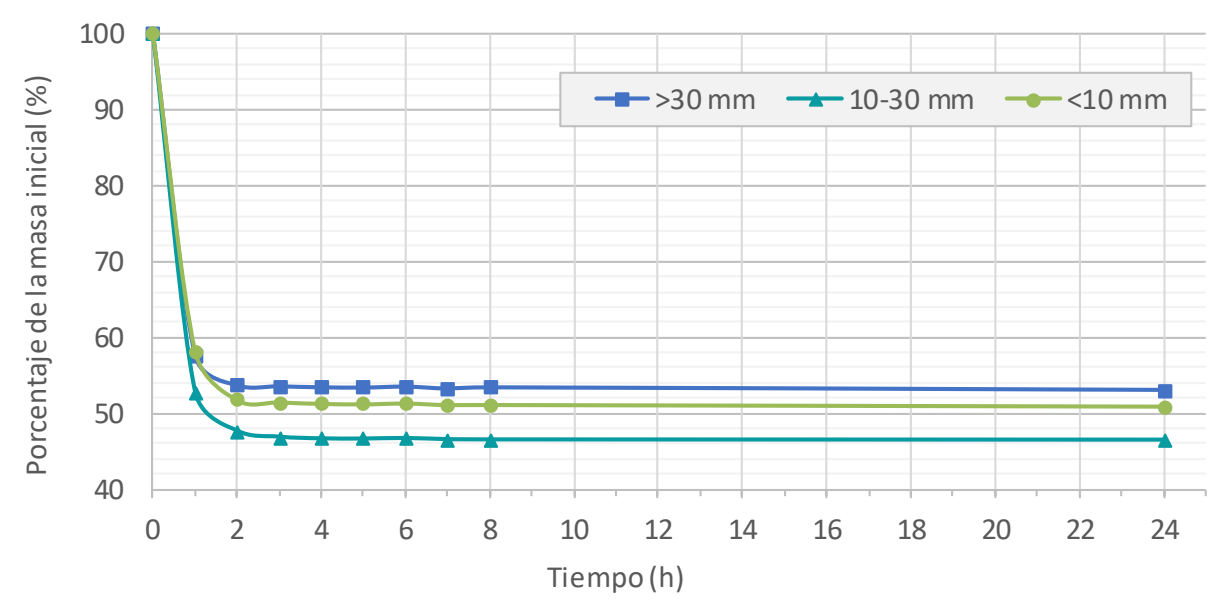

Figura 7.44 Variación del porcentaje de masa inicial del H6090-G a lo largo del tiempo de secado

\subsubsection{Hundido del trómel recuperación de la PRC de Guadassuar (H70-G)}

El H70-G es una corriente intermedia del tratamiento de la PRC de Guadassuar, está formada por el hundido del trómel existente en la etapa de recuperación de envases y su destino es el compostaje. Las bandejas utilizadas en la monitorización del proceso de secado para cada categoría de tamaño se muestran en la Figura 7.45 .

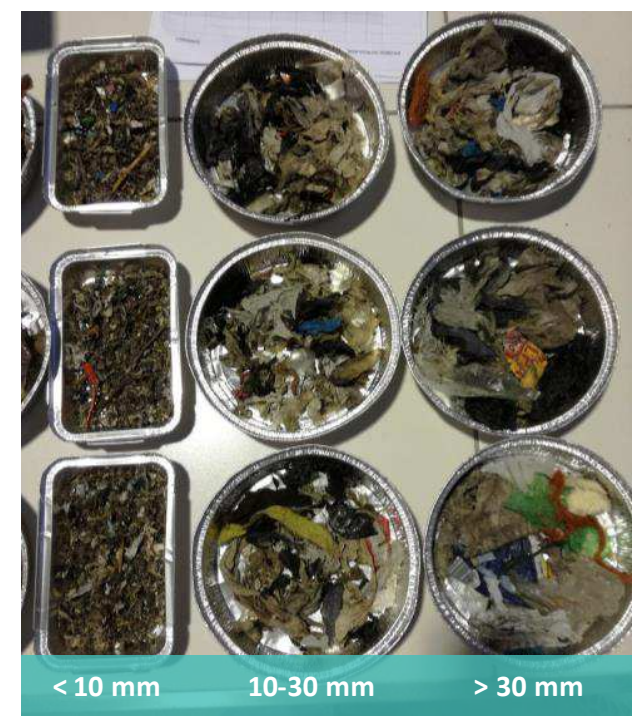

Figura 7.45 Bandejas de H70-G para la monitorización del proceso de secado

El H70-G, a pesar de destinarse a compostaje, está compuesto por una amplia variedad de materiales con: un $39,30 \%$ de textil, un $16,45 \%$ de plástico film, un $14,42 \%$ de papel/cartón, un $10,88 \%$ de plástico rígido, un $9,26 \%$ de madera y un $6,11 \%$ de materia orgánica (Tabla 7.21 ). El resto de materiales se encuentran por debajo de $2 \%$. El tamaño de partícula predominante para este flujo es el de mayor de $30 \mathrm{~mm}(73,96 \%$ de las partículas), seguido por el de 10 a $30 \mathrm{~mm}$ (20,84\%). La distribución del tamaño de partícula y composición se muestra en la Tabla 7.21. 
Tabla 7.21 Distribución del tamaño de partícula y composición del H70-G

\begin{tabular}{c|c|c|c|c|c}
\hline $\begin{array}{c}\text { Tamaño de partícula (mm) } \\
\begin{array}{c}\text { Distribución de tamaño de } \\
\text { partícula (\%) }\end{array}\end{array}$ & 5,20 & $\mathbf{1 0}-\mathbf{3 0}$ & $>\mathbf{3 0}$ & TOTAL \\
\hline Material & \multicolumn{4}{|c|}{ COMPOSICIÓN (\%) } & 100,00 \\
\hline Materia orgánica & 62,90 & 6,10 & 2,13 & 6,11 \\
\hline Papel/Cartón & 24,19 & 31,27 & 8,99 & 14,42 \\
\hline Plástico Film & 3,07 & 12,19 & 18,59 & 16,45 \\
\hline Plástico Rígido & 2,31 & 13,09 & 10,85 & 10,88 \\
\hline Textil & 1,91 & 15,96 & 48,51 & 39,30 \\
\hline Metales & 3,31 & 8,55 & 0,00 & 1,95 \\
\hline Madera & 0,00 & 5,66 & 10,93 & 9,26 \\
\hline Brik & 0,00 & 0,00 & 0,00 & 0,00 \\
\hline Inertes & 0,00 & 7,19 & 0,00 & 1,50 \\
\hline RTP & 0,00 & 0,00 & 0,00 & 0,00 \\
\hline Vidrio & 2,26 & 0,00 & 0,00 & 0,12 \\
\hline Otros & 0,05 & 0,00 & 0,00 & 0,00 \\
\hline & & & & \\
\hline
\end{tabular}

Respecto a la determinación del tiempo de secado del H70-G, en la Figura 7.46 se observa que las tres clases de tamaño estudiadas necesitan 2 horas para que el porcentaje de la masa inicial se estabilice. Por lo tanto, se puede concluir que para esta corriente intermedia del tratamiento no existen diferencias en el tiempo de secado en función del tamaño de partícula o de la composición. Esto puede deberse a su origen, puesto que este flujo está formado por el hundido del trómel de la etapa de recuperación de materiales y la materia orgánica solo está presente en las partículas de menor tamaño, por lo que todos los materiales están más secos.

En la Figura 7.46 se puede observar que, cuando el porcentaje de masa se estabiliza, las partículas de diámetro menor a $10 \mathrm{~mm}$ son las que mayor humedad tienen con un $48 \%$ ( $52 \%$ de materia seca), puesto que en ellas se concentra la materia orgánica. No obstante, el contenido en humedad del material no influye en el tiempo de secado, ya que para los tres tamaños de partícula se ha obtenido el mismo valor (2 horas).

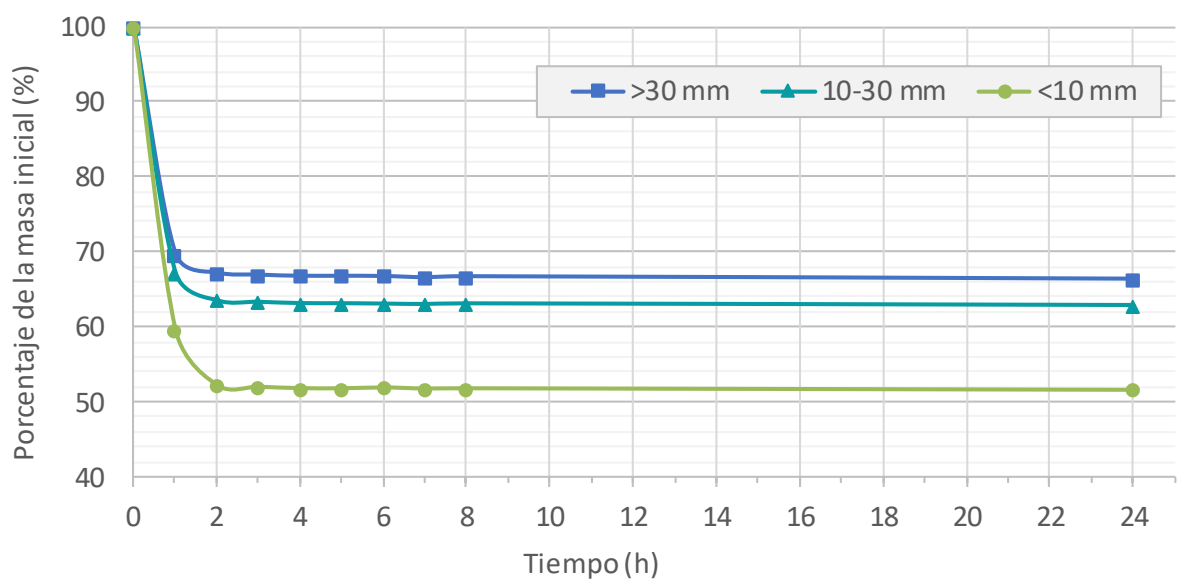

Figura 7.46 Variación del porcentaje de masa inicial del H70-G a lo largo del tiempo de secado 


\subsubsection{Tiempos óptimos de secado}

En base a los resultados obtenidos para las cuatro corrientes de rechazo analizadas y para los tres flujos intermedios del TMB, se han establecido diferentes tiempos óptimos de secado en función del tipo de rechazo, tamaño de partícula y materiales principales que los componen. Estos se exponen en la Tabla 7.22. Cabe señalar que en el caso que se quiera secar un rechazo con partículas de varios tamaños, será necesario coger el tiempo óptimo de secado más alto, de forma que todas las partículas y materiales se sequen completamente.

Tabla 7.22 Tiempos de secado óptimo

\begin{tabular}{|c|c|c|c|}
\hline Tipo de rechazo & $\begin{array}{l}\text { Tamaño de } \\
\text { partícula } \\
\text { (mm) }\end{array}$ & Materiales principales & $\begin{array}{l}\text { Tiempo óptimo } \\
\text { de secado }(h)\end{array}$ \\
\hline \multirow{3}{*}{$\begin{array}{l}\text { Rechazo de recuperación } \\
\text { manual de materiales }\end{array}$} & $>70$ & Plástico rígido y papel/cartón & 6* \\
\hline & $70-10$ & Papel/cartón y materia orgánica & 4 \\
\hline & $<10$ & Materia orgánica y vidrio & $2-3$ \\
\hline $\begin{array}{l}\text { Rechazo de afino primario } \\
\text { del bioestabilizado }\end{array}$ & - & $\begin{array}{c}\text { Materia orgánica, papel/cartón y plástico } \\
\text { rígido }\end{array}$ & 4 \\
\hline \multirow{4}{*}{$\begin{array}{l}\text { Rechazo de recuperación } \\
\text { automática de materiales } \\
\text { (fracción pesada) }\end{array}$} & $>70$ & Papel/cartón, plástico rígido y textil & $7-8^{*}$ \\
\hline & $70-30$ & Papel/cartón, plástico film y metales & $6-7$ \\
\hline & $30-10$ & Materia orgánica y papel/cartón & $5-6$ \\
\hline & $<10$ & Materia orgánica y vidrio & $2-3$ \\
\hline \multirow{2}{*}{$\begin{array}{l}\text { Rechazo de recuperación } \\
\text { automática de materiales } \\
\text { (fracción ligera) }\end{array}$} & $>70$ & Plástico film & 5 \\
\hline & $<70$ & $\begin{array}{l}\text { Plástico film, papel/cartón, plástico rígido y } \\
\text { textil }\end{array}$ & 2 \\
\hline \multirow{3}{*}{$\begin{array}{l}\text { Hundido trómel } \\
\text { pretratamiento (tamaño } \\
\text { menor a } 60 \mathrm{~mm} \text { ) }\end{array}$} & $>30$ & $\begin{array}{l}\text { Vidrio, materia orgánica, plástico rígido, } \\
\text { papel/cartón }\end{array}$ & $7^{*}$ \\
\hline & $30-10$ & $\begin{array}{l}\text { Materia orgánica (> } 80 \%) \text {, papel/cartón y } \\
\text { plástico rígido }\end{array}$ & 5 \\
\hline & $<10$ & Materia orgánica (> 80\%) y vidrio & 2 \\
\hline $\begin{array}{l}\text { Hundido trómel de } \\
\text { pretratamiento (tamaño } \\
\text { entre } 60-90 \mathrm{~mm} \text { ) }\end{array}$ & - & Papel/cartón, materia orgánica y plástico rígido & 3 \\
\hline $\begin{array}{c}\text { Hundido trómel de } \\
\text { recuperación de } \\
\text { materiales (tamaño menor } \\
\text { a } 70 \mathrm{~mm} \text { ) }\end{array}$ & - & $\begin{array}{c}\text { Textil, plástico film, papel/cartón y plástico } \\
\text { rígido }\end{array}$ & 2 \\
\hline
\end{tabular}

*Tiempo óptimo con el que se alcanza le secado completo del material cuando hay partículas de todos los tamaños

De la tabla anterior se puede concluir que, en la mayoría de los casos, el tiempo óptimo de secado depende del tamaño de partícula del material, siendo necesario un mayor número de horas para diámetros de partículas mayores.

Respecto a los rechazos, se puede afirmar que aquellas corrientes y categorías de tamaño que presentan un mayor contenido en plástico rígido y papel/cartón son las que más tiempo de secado necesitan. Esto se debe, por un lado, a los restos de líquidos que quedan atrapados en el interior de los envases de plástico y por otro a la absorción de humedad por parte del papel/cartón. 
En el caso de la fracción ligera de los rechazos de recuperación automática, el tiempo de secado es menor en comparación a los otros rechazos de recuperación debido a que está formada por materiales procedentes de una separación por aspiración, los cuales están más limpios.

Respecto a los flujos intermedios del TMB, los tiempos de secado más altos se dan para el hundido de trómel de pretratamiento cuyo tamaño de partícula es menor a $60 \mathrm{~mm}$, puesto que este flujo contiene una gran cantidad de materia orgánica y los materiales están más sucios. En cambio, para el hundido de la etapa de recuperación de materiales, el tiempo de secado es menor debido a que la materia orgánica es un componente minoritario y los materiales están más secos.

Finalmente, destacar que la Tabla 7.22 permite conocer los tiempos de secado de diferentes tipos de rechazos para su aplicación a la preparación de muestras de laboratorio para el control de calidad.

\subsection{CONCLUSIONES}

En el presente capítulo se ha propuesto un procedimiento de preparación de muestra de laboratorio para el análisis de los parámetros de calidad en los rechazos. El objetivo de este procedimiento es reducir la muestra tomada en la planta de tratamiento y cuyo tamaño se ha determinado en el capítulo 6, a una muestra de laboratorio más pequeña y representativa de la que tomarán las alícuotas para determinar el $\mathrm{PCl}, \mathrm{Cl}$ y $\mathrm{Hg}$.

El procedimiento se ha dividido en dos etapas. La primera consiste en la recomposición de una muestra inicial representativa de $2 \mathrm{~kg}$ con la misma composición que la muestra de rechazo original tomada en planta. La segunda consiste en la preparación de una muestra de laboratorio representativa de un tamaño menor, a partir de la cual se analizarán los parámetros de calidad. De esta segunda etapa cabe destacar los procesos de división de muestra y de secado.

Respecto a la división de muestra, uno de los principales aspectos es determinar el tamaño de muestra de laboratorio con el que se obtienen resultados representativos. Para ello se ha desarrollado una metodología experimental que permite determinar dicho tamaño y establecer los procedimientos de reducción de tamaño de partícula y división de muestras más adecuados para alcanzarlo. Con el objetivo de que las muestras de partida del ensayo tengan la misma composición y propiedades y de que los resultados sean comparables, se han diseñado una serie muestras de rechazo artificiales a partir de la mezcla de componentes o materiales "limpios" utilizando una composición real de referencia. Asimismo, se ha diseñado un experimento que permite obtener muestras de laboratorio de diferentes pesos y con distintos diámetros de partícula. Estas muestras se han analizado químicamente, realizándose en total casi 300 análisis, para determinar el tamaño mínimo de muestra de laboratorio.

En el caso del PCl, cuando no se lleva a cabo una reducción inicial del tamaño de partícula o esta se realiza a un diámetro mayor o igual a $60 \mathrm{~mm}$, el tamaño de muestra de laboratorio puede reducirse desde los $2 \mathrm{~kg}$ hasta $1 \mathrm{~kg}$ mediante cuarteo. En el caso de realizarse una reducción inicial del diámetro de partícula a $30 \mathrm{~mm}$, el tamaño puede disminuirse hasta los $0,500 \mathrm{~kg}$ sin que pierda representatividad.

Para el análisis del $\mathrm{Cl}$, cuando no se realiza una reducción inicial del tamaño de partícula o esta se hace a un diámetro de $60 \mathrm{~mm}$, el tamaño de muestra de laboratorio puede reducirse desde los $2 \mathrm{~kg}$ hasta los 0,500 $\mathrm{kg}$ mediante dos cuarteos sucesivos. En el caso de que el tamaño de partícula se reduzca a un diámetro de 30 $\mathrm{mm}$, el tamaño de muestra de laboratorio se puede disminuir mediante cuarteo a $0,250 \mathrm{~kg}$ sin perder representatividad.

Para el análisis del $\mathrm{Hg}$, cuando no existe una reducción inicial el tamaño de partícula, el tamaño de muestra de laboratorio corresponde al tamaño de la muestra recompuesta $(2 \mathrm{~kg})$, puesto que se ha observado que los resultados dejan de ser representativos si esta se cuartea. Cuando se realiza una reducción inicial del tamaño de partícula a $60 \mathrm{~mm}$, el tamaño de muestra de laboratorio puede disminuirse a $1 \mathrm{~kg}$ mediante cuarteo sin perder representatividad; mientras que si el diámetro se reduce a $30 \mathrm{~mm}$, el tamaño de muestra de laboratorio puede ser mucho más pequeño, de $0,065 \mathrm{~kg}$.

En el caso que se quiera llevar a cabo el control de la calidad de los rechazos teniendo en cuenta los tres parámetros, el tamaño de muestra será siempre el más restrictivo de todos: 
- $\quad 2$ kg si no se lleva a cabo ninguna reducción inicial del tamaño de partícula, que corresponde con la muestra recompuesta.

- $1 \mathrm{~kg}$ si antes de la división por cuarteo se lleva a cabo una reducción inicial del tamaño de partícula a $60 \mathrm{~mm}$.

- $\quad$ 0,500 kg si antes de la división por cuarteo se lleva a cabo una reducción inicial del tamaño de partícula a $30 \mathrm{~mm}$.

En base a los resultados obtenidos se puede concluir que, a medida que el tamaño de partícula de la muestra de rechazo recompuesta se reduce, el tamaño de muestra de laboratorio con el que se obtienen resultados representativos es menor.

La reducción de la muestra tomada en planta a una muestra de laboratorio mucho más pequeña y representativa facilita el análisis de los parámetros de calidad, puesto que minimizan la carga de trabajo necesaria para llevarlos a cabo (por ejemplo, se necesita secar y triturar a un $1 \mathrm{~mm}$ una menor cantidad de material), lo que también supone un ahorro importante en tiempo y dinero.

Por último, a partir de la experimentación se ha obtenido una tabla en la que se presentan los tamaños de muestra de laboratorio necesarios para llevar a cabo el control de calidad en función del procedimiento de reducción de tamaño de partícula utilizado y el parámetro que se quiera analizar.

Respecto al secado, el objetivo ha sido determinar el tiempo óptimo de secado para diferentes muestras de rechazo y corrientes intermedias del TMB, las cuales tienen composiciones y tamaños de partícula distintos. Para cada una de las corrientes de materiales se han obtenido tiempos óptimos diferentes, que van desde las 7 - 8 horas para las categorías de tamaño de partículas más grandes de los rechazos de recuperación, a las 2 - 3 horas para las categorías de tamaño más pequeñas y para algunos flujos intermedios del tratamiento.

En base a los resultados obtenidos y de forma general se puede decir que, en la mayoría de los casos, el tiempo óptimo de secado varía en función del tamaño de partícula, siendo necesario un mayor número de horas para partículas de diámetros más grandes, sobre todo en los rechazos generados en las etapas de recuperación de materiales. Por otra parte, se ha advertido que un mayor contenido en humedad en el material no supone un tiempo óptimo de secado mayor, sino que el tiempo necesario está relacionado con el tamaño de partícula y cómo de retenida esté la humedad en el propio material.

Respecto a los rechazos, se puede concluir que las corrientes y categorías de tamaño con un mayor contenido en plástico rígido y papel/cartón son las que necesitan un mayor tiempo de secado, sobre todo cuando el diámetro de partícula es elevado. Esto puede estar relacionado, por un lado, con la absorción de humedad de los residuos por parte del papel/cartón, por otro, con los líquidos que quedan atrapados en el interior de envases de plástico rígido y que dificultan el secado. Por el contrario, para las corrientes compuestas principalmente por materia orgánica de pequeño tamaño el tiempo de secado necesario es menor.

En el caso de la fracción ligera de los rechazos de recuperación automática, el tiempo óptimo de secado es menor en comparación al de los otros rechazos de recuperación. Esto es debido a que los materiales que forman esta corriente proceden de una separación por aspiración y, por lo tanto, están más limpios y secos.

En cuanto a los flujos intermedios del TMB, los tiempos óptimos de secado obtenidos son un poco diferentes a los de los rechazos. Para estas corrientes se puede concluir que, los flujos con un elevado contenido en materia orgánica y cuyos materiales están más sucios presentan un tiempo óptimo de secado mayor. Por el contrario, para aquellas corrientes donde la materia orgánica se encuentra en porcentajes muy pequeños y los materiales están más limpios, el tiempo necesario es menor.

Por último, a partir de los resultados obtenidos para las 7 corrientes se ha presentado una tabla con diferentes tiempos óptimos de secado en función del tipo de rechazo, tamaño de partícula y materiales principales que componen la corriente. Estos tiempos son de gran utilidad en la preparación de muestras para el control de calidad de los rechazos. 


\subsection{REFERENCIAS}

Aldrian, A., Sarc, R., Pomberger, R., Lorber, K.E., Sipple, E.M., 2016. Solid recovered fuels in the cement industry - Semi-automated sample preparation unit as a means for facilitated practical application. Waste Manag. Res. 34, 254-264. https://doi.org/10.1177/0734242X15622816

Bessi, C., Lombardi, L., Meoni, R., Canovai, A., Corti, A., 2016. Solid recovered fuel: An experiment on classification and potential applications. Waste Manag. 47, 184-194. https://doi.org/10.1016/j.wasman.2015.08.012

Di Lonardo, M.C., Franzese, M., Costa, G., Gavasci, R., Lombardi, F., 2016. The application of SRF vs. RDF classification and specifications to the material flows of two mechanical-biological treatment plants of Rome: Comparison and implications. Waste Manag. 47, 195-205. https://doi.org/10.1016/j.wasman.2015.07.018

Edo-Alcón, N., 2012. Posibles alternativas de tratamiento para la valorización y aprovechamiento energético del rechazo de las Plantas de Selección de Envases Ligeros (Trabajo Final de Carrera). Universidad Politécnica de Valencia, Escuela Politécnica Superior de Gandia.

Edo-Alcón, N., Gallardo, A., Colomer-Mendoza, F.J., 2016. Characterization of SRF from MBT plants: Influence of the input waste and of the processing technologies. Fuel Process. Technol. 153, 19-27. https://doi.org/10.1016/j.fuproc.2016.07.028

Flamme, S., Geiping, J., 2014. Quality assurance of solid recovered fuels (SRF). ZKG Int. 67, 54-57.

Flamme, S., Geiping, J., 2012. Quality standards and requirements for solid recovered fuels: a review. Waste Manag. Res. 30, 335-53. https://doi.org/10.1177/0734242X12440481

Gallardo, A., Carlos, M., Bovea, M.D., Colomer, F.J., Albarrán, F., 2014. Analysis of refuse-derived fuel from the municipal solid waste reject fraction and its compliance with quality standards. J. Clean. Prod. 83, 118-125. https://doi.org/10.1016/j.jclepro.2014.07.085

Gallardo, A., Gómez, A., Colomer, F.J., Edo, N., Pascual, P., 2015. Design of an SRF from Refuse from a Municipal Waste, in: Ayuso Muñoz, J., Yagüe Blanco, J., Capuz-Rizo, S. (Eds.), Project Management and Engineering. Lecture Notes in Management and Industrial Engineering. Springer, Cham, pp. 157-165.

Petersen, L., Dahl, C.K., Esbensen, K.H., 2004. Representative mass reduction in sampling - A critical survey of techniques and hardware. Chemom. Intell. Lab. Syst. 74, 95-114. https://doi.org/10.1016/j.chemolab.2004.03.020

Riber, C., Rodushkin, I., Spliid, H., Christensen, T.H., 2007. Method for fractional solid-waste sampling and chemical analysis. Int. J. Environ. Anal. Chem. 87, 321-335. https://doi.org/10.1080/03067310701189067

Rotter, V.S., Lehmann, A., Marzi, T., Möhle, E., Schingnitz, D., Hoffmann, G., 2011. New techniques for the characterization of refuse-derived fuels and solid recovered fuels. Waste Manag. Res. 29, 229-236. https://doi.org/10.1177/0734242X10364210

Sarc, R., Lorber, K.E., 2013. Production, quality and quality assurance of Refuse Derived Fuels (RDFs). Waste Manag. 33, 1825-1834. https://doi.org/10.1016/j.wasman.2013.05.004

Schwarzböck, T., Aschenbrenner, P., Rechberger, H., Brandstätter, C., Fellner, J., 2016. Effects of sample preparation on the accuracy of biomass content determination for refuse-derived fuels. Fuel Process. Technol. 153, 101-110. https://doi.org/10.1016/j.fuproc.2016.07.001

Sever Akdağ, A., Atimtay, A., Sanin, F.D., 2016. Comparison of fuel value and combustion characteristics of two different RDF samples. Waste Manag. 47, 217-224. https://doi.org/10.1016/j.wasman.2015.08.037

Smidt, E., Meissl, K., Tintner, J., 2008. The influence of waste sample preparation on reproducibility of thermal data. Thermochim. Acta 468, 55-60. https://doi.org/10.1016/j.tca.2007.11.021

Suez Advanced Solutions Spain, n.d. Protocolo de toma de muestra, caracterización y análisis de RSU. Suez Advanced Solutions Spain. 
UNE-EN 15400, 2011. Combustibles sólidos recuperados. Determianción del poder calorífico. AENOR, Asocición Española de Normalizaciónj y Certificación, Madrid, España.

UNE-EN 15407, 2011. Combustibles sólidos recuperados; Métodos para la determinación del contenidos en carbono (C), hidrógeno (H) y nitrógeno (N). AENOR, Asocición Española de Normalizaciónj y Certificación, Madrid, España.

UNE-EN 15408, 2011. Combustibles sólidos recuperados: Métodos para la determinación del contenidos en azufre $(\mathrm{S})$, cloro $(\mathrm{Cl})$, flúor $(\mathrm{F})$ y bromo $(\mathrm{Br})$. AENOR, Asocición Española de Normalizaciónj y Certificación, Madrid, España.

UNE-EN 15411, 2011. Combustibles sólidos recuperados: Método para la determianción del contenido en oligoelementos (As, Ba, Be, Cd, Co, Cr, Cu, Hg, Mo, Mn, Ni, Pb, Sb, Se, Tl, V y Zn). AENOR, Asocición Española de Normalizaciónj y Certificación, Madrid, España.

UNE-EN 15414-3, 2011. Combustibles Sólidos Recuperados: Determinación del contenido en humedad por el método de secado en estufa. Parte 3: Humedad de la muestra para análisis general. AENOR, Asocición Española de Normalizaciónj y Certificación, Madrid.

UNE-EN 15415-2, 2012. Combustibles sólidos recuperados: Deteminación de la distribución de tamaño de partícula. Parte 2: Método (manual) de la longitud máxima proyectada para particulas de grandes dimensiones. AENOR, Asocición Española de Normalizaciónj y Certificación, Madrid.

UNE-EN 15443, 2011. Combustibles sólidos recuperados: Métodos para la preparación de la muestra de laboratorio. AENOR, Asocición Española de Normalizaciónj y Certificación, Madrid.

UNE-EN ISO 10304-1, 2009. Calidad de agua: Determinación de aniones disueltos por cromatografía de iones en fase líquida. Parte 1: Determianción de bromuro, cloruro, fluoruro, nitrato, nitrito, fosfato y sulfato. AENOR, Asocición Española de Normalizaciónj y Certificación, Madrid, España.

US EPA, 2007. Method 7473. Mercury in Solids and Solutions by Thermal Decomposition, Amalgamation, and Atomic Absorption Spectrophotometry. United States Environmental Protection Agency, Washington D. C, United States of America.

Vaccaro, S., Locoro, G., Contini, S., Roebben, G., Emteborg, H., Ciceri, G., Giove, A., lacobellis, S., Flamme, S., Maier, J., Gawlik, B.M., 2008. QUOVADIS Project: Organization of Validation Exercises (JRC Scientific and Technical Reports. EUR 23552). European Commision: Joint Research Centre. Office for Official Publications of European Communities, Luxembourg. 

$\begin{array}{llll}0 & 0 & 0 & 0 \\ 0 & 0 & 0 & 0 \\ 0 & 0 & 0 & 0 \\ 0 & 0 & 0 & 0\end{array}$

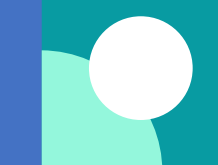

08

CAPÍTULO 8

CONCLUSIONES Y DESARROLLOS FUTUROS

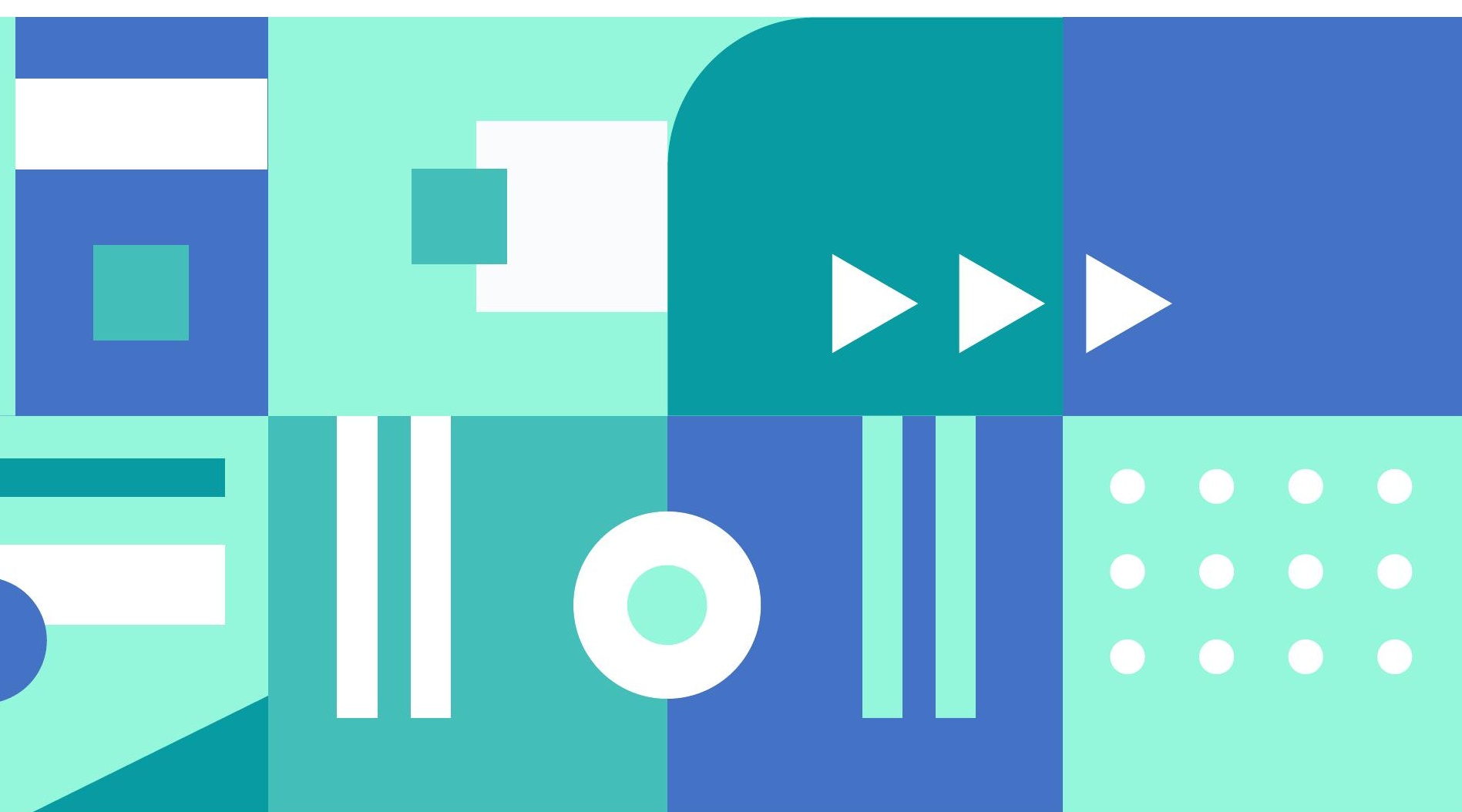





\subsection{CONCLUSIONES}

El objetivo general de la presente tesis ha sido diseñar una metodología para llevar a cabo el control de calidad de los rechazos generados en las plantas de TMB, de forma que se facilite su transformación a un CSR con características definidas, comercializable y que cumpla los estándares de calidad para este tipo de combustibles.

Para alcanzar este objetivo se han tenido que llevar a cabo diferentes tareas, las cuales se enumeran a continuación:

- Se han clasificado y modelizado los diferentes tipos de plantas de TMB existentes, lo que ha permitido identificar las corrientes de rechazo generadas y que son susceptibles de ser transformadas en CSR en cada una de ellas, tanto en número como en origen.

- Se ha estudiado la situación actual de dicho tratamiento en España, lo que ha aportado información en relación a las cantidades de rechazo generadas y su potencial como fuente de energía.

- Se han identificado las variables y parámetros que están implicados en el diseño de la metodología.

- Se han revisado los métodos y normas existentes para el muestreo y caracterización de RSU y CSR, obteniendo los fundamentos necesarios para el desarrollo de la metodología.

- Se han revisado los procedimientos estadísticos aplicables a los residuos y rechazos, obteniendo las herramientas necesarias para el análisis estadístico de los resultados obtenidos en las experimentaciones realizadas.

- Se ha desarrollado un plan de muestreo para el control de calidad de los rechazos de una planta de TMB y que, además, se ha aplicado a dos plantas de TMB distintas.

- Finalmente, se ha establecido un procedimiento para la preparación de muestras de rechazo para el análisis de los parámetros de calidad.

En el este apartado se presentan las principales conclusiones obtenidas en cada uno de los aspectos tratados en la tesis.

Las conclusiones en relación a la modelización de las plantas de tratamiento mecánico-biológico de RSU (Capitulo 3) son:

- Las plantas de TMB se clasifican en función de los RSU tratados, las etapas que conforman el proceso de tratamiento, las tecnologías y procesos de tratamiento mecánico y las tecnologías y procesos del tratamiento biológico.

- Las plantas donde se tratan RSU mezclados se clasifican en cuatro categorías principales que, en función de la alternativa de tratamiento mecánica y biológica escogida, dan lugar a 16 tipos de plantas distintas.

- Las plantas donde se trata la FORS se clasifican en 2 categorías principales que, a su vez, pueden utilizar diferentes alternativas para el tratamiento biológico, dando lugar a 6 tipos distintos de plantas.

- En una planta de TMB de RSU, la etapa mecánica se divide en tres subetapas: el pretratamiento de los residuos entrantes; la recuperación de los materiales reciclables, y el control de calidad y adecuación de los materiales recuperados. La etapa biológica, si consiste en el compostaje, se divide en dos subetapas: el compostaje de la fracción orgánica y el afino del material bioestabilizado; o si consiste en la biometanización y compostaje en tres: la biometanización de la fracción orgánica, el compostaje del digestato y el afino del bioestabilizado. Los flujos de salida identificados para una planta de TMB de RSU mezclados son: voluminosos, materiales recuperados, bioestabilizado, biogás (solo en instalaciones con biometanización), rechazo fino (solo en plantas de triaje), rechazo de recuperación, rechazo de afino primario del bioestabilizado y rechazo de afino secundario del bioestabilizado. 
- En una planta de TMB de la FORS, la etapa mecánica inicial de acondicionamiento se puede dividir en dos subetapas: pretratamiento del material entrante y recuperación de materiales. La etapa biológica, si consiste en el compostaje, se puede dividir en dos subetapas: el compostaje de la FORS y el afino del compost; o si consiste en la biometanización en tres: la biometanización de la FORS, el compostaje del digestato y el afino del compost. Los flujos de salida de este tipo de instalaciones son: metales férricos, compost, biogás (solo en plantas con biometanización), rechazo de limpieza inicial y rechazo de afino del compost.

- A partir de los modelos se han identificado 17 corrientes de rechazo diferentes entre todos los tipos de plantas de TMB que son susceptibles de ser transformados en CSR.

Las conclusiones en relación a la situación actual del tratamiento mecánico-biológico de RSU en España (Capítulo 3) son:

- A finales del año 2018 se contaba con 137 plantas de TMB con un alto grado de cobertura, puesto que todas las CC.AA. cuentan con al menos una instalación de este tipo en su territorio. Las PRC son las más utilizadas para el tratamiento de RSU mezclados, con 67 instalaciones, seguidas por las PRBC, con 22. Para el tratamiento de la FORS las PCFO son las predominantes, con 34 instalaciones.

- El proceso de recuperación de materiales de los RSU mezclados se realiza en 54 instalaciones de forma manual y en 41 de forma automática. La limpieza y acondicionamiento de la FORS se realiza de forma mecánica y manual en todas las instalaciones de este tipo.

- Los sistemas más utilizados para el compostaje son: el de nave cerrada para la fracción orgánica presente en los RSU mezclados, el de nave abierta para la FORS y el de túneles para el digestato obtenido en la biometanización. Además, en el caso del digestato nunca se realiza en nave abierta porque el proceso genera fuertes olores y necesita un sistema para la depuración de los mismos.

- En el año 2016 la cantidad total de RSU tratados en las plantas de TMB españolas fue de 13 Mt, correspondiendo 12,3 Mt a RSU mezclados, 0,55 Mt a FORS y 0,16 Mt a otros residuos biodegradables como restos de poda y lodos. Respecto a los RSU mezclados un $8,27 \%$ fue tratado en PT, un $65,12 \%$ en PRC, un $0,51 \%$ en PBSR y un $26,10 \%$ en PRBC. En cuanto a la FORS un $54,76 \%$ fue tratada en PCFO y un $45,24 \%$ en PBFO.

- $\quad$ Respecto al total de RSU mezclados generados en 2016 en España (18,1 Mt), un 44,45\% fueron tratados las PRC, un $17,82 \%$ en las PRBC, un $5,65 \%$ en las PT y un $0,34 \%$ en las PBSR (el resto se destinaron a incineración o vertido directo). En el caso de la FORS, respecto a la cantidad de biorresiduos recogidos selectivamente $(0,8 \mathrm{Mt}$ ) en 2016, las PCFO españolas trataron un $36,20 \%$ y las PBFO un $29,99 \%$, sumando un total de $66,29 \%$.

- En el año 2016 en las plantas de TMB españolas se recuperaron un total de 662.182 t de materiales reciclables, correspondiendo un $29,44 \%$ a plásticos, un $27,23 \%$ a metales y otro $27,23 \%$ a papel/cartón. Los rendimientos de recuperación para todos los tipos de plantas fueron muy parecidos, alrededor del $5 \%$.

- En cuanto al tratamiento biológico, en las plantas de TMB de RSU mezclados en total se produjeron 727.504 t de bioestabilizado y 68 millones de $\mathrm{m}^{3}$ de biogás, mientras que en las instalaciones de tratamiento de la FORS se produjeron $105.232 \mathrm{t}$ de compost y 2,5 millones de $\mathrm{m}^{3}$ de biogás. Las PRC tuvieron los rendimientos más altos en la producción de bioestabilizado $(7,75 \%)$ y PCFO en la producción de compost (12,64\%). A nivel global destacan las plantas donde se trata la FORS por su mayor rendimiento y eficiencia debido a que el material entrante tiene un menor contenido en impropios.

- La generación de rechazo en las plantas de TMB españolas alcanzo las 8,9 Mt en 2016, siendo las PRC y las PRBC las mayores productoras. Las instalaciones de tratamiento de RSU mezclados son las que mayor porcentaje de rechazo generan respecto al material entrante, con valores entre el $67 \%$ y $77 \%$. Esto se debe, por un lado, a la heterogeneidad de los RSU mezclados y, por otro lado, al bajo rendimiento de las plantas. En el caso de las plantas de tratamiento de la FORS, debido a que el material de entrada es más homogéneo, el porcentaje de rechazo disminuye a valores entorno al $29 \%$. 
- En 2016 el 84,29\% del rechazo generado tuvo como destino el vertedero y tan solo el $15,71 \%$ se valorizó energéticamente.

Las conclusiones en relación a las variables y parámetros implicados en el diseño de la metodología para el control de calidad de los rechazos (Capítulo 4) son:

- Se han determinado las variables influyentes en las propiedades de los rechazos y se han clasificado en tres categorías: variables del entorno (estacionalidad, climatología y área geográfica), variables socio-económicas (turismo, nivel de renta, modo de vida, tipo de población, nivel de urbanización y edad de la población) y variables relacionadas con el sistema de gestión de RSU (tipo de recogida, frecuencia de recogida, días de funcionamiento de la instalación, tipo de instalación y procesos de tratamiento). Todas ellas se han incluido en la determinación del número de muestras para el control de calidad de los rechazos (etapa II del plan de muestreo).

- Las variables que afectan al tamaño de muestra son: la heterogeneidad, el tamaño y distribución del tamaño de partícula, la forma de partícula y la densidad. Todas ellas están relacionadas con aspectos geométricos del material involucrados en el muestreo y con cómo se distribuyen las partículas en el lote de rechazos a muestrear. Estas variables se han considerado a la hora de determinar el tamaño mínimo de muestra necesario para el control de calidad de los rechazos (etapa I del plan de muestreo).

- Tras la revisión de 9 estándares de calidad de diferentes países se han identificado 33 parámetros diferentes que definen la calidad de los CSR. Los parámetros más utilizados son el PCI, el contenido en $\mathrm{Cl}$ y el contenido en $\mathrm{Hg}$, los cuales se han utilizado para determinar los procedimientos de preparación de muestras en el laboratorio para el control de calidad de los rechazos.

Las conclusiones en relación a la revisión de las técnicas de muestreo estadístico y métodos de muestreo y caracterización de RSU y CSR (Capítulo 5) son:

- En cuanto a las técnicas de muestreo estadístico, dentro del muestreo aleatorio probabilístico, el muestreo estratificado tiene una gran utilidad en el campo de los RSU, puesto que permite analizar distintas muestras seleccionadas en varias temporadas o condiciones. El muestreo a juicio de experto también es muy útil, ya que en muchas ocasiones el muestreo de toda producción de residuos (como requieren las técnicas probabilísticas) es prácticamente imposible o los recursos no lo permiten.

- Respecto a los RSU se puede concluir que en la actualidad se ha desarrollado una gran variedad de metodologías distintas para su muestreo y caracterización. Estas se aplican en cada región o país con diferentes criterios de muestreo y métodos para el cálculo de número y tamaño de muestras; los cuales se adaptan a las condiciones de cada caso y a la información que se quiere obtener a partir de su aplicación. A nivel europeo tampoco existe ninguna metodología estandarizada, a pesar de que la Comisión Europea ha desarrollado una propia en colaboración con diferentes países.

- La mayoría de las metodologías para RSU proponen la estratificación de la población a muestrear en función de una serie de factores. Algunas de ellas recomiendan la utilización de entre 4-5 estratos y, como mínimo, tener siempre en cuenta la estratificación por estacionalidad. Además, con el objetivo de evitar la variabilidad que puede existir entre los días de la semana, también recomiendan que la duración de cada periodo de muestreo sea de al menos una semana. Para el cálculo del número de muestras, varias de las metodologías revisadas utilizan la fórmula propuesta por la ASTM. No obstante, algunos autores plantean que no es adecuada debido a que los datos de los RSU no siguen una distribución Normal o solo lo hacen con un número de muestras mayor a 40, lo que en muchos casos no es viable. Por otro lado, varias metodologías recomiendan tomar como mínimo 10 muestras. En cuanto al tamaño de muestra, tampoco existe un consenso común entre las diferentes metodologías de RSU. Algunas utilizan adaptaciones de la ecuación de Gy para su cálculo y otras proponen diferentes pesos, los cuales van desde los $91 \mathrm{~kg}$ a $250 \mathrm{~kg}$, siendo el valor más típico el de $100 \mathrm{~kg}$.

- $\quad$ Respecto a los CSR, se puede concluir que para este tipo de materiales hay un menor número de metodologías. Esto se debe a que a partir de 2011 y a nivel europeo existe una serie de estándares 
para el muestreo y análisis de estos combustibles. El número de muestras recomendado por la norma para el muestreo de CSR es de 10 al año, las cuales se deben tomar de forma combinada, seleccionando varios incrementos dispersos por el lote. En cuanto al tamaño de muestra, la norma propone una fórmula para su cálculo, la cual es una una adaptación de la ecuación de Gy.

- Tras la revisión de los diferentes normas y metodologías existentes, se ha observado que ninguna de ellas es completamente aplicable a los rechazos debido a la naturaleza de los mimos. Por un lado, los rechazos son un material más homogéneo que los RSU mezclados, por otro, están formados por componentes con diferentes tamaños de partícula, normalmente mayores de los que forman parte de un CSR.

Las conclusiones en relación a la revisión de los procedimientos estadísticos aplicables a los residuos y rechazos (Capítulo 5) son:

- La descripción de las características y el comportamiento de una variable en estadística se puede llevar a cabo mediante tablas, gráficos y medidas resumen. Los gráficos de mayor utilidad en el ámbito de los residuos son los histogramas y los diagramas de cajas y bigotes. Las medidas resumen más utilizadas son: la media y mediana como medida de posición central; los cuartiles y percentiles como medida de posición no central; la desviación estándar, varianza y coeficiente de variación como medida de dispersión, y la asimetría y curtosis como medidas de forma.

- La distribución Normal es una de las más importantes en la estadística, ya que la mayoría de los procedimientos de la inferencia requieren que el conjunto de datos se distribuya Normalmente. No obstante, para las propiedades físico-químicas de los residuos se observan generalmente distribuciones de datos no Normales, con una asimetría positiva.

- La distribución logaritmo-Normal se caracteriza por tener una asimetría positiva, típica de los datos ambientales y de residuos. Una de las ventajas de que los datos sigan esta distribución es que se les pueden aplicar una serie de transformaciones matemáticas para aproximar los datos a una distribución Normal, lo que facilita la aplicación de las diferentes técnicas de la inferencia estadística. Las transformaciones aplicadas en la presente tesis han sido las siguientes: transformación arcoseno para los datos de composición y contenido en cloro y transformación logarítmica para el PCl y el contenido en $\mathrm{Hg}$.

- Dentro de la inferencia estadística, la comparación de medias y varianzas mediante contrastes de hipótesis son dos tipos de pruebas de significación más utilizados en el análisis de datos experimentales en el ámbito de los RSU. Además, estas pruebas han tenido un papel fundamental en la presente tesis.

- Tras la revisión de los diferentes test aplicables a los RSU para la comparación de dos o más grupos de muestras, tanto paramétricos como no paramétricos, se han desarrollado los procedimientos estadísticos que se han utilizado en el diseño de la metodología para el control de calidad de los rechazos. Además, estos también han servido para analizar y extraer conclusiones sobre los datos obtenidos en los diferentes experimentos realizados en la presente tesis.

Las conclusiones en relación al desarrollo del plan de muestreo para el control de calidad de los rechazos (Capítulo 6) son:

- El plan de muestreo para el control de calidad de los rechazos diseñado está formado por tres etapas: la primera es la determinación del tamaño mínimo de muestra, la segunda es la determinación del número mínimo de muestras necesarias y la tercera son las directrices para el correcto muestreo y caracterización de los rechazos.

- En la primera etapa se ha propuesto y desarrollado una metodología que permite determinar el tamaño de mínimo de muestra más adecuado a las características de las diferentes corrientes de rechazo que se generan en una planta de TMB. En ella, partiendo de un tamaño de muestra inicial, se propone un procedimiento de división de dicho tamaño para obtener muestras de diferentes pesos. Estas muestras se caracterizan y se comparan estadísticamente para determinar el tamaño mínimo de muestra con el que se obtienen resultados representativos. 
- En la segunda etapa se ha propuesto y desarrollado una metodología que permite calcular el número mínimo de muestras necesarias para el control de calidad de la producción anual de rechazo de una planta TMB. Esta metodología se basa en la estratificación de la producción en función de unos niveles de variación (mensual, semanal y diario), los cuales están relacionados con las variables responsables de la variación temporal de las propiedades de los rechazos. Finalmente, se propone una fórmula que permite calcular de forma sencilla el número mínimo de muestras necesario para cada corriente de rechazo.

- En la tercera etapa se han propuesto una serie de recomendaciones que se deben de tener en cuenta a la hora de llevar a cabo del muestreo y caracterización de los rechazos en plantas de TMB. Estas incluyen aspectos como: equipamiento de protección individual, material de trabajo, consideraciones para la programación de las caracterizaciones, localización y condiciones para realizar las caracterizaciones y casos especiales en la clasificación de los materiales.

- El plan de muestreo desarrollado puede aplicarse a cualquier tipo de planta de TMB identificado en el Capítulo 3, adaptándose a las características específicas de la instalación donde vaya a ser implementado. Mediante su aplicación se consigue obtener el tamaño y número de muestras necesarias para llevar a cabo el control y seguimiento de calidad de sus rechazos, lo que facilitará la transformación de dichos rechazos en una CSR fiable, comercializable y que cumpla los estándares definidos por la normativa europea para estos combustibles.

Las conclusiones en relación a la aplicación de la primera etapa del plan de muestreo a dos plantas de TMB (Capítulo 6) son:

- La metodología para la determinación del tamaño mínimo de muestra ha podido ser implementada completamente en dos plantas de TMB diferentes, adaptándose a los diversos tipos de rechazos generados en cada una de ellas: la planta de recuperación y compostaje de Onda y la planta de biosecado y recuperación de Cervera del Maestre. Esto ha permitido determinar el tamaño mínimo de muestra necesario para el control de su calidad.

- $\quad$ En base a los resultados obtenidos en ambos casos, se ha comprobado que los pesos de muestra determinados mediante la metodología propuesta son menores a los que se obtienen a partir de la norma de muestreo de los CSR o a los recomendados en la mayoría de las metodologías de RSU, las cuales no se ajustan a las propiedades específicas de los rechazos. Por lo tanto, su aplicación y utilización en el control de calidad de estos materiales permite minimizar el coste y la carga de trabajo necesarios.

- Se ha observado que el tamaño mínimo de muestra necesario para el control de calidad de los rechazos generados en una planta de TMB es diferente en función del tipo de instalación. Esto es debido a que el proceso de tratamiento y las tecnologías utilizadas en cada planta son muy diferentes $y$, como consecuencia, los rechazos generados tienen unas características distintas. Por lo tanto, a la hora de implementar la metodología, es necesario estudiar cada instalación y corriente de rechazo por separado.

- Adicionalmente se ha establecido que existe una relación exponencial entre el tamaño de partícula de los rechazos y el peso mínimo de muestra determinado en las dos plantas estudiadas. A partir de esta relación, para cada instalación, se ha obtenido una ecuación que permite calcular el tamaño de muestra necesario de cualquier otra corriente de rechazo que se genere en las mismas sin tener que aplicar de nuevo toda la metodología.

- Respecto al tiempo invertido en la caracterización de los rechazos, se ha confirmado que la utilización del tamaño de muestra determinado mediante la metodología propuesta supone un ahorro en tiempo en comparación al uso de otras metodologías que no están adaptadas a la naturaleza de estos materiales. 
Las conclusiones en relación a la aplicación de la segunda etapa del plan de muestreo a la PRC de Onda (Capítulo 6) son:

- La metodología para la determinación del número mínimo de muestras se ha aplicado en la planta de recuperación y compostaje de Onda; adaptándose a los tres rechazos distintos identificados como susceptibles de convertirse en CSR y a la variabilidad temporal de sus propiedades.

- La validación de la metodología ha confirmado que la diferenciación de los tres rechazos es adecuada, puesto que cada uno de ellos tiene una composición y propiedades distintas. En cuanto a la estratificación de la producción, en base a los resultados obtenidos se puede concluir que es correcta.

Las conclusiones en relación al procedimiento de preparación de muestras de rechazo para el análisis de los parámetros de calidad propuesto (Capítulo 7) son:

- Se ha desarrollado un procedimiento para la preparación de muestras de laboratorio para el análisis de los parámetros de calidad. La primera etapa permite reducir la muestra tomada en la planta de TMB a una muestra inicial representativa de $2 \mathrm{~kg}$ con la misma composición. La segunda etapa consiste en preparar una muestra de laboratorio de menor peso de la que se toman las alícuotas para determinar el $\mathrm{PCl}, \mathrm{Cl}$ y $\mathrm{Hg}$. De esta segunda etapa cabe destacar los procesos de división de muestra y de secado.

- Respecto al proceso de división de muestra se ha determinado el tamaño de muestra de laboratorio con el que se obtienen resultados representativos y se han establecido los procedimientos de reducción de tamaño de partícula y división de muestras más adecuados para alcanzarlo. Los resultados más destacables son los siguientes:

> Para el análisis del $\mathrm{PCl}$, cuando no se lleva a cabo una reducción inicial del tamaño de partícula o esta se realiza a un diámetro mayor o igual a $60 \mathrm{~mm}$, el tamaño de muestra de laboratorio puede reducirse desde los $2 \mathrm{~kg}$ hasta $1 \mathrm{~kg}$. En el caso de realizarse una reducción inicial del diámetro de partícula a $30 \mathrm{~mm}$, el tamaño puede disminuirse hasta los 0,500 $\mathrm{kg}$ sin que pierda representatividad.

> Para el análisis del $\mathrm{Cl}$, cuando no se realiza una reducción inicial del tamaño de partícula o esta se hace a un diámetro de $60 \mathrm{~mm}$, el tamaño de muestra de laboratorio puede reducirse desde los $2 \mathrm{~kg}$ hasta los 0,500 kg. En el caso de que el tamaño de partícula se reduzca a un diámetro de $30 \mathrm{~mm}$, el tamaño de muestra de laboratorio se puede disminuir a 0,250 kg sin perder representatividad.

> Para el análisis del $\mathrm{Hg}$, cuando no existe una reducción inicial el tamaño de partícula, el tamaño de muestra de laboratorio corresponde al tamaño de la muestra recompuesta $(2 \mathrm{~kg})$, puesto que si se cuartea deja de ser representativa. Cuando se realiza una reducción inicial del tamaño de partícula a $60 \mathrm{~mm}$, el tamaño de muestra de laboratorio puede disminuirse a $1 \mathrm{~kg}$; mientras que si el diámetro se reduce a $30 \mathrm{~mm}$, el tamaño de muestra de laboratorio puede ser mucho más pequeño, de $0,065 \mathrm{~kg}$.

$>$ Para el análisis de la calidad global, teniendo en cuenta los tres parámetros, los tamaños de muestra de laboratorio necesarios son: $2 \mathrm{~kg}$ si no se lleva a cabo ninguna reducción inicial del tamaño de partícula; $1 \mathrm{~kg}$ si antes de la división por cuarteo se lleva a cabo una reducción inicial del tamaño de partícula a $60 \mathrm{~mm}$, y 0,500 kg si antes de la división por cuarteo se lleva a cabo una reducción inicial del tamaño de partícula a $30 \mathrm{~mm}$.

> La reducción de la muestra tomada en planta a una muestra de laboratorio más pequeña y representativa facilita el análisis de los parámetros de calidad, puesto que disminuye la carga de trabajo, lo que supone también un ahorro en tiempo y dinero.

> Finalmente, se ha obtenido una tabla en la que se presentan los tamaños de muestra de laboratorio necesarios para llevar a cabo el control de calidad en función del procedimiento de reducción de tamaño de partícula utilizado y el parámetro que se quiera analizar. 
- Respecto al secado, se ha determinado el tiempo necesario para el completo secado de varias muestras de rechazo y corrientes intermedias del TMB con composiciones y tamaños de partícula distintos. Los resultados más destacables son los siguientes:

$>$ Los tiempos óptimos de secado obtenidos van desde las 7 - 8 horas para las partículas con diámetros más grandes de los rechazos de recuperación, a las 2 - 3 horas para las partículas de diámetros más pequeñas. Por lo que se puede afirmar que el tiempo de secado varía en función del tamaño de partícula. Además, se ha advertido que un mayor contenido en humedad en el material no supone un tiempo óptimo de secado mayor, sino que el tiempo necesario está relacionado con el tamaño de partícula y cómo de retenida esta la humedad en el propio material.

> Las corrientes de rechazo con un mayor contenido en plástico rígido y papel/cartón son las que necesitan un mayor tiempo de secado, sobre todo cuando el diámetro de partícula es elevado. Esto está relacionado con la absorción de la humedad por parte del papel/cartón y con los líquidos que quedan atrapados en el interior de los envases. Por el contrario, para las corrientes compuestas principalmente por materia orgánica de pequeño tamaño, el tiempo de secado necesario es menor.

$>$ La fracción ligera de los rechazos de recuperación automática necesitan un menor tiempo de secado en debido a que los materiales que la componen están más limpios y secos.

$>$ Los flujos intermedios del TMB con un elevado contenido en materia orgánica necesitan un tiempo de secado mayor que aquellas corrientes donde la materia orgánica se presenta en porcentajes muy pequeños.

$>$ Finalmente, se ha obtenido una tabla con diferentes tiempos óptimos de secado en función del tipo de rechazo, tamaño de partícula y materiales principales que componen la corriente. Estos tiempos son de gran utilidad en la preparación de muestras para el control de calidad de los rechazos.

En definitiva, gracias a la metodología propuesta se puede diseñar e implementar un sistema de control de calidad de los rechazos generados a lo largo de un año por una planta de TMB, y que son susceptibles de ser transformados en un CSR; desde la toma de muestras en la propia planta de tratamiento, al análisis de los parámetros de calidad en el laboratorio. El control de calidad de los rechazos permitirá producir un CSR con unas propiedades definidas y predecibles, lo que es de extrema importancia para su valorización. En general esto contribuye a la recuperación energética de una fracción importante de residuos que actualmente se destina a vertedero, ayudando a cumplir los nuevos objetivos sobre la reducción de vertido de la Directiva europea de residuos (Directiva 2018/851/UE) y favoreciendo la transición hacia una economía circular.

\subsection{DESARROLLOS FUTUROS}

Tras la finalización del trabajo de investigación se han obtenido resultados en los que sería interesante profundizar, pudiendo servir de base para el desarrollo de futuras investigaciones relacionadas con la tesis. Estas se presentan a continuación:

Relacionadas con el plan de muestreo para el control de calidad de los rechazos:

- Ampliar la aplicación del plan de muestreo diseñado a todos los tipos de plantas de TMB identificadas en el Capítulo 3, cuyas tecnologías de tratamiento difieren a las de las plantas estudiadas en la presente tesis. De esta forma se comprobará si también se adapta a las características específicas de los rechazos generados en las mismas.

- Ampliar la aplicación del plan de muestreo diseñado a otras corrientes de materiales generados en las plantas de TMB y que también requieren de un control de calidad, como son los distintos materiales reciclables recuperados, el bioestabilizado y el compost.

- Determinar si, para cada tipo de planta de TMB, la relación exponencial entre el tamaño de partícula de los rechazos y el peso mínimo de muestra se ajusta a la misma ecuación. Esto permitiría obtener 
una ecuación general para el cálculo del tamaño de muestra en función del tipo de instalación sin necesidad de aplicar toda la metodología.

Relacionadas con la preparación de muestras de rechazo en el laboratorio:

- Ampliar la determinación del tamaño de muestra de laboratorio y tiempo óptimo de secado al material bioestabilizado o el compost generado en las plantas de TMB, puesto que estos materiales también necesitan el análisis químico de ciertos parámetros (por ejemplo, contenido en metales pesados) para comprobar su calidad como enmienda orgánica.

Finalmente sería necesario trabajar en el desarrollo de una normativa específica para el muestreo y caracterización de rechazos de plantas de TMB, semejante a las que ya existen para los CSR y los RSU. 



\section{PUBLICACIONES}

Los resultados obtenidos en las investigaciones realizadas durante el desarrollo de la tesis han sido publicados a nivel nacional e internacional.

\section{Publicaciones indexadas}

Gallardo, A., Carlos, M., Colomer, F.J., Edo-Alcón, N., 2018. Analysis of the waste selective collection at drop-off systems: Case study including the income level and the seasonal variation. Waste Manag. Res. 36, 30-38. https://doi.org/10.1177/0734242X17733539

Edo-Alcón, N., Gallardo, A., Colomer-Mendoza, F.J., 2016. Characterization of SRF from MBT plants: Influence of the input waste and of the processing technologies. Fuel Process. Technol. 153, $19-27$. https://doi.org/10.1016/j.fuproc.2016.07.028

Gallardo, A., Edo-Alcón, N., Carlos, M., Renau, M., 2016. The determination of waste generation and composition as an essential tool to improve the waste management plan of a university. Waste Manag. 53, 3-11. https://doi.org/10.1016/j.wasman.2016.04.013

\section{Publicaciones no indexadas}

Gallardo, A., Edo-Alcón, N., Carlos, M., Colomer, F.J., Esteban-Altabella, J., Muñoz-Capitán, N., Badenes, C., Beltrán, I., Colás, V., Muñoz, A., 2017. Hacia el quinto contenedor: experiencia piloto de recogida selectiva de residuos orgánicos en Castellón de la Plana. Equip. y Serv. Munic. 182, 24-31.

Gallardo, A., Edo-Alcón, N., Albarrán, F., 2017. El combustible sólido recuperado: Producción y marco regulador. RETEMA 197, 8-16.

\section{Capítulos de libros}

Gallardo, A., Edo-Alcón, N., Sánchez-López, I., 2019. Producción de combustibles sólidos a partir de residuos domiciliarios, in: Gallardo Izquierdo, A., Colomer Mendoza, F.J., Campos Rodríguez, R., Arias Aguilar, D. (Eds.), Aprovechamiento Energético de Residuos. Publicaciones de la Universitat Jaume I, Castellón de la Plana, España, pp. 39-68. ISBN: 978-84-17429-59-1

Sánchez-López, I., Gallardo, A., Edo-Alcón, N., 2017. Study of the energy recovery of the reject materials from municipal solid waste treatment plants in Spain, in: Ayuso Muñoz, J.L., Yagüe Blanco, J.L., Capuz-Rizo, S. (Eds.), Project Management and Engineering Research. AEIPRO 2016. Springer International Publishing, Switzerland, pp. 81-93. ISBN: 978-3-319-51858-9

Gallardo, A., Gómez Parra, A.M., Colomer-Mendoza, F.J., Edo-Alcón, N., Pascual, P., 2015. Design of an SRF from Refuse from a Municipal Waste Treatment Plant, in: Ayuso Muñoz, J.L., Yagüe Blanco, J.L., Capuz-Rizo, S.F. (Eds.), Project Management and Engineering: Selected Papers from the 17th International AEIPRO Congress Held in Logroño, Spain, in 2013. Springer International Publishing, Switzerland, pp. 157-166. ISBN: 978-3-319-12753-8

\section{Publicaciones en congresos internacionales}

Edo-Alcón, N., Gallardo, A., Colomer Mendoz, F.J., 2019. El tratamiento mecánico biológico de residuos sólidos urbanos: tipos de plantas, tecnologías y equipamientos disponibles. En: Libro de Actas: VIII Simposio Iberoamericano en Ingeniería de Residuos: "Hacia una Gestión más Eficiente de los Residuos". Universidad Católica Nuestra Seño de Asunción, Asunción (Paraguay). 
Gallardo, A., Edo-Alcón, N., Colomer Mendoza, F.J., Jorge, A., Badenes, C., Colás, V., Apolinar, V., 2019. Recogida separada de la facción orgánica procedente de los residuos sólidos urbanos: resultados de la experiencia piloto desarrollada en Castellón de la Plana (España). En: Libro de Actas: VIII Simposio Iberoamericano en Ingeniería de Residuos: "Hacia una Gestión más Eficiente de los Residuos". Universidad Católica Nuestra Seño de Asunción, Asunción (Paraguay).

Edo-Alcón, N., Gallardo, A., Colomer Mendoza, F.J., Esteban Altabella, J., Albarrán, F., 2018. Análisis de la variación anual de la composición de los rechazos de una planta de TMB de residuos sólidos urbanos. En: Proceedings - Actas: 22th International Congress on Projects Management and Engineering, Madrid, España, pp. 1145-1157. ISBN: 978-84-09-05132-8

Esteban Altabella, J., Colomer Mendoza, F.J. Gallardo, A., Edo-Alcón, N., 2018. Uso de áridos reciclados en un depósito controlado de residuos sólidos urbanos. En: 9o Encuentro Nacional de Expertos en Residuos Sólidos (ENERS): Los Residuos sólidos como Recurso, Guadalajara, Jalisco, México. ISSN: 2395-8170

Esteban Altabella, J., McDougall, J., Colomer Mendoza, F.J., Gallardo, A., Edo-Alcon, N., 2017. Review and application of a Settlement model for landfills. En: Proceedings Sardinia 2017: 16th International Waste Management and Landfill Symposium. ISBN: 978-88-6265-010-6. ISSN: 2282-0027

Sánchez-López, I., Gallardo, A., Edo-Alcon, N., 2017. Study of the gasification process of the refuse derived fuels through simulation in a bubbling fluidized bed reactor. En: Proceedings Sardinia 2017: 16th International Waste Management and Landfill Symposium. ISBN: 978-88-6265-010-6. ISSN: 2282-0027

Edo-Alcón, N., Gallardo, A., Colomer Mendoz, F.J., 2017. Diseño de una metodología para el muestreo de corrientes de rechazo producidas en las plantas de tratamiento de residuos. En: Libro de Actas: VII Simposio Iberoamericano de Ingeniería de Residuos, pp. 359-364. Universidad de Cantabria (España). ISBN: 978-84697-3824-5

Carlos, M., Gallardo, A., Colomer Mendoz, F.J., Edo-Alcón, N., 2017. Producción y consumo de combustibles sólidos recuperados. Estudio comparativo de la situación europea. En: Libro de Actas: VII Simposio Iberoamericano de Ingeniería de Residuos, pp. 124-129. Universidad de Cantabria (España). ISBN: 978-84697-3824-5

Badenes Catalán, C., Gallardo, A., Edo-Alcón, N., 2017. Identificación de variables que determinan el funcionamiento de los puntos limpios. En: Libro de Actas: VII Simposio Iberoamericano de Ingeniería de Residuos, pp. 366-371. Universidad de Cantabria (España). ISBN: 978-84-697-3824-5

Fas Argamasilla, N., Gargori García, C., Edo-Alcón, N., Monrós Andreu, G., Llusar Vicent, M.I. 2017. Inertización de níquel y magnesio en pigmentos ni-ilmenta de magnesio mediante la adición de fluoruros. En: Libro de Actas: VII Simposio Iberoamericano de Ingeniería de Residuos, pp. 556-561. Universidad de Cantabria (España). ISBN: 978-84-697-3824-5

Badenes Catalán, C., Gallardo, A., Edo-Alcón, N., 2016. Estudio de las soluciones a la problemática de los microvertederos incontrolados: aplicación al caso de Castellón. En: Proceedings - Actas: 20th International Congress on Projects Management and Engineering, Cartagena, España, pp. 1350-1362. AEIPRO: Asociación Española de Dirección e Ingeniería de Proyectos, (España). ISBN: 978-84-617-4180-9

Edo-Alcón, N., Sánchez-López, I., Esteban Altabella, J., Gallardo, A., 2015. Estudio técnico-económico de alternativas para minimizar el vertido de RSU. En: Memorias del VI Simposio Iberoamericano de Ingeniería de Residuos Sólidos, hacia la carbono neutralidad 2021, pp. 582-589. Editorial Tecnológica de Costa Rica (Costa Rica). ISBN: 978-9968-641-28-9

Gallardo, A., Edo-Alcón, N., Badenes, C., Fas Argamasilla, N., 2015. Eficiencia de la recogida de RSU mediante puntos limpios en Castellón de la Plana. En: Memorias del VI Simposio Iberoamericano de Ingeniería de Residuos Sólidos, hacia la carbono neutralidad 2021, pp. 328-333. Editorial Tecnológica de Costa Rica (Costa Rica). ISBN: 978-9968-641-28-9 
Gallardo, A., Sánchez-López, I. Edo-Alcón, N., 2015. Análisis del pago de tasas de depósito de residuos en Europa. En: Memorias del VI Simposio Iberoamericano de Ingeniería de Residuos Sólidos, hacia la carbono neutralidad 2021, pp. 224-230. Editorial Tecnológica de Costa Rica (Costa Rica). ISBN: 978-9968-641-28-9

Esteban Altabella J., Colomer Mendoza, F.J., Gallardo, A., Edo-Alcón, N., Gargori García, C., 2015. Simulación del comportamiento de un vertedero de rechazos a escala de laboratorio. En: Memorias del VI Simposio Iberoamericano de Ingeniería de Residuos Sólidos, hacia la carbono neutralidad 2021, pp. 400-405. Editorial Tecnológica de Costa Rica (Costa Rica). ISBN: 978-9968-641-28-9

Gallardo, A., Edo-Alcón, N., Colomer Mendoza, F.J. Carlos, M., 2015. Estudio de la eficiencia en la recogida de residuos domiciliarios especiales mediante puntos limpios. En: Proceedings - Actas: 19th International Congress on Projects Management and Engineering, Granada, España, pp. 1219-1228. AEIPRO: Asociación Española de Dirección e Ingeniería de Proyectos, (España). ISBN: 978-84-608-2864-8

Sánchez-López, I., Gallardo, A., Edo-Alcón, N., 2015. Estudio del aprovechamiento energético del rechazo de las plantas de tratamiento de Residuos Sólidos Urbanos. En: Proceedings - Actas: 19th International Congress on Projects Management and Engineering, Granada, España, pp. 1219-1228. AEIPRO: Asociación Española de Dirección e Ingeniería de Proyectos, (España). ISBN: 978-84-608-2864-8

Sánchez-López, I., Esteban Altabella, J., Edo-Alcón, N., 2015. Estudio de alternativas del aprovechamiento de los rechazos de una Planta de Recuperación y Compostaje. En: Coolsweep Bilbao International Conference From waste to energy. Bilbao, España. 
